\title{
The Case for Special Protection for Older People in International
}

\section{Law}

\author{
Quinn-Butler, Rosalind M.
}

How to cite:

Quinn-Butler, Rosalind M. (2018) The Case for Special Protection for Older People in International Law. Doctoral thesis, Swansea University.

http://cronfa.swan.ac.uk/Record/cronfa43238

Use policy:

This item is brought to you by Swansea University. Any person downloading material is agreeing to abide by the terms of the repository licence: copies of full text items may be used or reproduced in any format or medium, without prior permission for personal research or study, educational or non-commercial purposes only. The copyright for any work remains with the original author unless otherwise specified. The full-text must not be sold in any format or medium without the formal permission of the copyright holder. Permission for multiple reproductions should be obtained from the original author.

Authors are personally responsible for adhering to copyright and publisher restrictions when uploading content to the repository.

Please link to the metadata record in the Swansea University repository, Cronfa (link given in the citation reference above.)

http://www.swansea.ac.uk/library/researchsupport/ris-support/ 


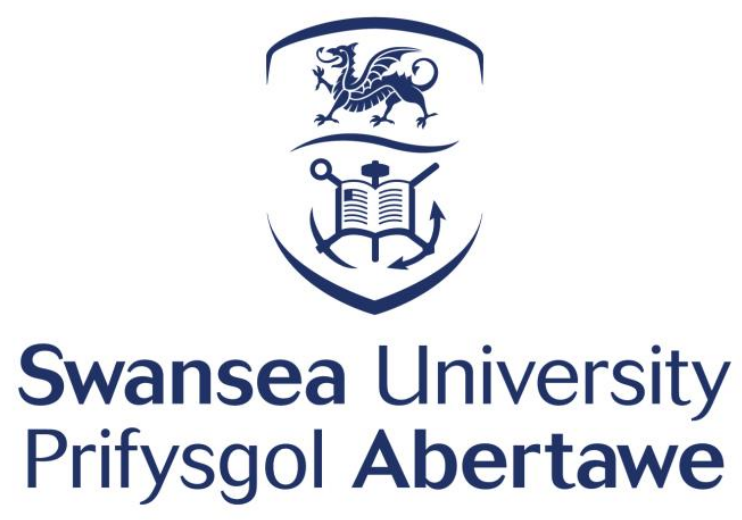

The Case for Special Protection for

Older People in International Law

\section{Rosalind M. Quinn-Butler}

Submitted to Swansea University in fulfilment

of the requirements for the Degree of Doctor of Philosophy 


\section{$\underline{\text { SUMMARY }}$}

The thesis makes the case for special protection of older people in international human rights law. This begins with an approach to human rights combining concepts of Human Dignity and Vulnerability. An interdependent relationship is identified, promoting grounds for both to underpin human rights. From this, a vulnerability framework is devised directing findings of research into the "vulnerability position" of older people, and examination of existing international rights.

The overarching theme is the fulfilment of interests of older people in human rights. Such interests are examined using principles of Interest Theory. Research method into threats to dignity and related vulnerabilities comprises Theories of Ageing and lived experiences. The findings assist in identification of older people as a vulnerable group, predominantly by reference to academic literature, standards defined by the European Court of Human Rights, and the vulnerabilities framework.

The central hypothesis is the potential inadequacy of the existing international framework of human rights to protect the inherent dignity and vulnerable position of older people. Existing international human rights are examined from normative and implementation perspectives. Normative results are discussed and recorded in relation to the vulnerability framework. These results are also employed, using a modified version of the Capabilities Approach, to create a unique listing of Fundamental Capabilities to underpin normative content and capabilities outcomes. Aimed at fulfilling interests of older people in human rights, the listing grounds the examination of implementation of the existing rights construct, and directs indicators of special protection rights.

The outcome of all research proves a need for special protection of older people in international human rights. Therefore, progress by the $\mathrm{UN} \mathrm{OEWG}^{1}$ is surveyed; the result demonstrating a preference for improved implementation of the existing international framework. To date, the position of older people in international human rights has stagnated in OEWG discussions.

${ }^{1}$ Open Ended Working Group on Ageing 


\section{DECLARATION}

In accordance with the requirements for submission I declare that:

1. The work contained in this thesis has not previously been accepted in substance for any degree and is not being concurrently submitted in candidature for any degree

2. The thesis is the result of my own investigations

3. All sources used are acknowledged by footnotes and a bibliography is appended

4. I give consent for the thesis, if accepted to be made available online in the University's Open Access Repository and for inter-library loan, and for the title and summary to be made available to outside organisations 
TABLE OF CONTENTS

Chapter

$\underline{\text { Title }}$

Page

Acknowledgements

Tables

14

Abbreviations

Introduction to Thesis

15

Chapter Summary

19

Part I

Introduction to Human Rights;

Protections for Older People; and

Methodology

Chapter 1

Introduction to Human Rights

28

1.1

Introduction

1.2

Theoretical Underpinnings of Human

Rights

1.2.1

Natural Rights and Positive Rights

1.3

General Underpinnings of Human Rights

1.3.1

Moral Human Nature

1.3.2

Human Need

1.3.3

Human Dignity 
Civil and Political Rights; and Social, Economic and Cultural Rights

Distinctions Between Civil and Political and Social, Economic and Cultural Rights

Positive and Negative Rights

Individual and Collective Rights

Will Theory and Interest Theory

1.6.1

Will Theory

1.6.2

1.6.2.1

Interest Theory

A Note on Interest Theory for Rights of Older People

Conclusion

Chapter 2

International Context of Human Rights for Older People

Introduction

Ageing Population

Recognition of older people in international law

Characteristics common to older people as a group

Approach to international rights provision for older people

Special protection and older people

Conclusion 
3.1

3.2

3.3

3.4

3.5

Part II

Chapter 4

4.1

4.2

4.2.1

4.2.2

4.2.3

4.2.4

4.2.4.1

4.2.4.2

4.2.4.3

4.2.4.4

4.2.4.5

4.2.5

4.2.6
Introduction

Critical Design and Theoretical Framework

Relationship between research objectives and research questions

Primary research questions methods

Conclusion

\section{Approaching Human Rights}

Human Dignity and Human Rights

61

Introduction

61

Concept of Human Dignity

62

Status

63

Inherent Dignity

64

Individual Identity

65

The key pillars of Human Dignity

65

Freedom

65

Autonomy

66

Equality

66

Human Need

67

Personality

68

Respect

68

Self-Respect

69 
Relationship between components of Human Dignity human rights

Conclusion

Definitions and descriptions of the concept of Vulnerability

Turner's thesis human rights? 
for human rights? Approach 
Part III

Chapter 8

8.2

8.2.1

8.3

8.4

8.4 .1

8.4.1.1

8.4 .2

Introduction

\section{Researching Older People for Human}

Rights

Theories of Ageing

Modernisation Theory

Industrialisation, urbanisation, and isolation

Industrialisation and the effects on older people

Urbanisation, changes to family structure, 146 and loss of family support

Filial obligation

Productivity

151

Productivity as 'usefulness'

151

Productivity as 'successful ageing' 162

Disengagement Theory, Selective

153

Optimization with Compensation Model, and Socioemotional Selectivity Theory

Disengagement Theory

Criticisms of Disengagement Theory

155

Selective Optimization with

Compensation Model

Socioemotional Selectivity Theory 
stereotypes and Chronological Age of morbidity in old age 
Introduction

Social Isolation, Disengagement, and

Loneliness

Conclusion

Normative Framework A Vulnerability Perspective 
Social and Cultural Rights

with Disabilities

The Convention on the Elimination of All

Forms of Discrimination against Women

Instruments

People

Devising Normative Provision of Special

Protection Human Rights using a

Capabilities Approach

Listings of Capabilities - An Overview

Methods of Development of Thematic

Domains and listings of Capabilities

Development of Thematic Domains and a listing of Fundamental Capabilities for Older People 
Domain

Discrimination

A Capabilities Approach to

Implementation

Capability Implementation Framework with Fundamental Capabilities for Older People new instrument 
Right to the highest possible standard of 326 health

13.2 .5

Violence and abuse

Social Protection and Social Security

Employment

Continue provision via existing

international human rights instruments

Normative v Implementation Gaps

In favour of a special protection international Convention 


\section{ACKNOWLEDGEMENTS}

With appreciation to my supervisor, Dr. Simon Hoffman, for sharing his knowledge, and for his advice and guidance throughout this process.

Without the patience and support of my husband, Edward, undertaking the work for this thesis would not have been possible.

In acknowledgement of, and with deepest love and respect for, my parents and parents-in-law; the inspiration for this research. 


\section{TABLES}

Table Number

Table Number 1 Relationship Between Central Hypothesis, Research Objectives, and Research Questions

Table Number 2 Relationship Between Research Questions

Table Number 3 Healthy and Disability Free Life Expectancy at Birth in U.K. 2009-2011

Table Number $4 \quad$ Changes in Healthy Life Expectancy at age 65 between 2000-2002 and 2009-2011: U.K.

Table Number 5 Changes in Disability-Free Life Expectancy at age 65 between 2000-2002 and 2009-2011: U.K.

Table Number 6 EU 28 countries Healthy Life Expectancy v Life Expectancy at age 65: 2010-2015

Table Number 7 European Intra-Regional Disparity in Healthy Life-Expectancy post 65: $2010-2015$

Table Number $8 \quad$ Percentage of Dementia Sufferers by Age

Table Number 9 Self reported memory by education, age and sex (\% reporting fair or poor)

Table Number 10 Predicted numbers of dementia sufferers in high-income and medium and low-income countries

Table Number 11 Summary of Protection of Vulnerabilities of Older People by International Human Rights Framework

Table Number 12 Fundamental Capabilities of Older People

Table Number 13 Comparison of United Nations Rights Attributes with Fundamental Capabilities of Older People 


\section{ABBREVIATIONS}

ASEAN

ECtHR

GC

HRI

MIPAA

OEWGA / OEWG

$\mathrm{OHCHR}$

UN

UNCCPR / ICCPR

UNCEDAW / CEDAW

UNCESCR / CESCR

UNCESCR / ICESCR

UNCRC

UNCRPD / CRPD

UNDHR / UDHR

UNGA

UNHRC / HRC

UNPOP

VIPAA

WHO
Association of Southeast Asian Nations

European Court of Human Rights

General Comment

Human Rights Instrument

Madrid International Plan of Action on Ageing

Open Ended Working Group on Ageing

Office of High Commissioner for Human Rights

United Nations

United Nations International Covenant on Civil and Political Rights

United Nations Convention on the Elimination of All Forms of

Discrimination Against Women

United Nations Committee on Economic, Social, and Cultural Rights

United Nations International Covenant on Economic, Social and Cultural Rights

United Nations Convention on the Rights of Children

United Nations Convention on the Rights of Persons with

Disabilities

United Nations Universal Declaration on Human Rights

United Nations General Assembly

United Nations Human Rights Committee

United Nations Principles for Older People

Vienna International Plan of Action on Ageing

World Health Organisation 


\section{INTRODUCTION TO THESIS}

\section{$\underline{\text { Thesis Statement and Objectives }}$}

The central hypothesis of this thesis is that the existing international framework of human rights potentially does not protect the interests held in rights by older people. Three core objectives flow from this position. The first is to undertake detailed scrutiny of the interests held in human rights by older people. This seeks to examine in particular the ways in which older people might be identified as a vulnerable group, and lived vulnerable experiences which serve to violate dignity.

The second core objective is to perform a rigorous examination of the international rights framework in respect of the position of older people, with a view to identifying normative and implementation barriers to protection of interests. The aim is to analyse the adequacy of specific aspects of existing rights which protect, or fail to protect, the dignity and against vulnerabilities suffered by older people. The analysis also aims to identify the adequacy of specified human rights instruments to arrive at a complete conclusion of protection of older people by international rights.

The third core objective is to provide an alternative approach to critique existing human rights, and to normative provision of special protection. It is intended to devise a method combining the vulnerable subject. Therefore, a vulnerabilities-grounded approach, with a modified version of a Capabilities Approach is adopted. The aim is to critique the protection of rights of older people in the first instance taking a vulnerabilities approach, rather than using existing human rights as the starting point and attempting to manipulate interests or rights such that the two correspond. A Capabilities Approach adapted to accommodate the vulnerabilities approach will be used to construct a listing of Fundamental Capabilities specific to older people from which normative content and outcomes of rights can be derived.

\section{$\underline{\text { Thesis Structure }}$}

The following chapter provides a chapter summary of the thesis. Therefore, this section of the chapter will explain the structure and aims of the three substantive parts of the thesis.

The research for this thesis was conducted in primarily three stages. The first constituted an analysis of approaches to human rights; namely the concepts of Human Dignity and Vulnerability, and the Capabilities Approach. The aim of the conceptual analysis was substantively to establish the relationship between Human Dignity and Vulnerability, and the significance of the concepts jointly and individually to human rights per se and human rights for older people. The relationship is 
established as reciprocal. Threats to dignity, once manifested, create a risk of vulnerability. If not protected against, the individual is subject to an outcome of vulnerability, which further harms dignity. Combined in this way, the concepts illustrate the properties required of human rights to break the cycle of harm. The ability of the concepts to impact one another is particularly great in light of the holistic version of Human Dignity adopted by the thesis. Dignity is viewed throughout this research in terms of the five pillars proposed by Dupré in place of the traditionally accepted three pillars. The holistic approach adds existence and personality to the existing pillars of autonomy, freedom, and equality. Selected on the basis of its more accurate representation of the inherent worth of the individual, this version of the concept of Human Dignity requires human rights to protect against a wider range of threats and vulnerabilities, all of which have particular relevance to older people, due to the range and severity of vulnerabilities experienced.

The detail of the vulnerabilities of older people is the subject of the second stage of the research. However, the study of the concept of Vulnerability generated a framework in which all vulnerabilities experienced by the group can be represented. Categorised broadly as embodied, institutional, and pathogenic, the framework also demonstrates the interlinked nature of vulnerability.

Individually, the construct of both concepts have the capability to provide moral and conceptual underpinnings of rights. Both serve to inform the normative content and outcomes of rights.

The study of the concept of Vulnerability led to the method of determining a vulnerable group for the purposes of special protection. The guidance provided by the European Court of Human Rights was adopted by the thesis, and links to the aim of identification of older people in the next stage of research. The Court requires the following of a group to be considered vulnerable in this context. The vulnerabilities must be particular to the group, with particular defined by type of vulnerability, type and severity of harm. Additionally, the group should be able to be considered more vulnerable than most individuals, predominantly by virtue of aggravated vulnerability. Finally, the group should represent a minority of society. Each of these requirements for vulnerable group status will, in turn, inform special protection rights.

The Capabilities Approach was selected as a lens through which to view human rights due to its focus on the 'actual opportunities a person has, ${ }^{2}$ on what a person 'is able to do and be.' This central principle of the Capabilities Approach collaborates well with an approach of identification of

\footnotetext{
${ }^{2}$ Rod Hick, 'The Capabilities Approach: Insights for a new poverty focus,' LSE Research Online. $<$ http://eprints.lse.ac.uk/39745/>
} 
vulnerabilities to inform human rights. A strength of the Capabilities Approach is the ability to contribute to analysis frameworks. Aspects of the Capabilities Approach provide the basis for a method of identification of the normative content and outcomes of special protection developed by this thesis. In particular the method employed in Part IV draws on the notion of listings of capabilities for 'special purposes' to inform the content of rights and develop capabilities as outcomes. These outcomes serve to direct human rights, and can inform implementation indicators.

The focus of the second stage of the research was identification of older people as a group for purposes of special protection. The review of Theories of Ageing aimed at identifying the effects of societal influences on vulnerabilities of older people. The study of the process of senescence identified older people by inevitable bodily vulnerability, detailing the range of age-dependent and age-related illness and disabilities which can be suffered. The fact that this can occur co-morbidly serves to exacerbate this form of vulnerability. The interlinked nature of vulnerability increases the propensity of older people to suffer aggravated vulnerability. This was substantiated by a survey of the lived vulnerable experiences of older people. The survey of prior research undertaken by a range of academics, expert bodies and international bodies generated common themes of vulnerability experienced by older people across a range of geographical regions and developed and developing countries. The common themes incorporated the means of identification proposed in theories and the ageing process, and encompassed all aspects of the vulnerability framework developed in the first stage of research. Furthermore, the findings correlate to the qualifications for vulnerable group status and special protection as set out by the ECtHR. Therefore, the next stage of the research aimed to analyse the adequacy of international human rights in the protection of interests held in rights, threats to dignity, and vulnerabilities suffered by older people.

The final stage of research comprised an analysis of the normative provision and implementation of international human rights instruments vis à vis the vulnerabilities of older people identified in the previous stage of research.

Using the vulnerabilities framework devised in the first research stage the rights directly related to each vulnerability were examined for normative content able to protect against effects of vulnerabilities. Upon completion of this rigorous examination the combined adequacy of all instruments in providing for needs of older people was assessed. The instruments selected were the Universal Declaration of Human Rights, the International Covenant on Civil and Political Rights, The International Covenant on Economic, Social and Cultural Rights, the Convention on the Rights of Persons with Disabilities, and the Convention to Eliminate All Forms of Discrimination Against Women. 
By adopting a specially devised joint vulnerabilities and capabilities approach the thesis formulated a capabilities 'special purpose' listing of Fundamental Capabilities to inform the normative content of a set of special protection rights for older people. In addition, capabilities outcomes of rights were stipulated.

The final aspect of this examination of adequacy of international human rights for older people involved an examination of rights from an implementation perspective. This was conducted in the context of the listing of Fundamental Capabilities and capabilities outcomes. Also, the United Nations Framework of Implementation was analysed from the perspective of Fundamental Capabilities and capabilities outcomes to assess the full implications of adequacy of the existing international framework.

This stage of research concluded with a review of the discussions of the Open Ended Working Group on Ageing regarding key areas of concern in human rights for older people and the most appropriate method of providing for necessary protections. This demonstrates the rationale influencing the perpetuating reluctance to provide special protection for older people.

\section{Originality}

The thesis makes numerous claims to originality. The primary claim, evident throughout the thesis is that of approach. Given that the research problem is to make the case for special protection for older people, the methodological design chosen was critical rather than affirmative. Therefore, rather than limiting the approach to examination of the existing law, an original method of rights provision for the purpose of effecting change developed throughout the thesis.

The approach began by determining how older people are identified, defined, and the lived vulnerabilities experienced. At this point the concept of Vulnerability was introduced to the discussion, leading to the inclusion of the concept in conjunction with Human Dignity as the foundation of human rights. Having established a reciprocal relationship between the two, the thesis challenged the traditionally accepted version of Human Dignity, adopting instead a holistic version allowing full integration between both concepts. Identification of violations of dignity and association outcomes of vulnerability provided the basis for outcomes of human rights necessary to fulfil the interests held in rights by older people. Therefore, in brief, the approach has as the starting point what is required of rights rather than what can be expected of rights.

The concept of vulnerability adopted by the thesis was an amalgam of three theses of vulnerability, rather than traditionally offered definitions, in order that problem-solving be grounded in versions of 
concepts bespoke to the interests of older people. Upon completion of the examination of the adequacy of the existing human rights construct a version of the Capabilities Approach, modified by the thesis for the purpose of addressing the stated research problem, is applied. The result provides a listing of Fundamental Capabilities for Older People as a basis for normative content and outcomes of rights. These outcomes, and the attributes and indicators of rights informed by the modified Capabilities Approach provide the measure of success of rights.

The Vulnerabilities Framework implemented is unique to the thesis, resulting from the bespoke version of the concept of Vulnerabilities created. Comprising a customised version of embodied vulnerability; institutional; and pathogenic vulnerabilities, the framework accommodates all forms of harm suffered by older people. The implementation of the framework is also adds to the originality of the research. The Vulnerabilities Framework provides the basis for the analysis of the extent to which the interests held by older people in rights are fulfilled, and the adequacy of rights in meeting needs. Individual rights and overall adequacy of the international framework are assessed in accordance with each stated vulnerability. In this way the framework affords the initial stage of informing normative provision of rights.

Another tool devised by the thesis, and therefore contributing to the originality of the research, is the Frame of Reference and Sclae for Measurement of Effectiveness of Rights and the International Framework. The points of measurement are specific to the vulnerabilities of older people, which are determined with specific regard to the following: relevance of universal standards; degree of protection against type and severity of harm; recognition of linked vulnerabilities; and the potential for normative content to be developed. Therefore, the adequacy of the current international construct of human rights is assessed in a unique manner, and in a way not previously undertaken.

A further original tool devised by the thesis is a listing of Fundamental Capabilities for Older People. The thesis employed a hybrid of a Capabilities/Vulnerabilities Approach to the creation of a listing of Fundamental Capabilities for Older People. The principle embedded in the Capabilities Approach that measurement of Human Dignity and the success of rights are best represented in the outcome of rights informed the creation of a 'special purpose' listing of capabilities. This represents the only such listing of capabilities for older people. Furthermore, the method of construction of the listing differs from listings for other vulnerable groups; specifically that created for children by Burchardt et al. Previous 'special purpose' listings are grounded in existing human rights. Given that one of the aims of the instant listing is to inform normative content of special protection rights, the thematic domains were extracted from the previously devised Vulnerabilities Framework, research into theories of ageing and lived experiences. The structure is primarily grounded in the Vulnerable 
Subject. Existing rights are used as a secondary source to incorporate principles and objectives of fundamental rights. Legitimacy is claimed by use of research by expert groups into identification of global vulnerabilities of older people. 


\section{CHAPTER SUMMARY}

Chapter 1

The chapter introduces human rights concepts for the purpose of contextualising rights provision in response to primary research questions at various stages of the thesis. Theories of natural and positive rights are discussed from the perspective of contribution made to perceptions of human rights. Additionally, Kantian and Lockean approaches to the concept of Human Dignity, included in the chapter, are instructive to the combined roles of the concepts of Human Dignity and Vulnerability in human rights, explored in Part II. An assessment of Will and Interest Theories suggests the latter as an approach to the entitlement to, and application of, rights of older people. Aspects of Interest Theory are drawn upon, particularly in Part IV, with most frequent reference to interests held in rights, the significance of interests, and the facilitation of rights.

The introduction of the holistic approach to Human Dignity proffered by Dupré argues that human need drives human rights. This perception of the concept of Human Dignity is essential to arguments later in the thesis which contribute to the originality of the approach taken in determining the adequacy of existing international human rights for older people. Specifically, the proposal that the concepts of Human Dignity and Vulnerability jointly underpin the normative content and outcome of human rights is influenced by the holistic version.

The chapter discusses State obligations in terms of the duties to respect, protect and fulfil rights; thus emphasising the roles of each in giving effect to civil and political and economic, social and cultural rights. The implications of obligations and the impact on both sets of rights are central to the examination of the implementation of international human rights vis à vis the interests of older people in rights later in the thesis. Furthermore, the effect of obligation on implementation is a factor in the argument for a Capabilities Approach to fulfilment of rights. The distinction drawn between civil and political and socio-economic rights ground later discussion demonstrating the interests held in rights by older people; identification of normative and implementation gaps; and the suitability of a Capabilities Approach to human rights.

\section{Chapter 2}

Chapter 2 provides a brief overview of the current position of older people in international human rights. The changing global demographic opens the discussion in order to provide context for the implications, globally and regionally, of an ageing population. Key issues discussed in detail throughout the thesis are introduced and the significance of each outlined. In brief, those presented are: recognition of older people in international law; characteristics common to older people as a group; the present approach to international rights provision for older people; and special protection and older people.

The chapter introduces the significance of factors leading to the "invisibility of older people" in human rights. Not recognising older age as a ground for non-discrimination is pivotal to this outcome. Furthermore, attention is drawn to the fact that universal human rights do not beget universal fulfilment of interests held in 
rights by vulnerable groups. The characteristics common to older people as a group reference the theories of ageing and lived experiences discussed in Part III of the thesis, which also appear in the scrutiny of rights provision in Part IV.

The broad positions of human rights provision for older people are presented; instructive for the debate which follows. The position of older people in human rights is influenced by such positions, inclusive of: sufficient protection offered by universal rights; particular protection provided via numbers instruments of special protection; extra provision offered through General Comments; distinct instruments in human rights not addressed in the current construct.

The statement of current thinking on human rights provision for older people is followed by presentation of the rationale behind special protection per se. Comparison is made between the basis upon which social groups are determined as "vulnerable," and therefore qualify for special protection, and the attempts to fulfil the interests of older people without designated special protection.

\section{Chapter 3}

The methodology chapter explains the approach taken in response to the overarching research problem. The critical design aimed to fulfil the research objectives detailed in the introduction to the thesis. The chapter discusses the critical approach, including the concepts and theoretical framework which is visible throughout the thesis. In addition, the relationship between the central hypothesis, research objectives, and primary research questions of the thesis is discussed, and the connectivity between them demonstrated. Finally, the methods adopted per research question are detailed

\section{Chapter 4}

"Human Dignity and Human Rights" builds on the concept introduced in chapter 1. The chapter debates the various contributions to the concept, and subsequently, to human rights. The understanding of Human Dignity as the "inherent worth" of the individual prompts discussion of qualification. Of significance to older people are the opposing arguments claiming inherent worth to require a capability to reason, and stating worth to be "ontological...not reliant on personal characteristics." The meaning given as "equal worth intrinsic to every person" is adopted by this thesis, and provides the standard in later discussion.

To effect understanding of the role of Human Dignity in human rights, the components of the concept are explored. The holistic version offered by Dupré is preferred, and the traditional three-pillar definition developed. Human need and personality are thus added to the conventionally accepted autonomy, equality, and freedom. This "five pillar" version of Human Dignity links the concept to Vulnerability in the next chapter, grounding rationale for both to underpin normative content and outcomes of human rights later in the thesis.

Processes of violations of Human Dignity consider objective and subjective norms of treatment and selfrespect. The conclusion that treatment which causes feelings of humiliation is a violation of dignity directs the 
chapter to identify spaces in which humiliating and degrading treatment occur. The natural condition of older people is identified as providing three forms of motivation for humiliating treatment. Negative perceptions and stereotyping, shared characteristics, and substituted decision-making are cited, and are instructive to the research undertaken in Part III.

Finally, the chapter details how the notion of Human Dignity is incorporated into international human rights instruments. The highlighted perceived meanings and interpretations of Human Dignity as a malleable concept assist understanding of the examination of normative content and implementation of international rights in Part IV.

The chapter lays the foundations for further development of answers to research questions. Threats to dignity will be identifiable, and will inform needs for special protection. The basis for the relationship between Human Dignity and the concept of Vulnerability and the significance of this in a human rights context is introduced. Moreover, aspects of Human Dignity identifiable as threatened commence determination of the vulnerability of older people and as a group for the purposes of special protection.

\section{Chapter 5}

The chapter examines classifications of vulnerability, and recognising the significance of embodied, institutional, and pathogenic vulnerabilities to older people, develops a framework specific to the vulnerability experiences of the group. The framework contributes to the originality of the thesis, and will be instrumental in the identification of normative gaps in international rights, and in determining a need for special protection. The framework acknowledges the forms of vulnerability as distinct and interconnected, which supports later arguments for special protection incorporating both generations of rights. Furthermore, the framework will ultimately inform the normative content and outcomes derived from an examination of the lived experiences of older people, the normative study of international rights, and application of a version of a Capabilities Approach to human rights developed for this thesis. The framework contributes further to the originality of the thesis, influencing the Capabilities Approach framework developed in Parts III and IV; the objective of which is to inform normative content and outcomes of special protection rights for older people. Thus, the vulnerabilities framework contributes also to the examination of implementation gaps in international human rights in the context of older people.

Through an examination of the reciprocal relationship between the concepts of Vulnerability and Human Dignity, incorporating the notion of the vulnerable subject from Fineman's thesis of vulnerability, it is argued that both underpin human rights. This approach to human rights also ultimately contributes to the originality of the research. In developing a Capabilities Approach suitable to construction of a Fundamental Capabilities listing for the "special purpose" of fulfilling the interests held in human rights by older people, the first consideration is vulnerabilities of the subject. From this perspective the suitability of existing rights, and the need for special protection are considered. This differs from approaches taken to date towards the issue of rights for older people, which focus in the first instance on existing international rights. The latter approach 
has regularly produced arguments by States, and often the UN, for acceptance of sufficiency of the universality of existing rights. This issue is raised in Chapter 13, "Progress by the United Nations on special protection of older people." In addition, a further role for human rights is identified per Turner's vulnerability thesis. The institution-building function of human rights, motivated by the vulnerability experienced by individuals reliant upon precarious institutions, is supported by evidence in Part III of the effect on the vulnerability experience of older people of failure of institutions.

The chapter concludes with the observation that vulnerable groups "lie outside the scope of the purportedly universal protection of human rights." Guidance provided by the European Court of Human Rights is included, which informs later discussion and answers to primary research questions related to identification of older people as a group in need of discrete protection. Overall, the chapter contributes to questions regarding ways in which the group is vulnerable in society; the adequacy of international rights; and the overarching question of the need for special protection in international human rights law.

\section{Chapter 6}

Chapter 6 discusses the Capabilities Approach. The rationale for inclusion and examination of the Capabilities Approach in the thesis lies in the focus on the "actual opportunities a person has," and what a person "is able to do and be." This fundamental premise of the approach corresponds to the method of viewing the position of older people in international human rights in terms of the "vulnerable subject," the vulnerability framework, and identification of threats to dignity.

The chapter necessarily explains factors and the operation of the Capabilities Approach. Of specific relevance are the composition of valued functionings and capabilities; and functions of capabilities in achieving fundamental freedoms and choosing "capabilities sets," or "available lives." Of specific significance to the context in which the Capabilities Approach is utilised later in the thesis are issues of entitlement, listings of capabilities, positive State duty, obligation, and a broad base of rights.

The Capabilities Approach views both capabilities and human rights as entitlements. Therefore, the reciprocal relationship is one in which capabilities facilitate human rights, and human rights provide the outcome of capability. The differing opinions of Sen and Nussbaum on the subject of listings of capabilities are discussed in this chapter. Nussbaum's insistence on the adequacy of a single universal listing is compared to Sen's view of "special purpose" listings in response to circumstance. In Part IV the thesis creates a "special purpose" listing of Fundamental Capabilities for older people, and demonstrates the role of the listing in special protection rights. This also draws on proposals by the Capabilities Approach, included in this chapter, for a positive State duty to provide capabilities, and a broad base of rights to be informed by capabilities listings. Chapter 6 draws attention to the emphasis placed on de facto obligation by the Capabilities Approach, in addition to those of respect and result discussed in Chapter 1 . This reflects the consequence sensitive nature and aim of the approach to provide human rights relevant to the situation of the person or group. 
The final focus of the chapter is the compatibility of the Capabilities Approach with Fineman's vulnerable subject and the vulnerability framework. The Capabilities Approach provides a tool for assessment of vulnerabilities by virtue of the aim to determine "what a person is able to do and be." From this the following are identified: required outcome; capabilities needed to protect against vulnerabilities; content of rights; and de facto obligation of the State.

The combination of the vulnerability framework developed in Chapter 5, the principle of the centrality of vulnerable subject, and the Capabilities Approach contribute to the originality of the thesis. In Part IV the vulnerable subject, identified using the method of the vulnerability framework, emerges. The vulnerable subject, rather than existing human rights, remains the focus for the Capabilities Approach and the "special purpose" capabilities listing created to under pin and provide outcomes for special protection rights to fulfil the interest of the vulnerable subject in human rights.

Chapter 7

Chapter 7 synthesises the concepts and approaches discussed in Part II, and discusses contributions to answers provided to primary research questions. The relationship between the concepts of Human Dignity and Vulnerability is concluded as universal due to the ontological nature of both. Additionally, the "inherent worth" of Human Dignity is constantly threatened by the universal human capacity to suffer. This forms the basis of the viscous circle in which threats to dignity cause the individual to be vulnerable, which further threatens human dignity. Threats to dignity which manifest in outcomes of vulnerability violate dignity. The holistic definition of the concept of Human Dignity provides the scope of potential violations to dignity. The vulnerability framework defines the potential forms of vulnerability to which five pillars of Human Dignity are exposed. The pillars of Human Dignity are concluded as providing the guidance and broad scope for human rights; vulnerability the specific outcomes caused by objective or subjective humiliation. This relationship assists in identifying ways in which dignity of population groups is threatened, and how such groups become vulnerable and in need of special protection. In brief, identification of vulnerable groups involves some or all of the following: vulnerabilities or suffering particular to the group; distinct group-based experiences; specific type or severity of harm suffered; aggravated vulnerability; marginalisation or discrimination.

The range of assets required to defend the inherently vulnerable subject against threats to dignity grounds the necessity for inclusion of both generations of human rights in special protection. A Capabilities Approach to human rights advocates a broad base of human rights in this context. The relationship between the concepts of Human Dignity and Vulnerability serve to identify specific need of groups which fall outside the scope of universal human rights, and influences the argument that both concepts underpin human rights. When derived from natural conditions, such as age, humiliating and degrading treatment can be acute. Inadequate existing protection in such cases drives the identification of new special protection groups and rights.

The Capabilities Approach assists in identification of population groups in need of special protection, and the composition of that protection. As innate, internal, and combined capabilities are vulnerable, all pillars of 
Human Dignity are represented. Furthermore, in identifying "what a person is able to be and do," the approach places the vulnerable subject at the heart of human rights considerations. Through incorporation of a broad base of rights, the approach is capable of addressing all vulnerabilities of the vulnerability framework, and correspondingly, all aspects of Human Dignity. The view of the Capabilities Approach that human rights respond to need also assists in identification and closing of normative and implementation gaps; the subject of Part IV of the thesis. Also of significance to later findings of the thesis is that capabilities found the content of human rights, and the outcome to be achieved by rights. The chapter also concludes that as a result of using capabilities as the de facto outcome of rights, and as the indicator of rights, equality in dignity is achieved.

The interrelation of the concepts of Human Dignity and Vulnerability together with the Capabilities Approach work to identify vulnerable groups, and the special protection required. Furthermore, the normative framework of special protection and implementation mechanisms are informed by the interaction of each, and will be further discussed in Part IV.

\section{Chapter 8}

The chapter discusses theories of ageing, with a focus on processes and situations leading to threats to dignity and vulnerable outcomes suffered by older people. The range of theories included offer various rationales for the perceptions and practices resulting in the experiences of vulnerability suffered by the group, and ground the outcomes discussed in Chapter 10, and the position of older people in international human rights law examined in Part IV. Furthermore, the theories provide guidance for identification of older people as a group, and the threats to dignity and vulnerabilities that exist. The claims of Modernisation Theory that industrialisation and urbanisation create situations of lone living, poverty, reduced social engagement, loss of self-respect, and downgraded status amongst older people, resonate with the lived experiences of the group. The chapter recognises that vulnerability claimed as a result of the precariousness of the institution of the family, is contested. However, the vulnerable outcomes of older people discussed in Chapter 10 demonstrate a correlation between the modernising society and weakened family support. Other theories of ageing support aspects of Modernisation Theory in addition to presenting further causes of vulnerability and means of identifying older people as a group. The negative perception of older people as unproductive, featured in Modernisation Theory, is discussed further in the next section of the chapter. The traditional view of "useful" productivity is countered by a holistic approach, in order to highlight the ways in which older people should be regarded as, and able to choose to be, productive. Reduction in number and range of relationships enjoyed by older people, and social isolation, are discussed via theories of social disengagement. Arguments claiming that society disengages from older people, and vice versa, are presented. In some instances theories claim disengagement initiated by older people to be a natural, and beneficial, process of ageing. However, this thesis accepts the claim that outcomes of disengagement are harmful to the health and well-being of individuals, and older people as a group. Later examination of the lived experiences of older people demonstrates lone living to be a common theme. When accompanied by the unwillingness or inability to practice filial obligation in modernising society, the severity of harm is exacerbated. The chapter also 
addresses the problem of such perceptions being adopted in older age towards the self. Self-perception Theory propounds the potential for thoughts, emotions and anxieties relating to ageing to lead to physical and psychological manifestation of perceptions. The chapter demonstrates the negative effect of social perceptions of older people, primarily through the acceptance of such perceptions by the group, by reference to previously undertaken research projects. The common theme of general discrimination, born of societal perceptions, is recognisable in research of the lived experiences of older people reported in Chapter 10. Furthermore, the examination of international rights instruments in Part IV argues that non-discrimination on the grounds of age is questionable.

Activity Theory is included in the chapter as emphasis of the harmful effects of disengagement and negative self-perception, and the contribution of activity to successful ageing. Promotion of dignity and protection from vulnerability are achieved not merely through prevention of the effects of modernisation, disengagement, and negative perception. A positive duty to facilitate active engagement should also exist in rights of older people. This forms part of the discussion of Part IV. Life-Course Theory is the final theory discussed, accentuating the heterogeneity of older people. Significantly, the theory introduces the effect of advantage or disadvantage accumulated throughout life on the older person. Additionally, the relevance of relationships and dependence is discussed, drawing parallels with Fineman's Dependency Theory. Moreover, autonomy and the older person from the Life-Course perspective emphasises the individuality of decisions, necessitating prohibition of universal decisions and recognition to be made on behalf of the group. This view of autonomy supports the proposal for supported rather than substituted decision-making in Chapter 12.

\section{Chapter 9}

Chapter 9 examines defining older people by the ageing process and chronological age. The aim is to substantiate claims of the inevitability of embodied vulnerability, the dependence generated, and further vulnerabilities that the ageing process attracts. The aggravated vulnerability caused by problems of comorbidity, expansion of morbidity, and the range of physical and cognitive diseases are discussed. Research is also drawn on to demonstrate the effects of aggravated disadvantage on embodied vulnerability in older age. Common thematic ground of the ageing process, and the vulnerabilities derived is demonstrated in Chapter 10. The chapter also aims to identify an age at which special protection is available to older people as a group. Specific approaches of retirement age and years left to live are discussed. Debate of the drafters of the UNCRC is drawn on for guidance. Alternatives to chronological age were considered by States parties as qualification for special protection including stage of life abilities and evolving capacity. However, the abiding aim for protection to "apply to as large an age group as possible" underscores the practicality of age for both the UNCRC and older people. Furthermore, the approach taken by the UNCRC aligns to the heterogeneity of older people as a group and the risk of vulnerability to accumulated disadvantage. Therefore, the lowest age at which risk of vulnerability exists is suggested by the chapter for protection of older people. 


\section{Chapter 10}

The chapter explores the vulnerability framework, theories of ageing and the process of ageing in terms of the lived experiences of older people. The aim is to identify thematic commonalities of vulnerability. It is appreciated that not all outcomes of vulnerability will be identical. It is beyond the scope of the thesis to undertake a global examination of every type of vulnerability. Nonetheless, comparison is made between regions or nations where possible in order to confirm that older people suffer similar vulnerabilities and require a human rights response of special protection. The UK experience is included in order to highlight the domestic situation, and as an example of the position of older people in an economically advanced and modernised country. Sources of research included domestic, regional and international surveys and reports from expert and special interest bodies.

Findings grounded in embodied, pathogenic, and institutional vulnerability inform the examination of the international framework in Part IV. Furthermore, thematic domains, normative content and outcomes of human rights for older people are instructed by this chapter in the context of previous discussions of dignity, vulnerability, capabilities, and theories. Moreover, practical clarification of the position of older people in international human rights begins.

\section{Chapter 11}

Chapter 11 continues to clarify the position of older people in international rights. The chapter undertakes an examination of the normative provision of international human rights vis à vis the vulnerabilities of older people, and in accordance with the vulnerability framework developed in Part II. The UDHR is initially examined as the blueprint for subsequent international human rights instruments in this context. Examination of the International Covenant on Civil and Political Rights, and the International Covenant on Economic, Social and Cultural Rights follows. In addition, regional instruments which include older people are explored, and instruments of special protection to which older people have access by virtue of group membership. The adequacy of each instrument and each right are tabulated as an overview of protection provided the group, followed by a detailed discussion of positive and negative aspects of normative rights provision. The findings contribute to the answers to questions of the adequacy of the existing international framework, and the need for special protection for older people.

The chapter concludes with the application of a modified Capabilities Approach to determining normative human rights provision for older people. The modification of the Capabilities Approach and the subsequent listing of Fundamental Capabilities for Older People to ground normative content of special protection human rights contribute to the originality of this thesis. The chapter incorporates the approach to establish "what a person is able to be and do," with an emphasis on what the person is not able to be and do and should be able to be and do in order to attain equality of dignity and prevent vulnerability. The vulnerability framework and experiences of older people form the basis of outcomes required of Fundamental Capabilities. A Listing of universal central capabilities created by Nussbaum, and the listing created by Vizard et al for children as a 
vulnerable group were grounded in the existing international rights framework. The Fundamental Capabilities listing proposed by this thesis is grounded first and foremost in vulnerability, and secondarily in existing rights. As outcomes, the listing informs the normative provision and indicators of special protection rights.

Chapter 12

Following the normative examination of human rights provision in the international framework, this chapter explores implementation of rights. Findings build on research of the previous chapter and Part III (Researching older people for human rights), thereby contributing to questions of adequacy of existing rights for older people, and the necessity of special protection. The method of examining implementation for purposes of assessing inadequacies continues the approach developed by this thesis, grounded in vulnerability and a Capabilities Approach. Implementation of the rights of the international framework will be scrutinised in the context of the "special purpose" listing of Fundamental Capabilities developed in the previous chapter. The capabilities listing for older people, and the method in which it was developed, are original aspects of the research of this thesis. Therefore, examining how effect is given to the Fundamental Capabilities through implementation of the existing rights construct adds to the originality of the research.

The instruments on which the chapter focuses are the ICCPR, ICESCR, UNCRPD and CEDAW, together with instructions for implementation in associated General Comments. Thus, the chapter considers universal rights and rights of special protection to which sub-groups of older people have access. Applying a Capabilities Approach to the task is defined by this thesis as "providing the individual with the capabilities to the right to the capability." As a result of initiating the process with a vulnerabilities approach, the role of the Capabilities Approach becomes one in which capabilities are provided to overcome vulnerabilities preventing opportunity to the right. The right is the right to the outcome of capability to achieve an end result representative of equality in dignity. The chapter continues with a discussion of how aspects of a Capabilities Approach to human rights provide a means of implementation in order to give effect to rights such that specified outcomes are achieved. Aspects include obligations of de facto, a broad class of human rights, positive State and international duty, and indicators grounded in Fundamental Capabilities. The chapter concludes with a comparison of an implementation framework developed by the United Nations, including identified attributes of rights used to inform indicators, and outcome indicators, with the listing of Fundamental Capabilities for older people. The chapter finds the UN implementation framework to give effect to universal rights in the context of the liberal, rather than the vulnerable subject; the vulnerable being the older person. International rights are proven not to be implemented in order to give effect to the interests held in rights by older people. The chapter suggests that de facto indicators derived from capabilities outcomes are, therefore, required; once more adding to the originality of the research. 


\section{Chapter 13}

Chapter 13 examines the progress made by the UNOEWGA to fulfil the interests held by older people in human rights. The observations of the OEWG including areas requiring 'special attention' and 'key areas for explicit consideration in a new instrument' form part of the focus. In addition, the chapter considers the methods proposed to deliver rights for older people by the Group. Offerings by the Group largely support, in broad terms, the vulnerability findings of the thesis. However, in contrast with the thesis, methods suggested by the Group do not include the creation of a special protection Convention. Instead, the recommendations include: fully implementing existing universal rights; directing older people to the CRPD; and developing regional responses to older people. Furthermore, the OEWGA determines that signatories to a Convention would be limited due to costs associated with implementation of older people's rights. 


\section{CHAPTER 1}

\section{CONCEPTS AND INTRODUCTION TO HUMAN RIGHTS}

\subsection{Introduction}

The purpose of the chapter is to provide an introduction to fundamental concepts of human rights which will inform discussion elsewhere in this thesis. It is not intended to provide a comprehensive explanation of human rights theory, but instead to provide an adequate theoretical framework to support discussion in following chapters. It begins by discussing different accounts of human rights, grounded in natural rights and positive rights theory. This is followed by an introduction to the debate surrounding the validity of Will Theory and Interest Theory, as competing explanations of rights-holding and entitlement, to shed light on how rights might function for older people. Interest Theory is preferred to Will Theory; justified later in this thesis by reference to vulnerability, dignity, and the purpose of rights and instruments.

The chapter explains the concepts of moral human nature, human need and dignity as underpinning human rights. The chapter also discusses typologies of human rights, i.e. moral, legal, civil and political, socio-economic, positive, negative, individual, and group rights. Moral rights are discussed for their role as a guide to legal rights. The major categories of civil and political and socio-economic rights are explained initially in terms of content. This leads to a brief discussion of justiciability. This is significant for older people as the justiciability of socio-economic rights, which are often directed at meeting the vulnerability of social groups, is contested. It is asserted that all rights can be held either individually or by individuals as members of a group. The treatment of group rights by Interest Theory prepares the ground for inclusion of the theory in this discussion.

\subsection{Theoretical Underpinnings of Human Rights}

The purpose of this presentation of some theoretical underpinnings of human rights is not to provide analysis of the philosophies of rights. Rather, it is, to borrow from Shestack, to draw on them to provide an understanding of the obscure sphere of human rights. ${ }^{3}$ Therefore, under this heading two of the main theories of human rights will be discussed. The settings of natural rights and positive rights are examined for contextual purposes, but the rationale, aims and outcomes of both are of most relevance to understanding the nature and role of contemporary rights. Therefore, the aim of this discussion is to draw attention to the underpinning themes of human rights which are most pertinent to this thesis, themes which relate to issues of dignity, vulnerability and capability

${ }^{3}$ J.J. Shestack, 'The Philosophic Foundations of Human Rights,' HRQ 20:2, May 1998, 203-204 
which are the subjects of later chapters, and in the assessment of human rights most suitable for older people in Part IV. Reference will also be made to Interest Theory and Will Theory, in particular to establish which approach to rights-holding is most suitable to give effect to human rights for older people.

\subsubsection{Natural Rights and Positive Rights}

The strength of influence of natural rights in the domain of human rights is summed up by Cranston, stating that, 'Human rights is the twentieth-century name for what has been traditionally known as natural rights. ${ }^{4}$ Natural rights provide a source of objective moral values and the standards of 'right and wrong, ${ }^{5}$ and, subsequently, the measure for man made laws. ${ }^{6}$ By establishing personal goals, they direct human flourishing, and provide a guide for human interaction. ${ }^{7}$ This measure evolved as 'Whatever conformed to the [rational] nature, ${ }^{8}$ and it seemingly became necessary to have rational agency in order to qualify as a rights holder. This presented problems of rights-entitlement to the non-rational, non-autonomous agent. This dilemma is faced in the access of human rights, and recognised by Interest Theory.

Some of the ways in which contemporary human rights are based in natural rights are identifiable in the views of Hobbes and Locke. Hobbes saw 'rational desiring beings, ${ }^{9}$ as creating a state of insecurity ${ }^{10}$ in which individual's rights were unprotected, and proposed that rights be held by the sovereign on behalf of the individual. ${ }^{11}$ The application and enforcement of rights required formal administration, legal systems, and stated law. Set in the global reality of multiple sovereign governments, with domestic laws and interpretation, he concluded universal morality and universal law impossible. ${ }^{12}$ Locke's state of nature saw man as naturally free, ${ }^{13}$ and all people equal, ${ }^{14}$

\footnotetext{
${ }^{4}$ M. Cranston, What are Human Rights? (1973; Bodley Head), 1

${ }^{5}$ The central tenet of which was said by Aquinas to be 'good is to be done and pursued and evil is to be avoided.'Aquinas quoted inE. Feser, 'The metaphysical foundations of natural rights' in T. Cushman (ed.) Handbook of Human Rights (2014; Routledge), 25

${ }^{6}$ M.D.A. Freeman, Lloyd's Introduction to Jurisprudence (2001; Sweet \& Maxwell), 59

${ }^{7}$ E. Feser, 'The metaphysical foundations of natural rights' in T. Cushman (ed.) Handbook of Human Rights (2014; Routledge), 25

8 J.J. Shestack, 'The Philosophic Foundations of Human Rights,' HRQ 20:2, May 1998, 207

9 J. Gorman, Rights and Reason (2003; Acumen Publishing Limited), 41

${ }^{10}$ C. Harvey, 'Talking about Human Rights', E.H.R.L.R. 2004, 5, 500, 502; M. Macdonald, 'Natural Rights' in J. Waldron, Theories of Rights (1984; Oxford University Press), 26

The resulting state of nature he described as, 'Warre of every one against every one... It followeth, that in such a condition, every man has a Right to every thing, even to one another's body.' T. Hobbes, 'The Levithian' (1651) in R. Tuck (ed.) (1996; Cambridge University Press), 89, cited in C. Harvey, 'Talking about human rights,' EHRLR 2004; 5, 500, 501

${ }^{11}$ E. Feser, 'The metaphysical foundations of natural rights' in T. Cushman (ed.) Handbook of Human Rights (2014; Routledge), 27

12 J. Gorman, Rights and Reason: An Introduction to the Philosophy of Rights (2003; Acumen Publishing), 11
} 
Regarding duty, Locke's natural rights placed the burden on individuals and the state to protect the life and rights of oneself and others, and enable development and flourishing. Therefore, the noninterference duty of the state was emphasised, and still persists, particularly in civil and political rights. Recognising the aforementioned potential for conflict between interests raised by rational choice, ${ }^{15}$ Locke's solution is a society in which individuals are rights-holders and the State bears the duty. The duty is enforceable by contemporary rights, to protect, preserve, and make rights attainable via the obligation of non-violation. Furthermore, the duty owed depends on rational choice to make a claim upon it, which grounds Will Theory.

The work of Kant also makes a significant contribution to understanding contemporary human rights. Crucially, he saw rights founded in freedom, equality, reason and universality, ${ }^{16}$ and owed by virtue of a person's humanity. ${ }^{17}$ The human was defined in terms of capacity for autonomy and reason, and ability to determine one's goals. ${ }^{18}$ Agency did not merely constitute rationality. Moral agency was viewed as influential in human dignity and human rights. ${ }^{19}$ 'Moral agency' makes the person an end in herself, with an inherent dignity. In Kantian theory, the value of the person lies in inherent dignity. ${ }^{20}$ Of the subject-matter of rights Kant insisted, 'There is Only One Innate Right, ${ }^{21}$ not to be controlled, forced into action or decision, or to have personal choice interfered with,' implying an 'innate equality.' With overtures of Lockean theory, Kant informs us that rights exist independent of civil society, and that the duty of the State is to protect and promote these specific freedoms.

The idea of natural rights received its strongest criticism from Bentham, who took the view that rights only exist by reason of recognition by legal authority. Condemning the source of natural rights

\footnotetext{
${ }^{13}$ D.J. O'Byrne, Human Rights (2003; Pearson), 19 \& 30

${ }^{14}$ J.J. Shestack, 'The Philosophic Foundations of Human Rights,' HRQ 20:2, May 1998, 201, 207

${ }^{15}$ Covenant of the League of Nations, Article 23(b), in G. Scott, The Rise and Fall of the League of Nations (1973; Hutchinson), 417, cited in J. Waldron, Nonsense Upon Stilts: Bentham, Burke and Marx on the Rights of Man (1987: Methuen), 9

${ }^{16}$ L. Ceranti, 'Kant's Theory of Human Rights' in T. Cushman, (ed.) Handbook of Human Rights (2014; Routledge), 37

${ }^{17}$ L. Ceranti, 'Kant's Theory of Human Rights' in T. Cushman, (ed.) Handbook of Human Rights (2014; Routledge), 37

${ }^{18}$ L. Ceranti, 'Kant's Theory of Human Rights' in T. Cushman, (ed.) Handbook of Human Rights (2014; Routledge), 37

${ }^{19}$ L. Ceranti, 'Kant's Theory of Human Rights' in T. Cushman, (ed.) Handbook of Human Rights (2014; Routledge), 38

${ }^{20}$ Issues which are relevant to later discussions of human dignity. See Chapter 4, 'Human Dignity.' L. Ceranti, 'Kant's Theory of Human Rights' in T. Cushman, (ed.) Handbook of Human Rights (2014; Routledge), 40

${ }^{21}$ Echoes of this principle are heard in the argument surrounding the ability and freedom to enforce or waive a claim, duty and recompense for a breach of duty.
} 
as vague and unsubstantiated, he viewed positive law as the source of rights. ${ }^{22}$ In this vein, rights are incorporated into international instruments, domestic constitutions, or legislation and enforced through the judiciary, governmental instruments and policy. ${ }^{23}$

A key point of departure from Behntham's positive rights theory by the present human rights construct exists in the proposal that rights should serve 'the happiness of society' first, and the individual only derivatively. ${ }^{24}$ This approach does not find a home in individual rights or special protection rights, as human rights address the concerns of individuals. Special protection is provided to enhance individual rather than collective concerns.

Bentham's positive rights placed the duty to facilitate human rights on the sovereign, and subject to sanction for failure to comply. ${ }^{25}$ This idea of recompense for breach of duty is accepted by both natural rights and positive rights theories as an aspect of the practical implementation of rights. Such duty, he claimed, could only be owed for rights which can be formally enforced. In positive rights theory, moral rights attract no duty.

At the level appropriate to discussion of rights theory in this thesis there is some potential to draw on correspondence between both theories. Notably, the moral grounding of natural rights may also underpin positive rights which are offered protection by a legal authority. However, when enforcement cannot be guaranteed the differences emerge once more. The essential coercive power which Bentham prioritises means that lack of enforcement would downgrade the status of a right to that of moral claim, rather than enforceable right. ${ }^{26}$ In this respect, considering that moral rights, or legal rights that are morally defensible; and must have a basis in 'human interests, needs or welfare, ${ }^{27}$ there is good reason for the claim that 'Bentham took rights a bit too seriously. ${ }^{28}$

\footnotetext{
${ }^{22}$ The famous disparaging comments on natural rights, and justification of positive rights being: 'Right ... is the child of law: from real laws come real rights; but from imaginary laws, from laws of nature, ... come imaginary rights ... Natural rights is simple nonsense: natural and imprescriptible rights, rhetorical nonsense - nonsense upon stilts.' J. Bentham, 'Anarchical Fallacies' in The Works of Jeremy Bentham Volume II (1843; William Tait).see pp 501-523, cited in D.A. Habibi, 'Human Rights and Politicized Human Rights; A Utilitarian Critique,' 'Journal of Human Rights' 2007; 6: 3, 4

${ }^{23}$ D.A. Habibi, 'Human Rights and Politicized Human Rights; A Utilitarian Critique,' 'Journal of Human Rights' 2007; 6:3, 5

${ }^{24}$ J. Bentham, 'Anarchical Fallacies,' cited in J. Waldron, Nonsense upon Stilts; (1987; Methuen), 40

${ }^{25} \mathrm{~J}$. Waldron, Nonsense upon Stilts; (1987; Methuen), 35

${ }^{26} \mathrm{~J}$. Waldron, Nonsense upon Stilts; (1987; Methuen), 35

27 D. Lyons, 'Utility and Justice' in J. Waldron, Theories of Rights, (1984; Oxford University Press), 120

${ }^{28}$ D. Lyons, 'Utility and Justice' in J. Waldron, Theories of Rights, (1984; Oxford University Press), 122
} 


\subsection{General Underpinnings of Human Rights}

A number of conceptual accounts may be seen as underpinning human rights. Moral human nature - especially when linked to natural rights -, human need, and human dignity have all been advanced as the basis for human rights. Whilst all are independent foundations for human rights, a degree of connectivity can be identified between them. The contribution of each to human rights will be discussed with a view to bringing the underlying sources of, and reasons for, human rights to the fore.

\subsubsection{Moral human nature}

Natural rights are derived from moral human nature, which is closely linked to dignity. Moral human nature is seen as extending to prescriptive norms of behaviour as well as development ${ }^{29}$ which underpin human rights and set standards for a life of human dignity. The association of these norms with dignity is the motivation for their incorporation in human rights instruments (treaties), as rights are seen as needed to guarantee a life of human dignity. ${ }^{30}$ The relationship between moral human nature and human rights is reciprocal, and the norms underpinning rights are influenced by the nature that human rights help mould. ${ }^{31}$ Therefore human rights are constantly adapting to needs of society, ${ }^{32}$ and groups requiring special protection. As will be discussed in later chapters, international human rights are universal. Morality, however, is not universal, ${ }^{33}$ but the fundamental requirements of preservation of human life and human dignity may be universal moral values which provide a connection to universal human rights norms. ${ }^{34}$ These norms are also closely related to the remaining two concepts of human need and human dignity which are considered below.

\footnotetext{
${ }^{29}$ D. Donnelly, Universal Human Rights In Theory and Practice (2000; Cornell University Press), 14

${ }^{30}$ D. Donnelly, Universal Human Rights In Theory and Practice (2000; Cornell University Press), 14

31 'Human rights shape human beings, so as to realize the possibilities of human nature, which provided the basis for these rights in the first place.' D. Donnelly, Universal Human Rights In Theory and Practice (2000; Cornell University Press), 16-17

32 D. Donnelly, Universal Human Rights In Theory and Practice (2000; Cornell University Press), 15 to help rights assist the person 'to be that which you are not yet.' M. MacDonald, 'Natural Rights' in J. Waldron (ed.), Theories of Rights (1984; Oxford University Press), 24

${ }^{33}$ See Hobbes in 1.2.1 'Natural Rights.'

${ }^{34}$ J. J. Shestack, 'The Philosophic Foundations of Human Rights, ' 'Human Rights Quarterly' 20:2, May 98, 201, 202
} 


\subsubsection{Human Need}

Human need is increasingly suggested as the motivation for human rights. ${ }^{35} \mathrm{Need}$, as defined by Bay, will be identifiable in discussions of vulnerability which follow later in this work, ${ }^{36}$ and in discussion for what it means to be an older person ${ }^{37}$

any requirement for a person's survival, health, or basic liberties; basic meaning that,

to the extent that they are inadequately met, mental or physical health is impaired.

Thus, 'need' refers to necessities for not only biological survival but also for the health and development (physical and mental growth) of persons as human beings. ${ }^{38}$

It is relevant that self-respect is included in 'basic liberties, ${ }^{39}$ which features in aspects of human dignity, vulnerabilities, and ageing theory. ${ }^{40}$ The interest a person has in a need must be sufficiently important to life to qualify as a human right. 'Real needs,' are 'vital ones- nourishment, clothing, lodging, ${ }^{41}$ which find favour with socio-economic rights, and are those which a person has an unqualified claim to satisfy. ${ }^{42}$

Bay proposes that 'rights should be enacted ... and enforced ... according to priorities of human need. ${ }^{43}$ In light of this he listed and prioritised categories of human needs as follows: 'survival needs, health protection needs, community solidarity needs, and individual freedom needs. ${ }^{.44}$ Unequivocally, dire human needs and claims emanating from them have ultimate priority over every other type of claim, be it moral or legal. ${ }^{45}$ In effect, this is the inventory of needs that directly inform

\footnotetext{
${ }^{35}$ C. Bay, 'Self-Respect as a Human Right: Thoughts on the Dialectics of Wants and Needs in the Struggle for Human Community,' HRQ Vol. 4, No. 1 (Spring 1982), 53, 62

${ }^{36}$ Chapter 5, 'Vulnerability'

${ }^{37}$ Chapter 8, 'Theories of Ageing;'Chapter 9 'Defining Older People by Ageing Process and Chronological Age;' and Chapter 10, 'What it Means to be an Older Person: Research of the Vulnerable Experience'

${ }^{38}$ C. Bay, 'Self-Respect as a Human Right: Thoughts on the Dialectics of Wants and Needs in the Struggle for Human Community,' HRQ Vol. 4, No. 1 (Spring 1982), 53, 67

${ }^{39}$ C. Bay, 'Self-Respect as a Human Right: Thoughts on the Dialectics of Wants and Needs in the Struggle for Human Community,' HRQ Vol. 4, No. 1 (Spring 1982), 53, 67

${ }^{40}$ See Chapter 8, 'Theories of Ageing'

${ }^{41}$ Marcuse, 1955, 4-5, cited in R. Fitzgerald, 'Human Needs and Politics: The Ideas of Christian Bay and Herbert Maracuse,' Political Psychology, 6:1 March 1985, 87, 88

${ }^{42}$ Marcuse, 1955, 4-5, cited in R. Fitzgerald, 'Human Needs and Politics: The Ideas of Christian Bay and Herbert Maracuse,' Political Psychology, 6:1 March 1985, 87, 88

${ }^{43}$ C. Bay, 'Self-Respect as a Human Right: Thoughts on the Dialectics of Wants and Needs in the Struggle for Human Community,' HRQ Vol. 4, No. 1 (Spring 1982), 53, 62

This principle finds favour with the Capabilities Approach, which is the subject of Chapter 6, and which is used to assess the adequacy of human rights provision for older people in Part IV

${ }^{44}$ C. Bay, 'Self-Respect as a Human Right: Thoughts on the Dialectics of Wants and Needs in the Struggle for Human Community,' HRQ Vol. 4, No. 1 (Spring 1982), 53, 66

${ }^{45}$ C. Bay, 'Self-Respect as a Human Right: Thoughts on the Dialectics of Wants and Needs in the Struggle for Human Community,' HRQ Vol. 4, No. 1 (Spring 1982), 53, 62
} 
the content of human rights, and may help resolve conflict between rights, e.g. where extreme need may impact on survival, any right which meets need in these circumstances should be prioritised. ${ }^{46}$

The needs identified and prioritised are applicable to every human being; they are universal. Therefore, it follows that human rights based on meeting need must be universal to promote and protect individual rights holders. Additionally members of society with claims to have the most basic human needs met are the most vulnerable to harm, including death. Such vulnerable individuals should take priority for rights. ${ }^{47}$ The final word in this section on human need and human rights is the definition of human rights provided by Bay:

'[Human rights are] all categories of individual claims (including claims on behalf of individuals or groups) which ought to have legal protection, as well as social and moral support, because the protection of these claims is essential to meet basic human needs. ${ }^{48}$

\subsubsection{Human Dignity}

The concept of Human Dignity is discussed in detail in Chapter 4, 'Human Dignity and Human Rights.' Therefore, this section will explore the fundamental principles of the concept as they relate to human rights. Human dignity is considered foundational to human rights. In return, human rights aim to protect human dignity. There is, amongst the various discussions surrounding sources of rights, what constitutes rights, and the aims of rights, a general consensus for human rights to contribute towards 'human existence in dignity and freedom. ${ }^{49}$

The definition of human dignity continues to evolve. The traditional components of autonomy, freedom, and equality are increasingly accompanied by human need. A recognisable relationship exists between human dignity and vulnerability, ${ }^{50}$ and will be evidenced in the vulnerabilities of older people. ${ }^{51}$

Autonomy is one of the components of Human Dignity. When autonomy grounds rights the individual is able to choose between rights for optimal fulfilment of interests and need. The

\footnotetext{
${ }^{46}$ It also bears striking similarity to the vital capabilities which are discussed in Chapter 6.

${ }^{47}$ R. Fitzgerald, 'Human Needs and Politics: The Ideas of Christian Bay and Herbert Maracuse,' Political Psychology, 6:1 March 1985, 87, 103

${ }^{48}$ Bay, C., 1979, 9-14, cited in R. Fitzgerald, 'Human Needs and Politics: The Ideas of Christian Bay and Herbert Marcuse,' 'Political Psychology' 6:1 (March 1985), 87, 104

${ }^{49}$ C. Tomuschat, Human Rights Between Idealism and Realism (2014; Oxford University Press), 4

${ }^{50}$ Which will be demonstrated in chapters 4, 'Human Dignity,' 5, 'Vulnerability,' and 7, 'Synthesis.'

${ }^{51}$ See chapter 10, 'What it Means to be an Older Person: Research of the Vulnerable Experience.'
} 
freedom so closely associated with autonomy is of 'self determination,' which creates rights allowing the holder to flourish and develop. Autonomy creates non-coercive rights, in return permitting freedom. The central position of autonomy in the human rights concept sees autonomy both enable, and be protected by, rights. However, autonomy also stands accused of leaving the most vulnerable 'by and large excluded from the protection offered by autonomy-based human rights. ${ }^{52}$ This is particularly the case for the person lacking decision-making ability, and dependent upon inconsistent judicial and policy interpretation of rights and dignity. ${ }^{53}$ Furthermore, autonomy is criticised as an 'incomplete foundation' to dignity and human rights for the person for whom dignity is a matter of human need.

The role of equality in dignity and human rights is to ensure equal access to rights, freedom, and autonomy. Through this, equality in provision and protection against vulnerability brought about by need or want is achieved. When equality is fully incorporated into rights, discrimination is prevented, and the equal worth of all individuals is recognised independent of capability. ${ }^{54}$ The effect is felt across all categories of rights, emphasising the role of 'equality-promoting' rights which relate to social or economic issues affecting social groups. ${ }^{55}$ This eases provision for human need, addressing vulnerabilities, compensating for a lack of capability, and achieving equality in human dignity for individuals.

These three elements of dignity have a close relationship. Donnelly describes the effect of equality and autonomy in human rights in terms of 'individuals are entitled to make choices about what constitutes the good life (for them), with whom they associate and how. ${ }^{56}$ He then draws association between freedom and equality, or non-discrimination, '...the liberty to choose and pursue one's own life, clearly is entailed by the idea of equal respect. ${ }^{, 57}$

However, the non-autonomous agent, requires a more holistic approach to dignity. ${ }^{58}$ Therefore, the following are added to the dignity mix, : moral and physical integrity; psychological integrity; selfworth, ${ }^{59}$ and all issues associated with independence. ${ }^{60}$ The role of the traditional factors of

\footnotetext{
${ }^{52}$ C. Dupre, 'Unlocking human dignity: towards a theory for the $21^{\text {st }}$ century,' EHRLR, 2009; 2, 190, 194

${ }^{53}$ C. Dupre, 'Unlocking human dignity: towards a theory for the $21^{\text {st }}$ century,' EHRLR, 2009; 2, 190, 193-194

${ }^{54}$ G. Kateb, Human Dignity, (2011; Harvard University Press), 5 and 8-9

${ }^{55}$ S. Fredman, Human Rights Transformed, Positive Rights and Positive Duties (2009; Oxford University Press), 66

${ }^{56}$ D. Donnelly, Universal Human Rights In Theory and Practice (2000; Cornell University Press), 44

${ }^{57}$ D. Donnelly, Universal Human Rights In Theory and Practice (2000; Cornell University Press),.44

${ }^{58}$ C. Dupre, 'Unlocking human dignity: towards a theory for the $21^{\text {st }}$ century,' EHRLR, 2009; 2, 190, 194

${ }^{59}$ C. Dupre, 'Unlocking human dignity: towards a theory for the $21^{\text {st }}$ century,' EHRLR, 2009; 2, 190, 192-197
} 
autonomy, freedom, and equality in human dignity remain vital, the less abstract factors giving support to human need. As will be discussed later in this work, a holistic account of human dignity is best able to underpin civil and political and socio-economic rights,

The three concepts underpinning human rights are interrelated. Moral human nature provides the universal moral norms for a life of human dignity. Human need points the way to the content of rights to counter vulnerability. The need which underpins rights is universal and must be fundamental to existence, basic liberties and dignity. The three traditional components of dignity are essential, as freedom to direct one's life, to choose and to have rights available without discrimination give the person dignity. Yet they are of little worth if they do not provide the dignity found by fulfilling need through rights which are bound by moral norms.

\section{$1.4 \quad$ Obligations}

In order to ensure human rights are effective there are specific obligations to respect, protect and fulfil. Respect equates to non interference in order not to deprive a person of his/her rights. Protection is achieved by preventing third parties depriving rights. Human rights are fulfilled by facilitating the exercise of rights. ${ }^{61}$ There are specific guidelines for socio-economic rights regarding how these obligations are to be achieved. States are instructed to 'take appropriate legislative, administrative, budgetary, judicial and other measures towards the full realization of such rights. ${ }^{62}$ Each obligation has duties of conduct and result. The first of these involves undertaking action reasonably expected of the state to fulfil a right. The second demands that States meet stipulated targets to 'satisfy a detailed substantive standard. ${ }^{163}$ States are permitted a margin of discretion in the means through which they achieve obligations. However, there are universal minimum standards and a general consensus of the scope, nature and limitation of economic, social and cultural rights which must be met. These have been arrived at through the application of policy and rights norms by domestic and international courts and monitoring bodies to concrete cases. ${ }^{64}$ Importantly, the progressive realisation principle available to socio-economic rights does not

\footnotetext{
${ }^{60}$ C. Dupre, 'Unlocking human dignity: towards a theory for the $21^{\text {st }}$ century,' EHRLR, 2009; 2, 190, 198

${ }^{61}$ Polly Vizard, Sakiko Fukuda-Parr \& Diane Elson, 'Introduction: The Capability Approach and Human Rights,' Journal of Human Development and Capabilities, Vol. 12, No. 1, February 2011, 1, 7

${ }^{62}$ Masstricht Guidelines on Violations of Economic, Social and Cultural Rights, Maastricht, January 22-26, 1997. II.6

${ }^{63}$ Masstricht Guidelines on Violations of Economic, Social and Cultural Rights, Maastricht, January 22-26, 1997. 11.7

${ }^{64}$ Masstricht Guidelines on Violations of Economic, Social and Cultural Rights, Maastricht, January 22-26, 1997. II.8
} 
diminish the responsibility to fulfil obligations expeditiously, and to the maximum of available resources. ${ }^{65}$ The Committee on Economic, Social and Cultural Right determined minimum core obligations for second generation rights. These are minimum essential levels which 'apply irrespective of the availability of resources of the country concerned or any other factors and difficulties. $^{66}$ Indeed, availability of resources is not a basis to relieve a state of minimum obligations regarding the implementation of economic, social and cultural rights. ${ }^{67}$

Differentiation between civil and political and socio-economic rights extends to the timing of State obligation. The duty attached to socio-economic rights can be fulfilled through 'progressive realisation' 'to the maximum of available resources' due to the demands that their provision can create on limited resources. However, this impreciseness exposes them to the vagaries of economic downturn, unless they are protected by the obligation, available to some socio-economic rights only, of 'immediate effect.' The duty borne for civil and political rights is of 'immediate obligation. ${ }^{68}$

The duty of progressive realisation and the indeterminate nature of socio-economic rights highlighted earlier are associated with positive duties. Immediate realisation is a factor of negative duties. In order to give greater immediacy and determinacy to positive rights a minimum core obligation has been recommended. This would comprise the 'minimum essentials' of a right and that states 'must demonstrate that every effort has been made to use all resources at its disposition in an effort to satisfy, as a matter of priority, those minimum obligations. ${ }^{69}$ Difficulties occur in the application, however, including creating an immediate demand from all rights holders for the minimum core obligation drawing on all resources at the state's disposal. ${ }^{70}$ However, it is possible for the state to overcome problems of inability to meet such demand by demonstrating that 'every effort has been made to use all resources ... at its disposition in an effort to satisfy, as a matter of

\footnotetext{
${ }^{65}$ Masstricht Guidelines on Violations of Economic, Social and Cultural Rights, Maastricht, January 22-26, 1997. II.8

${ }^{66}$ Masstricht Guidelines on Violations of Economic, Social and Cultural Rights, Maastricht, January 22-26, 1997. 11.9

${ }^{67}$ Limburg Principles 25-28; Masstricht Guidelines on Violations of Economic, Social and Cultural Rights, Maastricht, January 22-26, 1997. II.10

${ }^{68}$ T. Van Boven, 'Categories of Rights' in D. Moeckli, S. Shah, \& S. Sivakumaran (eds.) with D. Harris, (Consultant Editor), International Human Rights Law (2010; Oxford University Press), 175

${ }^{69}$ CESCR. General Comment 3, The nature of States parties obligations (Fifth session 1990) UN Doc E/1991/23, Annex III, para 9, cited in S. Fredman, Human Rights Transformed, Positive Rights and Positive Duties (2009; Oxford University Press), 84

${ }^{70}$ Khosa and Mahlaule v Minister for Social Development 2004 (6) BCLR 569 (South African Constitutional Court) para 34, cited in S. Fredman, Human Rights Transformed, Positive Rights and Positive Duties (2009; Oxford University Press), 85
} 
priority, those minimum obligations. ${ }^{, 71}$ Issues of prioritisation remain beyond those of the basic right of survival and those in dire need, but this approach points the way to making socio-economic rights less aspirational, and including them in the general understanding of the "human rights package.'

\subsection{Typologies of Rights}

At this stage, and to aid discussion in later chapters, it is worth discussing how various rights (informed by the concepts discussed above) may be categorised. It is possible for rights to be explained using a number of categories or typologies. Those presented here are: civil and political and socio-economic; positive and negative rights; and individual and group rights. They are considered in terms of nature and, where applicable, content, duty, and expression in human rights instruments. This will provide background to the research on human rights instruments in Part IV of this thesis.

\subsubsection{Civil and Political Rights; and Social, Economic and Cultural Rights}

Civil rights are those 'calculated to protect an individual's physical and mental integrity,' and 'to ensure that they are not the victims of discrimination.' Political rights 'are those which ensure that individuals are able to participate fully in civil society. Such rights include rights of democratic participation, such as the right to vote and to participate in the public life of the state, freedom of expression and assembly, and freedom of thought, conscience and religion. ${ }^{72}$ Some civil and political rights can be considered hybrid rights, such as the right to marry and found a family, which is also social in nature. Additionally, the right to non-discrimination is applicable to all categories of rights. $^{73}$

Social, economic and cultural rights are considered the more practical of human rights, with direct impact on 'real' human needs. Although often supportive of civil and political rights, they exist independently. These rights may be described under the broad headings of those human rights

\footnotetext{
${ }^{71}$ Khosa and Mahlaule v Minister for Social Development 2004 (6) BCLR 569 (South African Constitutional Court) para 10, cited in S. Fredman, Human Rights Transformed, Positive Rights and Positive Duties (2009; Oxford University Press), 85

72 A. Conte \& R. Burchill, Defining Civil and Political Rights: The Jurisprudence of the United Nations Human Rights Committee (2009; Ashgate),3

${ }^{73}$ A. Conte \& R. Burchill, Defining Civil and Political Rights: The Jurisprudence of the United Nations Human Rights Committee (2009; Ashgate),4
} 
relating to the workplace, social security, family life, participation in cultural life, and access to housing, food, water, health care and education.

Despite this segregation civil and political rights frequently rely upon socio-economic rights to provide the means required to enable individuals to realise civil and political rights. . Examples include the right to life and the right to freedom from degrading treatment which find support in socio-economic rights to health, sustenance and shelter. ${ }^{74}$ Civil and political rights also offer some underpinning for socio-economic rights. Freedom of speech is regularly quoted as central to raising awareness and 'the conceptualisation of economic needs. ${ }^{75}$

\subsubsection{Distinctions Between Civil and Political and Social, Economic and Cultural Rights}

It is often argued that civil and political rights draw, in the main, on minimal resources, whilst socioeconomic rights invariably require resources to be allocated or redistributed in order to be realised. It is generally considered that it is the resource-dependency of socio-economic rights that prevents them receiving the weight of legal support granted to civil and political rights ${ }^{76}$ This difference between the two generations of rights is potentially the greatest barrier faced by human rights in attempts to achieve equality in human dignity, particularly when the requirement is to address numerous vulnerabilities.

On the basis of the legal recognition afforded civil and political rights over socio-economic rights the former are considered superior; one of the consequences being that breaches of socio-economic rights are considered more acceptable despite their more practically beneficial impact on wellbeing. ${ }^{77}$ The significance of both sets of rights was recognised in the Universal Declaration on Human Rights. However, since that time, with the exception of some regional and special human rights group instruments, they are divided, rather than united, by international and regional human rights conventions, covenants, charters and declarations. ${ }^{78}$

\footnotetext{
${ }^{74}$ T. Van Boven, 'Categories of Rights' in D. Moeckli, S. Shah, \& S. Sivakumaran (eds.) with D. Harris, (Consultant Editor), International Human Rights Law (2010; Oxford University Press),179

${ }^{75}$ S. Fredman, Human Rights Transformed, Positive Rights and Positive Duties (2009; Oxford University Press), 67

${ }^{76}$ R. Stone, Civil Liberties and Human Rights (2010; Oxford University Press), 8

${ }_{77}^{7}$ R. Stone, Civil Liberties and Human Rights (2010; Oxford University Press),.8

${ }^{78}$ Part IV will contain an examination of human rights instruments
} 


\subsubsection{Positive and Negative Rights}

Rights, including human rights, are often categorised as positive or negative rights. This reflects primarily the obligation imposed on the State. A duty of restraint, or the duty to respect right imposed on the State, is conceived as a negative duty. Where a right imposes such a duty of restraint it will be referred to as a negative right. Conversely, a duty to take action to fulfil rights is a positive duty. Rights which require positive State action will be referred to as positive rights. Duties of non-interference are habitually connected to 'freedom-protecting' and are seen primarily as a feature of civil and political rights. Duties to act are frequently associated to 'equality-promoting' socio-economic rights. ${ }^{79}$ However, this perceived allocation of duty is not absolute. The right to life places a duty of the state not to unlawfully take life. However, if freedom is considered 'to act to fulfil oneself' positive duties to provide healthcare, sustenance and shelter could be imposed. A similar response could exist to freedom from inhuman and degrading treatment. Socio-economic rights can attract negative duties. Fredman cites the right to be housed which also demands freedom from unlawful eviction, and finds favour with the civil and political right to a home. ${ }^{80}$ Additionally, many rights which attract a negative duty depend on a positive duty to enact laws prohibiting intervention to protect them. ${ }^{81}$

\subsubsection{Individual and Collective Rights}

Rights have also been categorised as individual or collective. Collective rights can refer to society generally, or to an identity group. When referring to society generally the issue at stake is whether the interests of the individual or the community should take precedence. ${ }^{82}$

Borrowing from Dworkin, there is a place for both in the application and categorisation of rights. The interests of the majority should not routinely override those of the individual. It may be argued that governments must be able to defend any restriction of liberty. This is normally by means of a positive effect for the public outweighing the effect of denying the right of the individual. ${ }^{83}$ Government cannot 'be justified in overriding' a right 'on the minimal grounds that would be

\footnotetext{
${ }^{79}$ S. Fredman, Human Rights Transformed, Positive Rights and Positive Duties (2009; Oxford University Press), 66

${ }^{80}$ S. Fredman, Human Rights Transformed, Positive Rights and Positive Duties (2009; Oxford University Press), 67-69

${ }^{81}$ A. Gerwith, The Community of Rights (1996; University of Chicago Press , 34-35

${ }^{82}$ T. Van Boven, 'Categories of Rights' in D. Moeckli, S. Shah, \& S. Sivakumaran (eds.) with D. Harris, (Consultant Editor), International Human Rights Law (2010; Oxford University Press), 176

${ }^{83}$ R. Dworkin, Taking Rights Seriously (1977; Duckworth), 191
} 
sufficient if no such right existed. ${ }^{84}$ Each occurrence of competing rights must be evaluated as right against right, and interest against interest. ${ }^{85}$

The emphasis on individual rights does not, however, prevent identified groups of individuals holding rights. Group rights in this sense belong to groups of people who share common characteristics, such as being in some other way vulnerable. The United Nations has recognised the fact that such special protection human rights groups exist, all entitled in equality and universality to the same human rights as every other person, yet also possessing 'collective rights which are indispensable for their existence, well-being and integral development. ${ }^{, 86}$

\subsection{Will Theory and Interest Theory}

The will and interest theories will be presented as concepts of human rights holding. Both theories proffer explanations of the function of rights for the rights-holder. They serve as a means of considering rights in the conceptual arena and are attempts to justify the purpose of rights. ${ }^{87}$

\subsubsection{Will Theory}

Throughout Will Theory there is a focus on self-determination and agency. ${ }^{88}$ Conceptually, Will Theory does not recognise a right prior to any claim made on it, as it works as 'a vehicle for some aspect of an individual's self-determination. ${ }^{89}$ The relationship between right and right-holder in Will Theory is set out by Hart, who argues that the right exists only when the holder has the power to enforce or waive the right. ${ }^{90}$ The rights holder thus becomes 'a small scale sovereign, ${ }^{91}$ able to demand that the duty correlative to the right be fulfilled or waived. When the duty is not waived, but breached by the duty-bearer, the power becomes the choice to seek a remedy. ${ }^{92}$ Significantly,

\footnotetext{
${ }^{84}$ R. Dworkin, Taking Rights Seriously (1977; Duckworth, London), 191-192

${ }^{85}$ R. Dworkin, Taking Rights Seriously (1977; Duckworth, London), 194

${ }^{86}$ Preamble of United Nations Declaration on the Rights of Indigenous Peoples (2007), cited in T. Van Boven, 'Categories of Rights' in D. Moeckli, S, Shah, \& S, Sivakumaran, (eds.) with D. Harris, (Consultant Editor), International Human Rights Law (2010; Oxford University Press), 177

${ }^{87}$ A. Harel, 'Theories of Rights' in M.P Golding \& W.A. Edmundson, The Blackwell Guide to the Philosophy of Law and Legal Theory (2005; Blackwell), 193

${ }^{88}$ W. A. Edmonson, An Introduction to Rights (2004; Cambridge University Press), 122

${ }^{89}$ M.H. Kramer, 'Rights Without Trimmings' in M.H. Kramer, N.E. Simmonds and H.A. Steiner, A Debate Over Rights, (2002; Oxford University Press), 62

${ }_{90}^{0}$ M.H. Kramer, 'Rights Without Trimmings' in M.H. Kramer, N.E. Simmonds and H.A. Steiner, A Debate Over Rights, (2002; Oxford University Press), 75

${ }^{91}$ N. MacCormick, H.L.A. Hart (1981; Edward Arnold), 89

92 H.L.A. Hart, Essays on Bentham: Jurisprudence and Political Philosophy (1982; Oxford University Press), 183185
} 
this power must be held at each decision-making stage. ${ }^{93}$ This principle of 'decisive control' over the duty correlative to the right is key to Will Theory. ${ }^{94}$ However, insistence on power to enforce or waive a duty reveals a weakness of Will Theory, as it fails to deal effectively with the notion of inalienable rights, or rights which cannot be waived, ${ }^{95}$ and only the power to enforce remedy for breach of duty applies. ${ }^{96}$

Possibly the strongest criticism of Will Theory is the denial of rights to those 'factually and legally incompetent to choose between enforcing and waiving their claims against others,' creating a 'rightless' sub-class of the most vulnerable. ${ }^{97}$ This is of particular significance in the context of this thesis, which will later examine vulnerabilities of older people. A rights-holder is required to be 'competent and authorised to demand or waive the enforcement of the right." ${ }^{98}$ Thus the rightsholder must be 'factually capable of making the choice. ${ }^{99}$ Significantly, on the basis of ability to exercise agency, children, the comatose and severely mentally disabled are not considered rightsholders by Will Theory. ${ }^{100}$ The theory contrasts the permanently incapable person with the temporarily incapable, ${ }^{101}$ creating a situation in which permanently incapable will never hold rights. Furthermore, the unknown future capacity to control duty also extinguishes entitlement to holding rights. ${ }^{102}$ Will Theory attempts to justify this position by offering a moral 'duty not to ill-treat' held by all. ${ }^{103}$ However, the moral 'wrong to ill-treat' does not beget 'a right to proper treatment. ${ }^{104}$ Will Theory does permit powers of rights holders to be 'exercised on their behalf by appointed

\footnotetext{
${ }^{93}$ M.H. Kramer, 'Some Doubts About Alternatives to Interest Theory of Rights,' 'Legal Studies Research Paper Series,' University of Cambridge, Paper No. 44/2011, September 2011, 7 www.law.cam.ac.uk/ssm. Accessed $17 / 03 / 2016$

${ }^{94}$ M.H. Kramer, 'Some Doubts About Alternatives to Interest Theory of Rights,' 'Legal Studies Research Paper Series,' University of Cambridge, Paper No. 44/2011, September 2011, 251 www.law.cam.ac.uk/ssm. Accessed $17 / 03 / 2016$

${ }^{95} \mathrm{C}$. Bisaz, The Concept of Group Rights in International Law as Contested Right-Holders, Subjects and Legal Persons (2012; Martinus Nijhoff Publishers), 14

${ }_{96}^{96}$ N. MacCormick, H.L.A. Hart (1981; Edward Arnold),.89

${ }^{97}$ H. Steiner, An Essay on Rights (1994; Blackwell,), 69

${ }_{98}$ M.H. Kramer, 'Rights Without Trimmings' in M.H. Kramer, N.E. Simmonds, and H. Steiner, A Debate Over Rights, (2002; Oxford University Press), 62

${ }_{99}$ M.H. Kramer, 'Rights Without Trimmings' in M.H. Kramer, N.E. Simmonds, and H. Steiner, A Debate Over Rights, (2002; Oxford University Press), 63-64

${ }^{100} \mathrm{C}$. Bisaz, The Concept of Group Rights in International Law as Contested Right-Holders, Subjects and Legal Persons (2012; Martinus Nijhoff Publishers), 14

${ }^{101}$ W.A. Edmonson, An Introduction to Rights (2004; Cambridge University Press), 128

${ }_{102}$ I. Carter, 'Introduction' W. de Wijze, M.H. Kramer, and I. Carter, Hillel Steiner and the Anatomy of Justice Themes and Challenges (2009; Routledge), xxi

${ }^{103}$ M.H. Kramer, 'Rights Without Trimmings' in M.H. Kramer, N.E. Simmonds, and H. Steiner, A Debate Over Rights, (2002; Oxford University Press), 69

${ }^{104}$ H.L.A. Hart, 'Natural Rights' cited in M.H. Kramer, 'Rights Without Trimmings' in M.H. Kramer, N.E. Simmonds, and H. Steiner, A Debate Over Rights, (2002; Oxford University Press), 69
} 
representatives and their exercise may be subject to approval by a court ${ }^{105}$ when the person only holds legal authorisation. ${ }^{106}$ However, this solution of the State holding and controlling rights for people lacking factual and legal competence contradicts the human rights objective of protection from State interference. The State that controls powers of imposition or waiver of duties also holds the ultimate power to violate human rights unchallenged. ${ }^{107}$

Regarding the content of rights, the only stated object of rights in Will Theory is liberty, ${ }^{108}$ interpreted as 'choices available to agents.' All rights are, therefore, viewed as deriving from such choices. ${ }^{109}$ For Will Theory, the only individual interest worthy of protection via rights is the interest in exercising autonomous choice, on the basis that it is fundamental to the achievement of all rights. ${ }^{110}$ The insistence on possession of powers to waive or enforce claims and duties, however, leads to a questionable inventory of rights. 'Relatively inconsequential interests,' if accompanied by the required powers, can qualify as rights whilst 'truly vital interests' can be ignored. ${ }^{111}$

\subsubsection{Interest Theory}

The concept and function of a right and who might be considered a rights-holder are the main points of difference between Interest and Will theories. The rationale for the creation of rights in Interest Theory is to protect and promote the interests held in rights when those rights are deemed good for the person. The theories take differing stances on other essential rights issues including individual and group rights and the content of rights. Significantly, Interest Theory does not consider it necessary that a person be competent, in the Kantian Will Theory sense, to be a holder of rights.

\footnotetext{
${ }^{105}$ H.L.A. Hart, 'Legal Rights,' in Essays on Bentham (1982; Oxford University Press), 184, cited in M.H. Kramer, 'Rights Without Trimmings' in M.H. Kramer, N.E. Simmonds, and H. Steiner, A Debate Over Rights, (2002; Oxford University Press), 70; I. Carter, 'Introduction' W. de Wijze, M.H. Kramer, and I. Carter, Hillel Steiner and the Anatomy of Justice Themes and Challenges (2009; Routledge), xxi

${ }^{106}$ Edmonson, W.A., An Introduction to Rights (2004; Cambridge University Press) p.124

${ }^{107}$ M. Hastings, 'For an Interest Theory Conception of Human Rights,' 6 www.academia.edu. Accessed $01 / 04 / 2016$

${ }^{108}$ I. Carter, 'Respect for Persons and the Interest in Freedom,' in W. de Wijze, M.H. Kramer and I. Carter, Hillel Steiner and the Anatomy of Justice Themes and Challenges (2009; Routledge), 173

${ }^{109}$ I. Carter, 'Introduction' W. de Wijze, M.H. Kramer, and I. Carter, Hillel Steiner and the Anatomy of Justice Themes and Challenges (2009; Routledge), xvii. Note: Steiner's use of 'original' right is the equivalent of Hart's term 'natural' right.

${ }^{110}$ W.A. Edmonson, An Introduction to Rights (2004; Cambridge University Press), 126-127; M.H. Kramer, 'Rights Without Trimmings' in M.H. Kramer, N.E. Simmonds, and H. Steiner, A Debate Over Rights, (2002; Oxford University Press), 62

${ }^{111}$ D.N. MacCormick, 'Rights in Legislation' in P.M.S. Hacker, and J. Raz (eds.) Law, Morality and Society: Essays in Honour of H.L.A. Hart (1977; Clarendon Press), 196, cited in M.H. Kramer, 'Rights Without Trimmings' in M.H. Kramer, N.E. Simmonds, and H. Steiner, A Debate Over Rights, (2002; Oxford University Press), 73
} 
Raz summarises Interest Theory. He states that ' $X$ has a right if and only if $X$ can have rights, and, other things being equal, an aspect of X's well-being (his interest) is a sufficient reason for holding some other person(s) to be under a duty. ${ }^{112}$ The $X$ to whom Raz refers is the being that can be granted rights. ${ }^{113}$ Kramer is explicit that it is inclusive of the human individual and group. ${ }^{114}$ With regard to the interests which 'ought to be respected and protected, ${ }^{115}$ it is instructive to briefly consider how an interest becomes a right. Each right is depicted in terms of 'the value of what the right is to, and to the competing interests of those on whom the right would impose obligations. ${ }^{116}$ Something considered of benefit to the individual does not automatically constitute a right. A mere 'benefit' is insufficient if it lacks a legal norm to provide authority and enforceability. ${ }^{117}$ Similarly, the status of right does not apply to every interest that a person might hold. Trivial interests do not qualify as rights. Additionally, the topic of the interest must be intrinsically valuable. ${ }^{118}$ Interests of vital importance to existence and well-being will be considered of 'primary value' and achieve rights status ahead of non-vital interests. Such interests will also take precedence over lesser value competing rights of others. However, the relationship of an interest with that of others is more complex than this simple equation. Regardless of the importance of a given interest to the individual, if it is harmful to the interests or well-being of others the exercise of that right can be denied without constituting a rights violation. ${ }^{119}$ In addition, those interests which generate actual or potential consequences of value to the wider community, or which represent the interests of others beyond the initial holder of the interest can form rights. ${ }^{120}$ Significantly, the right need only serve some interest, not on balance, the holder's interests overall. ${ }^{121}$

The benefit of an interest can contribute to the universality of human rights. This would require interests to be 'beneficial to typical human beings in most circumstances - if they are to qualify as

\footnotetext{
112 J. Raz, The Morality of Freedom (1986; Clarendon Press), 166

${ }^{113}$ M.H. Kramer, 'Rights Without Trimmings' in M.H. Kramer, N.E. Simmonds, and H. Steiner, A Debate Over Rights, (2002; Oxford University Press), 78

${ }^{114}$ M.H. Kramer, 'Some Doubts About Alternatives to Interest Theory of Rights,' 'Legal Studies Research Paper Series,' University of Cambridge, Paper No. 44/2011, September 2011, 3 www.law.cam.ac.uk/ssm. Accessed $17 / 03 / 2016$

${ }^{115}$ A. Gerwith, The Community of Rights, (1996; University of Chicago Press), 9

${ }^{116} \mathrm{~J}$. Thomas, Public Rights Private Relations (2015; Oxford University Press), 65

${ }^{117}$ M.H. Kramer, 'Some Doubts About Alternatives to Interest Theory of Rights,' 'Legal Studies Research Paper Series,' University of Cambridge, Paper No. 44/2011, September 2011, 3 www.law.cam.ac.uk/ssm. Accessed 17/03/2016. This is the belief of both Will Theory and Interest Theory.

118 J. Raz, The Morality of Freedom, (1990; Clarendon), 177

119 J. Thomas, Public Rights Private Relations (2015; Oxford University Press), 66

120 J. Raz, The Morality of Freedom, (1990; Clarendon), 179-180

${ }^{121}$ R. Cruft, 'Rights: Beyond Interest Theory and Will Theory?' 'Law and Philosophy,' Vol. 23 No. 4 (Jul., 2004), 347,372
} 
rights at all,'122 and to 'protect some aspect of the right-holder's situation that is normally to the benefit of a human being. ${ }^{123}$ Thus, in an Interest Theory context, the assignment of human rights would be to protect distinct universal and primary interests of rights-holders. When an interest is universally relevant, unwaivable rights are recognised, and trivial interests justifiably rejected. ${ }^{124}$

Using Interest Theory, rights can also be held by groups and nations with common interests and to whom common duties are owed. ${ }^{125}$ To hold a group right is to hold a right by virtue of membership of that group due to the significance that specific interests hold for all members. The interests of the group are defined in terms of the interests of individuals. On this basis rights are assigned to groups of individuals, howsoever identified, as an entity. ${ }^{126}$

When a right is to promote and protect an interest, that interest also grounds the associated duty. The value of the interest dictates the extent of the duty held by others. ${ }^{127}$ Interest Theory does not see choice as the means to activate duty, or as to who might hold rights. ${ }^{128}$ This allows the 'noncompetent,' dead and future human beings, and collectives to be rights-holders. ${ }^{129}$ Furthermore, the person whose right is held by a proxy under Interest Theory does not merely benefit from the right, but retains ownership of it whilst it is held on her behalf by a guardian. ${ }^{130}$ Choice is enabled via rights, making it an interest, and one which is defended in direct relation to its furtherance of other interests. ${ }^{131}$ As a result, Interest Theory covers a wider spectrum of rights than Will Theory. ${ }^{132}$ Rejection of the Will Theory insistence for control over duty by the rights-holder allows Interest

${ }^{122}$ M.H. Kramer, 'Rights Without Trimmings' in M.H. Kramer, N.E. Simmonds, and H. Steiner, A Debate Over Rights, (2002; Oxford University Press), 97. My emphasis.

${ }^{123}$ M.H. Kramer, and H. Steiner, 'Theories of Rights: Is there a third way?' Oford Journal of Legal Studies, 2007; 27(2), 289. My emphasis.

${ }_{124}$ M. Hastings, 'For an Interest Theory Conception of Human Rights,' 4 www.academia.edu. Accessed 01/04/2016

${ }^{125}$ J. Raz, The Morality of Freedom (1986; Clarendon Press), 180

${ }^{126}$ C. Fabre, 'Preconception Rights' in W. de Wijze, M.H. Kramer, and I. Carter, Hillel Steiner and the Anatomy of Justice Themes and Challenges (2009; Routledge), 64

127 J. Thomas, Public Rights Private Relations (2015; Oxford University Press), 66

${ }^{128}$ Kramer describes this as ' $X$ 's being competent and authorised to demand or waive the enforcement of a right is neither sufficient nor necessary for $X$ to be endowed with that right.' M.H. Kramer, 'Rights Without Trimmings' in M.H. Kramer, N.E. Simmonds, and H. Steiner, A Debate Over Rights, (2002; Oxford University Press), 62

${ }^{129}$ M.H. Kramer, 'Some Doubts About Alternatives to Interest Theory of Rights,' 'Legal Studies Research Paper Series,' University of Cambridge, Paper No. 44/2011, September 2011, 3 www.law.cam.ac.uk/ssm. Accessed $17 / 03 / 2016$

${ }^{130}$ J. Raz, The Morality of Freedom (1986; Clarendon Press), 180

${ }^{131}$ A. Harel, 'Theories of Rights' in M.P Golding \& W.A. Edmundson, W.A., The Blackwell Guide to the Philosophy of Law and Legal Theory (2005; Blackwell), 195

${ }^{132}$ C. Bisaz, The Concept of Group Rights in International Law as Contested Right-Holders, Subjects and Legal Persons (2012; Martinus Nijhoff Publishers), 15 
Theory to acknowledge unwaivable rights. Therefore, protection of interests vital to existence and well-being are not at risk.

\subsubsection{A Note on Interest Theory for rights of older people}

The focus of rights on the protection of well-being, and protection of interests makes Interest Theory suitable to rights provision for older people. The applicability of Interest Theory rights to groups and individuals is of relevance, as older people will be considered later in the thesis as a candidate for a group requiring special protection. The fact that primacy is given to fundamental rights, and that inalienable rights essential to human need and dignity are supported, are also influential when considering the role of rights for older people. The central role of interests in this theory allows for rights to be interpreted, applied, and possibly adapted and created, to respond to particular vulnerabilities of older people. This question will be considered in examination of special protection for the elderly. ${ }^{133}$ The fact that interests ground rights, and rights ground duties also means that duty will respond to need. ${ }^{134}$ The fact that Interest Theory does not limit rights on the basis of capability to choose or exercise power over the duty correlative to the right allows the cognitively disabled to be considered a rights-holder, and that a duty will be owed to that person. Additionally, by permitting a right to be held by an authorised proxy whilst still owned by someone lacking capacity ${ }^{135}$ provides that person protection from coercive State intervention. Also, by promoting and protecting the interests a person has in rights, Interest Theory allows for bespoke rights to provide special protection. In doing to, it supports dignity and protects against vulnerability.

\subsection{Conclusion}

This brief examination of theoretical underpinnings for human rights paves the way for discussion of substantive rights in later chapters, and will help frame the central premise of this thesis, that older people are in need of special protection in international human rights law. The discussion of key principles of Will and Interest Theory will assist in understanding the requirements for special protection of the elderly from human rights. The discussion of these theories at this point will also serve as the basis for understanding, as the thesis progresses, the dangers for the vulnerable, including the elderly, of grounding rights in the demands of agency and the ability - or capacity - to

\footnotetext{
${ }^{133}$ See Part IV

${ }^{134}$ Providing rights in accordance with need is a topic of Capabilities Approach which will also provide a means of assessing the provision of rights for the elderly in Part IV.

${ }^{135}$ Such as older people suffering with dementia or cognitive disability caused by other illness.
} 
enforce or waive duties imposed on the State. Such a demarcated approach, prioritising Will Theory could see the elderly 'rightless,' and potentially vulnerable to state coercion, or lacking in State protection against abuse by third parties. Additionally, the Will Theory focus on choice and the freedom it supposes as the only or dominant objective of rights would produce a limited range of rights, and no guarantee that human need or dignity will be fully addressed. Therefore, Interest Theory emerges as the theory which best accommodates the needs, vulnerabilities, and objective of dignity for the elderly. Central to this is how Interest Theory grounds rights in actual interests, making the function of rights to serve need and dignity. In this context, Interest Theory permits those lacking agency to be rights-holders. Agency itself becomes an interest in rights, not a qualification for holding rights. For the elderly who are incapable of exercising agency, or particular agency in respect of rights, rights continue and they continue to hold rights, but rights can be simultaneously held by a proxy.

Looking ahead in this thesis, a key benefit of taking Interest Theory as the explanation of rightsholding, including for the elderly, is that Interest Theory permits for a wide range of interests to be seen as rights. Section Two this thesis, which researches what it means to be elderly, will help draw attention to the needs of the elderly for rights by establishing their need and therefore their interests. Whilst rights-holding will be focused on the individual, it will be argued that it is possible to determine shared characteristics for the elderly, and that as a collective they are in need of special protection from human rights.

Norms grounded in moral human nature inform human rights to protect life and autonomy. Human need informs rights to essentials under the broad need-based headings of survival, health and development. These are the foundations for civil and political as well socio and economic rights. All support human dignity. Section two will discuss how the needs of the elderly may touch on the different categorisations of rights. This includes recognising their need for autonomy, freedom, and equality, and the need for self-determination and freedom to chose and exercise rights without discrimination, alongside the need for resources of the sort typically associated with economic or social rights. Dignity is insulted by vulnerability, and the next two sections will reflect on this relationship and will be drawn upon to examine what it means to be elderly, how human rights are interpreted and applied to the elderly, and whether, and if so what, special protection is required in the remainder of the thesis. 


\section{CHAPTER 2}

\section{INTERNATIONAL CONTEXT OF HUMAN RIGHTS FOR OLDER PEOPLE}

\section{$2.1 \quad$ Introduction}

The purpose of this chapter is to provide an overview of position of older people in international rights. It is not the intention to provide scrutiny of rights provision vis à vis specific vulnerabilities or experiences of older people, as that is the subject of Part IV of the thesis. Rather, this short chapter provides a brief statement of the present situation.

The overview will introduce issues pertinent to further discussion in the thesis, and will focus on key issues which influence the position of older people in international law as it stands. In order to provide context for the position of older people, the chapter opens with an overview of the changing global demographics, specifically the contribution of the ageing population to such change. Initially, how older people are recognised by international instruments is discussed, with a focus on grounds for non-discrimination and inclusion in specific rights. The overview then considers the characteristics and experiences of lived vulnerabilities experienced by older people, with a view to relating them to the grounds for vulnerable group status and special protection offered by the European Court of Human Rights. Discussion surrounding the need for special protection for older people as a population group, which arises from the human rights position of older people in international law will also be introduced. Issues raised will inform the research objectives of this thesis, primary research questions, and the overarching question of the need for special protection of older people in international human rights law. The objectives and research questions will be addressed in the following chapter.

\subsection{The Ageing Population}

The global population is ageing, and at such pace as to effect "a process without parallel in the history of humanity." ${ }^{136}$ Younger people will comprise a smaller proportion of the population ${ }^{137}$ as the numbers of older people continue to increase. The total of older people, defined by the UN as

\footnotetext{
136 "World Population Ageing: 1950-205-," 2002; United Nations Department of Economic and Social Affairs Population Division www.un.org/esa/population/publications/worldageing19502050 Accessed 15/09/2014

137 "World Population Ageing: 1950-2050," 2002, 15-20, United Nations Department of Economic and Social Affairs Population Division www.un.org/esa/population/publications/worldageing19502050 Accessed $15 / 09 / 2014$

"By 2030, older persons will outnumber children aged 0-9 years (1.4 billion versus 1.3 billion); by 2050, there will be more people aged 60 years or over than adolescents and youth aged 10-24 years ( 2.1 billion versus 2.0 billion)." "World Population Ageing Report 2015," United Nations, 3
} 
age 60, quadrupled between 1950 and 2013 from 202 million to 841 million. ${ }^{138}$ The global figure was recorded in 2015 as $901 \mathrm{~m}$, and projected to more than double by 2050, reaching 2.1 billion. ${ }^{139}$ This transition is taking place at varying rates across the globe, with consequences for individual countries and the vulnerability experiences of older people. Actual numbers of older people are higher in poorer territories, increasing from 108 million in 1950 to 554 million in 2013, and projected to increase to 1.6 billion in 2050. By comparison, the modernised world shows increases from 94 million in 1950 to 287 million in 2013, projected to reach 417 million in $2050 .{ }^{140}$

The proportion of older people worldwide is also changing. The over 60 s comprised $8 \%$ in $1950,12 \%$ in 2013 , projected to reach $21 \%$ in 2050 . The West has a greater proportion of older people in the population, and predictions are also higher. ${ }^{141}$ However, of significance to developing countries is the faster pace at which older people with special protection needs is increasing. Growth is expected to take place most rapidly in areas yet to modernise fully. The period 2015-2030 is forecast to see growth rates of $71 \%$ in Latin America and the Caribbean; 66\% in Asia; 64\% in Africa; and $47 \%$ in Oceania. Europe is predicted to see a much slower rate of growth of this sector of the population of $23 \%{ }^{142}$

Forecasts by the UN for 2030 predict the increase in older people as a share of regional population to be greatest in Latin American and the Caribbean. ${ }^{143}$ Asia $^{144}$ and Africa ${ }^{145}$ are predicted to have the next highest growth rates, highlighting a rapid increase in need and vulnerability experienced by the group in some of the poorest countries. Of all the regions, Asia has the highest share of the global older population. The majority of the global older population are in the Asian region, ${ }^{146}$ and is forecast to increase to $62 \%$ by $2050 .{ }^{147}$ The global share of Latin America and the Caribbean, ${ }^{148}$ and Africa is much lower, ${ }^{149}$ as are predicted global shares, ${ }^{150}$ despite growth.

\footnotetext{
138 “World Population Ageing Report 2013," United Nations, 9

139 "World Population Ageing Report 2015," United Nations, 2

140 "World Population Ageing Report 2013," United Nations, 9

${ }^{141}$ The proportion of people 60 years of age or more in 1950 was $12 \%$, growing to $23 \%$ in 2013 contrasting with figures of $6 \%$ and $9 \%$ respectively for developing countries. Predictions are for wealthier regions to expect 32\% of the population to be aged over 60 in 2050, whilst the expectation for the less wealthy is $19 \%$. "World Population Ageing Report 2013," United Nations, 1

142 "World Population Ageing Report 2015," United Nations, 2

${ }^{143}$ With a $71 \%$ increase in those aged 60 years or more

${ }^{144}$ With a $66 \%$ increase in those aged 60 years or more

${ }^{145}$ With a $64 \%$ increase in those aged 60 years or more

${ }^{146}$ In 2015508 million older people, or 56\% of the global older population lived in Asia.

${ }^{147}$ Numbers are forecast to reach 845 million in Asia by 2030.

${ }^{148}$ The global share of the global older population in 2015 was $7.9 \%$, or 71 million

${ }^{149}$ The global share of the global older population in 2015 was $7.2 \%$, or 64 million

${ }^{150}$ The predicted share of the global older population in 2030 is $8.6 \%$ or 121 million in Latin America and the Caribbean, and $7.5 \%$ or 105 million in Africa
} 
The UN states that $59 \%$ of the "oldest old"151 of the global population will also live in Asia by $2050,{ }^{152}$ an increase from $48 \%$ in 2015 . As a proportion of regional population, the oldest old will increase most rapidly in Latin America and the Caribbean. Oceania and Asia will experience similar growth rates, and Africa the least. ${ }^{153}$

Developed regions such as Europe and North America are forecast to experience a much slower rate of growth of numbers and share of older people in domestic populations. Furthermore, share of global older population will fall. Numbers of older people in Europe increased from 147 million in 2000 to 177 million in 2015, and are projected to reach 217 and 242 million in 2030 and 2050 respectively. However, this reflects a reduction in global share from $25 \%$ to $16 \%$, and $12 \%$ in the same period. The North American experience is similar. The 75 million of over 60s in 2015 is forecast to increase to 123 million in 2050, representing a reduction in global share from $8.5 \%$ to $5.9 \%$

Numbers of the "oldest old," defined as 80 years and over, are increasing at a faster rate than numbers of older people as a group. Recorded at 125 million in 2015, the projection is for numbers to triple by 2050, reaching 434 million. The proportion of the population comprising this age group is expected to increase from $14 \%$ to more than $20 \%$ in the same period. ${ }^{154}$ The regional rate of growth of this age group is again significant given the intensity of vulnerabilities experienced, and the ability of individual countries to protect against them. Europe and North America will maintain the highest share of the oldest old within their populations. ${ }^{155}$ Latin America and the Caribbean and Asia will experience similar rates of growth, with the share of the over 80s remaining almost static in Africa. ${ }^{156}$

All age groups of older people comprise greater numbers of women than men. This fact is relevant given that older women are subject to aggravated vulnerability, as demonstrated later in this chapter. Globally, $54 \%$ of the over 60 s, and $61 \%$ of the over 80 s were women in 2015 . This share is

\footnotetext{
${ }^{151}$ Defined as 80 years of age and over.

152 The UN states "more than half" of the world's oldest old will live in Asia in 2030,

${ }^{153}$ Latin America and the Caribbean are projected to have increases in the share of the oldest old of the regional population of 81\% between 2015 and 2030; Oceania 77\%; Asia 73\%; and Africa 64\% 154 "World Population Ageing Report 2015," United Nations, 2

155 The population of Europe is expected to increase its share of the oldest old from $20 \%$ in 2015 to $29 \%$ in 2050 , North America is projected for the over 80 s to comprise $30 \%$ of its population by 2050 . "World Population Ageing Report 2015," United Nations, 20

${ }^{156}$ The share of the oldest old in the population of Latin America and the Caribbean is projected to be $22 \%$ in 2050, from 15\% in 2015; Asia is set to increase from $12 \%$ to $20 \%$, and Africa from $9 \%$ to $10 \%$ in the same period. "World Population Ageing Report 2015," United Nations, 20
} 
projected to fall by 2050 due to improvements in men's health. Nonetheless, those aged 80 and over, the most vulnerable of older people, are expected to consist of $58 \%$ of women by that date. ${ }^{157}$

Turning to life expectancy, globally, life expectancy at birth has increased at an unprecedented rate since the mid-twentieth century. The life expectancy at birth in developed countries has increased from 65 in 1950 to 78 in 2015. The UN is projecting an increase for this region to 83 by 2045$2050 .{ }^{158}$

Life expectancy of older people has also increased. Worldwide, the life expectancy of 60 year olds in the period 2010-2015 was 80. The trend in the West extends to this group, with 60 year olds living on average six years longer than those in the most underdeveloped nations, to the ages of 83 years and 77 respectively. ${ }^{159}$ Globally, projections for life expectancy of over 60s estimates 22 additional years, an increase of 2 years, again with disparity between developed and developing regions. ${ }^{160}$ Also of significance is the increasing life expectancy of the oldest old. At present, life expectancy at age 80 in the developed world is 89 , progressing to 91 by 2045-2050. The corresponding ages in the underdeveloped world are 87 and $88 .{ }^{161}$

\subsection{Recognition of Older People in International Law}

The position of older people in international human rights law has remained a contentious matter between United Nations Member States since the proposal by Argentina in 1948 that a set of rights be created for the purpose of special protection. Drafting of the United Nations Declaration on Human Rights ${ }^{162}$ was interrupted by the Draft Resolution which stated:

That old age rights, having the same origin and purpose as other universal social safeguards, are essential for the improvement of the living conditions of the worker and for his welfare when his physical strength is at an end and he is exposed to poverty and neglect $^{163}$

\footnotetext{
157 “World Population Ageing Report 2015," United Nations, 2

158 "World Population Ageing Report 2013," United Nations, 6

159 "World Population Ageing Report 2013," United Nations, 7

160 The populations of the most underdeveloped regions expected to live for 21 additional years to age 79 , compared to those of the developed regions expected to live for 26 additional years to age 86 . "World Population Ageing Report 2013," United Nations, 8

161 "World Population Ageing Report 2013," United Nations, 8

162 UN General Assembly Universal Declaration of Human Rights, Adopted by General Assembly Resolution 217 A (III) of 10 December 1948

${ }^{163}$ Preamble of UNGA Declaration of Old Age Rights Argentina: Draft Resolution A/C.3/213 30 September 1948
} 
However, all generic international human rights instruments, specifically the International Bill of Rights, have remained silent on the subject of age or older people, with the exception of occasional individual rights. Significantly, 'age' or 'older people' are not recognised as prohibited grounds for discrimination. Even more recent instruments of special protection, including the Convention on the Rights of Persons with Disabilities, and the Convention on the Elimination of All Forms of Discrimination Against Women, which can count older people among their respective cohorts, make scant mention of older people. The CRPD ${ }^{164}$ explicitly prohibits age-discrimination in two instances. The right to an adequate standard of living and social protection cites the need for older people to have access to social protection and poverty reduction programmes. ${ }^{165}$ Older people are definitively included also in the right to the highest attainable standard of health. The CRPD states entitlement of older people to 'services designed to minimise and prevent further disability. ${ }^{166}$ CEDAW makes minimal reference to older women, and in recognition of the fact the CEDAW Committee drafted and adopted a General Recommendation on Older Women.

Unsettled arguments persist regarding two main issues of recognition of older people. The first claims that the universal nature of generic instruments begets universal sufficiency of rights provision. The second involves the potential for older people to be included in the catch-all category of 'other status' in statements of non-discrimination in instruments. It is instructive that the Committee on Economic, Social and Cultural Rights concedes that it may not yet be possible to conclude that discrimination on the grounds of age is comprehensively prohibited by the Covenant. $^{167}$

The position of older people as a result of this silence was described by the United Nations as follows; 'the position of older people is weakened, the legal force of rights undermined, and older people become 'invisible as a group within the law.' ${ }^{168}$

The lived experiences of older people, and ways in which they are defined as a group, is argued to bear testimony to the inadequacy of international human rights in the protection and treatment of older people.

\footnotetext{
${ }^{164}$ UN General Assembly, Convention on the Rights of Persons with Disabilities: adopted by the General Assembly, 24 January 2007, A/RES/61/106

${ }^{165}$ Article 28(2)(b), UNCRPD

${ }^{166}$ Article 25(b), UNCRPD

${ }^{167}$ (CESCR), General Comment No. 6: The Economic, Social and Cultural Rights of Older Persons, 8 December 1995,E/1996/22, 12

${ }^{168}$ United Nations Department of Economic and Social Affairs Division for Social Policy and Development Programme on Ageing, Report of the Expert Group Meeting 'Rights of Older Persons' Convened in preparation for the report of the Secretary-General to the 64th session of the General Assembly 5-7 May 2009, Bonn, Germany, 15
} 


\section{4

Common characteristics shared by older people are readily identifiable in: inevitable physical and cognitive decline; ${ }^{169}$ poverty ${ }^{170}$ lower standards of living; ${ }^{171}$ and vulnerability to abuse. ${ }^{172}$ Characteristics identified by theories of ageing also translate into shared experiences. Included in such characteristics are: isolation; ${ }^{173}$ loss of filial obligation; ${ }^{174}$ dependence; ${ }^{175}$ reduction in numbers and range of relationships; ${ }^{176}$ reduction in numbers and range of activities; ${ }^{177}$ perceived inability to be productive ${ }^{178}$ negative stereotyping and self-stereotyping. ${ }^{179}$ Once these characteristics present sufficient threat to dignity, against which the individual has insufficient resilience, the risk of vulnerability develops. Upon materialisation of this risk, the older person experiences outcomes of vulnerability. The vulnerabilities suffered by older people can be categorised as embodied, institutional, and pathogenic; an in-depth discussion of the concept of Vulnerability takes place in Chapter 5. The outcomes are numerous, and are the subject of Parts III and IV, however, common themes bear reproduction at this stage.

Global themes of vulnerability suffered by older people include, but are not limited to the following:

- Co-morbidity of age-related and age-dependent illness and disease combining physical and mental illness.

- Older people in least developed countries experience starkly reduced life expectancy.

- Older people in developing countries are vulnerable to communicable and noncommunicable diseases.

- Older people in poorer countries have a lower healthy life expectancy.

- Availability to healthcare and medical care can be limited or financially prohibitive.

- Socio-economic factors influence accumulated disadvantage across the life-course

- Older people are vulnerable to poverty due to forced retirement; an inability to obtain and maintain suitable employment; and inadequate or no State pension provision or social security.

\footnotetext{
${ }^{169}$ See 9.2, 9.2.1, 9.2.1.1, 9.2.2, 9.2.3

${ }^{170}$ See 10.2 .2

${ }^{171}$ See 10.2 .3

${ }^{172}$ See 10.3 .1

${ }^{173}$ See 8.2.1.1

${ }^{174}$ See 8.2.2

${ }^{175}$ See 5.3.2.2

${ }^{176}$ See 8.4.1, 8.4.2, 8.4.3

${ }^{177}$ See 8.5

${ }^{178}$ See 8.3.1

${ }^{179}$ See 8.6.1
} 
- Older people in poorer countries can continue to work indefinitely as a matter of necessity.

- Older people are vulnerable to health problems due to retirement, social isolation, abuse, and discrimination.

- In many countries, and particularly in some regions, the vulnerability of women is aggravated.

Given that such vulnerabilities persist, it is necessary to examine the normative provision and implementation of human rights in the existing construct in order to assess the adequacy of international rights for the protection of interests held by older people in rights. This is an objective of Part IV, however, for the purposes of this overview, the approach to international rights provision for older people is summarised below.

\subsection{Approach to international rights provision for older people}

Scrutiny of the protection of human rights of older people in the international framework has generated disparate accounts of existing protection embedded in universal and special protection instruments. Broadly, opinion can be stated as follows:

The rights of older persons are theoretically addressed by virtue of their being human, even where they are not specifically mentioned...The treaty bodies have developed protections...including the rights of older persons, through General Comments...the rights of older persons are also enshrined in other instruments... ${ }^{180}$

The elderly have distinct human rights, which were not addressed specifically in the 1948 Universal Declaration of Human Rights or other relevant human rights instruments. ${ }^{181}$

The expectation is primarily for universal generic rights to protect the interests held by older people in rights in all situations. When this expectation fails, older people have the opportunity to make claims on various rights incorporated in a variety of human rights instruments. Many UN Member States hold the opinion that the CRPD protects all rights of all older people. The flaw in this argument is that not all older people are disabled, and therefore, not all have access to the protections of the Convention. A similar argument applies to CEDAW. Both of these instruments will be included in the examination of adequacy of rights for older people in Part IV. However, it can be stated that, as the instruments were drafted to provide for particular vulnerable subjects, the

\footnotetext{
${ }^{180}$ C Martin, D Rodriguez-Pinzon, B. Brown, Human Rights of Older People Universal and Regional Legal Perspectives 2015, 16 http://www.springer.com/978-94-017-7184-9 accessed 23/02/2017

181 'Status of Preparation of Publications, Studies and Documents for the World Conference. Addendum,' 55. World Conference on Human Rights Preparatory Committee Fourth session, 19-30 April 1993 A/CONF.157/PC/61/Add.8
} 
specific needs of older people were not in the contemplation of the drafters. This argument is similar to that offered by the Committee on the Rights of Economic, Social and Cultural Rights which claimed that 'when these instruments were adopted, the problem of demographic ageing was not as evident or as pressing as it is now. ${ }^{182}$ Finally, against the backdrop of international rights instruments which did not contemplate the needs of older people, a majority of Member States advocate universal implementation of the Madrid International Plan of Action on Ageing. However, the non-legally binding status of the Plan limits the protection to be guaranteed. These issues are discussed more fully in Part IV of the thesis.

With the needs of older people positioned beyond the scope of the protection of existing international rights the question of whether the group should be afforded special protection.

\subsection{Special Protection and Older People}

International human rights law directs special protection to facilitate equality in law and dignity, and the exercise of human rights for vulnerable groups. ${ }^{183}$ Special protection human rights instruments are dedicated to such groups on the basis of need for special assistance to enable protection and fulfilment of interests in rights particular to the group. ${ }^{184}$ The rationale behind special protection therefore acknowledges the precariousness of any guarantee to equality and the protection and fulfilment of rights expressed in the international framework. Such precariousness becomes manifest upon the inadequacy of the existing construct to fulfil interests, particularly vital interests, held in rights. ${ }^{185}$

The UN responds to situations of unfulfilled interests in rights through special protection, either via instructions of 'special procedures' or special protection human rights instruments. International law is interspersed with 'special measures' aimed at fulfilling interests in rights of older people. However, the emergence of special protection Conventions for 'vulnerable groups' intensifies scepticism of the ability of generic international rights to safeguard rights of older people, as expressed in the study of international rights of older people by Chinsung Chung:

\footnotetext{
182 (CESCR),General Comment No. 6: The Economic, Social and Cultural Rights of Older Persons, 8 December 1995,E/1996/22, 11

${ }^{183}$ C Martin, D Rodriguez-Pinzon, B. Brown, Human Rights of Older People Universal and Regional Legal Perspectives 2015, 47 http://www.springer.com/978-94-017-7184-9 accessed 23/02/2017

${ }^{184}$ C Martin, D Rodriguez-Pinzon, B. Brown, Human Rights of Older People Universal and Regional Legal Perspectives 2015, 82 http://www.springer.com/978-94-017-7184-9 accessed 23/02/2017

${ }^{185}$ See 1.6.2 'Interest Theory'
} 
just as women, children, indigenous groups, and the disabled have been recognized as distinct groups requiring special care and concern under the existing human rights regime, the elderly population must be recognized as a distinct group requiring special attention and care. ${ }^{186}$

Compliance of a population group with requirements for a 'group-specific rights approach ${ }^{187}$ is significant to the international rights context. Direction for identification of a vulnerable group in need of special protection rights is provided by the European Court of Human Rights, and correlates to the premise that 'people are differently vulnerable;' this 'difference' identifies a group and the 'different' protection required. ${ }^{188}$ The ECtHR considers the ways in which groups are 'differently' vulnerable in terms of type of vulnerability suffered and the severity and type of harm suffered. Furthermore, the group should be more vulnerable than most individuals, and comprise a minority of society. ${ }^{189}$

Despite the prima facie case for special protection for older people that can be drawn from this overview, the group remains without a dedicated Convention of human rights, an issue which will be discussed in Chapter 13.

\section{$2.7 \quad$ Conclusion}

This overview of the position of older people in the international context identifies key issues which are relevant to the overarching question of the need for special protection for older people. Despite the burgeoning ageing population, with the exception of special protection rights to which subgroups of older people have access, older people remain predominantly unrecognised in international human rights. Furthermore, the interests held by the group and individual members of the group in rights are unrecognised when those interests are beyond the scope of international rights. The characteristics common to the group form the basis for recognition on the grounds defined by the ECtHR for a vulnerable group. Moreover, the range and number of vulnerabilities, the type and degree of harm caused a group predisposed to aggravated vulnerability, would suggest that older people number among the most vulnerable. However, in order to uncover some

\footnotetext{
${ }^{186}$ Chinsung Chung, 'The necessity of a human rights approach and effective United Nations mechanism for the human rights of the older person,' Working paper 4 December 2009, 45, Human Rights Council Advisory Committee, A/HRC/AC/4/CRP.1

${ }^{187}$ Frédéric Mégret, 'The Human Rights of Older Persons: A Growing Challenge' 'Human Rights Law Review,' Volume 11, Issue 1, 1 March 2011, 37, 41

${ }^{188}$ Lourdes Peroni \& Alexandra Timmer, 'Vulnerable Groups: The promise of an emerging concept in European Human Rights Convention law,' p.1061

${ }^{189}$ Lourdes Peroni \& Alexandra Timmer, 'Vulnerable Groups: The promise of an emerging concept in European Human Rights Convention law,' p.1057; Alajos Kiss v Hungary App. No 38832/06, 20 May 2010, 42 (as cited in Lourdes Peroni \& Alexandra Timmer, 'Vulnerable Groups: The promise of an emerging concept in European Human Rights Convention law,' p.1057
} 
protection, this group must trawl through a host of rights instruments and appeal to the policy, if implemented of the MIPAA. The position as outlined will inform the primary research questions presented in the next chapter. 


\section{CHAPTER 3}

\section{METHODOLOGY}

\subsection{Introduction}

[d]edicated human rights committees extend human rights to older persons; before an argument or complaint can be made about the violation of an older person or group of older persons' rights, applicants must first explain how supposedly universal law applies to them. As a matter of course human rights cannot be accessed by older persons in the current framework. ${ }^{190}$

This argument forwarded by Riera, supports the methodology adopted by the thesis, which is the subject of this chapter.

The rationale of the methodology centres on achieving the following:

- Determination of the position of older people in international rights

- Question the underpinnings and approach to the creation and implementation of rights, with specific reference to older people

- Devise an approach to human rights that improves the ability to achieve change

- Demonstrate how a special protection rights instrument should be created and implemented

Consequently, the critical design, constant throughout the thesis, included a conceptual approach in order to determine norms and outcomes, and the most effectual method of achieving them. The reason for, and form of, this approach is discussed below. In addition, the theoretical framework at the heart of the critical design is also evident throughout the thesis, and is contributes to the critical design of the methodology. Following the section on the critical design of the methodology, the interaction between the objectives of the research and the primary research questions is explained prior to an examination of the connectivity between research questions. At this point the chapter will discuss the research methods implemented per primary research question.

\footnotetext{
${ }^{190}$ Rocio Barahona Riera, April 19, 2011, OEWG, New York (as cited in C. Martin, D. Rodrigues-Pinzon and B. Brown 'Human Rights of Older People and Universal Regional Legal Perspectives' (2015 Springer) 15. In this context the meaning of "extend" is to permit older people access to existing rights: it does not mean that rights are expanded or developed in response to the requirements of older people.
} 


\subsection{Critical Design and Theoretical Framework}

The overarching research question of a need for special protection for older people, and subsequent research objectives, provided the basis for the rejection of an affirmative methodological design approach which aims to reaffirm the status quo of a given situation. Instead, the requirement of the design was to challenge accepted assumptions and conceptions about: the foundations; universality; normative provision; implementation; and role of human rights. Therefore, the design adopts a critical perspective of the existing international human rights framework vis à vis older people. The approach examined alternative adaptations and applications of concepts as means to achieve change via human rights, to counter what is perceived by the thesis as 'human rights fatigue.' Ultimately the thesis rejects the traditional approach of rights as the starting point for explanations as to how rights are underpinned by concepts. Rather, the value of concepts in influencing the fulfilment of interests in rights by means of normative provision and implementation underlies the critical design.

The selection of a critical design approach impacted the theoretical framework which guides the research and is evident in the construction and development of the thesis. The principal theories drawn upon in this theoretical framework and the contribution to the thesis is the subject of this section of the chapter.

The theoretical framework is anchored by the research problem, and in turn influences the methods of research. The problem required examination of a number of theories. Therefore, the framework guiding the research was, in broad terms, an accumulation of: human rights theories; concepts of human dignity and vulnerability; theories of ageing; and a capabilities approach.

The principles of the Interest Theory of human rights are visible throughout the thesis. The ideal of when an interest becomes a right is influential in the assessment of how older people are vulnerable as a group and the suitability of existing human rights to the needs of individuals and the group. The fact that holders of interests become holders of rights is an underlying theme in the response to the overarching question of the thesis, whilst the lack of a requirement for the autonomous ability to make a claim on a right for a duty to be owed is significant to all 3 primary research objectives.

The combined concepts of Human Dignity and Vulnerability proved the lens through which human rights were viewed for purposes of determining how rights should be underpinned, and how the aims of rights should be devised. At this stage the methodology involved analysis of concepts as currently adopted, and the proposal of versions more suitable to the task of using rights to effect 
change. The five pillar version of the concept of Human Dignity ${ }^{191}$ emerged as more suitable than the traditional three pillar concept. ${ }^{192}$ The more holistic version complies more fully with the range of interests held by older people, and provides a more complete basis for the content and aims of rights. Furthermore, given the reciprocal relationship identified between the concepts of Human Dignity and Vulnerability, the interaction of the two in a human rights context would incomplete with a reliance on the more limited version of the former. The vulnerability framework devised by the thesis takes account of the five pillar concept of Human Dignity. This framework, which is the result of the drawing together of aspects of three theses of the concept of Vulnerability, provides the basis for the research required to fulfil principally the first two research objectives. The impact can be traced throughout the thesis.

A number of theories of ageing contribute to the theoretical framework of the thesis. The primary foci included: abandonment; isolation; lone living; loss of status; poverty; ill-health and disability; disengagement; lack of participation; perceptions of lack of productivity; and negative stereotyping and self-stereotyping. All theories are evident in the identification of older people as a vulnerable group, interests held in human rights, necessary normative content and implementation of rights in order to achieve requisite special protection. All are represented in the framework used to scrutinise current rights provision.

The final contributor to the theoretical framework of the thesis is the Capabilities Approach. The methodological approach uses a version of the Capabilities Approach specially adapted by the thesis in order to provide a new approach to the determination of the outcomes of rights necessary to fulfil the interests of older people. This necessitated the creation of an original set of Fundamental Capabilities for Older People to underpin the content and inform the implementation of rights. With the outcome of rights corresponding to the interests held in rights by individual members of this group informing special protection, the approach taken is complete, and the theories which construct the methodological framework visible throughout.

${ }^{191}$ Comprising autonomy, freedom, liberty, existence, and personality

${ }^{192}$ Comprising autonomy, freedom, and liberty 


\section{TABLE 1}

RELATIONSHIP BETWEEN CENTRAL HYPOTHESIS, RESEARCH OBJECTIVES, AND RESEARCH

CENTRAL HYPOTHESIS

The existing international framework of human rights potentially does not protect the interests held in

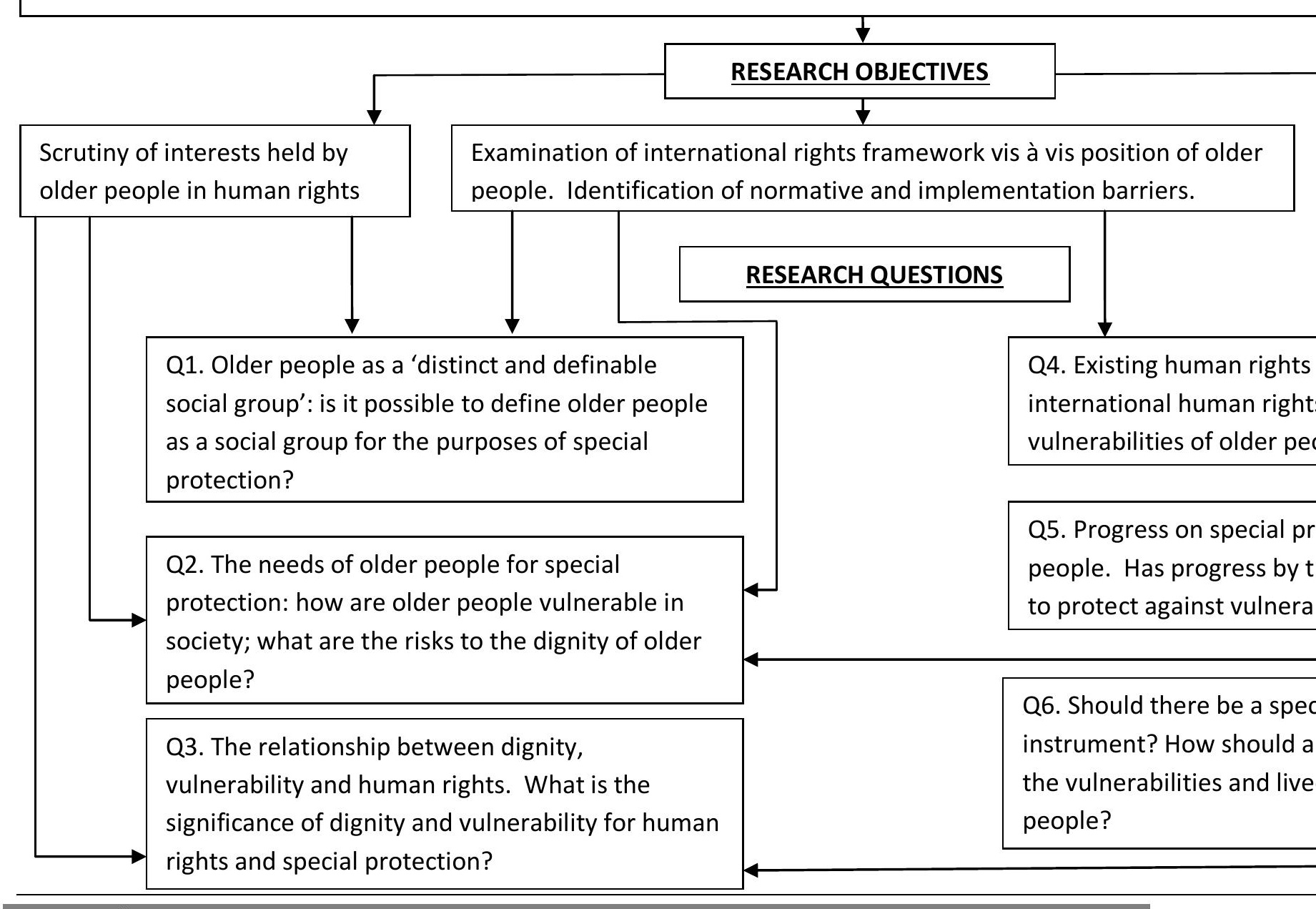




\section{TABLE 2}

\section{RELATIONSHIP BETWEEN RESEARCH QUESTIONS}

\section{CENTRAL HYPOTHESIS}

The existing international framework of human rights potentially does not protect the interests held in

\section{RESEARCH QUESTIONS}

Q1. Older people as a 'distinct and definable social group': is it possible to define older people as a social group for the purposes of special protection?

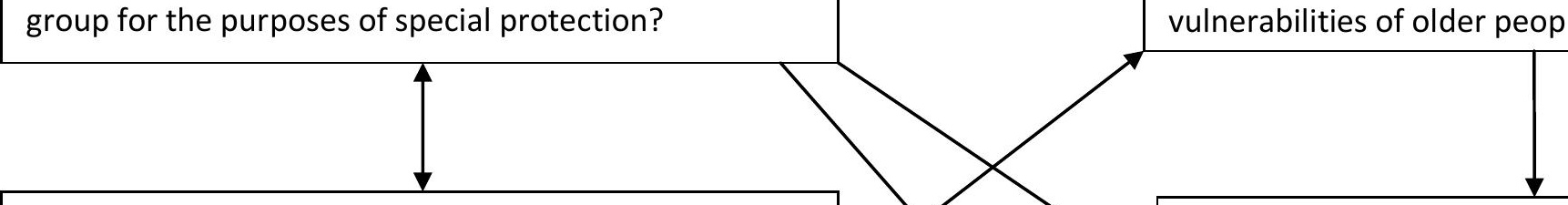

Q2. The needs of older people for special protection: how are older people vulnerable in society; what are the risks to the dignity of older people?

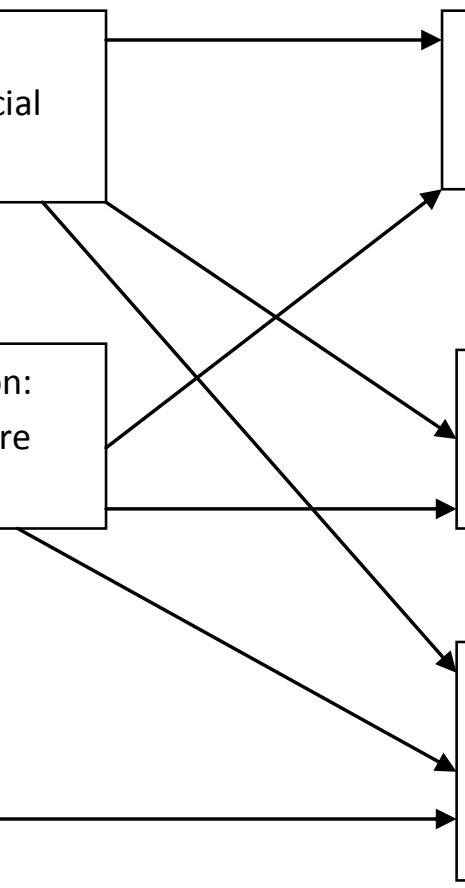

Q4. Existing human rights pr international human rights a vulnerabilities of older peop

Q5. Progress on special pro people. Has progress by th to protect against vulnerab

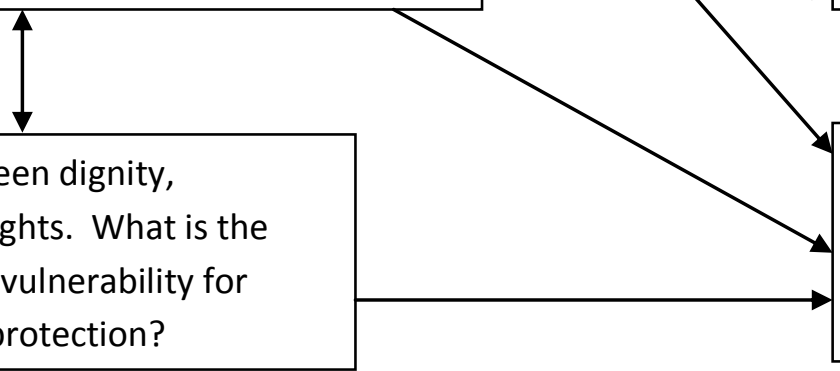

Q6. Should there be a speci instrument? How should an the vulnerabilities and lived people? 
The first two research objectives ${ }^{193}$ share the same starting point stated in research question 1. Identification of older people as a distinct and definable social group requires the research to reach beyond the assumed definition of chronological age. Therefore, Theories of Ageing and the ageing process were examined. The findings demonstrated the potential to define older people, inter alia, in terms of the following: physical and cognitive decline and disability; abandonment; isolation; poverty; productivity; disengagement; reduced status, negative stereotyping and self-stereotyping; resource-dependency; low living standards; homelessness; and a propensity to being abused. This research stage was the first point at which "vulnerability" as a definition was conceived, thereby introducing the concept of vulnerability to the debate surrounding foundations of human rights.

The second primary research question with a focus on how older people are vulnerable, and the risks to dignity flowed from the conclusions to the question of how older people are identified as a social group. This question drew, in the first instance, on the principles of Interest Theory to ground identification of the interests held by older people in human rights. Full recognition of the risks to dignity necessitated establishment of the relationship between the concepts of Human Dignity and Vulnerability; the reciprocal threats between the two, and outcomes for older people.

Given that the methodology involved progressing from the change required of human rights, to arrive at obligatory normative provision and implementation, the need to develop the relationship between the concepts of Human Dignity and Vulnerability for the purposes of human rights per se and special protection consequently formed the subject of the third primary research question. Furthermore, the findings of this question supported and advanced the conclusions of the question examining the needs of older people for special protection, the ways in which the group is vulnerable, and the risks to dignity.

The question of the adequacy of existing international human rights with reference to the interests of older people is informed by the first two primary research questions, and responds directly to the objective of providing alternative approaches to: critique existing human rights; develop normative provision; and implementation. The research undertaken by this question provides direct answers to the objective to examine the international rights framework in the context of the position of older people. The findings of this research question prompted the question surrounding progress made by the UNOEWGA to protect older people against vulnerability. The research undertaken to this point all contributed to the development of the final research question: 'Should there be a special

${ }^{193}$ Scrutiny of interests held by older people in human rights; and examination of international rights framework vis à vis the position of older people (identification of normative and implementation barriers). 
protection instrument? How should any instrument address the vulnerabilities and lived experiences of older people?' The method employed to answer this question contributed to the fulfilment of the final research objective to develop alternative approaches to: critique existing human rights; and to develop normative provision and implementation of rights.

\subsection{Primary Research Questions Methods}

The objectives of this thesis influence the focus of the research and the approach taken. Consequently, the emphasis will be primarily on literature; conceptual accounts; commentaries; analysis of prior research and studies; reports of expert groups and international bodies; United Nations reports; comparative studies; and instruments of international human rights law and associated Treaty Monitoring Bodies. Methods were selected from this resource in accordance with the primary research questions derived from the position of older people in the international context, as outlined in the previous chapter.

1. Older people as a 'distinct and definable social group'; is it possible to define older people as a social group for the purposes of special protection?

The first stage of research undertaken to respond to this question comprised a review of academic literature and definitions used by the European Court of Human Rights to identify characteristics which qualify groups for special protection. A review of academic literature was undertaken also of theories of ageing, primarily to assess the involvement of societal influences on the vulnerabilities experienced by older people. These influences included: processes of modernising societies; negative stereotyping; and perceptions and expectations of older people. In addition a review of academic literature pertaining to biological ageing and defining older people by chronological age was undertaken. Furthermore, a conceptual analysis of Human Dignity and Vulnerability contributed to identification of older people as a vulnerable group in accordance with the definitions of the ECtHR and the requirements of special protection. Following this, an examination of the lived experiences of older people was conducted. This examination drew on previously conducted research by expert bodies, international bodies, and academics. Bodies included: World Health Organisation; United Nations; International Labour Organisation; EuroStat and the Office of National Statistics. Documented research undertaken by HelpAge International and conference papers from the International Federation of Ageing were also sourced. Finally, research undertaken by academics on ageing cohorts regarding aspects of ageing contributed to findings. The majority of findings representative of a developed country were drawn from the UK, and others from Europe. 
The remainder of research information represents Europe, Africa, and Asia to varying degrees. In order to assess whether, by virtue of definition of older people as a social group, the defining characteristics were sufficient for the purposes of special protection. This required a study of the existing human rights instruments and corresponding General Comments of Treaty Monitoring Bodies, in addition to perspective of academic literature vis à vis the vulnerabilities of older people as a group. The instruments examined were: Universal Declaration of Human Rights; International Convention on Civil and Political Rights; International Convention on Economic, Social and Cultural Rights; Convention on the Rights of Persons with Disabilities; and Convention on Elimination of All Forms of Discrimination Against Women.

2. The needs of older people for special protection: how are older people vulnerable in society; what are the risks to the dignity of older people?

The conceptual analysis of Human Dignity and Vulnerability, and the review of the academic literature surrounding theories of ageing, together with the study of previously undertaken research and reports on the lived experiences of older people partially informed this question. Further conceptual analysis of Human Dignity and Vulnerability was required to assess the relationship between the two in terms of the risks each can cause the other in situations of a lack of rights protection.

3. The relationship between dignity, vulnerability and human rights. What is the significance of dignity and vulnerability for human rights and special protection?

The research methods employed to answer this question involved, in the first instance, conceptual analysis and a review of academic literature. The relationship between the two concepts was studied further in order to analyse the impact on human rights. Specifically, the analysis aimed to determine whether Vulnerability, in addition to the traditionally accepted Human Dignity underpinned human rights. Furthermore, it sought to establish whether, combined, the concepts informed the normative provision of human rights. A review of the academic literature aimed to establish whether both conceptually and morally underpin both generations of human rights, thereby substantiating the role in the normative content of human rights per se and in special protection. The relationship between Human Dignity and Vulnerability is of specific importance to special protection rights. This is because when violations of dignity and outcomes of vulnerability are beyond the reach of universal rights special protection must target the gap in provision. 
4. Existing human rights protections. How do international human rights address the particular vulnerabilities of older people? Is this adequate?

The way in which international human rights address the particular vulnerabilities of older people, and its adequacy was explored in the scrutiny of the generic and special protection rights instruments as follows: Universal Declaration of Human Rights; International Convention on Civil and Political Rights; International Convention on Economic, Social and Cultural Rights; Convention on the Rights of Persons with Disabilities; and Convention on Elimination of All Forms of Discrimination Against Women. Furthermore, specific regional instruments which include rights for older people, and the Protocol to the Charter on African Human and Peoples' Rights on the Rights of Older Persons were surveyed; the latter to establish inter-regional themes and the suitability of regional instruments for provision of special protection. In addition, the relevant Committee General Comments and Recommendations were examined for the same purpose. From a review of the academic literature the thesis derived a vulnerabilities framework to determine categories and the linked nature of vulnerabilities. Through the study of prior research conducted by expert bodies, international bodies, and academics the vulnerabilities of older people were substantiated in compliance with the vulnerability framework. Using the framework, and with reference to the vulnerabilities established from the study of previously undertaken research referenced above, the study of existing generic international and special protection instruments was conducted. Each right corresponding to vulnerabilities from each instrument was examined to this end. The aim is to determine the extent to which the normative content provides for vulnerabilities. The exercise was also conducted to establish the extent to which implementation of rights address the particular vulnerabilities of older people. Additionally, comparison was made between the UN Implementation Framework and the outcomes required by older people from rights derived from the unique listing of Fundamental Capabilities produced by this thesis. This comparison also demonstrated the originality of the research.

5. Progress on special protection for older people. Has progress by the OEWG been adequate to protect against vulnerability?

The research undertaken in respect of this question centred on an examination of the reports of the working sessions of the Open Ended Working Group on Ageing. The aim is two-fold. Firstly, the discussions of the group were studied to determine the key areas of existing rights which the group 
established as requiring protection. The second aspect of the Group reports examined comprised discussions of methods, including the provision of a special protection rights instrument, to achieve the protection of identified vulnerabilities. Commentaries on the discussions and outcomes of the working sessions were also reviewed.

6. Should there be a special protection instrument? How should any instrument address the vulnerabilities and lived experiences of older people?

In order to address the question of the need for a special protection instrument the arguments preferred by the delegates of the Open Ended Working Group on Ageing were reviewed. In addition academic literature was reviewed. The aim being to make the case for and against a special protection instrument in light of the vulnerabilities of older people established in earlier research. In order to derive an answer to the question of how any instrument should address the vulnerabilities and lived experiences of older people a review of the academic literature on the Capabilities Approach was undertaken. Furthermore, a comparative review of prior research undertaken by Burchardt et al on the subject of Capabilities, human rights and children in $21^{\text {st }}$ century Britain. The latter also demonstrates the originality of this part of the research.

\subsection{Conclusion}

The methodological design responded to this aim of the thesis to examine beyond the existing situation in order to devise a unique approach to human rights in terms of the underpinning concepts, normative provision, outcomes and implementation. The approach to the development of special protection is, as a result, unique; at strict variance from that currently adopted by the United Nations. This is due largely to the conceptual method adopted, rather than a dependence on analysis of contemporaneous legal rules and principles. The critical design and theoretical framework incorporated therein resulted in a complex connectivity between the research questions and inter-relationship with the research objectives. The research methods for each primary research question are drawn from the principles of challenging accepted assumptions and beliefs, and progress, in conjunction with the theoretical framework, to contribute to the construction and development of the thesis. 
PART II

APPROACHING HUMAN RIGHTS 


\section{CHAPTER 4}

\section{HUMAN DIGNITY AND HUMAN RIGHTS}

\subsection{Introduction}

Human dignity has been introduced to this thesis as underpinning human rights. In return, human rights are entrusted with protecting human dignity. The question of the adequacy of current human rights provision for older people is, therefore, partly a question of human dignity and the relationship between human dignity and human rights. To respect, protect and promote dignity is an objective of human rights; therefore what comprises dignity will be discussed here to inform further discussion of the content of human rights in later chapters. Dignity, and discussion of how dignity is understood, will be instructive on issues including how a person is made vulnerable, and areas of focus for the Capabilities Approach discussed in the next chapter as a mechanism for giving substance to human rights. Discussion of the concept will contribute to identification of older people as a group in need of special protection by human rights, as Human Dignity features in particular vulnerabilities and lived problems faced by older people. Combined, these aspects of human dignity will form part of the examination of current human rights provision via instruments and judicial application of rights later in the thesis.

The construct of Human Dignity is considered, initially via an exploration of meaning. Understanding dignity as the 'inherent worth' of the human person gives a universal and inalienable value to all humanity. It will be argued that this negates any argument for qualification of the concept by virtue of physical or mental ability. In this context the key pillars of human dignity are introduced. Comprising objectives and principles of human rights, it will be argued that all are 'owned' by the individual. Coverage contributes to awareness of what dignity is seen as providing the person, and how it contributes to well-being. Furthermore, how the concept underpins and informs human rights is expanded upon. Discussion at this point turns to the requirement to 'respect' human dignity, which influences content and application of human rights. For clarification purposes, 'respect' as used in this chapter refers to objective and subjective approaches to respect and selfrespect, rather than the term as used in the context of state duty for human rights. Treatment which supports respect for human dignity will be defined by standards of conduct prescribed by human rights. Norms are objective and subjective to comply with the nature of respect and self-respect, and provide strong guidance for violations of dignity. The feelings of humiliation, the tangible outcomes of humiliating and degrading treatment, and violations to dignity are argued to be the subjectmatter for protection by human rights. Having set out the concept of human dignity, the relationship 
the concept has with human rights is considered in more depth. The chapter continues by considering how human dignity helps provide the content of human rights, the normative basis of treatment of individuals, as well as helping understand rights-holding.

The following chapter will examine the relationship shared by the concepts of Human Dignity and Vulnerability with human rights. Additionally, the normative provision of human rights in the context of older people will be examined in Part IV. ${ }^{194}$ This chapter contributes to both by finally considering how dignity is embedded into human rights instruments.

\subsection{Concept of Human Dignity}

There is contested debate surrounding the concept and content of Human Dignity. There is no universally accepted definition. As a result, the concept has been dismissed as a 'pompous façade,' having no sound philosophical or tangible basis. ${ }^{195}$ The purpose of the concept is criticised; 'Dignity is a useless concept. It means no more than respect for persons or their autonomy. ${ }^{196}$ Human dignity therefore stands accused of having '...an intrinsic meaning...left to intuitive understanding, conditioned in large measure by cultural factors,' ${ }^{197}$ which has produced something 'rather blurred, vague, or even ambiguous. ${ }^{\text {,198 }}$ As 'a rather eclectic...notion that cannot be precisely defined' it takes on 'different types of justification and presentations which have evolved in the course of philosophical thinking. ${ }^{199}$ In the context of examination of Human Dignity in this thesis the 'multifaceted' account is not negative. The different philosophical proposals contribute to an everbroadening understanding more representative of the requirements of a 'life of dignity.' The benefit is an account of dignity with greater scope for interpretation and application to concrete circumstances, but also greater scope for violation of dignity (broadly understood), and thus a greater breadth of human rights coverage. Furthermore, understood in this way dignity is capable

\footnotetext{
194 See Chapter 11, 'Normative Protection'

195 M Rosen, Dignity, (2012; Harvard University Press, Cambridge, Massachusetts \& London), 1

${ }^{196}$ R Macklin, 'Dignity is a useless concept,' 'British Medical Journal,' Dec 20 2003, 327 (7429) 1490-1420, 1490. However, both of these principles are themselves fundamental to human dignity, as this chapter will demonstrate.

${ }^{197}$ O Schachter, 'Dignity as a Normative Concept,' 'The American Journal of International Law' Vol.77, No. 4 (Oct 1983), 848, 849

The general consensus on the intuitive notion is stated by Martha Nussbaum as being 'by no means utterly clear,' and thus of little assistance to any definition. Martha Nussbaum Creating Capabilities. The Human Development Approach. Harvard University Press, 29

${ }^{198}$ Nathan Rotenstreich, Man and His Dignity (1983, Magness Press, Jerusalem), (as cited in D Shultziner, 'Human Dignity - Functions and Meanings,' 'Global Jurist Topics,' Vol. 3, Issue 3, Article 3 1, 2. www.bepress.com/gs/topics/vol3/iss3/art3. Accessed 20/03/2016

${ }^{199}$ D Shultziner, 'Human Dignity - Functions and Meanings,' 'Global Jurist Topics,' Vol. 3, Issue 3, Article 31,2 www.bepress.com/gs/topics/vol3/iss3/art3. Accessed 20/03/2016
} 
of informing a range of normative standards, requiring a range of remedies. This is not to ignore issues of conflict and 'outright contradictions at every turn' ${ }^{200}$ which such an idea attracts.

\subsection{1 $\underline{\text { Status }}$}

The lexical origin of 'dignity,' or dignitas, is informative of meaning. The literal translation of 'worth' features in many philosophical discussions, ${ }^{201}$ both directly and by association, and is quoted in human rights instruments (see section 4.6, below and Chapter 11, 'Normative Provision'). Originally, the idea of 'worth' was dependent upon individual status or rank, and commanded commensurate measure of social appreciation ${ }^{202}$ and respect. ${ }^{203}$ Whilst there remains a place for each in the notion of human dignity discussed for the purposes of this thesis, the change in the relationship between 'worth' and 'status,' discussed below, engendered change to application, and broadened the scope of the concept.

Significantly, the dignity debate no longer positions itself between individuals, but between species. Dignity now 'expresses the idea of the high and equal rank of every human person' ${ }^{204}$ differentiating human dignity from that of all other species. The traits, characteristics and capacities responsible for this status, ${ }^{205}$ are influential in all aspects of the dignity concept. ${ }^{206}$ They include the 'vastly superior...mind, developed by study and reflection, ${ }^{207}$ also recognised by imago dei. $^{208}$ This rationale is credited as providing human beings with the capability 'of self-knowledge, of self-

\footnotetext{
${ }^{200}$ Stephen Pinker, 'The Stupidity of Dignity,' New Republic, May 28, 2008, available at http://www.tnr.com/story-print.html?id=d8731cf4-e87b-4d88-b7e7-f5059cdobfbd (as cited in Jeremy Waldron, 'Dignity, Rank, and Rights,' The Tanner Lectures on Human Values Delivered at University of California, Berkeley, April 21-23, 2009).

${ }^{201}$ O Schachter, 'Human Dignity as a Normative Concept,' 'The American Journal of International Law,' Vol.77, No. 4, Oct 1983, 848, 849

${ }^{202}$ Associated with perception of individuals and groups of individuals; 'appreciation is expressed and conditioned by a certain attitude of society.' D Shultziner, 'Human Dignity - Functions and Meanings,' 'Global Jurist Topics,' Vol. 3, Issue 3, Article 3 1, 10. www. bepress.com/gs/topics/vol3/iss3/art3. Accessed 20/03/2016 C McCrudden, 'Human Dignity and Judicial Interpretation of Human Rights,' EJIL, 2008; Vol.19, No.4 655, 657 ${ }^{203}$ Linked with dignified treatment, and non-discrimination Rotenstreich, N., Man and His Dignity (1983; Magnes Press, Jerusalem) cited in D Sihultziner, 'Human Dignity - Functions and Meanings,' ‘Global Jurist Topics,' Vol. 3, Issue 3, Article 3 1, 10. www.bepress.com/gs/topics/vol3/iss3/art3. Accessed 20/03/2016 See also the headings of 'Respect' and 'Self-respect' later in this chapter.

204 J Waldron, 'Dignity, Rank, and Rights' The Tanner Lectures on Human Values delivered at University of California, Berkeley, April 21, 210

${ }^{205}$ Which is treated as superior

${ }^{206}$ G Kateb, Human Dignity, (2011; Harvard University Press), 6

${ }^{207}$ Cicero, De Officiis, 1, at 30, cited in C McCrudden, 'Human Dignity and Judicial Interpretation of Human Rights,' EJIL, 2008; Vol.19, No.4 655, 657

${ }^{208}$ Created in the image of God
} 
possession and of ...entering into communion with other persons, ${ }^{209}$ and the capacity for reason. Of these, the ability to reason is often credited as the justification for the superiority of man. ${ }^{210}$ Kant's claim that man has the ability 'to be lord of his fate and shaper of his future'211 is contributory to securing the superior status of humankind, fixed in rationality and the capacity to reason. This setting of one's own 'ends' advances the constant state of change and development of the human person $^{212}$ as entitlement to dignity. However, attributes and capabilities in addition to those grounded in rationality have been argued as contributory to humanity's superior status, and, therefore, shed more light on the concept of human dignity. The Capabilities Approach supports this argument, and will be discussed in further detail in Chapter 6

\subsection{2 'Inherent Dignity'}

Human dignity is argued as 'inherent,' or 'involved in the constitution or essential character ${ }^{\prime 213}$ of every person. '...an unconditional, incomparable value'. ${ }^{214}$ It is 'permanent...inseparable from the human condition. ${ }^{215}$ The ontological nature is not reliant on personal characteristics 'such as...being young or old...healthy or sick.' ${ }^{216}$ Instead, it is universal and inalienable; unable to be surrendered by or removed from the individual. Even when dignity is violated it is retained by the person. Dignity is considered the 'inherent worth' or value of the person. The widely accepted representation of this 'worth' is Kant's 'setting of one's own ends, ${ }^{217}$ as the person who serves as another's means has only a 'relative worth,, ${ }^{218}$ exchangeable for means of comparable worth. ${ }^{219}$ This

\footnotetext{
${ }^{209}$ The Catechism of the Catholic Church, Part One: The Profession of Faith, Section 2: The Profession of the Christian Faith. Chapter 1, Article 1, paras, 6 and 356-357, cited in C McCrudden, 'Human Dignity and Judicial Interpretation of Human Rights,' EJIL, 2008; Vol.19, No.4 655, 658

${ }^{210}$ C McCrudden, 'Human Dignity and Judicial Interpretation of Human Rights,' EJIL, 2008; Vol.19, No.4 655, 659. This conclusion by the Renaissance philosophers followed the reasoning of Acquinas.

${ }^{211}$ Arieli, 'On the Necessary and Sufficient Conditions for the Emergence of the Dignity of Man and His Rights,' in Kretzmner and Klein The Concept of Human Dignity in Human Rights Discourse (2002), 109, cited in C McCrudden, 'Human Dignity and Judicial Interpretation of Human Rights,' EJIL, 2008; Vol.19, No.4 655, 659 ${ }^{212}$ Proposed by Pico della Mirandola.

${ }^{213}$ Roberto Andorno 'Human Dignity and Human Rights as a Common Ground for a Global Bioethics' J Med Philos (2009) 34(3): 223, 229.

${ }^{214}$ I Kant, Groundwork of the Metaphysics of Morals (M Gregor, trans and ed) (1991; Cambridge University Press) 4:436, cited in M Rosen, Dignity, (2012; Harvard University Press), 21

${ }^{215} \mathrm{R}$ Spaemann, 1996, Personen. Versuche über den Unterschied zwischen, etwas 'und jemand' (as cited in Roberto Andorno 'Human Dignity and Human Rights as a Common Ground for a Global Bioethics' J Med Philos (2009) 34(3): 223, 229

${ }^{216}$ Roberto Andorno 'Human Dignity and Human Rights as a Common Ground for a Global Bioethics' J Med Philos (2009) 34(3): 223, 229.

${ }^{217}$ G Kateb, Human Dignity, (2011; Harvard University Press), 6

${ }^{218}$ C Dupré, The Age of Dignity, (2015; Hart Publishing), 31-32

${ }^{219}$ I Kant, Groundwork of the Metaphysics of Morals (M Gregor, trans and ed) (1991; Cambridge University Press) 4:436, cited in M Rosen, Dignity, (2012; Harvard University Press), 21
} 
relationship between inner worth, ends and dignity is significant for the purposes of this chapter, and is explained in the following excerpt from Groundwork of the Metaphysics of Morals:

In the kingdom of ends everything has either a price or a dignity (Würde). ${ }^{220}$ What has a price can be replaced by something else as its equivalent; what...admits of no equivalent has a dignity. ...something can be an end in itself has ... an inner worth, that is dignity. ${ }^{221}$

The nature of 'inner worth' and 'inherent dignity' translates as equal worth intrinsic to every person.

\subsubsection{Individual Identity}

Notwithstanding species membership, the inherent dignity of the person is de facto a matter of individuality. ${ }^{222}$ Individual choice exists within a group, yet the choices of the group must be assured for anything essential to group dignity. ${ }^{223}$ Despite this, assumptions made on the basis of group membership ${ }^{224}$ serve only to insult dignity. Only the dignity of the individual is universal. ${ }^{225}$

Having discussed the concept of dignity as a consequence of the human species, it is timely to consider the key pillars of human dignity: freedom, autonomy, equality, and human need.

\subsubsection{The key pillars of human dignity}

\subsubsection{Freedom}

Freedom incorporates rational thought, agency, active striving, functioning, and Kantian inherent worth. The initial focus of freedom is the distinctive ability of the individual to self-determine. ${ }^{226}$ This is inherent in humankind, and 'can at no point... come to a complete cessation. ${ }^{227}$ This 'almost unlimited power of self transformation ${ }^{\prime 228}$ also lies at the heart of the principle to 'choose to be what

\footnotetext{
220 'Wurde' is translated as 'worth' or 'value'.

${ }^{221}$ I Kant, Groundwork of the Metaphysics of Morals (M Gregor, trans and ed) (1991; Cambridge University Press) 4:429, 38, cited in M Rosen, Dignity, (2012; Harvard University Press) 20-21

${ }^{222}$ G Kateb, Human Dignity, (2011; Harvard University Press) 11

${ }^{223}$ O Schachter, 'Human Dignity as a Normative Concept,' 'The American Journal of International Law,' Vol.77, No. 4, Oct 1983, 848, 851

${ }^{224}$ by virtue of, for example, age, regarding characteristics, traits, skills, capacities, capabilities and significant interests held in rights. See J Mann, 'Dignity and Health: The UDHR's Revolutionary First Article,' 'Health and Human Rights' Vol. 3, No.2, Fiftieth Anniversary of the Universal Declaration of Human Rights (1998), 30, 33

${ }^{225}$ Roberto Andorno 'Human Dignity and Human Rights as a Common Ground for a Global Bioethics' J Med Philos (2009) 34(3): 223, 229.

${ }^{226}$ C Dupré, The Age of Dignity, (2015; Hart Publishing) 32

${ }^{227}$ E Cassirer, On dignity after 1945, see Chapter 3, cited in C Dupré, The Age of Dignity, (2015; Hart Publishing) 32

${ }^{228}$ E Cassirer, On dignity after 1945, see Chapter 3, cited in C Dupré, C., The Age of Dignity, (2015; Hart Publishing) 32
} 
[a person] wants to be, ${ }^{229}$ and links naturally with the human aptitude for improvement. ${ }^{230}$ Dignity is defined in terms of this special freedom, which in turn is reliant on autonomy.

\subsubsection{Autonomy}

It is argued by some that human superior status and human dignity exists by virtue of rationality and reason; it is claimed '...all our dignity consists in thought. ${ }^{231}$ These attributes also define dignity in terms of autonomy, as autonomy permits the person to 'pursue what we ourselves decide is a good life.' $^{232}$ Such pursuit of personal goods is only possible where the person is 'lord of his fate and shaper of his future. ${ }^{233}$ The autonomy to set one's own ends ${ }^{234}$ in this way makes for a life of dignity by preventing, at a normative level, all forms of coercion. This includes coercion through decisionmaking, or discrimination. ${ }^{235}$ Autonomy, therefore, contributes to the freedom deemed necessary as an underpinning for dignity. Furthermore, autonomy contributes to existence as an end in itself, ${ }^{236}$ so that no person endures the indignity of 'relative worth'. This supports the notion of equality as an aspect of dignity.

\subsubsection{Equality}

Equality embraces the concepts of status, inner worth, freedom and autonomy. With 'dignitas' firmly in the space of species dignity, 'humanness' designates equality in a dignity which can neither be given away nor removed; ${ }^{237}$ '...all humans are equally human...humanness is permanent. Because human dignity is derived from this humanness, human dignity is irrevocable. ${ }^{238}$ Humanness and equality in dignity cannot be separated from the notion of inner worth, establishing the equal value of every person. Equality in human dignity also exists by virtue of the principle of inner worth. As equality precludes any measure of relative worth (of individuals or groups), or relative capacity or capability (inter alia, perceived physical or intellectual capacity, including as influenced by or

${ }^{229}$ C McCrudden, 'Human Dignity and Judicial Interpretation of Human Rights,' EJIL, 2008; Vol.19, No.4 655, 659

This ideal is an underlying principle of the Capabilities Approach. See Chapter 4

${ }^{230}$ C Dupré, The Age of Dignity, (2015; Hart Publishing), 31

231 Pascal, Pensees, (1966, Penguin, Harmondsworth) ,200, cited in M Rosen, Dignity, (2012; Harvard University Press), 18

232 J Griffin, 'First Steps in an Account of Human Rights' European Journal of Philosophy (2001) 306-307 cited in C Gearty, The Hamlyn Lectures 2005 Can Human Rights Survive? (2006; Cambridge University Press) 47.

${ }^{233}$ Arieli, 'On the Necessary and Sufficient Conditions for the Emergence of the Dignity of Man and His Rights,' in Kretzmner and Klein The Concept of Human Dignity in Human Rights Discourse (2002), 109, cited in C McCrudden, 'Human Dignity and Judicial Interpretation of Human Rights,' EJIL, 2008; Vol.19, No.4 655, 659

${ }^{234}$ C Dupré, The Age of Dignity, (2015; Hart Publishing), 33

235 O Schachter, 'Human Dignity as a Normative Concept,' 'The American Journal of International Law,' Vol.77, No. 4, Oct $1983,848,849$

${ }^{236}$ C Dupré, The Age of Dignity, (2015; Hart Publishing), 31-32

${ }^{237}$ G Kateb, Human Dignity, (2011; Harvard University Press), 5

${ }^{238}$ Y M Barilan, Human Dignity, Human Rights and Responsibility, (2012; MIT Press), 93 
circumstance or opportunity), from determining the dignity of individuals, or whether individuals have dignity. ${ }^{239}$ Therefore, universal access to the two preceding pillars of freedom and autonomy must be unconstrained by discrimination or coercion.

\subsubsection{Human Need}

Dupré argues for a broader, more holistic definition of Human Dignity. ${ }^{240}$ The first observation is the limited value of freedom and autonomy to the individual lacking the basic means to survive. Dupré borrows from Kateb in stating Human Dignity is, primarily 'about human existence: ${ }^{241}$ sustenance, shelter, health, and living conditions. ${ }^{242}$ Being 'born free and equal in dignity ${ }^{243}$ does not provide a life of dignity to the person unable to sustain or move beyond basic subsistence, or to develop or live independently, even if that person is rational, free and autonomous (to the extent that this possible in circumstances of dire need). ${ }^{244}$ A person's human and material need ought therefore to be amongst the first aspects of dignity addressed by human rights. ${ }^{245}$

\footnotetext{
${ }^{239}$ G Kateb, Human Dignity, (2011; Harvard University Press), 8-9

${ }^{240}$ The three pillars of freedom, autonomy, and equality.

${ }^{241}$ G Kateb, Human Dignity, (2011; Harvard University Press), 10-17

${ }^{242}$ '[g]ive him food and shelter: When you have covered his nakedness, dignity will follow...' Hubert Canick, ' 'Dignity of Man' and 'Persona' in Stoic Anthropology: Some Remarks on Cicero, De Officiis I, 105-107,' in David Kretzmer and Eckart Klein (eds) The Concept of Human Dignity in Human Rights Discourse (Kluwer Law Int'I 2002) 36 (as cited in Christopher McCrudden, 'Human Dignity and Judicial Interpretation of Human Rights' (2008) 19(4) EIJL 655, 660 <http://ejil.org/pdfs/19/4/1658.pdf> accessed 24 March 2016) ${ }^{243}$ UDHR Article 1

${ }^{244}$ Schachter tells us that any person 'in abject condition, deprived of adequate means of subsistence...suffers a profound affront to his sense of dignity and intrinsic worth.'

O Schachter, 'Dignity as a Normative Concept,' 'The American Journal of International Law,' Vol.77, No. 4 (Oct 1983) 848,851

${ }^{245}$ World Bank 1976 annual meetings of the Board of Govenors: summary proceedings, Washington D.C. 14 (as cited in Corinna Mieth 'The Double Foundation of Human Rights in Human Nature' in Marion Albers, Thomas Hoffmann, Jöm Reinhardt (eds), Human Rights and Human Nature (Springer 2014) 13
} 


\subsubsection{Personality}

Dupré further broadens the definition of dignity to 'personality and life in dignity. ${ }^{246}$ Personality initially relates to individual 'uniqueness,' or the characteristics and composition of the person. The purpose is to address the exclusion of some individuals from dignity because of a lack of autonomy. ${ }^{247}$ This aspect does not permit any qualification of human dignity by reason of incapacity or limited capability choices. ${ }^{248}$ The argument is that personality ${ }^{249}$ must be allowed to develop if individual dignity is to be protected. Given the vulnerabilities of older people, including weaknesses in capacity and capability associated with older age, made clear in Section III, this thesis will proceed on the broadest, most holistic approach to human dignity, encompassing all aspects of dignity as discussed thus far. This understanding is the only understanding which provides 'fuller protection for those who are particularly vulnerable ${ }^{\prime 250}$ Significantly for the purposes of this thesis, it also protects the dignity of those 'unable to make decisions.' 251

Discussions of human dignity and 'inner worth"252 almost invariably demand that all aspects of dignity be treated with respect if these, and dignity itself, are to be protected. ${ }^{253}$ What follows is an explanation of 'respect' and how it impacts on dignity. Respect is viewed and applied here in the specific context of treatment of the person and self-respect. The purpose is not to draw on principles of state duty to respect, protect and fulfil.

\subsection{5 $\underline{\text { Respect }}$}

Respect may be shown objectively and subjectively; the former is manifested by treatment, the latter through perception and expressed opinion of the parties administering and receiving treatment. ${ }^{254}$ For respect to be complete it must embrace the whole of personal identity, and

\footnotetext{
${ }^{246}$ Catherine Dupré 'Human dignity and the withdrawal of medical treatment: a missed opportunity?' (2006) 6 EHRLR 678, 687.

${ }^{247}$ Catherine Dupré 'Human dignity and the withdrawal of medical treatment: a missed opportunity?' (2006) 6 EHRLR 678, 690

${ }^{248}$ For Dupré it serves as 'a crucial reminder that the incompetent person is and remains a human person and deserves to be treated as such.' Catherine Dupré 'Human dignity and the withdrawal of medical treatment: a missed opportunity?' (2006) 6 EHRLR 678, 690

${ }^{249}$ As opposed to personhood, 'the quality of being a human being.' Catherine Dupré 'Human dignity and the withdrawal of medical treatment: a missed opportunity?' (2006) 6 EHRLR 678, 687 n.40.

${ }^{250}$ Catherine Dupré 'Human dignity and the withdrawal of medical treatment: a missed opportunity?' (2006) 6 EHRLR 678, 690

${ }^{251}$ Catherine Dupré 'Human dignity and the withdrawal of medical treatment: a missed opportunity?' (2006) 6 EHRLR 678, 690

${ }^{252}$ C Dupré, The Age of Dignity, (2015; Hart Publishing), 35

${ }^{253}$ Rutger Claassen, 'Human Dignity in the Capability Approach,' Marcus Düwell, Jens Braarvig, Roger Brownsword, Dietmar Mieth (eds.) The Cambridge Handbook of Human Dignity (CUP, 2014) 240-249, 244

${ }^{254}$ O Schachter, 'Dignity as a Normative Concept,' 'The American Hournal of International Law' Vol.77, No. 4 (Oct 1983) 848, 849.
} 
collectively, the identity of the group to which a person belongs. ${ }^{255}$ Respect and treatment of human dignity is considered in 4.3 , below.

\subsubsection{Self-respect}

Respect for human dignity impacts self-respect; the reflection of perceived worth of oneself in response to the respect shown by others. ${ }^{256}$ The parties showing respect include institutions and the State via recognition of equal moral status and access to rights and capabilities. ${ }^{257}$ Self-respect is also influenced by the availability of the freedom to 'fulfil one's intentions, ${ }^{258}$ direct one's own life, autonomy, the ability to act morally, ${ }^{259}$ and the capability to be and do all that the person values. Of all the 'goods' required for a life of dignity, self-respect is often cited as 'the most important basic good for a good life. ${ }^{260}$ As a consequence, self-respect, or the lack of self-respect, provides a proxy, a measure of violation of dignity, and the effectiveness of human rights which underpin it.

Self-respect also has subjective and objective aspects. The subjective, or psychological, interpretation of self-respect describes the 'attitude each individual has toward him or herself, based on a standard for worthiness and excellence endorsed by the individual. ${ }^{261}$ On this basis, selfrespect can be held by people whose human dignity is not respected by others, as their lives comply with their idea of worth. ${ }^{262}$ This leads to realisation of problems of adaptive preference, where any improvement to a person's treatment will satisfy self-worth, despite violations of dignity. ${ }^{263}$ Feelings of worth and self-perception ${ }^{264}$ are dealt a blow only when personal ideas of worthy behaviour ${ }^{265}$ or subjective standards are insulted. This dichotomy gives purpose to objective standards of the way

\footnotetext{
255 O. Schachter, 'Human Dignity as a Normative Concept,' 'The American Journal of International Law,' Vol.77, No. 4, Oct $1983,848,851$

${ }^{256}$ See generally Avishal Margarlit The decent society (HUP 1996)

${ }^{257}$ Corinna Mieth 'The Double Foundation of Human Rights in Human Nature' in Marion Albers, Thomas Hoffmann, Jöm Reinhardt (eds), Human Rights and Human Nature (Springer 2014) 14 n.3

${ }^{258}$ John Rawls (1971) 440 (as cited in Corinna Mieth 'The Double Foundation of Human Rights in Human Nature' in Marion Albers, Thomas Hoffmann, Jöm Reinhardt (eds), Human Rights and Human Nature (Springer 2014) 14).

${ }^{259}$ Corinna Mieth 'The Double Foundation of Human Rights in Human Nature' in Marion Albers, Thomas Hoffmann, Jöm Reinhardt (eds), Human Rights and Human Nature (Springer 2014) 14

260 John Rawls (1971) 440 (as cited in Corinna Mieth 'The Double Foundation of Human Rights in Human Nature' in Marion Albers, Thomas Hoffmann, Jöm Reinhardt (eds), Human Rights and Human Nature (Springer 2014) 14)

${ }^{261}$ Daniel Statman, 'Humiliation, dignity and self-respect' (2000) 13(4) PHIL LIT 523, 526)

${ }^{262}$ Daniel Statman, 'Humiliation, dignity and self-respect' (2000) 13(4) PHIL LIT 523, 527)

${ }^{263}$ See Chapter 1 and Chapter 6 for discussions on the principle of Adaptive Preference. The notion that slight improvements to a person's situation are acceptable in the face of continued violations of human rights is applicable to the elderly person whose sense of self-worth is low.

${ }^{264}$ Problems for older people associated with self-perception are discussed in Part III. Primarily they include the 'turning inward' of life-long prejudice held against ageing and the aged.

${ }^{265}$ S.J. Massey, 'Is self-respect a moral or psychological concept?' (1983) 93 Ethics 246, 248 (as cited in Daniel Statman, 'Humiliation, dignity and self-respect' (2000) 13(4) PHIL LIT 523, 526)
} 
people 'ought to value themselves. ${ }^{266}$

Objective standards are concerned with 'valuing oneself properly, and are therefore difficult to agree and implement. Older people are at higher risk of adaptive preference issues, ${ }^{267}$ and can benefit from the protection offered by objective standards. However, if protection is to be complete the special needs of individuals and the group must be incorporated into standards of special treatment. ${ }^{268}$

\subsection{Respect and treatment of Human Dignity}

To respect human dignity (in the sense used in this chapter) may involve abstinence from acts which violate a person's dignity, ${ }^{269}$ or may extend to positive actions which support dignity. ${ }^{270}$ Whether respect is delivered through abstinence or positive acts, both may be seen as contributory to a 'life of dignity'. ${ }^{271}$ Both may be the subject matter of normative standards of conduct covered by human rights. $^{272}$

Conclusive accounts of treatment which respects human dignity are, like the concept itself, disputed. However, descriptions of treatment which harms dignity are informative to understandings of dignified treatment. In general terms the description of conduct harmful to human dignity is 'inhuman treatment.' However, the outcomes of this sort of treatment can be varied, and it is often the case that such outcomes are not amenable to a definitive measure beyond individual feelings. ${ }^{273}$ Psychological effects are key, 'nothing is so clearly violative of the dignity of the person as treatment that demeans or humiliates. ${ }^{274}$ This is significant as it determining what human rights might be

\footnotetext{
${ }^{266}$ Daniel Statman, 'Humiliation, dignity and self-respect' (2000) 13(4) PHIL LIT 523, 527)

${ }^{267}$ As noted in 'Self-Perception Theory' which is covered in detail in Part III of this thesis. Self-Perception Theory is a theory of ageing which describes how individuals are influenced by societal prejudices towards the aged throughout life, and turn those perceptions inward when they too become aged. See chapter 8 for a fulsome discussion of the theory.

${ }^{268}$ If objective standards are not adapted to accommodate the needs of the elderly self-respect will still be insulted despite generally societally, and legally, accepted objective standards being complied with.

${ }^{269}$ Described as simple 'observation' of the law. M. Rosen, Dignity, (2012; Harvard University Press), 5

${ }^{270}$ In accordance with Feinberg's proposal that dignity is 'the recognisable capacity to assert claims.' Feinberg, 'The Nature and Value of Rights' in Rights, Justice and the Bounds of Liberty (1980; Princeton University Press) 143 , cited in J. Anderson. and A. Honneth, 'Autonomy, Vulnerability, Recognition and Justice' in J. Christman and J. Anderson (eds), Autonomy and the Challenge to Liberalism: New Essays (2005; Cambridge University Press) 132

${ }^{271}$ Stephen Darwall, Review of Michael Rosen, 'Dignity: Its History and Meaning'

${ }^{272}$ Stephen Darwall, Review of Michael Rosen, 'Dignity: Its History and Meaning' states this in terms of positive actions only. However, it is claimed in this thesis that all forms of treatment of human dignity requires norms if there is to be any useful guidance as to what constitutes 'undignified treatment' or treatment which harms dignity.

${ }^{273}$ The argument here is that whether dignity is respected can be determined by the way treatment makes a person feel. O. Schachter, 'Human Dignity as a Normative Concept,' 'The American Journal of International Law,' Vol.77, No.4, Oct 1983, 848, 850

${ }^{274}$ O Schachter, 'Human Dignity as a Normative Concept,' 'The American Journal of International Law,' Vol.77, No.4, Oct 1983, 848, 850
} 
relevant to preserve the dignity of older people, particularly those at risk of having their dignity violated, it may be necessary to determine the sort of treatment likely to engender 'feelings' of humiliation in older people, or sub-sets of older people such as the physically frail. As a starting point, human rights might seek to prevent ' $[A]$ ny sort of behaviour or condition that constitutes a sound reason for a person to consider his or her self-respect injured, ${ }^{275}$ caused by the act or omission of another. The sound reason could be seen as providing the basic content of normative standards, ${ }^{276}$ and informing claims to dignity. ${ }^{277}$ The norms generated could result in adapted or new human rights which adequately reflect how groups and groups of individuals are humiliated. Identification of spaces in which humiliating treatment occurs provides guidance as to origins and motivation for violations of dignity. ${ }^{278}$ The first of these is natural condition, inclusive of old age, sickness or disability. ${ }^{279}$ Of itself, natural condition does not cause humiliation. However, negative attitudes, perceptions and stereotyping of older people, or the acts and omissions of others based on these factors, can lead to humiliating treatment. ${ }^{280}$ Characteristics shared by groups experiencing the same natural conditions are also a potential catalyst for humiliating treatment. ${ }^{281}$ Causes of humiliation are also formulated from principles of autonomy and freedom to direct one's own life. Restriction or curtailment of individual autonomy and misrepresentation of priorities and values are $\mathrm{key}^{282}$ as they focus on personhood and individuality. ${ }^{283}$ Of particular danger to those needing special protection is 'psychological coercion to impose conformity'284 when their needs or values demand bespoke treatment. In all instances, actual interference with autonomy and freedom is not necessary; the threat of disrespect for one's choices can be sufficient cause for humiliation. ${ }^{285}$

\footnotetext{
${ }^{275}$ A. Margarlit, The decent society (HUP 1996) 9

${ }^{276}$ This norm should be in line with reasonable expectations, and not be born of simple whim. It should be able to be represented by the human right aimed at protecting dignity, and provide guidance for implementation.

${ }^{277}$ A. Margarlit, The decent society (HUP 1996) 9

278 Particularly when determining 'sound reason' and actual humiliation.

${ }^{279}$ All of which can be formed by the self and others. This problem is recognised in theories of ageing featured in Part III Chapter 8

${ }^{280}$ It is important to note that as a group, older people are at risk of exposure to each of the threats quoted, making them 'multiply vulnerable.' The idea of multiple, or aggravated, vulnerability is discussed in chapter 5 , 'Vulnerability and Human Rights.' It is also dealt with in Part III, chapters 8, 'Theories of Ageing' and 10 'What it Means to be an Older Person.'

Avishai Margalit, The Decent Society HUP 1996, 10

${ }^{281}$ Including ill-health, material need, and dependency. O. Schachter, 'Dignity as a Normative Concept,' 'The American Journal of International Law' Vol.77, No. 4 (Oct 1983) 848, 852

${ }^{282}$ Whether this be the conduct of a person, the state, or institutions. Avishai Margalit, The Decent Society HUP 1996, 13-14

${ }^{283}$ Primarily when a lack of appreciation for, disregard or prohibition of beliefs, ideas, feelings, attitudes and valued capabilities are involved. Avishai Margalit, The Decent Society HUP 1996, 16

${ }^{284}$ Also dangerous because it is dismissive of equality. O. Schachter, 'Human Dignity as a Normative Concept,' 'The American Journal of International Law,' Vol.77, No. 4, Oct 1983, 848, 850

${ }^{285}$ Moreso when a person is reliant on institutions. Avishai Margalit, The Decent Society HUP 1996, 13-14
} 
Humiliating treatment touches on all aspects of dignity. The most obvious forms of suffering are physical and mental pain. ${ }^{286}$ However, failing to respect a person's dignity also occurs when a person is left without the essentials for existence or resources to support capacity to develop, strive, and flourish. When this is a result of natural conditions of life some of the greatest violations of dignity take place. This may be particularly acute where a person is cognitively incapacitated, unaware of what constitutes a life of dignity and dignified treatment who 'can be manipulated, controlled, or conditioned softly and subtly, or even invisibly, and not feel that they have been degraded or even wronged. ${ }^{287}$

On the basis of this understanding of what constitutes violation of human rights it may be possible to gather 'standards in dignity' which address these risks to dignity, and which could be used as the basis of a normative framework to protect dignity. Included are: living conditions; deprivation of basic needs including health, care, shelter and sustenance; physical and psychological abuse; and insensitivity to choice and requirements of human personality. ${ }^{288}$

\subsection{Difficulties inherent in the concept of Human Dignity}

Notions which inform the concept and our understanding of human dignity can present some problems when seeking to use dignity to inform human rights. Therefore, prior to further consideration of the relationship between dignity and human rights later in this thesis, these problems will be mentioned at this stage.

\subsubsection{Entitlement}

The first problem of particular relevance to this work stems from the discussion of status. The grounding of human superior status and claims to dignity of the human person in rationality and the capacity for decision-making represents an obstruction to dignity for the cognitively impaired. Dignity based on the ability for thought and 'to choose to be what he wants to be' denies membership of the 'human family,' and human dignity, ${ }^{289}$ to those lacking capacity. Whilst

\footnotetext{
${ }^{286}$ Violation of dignity can range from feeling degraded to 'nonhuman.' G. Kateb, Human Dignity, (2011; Harvard University Press) 14

Being 'non-human' is also described as denial of membership of the 'human family.' Bruce M. Landesman, 'Book Review' (1997) 107 (4) Ethics 729, 730; Corinna Mieth 'The Double Foundation of Human Rights in Human Nature' in Marion Albers, Thomas Hoffmann, Jöm Reinhardt (eds), Human Rights and Human Nature (Springer 2014) 13-15

${ }^{287}$ G. Kateb, Human Dignity, (2011; Harvard University Press) 19

${ }^{288}$ These also provide the focus of fundamental human rights. O. Schachter, 'Human Dignity as a Normative Concept,' 'The American Journal of International Law,' Vol.77, No. 4, Oct 1983, 848, 852

${ }^{289}$ Bruce M. Landesman, 'Book Review' (1997) 107 (4) Ethics 729, 730; Corinna Mieth 'The Double Foundation of Human Rights in Human Nature' in Marion Albers, Thomas Hoffmann, Jöm Reinhardt (eds), Human Rights and Human Nature (Springer 2014) 13-15
} 
autonomy may be seen as contributory to dignity, lack of '...appropriate mental abilities...to be maker or author of his own life ${ }^{290}$ ought not to disqualify a person from human dignity. A similar point can be made concerning Nussbaum's requirement of agency, active functioning or striving, and sentience. Her account makes dignity available to the non-rational person. However, it is denied to the most cognitively and physically impaired, for example, the requirement of sentience and minimum levels of agency or activity rules out those in a permanently vegetative state. ${ }^{291}$ Since, under Nussbaum's account, it is the aggregate of capabilities that is significant when determining the value of a life worth living, not the physical body, ${ }^{292}$ those who are incapacitated could be assigned the status of 'non-human' or 'sub-human', and therefore, suffer the ultimate degradation of non-entitlement to human dignity.

This thesis presupposes that all stipulations on entitlement to dignity negate the inalienable nature of inherent dignity. ${ }^{293}$ To accept otherwise would mean that dignity is lost through cognitive or physical disease or accident. ${ }^{294}$ Since cognitive and physical disability is a particular threat to older people, this social group is at an increased risk of losing human entitlement to inherent dignity (which, it is argued, cannot be lost, removed, or given away).

This thesis therefore accepts human dignity as 'some given feature that all humans possess...irrespective of their rational or moral capacities, and irrespective of the exercise of these capacities $^{295}$ for older people to possess human dignity, leading to respect for dignity, and a life of dignity. Furthermore, if there is to be rationality as a prerequisite of dignity, it need only be 'some basic rationality, ${ }^{296}$ which need not be practised. ${ }^{297}$ This removes the threat of alienability and thereafter 'justifiable' inhuman treatment. ${ }^{298}$ As for the principle of equal status within the species,

\footnotetext{
290 Joseph Raz, The Morality of Freedom (Clarendon Press 1986) 372

${ }^{291}$ The concern is the effect on the elderly person who by virtue of the physical and cognitive ageing process, outlined in Section 2, chapter 1, 'Defining the Elderly,' of an approach which denies human status or dignity to the most incapacitated.

${ }^{292}$ Thus, a living person that represents a living body only, neither possesses nor is deserving of respect for dignity. Paola Bernadini, 'Human Dignity and Human Capabilities in Martha C. Nussbaum' (2010) V.I IAS <http://ias.jak.ppke.hu/hir/ias/20104sz/15> accessed 30 March 2016

293 Paola Bernadini, 'Human Dignity and Human Capabilities in Martha C. Nussbaum' (2010) V.I IAS <http://ias.jak.ppke.hu/hir/ias/20104sz/15> accessed 30 March 2016

${ }^{294}$ Paola Bernadini, 'Human Dignity and Human Capabilities in Martha C. Nussbaum' (2010) V.I IAS

<http://ias.jak.ppke.hu/hir/ias/20104sz/15> accessed 30 March 2016

${ }^{295}$ Daniel Statman, 'Humiliation, dignity and self-respect' (2000) 13(4) PHIL LIT 523, 525

${ }^{296}$ Such as that held by babies.

297 Daniel Statman, 'Humiliation, dignity and self-respect' (2000) 13(4) PHIL LIT 523, 524

${ }^{298}$ Although inhuman treatment of a human person is never justifiable.
} 
'the bare fact of being a living human being: born from human parents ${ }^{299}$ provides the most suitable basis for the concept of human dignity

\subsubsection{Relationship between components of Human Dignity}

Not all factors contributing to human dignity enjoy an easy relationship. Equality and freedom can conflict, as can equality and autonomy, as well freedom and autonomy enjoyed by different persons. One person's freedom to choose can compromise the freedom to act of another, the result, for one of these individuals at least, can be coercion, restriction of freedom or autonomy. ${ }^{300}$ Therefore, autonomy may need to be made subject to restraint (perhaps favouring one individual over another). ${ }^{301}$ Furthermore, when issues of autonomy and freedom are given prominence, repeated instances of inequality caused by material need, hardship, lack of essentials for existence, and discrimination can remain untreated for some groups. For these, human dignity and the special protection required can be overlooked. ${ }^{302}$

\subsection{Relationship between Human Dignity and Human Rights}

The relationship between human dignity and human rights is complex. Human dignity both underpins, and is a central aim of, human rights. As has been shown, the content of human rights may be derived from or informed by factors which influence conceptions of human dignity, ${ }^{303}$ and may be claimed to be the international community's 'response to specific violations of human dignity. ${ }^{304}$ Thus the relationship between these two concepts is possibly reducible to fundamental characteristics of the human being, and that which the human being needs for existence. Since the vital features of a human being, personality and individuality are embodied in dignity, ${ }^{305}$ they also ground fundamental human rights. '[T]he essential rights of man...are based upon attributes of his

\footnotetext{
${ }^{299}$ Nussbaum reference 'Human Rights and Capabilities Approach' book polly vizard et al

${ }^{300}$ O. Schachter, 'Human Dignity as a Normative Concept,' 'The American Journal of International Law,' Vol.77, No.4, Oct 1983, 848, 851

${ }^{301}$ Conor O'Mahony, 'There is no such thing as a right to dignity,' (2012) 10(2) IJCL $<$ http://icon.oxfordjournals.org/content/10/2/551>, 566-567 accessed 24 March 2016

Also reinforcing the ideal that equal treatment trumps autonomy. Conor O'Mahony, 'There is no such thing as a right to dignity,' (2012) 10(2) IJCL <http://icon.oxfordjournals.org/content/10/2/551>, 570-571 accessed 24 March 2016

${ }^{302}$ C. Albertyn \& B. Goldblatt, 'Facing the Challenge of Transformation: Difficulties in the Development of an Indigenous Jurispurdence of Equality' (1998) 14 SAJHR 248, 257-258 (as cited in Sandra Liebenberg, 'The Value of Human Dignity In Interpreting Socio-Economic Rights'21 S Afr. J. on Hum. Rts. 1 2005, 1, 6)

${ }^{303}$ Doron Shultziner, 'Human Dignity - Functions and Meanings' (2003) 3(3) GJ 1,2

$<$ http://www.bepress.com/gj/topics/vol3/iss3/art3> accessed 24 March 2016

${ }^{304}$ Jürgen Habermas, 'The Concept of Human Dignity and The Realistic Utopia Of Human Rights' (2010) 41(4)

Meta 464, 464

${ }^{305}$ Doron Shultziner, 'Human Dignity - Functions and Meanings' (2003) 3(3) GJ 1,2

<http://www.bepress.com/gj/topics/vol3/iss3/art3> accessed 24 March 2016
} 
human personality. ${ }^{306}$ Therefore, human rights must protect, promote and provide for practices which preserve all aspects of dignity. ${ }^{307}$ The purpose of human rights is to defend, enable and develop human dignity, and with it, all that a person considers necessary for a 'good life. ${ }^{308}$

Dignity also impacts on the mechanisms for enforcement of rights ${ }^{309}$ as human rights convert what is essentially a moral component to legal duty, and moral claims (to worth, value or dignity) to legal claims. ${ }^{310}$ Claims based on human rights may be seen as claims for individual or group dignity to be respected, ${ }^{311}$ placing obligations on the human rights duty bearer. ${ }^{312}$ Human rights make a 'moral promise' to respect the whole of the person and personality. Human rights make this into a legal claim. Rarely does a violation of human dignity involve an act against a single feeling, or impact a single 'good' of a life in dignity. Therefore, dignity demands the indivisibility of rights across all categories, to provide a complete remedy to all persons equally. ${ }^{313}$

When the norms born of the inexhaustible incidents of humiliation and degradation find no exact counterpart in human rights human dignity drives the creation of new human rights. ${ }^{314}$ The intrinsic worth of every person permits the extension and strengthening of human rights. ${ }^{315}$ At the heart of new experiences of humiliation and degradation are often individuals or groups identifiable by natural condition, such as age. ${ }^{316}$ Furthermore, the inviolability of dignity in time allows the

\footnotetext{
${ }^{306}$ American Declaration of the Rights and Duties of Man, OAS Res XXX adopted by the Ninth International Conference of American States (1948) reprinted in Basic Documents Pertaining to Human Rights in the InterAmerican System OEA/SerLV/1182 Dec 6 Rev I at 17 (1992) (as cited in Doron Shultziner, 'Human Dignity Functions and Meanings' (2003) 3(3) GJ 1,3 <http://www.bepress.com/gj/topics/vol3/iss3/art3> accessed 24 March 2016)

${ }^{307}$ Rational thought, autonomy, freedom, human need and the opportunity for equality in human dignity. ${ }^{308}$ See Chapter 6 on the Capabilities Approach

309 Jürgen Habermas, 'The Concept of Human Dignity and The Realistic Utopia Of Human Rights' (2010) 41(4) Meta 464, 466

Doron Shultziner, 'Human Dignity - Functions and Meanings' (2003) 3(3) GJ 1,2 <http://www.bepress.com/gj/topics/vol3/iss3/art3> accessed 24 March 2016

${ }^{310}$ Jürgen Habermas, 'The Concept of Human Dignity and The Realistic Utopia Of Human Rights' (2010) 41(4) Meta 464, 476

${ }^{311}$ Jürgen Habermas, 'The Concept of Human Dignity and The Realistic Utopia Of Human Rights' (2010) 41(4) Meta 464, $469 \& 472$.

312 Daniel Statman, 'Humiliation, dignity and self-respect' (2000) 13(4) PHIL LIT 523, 525

${ }^{313}$ Georg Lohmann, “Die Menschenrechte: Unteilbar und gleichgewichtig?" in Menschenrechtszentrum der Universita" tsverlag Potsdam (ed.), Studien zu Grund- und Menschenrechten11 (Potsdam: Universita" tsverlag Potsdam, 2005), pp. 5-20. (as cited in Jürgen Habermas, 'The Concept of Human Dignity and The Realistic Utopia Of Human Rights' (2010) 41(4) Meta 464, 468-469).

${ }^{314}$ Jürgen Habermas, 'The Concept of Human Dignity and The Realistic Utopia Of Human Rights' (2010) 41(4) Meta 464, 468

315 O. Schachter, 'Human Dignity as a Normative Concept,' 'The American Journal of International Law,' Vol.77, No.4, Oct 1983, 848, 853.

${ }^{316}$ Which is regularly accompanied by problems of infirmity and living circumstance including deprivation, isolation, and dependence.
} 
development of new inviolable rights for those facing new and growing vulnerabilities requiring special protection. ${ }^{317}$ Neither can be taken away by the state in the present or the future. ${ }^{318}$

\subsection{Conclusion}

This conceptual account of human dignity and its relationship with human rights set out above has identified issues which will inform the discussion in forthcoming chapters, and which will help answer the questions raised as central to the thesis. The facets of dignity that underpin human rights will be presented from this point forward as prerequisites for protection in order to protect against vulnerabilities. This contributes toward defending vulnerable individuals or groups, including older people, from violation of their dignity (vulnerability will be discussed in the next chapter). How human rights are relevant to the particular vulnerabilities of older people, as well as the gaps in human rights protection leave older people at risk of violation of their dignity will be amongst the themes discussed in this thesis.

It is significant that every person has an 'inherent worth', unaffected by capability or capacity. This means that dignity may be seen as universal: unable to be surrendered or removed, even in situations where dignity is violated. The objective of human rights is to protect dignity. To achieve this protection, all the pillars of dignity discussed above must be protected. The reciprocal relationship between freedom and autonomy highlights rationality as a unique human characteristic. Autonomy enables claims on rights and underpins freedom, and both underpin dignity. Equality, the third pillar of human dignity recognises that all humanity is equally human. Equality operates to guarantee equality in freedom, autonomy and human dignity by recognising the equal worth of every person. The concept of dignity discussed in this chapter, and adopted, includes the three traditional pillars of human dignity. However, the concept preferred for the purposes of this thesis goes further, to a more holistic definition inclusive of human need. Protection of each and all of the three pillars without attending to human need provides only partial protection for human dignity. The outcome of this reasoning is that human rights, as a concept and in normative standard setting, older people must extend to include the fourth pillar of human need.

The discussion above included examination of what it means to respect dignity through treatment. Importantly, treatment was determined as comprising both prohibition and positive instruction to act. The most effective definition of treatment which respects human dignity was shown to be that which does not humiliate and degrade; that which does not constitute inhuman treatment. This is taken as a guide to the content of human rights for older people discussed in later chapters. Since

${ }^{317}$ Catherine Dupré, The Age of Dignity (Hart Publishing, 2015) 144

${ }^{318}$ Catherine Dupré, The Age of Dignity (Hart Publishing, 2015) 190 
groups with particular needs and vulnerabilities will demonstrate 'sound reasons' for human rights protection these reasons can provide the norms for protection by special protection rights. Understanding the predominant forms of humiliating treatment, including natural condition, physical and mental pain and aspects of a standard of living, will also be influential on standard setting by human rights.

Human dignity shares a relationship not only with human rights, but vulnerability, as will become evident in the next chapter. Following this, the concept of a Capabilities Approach will be considered as a tool through which human rights can be given effect, and as a consequence dignity can be protected. 


\section{CHAPTER 5}

\section{VULNERABILITY}

\subsection{Introduction}

Consideration of vulnerability as a rationale for rights, and later the particular vulnerabilities of older people, will help develop the case for special protection for older people in international law. The position of this chapter between those on human dignity and the capabilities approach will facilitate links between the needs, interests and dignity of older people; as well as with the Capabilities Approach as a possible means to meet these needs and interests. The chapter aims to inform Part III of this thesis which will identify the particular vulnerabilities suffered by older people. Furthermore, this chapter will contribute to the examination of current human rights provision and the question of whether a need exists for special protection in Part IV. This chapter also provides, in broad terms, guidance for analysis of existing human rights instruments in Part IV, where the objectives are to determine the influence of vulnerability in human rights provision, and the adequacy of human rights protection for the most vulnerable. Moreover, this chapter will identify similarities and association between the concepts of Human Dignity and Vulnerability, and the relationship they share with human rights.

A number of theories of vulnerability will be discussed below. The focus is on embodied, institutional, and pathogenic vulnerability; to emphasise the inevitable and universal nature of human vulnerability. An exploration of embodied vulnerability enables correlation with the pillars of human dignity. The role of institutions in defending individuals against threats to human vulnerability by developing resilience through the provision of 'assets' is discussed, including the precariousness of the 'sacred canopy' protecting individuals provided by these institutions. Specific reference is made in this regard to the vulnerabilities this can generate and deepen, and the dependencies it can create. The final vulnerability discussed, to complete the framework, is pathogenic. This particularly disturbing form of vulnerability presents the worst threat to the person, and is perhaps the most dangerous example of vulnerability in older people.

This discussion is followed by consideration of human rights from a vulnerability perspective. The chapter will discuss Turner's thesis on human rights and institution-building. Primary areas of Fineman's thesis will be discussed, including dependency, the particular and universal nature of universal vulnerability, and the question of the liberal versus the vulnerable subject. 
The role of the concept of vulnerability in human rights, and how human rights can respect and protect the needs of the most vulnerable is examined to establish how vulnerability may underpin human rights. Arguments for both ethical and conceptual underpinning are included. Attention then turns to vulnerability as a conceptual underpinning for human rights, and the influence of the notion of embodied vulnerability as discussed by both Turner and Grear in this regard. This necessarily involves presenting the corresponding positions on the role of vulnerability in civil and political and social, economic and cultural rights. The final word on conceptual founding of human rights is given to Grear on the location of the 'vulnerable subject.' Whilst she advocates that it should be at the heart of human rights, it does, she concedes, at best share its place with the 'liberal subject.' The historical influence of the latter has also stressed the importance of the rational, autonomous person and left some vulnerable individuals and groups beyond the scope of human rights protection. The solution of recognising and responding to 'group vulnerability' is the final topic of the chapter. Recognition of vulnerability affecting a recognisable social group in society opens up the possibility of special protection in international human rights law, as a mechanism to ensure that the most vulnerable in society receive the protection of the State. However, the chapter ends by warning against the problems of allocating the 'aggravated' vulnerable to a group, the stigmatisation which a designation of vulnerability can attract, and paternalism which has the ability to exacerbate the powerlessness of vulnerability.

\subsection{Definitions and descriptions of the concept of Vulnerability}

The concept of vulnerability is accused of being vague, 'lacking a developed theory and appropriate indicators and methods of measurement. ${ }^{319}$ Therefore, in order to give substance to vulnerabilities discussed in the chapter, definitions and broad descriptions of some of the themes of vulnerability will be presented.

Vulnerable is derived from the Latin vulnus, or 'wound.' Later interpretations have included 'capable of being physically wounded,' 'susceptible of being emotionally damaged or offended, ${ }^{320}$ and helplessness against non-physical harm, thereby broadening the meaning and scope. ${ }^{321}$ The nature of wounding and its causes are the subject of definitions of the concept. Amongst the variety of definitions offered, there is general agreement that vulnerability is the outcome of threats and a lack of capacity or ability to respond. Social variation, dependence and inequalities in access to

\footnotetext{
${ }^{319}$ R. Chambers, 'Vulnerability, Coping and Policy' (Editorial Introduction), IDS Bulletin, Volume 37, Number 4, September 2006, 34

${ }^{320} \mathrm{C}$. Levine et al, 'The Limitations of 'Vulnerability' as a Protection for Human Research Participation,' Am J Bioethics, 2004; Summer, 4(3): 44, 47

${ }^{321}$ The physical, emotional and non-physical aspects of vulnerability, together with the 'capacity' or 'capability' and 'susceptibility' to be harmed appear in the main vulnerability theses considered in this chapter.
} 
protection are contributory to threats, and may compound vulnerability caused by lack of capacity to respond to threats. ${ }^{322}$

There are two definitions of particular relevance to this thesis. The first alerts us to four components which feature in discussions of the concept of vulnerability; ${ }^{323}$

Vulnerability is the outcome of complex interactions of discrete risks, namely of being exposed to a threat, of a threat materialising, and of lacking the defences or resources to deal with a threat. ${ }^{324}$

Since vulnerability is defined here as a combination of risks, the meaning of 'risk' and how it operates to create vulnerability will be briefly explained. 'Risk' can be described as the 'risk of occurrence' ${ }^{325}$ or the 'probability of a particular outcome. ${ }^{326}$ To refer to a person who is 'at risk' is not necessarily to refer to a vulnerable person, rather a person who is at risk of vulnerability. As the outcome of risks, vulnerability is a means of identifying threat and harm, and the protection required by those lacking defences. ${ }^{327}$

An explanation of vulnerability, incorporating threats and effects if coping capacities ${ }^{328}$ are compromised, is offered by Chambers. It is identifiable in the vulnerability framework and theses discussed in this chapter.

... Vulnerability has thus two sides: an external side of risk, shocks and stress to which an individual or household is subject; and an internal side which is defencelessness, meaning a lack of means to cope without damaging loss. Loss can take many forms - becoming or being physically weaker, economically impoverished, socially dependent, humiliated or psychologically harmed. ${ }^{329}$

\footnotetext{
${ }^{322}$ E. Schröder-Butterfill, R. Marianti, 'A framework for understanding old-age vulnerabilities,' Aging \& Society (2006) 26, 9, 9.

${ }^{323}$ Exposure, threats, coping capacities, and outcomes.

${ }^{324}$ E. Schröder-Butterfill, R. Marianti, 'A framework for understanding old-age vulnerabilities,' Aging \& Society (2006) 26, 9 , 9.

${ }^{325}$ Whether vulnerability will occur.

${ }^{326}$ K. Brown, Vulnerability and Young People: Care and Social Control in Policy and Practice; (2015; Policy Press) 42

${ }^{327}$ K. Brown, Vulnerability and Young People: Care and Social Control in Policy and Practice; (2015; Policy Press) 42

${ }^{328}$ General 'coping capacities' include individual abilities, availability of and access to support, community and interpersonal relationships and resources to create or assist such capacities.

Bruce C. Vladeck, 'Vulnerable People, Groups and Populations: Societal View', H.A., no. 5 (2007): 1220-1230

,1222 http://www.healthaffairs.org/doi/references/10.1377/hlthaff.26.5.1231 accessed 10/10/2016

${ }^{329}$ Robert Chambers, 'Vulnerability, Coping and Policy' IDS Bulletin,20, 2, 1-7, Institution of Development Studies, University of Sussex (as cited in E. Schröder-Butterfill, R. Marianti, 'A framework for understanding old-age vulnerabilities,' Aging \& Society (2006) 26, 9/10)
} 
The means to resist and respond is a vital contributor to vulnerability, and the degree to which a person becomes vulnerable can be mitigated by the resources and advantages a person is able to draw on. ${ }^{330}$ The description offered by Moser explains this, and the need for 'assets,' something which re-appears in the discussion of 'institutional vulnerability' later in this chapter.

Analysing vulnerability involves identifying not only the threat but also the resilience or responsiveness in exploiting opportunities, and in resisting or recovering from the negative effects of a changing environment. The means of resistance are the assets and entitlements that individuals, households, or communities can mobilise and manage in the face of hardship. ${ }^{331}$

The most well documented accounts of vulnerability are those which refer to a person being 'fragile, to be susceptible to wounding and to suffering, ${ }^{332}$. This suggests that certain individuals and groups are at increased risk. In this regard causes of vulnerability can be identified, including: extremes of age; physical or mental disability; and living as part of a marginalised minority group. ${ }^{333}$ Sub-groups have also been suggested, to include the cognitively or communicatively and decisionally impaired; the seriously and terminally ill; economically dependent; and institutionalised. ${ }^{334}$

All factors of these definitions and themes feature in the accounts of vulnerability discussed in this chapter, and in the vulnerability framework identified for later comparison with the lived vulnerabilities and problems of older people. Also of note is that older people will be seen to be at risk of 'aggravated' ${ }^{335}$ vulnerability and can claim membership of many vulnerable sub-groups. Being representative of some of the most vulnerable in society is a factor in the case for special human rights protection.

Defencelessness and lack of coping capacity feature in a number of ageing theories; Chapter 8, 'Ageing Theories,' and in and Chapter 10, 'What it Means to be an Older Person' Included in loss are 'becoming or being physically weaker, economically impoverished, socially dependent, humiliated or psychologically harmed.' Robert Chalmers, 'Vulnerability, Coping and Policy (Editorial Introduction)' IDS Bulletin Volume 37, 4 September 2006. Anthology 33, 33 $<$ https://opendocs.ids.ac.uk/opendocs/bitstream/handle/123456789/662/Chambers.pdf> accessed 23/02/2016

${ }^{330}$ Also referred to as 'reserves,' these are listed as: mental and physical health status, family relationships and social networks, coping strategies, personality and social skills, wealth and other material resources and legal or moral rights to various forms of inter-generational or collective support.

Emily Grundy, 'Ageing and vulnerable elderly people. European perspectives', Ageing \& Society 26 (2006) 105134,107. https://www.cambridge.org/core/journals/ageing-and-society/article/ageing-and-vulnerable-elderlypeople-european-perspectives/38FE71F6EC2FA12FBAFD30825B011E12 accessed 11/11/2017

${ }^{331}$ C. Moser, (1998) 'The Asset Vulnerability Framework: Reassessing Urban Poverty Reduction Strategies,' World Development Vol.26, No.2, pp1-19, cited in P. Damas and R. Israt, 'Vulnerability and Poverty: What are the causes and how are they related?' 2004; ZEF Bonn, Universitae Bonn ,5, www.zef.de accessed 02/03/2016 ${ }^{332}$ C. Mackenzie, W. Rogers and S. Dodds, (eds.) Vulnerability: New Essays in Ethics and Feminist Philosophy (2014; Oxford University Press) 4

${ }^{333}$ G. T. Couser, Vulnerable Subjects Ethics and Life Writing (2004; Cornell University Press)xii

${ }^{334} \mathrm{~T}$. Rightmer, www.yale.edu/hrpp/resources/Protection of Vulnerable Subjects in Research

${ }^{335}$ Where 'aggravated' means suffering from more than one form of vulnerability. 


\subsection{The concept of Vulnerability}

\subsubsection{Vulnerability framework}

Vulnerability is discussed under different headings, and the various forms it takes, primarily embodied, institutional, and pathogenic ${ }^{336}$ are gathered to construct a framework of vulnerability. This framework will provide a reference for the vulnerabilities faced by older people and the implementation of human rights in concrete situations. It will also inform whether older people form a distinct and definable group for the purposes of special protection.

\subsubsection{Embodied vulnerability}

The primary form of vulnerability, and the first part of this framework is embodied vulnerability. Associated to biological 'wounding' in the form of illness, disease, death, and the senescence of the ageing body ${ }^{337}$ the 'ontological condition of our humanity' is the starting point for embodied vulnerability. ${ }^{338}$ This fact of the faltering physical and mental ${ }^{339}$ body is critical to the universality and inevitability of embodied vulnerability. The physiological nature of vulnerability makes it intrinsic to being human, constantly exposing the person to threat ${ }^{340}$ on a permanent, temporary, or intermittent basis. Embodied vulnerability often imposes itself on individuals previously unimpaired, and is associated to life stages. ${ }^{341}$ Turner looked beyond the physical for a comprehensive definition of 'embodied vulnerability,' to include psychological, ${ }^{342}$ moral, and spiritual 'bodily' characteristics, ${ }^{343}$

\footnotetext{
${ }^{336}$ It is noted that other classifications of vulnerability include: 'innate,' which is included here in the category of 'embodied;' 'situational,' which is context specific, and refers heavily to economic, attitudinal, personal experiences and circumstance, and which is represented here under all categories; 'permanent,' and 'temporary,' which also appear under all categories in this work.

SeeK. Brown, Vulnerability and Young People: Care and Social Control in Policy and Practice; (2015; Policy Press) 45, and C. Mackenzie, W. Rogers, and S. Dodds (eds.) Vulnerability: New Essays in Ethics and Feminist Philosophy (2014; Oxford University Press) 7 for more on 'situational vulnerability.'

${ }^{337}$ Bryan S. Turner, Vulnerability and Human Rights (2006, Pennsylvania State University Press) 29

${ }^{338}$ C. Mackenzie, W. Rogers and S. Dodds, (eds.) Vulnerability: New Essays in Ethics and Feminist Philosophy (2014; Oxford University Press) 4

${ }^{339}$ K. Brown, Vulnerability and Young People: Care and Social Control in Policy and Practice; (2015; Policy Press) p.43

${ }^{340}$ Where 'threat' means the constant exposure to risk of harm and injury whether by misfortune or purposeful attack, including minor mishaps and complete devastation.

M.A. Fineman, 'The Vulnerable Subject and the Responsive State,' 60 Emory L.J. 2010-2011, 251, 267

${ }^{341} \mathrm{~K}$. Brown, Vulnerability and Young People: Care and Social Control in Policy and Practice; (2015; Policy Press) 43; M.A. Fineman, 'The Vulnerable Subject and the Responsive State,' 60 Emory L.J. 2010-2011, 251, 267

${ }^{342}$ By including the psychological self, it becomes inseparable from the physical self, meaning 'embodiment' cannot be viewed purely in physical terms. Also, that the experience of living develops physical abilities, reason, habits and preferences demonstrates the permanent interlinking of the physical, psychological, spiritual and moral. This principle of 'enselfment' is borrowed from Pierre Bourdieu, Pascalian Meditations; 2000. B.S. Turner, Vulnerability and Human Rights. Essays on Human Rights, (2006; Pennsylvania State University Press) ,27

${ }^{343}$ B.S. Turner, Vulnerability and Human Rights. Essays on Human Rights, (2006; Pennsylvania State University Press) 28
} 
and the place where life is experienced. ${ }^{344}$ This all-encompassing version of embodiment is used to identify tangible vulnerability. The physical self is not merely vulnerable to internal biological problems, but external threat including inhuman treatment such as torture or abuse, and inadequate provision of that necessary to maintain life. ${ }^{345}$ The psychological self is damaged by lack of respect for human dignity, and is also vulnerable to cognitive failure of the individual. Loss of decision-making capacity undermines two of the essential pillars of dignity: autonomy, and freedom to determine one's own life. ${ }^{346}$ A dependency on others to decide or ensure one's wishes are carried out develops, and ultimately, a loss of self-respect and trust in one's own judgement can arise, particularly when choices and values are deemed inconsequential or wrong. This further undermines autonomy, ${ }^{347}$ harming the psychological self. The greatest threat to 'place' is exclusion. Turner concentrates on removal from, or loss of, physical home and property. This is extended in this research to include home life, ${ }^{348}$ and exclusion from society or family, by means of societal attitude, and self-perception. ${ }^{349}$ The latter features further as a component of 'institutional vulnerability,' below. Embodied vulnerability, therefore, incorporates all 'bodily' aspects of the human condition, including personality, enselfment and emplacement, which can become vulnerable by virtue of inability to counter and adapt to internal and external threat individually and collectively. The vulnerability of one can cause and attract the vulnerability of others. Thus humanity can be defined in terms of vulnerability, ${ }^{350}$ with the consensus that vulnerability is 'a

\footnotetext{
${ }^{344}$ Turner borrows from Heidegger and the idea of Dasein or 'there-being' for this. Termed 'emplacement,' where all physical, psychological, spiritual and moral experience takes place also contributes to embodiment, and is vulnerable to attack. Martin Heidegger Being and Time; 1962. B.S. Turner, Vulnerability and Human Rights. Essays on Human Rights, (2006; Pennsylvania State University Press). 27

${ }^{345}$ Including sustenance, healthcare, shelter and material need; one of the components of human dignity. See Chapter 4, 'Human Dignity,'

${ }^{346}$ Both of these fundamentals of human dignity are vulnerable in such instances when autonomy is understood as 'an acquired set of capabilities to lead one's own life.' Joel Anderson and Axel Honneth, 'Autonomy, Vulnerability, Recognition, and Justice,' August 24 2004, 127, 127. When understood in this way, the principles of the Capabilities Approach become relevant, in that external capabilities must combine with internal capabilities to provide the opportunity for the individual to do and be all that is of value to them. In this case by supporting decision-making capacity autonomy and freedom are protected. See Chapter 6, 'The Capabilities Approach,' It also helps make the case for state responsibility for the vulnerable subject .

${ }^{347}$ Joel Anderson and Axel Honneth, 'Autonomy, Vulnerability, Recognition, and Justice,' August 24 2004, 127, 130-131.

${ }^{348}$ One might retain a physical home, yet lose the family, life and familiarity that once were synonymous with it. The loss might be of possessions more valuable than material; rather it could be of individuals with whom home the material home was once shared. It is possible to lose both if removed from one's physical home and family life, as in the case of older people person taken from his or her own home and family and placed in residential care.

${ }^{349}$ Refer to modernisation, disengagement, abandonment, and self-perception theories in Chapter 8 , 'Theories of Ageing' which considers how such exclusion takes place, and Chapter 10, which outlines the effects of exclusion in all its forms on older people.

${ }^{350}$ B. S. Turner, Vulnerability and Human Rights. Essays on Human Rights (2006, Pennsylvania State University Press) 1
} 
universal, inevitable, enduring aspect of the human condition ${ }^{351}$ which deepens during the ageing process. $^{352}$

\subsubsection{Institutional Vulnerability}

'[W]e are born, live, and die within a fragile materiality that renders us constantly susceptible to destructive external forces and internal disintegration, ${ }^{353}$ which we lack the 'instinct' to deal with. ${ }^{354}$

In response, a defence system of institutions ${ }^{355}$ aimed at protecting against persistent threats has developed. ${ }^{356}$ Considering the variety, number and constancy of threats faced, the amount and nature of institutions required is unbounded. Furthermore, they overlap to offer 'layered possibilities' of resilience and coping mechanisms, individually and combined ${ }^{357}$ due to the complexity and interconnected nature of vulnerability.

These institutions are understood as providing 'assets' which offer the means to cope with, and adapt to, threats. Kirby classifies these as physical, human, and social, ${ }^{358}$ each supporting quality of life and well-being. Physical assets provide financial or material benefit ${ }^{359}$ with the potential to alleviate current, and minimise future, vulnerabilities. ${ }^{360}$ Human assets are described as the 'innate or developed abilities to make the most of a given situation. ${ }^{361}$ They are the personal assets that

\footnotetext{
${ }^{351} \mathrm{M}$. A. Fineman, 'The Vulnerable Subject: Anchoring Equality in the Human Condition,' Yale Journal of Law and Feminism, 2008; Vol. 20:1, 1, 8

${ }^{352}$ See chapter 9 for detail on the ageing process.

${ }^{353}$ M.A. Fineman, 'The Vulnerable Subject: Anchoring Equality in the Human Condition,' Yale journal of Law and Feminism, 2008; Vol. 20:1, 1, 10; B. S. Turner, Vulnerability and Human Rights. Essays on Human Rights (Pennsylvania State University Press, 2006) 12

${ }^{354}$ B.S. Turner, Vulnerability and Human Rights (2010; Pennsylvania University State Press). 28

${ }^{355}$ These institutions include: societal, such as family, religion, rituals, eating patterns, sleeping arrangements; economic; political; and legal, including human rights provision.
}

B. S. Turner, Vulnerability and Human Rights. Essays on Human Rights (Pennsylvania State University Press, 2006) 28,29

${ }^{356}$ M.A. Fineman,., 'The Vulnerable Subject: Anchoring Equality in the Human Condition,' Yale journal of Law and Feminism, 2008; Vol. 20:1, 1, 10; B. S. Turner, Vulnerability and Human Rights. Essays on Human Rights (Pennsylvania State University Press, 2006) 1.

${ }^{357}$ M.A. Fineman,., 'The Vulnerable Subject: Anchoring Equality in the Human Condition,' Yale journal of Law and Feminism, 2008; Vol. 20:1, 1, 13-14.

It is important to recognise that these institutions cannot eradicate vulnerability; their role is to provide resilience via the means to tackle it. Martha Albertson Fineman, 'The Vulnerable Subject and the Responsive State,' 60 Emory L.J. 251 2010-2011, 269

${ }^{358}$ M.A. Fineman,., 'The Vulnerable Subject: Anchoring Equality in the Human Condition,' Yale journal of Law and Feminism, 2008; Vol. 20:1, 1, 13-14

${ }^{359}$ Provided via the distribution of wealth. The vulnerabilities of older people call overwhelmingly for welfare provision in the form of financial aid and material benefit such as suitable housing provision.

${ }^{360}$ Future threats can be protected against if the physical asset is able to be accumulated for future use.

${ }^{361}$ M.A. Fineman,., 'The Vulnerable Subject: Anchoring Equality in the Human Condition,' Yale journal of Law and Feminism, 2008; Vol. 20:1, 1, 14

The phraseology used by Kirby is similar to that of Nussbaum in her version of the Capabilities Approach, and whilst the subject of chapter 6, 'The Capabilities Approach.' it is appropriate to provide a brief explanation at 
determine which threats a person is most susceptible to, and their ability to counter and adapt to them. It is notable that having reached their optimum, innate assets will regress with the ageing process, influencing the degree to which a person will become dependent and vulnerable in old age, ${ }^{362}$ and thus reliant on institutional support. One of the principal assets to be provided by institutions in order to protect and develop these 'innate abilities,' states Kirby, is healthcare. ${ }^{363}$ Kirby's social assets are social interactions and relationships ${ }^{364}$ which refer to the supportive networks of social, kinship, and cultural relations. ${ }^{365}$ Relations between the state and the individual, particularly for the accumulation of social assets, the most important of which for the subject of this thesis is the provision of welfare, ${ }^{366}$ are also 'interactions.' Fineman adds 'existential' assets, enabling the practice of beliefs, religion, and moral values. ${ }^{367}$ The particularly complex vulnerabilities of older people, identified in chapters 8,9 , and 10 create a dependency on most, if not all, of these institutions and their assets, necessitating the inclusion of vulnerabilities associated to institutions in the framework.

this juncture of Nussbaum's 3 types of capabilities. Nussbaum describes the 'innate equipment' with which each person is born as the traits, attributes, and abilities of the person which develop and mature during life stages. When this occurs the 'basic capabilities,' or 'innate equipment,' become 'internal capabilities.' Necessary to this process are the opportunity and freedom to so develop. Where compromised, these capabilities and opportunities must be provided either in whole or in part, and compensated for by the state and its institutions; making for 'combined capabilities.' Thus, parallels may be drawn between the capabilities approach and Kirby's idea of 'human assets' which institutions provide to combat vulnerability.

See Rosalind Butler, 'Capabilities: A New Approach to Human Rights for the Elderly,' Edinburgh Student L. Rev. (2013-2016) 17, 19-20

${ }^{362}$ These topics receive detailed coverage in Part III of this thesis. The main thrust of the ageing process deals with physical and cognitive degeneration, illness and disability. The association with capabilities is its influence over inability to exercise elements of human dignity including autonomy, freedom to direct life, and live independently.

${ }^{363}$ Others included in Kirby's listing are education and employment opportunities. However, for older people the assets required are more likely to be personal care, assistance with daily living, and development or lessening decline of existing capabilities.

${ }^{364}$ M.A. Fineman,., 'The Vulnerable Subject: Anchoring Equality in the Human Condition,' Yale journal of Law and Feminism, 2008; Vol. 20:1, 1, 14 \& 15

${ }^{365}$ Ageing theories, which are the subject of Chapter 8, discuss the effects of loss of these assets. Among the effects are withdrawal from society, societal and familial abandonment, isolation and the exacerbation of physical and cognitive effects of ageing, and dependency on institutions.

Also, see Richard Wilkinson \& Kate Pickett, The Spirit Level (2010, Bloomsbury Press) at 76 for connection between social asset and rates of cardiovascular disease, recovery from heart attacks, and instances of illness, Martha Albertson Fineman, 'The Vulnerable Subject and the Responsive State,' 60 Emory L.J. 251 2010-2011, n.66

${ }^{366}$ By 'welfare' is meant everything necessary to bolster resilience to vulnerability caused by economic, health, and social influence. This would include financial assistance, healthcare provision, and access to social and supportive networks.

M.A. Fineman, 'The Vulnerable Subject: Anchoring Equality in the Human Condition,' Yale journal of Law and Feminism, 2008; Vol. 20:1, 1, 14

${ }^{367}$ Martha Albertson Fineman, 'The Vulnerable Subject and the Responsive State,' 60 Emory L.J. 2512010 2011, 271 
The institutions created to provide these assets, and upon which the vulnerable person can become dependent $^{368}$ are themselves 'imperfect, inadequate, and precarious. ${ }^{369}$ Vulnerable to internal and external attack, including economic failure; policy and political change; societal attitude, priorities, practices and prejudices; cultural change; and global cultural differences, institutions become compromised. ${ }^{370}$ When this occurs, the failure of one has repercussions on others. ${ }^{371}$ The effect on the person dependent upon institutions offering lesser resilience is to deepen vulnerability ${ }^{372}$ and weaken security. ${ }^{373}$ Modernisation, with its rapidly changing norms, is a major cause of institutional vulnerability; ${ }^{374}$ the "personality' living in a 'lonely crowd" ${ }^{375}$ becomes a reality. Additionally, the changes prompting institutional modification create reluctance among the dependent vulnerable to turn to institutions. ${ }^{376}$ Institutions are primarily viewed as supporting the human need aspect of dignity; however, in doing this, and by providing social assets, autonomy and freedom are also protected. ${ }^{377}$ The significant social relations are those that demonstrate respect and care, or mutual recognition of individuals' choices and values, as to 'pursue one's own conception of a worthwhile life' is only possible 'under socially supportive conditions. ${ }^{378}$ Whilst not specifically mentioned in the literature, this thesis includes the 'social relationship' with the state of non-interference in personal agency. Loss of the capabilities to act as an autonomous agent ${ }^{379}$ resulting from lack of social assets

\footnotetext{
${ }^{368}$ The association between vulnerability and dependency is discussed in Chapter 5

${ }^{369}$ B.S. Turner, Vulnerability and Human Rights (2010; Pennsylvania University State Press) p. 1 \& 28

${ }^{370}$ M.A. Fineman,., 'The Vulnerable Subject: Anchoring Equality in the Human Condition,' Yale journal of Law and Feminism, 2008; Vol. 20:1, 1, 12

371 Due to the interconnected relationship of institutions and the assets they provide.

${ }^{372}$ M.A. Fineman,.. 'The Vulnerable Subject: Anchoring Equality in the Human Condition,' Yale journal of Law and Feminism, 2008; Vol. 20:1, 1, 13

${ }^{373}$ B. S. Turner, Vulnerability and Human Rights. Essays on Human Rights (Pennsylvania State University Press, 2006) 28.

${ }^{374}$ B. S. Turner, Vulnerability and Human Rights. Essays on Human Rights (Pennsylvania State University Press, 2006) 30.

${ }^{375}$ D. Riesman, 1950. The Lonely Crowd: A Study of the Changing American Character. New Haven, Conn.: Yale University Press (as cited in B. S. Turner, Vulnerability and Human Rights. Essays on Human Rights (Pennsylvania State University Press, 2006) 30).

${ }^{376}$ M.A. Fineman,., 'The Vulnerable Subject: Anchoring Equality in the Human Condition,' Yale journal of Law and Feminism, 2008; Vol. 20:1, 1, 13

In the case of older people, the combination of changes to lifestyle priorities, the structure of the institution of the family, and an ageing population provide an example of this. With fewer elderly people living with their adult children, increasing numbers are living alone, or in isolation. Additionally, with care of elderly family members increasingly entrusted to the state, it becomes accepted that relationships and kinship ties are weakened. The principles of these issues, and problems associated with them are the subject of Part III, principally chapters 8 , 'Theories of Ageing,' and 10, 'What it Means to be an Older Person.'

377 Joel Anderson and Axel Honneth, 'Autonomy, Vulnerability, Recognition, and Justice,' August 24 2004, 127, $127 \& 130$.

378 Joel Anderson and Axel Honneth, 'Autonomy, Vulnerability, Recognition, and Justice,' August 24 2004, 127, $127 \& 130$.
}

The role of developing and pursuing ones conception of a worthwhile life in the promotion and protection of human dignity is covered in Chapter 4, 'Human Dignity,'

379 'self-trust,' 'self-esteem,' and 'self-trust,' 
and the general precariousness of social and political institutions can cause a set of interrelated problems for older people. This includes: marginalisation; ${ }^{380}$ failure to protect interests; and failure to balance conflicts of collective and individual interests. ${ }^{381}$ This particularly aggravates vulnerabilities generated by resource distribution, especially when the good of the majority is prioritised. ${ }^{382}$ When institutions fail, the outcome can be a sub-set ${ }^{383}$ treated without respect for human dignity. When the vulnerabilities are unique or aggravated, as with older people, the case for special protection gathers pace.

\subsubsection{Pathogenic vulnerability}

A particularly concerning form of situational vulnerability is that classed as 'pathogenic.' With origins in immoral or abusive behaviour, either interpersonal or socio-political, it is an example of vulnerability attracting vulnerability. Embodied and institutional vulnerabilities attract pathogenic vulnerability with the physically or cognitively disadvantaged prime victims. ${ }^{384}$ Abuse by institutions takes the form of discriminatory treatment which disrespects human dignity and inherent worth, generating and perpetuating inequality. However, not all pathogenic vulnerability is the result of deliberate acts by institutions. Institutional assets can introduce abuse to the vulnerable life. Impaired autonomy is further destabilised when the person is dependent on institutional decisionmaking. The outcome is a combination of loss of esteem, judgement, self-trust, and the fear that personal choice will be disregarded. ${ }^{385}$ The person dependent upon help with daily living can find herself victim of personal abuse in all its forms by those entrusted with her care. As a group whose vulnerability corresponds to the first two categories of the framework, older people are susceptible to pathogenic vulnerability. Their position 'exacerbates the sense of powerlessness engendered by

\footnotetext{
380 Individually and as a group. C.E. Brown, 'The Concept of Vulnerability and its Use in the Care and Control of Young People,' University of Leeds, 130, www.etheses.ac.uk accessed 03/03/2016

${ }^{381}$ B. S. Turner, Vulnerability and Human Rights. Essays on Human Rights (Pennsylvania State University Press, 2006) 31.

${ }^{382}$ Possibilities include distribution of resources in accordance with the ability of the individual to contribute to society in the future. When individual interests are pitted against collective interests in such a way the needs of those limited in how they might contribute, such as older people, are at risk of being relegated or overlooked. Such resources can include financial assistance, housing, and healthcare.

${ }^{383} \mathrm{~K}$. Brown, 'Beyond protection: 'the vulnerable in the age of austerity' in Harrison, M. and Sanders, T., Social Policies and Social Control: New perspectives on the 'not-so-big society' (2016; Policy Press University of Bristol) 49

${ }^{384}$ C. Mackenzie and W. Rogers (eds.) Vulnerability: New Essays in Ethics and Feminist Philosophy (2014; Oxford University Press) 9

The most common forms are noted here as: financial, psychological, and physical. There is also an argument that due to the physical and cognitive frailty of the victim, a lack of resilience, and the potential for abuse to be repetitive that this treatment breaks the threshold of humiliating and degrading treatment, and falls into the realms of torture.

${ }^{385}$ See Chapter 4, 'Human Dignity,' 'Autonomy.' 
vulnerability in general. ${ }^{386}$ Chapter 10 of this thesis provides substance for this element of the vulnerability framework.

\subsubsection{The interconnected framework}

The framework of vulnerability for older people comprises embodied, institutional, and pathogenic, and recognises the innate nature of some and situational nature of others. Each is inextricably entangled with the other. Corporeal vulnerability is to some extent caused, certainly worsened by, societal systems, economic circumstance, government policy, and dependency. However, embodied vulnerability is not always the victim of other vulnerabilities. Personal inabilities can lead to hardship which in turn creates pressure for institutions, causing risk of failure. ${ }^{387}$ Additionally, institutions are vulnerable to the workings of their own socio-political systems. When lacking the resilience provided by institutions, those suffering the manifestations of embodied vulnerability are at aggravated risk of harm from abuse. Such risk requires the 'sacred canopy' ${ }^{\prime 38}$ of institutions. Embodied vulnerability and the precariousness of the institutions inevitably create dependency. At this point pathogenic vulnerability can enter the already vulnerable subject's life, illustrating the ethical ambiguity of vulnerability. There is sympathetic and empathetic reaction to vulnerability. There is also a human propensity to reject liability for suffering inflicted ${ }^{389}$ and violate the disadvantaged and incapacitated. ${ }^{390}$ Therefore, embodied vulnerability requires prescriptive force, offered by human rights underpinned by vulnerability. When such rights inform institutions they protect the vulnerable, and defend against institutional breakdown ${ }^{391}$ and aggravated dependency.

\footnotetext{
${ }^{386}$ C. Mackenzie and W. Rogers (eds.) Vulnerability: New Essays in Ethics and Feminist Philosophy (2014; Oxford University Press) 9

${ }^{387}$ M.A. Fineman,., 'The Vulnerable Subject: Anchoring Equality in the Human Condition,' Yale Journal of Law and Feminism, 2008; Vol. 20:1, 1, 10

${ }^{388}$ P.L. Berger, 1967 The Sacred Canopy. New York: Doubleday (as cited in Bryan S. Turner, Vulnerability and Human Rights (2010; Pennsylvania University State Press) 29)

${ }^{389}$ B.S. Turner, Vulnerability and Human Rights (2010; Pennsylvania University State Press) 40

${ }^{390}$ See generally Judith Butler, Frames of War. When Is Life Grievable? (Verso, London, 2009)

${ }^{391}$ Alexandra Timmer, 'A Quiet Revolution: Vulnerability in the European Court of Human Rights' in Martha Albertson Fineman (ed), Gender in Law, Culture, and Society: Vulnerability Reflections on a New Ethical Foundation for Law and Politics (Ashgate 2013) 149.
} 


\subsubsection{Fineman, Grear, and Turner}

The vulnerability framework described has drawn largely on the theses of Fineman, Turner and Grear. The same theses are henceforth considered in specific contexts. Specifically, the theses are discussed in terms of the relationship of the concept of Vulnerability with human rights; human rights provision for older people; and special protection.

\subsubsection{Turner's thesis}

It is instructive that Turner views vulnerability through the lens of pain and suffering. ${ }^{392}$ Pain creates a threat to security of the person, and suffering results in loss of dignity. Combined, they attack the physical, psychological and spiritual self, ${ }^{393}$ and are considered universal features of being human. Embodied vulnerability accepts pain as universal, ${ }^{394}$ and Turner dismisses cultural relativity arguments against suffering by stating the capacity to suffer, and its threat, are universal. ${ }^{395}$ Furthermore, suffering creates need, and is an outcome of all aspects of embodied vulnerability. Common to all categories of the framework offered, it creates a need for protective institutions. ${ }^{396}$ Finally, as a form of humiliation, suffering is a threat to human dignity. Turner's views of suffering and institution-building are key to how he relates the concept of vulnerability to human rights. ${ }^{397}$

\subsubsection{Fineman's Thesis}

At the heart of this thesis of vulnerability is the 'vulnerable subject.' Fineman's vulnerable subject lives in all categories of the framework, the process beginning with embodied vulnerability. This thesis adopts the 'universal, inevitable, enduring aspect of the human condition' ${ }^{398}$ initially caused

\footnotetext{
${ }^{392}$ Alexandra Timmer, 'A Quiet Revolution: Vulnerability in the European Court of Human Rights' in Martha Albertson Fineman (ed), Gender in Law, Culture, and Society: Vulnerability Reflections on a New Ethical Foundation for Law and Politics (Ashgate 2013) 149

${ }^{393}$ B. S. Turner, Vulnerability and Human Rights. Essays on Human Rights (Pennsylvania State University Press, 2006) $1 \& 27$

${ }^{394}$ Pain and its effect is strongly persuaded by tradition, culture, social expectation and mental attitude. It is both a matter of individual feeling and endurance and culture; but despite its effect by degree, the fact that it can affect the embodied individual is universal.

See Morris, D.B., The Culture of Pain (1991; University of California Press, Berkeley) 14,(as cited in A. Grear, Redirecting human Rights: Facing the Challenge of Corporate Legal Humanity, (2010; Palgrave Macmillan) 134)

${ }^{395}$ B.S. Turner, Vulnerability and Human Rights (2010; Pennsylvania University State Press) p.9

${ }^{396}$ A. Grear, Redirecting human Rights: Facing the Challenge of Corporate Legal Humanity, (2010; Palgrave Macmillan) 134

${ }^{397}$ Alexandra Timmer, 'A Quiet Revolution: Vulnerability in the European Court of Human Rights' in Martha Albertson Fineman (ed), Gender in Law, Culture, and Society: Vulnerability Reflections on a New Ethical Foundation for Law and Politics (Ashgate 2013) 149

${ }^{398}$ M. A. Fineman, 'The Vulnerable Subject: Anchoring Equality in the Human Condition,' Yale Journal of Law and Feminism, 2008; Vol. 20:1, 1, 8
} 
by a physiological propensity to internal degeneration and external harm. ${ }^{399}$ Albeit universal and inevitable, experience of vulnerability is particular to the individual. It is explicit in this thesis that many causes of vulnerability are beyond human control, and whilst possible to mitigate their effects, the risk of their materialisation cannot be eradicated. ${ }^{400}$ Similarly to Turner, Fineman recognises the creation and significance of institutions in order to reduce and compensate for, whilst not eliminating, vulnerabilities. ${ }^{401}$ Dependency as an inescapable aspect of vulnerability and being human $^{402}$ is significant to Fineman's vulnerability thesis. Vulnerability begets dependency, in return dependency causes vulnerability. ${ }^{403}$ The way that dependency is '[a]nchored at each end of ... lives ${ }^{404}$ makes it inevitable, and suggests older people as a dependent group in need of special protection. The primary cause and most recognisable form of inevitable dependency is physiological. ${ }^{405}$ Other dependencies stem from physiological, but can exist independently. ${ }^{406}$ However, as the sole universal dependency, physiological is the only one classed as inevitable. ${ }^{407}$

Inevitable dependency can also breed 'derivative dependency,' on monetary or material resources and institutional assistance by carers of the inevitably dependent. ${ }^{408}$ Changes to institutions, particularly the family, can create a group of derivatively dependent ${ }^{409}$ and has resulted in older

\footnotetext{
${ }^{399}$ Including 'biologically-based catastrophes,' economic, environmental, and institutional. M. A. Fineman, 'The Vulnerable Subject: Anchoring Equality in the Human Condition,' Yale Journal of Law and Feminism, 2008; Vol. 20:1, 1-23, at p9-10

${ }^{400}$ M. A. Fineman, 'The Vulnerable Subject: Anchoring Equality in the Human Condition,' Yale Journal of Law and Feminism, 2008; Vol. 20:1, 1, 9

${ }^{401}$ M. A. Fineman, 'The Vulnerable Subject: Anchoring Equality in the Human Condition,' Yale Journal of Law and Feminism, 2008; Vol. 20:1, 1, 10

402 Martha Albertson Fineman, 'Cracking The Foundational Myths: Independence, Autonomy, And SelfSufficiency' Journal of Gender, Social Policy \& The Law Vol8:13, 18

${ }^{403}$ M, Albertson Fineman, The Autonomy Myth: A Theory of Dependency (2004; The New York Press) 35

${ }^{404}$ Martha Albertson Fineman, 'The Vulnerable Subject: Anchoring Equality in the Human Condition,' (2008) 20 YJLF 1, 12

${ }^{405}$ To include both physical and cognitive capacities and abilities; a predisposition to diseases and illness, the inevitability of death, the impairment and disability of the ageing human, and the 'developmentally dependent.' 'Developmentally dependent' is extended in this context to the person whose development is regressing, rather than limiting it to the person who is yet to develop, such as the infant or child.

M, Albertson Fineman, The Autonomy Myth: A Theory of Dependency (2004; The New York Press)228

Developmental dependence is interpreted here as the result of innate vulnerability or lack of opportunity to develop, in line with the Capabilities Approach. See chapter 6, 'The Capabilities Approach.'

${ }^{406}$ Such as economic, psychological or emotional dependence.

${ }^{407}$ Martha Albertson Fineman, 'Cracking The Foundational Myths: Independence, Autonomy, And SelfSufficiency' Journal of Gender, Social Policy \& The Law Vol8:13, 18

${ }^{408}$ M, Albertson Fineman, The Autonomy Myth: A Theory of Dependency (2004; The New York Press) 35 Martha Albertson Fineman, 'Cracking The Foundational Myths: Independence, Autonomy, And Self-Sufficiency' Journal of Gender, Social Policy \& The Law Vol8:13, 19

${ }^{409}$ M, Albertson Fineman, The Autonomy Myth: A Theory of Dependency (2004; The New York Press)18
} 
people $^{410}$ assuming this role, potentially exposing them to both inevitable and derived dependency. ${ }^{411}$

Significantly, Fineman also compares the vulnerable subject to the 'liberal subject.' The latter not experiencing vulnerability, occupies the stage of life between the dependent, incapacitated beginning and end. ${ }^{412}$ The liberal subject is autonomous, rational, freely directs his life, ${ }^{413}$ is selfsufficient, capable of undertaking multiple and concurrent roles, ${ }^{414}$ and engages in social relations. ${ }^{415}$ Dupré dismissed this person as, at best, not typical in her theory of human dignity. To consider this subject the norm denies the universal and inevitable nature of vulnerability, and the threat of dependency. The vulnerable subject is 'a more accurate and complete universal figure,' 'far more representative of actual lived experience and the human condition... ${ }^{416}$ As a result, in similar vein to the Capabilities Approach, a vulnerability approach looks to the State to equalise dignity. Fineman's vulnerability thesis specifically gives the State responsibility for responding on the basis of need, capacity, and capabilities via institutions. ${ }^{417}$ In doing so, the vulnerable subject ${ }^{418}$ takes centre stage in all institutional provision, ${ }^{419}$ including human rights via legal institutions.

Several points of reference for human rights can be taken from Fineman's vulnerability thesis some of which concur with others. Firstly, embodied vulnerability is universal and inevitable, and also particular to the individual. Dependence is taken as an aspect of vulnerability, in inevitable and derived forms, and must be included in all considerations of vulnerability. The role of the State is essential to respecting the dignity and needs of the individual, and protecting against vulnerability. Furthermore the State must be responsive to the vulnerable subject. Finally, the situation of the vulnerable subject needs to influence the content, implementation and interpretation of rights. The

\footnotetext{
${ }^{410}$ Mainly spouses, partners or siblings.

${ }^{411}$ Martha Albertson Fineman, 'Cracking The Foundational Myths: Independence, Autonomy, And SelfSufficiency' Journal of Gender, Social Policy \& The Law Vol8:13, 18

${ }^{412}$ Martha Albertson Fineman, 'The Vulnerable Subject: Anchoring Equality in the Human Condition,' (2008)

20 YJLF 1,12

${ }^{413}$ The liberal person tends also to portray the male subject.

${ }^{414}$ Fineman uses the examples of 'the employee, the employer, the spouse, the parent, the consumer, the manufacturer, the citizen, the taxpayer...'

${ }^{415}$ Martha Albertson Fineman, 'The Vulnerable Subject: Anchoring Equality in the Human Condition,' (2008) 20 YJLF 1, 10-11

${ }^{416}$ Fineman cited in A. Grear, Redirecting human Rights: Facing the Challenge of Corporate Legal Humanity, (2010; Palgrave Macmillan) 128

${ }^{417}$ Which also takes a positive rather than wholly anti-discrimination approach.

Again, in similar vein to the Capabilities Approach, 'sameness of treatment' is not advocated to achieve equality in dignity.

Martha Albertson Fineman, 'The Vulnerable Subject And The Responsive State,' 60 Emory L.J. 251 2010-2011, $251,251 \& 256$

${ }^{418}$ And not the liberal subject.

${ }^{419}$ Martha Albertson Fineman, 'The Vulnerable Subject: Anchoring Equality in the Human Condition,' (2008) 20 YJLF 1,8
} 
fact that the pillars of dignity are represented in the liberal subject does not make him any less deserving of human rights. However, the argument that the vulnerable subject should be central is key, and given further emphasis by Grear in her writing on 'disembodiment.'

\subsubsection{Grear's Thesis}

Grear discusses the value of placing the vulnerable subject at the heart of human rights by presenting the 'disembodied' subject, ${ }^{420}$ which does not represent bodily features of vulnerability. ${ }^{421}$ It is, instead, 'possessed of reason and autonomous moral will, ${ }^{422}$ which is not reliant on interaction with the body or emotions. ${ }^{423}$ That which is universal ${ }^{424}$ to the disembodied subject is suited to law which is 'abstract, general, universal, relatively 'blind' to concrete particularities.' Grear sees this 'persona ... put on real people who ... hurt, feel pain and suffer. ${ }^{425}$ Understood in these terms, the argument for placing the vulnerable subject at the heart of human rights if they are to respect, protect, and fulfil the needs of the individual is strengthened. ${ }^{426}$

\subsection{Vulnerability and Human Rights}

Both Turner and Grear suggest vulnerability as conceptually and ethically underpinning human rights. $^{427}$

\subsubsection{Vulnerability: An ethical underpinning for human rights?}

Embodied vulnerability provides the essentials for an ethical grounding of human rights: the threats of bodily attack and the fundamentals for existence. However, Grear considers ethically-driven rights

\footnotetext{
${ }^{420}$ Also referred to by Grear as the 'liberal subject,' the 'legal subject,' and the 'universal legal subject.'

${ }^{421}$ Anna Grear, Redirecting Human Rights Facing the Challenge of Corporate Legal Humanity (Palgrave Macmillan 2010) 97

${ }^{422}$ U Baxi, The Future of Human Rights (Oxford, OUP, 2002) 29 (as cited in Anna Grear, Redirecting Human Rights Facing the Challenge of Corporate Legal Humanity (Palgrave Macmillan 2010) 111)

${ }^{423}$ SJ Williams and G Bendelow, The Lived Body: Sociological Themes, Embodied Issues (London, Routledge, 1998) 174 (as cited in Anna Grear, Redirecting Human Rights Facing the Challenge of Corporate Legal Humanity (Palgrave Macmillan 2010) 116)

Anna Grear, Redirecting Human Rights Facing the Challenge of Corporate Legal Humanity (Palgrave Macmillan 2010) 96

${ }^{424}$ Anna Grear, Redirecting Human Rights Facing the Challenge of Corporate Legal Humanity (Palgrave Macmillan 2010) 98

${ }^{425}$ Anna Grear, Redirecting Human Rights Facing the Challenge of Corporate Legal Humanity (Palgrave Macmillan 2010) 97

${ }^{426}$ Anna Grear, Redirecting Human Rights Facing the Challenge of Corporate Legal Humanity (Palgrave Macmillan 2010) 43

${ }^{427}$ Alexandra Timmer, 'A Quiet Revolution: Vulnerability in the European Court of Human Rights' in Martha Albertson Fineman (ed), Gender in Law, Culture, and Society: Vulnerability Reflections on a New Ethical Foundation for Law and Politics (Ashgate 2013) 149.
} 
must extend beyond 'basic existence ${ }^{428}$ into the realms of situational improvement and wellbeing. ${ }^{429}$ A complete ethical foundation would extend interpretations to embodied vulnerabilities specific to groups, resulting in special protection and negating perceptions of 'stigmatised subjectives. ${ }^{430}$ Furthermore, to found universal human rights in morality which specifically protects against vulnerability makes it universal. As such, issues of cultural relativism cannot be used to undermine moral values which defend against threats, particularly to dependent groups. ${ }^{431}$ Grear also includes moral duty in ethical underpinnings of rights. Quoting the person who is 'less' than me' displaying the 'very destitution or vulnerability that summons me to respond, ${ }^{432}$ she speaks of an ethical duty ${ }^{433}$ which should be universal. Such duty should form the basis of human rights and judicial interpretation if they are to have legal force. ${ }^{434}$ Turner also invokes duty to respond in arguments against exclusion. He rallies against entitlement on the basis of social contribution ${ }^{435}$ and values which cast anyone, by virtue of capacity or capability, as 'not truly human., ${ }^{436}$ Moral recognition is also a principle of ethical grounding of rights. Relating the issue directly to ageing, Turner explains that to see the future in the predicament and misery of others provides impetus to

\footnotetext{
${ }^{428}$ She terms this 'thin' interpretations.

${ }^{429}$ Amongst the threats to the ageing embodied vulnerable included in this would be: co-morbidity; loss of autonomy and freedom; and dependency.

A. Grear, Redirecting human Rights: Facing the Challenge of Corporate Legal Humanity, (2010; Palgrave Macmillan) 128

This ethical foundation is in addition to a conceptual foundation. A. Grear, Redirecting human Rights: Facing the Challenge of Corporate Legal Humanity, (2010; Palgrave Macmillan) 156

${ }^{430}$ A. Grear, Redirecting human Rights: Facing the Challenge of Corporate Legal Humanity, (2010; Palgrave Macmillan) 128

${ }^{431}$ Turner quotes Ignatieff; 'Relativism is the invariable alibi of tyranny. There is no reason to apologize for the moral individualism at the heart of human rights...it is precisely this that makes it attractive to dependent groups' Ignatieff 2001, 74-75 (as cited in B.S. Turner, Vulnerability and Human Rights (2010; Pennsylvania University State Press) p.7)

${ }^{432}$ E. Levinas, 'Ethics as First Philosophy' in The Levinas Reader (S. Hand and M. Temple (trans)) (Maiden, M. A: Blackwell, 1984) 75, 87 (as cited in A. Grear, Redirecting human Rights: Facing the Challenge of Corporate Legal Humanity, (2010; Palgrave Macmillan) 166.)

${ }^{433}$ A. Grear, Redirecting human Rights: Facing the Challenge of Corporate Legal Humanity, (2010; Palgrave Macmillan) at $\mathrm{p} 167$.

${ }^{434}$ A. Grear, Redirecting human Rights: Facing the Challenge of Corporate Legal Humanity, (2010; Palgrave Macmillan) 167.

${ }^{435}$ Since this is regularly a topic of human rights for persons with disabilities, the emphasis is invariably on physical or cognitive vulnerability.

B. S. Turner, Vulnerability and Human Rights. Essays on Human Rights (Pennsylvania State University Press, 2006) 97.

${ }^{436}$ B.S. Turner, Vulnerability and Human Rights (2010; Pennsylvania University State Press) 40 -41
} 
minimise and protect against such vulnerability. ${ }^{437}$ Finally, Turner recognises the institution of human rights as the antidote to the ethical ambiguity of vulnerability. ${ }^{438}$

\subsubsection{Vulnerability: A conceptual underpinning for human rights?}

For Turner, human rights are based on the human capacity for pain and suffering. ${ }^{439}$ As previously discussed, cultural relativism does not detract from this capacity. This universal capacity is, by this reasoning, the basis of the universality of human rights. Additionally, Turner proposes that extreme suffering beyond 'common experiences of ordinary suffering' can form the basis of group identity and marginalisation. ${ }^{440}$ Therefore, group-specific vulnerabilities based in suffering inform special protection rights. With suffering the outcome of vulnerability, and institution-building the response to vulnerability, for Turner human rights both comprise an institution and build institutions. Through human rights the resilience and assets provided by institutions, needed to combat vulnerability, are formalised and accessed.

Whilst Turner relates to all forms of vulnerability, his concept of human rights focuses on embodied human vulnerability; human dependency and the concentrated effect during specific life stages; the interrelated nature of social life; and the precariousness of social institutions. ${ }^{441}$ His particular concern with 'ontological insecurity' turns his attention principally to socio-economic rights, which are 'directly connected to human need and the protection of human life. ${ }^{442}$ This is not to overlook cultural rights. Individuals and groups with reduced cultural rights are made vulnerable, as they are 'significant in defining what it is to be human,' and concerned with issues of personal identity. Often, these issues will bring the need for rights of minorities and the marginalised to the fore particularly when, as a result of their group membership, universal rights are less accessible or have different application. ${ }^{43}$ Turner's approach of grounding human rights in vulnerability, makes second generation rights of principal significance to the vulnerable subject. Civil and political rights are indirectly linked.

\footnotetext{
${ }^{437}$ This impetus is grounded in 'sympathy....towards whom our moral concern should be directed.' B.S. Turner, Vulnerability and Human Rights (2010; Pennsylvania University State Press) 41

${ }^{438}$ Alexandra Timmer, 'A Quiet Revolution: Vulnerability in the European Court of Human Rights' in Martha Albertson Fineman (ed), Gender in Law, Culture, and Society: Vulnerability Reflections on a New Ethical Foundation for Law and Politics (Ashgate 2013) 149.

${ }^{439}$ B.S. Turner, Vulnerability and Human Rights (2010; Pennsylvania University State Press) 9

${ }^{440}$ B. S. Turner, Vulnerability and Human Rights. Essays on Human Rights (Pennsylvania State University Press, 2006) 102-103.

${ }_{441}$ B.S. Turner, Vulnerability and Human Rights (2010; Pennsylvania University State Press) 25

${ }^{442}$ B.S. Turner, Vulnerability and Human Rights (2010; Pennsylvania University State Press) 10

${ }^{443}$ B. S. Turner, Vulnerability and Human Rights. Essays on Human Rights (Pennsylvania State University Press, 2006) 49
} 
The rationale for the indirect relationship between civil and political rights and vulnerability lies in the relationship between the two generations of rights. The link between the sets of rights, Turner argues, subsists largely through the rights of association and democratic participation. By permitting association with political groups and participation in the democratic process the opportunity is given to influence issues which affect enjoyment of second generation rights. These include: accessibility and meaning of rights; non-discriminatory practices on the basis of capability, capacity, dependence, or need; situations of vulnerability to which rights should apply; identification of groups exposed to vulnerabilities requiring special protection. Thus, civil and political rights assist social, economic and cultural rights to defend against vulnerability. Another indirect link with vulnerability is via socioeconomic rights which are informed by, and support, fundamental civil and political rights. Notable are the rights to life $\mathrm{f}^{444}$ and freedom from inhuman and degrading treatment. Specifically, these rights are given effect through rights including health, adequate sustenance and shelter, and all which work to alleviate dependence. Furthermore, some civil and political rights can facilitate socioeconomic and cultural rights, such as the right to freedom of expression. The interrelation between the two types of rights is accepted. However, it is also suggested that the varied nature of vulnerability can create a direct reliance on first generation rights. ${ }^{445}$ The right to association, proven to impact morbidity and life expectancy ${ }^{446}$ can be added to rights relating directly to existence and well-being; the right to liberty to Turner's 'emplacement' vulnerability; and the right to manifest religion to his 'spiritual' vulnerability. Others can simply be argued to be linked to human ontology as they create 'the good society' in which life and well-being thrives. ${ }^{447}$ Nonetheless, without effective socio-economic rights which protect existence and health, some civil and political rights could not be exercised. ${ }^{448}$ In this way, the first generation rights are dependent upon rights which defend against vulnerability.

How vulnerability underpins human rights is considered differently by Grear. Seeing vulnerability as presuppositional to human rights, Grear makes a case for embodied vulnerability as the foundation

\footnotetext{
${ }^{444}$ B. S. Turner, Vulnerability and Human Rights. Essays on Human Rights (Pennsylvania State University Press, 2006) 1

${ }^{445}$ There is potential for the Right to Life to become of increasing significance to older people suffering the effects of the ageing process, as discussed in chapters 8 and 9,' in light of legal debates surrounding assisted suicide and the need for protection of the vulnerable.

${ }^{446}$ B. S. Turner, Vulnerability and Human Rights. Essays on Human Rights (Pennsylvania State University Press, 2006) 37.

${ }^{447}$ Article 3 of ICESCR, 'everyone has the right to life, liberty and security of the person' is an example of this. B. S. Turner, Vulnerability and Human Rights. Essays on Human Rights (Pennsylvania State University Press, 2006) 10.

${ }^{448}$ B. S. Turner, Vulnerability and Human Rights. Essays on Human Rights (Pennsylvania State University Press, 2006) 37.
} 
of all types of rights in an examination of the UDHR. ${ }^{449}$ Socio-economic rights, with their direct reference to fundamental human need ${ }^{450}$ and embodied existence and flourishing, ${ }^{451}$ claims Grear, identifies rights specifically designed to protect 'bodily' needs. ${ }^{452}$ Grear cited: adequate standard of living, or food, clothing and shelter; ${ }^{453}$ social security; ${ }^{454}$ health care; ${ }^{455}$ and cultural participation, to enable social inclusion. ${ }^{456}$ Some civil and political rights of the UDHR are immediately evident as providing for embodied vulnerability in its fundamental form. Included are rights to: life; liberty and security of the person; and protection against torture and inhuman degrading treatment. Others respect and protect broader interpretations of embodied vulnerability and the association with human dignity, including freedom to direct one's life, autonomy, and equality. Examples are: freedom from arbitrary arrest or detention; right to freedom of movement; to marry and found a family; assembly and participation; and freedom of expression. ${ }^{457}$ The impact of rights seen as founding broader versions of embodied vulnerability also affects the basic physical and psychological aspects. For example, freedom of opinion and expression 'directly protects embodied personalities' from coercion due to beliefs or opinion with repercussions on choices including medical treatment; ${ }^{458}$ where, with whom, and how independently to live; relationships to forge; ${ }^{459}$ and religion to practice. ${ }^{460}$ This civil and political right also facilitates requests for assistance, respect and protection. ${ }^{461}$ Grear makes the final point that civil and political rights which work against discrimination prevent targeted vulnerability when embodied impairment is used as a 'foundational strategy for the imposition of inequalities...and exclusions. ${ }^{462}$ Grear's study demonstrates a more comprehensive vulnerability base for human rights. Given the reach of embodied vulnerability into

${ }^{449}$ Alexandra Timmer, 'A Quiet Revolution: Vulnerability in the European Court of Human Rights' in Martha Albertson Fineman (ed), Gender in Law, Culture, and Society: Vulnerability Reflections on a New Ethical Foundation for Law and Politics (Ashgate 2013) 149

${ }^{450}$ Recognised as a component of human dignity in Chapter 4, 'Human Dignity.'

${ }^{451}$ A. Grear, Redirecting human Rights: Facing the Challenge of Corporate Legal Humanity, (2010; Palgrave Macmillan) 156

${ }^{452}$ Outlined by Fineman and Turner. See heading 5.3.1.1, 'Embodied Vulnerability.'

${ }^{453}$ Which if provided via the institution of legal human rights can be related to Kirby's 'physical assets' and 'human assets'

${ }^{454}$ Which if provided via the institution of legal human rights can be related to Kirby's 'physical assets'

${ }^{455}$ Which if provided via the institution of legal human rights can be related to Kirby's 'human assets'

${ }^{456}$ Which if provided via the institution of legal human rights can be related to Kirby's 'social assets'

${ }^{457}$ A. Grear, Redirecting human Rights: Facing the Challenge of Corporate Legal Humanity, (2010; Palgrave Macmillan) 160

${ }^{458}$ Impacting physical and mental health.

${ }^{459}$ Impacting physical and mental health, and social support.

${ }^{460}$ Impacting the spiritual person.

${ }^{461}$ A. Grear, Redirecting human Rights: Facing the Challenge of Corporate Legal Humanity, (2010; Palgrave Macmillan) 161

${ }^{462}$ A. Grear, Redirecting human Rights: Facing the Challenge of Corporate Legal Humanity, (2010; Palgrave Macmillan) 161. Such inequalities and exclusions can find a home in resource distribution, such as healthcare and welfare, and social exclusion. 
other categories of vulnerability, and the interrelated nature of all, her view of the concept directly grounding, and being discreetly pervasive, in civil and political rights is accepted. Furthermore, the human rights instruments born of the UDHR represent both types of rights. Indeed the instruments of the International Bill of Rights combined, ${ }^{463}$ claim Grear, 'make no conceptual sense without presupposing a vulnerable living body' as whether directly, or less overtly, all exist to protect the embodied person. ${ }^{464}$ Referring once again to the vulnerability framework, and the complex nature of vulnerability of older people, ${ }^{465}$ it is necessary to access both sets of rights.

Having demonstrated the reality of vulnerability underpinning human rights, Grear questions whether the vulnerable subject lies at the heart of rights. The first dilemma is the vulnerable person being a legal subject and recipient of legal rights. The legal subject is the disembodied, or at least quasi-disembodied subject, and even in the international human rights arena the 'full implications of human embodiment are systematically suppressed. ${ }^{466}$ Grear reproaches the historical development of rights which placed the liberal subject at the heart. Whilst it is not the intention to plot the history of this process, the implications are noted. The emphasis on rationality of the legal subject has echoes of the rational species. ${ }^{467}$ Immediately the embodied vulnerable person is distanced, as the body 'plays no role in characterizing the nature of reason. ${ }^{468}$ Any entitlement based in rationality and autonomy exclude embodied vulnerable groups and individuals, and is associated with the principles of Will Theory, rather than serve the interests of the individual. The outcome is justification of suffering of the non-legal subject. ${ }^{469}$ This is particularly visible for groups requiring special human rights protection as a result of 'aggravated' vulnerability served by a single, universal set of rights. ${ }^{470}$ Grear cites the 'species being' to be at the heart of the UDHR, yet the purpose of the instrument was to rail against embodied vulnerability. In her argument for the UDHR focusing on embodied vulnerability, Grear also recognises the presence of the disembodied legal subject, equipped with rationality and autonomy. By introducing the universal subject to human rights, the

\footnotetext{
${ }^{463}$ UHDR, ICCPR, and ICESCR

${ }^{464}$ A. Grear, Redirecting human Rights: Facing the Challenge of Corporate Legal Humanity, (2010; Palgrave Macmillan) p161

${ }^{465}$ See Chapters 8 and 10

${ }^{466}$ A. Grear, Redirecting human Rights: Facing the Challenge of Corporate Legal Humanity, (2010; Palgrave Macmillan) 97

${ }^{467}$ See Chapter 4, 'Human Dignity.'

${ }^{468}$ G. Lakoff, Women, Fire and Dangerous Things: What Categories Reveal About the Mind (Chicago: University of Chicago Press, 1987) at 174 (as cited in A. Grear, Redirecting human Rights: Facing the Challenge of

Corporate Legal Humanity, (2010; Palgrave Macmillan) 116)

It must be emphasised that embodied vulnerability incorporates the mind and physical.

${ }^{469}$ Grear on Baxi A. Grear, Redirecting human Rights: Facing the Challenge of Corporate Legal Humanity, (2010; Palgrave Macmillan) 111

${ }^{470}$ A. Grear, Redirecting human Rights: Facing the Challenge of Corporate Legal Humanity, (2010; Palgrave Macmillan) 112
} 
particular embodied vulnerability of the individual is overlooked. ${ }^{471}$ Groups with shared vulnerabilities that are not the liberal model lie 'outside the scope of the purportedly universal protection of human rights. ${ }^{472}$ The solution to these problems is special protection. ${ }^{473}$

\subsubsection{Vulnerable groups and human rights}

The legacies of the liberal subject at the heart of human rights continue to be mitigated by the creation of human rights groups and corresponding bespoke rights, defined by embodied vulnerability, to protect the most vulnerable. The aim of recognising vulnerable groups is to counter marginalisation, and the inability of human rights in their existing construct to respect, protect and fulfil the needs of the particularly vulnerable. ${ }^{474}$ This does not detract from the universality of vulnerability, but reinforces that 'people are differently vulnerable;' this 'difference' identifies a group and the 'different' protection required. ${ }^{475}$

Guidance for relevant 'difference' and recognition of groups as vulnerable is provided by the European Court of Human Rights. ${ }^{476}$ The approach of the ECtHR is instructive to qualification for special protection, and bears reporting. Categorisation of special protection groups using vulnerability includes: type of vulnerability suffered; that they comprise a minority of society; are more vulnerable than most individuals; and are marginalised or discriminated against. ${ }^{477}$ The nature of the vulnerability suffered is also of significance for identification of a special protection group, which involves a determination of its relational, particular, and harm-based characteristics. ${ }^{478}$ When vulnerability is born of, and perpetuated by, social, historical and institutional influence it has the propensity to attack the security and dignity of a group. The vulnerability of an individual must be

\footnotetext{
${ }^{471}$ Lourdes Peroni \& Alexandra Timmer, 'Vulnerable Groups: The promise of an emerging concept in European Human Rights Convention law,' 1061

${ }^{472}$ Lourdes Peroni \& Alexandra Timmer, 'Vulnerable Groups: The promise of an emerging concept in European Human Rights Convention law,' 1061

${ }^{473}$ Lourdes Peroni \& Alexandra Timmer, 'Vulnerable Groups: The promise of an emerging concept in European Human Rights Convention law,' 1057 \& 1062

${ }^{474}$ The human rights universal is accused of particularly not protecting the marginalised. ${ }^{474}$ Lourdes Peroni \& Alexandra Timmer, 'Vulnerable Groups: The promise of an emerging concept in European Human Rights Convention law,' 1062

${ }^{475}$ Lourdes Peroni \& Alexandra Timmer, 'Vulnerable Groups: The promise of an emerging concept in European Human Rights Convention law,'.1061

${ }^{476}$ Hereafter referred to as ECtHR

${ }^{477}$ Lourdes Peroni \& Alexandra Timmer, 'Vulnerable Groups: The promise of an emerging concept in European Human Rights Convention law,' p.1057; Alajos Kiss v Hungary App. No 38832/06, 20 May 2010, 42 (as cited in Lourdes Peroni \& Alexandra Timmer, 'Vulnerable Groups: The promise of an emerging concept in European Human Rights Convention law,' 1057

${ }^{478}$ Lourdes Peroni \& Alexandra Timmer, 'Vulnerable Groups: The promise of an emerging concept in European Human Rights Convention law,' 1063
} 
considered in the relational context of the group to which they belong. ${ }^{479}$ Particular vulnerability is that formed by distinct group-based experiences. Vulnerability 'particular' to a group, especially when that group suffers greater vulnerability than others, is one requiring discrete protection. The outcomes of vulnerability, in all its guises, are a form of harm. Therefore, when there is a type or degree of harm specific to a group, or the harm is compounded in that group, this is another inequality requiring a response from human rights. ${ }^{480}$

Identification of group vulnerability is accepted as the solution to the failure of existing universal rights to respect, protect and provide for need, and the subsequent marginalisation, suffering, and harm caused. However, this should be viewed in conjunction with individual vulnerability. As individual members of a group will have a particular experience of vulnerability, the entire group cannot be claimed to suffer the same combination and degree of harm. Additionally, there are individuals who, by virtue of this experience, can claim membership of more than one vulnerability group, which is particularly relevant to older people. Thus, each individual must have a human rights response, grounded in vulnerability, in accordance with the resilience and assets needed. ${ }^{481}$

Whilst the designation of group vulnerability status has proven a successful solution to the 'particularly' vulnerable, ${ }^{482}$ it is possible to exacerbate certain problems. Some groups will struggle to be granted the status, as potential members could be made to access human rights protection via a number of different groups. Also, the vulnerabilities of some groups might not be considered as urgent as others, and might suffer issues of prioritisation of rights protection. Problems of stigmatisation of vulnerabilities and individuals suffering them could increase once herded into an identity group, despite the benefits of overcoming marginalisation. Finally, the identification of vulnerable groups has attracted criticism of paternalism. When autonomy and freedom to direct one's life are denied with reference to group vulnerability, the essentials of human dignity are insulted, with feelings of powerlessness which accompany vulnerability reinforced. ${ }^{483}$

\footnotetext{
${ }^{479}$ Lourdes Peroni \& Alexandra Timmer, 'Vulnerable Groups: The promise of an emerging concept in European Human Rights Convention law,' 1064

${ }^{480}$ Lourdes Peroni \& Alexandra Timmer, 'Vulnerable Groups: The promise of an emerging concept in European Human Rights Convention law,' 1064-1065

${ }^{481}$ Lourdes Peroni \& Alexandra Timmer, 'Vulnerable Groups: The promise of an emerging concept in European Human Rights Convention law,' 1071

${ }^{482}$ Examples include children, women, ethnic and sexual minorities, and persons with disabilities.

${ }^{483}$ Lourdes Peroni \& Alexandra Timmer, 'Vulnerable Groups: The promise of an emerging concept in European Human Rights Convention law,' 1072-1073
} 


\subsection{Conclusion}

This chapter undertook an examination of vulnerability as contributory to developing the case for older people as deserving of special human rights protection. Given the role of human rights to respect human dignity, protect against violation and fulfil human need, a vulnerability to the outcomes of threats to each of these that place a person, or group of persons, outside the scope of the human rights universal must be proven. This task will be developed in further chapters, and will build upon the subject of vulnerability.

The framework constructed from embodied, institutional, and pathogenic vulnerability, informs the findings of Part III of this thesis, and provides a reference for qualification for vulnerable group status. Significantly, the framework incorporates every form of 'wounding' to which the person is susceptible. The inevitability, universality, and outcomes of embodied vulnerability are key to the involvement of all categories of the framework, and the implications to older people. Internal and external threats to the biology, 'enselfment,' and 'emplacement' of the person combine to present threats to the physical, psychological, moral, and spiritual self, and to the pillars of human dignity. ${ }^{484}$ The fact that each of these turns to institutions for the resilience and assets to combat and minimise the effects of threats and vulnerability, and protect dignity, makes vulnerability of these institutions crucial. Furthermore, it grounds the argument that institutional assets must be incorporated into human rights provision. Institutional vulnerability is included in the framework due to the way it deepens and introduces further vulnerability. Both embodied and institutional vulnerability are shown to invite pathogenic vulnerability into the lives of the already vulnerable, and the part played by institutions is significant. The embodied vulnerable person can be the victim of discriminatory treatment, of paternalistic decision-making which disregards inherent values and choices, and with it, inherent dignity. The provision of assets can also introduce abuse and intensify dependency. This thesis will go on to demonstrate that each form of vulnerability has a place in the vulnerability experience of older people as a group. Also, many parallels will be drawn between this framework and theories of ageing, in particular modernisation, abandonment, and disengagement.

Pivotal to the relationship between vulnerability and human rights are central tenets of the theses of Turner, Fineman and Grear. Fundamental is that embodied vulnerability underpins human rights. It also provides rationale for their universality. However, Turner's universality based in the capacity to suffer is recognised as disproportionately relevant to the experience of older people, and must also be a means of interpretation and application of rights in concrete cases. The debate surrounding the type of right grounded in vulnerability is relevant to the question of the adequacy of rights for the

${ }^{484}$ including autonomy, freedom, self-respect, need, and personality. 
vulnerable person or groups. The reliance of ontological vulnerability on rights relating directly to existence, and the connection to human need and the protection of life confirms the relationship with socio-economic rights. Similarly, cultural rights often highlight problems of the marginalised in accessing rights. However, to disregard, even partially, the role of civil and political rights in the fight against vulnerability, or as being rooted in the concept, is not accepted. An accurate account of the association between vulnerability and rights is arrived at via acknowledgement of the interrelation of both sets of rights. Indirect links of civil and political rights with vulnerability via democratic rights and the support of socio-economic rights are not discounted, but direct association to content and broader interpretations relating to dignity, which in turn impact human ontology, are of equal importance. The International Bill of Rights, comprising both types, exemplifies the need for both. The fact that vulnerability 'makes no conceptual sense without presupposing a vulnerable living body' is instrumental to the examination of human rights instruments in Part IV, aimed at assessing the suitability of current human rights provision for older people.

Human rights conceptually and ethically underpin human rights. At first glance, and correct, is that with its ontological basis, embodied vulnerability ethically demands rights for existence. However, ethically-driven rights reach into all aspects of well-being and group-specific vulnerabilities. Additionally, the ethically ambiguous nature of vulnerability is the reason that human rights are called upon to contribute to institution building. Furthermore, refusal to accept entitlement to rights on the basis of capacity or capability complies with the inherent worth of the person. It also finds acceptance in the capabilities approach to fulfil need discussed in the next chapter.

The vulnerable subject is vital to the role of vulnerability in human rights and to assessments of the adequacy of the current construct of human rights. Placing the vulnerable subject at the heart of policy, and by extension, institutions, and taking it into the human rights arena is key. Fineman's liberal, fully autonomous, rational and independent subject shares the place of the vulnerable subject in human rights; the result being marginalisation by virtue of vulnerability. This relative focus on the vulnerable subject by human rights informs the solution offered; something which will be instrumental in answering questions of whether older people comprise a special protection group.

The solution to the most vulnerable falling outside the scope of the human rights universal is the creation of vulnerable groups. Significantly, any human rights group must not detract from the universality of embodied vulnerability or of rights per se, but must recognise the ways in which it is 'differently vulnerable.' Ways in which vulnerable groups are defined, are various. However, those suggested by the ECtHR are particularly helpful. By going beyond type of vulnerability, the group

\section{5}


forming a minority, and marginalisation the requirements consider societal influences, whether the vulnerability is 'particular' to the group, and the type of harm resulting.

The following chapter turns to the capabilities approach for a means of protection against vulnerability and to fulfil the needs it creates. 


\section{CHAPTER 6}

\section{THE CAPABILITIES APPROACH}

\subsection{Introduction}

The Capabilities Approach is a means of evaluating, and from there, giving effect to individual wellbeing and equality. With a focus on individual human development the approach centres on the 'actual opportunities a person has, ${ }^{485}$ on what a person 'is able to do and be.' The focus is not on traditional methods of evaluation of well-being such as wealth, desires, consumption, and expressed satisfaction. ${ }^{486}$ Originally conceived by Amartya Sen as an alternative approach to welfare economics, it is concerned with '...the quality of...life, and on removing obstacles in their lives so that they have more freedom to live the kind of life that, upon reflection, they have reason to value. ${ }^{487}$ This form of assessment has since proved conceptually applicable to numerous fields with an involvement with human development, of which human rights is one. This thesis will use the Capabilities Approach as a tool to analyse how human rights provide for the well-being of older people in lived situations. This examination will focus on the implementation of human rights to enable the person to be and do what is of value.

This chapter initially focuses on the work of Sen, but also discusses developments on the Capabilities Approach by Nussbaum. It necessarily begins with an explanation of the approach. That which a person values being or doing, or functionings, are described as achievable through capabilities, and the significance of the varying importance of types of functionings to well-being, to the individual, and to groups is made. The capabilities of opportunity, choice, personal ability and external conditions present the individual with alternative lives from which to choose. This objective of capabilities opens the coverage of their typology, operation, and measurement. Nussbaum's work is turned to for explanation of the categories of capabilities, and how each contributes to a person's ability to achieve valued functionings. This also helps identify areas in which a person can become vulnerable, and how capabilities must be developed and applied to overcome vulnerability by influencing the content and application of human rights. The further classification of capabilities into critical and non-essential for existence, well-being and development is discussed under the heading of 'vital capabilities.' Sen's 'basic capabilities' and Nussbaum's 'central capabilities' are

\footnotetext{
${ }^{485}$ Rod Hick, 'The Capabilities Approach: Insights for a new poverty focus,' LSE Research Online. $<$ http://eprints.lse.ac.uk/39745/>

${ }^{486}$ Rod Hick, 'The Capabilities Approach: Insights for a new poverty focus,' LSE Research Online, 3. $<$ http://eprints.Ise.ac.uk/39745/> ; Ingrid Robeyns, 'The Capability Approach: a theoretical survey,' Journal of Human Development, Vol. 6, No. 1, March 2005, 93, 94

${ }^{487}$ Ingrid Robeyns, 'The Capability Approach: a theoretical survey,' Journal of Human Development, Vol. 6, No. 1, March 2005, 93, 94
} 
acknowledged. Of particular importance to the use of the Capabilities Approach as a tool to analyse current human rights provision is the divergence of opinion on the listing of these vital capabilities. Nussbaum's ideal of a single, universal list of vital capabilities is compared to Sen's preference for a list applicable to purpose. Taking universality as a floor rather than a ceiling, and recognising the need to address particular vulnerabilities and achieve particular valued functionings, Sen's view is adopted for the purpose of arriving at a set of capabilities suited to the situation and lived problems of older people.

Measurement of the achievements of capabilities will be discussed. The alternatives of outcome of substantive freedoms; expressed satisfaction; and resource distribution, and the reason for the choice of 'outcome' explained. The final contribution of Nussbaum to the Capabilities Approach considered in this chapter concerns entitlement. Her suggestion that minimum agency and ability for active striving are necessary to capability, and to broaden the scope of dignity beyond rationality are accepted. However, in discounting the most vulnerable by virtue of permanent vegetative state or severe dementia, Nussbaum's version is not wholly suitable for human rights. Furthermore, this notion contradicts the objective of the Capabilities Approach to improve and provide capabilities.

In other ways, the Capabilities Approach proves a useful lens through which to develop and apply human rights. The effect on content by responding to need and through vital capabilities is noted as key, and responsible for placing civil and political and social, economic and cultural rights on equal footing. Also noted as influential over content, and in the creation of special protection rights is a capabilities list responding to need of vulnerable groups. How a Capabilities Approach secures human rights by placing a duty on the State to provide for need using both generations of rights, and how obligations are developing in international law are also considered. The chapter concludes with an evaluation of how the Capabilities Approach applies to vulnerable groups.

\subsection{The Capabilities Approach}

Grounded in the freedom of the individual to be and do all that is of value to him or her, the aim of Capabilities Approach is to develop and maintain the optimal capacity of the individual to 'do valuable acts or reach valuable states of being. ${ }^{\prime 488}$ The degree to which this overarching principle might be achieved is dependent upon the interaction of the core tenets. These comprise initially of substantive freedoms of 'functionings,' and 'capabilities,' which enable functioning via personal ability; process; and opportunity, including the opportunity to choose.

${ }^{488}$ M.C. Nussbaum, A. Sen, The Quality of Life (1996; Clarenden Press) 30. 


\subsubsection{Functionings}

'Functionings' comprise that which a person values being and doing. The essence has developed from origins in actions, known as 'doings,' through formulations of 'what a person is doing or achieving,' acknowledging that a state of being is necessary to achieve an action. ${ }^{489}$ A state of being can also be required of itself, such as being independent and autonomous. ${ }^{490}$ Therefore, functionings are now known as 'doings and beings, ${ }^{491}$ and the combination achieved is reflected in a person's well-being. ${ }^{492}$ Sen's idea that these substantive freedoms include the full range of a person's goals, are not limited to civil and political freedoms, ${ }^{493}$ and represent an individual's achievements ${ }^{494}$ led him to offer a range of functionings subjects, without agreeing a finite list. ${ }^{495}$ At this point Sen distinguishes between the very elementary, considered necessities for life, and the more complex which are reliant on the former having been achieved. ${ }^{496}$ The elementary include: being healthy and nourished, surviving premature morbidity, and being housed. ${ }^{497}$ Beyond this, being socially integrated, educated and able to express opinion can allow a more advanced 'state of being.' Acts or 'doings' include: casting a vote, earning an income, founding a family, practicing one's religion, ${ }^{498}$ disputing one's rights ${ }^{499}$ and protecting human dignity. ${ }^{500}$ Further 'aspects of living' such as 'being happy,' 'acting freely,' 'being able to choose' and 'having self-respect' also count as

\footnotetext{
${ }^{489}$ For example, being well-nourished and being healthy are states which could contribute to being able to live a life of expected length and to live an independent life.

${ }^{490}$ G.A. Cohen, 'Equality of What? On Welfare, Goods and Capabilities,' in M.C. Nussbaum, A. Sen, The Quality of Life (1996; Clarenden Press) 21

${ }^{491}$ Sen's early view of functionings is set out in an examination of the role of commodities in a person's capabilities when he described them as 'what the person succeeds in doing with the commodities...at his or her command.' A. Sen, 'Commodities and Capabilities' cited in G.A. Cohen, 'Equality of What? On Welfare, Goods and Capabilities,' in M.C. Nussbaum, \& A. Sen, The Quality of Life (1996; Clarenden Press) 21. (My italics).

${ }^{492}$ Which comprises a person's 'state of being,' itself inclusive of all functionings necessary to welfare, all acts done and states reached. A. Sen, 'Capability and Well-Being'

See also R. Sugden, 'Welfare, Resources, and Capabilities: A Review of Inequality Reexamined by Amartya Sen' Journal of Economic Literature Vol 31, No. 4 (Dec 1993) 1947-1962, 1952 for Sen's description of functionings in the welfare arena as 'constitutive of a person's being.'

Sugden also says of functionings that they make for the process of living, a process which can be enriched or compromised if some or any are unachievable. R. Sugden, 'Welfare, Resources, and Capabilities: A Review of Inequality Reexamined by Amartya Sen' 'Journal of Economic Literature' Vol, 31, No. 4 (Dec 1993) 1947,-1962, 1951

${ }^{493}$ T. Burchardt, 'Equality, Capability and Human Rights,' Centre for Analysis of Social Exclusion, London School of Economics, presentation given 16 March 2015

${ }^{494}$ L.W. Sumner, Welfare, Happiness and Ethics (2003; Oxford University Press) 61

${ }^{495}$ Given the range of functionings and that they often act as visitors throughout the life-course, it becomes difficult to construct a fixed list. F Comim, M Qizilbash, \& S Alkire, The Capability Approach (2008; Cambridge University Press) 2

${ }^{496}$ M.C. Nussbaum \& A. Sen (Eds.) Quality of Life (1996; Clarendon Press) 3

${ }^{497}$ F Comm, M Qizilbash, \& S Alkire, The Capability Approach (2008) 2

${ }^{498}$ I. Robeyns, 'The Capability Approach,' (2005) 6 (1) Journal of Human Development 93, 95

499 D. Gasper, 'Working Papers: What is the Capability Approach? Its Core, Rationale, Partners and Dangers,' June 2006; Working Paper Series No. 428, 9

${ }^{500}$ M.C. Nussbaum \& A. Sen (Eds.) Quality of Life (1996; Clarendon Press)3
} 
functionings. ${ }^{501}$ When choosing between functionings, the person decides between those she considers 'substantive goods' and 'substantive bads. ${ }^{502}$ Substantive bads can be personal choice, others are objectively accepted. These include 'loss of life, intense physical pain and mental or physical disability. ${ }^{503}$ Ultimately, substantive goods or bads are a matter of the beings and doings that a person has reason to value, and the value that functionings give to life.

\subsubsection{Valuing functionings}

Not all functionings valued by a person are considered equally valuable to life, human dignity, and to preventing vulnerability. ${ }^{504}$ Basic or vital functionings reflect those doings and beings of intrinsic value to the person, within this it is also possible to prioritise functionings. The value given to functionings ${ }^{505}$ relates directly to the manner and degree to which life is improved. Basic functionings improve all aspects of human life and dignity; complex functionings can have more direct association with specific aspects of dignity, such as self-respect. ${ }^{506}$ Both are required, with different emphasis according to need and vulnerabilities. The value of each functioning individually and as part of a group ${ }^{507}$ 'reflects a view of what is valuable and what is of no intrinsic value. ${ }^{508}$ However, individuals and groups value functionings differently. The individual values them subjectively, influenced by, inter alia, personal circumstance, ability and goals. For groups the status 'basic functioning' is based on shared values, and a formal ordering of them can be legitimately attempted. ${ }^{509}$ Importantly, functionings valued by a group must also reflect individual valued functionings and represent individual needs, vulnerabilities and goals.

\footnotetext{
${ }^{501}$ R. Sugden, 'Welfare, Resources, and Capabilities: A Review of Inequality Reexamined by Amartya Sen' 'Journal of Economic Literature' Vol, 31, No. 4 (Dec 1993) 1947, 1952

${ }^{502}$ T. Scanlon, 'Value, Desire, and Quality of Life' in M.C. Nussbaum and A. Sen, The Quality of Life (1996; Clarendon Press) 197

${ }^{503}$ T. Scanlon, 'Value, Desire, and Quality of Life' in M.C. Nussbaum and A. Sen, The Quality of Life (1996; Clarendon Press) 197

${ }^{504}$ Simply desiring or enjoying a functioning is not regarded in Sen's consideration of what makes it valuable. Trivial functionings are not considered valuable. In this regard Sen reflects the need for an interest to be of sufficient importance to become a human right.

L.W. Sumner, Welfare, Happiness and Ethics (2003; Oxford University Press) 60-61

${ }^{505}$ I. Robeyns, 'The Capability Approach,' (2005) 6 (1) Journal of Human Development 93, 95

${ }^{506}$ A. Sen, 'Capability and Well-Being' in A. Sen \& Nussbaum, M. (eds.) The Quality of Life (1993; Clarenden Press) 31

${ }^{507}$ The group could comprise any social group defined by commonalities including, but not limited to, shared standards, circumstances, abilities or vulnerabilities.

A. Sen, 'The Standard of Living,' in Sen, Muellbauer, Kanbur, Hart, and Williams, The Standard of Living: The Tanner Lectures on Human Values, (1987; Cambridge University Press) 29

${ }^{508}$ Although something of no intrinsic value could possibly be useful in the pursuit of other things of value.

${ }^{509}$ Sumner, L.W., Welfare, Happiness and Ethics (2003; Oxford University Press) 63
} 


\subsubsection{Capabilities}

'Capabilities' provide the means to achieve functionings ${ }^{510}$ by way of opportunity, choice, personal ability and external conditions. Those that are feasibly attainable can be gathered into alternative combinations or 'sets' ${ }^{511}$ representative of the capability the person has to achieve valuable functionings. Each person has multiple 'capability sets, ${ }^{512}$ which set out the 'alternative lives open to her. ${ }^{513}$ However, these alternatives require what Sen terms the 'opportunity' aspect of capabilities, particularly the opportunity to choose, or '...the opportunity to achieve valuable combinations of human functionings: what a person is able to do or be. ${ }^{514}$ The opportunity to exercise agency is defined in the Capabilities Approach as, 'what a person is free to do and achieve in pursuit of whatever goals or values he or she regards as important. ${ }^{515}$ 'Opportunity, therefore, begins converting valuing beings and doings into the ability to be and do, if not prevented by circumstance. ${ }^{516}$

The freedom of capabilities also relies on the process by which decisions about functionings are made. ${ }^{517}$ The opportunity to choose must be supported by the necessary 'process,' meaning that there must be no State interference, whether by coercion or veto, to impede full freedom of opportunity to choose. Even where the State's enforced choice corresponds to that of the individual, freedom is still infringed, as the process excluded personal choice. ${ }^{518}$ Furthermore, the opportunity to choose could be a valuable functioning, leaving both aspects of freedom violated. ${ }^{519}$

At this stage in the examination of the Capabilities Approach, it is timely to turn to the work of Nussbaum. Thus far she is in agreement with Sen. Her categorisation of capabilities into basic,

\footnotetext{
${ }^{510}$ A. Sen, 'The Standard of Living,' The Tanner Lectures on Human Values, Clare Hall Cambridge University, March 1985

${ }^{511}$ A. Sen, Development as Freedom (1998; Oxford University Press) 75

${ }^{512}$ Also referred to in literature of the Capabilities Approach as 'functioning vectors' or ' $n$-tuples' of functionings.

${ }^{513}$ D Gasper, 'Working Paper' Series no 428 at 9; I. Robeyns, 'The Capability Approach,' Journal of Human development, Vol. 6, No. 1, March 2005, 93, 100. It is also noted that Sen's terminology is of 'capability sets' and his earlier writings on the Capabilities Approach is in the singular. Nussbaum introduces the plural use of the phrase, which is more generally used, and which will be adopted in this thesis.

514 'Elements of a Theory of Human Rights,' Philosophy and Public Affairs (2004) 32 (4) 315, 331

${ }^{515}$ A. Sen, 'Well-being, Agency and Freedom' Journal of Philosophy 1985, 203

${ }^{516}$ A situation well represented by the often referred to comparison between fasting and starving. The person who starves due to poverty or any inability to access nutrition might share the same functioning as the person who chooses to fast, but not the same opportunity to choose that functioning.

${ }^{517}$ The 'freedom' of Sen's Capabilities Approach is reliant on what is termed the 'opportunity' and 'process' aspects of freedom.

${ }^{518}$ A. Sen, 'Elements of a Theory of Human Rights,' 'Philosophy and Public Affairs,' 15 September 2004; 32 (4): 315,331

${ }^{519}$ A. Sen, 'Elements of a Theory of Human Rights,' 'Philosophy and Public Affairs,' 15 September 2004; 32 (4): 315,331
} 
internal and combined provide an understanding of the operation of the Capabilities Approach, and are instructive in the role of human rights to protect against vulnerabilities and violations of dignity.

\subsubsection{Basic, internal and combined capabilities}

'Basic capabilities,' are the 'innate equipment' with which a person is born, comprising abilities and characteristics. ${ }^{520}$ They are the basis from which superior and more complex capabilities flourish. ${ }^{521}$ Internal capabilities are those which a person possesses as a result of the maturity of innate equipment 'sufficient...for the exercise of the requisite functions, ${ }^{1522}$ their maturation occurs as a consequence of numerous interventions, some internal, others external. ${ }^{523}$

The collaboration between external opportunity and internal capability creates 'combined capabilities,' defined as 'internal capabilities combined with suitable external conditions for the exercise of the function. ${ }^{524}$ When one or both elements are deficient, the person lacks capability. Without the prospect to act upon internal capabilities, mere possession renders them 'incapabilities. ${ }^{525}$ The role of external capabilities is to assist internal capabilities realise functionings. ${ }^{526}$ When either element of combined capabilities requires support, the entitlement to, or degree of assistance provided responds to need. The goal for the most needy is 'to have the same capabilities as 'normal' people, ${ }^{, 527}$ and the 'duty to secure human capabilities lies with the State. ${ }^{, 528}$

\footnotetext{
${ }^{520}$ M.C. Nussbaum, Creating Capabilities The Human Development Approach (2011; Harvard University Press) 24

${ }^{521}$ M C Nussbaum, 'Capabilities and Human Rights,' Fordham Law Review, (1997) 66 (2) 273, 289

Examples are innate equipment which would, with development, permit speech; expression; reasoning and decision making; and the ability to provide and care for oneself.

522 M C Nussbaum, 'Capabilities and Human Rights,' Fordham Law Review, (1997) 66 (2) 273, 289.

Cited as including, 'personality traits, intellectual and emotional capacities, states of bodily fitness and health, internalized learning, skills of perception and movement.' M.C. Nussbaum, Creating Capabilities The Human Development Approach (2011; Harvard University Press) 21

${ }^{523}$ Including age, family, society, culture and political and economic policy. M.C. Nussbaum, Creating Capabilities The Human Development Approach (2011; Harvard University Press) 24

${ }^{524}$ M C Nussbaum, 'Capabilities and Human Rights,' Fordham Law Review, (1997) 66 (2) 273, 300

${ }^{525}$ This incapability is exemplified by older people person with capacity choosing to live in her own home, but is forced by the State to live in residential care. The internal capability to make reasoned decision is worthless without the opportunity to exercise it.

${ }^{526}$ This explains Nussbaum's view that functionings are the ends of capabilities. M.C. Nussbaum Creating Capabilities The Human Development Approach (2011; Harvard University Press) 25 Whilst the classification of basic, internal and combined capabilities belong to the Nussbaum version of capabilities, Sen also acknowledged the rationale of combined capabilities by recognising the need to compensate for the substantive opportunities of the physically or cognitively disabled vis à vis the able-bodied or more able-minded. A Sen, 'Human Rights and Capabilities,' Journal of Human Development, 6 (2) (2005) 151,154

${ }^{527}$ M.C. Nussbaum Creating Capabilities The Human Development Approach (2011; Harvard University Press) 24
}

Nussbaum made this comment with direct reference to those with diminished cognitive ability. However, it is a principle which applies to any needy capability. 
The issue of need leads to the identification of capabilities identified as vital. They respond to the strongest needs, are essential to human function and dignity, and must be provided for, above all others.

\subsubsection{Vital Capabilities}

Both Sen and Nussbaum speak of vital capabilities. Initially identified by Sen as 'basic capabilities' necessary to achieve essential functionings related to 'basic needs, ${ }^{530}$ they carried a minimum standard, 'below which people count as being scandalously 'deprived." ${ }^{\prime 51}$ Nussbaum extended her focus to incorporate issues necessary for equality in human dignity and function. ${ }^{532}$ Each vital capability must be available to every person. As each is essential and impacts the other, ${ }^{533}$ the unavailability of any will have a detrimental effect on well-being. Vital capabilities are not interchangeable, ${ }^{534}$ and a deficit of one cannot be compensated for by an oversupply of another. ${ }^{535}$

Given that vital capabilities are fundamental to life and to the 'good life,' and that freedom and equality are central to the Capabilities Approach, both Sen and Nussbaum argue against a hierarchy of vital capabilities. However, Nussbaum suggests that vital capabilities which support a number of others ${ }^{536}$ can justify prioritisation. Similarly, any capability able to negate or minimise negative effects of others should have priority. ${ }^{537}$ Prioritisation of capabilities on the basis of resource distribution is disregarded by Sen. In this way, he promotes capabilities responding to need over prioritising resource allocation. However, Nussbaum is more flexible regarding the prioritisation of resource-dependent capabilities, and is prepared to see capabilities directly related to existence

\footnotetext{
${ }^{528}$ Martha C. Nussbaum, 'Capabilities, Entitlements, Rights: Supplementation and Critique,' Journal of Human Development and Capabilities: A Multi-Disciplinary Journal for People-Centered Development, 16 Feb 2011, $23,26$.

${ }^{529}$ Not to be confused with the use of the same terminology used by Nussbaum to describe 'innate equipment.'

${ }^{530}$ of, inter alia, food, shelter, clothing and healthcare

${ }^{531}$ A. Sen, 'Capability and Well-Being,' in M.C. Nussbaum and A. Sen (eds.), The Quality of Life (1996; Clarenden Press) 40-41

${ }_{532}$ M.C. Nussbaum, 'Capabilities and Human Rights,' Fordham Law Review, 1997; 66 (2) 273, 287-288

${ }^{533}$ Nussbaum says of her central capabilities that they 'are related to one another in many complex ways.' M.C. Nussbaum, 'Human Capabilities, Female Human Beings' in M.C. Nussbaum \& J. Glover (eds), Women, Culture and Development A Study of Human Capabilities (1995; Clarendon Press) 85

${ }_{534}$ M.C. Nussbaum, 'Capabilities and Human Rights,' Fordham Law Review, 1997; 66 (2) 273, 288

${ }^{535}$ The State that does not make it possible for a person to live to the end of their natural life, or to access necessary healthcare cannot discharge its duty in this regard by, for example, making it possible to laugh, play or enjoy recreational activities. Similarly, the person for whom exercise of freedom of expression is a valuable 'doing' can experience a violation of that freedom reardless of the fact that they may enjoy bodily integrity. ${ }^{536}$ Capabilities which she terms 'fertile capabilities.'

${ }^{537}$ M.C. Nussbaum Creating Capabilities The Human Development Approach (2011; Harvard University Press) 45
} 
allocated resources over others, ${ }^{538}$ despite any infringement of the 'process' aspect of freedom. ${ }^{539}$ Sen's approach to prioritisation when faced with problems of resource allocation fulfils opportunity. Nusbaum's prioritisation of 'fertile' capabilities is appropriate for the most vulnerable, and existence-related prioritising can be necessary when the alternative would cause harm. It is possible, therefore, for each to have a role depending on the concrete situation.

\subsubsection{Listing vital capabilities}

Sen and Nussbaum take different approaches to the matter of listing vital capabilities. Both arguments are key to application of the Capabilities Approach in Part IV. In line with her view of capabilities providing a framework for values Nussbaum devised a list of 'central capabilities.' This list aimed to define capabilities vital to existence and human dignity which provide an accurate measurement of equality. ${ }^{540}$ It discards the irrelevant, ${ }^{541}$ the trivial and possibly harmful, thereby elevating the capabilities it includes above all others. Stating them as universal capabilities, Nussbaum sees no need for additional lists. However, she concedes that they might be adapted or added to. ${ }^{542}$ The list was also constructed in response to the question, 'What does a life worthy of human dignity require?' Arranged under the headings of: life; bodily health; bodily integrity; senses, imagination, and thought; emotions; practical reason; affiliation; other species; play; and control over one's environment, ${ }^{543}$ the summarised outcomes bear reproduction for their relevance to the vulnerability framework, ${ }^{544}$ vulnerabilities of older people, ${ }^{545}$ and affiliation to fundamental human rights and pillars of human dignity.

The outcome of the capability to life is 'not dying prematurely, or before one's life is so reduced as to be not worth living; for bodily health it is 'good health...being adequately nourished and sheltered.' Bodily integrity includes 'being able to move freely...to be secure against violent assault,'

${ }^{538}$ M.C. Nussbaum Creating Capabilities The Human Development Approach (2011; Harvard University Press) 37

${ }^{539}$ This is an example of infringement of 'process' aspect of freedom. 'Process' is infringed even if the objective outcome for the individual is seen as benefitting well-being beyond that of the subjective outcome. ${ }^{540}$ M.C. Nussbaum, 'Capabilities As Fundamental Entitlements: Sen And Social Justice,' 'Feminist Economics' 2003; 9(2-3), 33, 35

${ }^{541}$ I. Robeyns, 'The Capability Approach in Practice,' 'The Journal of Political Philosophy' Volume 14, Number $3,2006,351,355$

${ }^{542}$ Described as 'not closed,' C. Harnacke, 'Disability and Capability: Exploring the Usefulness of Martha Nussbaum's Capabilities Approach for the UN Disability Rights Convention,' Journal of Law, Medicine \& Ethics (2013) 768, 770; see generally C. Harnacke, 'Disability and Capability: Exploring the Usefulness of Martha Nussbaum's Capabilities Approach for the UN Disability Rights Convention,' Journal of Law, Medicine \& Ethics (2013) 768-780

${ }_{543}$ M.C. Nussbaum, 'Capabilities and Human Rights,' Fordham Law Review, 1997; 66 (2) 273, 287-288

${ }^{544}$ See chapter 5 , 'Vulnerability.'

${ }^{545}$ See chapter 10 
whilst the fourth central capability includes freedom of expression, freedom of religious exercise, and the ability to have pleasurable experiences. Emotional capability includes human association, whilst practical reason involves autonomy and directing one's life. The capability of affiliation protects the freedoms of assembly and speech. Additionally, it engages with capabilities to have self-respect and being respected to a degree equal to others, all of which requires freedom from discrimination. ${ }^{546}$

Sen takes a different view to lists of capabilities, which has relevance to the person who falls outside the scope of the universal, and the group with particular vulnerabilities. He warns against a 'fixed list,' a 'frozen list' to which capabilities cannot be added, or existing capabilities amended 'for all societies for all times to come, irrespective of what the citizens come to understand and value. ${ }^{547} \mathrm{~A}$ 'frozen list' restricts all forms of development, and despite adaptation, ${ }^{548}$ pre-determined capabilities might struggle temporally to accurately respond to changing needs, vulnerabilities, and demands of human dignity. Furthermore, a single list, he claims cannot serve all masters. ${ }^{59}$ Any list would 'have to take note of the purpose of the exercise. ${ }^{550}$ Therefore, a vulnerable group with particular capabilities requirements, necessitates a 'special purpose' listing.

\subsubsection{Thresholds of capabilities}

In order to provide equality in human dignity thresholds should be observed. Minimum thresholds are crucial for vital capabilities, ${ }^{551}$ as 'bringing all human beings across a certain threshold of capability to choose' achieves equality of opportunity. ${ }^{522}$ Alternatives have been offered regarding this relative to the role of the capability. A Threshold representing 'bare minimum' is 'a threshold of capability to function beneath which a life will be so impoverished that it will not be human at all.' Another, aimed at flourishing and achieving valued functionings, is one "beneath which those

\footnotetext{
${ }^{546}$ M.C. Nussbaum, 'Capabilities As Fundamental Entitlements: Sen And Social Justice,' 'Feminist Economics' 2003; 9(2-3), 33, 41-42

${ }^{547}$ A. Sen, 'Human Rights and Capabilities,' Journal of Human Development, $2005 ; 6$ (2) 151,158

548 To which Nussbaum agreed.

${ }^{549}$ I. Robeyns, 'The Capability Approach: a theoretical survey,' 'Journal of Human Development,' March 2005; Vol. 6, No. 1, 93, 106

${ }^{550}$ A. Sen, 'Human Rights and Capabilities,' Journal of Human Development Vol.6 No.2, July 2005, 152, 159

${ }^{551}$ Nussbaum specifies the need for equal applicability of this threshold by stating; 'no matter where they are starting from in terms of circumstances, special talents, wealth, gender or race.' M.C. Nussbaum, 'Human Capabilities, Female Human Beings' in M.C. Nussbaum \& Glover, J. (eds), Women, Culture and Development A Study of Human Capabilities (1995; Clarendon Press) 86

${ }^{552}$ M.C. Nussbaum, 'Human Capabilities, Female Human Beings' in M.C. Nussbaum \& Glover, J. (eds), Women, Culture and Development A Study of Human Capabilities (1995; Clarendon Press) 86
} 
characteristic functions are available in such a reduced way that, ... we will not think it is a good human life. ${ }^{553}$

The nature of some of the capabilities and the role they fill requires a threshold of equality. ${ }^{554}$ Equality is not a ceiling or identical standards beyond which there is nothing higher. ${ }^{55}$ The standard is the minimum acceptable to achieve human dignity. To use one of the central capabilities as an example, '[h]aving the social bases of self-respect and non-humiliation ${ }^{, 556}$ must have a threshold of equality if the Capabilities Approach is to support the principle of equal inherent worth. However, it is noted that this treatment is an aim of the Capabilities Approach, and one which is achieved via thresholds of other capabilities. ${ }^{557}$

As a rule, capabilities related to civil and political liberties require a threshold of equality. Those that are resource-dependent require the 'ample minimum' threshold. To not achieve equality in the former would create or exacerbate situations of discrimination ${ }^{558}$ and failure to attain complete personhood. ${ }^{559}$ To provide equality in the latter would not protect against or diminish vulnerabilities, exposing human dignity. ${ }^{560}$ Dignity provides guidance for what constitutes the 'ample minimum,' 'it is the equal dignity of human beings. ${ }^{561}$ This combined with the interrelated nature of capabilities requires the threshold of each to be set individually, in response to each individual's concrete situation, and significantly, not subject to discrimination or stereotyping of groups to which the person might belong. ${ }^{562}$

\footnotetext{
${ }^{553}$ M.C. Nussbaum, 'Human Capabilities, Female Human Beings' in M.C. Nussbaum \& Glover, J. (eds), Women, Culture and Development A Study of Human Capabilities (1995; Clarendon Press) 81

${ }^{554}$ Nussbaum arrived at this conclusion as part of her study of capabilities and women in which she recognises that anything short of equality could see females having fewer opportunities to vote, or lesser importance given to votes cast by them.

${ }^{555}$ M.C. Nussbaum, 'Human Capabilities, Female Human Beings' in M.C. Nussbaum \& Glover, J. (eds), Women, Culture and Development A Study of Human Capabilities (1995; Clarendon Press) 86

${ }^{556}$ Capability 7B of Nussbaum's central capabilities.

${ }^{557}$ This makes sense of another of Nussbaum's claims for an equality threshold in situations where inequality in a capability would result in a 'deficit in dignity and self-respect.' M Nussbaum, 'The Capabilities of People with Cognitive Disabilities,' 'Metaphilosophy,' Vol. 40, Nos. 3-4, July 2009 331-351 ,335

${ }_{558}$ M Nussbaum, 'The Capabilities of People with Cognitive Disabilities,' 'Metaphilosophy,' Vol. 40, Nos. 3-4, July 2009 331, 336

${ }^{559}$ M.C. Nussbaum, 'Human Capabilities, Female Human Beings' in M.C. Nussbaum \& Glover, J. (eds), Women, Culture and Development A Study of Human Capabilities (1995; Clarendon Press) 86

${ }^{560}$ M Nussbaum, 'The Capabilities of People with Cognitive Disabilities,' 'Metaphilosophy,' Vol. 40, Nos. 3-4, July 2009; 331, 336; M.C. Nussbaum, Creating Capabilities The Human Development Approach (2011; Harvard University Press, Cambridge) 41

${ }^{561}$ M Nussbaum, 'The Capabilities of People with Cognitive Disabilities,' 'Metaphilosophy,' Vol. 40, Nos. 3-4, July 2009; 331, 335-337

${ }^{562}$ M Nussbaum, 'The Capabilities of People with Cognitive Disabilities,' 'Metaphilosophy,' Vol. 40, Nos. 3-4, July 2009; 331, 337-338
} 


\subsection{Measurement}

The aim of the Capabilities Approach is equality in the freedom to be and do all that is of value to the individual, and in access to the promise of human dignity inherent in the central capabilities. Both Sen and Nussbaum examined and discounted various options for the measurement of success of Capabilities Approach in this context. Given the vulnerabilities of older people as a group two deserving of mention are expressed satisfaction and resources.

\subsubsection{Expressed satisfaction}

Expressed satisfaction attracts criticism as a measure of equality. Since desires, goals, attitudes, expectations and preferences can be manipulated by circumstance and social trends problems of adaptive preference can occur. Adaptive preference is a barrier to self-determination ${ }^{563}$ as it is a state of resignation, acceptance of deprivation, subordination ${ }^{564}$ and vulnerability in all its forms. ${ }^{565}$ Individuals and groups can be unaware of entitlements, and potential functionings and opportunities available to them, ${ }^{566}$ yet experience mental states of satisfaction even when facing vulnerabilities, dignity and rights violations, and inequalities. ${ }^{567}$ Moreover the smallest improvement in situation could generate expressions of satisfaction despite continuing violations. ${ }^{568}$ Additionally, conditioning can create a belief that impaired internal capabilities beget lower standards of

\footnotetext{
${ }^{563}$ Which is inherent to human dignity

${ }^{564}$ Term used in Nussbaum's context of 'treating as lesser importance,' M.C. Nussbaum, 'Human Capabilities, Female Human Beings' in M.C. Nussbaum \& J. Glover(eds), Women, Culture and Development A Study of Human Capabilities (1995; Clarendon Press) 86

${ }^{565}$ Described as 'tantamount to heteronomy.' F. Comim, 'Capabilities and Happiness: Potential Synergies,' 'Review of Social Economy,' 2005; LXIII(2), 161, 165

${ }^{566}$ Often for reasons of, amongst others: lack of information; societal attitude; internal capability; discriminatory policy.

${ }^{567}$ A. Sen, 'Well-Being, Agency and Freedom: the Dewey Lectures, ' 'The Journal of Philosophy' 1979; LXXVI(9): 463, 188-189, cited inF. Comim, 'Capabilities and Happiness: Potential Synergies,' 'Review of Social Economy,' 2005; LXIII(2), 161, 166-167

By way of illustration of the vulnerable, yet happy, individual Sen asks us to consider

'...[a] very deprived person who is poor, exploited, overworked, and ill, but who has been made satisfied with his lot by social conditioning (through, say, religion, or political propaganda, or cultural pressure). Can we possibly believe that he is doing well just because he is happy and satisfied?

A. Sen, 'The Standard of Living,' The Tanner Lectures on Human Values. Delivered at Clare Hall, Cambridge University, March 11 and 12 1985, 12

568 Describing the problems of adaptive preference further Sen tells us:

'A person who has had a life of misfortune, with very little opportunities, and rather little hope, may be more easily reconciled to deprivations than others... The metric of happiness may, therefore, distort the extent of deprivation, in a specific and biased way. The hopeless beggar... may... 'take pleasures in small mercies.'
}

A. Sen, On Ethics and Economics (1987) 45-46 
entitlement. ${ }^{569}$ Therefore, deprivation and vulnerability can become an expectation. ${ }^{570}$ Expressed satisfaction is therefore an inaccurate measure of equality of the outcomes of capabilities.

\subsubsection{Distribution of resources}

The Capabilities Approach to what a person is able to do responds to need and dignity. Therefore, the resources allocated in achieving this are not included in assessment of equality. ${ }^{571}$ Disadvantage is caused by: internal capabilities; disparities in provision of public resources; external threats such as disease and societal attitude; ${ }^{572}$ and the result of a person's inability to convert resources into valuable functionings. ${ }^{573}$ Equal distribution which disregards such disadvantage insults the principle of vital capabilities for all and causes inequality of capability. ${ }^{574}$ Another approach opposed by Sen and Nussbaum was allocation of resources in accordance with ability to be productive and contribute to society. ${ }^{575}$ Therefore, to lessen disadvantage, and prevent inequality, the Capabilities Approach promotes resource distribution according to need. ${ }^{576}$

Since the aims of the Capabilities Approach are equality in freedoms to be and do what is valued and in human dignity, the correct measurement is outcome. ${ }^{577}$

\subsection{The worthy life}

The rationale of entitlement to the worthy life informs entitlement to capabilities. Nussbaum implies that central capabilities are open to all in her account that claim to central capabilities, and the human dignity essential to human function that they provide, lay in the 'bare fact of being a living human being.' However, she places a strict qualification on entitlement. The human dignity of

\footnotetext{
${ }^{569}$ Nussbaum, Creating Capabilities The Human Development Approach (2011; Harvard University Press) 84.

${ }^{570}$ M.C. Nussbaum 'Symposium on Amartya Sen's Philosophy: 5 Adaptive Preferences and Women's Options,' Economics and Philosophy, 2001; 17 67-88

${ }^{571}$ A. Sen, 'Human Rights and Capabilities,' 'Journal of Human Development,' July 2005; Vol. 6 No. 2, 15, 153154; M C Nussbaum, 'Capabilities and Human Rights,' Fordham Law Review, (1997) 66 (2) 273, 284

572 A. Sen, 'Human Rights and Capabilities,' 'Journal of Human Development,' July 2005; Vol. 6 No. 2, 151, 154

573 M C Nussbaum, 'Capabilities and Human Rights,' Fordham Law Review, (1997) 66 (2) 273, 284

${ }^{574}$ A. Sen, 'Equality of What?', The Tanner Lecture on Human Values. Delivered at Stanford University, May 22 1979, 215

Sen considered the Difference Principle, and Rawls' thinking of 'hard cases' and concluded that using this rationale the disadvantaged person would qualify him for no greater or lesser share of available resources. Any justification on the basis of being distracted by 'hard cases' that are 'distant from us' was not a 'moral perception' that sat comfortably with Sen's Capabilities Approach.

See A. Sen, 'Equality of What?', The Tanner Lecture on Human Values. Delivered at Stanford University, May 221979

${ }^{575}$ An approach sometimes mooted with regard to diverting healthcare resources from the less productive elderly members of society towards the economically active younger population. A. Sen, 'Equality of What?', The Tanner Lecture on Human Values. Delivered at Stanford University, May 22 1979, 203

${ }^{576}$ M C Nussbaum, 'Capabilities and Human Rights,' Fordham Law Review, (1997) 66 (2) 273, 284

${ }^{577}$ T. Burchardt, 'Equality, Capability and Human Rights,' Centre for Analysis of Social Exclusion, London School of Economics, presentation given 16 March 2015
} 
which Nussbaum speaks is aligned to personal striving; 'something inherent in the person that exerts a claim that it should be developed. ${ }^{578}$ This interpretation of dignity lies at the core of her notion of 'a life worthy of human dignity' which bears the requirement of 'a minimal level of agency or capacity for activity. That is enough to give a human being a dignity that is equal to that of every other human being.' Rationality is not considered necessary for this view of human dignity or entitlement to capabilities. ${ }^{579}$ The promise of human dignity inherent in the central capabilities therefore becomes a qualified one, as does entitlement to the capabilities. Specifically excluded, and without entitlement, are people in a persistent vegetative state and the anencephalic child. ${ }^{580}$ Expressly included are those with minimal agency, a description of which is useful to include for purposes of clarification: '...[h]uman beings with high levels of mental retardation, unable to use language, unable to move, and so forth, provided they have some degree of active functioning or striving. ${ }^{581}$ Persons qualifying for the central capabilities yet denied access to the human dignity they afford are unable to live in a manner 'worthy of the human dignity they possess, ${ }^{582}$ their lives instead become 'pinched and cramped; ... unable to unfold themselves, to choose, to act, to use key human powers.' In this regard they are lives of 'waste. ${ }^{583}$ For these central capabilities become most urgent, and thresholds must not be too aspirational. The mere 'living human being' without the necessary capacity does not, therefore, possess a life worthy of human dignity in Nussbaum's account. Justification for this is offered by the fact that central capabilities are combined capabilities, and therefore, require some level of internal capability together with suitable external conditions.

Furthermore, the need for minimal agency is explained by the way in which people value capabilities. Priority capabilities are those which 'people have reason to value.' This description of valuable 'beings' and 'doings' and capabilities has been used to give support to the ideal of freedom

\footnotetext{
${ }^{578}$ M.C. Nussbaum Creating Capabilities The Human Development Approach (2011; Harvard University Press) 31

${ }^{579}$ M.C. Nussbaum, 'Capabilities, Entitlements, Rights: Supplementation and Critique,' 'Journal of Human Development and Capabilities: A Multi-Disciplinary Journal for People-Centered Development,' 2011; 12:1, 23, 25

${ }_{580}$ M.C. Nussbaum, 'Capabilities, Entitlements, Rights: Supplementation and Critique,' 'Journal of Human Development and Capabilities: A Multi-Disciplinary Journal for People-Centered Development,' 2011; 12:1, 23, 25

${ }^{581}$ M.C. Nussbaum, 'Capabilities, Entitlements, Rights: Supplementation and Critique,' 'Journal of Human Development and Capabilities: A Multi-Disciplinary Journal for People-Centered Development,' 2011; 12:1, 23, 25. My emphasis.

${ }^{582}$ M.C. Nussbaum, Creating Capabilities The Human Development Approach (2011; Harvard University Press) 30

${ }^{583}$ M.C. Nussbaum, 'Capabilities, Entitlements, Rights: Supplementation and Critique,' 'Journal of Human Development and Capabilities: A Multi-Disciplinary Journal for People-Centred Development' 16 February 2011; 12:1, 23, 27-28
} 
to choose, to personal agency, but it also raises the question of 'being able to reason.' The latter is invoked when the freedom to choose is disputed; the central issues being what constitutes good and bad reason for valuing capabilities, and the capacity for arriving at well-reasoned decisions. ${ }^{584}$ Nussbaum occupies one extreme on the spectrum of opinion regarding the issue of capacity for making well-reasoned decisions concerning prioritising and valuing; the person must have 'capabilities for valuing, including capabilities for reasoning. ${ }^{585}$

Other positions along the spectrum include evaluation or prioritisation taking place based upon a person's 'freedoms to do and be what they value, ${ }^{586}$ making no mention of capability to reason; and on allowing people 'to lead the kind of lives they want to lead, to do what they want to do and be the person they want to be. ${ }^{587}$ These positions allow the suggestion that valuing a capability can be no more than a result of desire and simple preference, with decisions made accordingly, thus questioning the need for agency and active functioning or striving as entitlement to the central capabilities.

\subsection{Capabilities and human rights}

The Capabilities Approach and human rights have some fundamental principles in common. Whilst not fully representative of the other, the ways in which they support each other are sufficiently significant for the Capabilities Approach to be increasingly used as a lens through which to view and implement human rights. This section of the chapter will present those relevant to the task of assessing human rights protection of older people.

\footnotetext{
${ }^{584}$ D. Gasper, 'Working Papers: What is the Capability Approach? Its Core, Rationale, Partners and Dangers,' June 2006; Working Paper Series No. 428, 12. My emphasis.

${ }^{585}$ D. Gasper, 'Working Papers: What is the Capability Approach? Its Core, Rationale, Partners and Dangers,' June 2006; Working Paper Series No. 428, 12

${ }^{586}$ Alkire, S., 'Why the Capability Approach?' 'Journal of Human Development' Vol. 6, No 1, March 2005, 115, 125. Emphasis added.

${ }^{587}$ I. Robeyns, 'The Capability Approach: A Theoretical Survey,' 'Journal of Human Development,' March 2005; Vol. 6, No. 1, 95. Emphasis added.
} 


\subsubsection{Entitlement}

The Capabilities Approach views capabilities as entitlements ${ }^{588}$ and as informing human rights provision. Furthermore, capabilities help secure human rights. ${ }^{589}$ Therefore, the entitlement to capabilities extends to human rights. The reciprocal relationship also sees human rights as rights to capabilities. $^{590}$

Prima facie, capabilities and human rights are grounded in entitlement by virtue of being human. However, the argument that a degree of ability and striving is required to benefit from capabilities, has created some disparity which is of significance to vulnerable older people. The 'minimal level of agency or capacity for activity' qualifies entitlement in the 'bare fact of being a living human being.' The fact that the person in pvs, suffering severe dementia, or insentience has no entitlement to capabilities implies that the 'ends of human rights' are not capabilities in all cases. If the Capabilities Approach is to succeed in making human rights providers of capabilities, it is essential that the rights-holder also holds capabilities, and the benefit of the approach universally available.

\subsubsection{Content of human rights}

The subjects of functionings, capabilities, and human rights share common ground. Of importance to older people, given their range of vulnerabilities and threats to dignity, ${ }^{591}$ is that the Capabilities Approach includes socio-economic and civil and political rights. ${ }^{592}$ Since the Capabilities Approach aims to provide a means for the achievement of 'the full range of a person's goals ... not limited to civil and political freedoms,' the capabilities will be to functionings which fall into both generations of rights. The vital capabilities exemplify this. ${ }^{593}$ The similarity between the vital capabilities and fundamental human rights makes them appropriate outcomes of human rights, and thus influential over content and application. ${ }^{594}$ Whether or not formalised in a list, given that each functioning and capability to be achieved through human rights is to be treated equally, association with generation of right is immaterial. As equal partners in the needs and vulnerabilities of the person, fulfilment of capabilities on the basis of alignment to type of right is unjustifiable. This approach therefore becomes more relevant to vulnerable groups such as older people, for whom socio-economic rights

\footnotetext{
${ }^{588}$ M.C. Nussbaum, 'Capabilities, Entitlements, Rights: Supplementation and Critique,' Journal of Human Development and Capabilities, 12(1), February 2011, 23,23

${ }^{589}$ Martha C. Nussbaum, 'Capabilities and Human Rights,' Fordham Law Review 66(2), $273,292$.

${ }^{590}$ A. Sen, 'Human Rights and Capabilities,' Journal of Human Development, Vol. 6, No. 2, July 2005 151, 152

${ }^{591}$ See chapters 8, 9 \& 10

${ }^{592}$ Polly Vizard, Sakiko Fukuda-Parr \& Diane Elson, 'Introduction: The Capability Approach and Human Rights,' Journal of Human Development and Capabilities, Vol. 12, No. 1, February 2011, 1, 2

${ }^{593}$ Capabilities which Sen terms 'Basic Capabilities,' and Nussbaum terms 'Central Capabilities.'

${ }^{594}$ A. Sen, 'Human Rights and Capabilities,' Journal of Human Development, Vol. 6, No. 2, July 2005 151-166 ,152
} 
are of most value ${ }^{595}$ as it works to fill 'needs gaps. ${ }^{596}$ Thus, the Capabilities Approach takes fuller account of 'beings and doings' which are of value to this group, thereby reducing the potential to dictate the functionings and human rights available to the individual and presenting equality in these substantive freedoms. The contents of human rights are also influenced by Sen's 'opportunity' and 'process' aspects of freedom. If the opportunity for freedom and for human rights is viewed from a capabilities perspective the focus rests on the ability of a person or group to achieve valued functionings, highlighting needs and vulnerabilities. ${ }^{597}$ Thus, the content of human rights would correspond to need, and be better equipped to provide for vulnerable groups who fall beyond the scope of the universal. In addition, process would contribute to the content of rights by stating what must be achieved, or not refused, via process. ${ }^{598}$

\subsubsection{Lists of Capabilities for human rights}

This thesis accepts that a set of capabilities can guide the content, implementation and interpretation of human rights. However, Nussbaum's single list of universal capabilities is rejected for those who fall outside the scope of the universal. The dangers of accepting a 'frozen' list as a ceiling rather than a floor threaten the principle of rights adapting to need, ${ }^{599}$ and the ability to respect, protect and fulfil the interests, needs, and vulnerabilities of the most vulnerable. ${ }^{600}$ Fundamental human rights are more easily incorporated into a central list. ${ }^{601}$ However, if capabilities are to assist human rights provision for special protection groups and suffering which is beyond 'common experiences of ordinary suffering' capabilities should represent the opportunities to achieve valued functionings, and overcome the obstacles faced specific to each vulnerable group. This must take the form of a bespoke set of capabilities for each group based on need, type of vulnerability, and type and degree of harm suffered. When capabilities are set in the context of lived outcomes of vulnerability it increases the possibility of selecting capabilities which can be prioritised

\footnotetext{
${ }^{595}$ But often rationed on the basis of prohibitive cost.

${ }^{596}$ Specifically those created by prioritising civil and political rights.

${ }^{597}$ Amartya Sen, 'Human Rights and Capabilities,' Journal of Human Development, Vol. 6, No. 2, July 2005, 151, 153-154

${ }^{598}$ Sen offers examples for clarification, including permitting 'due process' and not refusing opportunities to rights, such as healthcare.

${ }^{599}$ This aim of the ECHR to evolve in response to changes in society, priorities and need is applicable to all human rights and all instruments in which they are enshrined. The principle is applicable to all human rights instruments, including those for vulnerable groups.

${ }^{600}$ See chapter 5, 'Vulnerability,' 'Vulnerable groups and human rights'.

${ }^{601}$ Amartya Sen, 'Human Rights and Capabilities,' Journal of Human Development, Vol. 6, No. 2, July 2005, 151, 159
} 
in situations of conflicting interests, thereby further assisting the vulnerable to escape situations and achieve valued functionings. ${ }^{602}$

A list of vital capabilities is of use, however, depending on its practical purpose, this needs to form the basis of a bespoke list aimed at particular vulnerabilities and harm. Furthermore, it must be constructed with the specific means of assessment in mind. ${ }^{603}$ Aware that the measurement of the success of capabilities and human rights using a Capabilities Approach is outcome rather than resource distribution or expressed satisfaction, the outcome of special protection human rights for older people is measured with direct reference to the pillars of human dignity, the vulnerability framework, and the lived situations of older people.

\subsubsection{Securing human rights using a Capabilities Approach}

A capabilities-based methodology supports the positive obligation to secure human rights. The inclusion of both generations of rights in capabilities means that both the negative and positive state duties they attract are engaged. Aspects of the approach are identifiable in international human rights law, and are instructive to its implementation. A 'broad class' of human rights, including civil and political and socio-economic, is increasingly available, particularly in special protection human rights instruments. ${ }^{604}$ Obligations are developed further in international law, and often include those of 'result ... conduct and the de facto ... human rights position of individuals and groups. ${ }^{605}$ These obligations reflect the key principles of 'consequence-sensitive' capabilities, ${ }^{606}$ equality in human dignity and '[E]nhancing the lives we lead and the freedoms we enjoy. ${ }^{607}$ They instruct states to provide human rights relevant to the situation of the person or group. This requires not merely appropriate content, but recognition of full range of duties ${ }^{608}$ and resource distribution and

\footnotetext{
${ }^{602}$ Amartya Sen, 'Human Rights and Capabilities,' Journal of Human Development, Vol. 6, No. 2, July 2005, 151, 156

${ }^{603}$ Amartya Sen, 'Human Rights and Capabilities,' Journal of Human Development, Vol. 6, No. 2, July 2005, 151, 159

${ }^{604}$ Polly Vizard, Sakiko Fukuda-Parr \& Diane Elson, 'Introduction: The Capability Approach and Human Rights,' Journal of Human Development and Capabilities, Vol. 12, No. 1, February 2011, 1, 6

${ }^{605}$ Polly Vizard, Sakiko Fukuda-Parr \& Diane Elson, 'Introduction: The Capability Approach and Human Rights,' Journal of Human Development and Capabilities, Vol. 12, No. 1, February 2011, 1, 7

${ }^{606}$ Polly Vizard, Sakiko Fukuda-Parr \& Diane Elson, 'Introduction: The Capability Approach and Human Rights,' Journal of Human Development and Capabilities, Vol. 12, No. 1, February 2011, 1, 3-4.

${ }^{607}$ A. Sen, Development as Freedom (1999; Oxford University Press) 14

${ }^{608}$ Including positive and negative. An example is the view taken by the UN Human Rights Committee on the Right to Life as including 'the obligation to take appropriate steps to safeguard the lives of those within their jurisdiction' in addition to the negative obligation to not intentionally take life. Polly Vizard, Sakiko FukudaParr \& Diane Elson, 'Introduction: The Capability Approach and Human Rights,' Journal of Human Development and Capabilities, Vol. 12, No. 1, February 2011, 1, 7
} 
institutional provision according to need ${ }^{609}$ 'to the maximum of available resources. ${ }^{610}$ Measuring the de facto position is informative as to the adequacy of human rights provision in concrete situations, and instructive as to how they should be adapted, interpreted and implemented in order to make them relevant. Also stressed is the importance of including socio-economic rights in achieving capabilities through human rights, complying with the normative framework of the UN Committee on Economic, Social and Cultural Rights. It is also exemplary of the weight given to the outcome of human rights. ${ }^{611}$

Having considered the association between the Capabilities Approach and human rights in broad terms, the chapter now turns to more precise links with human rights and vulnerable groups.

\subsubsection{Capabilities Approach and human rights for vulnerable groups}

The Capabilities Approach finds cohesion with Fineman's vulnerable subject, as there is no presumption of independence, uniform needs, abilities, and given standards of rationality. This aspect of the approach provides a suitable basis for examining situations of vulnerability, assessing and providing for need. ${ }^{612}$ Once assessed, the needs, and the person to whom they relate, should take centre stage of a set of capabilities, including vital capabilities, and those representative of 'particular' ${ }^{613}$ interests, the bespoke human rights they inform, and their implementation.

By asking the question 'what is a person actually able to do and be?' the Capabilities Approach states a position central to human rights support of the vulnerable. The answer is informative as to needs of the person, and the resources required. Implicit in the question is recognition of the fact that the vulnerable person is unable to achieve the same functionings as the independent, capable person with the same resources, where resources can mean institutional assets or human rights content and implementation.

\footnotetext{
609 Including 'social, economic and governance policies and organizations that ensure enjoyment of rights.' Polly Vizard, Sakiko Fukuda-Parr \& Diane Elson, 'Introduction: The Capability Approach and Human Rights,' Journal of Human Development and Capabilities, Vol. 12, No. 1, February 2011, 1, 7.

${ }^{610}$ ICESCR, Article 2.1. See Polly Vizard, Sakiko Fukuda-Parr \& Diane Elson, 'Introduction: The Capability Approach and Human Rights,' Journal of Human Development and Capabilities, Vol. 12, No. 1, February 2011, $1,7$.

${ }^{611}$ Polly Vizard, Sakiko Fukuda-Parr \& Diane Elson, 'Introduction: The Capability Approach and Human Rights,' Journal of Human Development and Capabilities, Vol. 12, No. 1, February 2011, 1, 8.

${ }^{612}$ Caroline Harnacke, 'Disability and Capability: Exploring the Usefulness of Martha Nussbaum's Capabilities Approach for the UN Disability Rights Convention,' Journal of Law, Medicine and Ethics, Winter 2013, 768, 772 ${ }^{613}$ 'Particular' as defined by the ECtHR in providing guidance for defining a vulnerable group. See 5.4.3. 'Vulnerable Groups.'
} 
The stance on varying abilities to convert resources into functionings due to unique combinations of basic, internal, and external capabilities is fundamental to human rights provision for vulnerable individuals and groups. This is particularly the case for those unable to achieve thresholds of, at least, vital capabilities. Viewing the person with greater need for resources to achieve a capability as having equal and 'legitimate claim to the development of...capability' as the person with lesser need, the Capabilities Approach helps mould human rights, and the duty of the State, to respond. ${ }^{614}$ When innate and internal capabilities are compromised, the role of external, or combined capabilities is to compensate for ability to attain valued functionings and thresholds of capabilities. As capabilities secure rights, a combined Capabilities Approach, which provides the capabilities to function as equals, secures equal rights. ${ }^{615}$

The process aspect of the freedom of capabilities, which facilitates the opportunity to choose and achieve, begins with the content of human rights. Special protection rights should include a comprehensive coverage of the vulnerabilities particular to the group, structured to negate harm. Human rights must be specific to the threats faced by members of the group, and the associated outcomes. The treatment stipulated by rights should respect human worth and prevent the harm which the vulnerabilities can cause. To construct a set of special protection rights which fully respond to defined group vulnerabilities requires a set of capabilities needed by the group. This set would include vital capabilities, which could be adapted according to specialist essential life needs. From this capabilities list designed for 'specific purpose' individual group members could have a number of 'capability sets' available to choose from. For this to be meaningful to the vulnerable person or group a mechanism is required to implement and give legal force to capabilities. The mechanism is a set of human rights, combined with positive State duty to provide capabilities. Significantly, the rights must recognise the detail of the needs, vulnerabilities and risks to human dignity and provide the means to respect, protect, and fulfil rights via access to institutional assets. The complete range of resources must be made available through rights which detail treatment. Combined with a positive State duty to provide on the basis of need rather than wider social benefit ${ }^{616}$ or equal distribution of resources, the vulnerable subject has the right to the capability to secure the right.

\footnotetext{
${ }^{614}$ Caroline Harnacke, 'Disability and Capability: Exploring the Usefulness of Martha Nussbaum's Capabilities Approach for the UN Disability Rights Convention,' Journal of Law, Medicine and Ethics, Winter 2013, 768, 772 ${ }^{615}$ Martha C. Nussbaum, 'Capabilities and Human Rights,' Fordham Law Review 66(2), 273, 294

${ }^{616}$ Which sees resources diverted to those most able to be productive and contribute to society.
} 
Nussbaum's qualification for capabilities does not secure equality of entitlement to every vulnerable person. The person made vulnerable by severe cognitive or physical impairment ${ }^{617}$ is excluded from the assistance of the Capabilities Approach, and explicit mention of the person suffering severe dementia in this category is of particular concern to vulnerable older people. Therefore, if the full benefit of the Capabilities Approach is to be felt by the vulnerable in a human rights context, such grounds for disqualification should be disregarded.

A Capabilities Approach to the construction of a human rights instrument for a vulnerable group would incorporate all necessary civil and political and socio-economic rights, and view them as interrelated. ${ }^{618}$ The framework would respond to what members of the group are able to be and do as a result of combined capabilities, and how those capabilities would need to compensate for inadequate outcomes. ${ }^{619}$ Furthermore, drawing on the view that 'human rights are capabilities that need to be provided by the State, ${ }^{620}$ the human rights contained would include all capabilities necessary to provide bespoke rights in accordance with the particular vulnerability and the harm generated, where the universal does not adequately do so. Little is said explicitly by the Capabilities Approach regarding dependency. However, as an inevitable aspect of vulnerability mention is made of the fact that the approach does view it 'among the primary needs.' Therefore, dependency needs to be incorporated in the construction of capabilities and human rights, as in doing so the capability to further capabilities is achieved. ${ }^{621}$ Consideration must also be given to any dependent care givers at this stage. Crucially, the capabilities that special protection human rights provide must reach the same threshold as capabilities achieved by persons not requiring the same protection with the measurement being outcome. ${ }^{622}$ This permits the Capabilities Approach to provide normative guidance for special protection rights. ${ }^{623}$

\footnotetext{
${ }^{617}$ Nussbaum makes specific mention of the person in a persistently vegetative state, suffering severe dementia, and the insentient in this regard.

${ }^{618}$ The UNCRPD is quoted as exemplary of this aspect of the Capabilities Approach. Caroline Harnacke, 'Disability and Capability: Exploring the Usefulness of Martha Nussbaum's Capabilities Approach for the UN Disability Rights Convention,' Journal of Law, Medicine and Ethics, Winter 2013, 768, 774

${ }^{619}$ Caroline Harnacke, 'Disability and Capability: Exploring the Usefulness of Martha Nussbaum's Capabilities Approach for the UN Disability Rights Convention,' Journal of Law, Medicine and Ethics, Winter 2013, 768, 774 ${ }^{620}$ Nussbaum's description of capabilities in a human rights context. Caroline Harnacke, 'Disability and Capability: Exploring the Usefulness of Martha Nussbaum's Capabilities Approach for the UN Disability Rights Convention,' Journal of Law, Medicine and Ethics, Winter 2013, 768, 773

${ }^{621}$ Included in care are: 'capabilities of life, health, and bodily integrity...stimulation for senses, imagination, and thought....emotional attachments...capacity for practical reason and choice....affiliation.... self-respect.' Martha C. Nussbaum, Frontiers of Justice: Disability, Nationality, Species Membership, (Harvard University Press, 2006) 168-169

${ }^{622}$ Caroline Harnacke, 'Disability and Capability: Exploring the Usefulness of Martha Nussbaum's Capabilities Approach for the UN Disability Rights Convention,' Journal of Law, Medicine and Ethics, Winter 2013, 768, 775 ${ }^{623}$ Caroline Harnacke, 'Disability and Capability: Exploring the Usefulness of Martha Nussbaum's Capabilities Approach for the UN Disability Rights Convention,' Journal of Law, Medicine and Ethics, Winter 2013, 768, 775
} 
The cognitively disabled present a 'particular' vulnerability which in some ways is well served by the Capabilities Approach. This vulnerable group also demonstrates how the approach needs to adapt in order to provide equality of human dignity. It cannot be overlooked that the Capabilities Approach requires the ability to act, and views individuals as 'striving agents,' thereby promoting autonomy. However, this need not exclude the cognitively impaired. How children are accommodated by the Capabilities Approach provides guidance. Providing all necessary means and processes to make the act possible ${ }^{624}$ is translated into permitting the freedom to take decisions in accordance with 'actual - or potential - capacity for rational and reasoned forms of choice, or judgment. ${ }^{, 625}$ This supports Articles 5 and 12 of the UNCRC ${ }^{626}$ and highlights how a Capabilities Approach can be used to extend the principle which permits decision-making within protected confines ${ }^{627}$ to anyone with impaired decision-making capacity, including older people who might have lost capacity. If 'cognitive maturity' will determine the weight given to the decision, other specialist capabilities and processes, including appointed decision-makers and best interests policies, can compensate for immature cognitive ability. ${ }^{628}$ The case of children makes mention of 'potential,' pointing to development and flourishing. It would be wrong to discount potential for the cognitively impaired, even the person impaired by continual degeneration such as dementia. The Capabilities Approach recognises the functioning of individuals equally, therefore, regardless of innate or internal capabilities, everyone 'equally deserves the capacity to achieve...potentials. ${ }^{629}$ The cognitively impaired require a list of capabilities not merely based on existence, but must include capabilities which give the opportunity to develop potential and flourish. Without this, the 'equality' pillar of human dignity is not served. As '...[e]very individual equally deserves to be able to meet their potential levels of functioning' capabilities must be included that will provide the opportunities and capabilities to meet those levels. ${ }^{630}$ The matter of what the cognitively disabled are owed links to thinking on entitlement. If the minimal agency or rationality criteria are used as qualification, the situation will arise whereby

\footnotetext{
${ }^{624}$ Serene Khader, 'Cognitive Disability, Capabilities, and Justice,' Essays in Philosophy: Vol.9: Iss.1, Article 11 (2008) 1, 3

${ }^{625}$ Rosalind Dixon \& Martha C. Nussbaum, 'Children's Rights and a Capabilities Approach: The Question of Special Priority,' Cornell Law Review, May 2012 Vol. 97, 549, 559-560

${ }^{626}$ Which combined deal with the State duty to act 'in a manner consistent with the evolving capacities of the child' by permitting the 'child who is capable of forming his or her own views...the right to express those views freely in all matters affecting the child.' The child's 'age and maturity' will determine the weight given to the decision.

${ }^{627}$ So as not to permit harm to the decision-maker.

${ }^{628}$ Where 'immature' can refer to declining ability in addition to undeveloped ability.

${ }^{629}$ Serene Khader, 'Cognitive Disability, Capabilities, and Justice,' Essays in Philosophy: Vol.9: Iss.1, Article 11 (2008) 1,5

${ }^{630}$ Serene Khader, 'Cognitive Disability, Capabilities, and Justice,' Essays in Philosophy: Vol.9: Iss.1, Article 11 (2008) 1,7
} 
'all human beings are owed $x$ by virtue of their humanity, but insofar as the cognitively disabled do not fit into our picture of humanity, they are owed something else. ${ }^{631}$ It is possible to provide for the 'something else' owed by creating a capabilities list to inform, and be achieved via human rights, which does not require given levels of rational functioning. However, using the Capabilities Approach to focus on positively achieving functioning will lead to the disabled person achieving functioning and flourishing, not necessarily to the same level, or in the same ways, as the nondisabled person, but equally. ${ }^{632}$ It is necessary to take the objective value, especially of capabilities to fundamental issues of existence and conditions of living, in instances of the severely cognitively impaired lacking decision-making capacity over individual preference. ${ }^{633}$ This is particularly the case when not to 'stand away from individual feelings ${ }^{\prime 634}$ would cause harm to the vulnerable subject.

\subsection{Conclusion}

The Capabilities Approach set out in this chapter will be used in the analysis of human rights provision vis à vis protection of older people against particular vulnerabilities and fulfilment of need in Part IV. The approach also serves as a lens through which to view the lived problems of this group, and highlight areas where capability is impaired or requires support in order to identify need areas, and achieve equality in dignity and valued functionings through human rights.

Therefore, going forward there are important issues to be taken from the approach and conclusions drawn. As the approach is concerned with what the person is able to be and do, the starting point must be an understanding of each person's basic, internal and combined capabilities and the capabilities sets available. With knowledge of the needs and vulnerabilities faced, an assessment of the capabilities required is possible. However, the opportunity aspect of capabilities is necessary to the success of achieving valued functionings, equality in human dignity, and protection against vulnerability. Specifically, the person must have the opportunity to choose. The analysis of human rights provision for older people must, therefore, consider the reality of a person's capabilities, the viable capabilities sets available, and whether the opportunity exists to convert valued functionings into the ability to be and do.

\footnotetext{
${ }^{631}$ Serene Khader, 'Cognitive Disability, Capabilities, and Justice,' Essays in Philosophy: Vol.9: Iss.1, Article 11 (2008) 1, 5

${ }^{632}$ Serene Khader, 'Cognitive Disability, Capabilities, and Justice,' Essays in Philosophy: Vol.9: Iss.1, Article 11 (2008) 1,7

${ }^{633}$ Serene Khader, 'Cognitive Disability, Capabilities, and Justice,' Essays in Philosophy: Vol.9: Iss.1, Article 11 (2008) 1, 2

${ }^{634}$ Serene Khader, 'Cognitive Disability, Capabilities, and Justice,' Essays in Philosophy: Vol.9: Iss.1, Article 11 (2008) 1,2
} 
Identification of vulnerable capabilities will influence content of rights. The Capabilities Approach does not recognise divides in typology of rights when providing for need. Therefore, any special protection rights would comprise the combination of civil and political and socio-economic rights which respond to particular vulnerabilities. Content will also be influenced by vital capabilities which are closely aligned to fundamental needs. Additionally, using Sen's rationale, a listing of capabilities beyond the universal with its specific 'purpose' will inform rights.

To achieve equality in dignity the Capability Approach needs to be guided by thresholds. It is acceptable for different thresholds to exist for different capabilities and the rights through which they are achieved. Vital capabilities require a 'bare minimum' threshold Capabilities which achieve flourishing and valued functionings must not fall below that at which a life will be considered a good human life. A threshold of equality is required when that is the minimum to achieve human dignity. Equality thresholds are most suitable to civil and political rights, the ample minimum to socioeconomic rights. Remembering that the focus of the approach is what a person is able to be and do, the measure of the success of reaching relevant thresholds, and the measure of equality needs to be outcome.

The conclusion of the Capabilities Approach on entitlement is also of central importance to the relationship with human rights. The approach states all capabilities as entitlements. The mutually beneficial relationship between the approach and human rights makes human rights entitlements via capabilities. However, human rights are held by virtue of being human, and by securing capabilities they secure the entitlement of the rights-holder to capabilities. Therefore, the analysis of human rights provision for older people will examine the reality of entitlement to capabilities for this group.

The Capabilities Approach places the duty to secure human rights, and through them, capabilities to the required threshold on the State. Since the approach places equal weight on all types of rights, any instruments created to protect vulnerable groups will see the State bear negative and positive duties in accordance with need. When considering how human rights should be incorporated into a special protection instrument for older people the approach will turn to international law for examples of how to secure capabilities through rights. Included will be obligations measured by consequence, equality in human dignity, with a content directly responding to need and vulnerability, an instruction to distribute resources according to need, and the imposition of the full range of duties to respect, protect, and fulfil on the State. 
This thesis turns now to a synthesis of the concepts of human dignity, vulnerability, and the Capabilities Approach to conclude Section II. 


\section{CHAPTER 7}

\section{SYNTHESIS}

\subsection{Introduction}

The final chapter of Part II highlights the relationship between the concepts of human dignity, vulnerability, the Capabilities Approach, and human rights. In doing this the aim is to emphasise that human rights are the response to vulnerabilities, and the objective of the response is to minimise the harm and outcomes, and protect human dignity. In drawing together main reciprocal influences of these concepts, and the influence over human rights, and special protection rights, this chapter will begin to provide answers to some of the primary research questions. Additionally, the central issue of the case for special protection of human rights for older people will begin to be addressed. All questions will be responded to further in later chapters.

This synthesis initially considers the related principles of dignity and vulnerability. The issues of ontological nature, universality, inherent worth, inevitability, and the human capacity to suffer, will be central to the discussion. The co-existence of the concepts which constantly exposes the person and dignity to threat will be visible throughout the connections drawn. This thread will be accompanied by another which sees human rights responding to vulnerability in order to protect dignity. These factors draw attention to the manner and extent of the impact of vulnerability on human dignity. In addition, significant influences over the nature, content, interpretation and requirements of human rights and special protection rights can be presented as interrelated. The centrality of the relationship to identification of how human dignity becomes vulnerable, and to the protection provided by universal and special protection rights will be demonstrated as the links between the two are explored.

How special protection rights are created is a focus of the correlation between human dignity and vulnerability. Another focus is the way in which it makes it possible to define a group for the purposes of special protection. How special protection rights respond in the first instance to vulnerabilities and the harm suffered as the first step in identifying a special protection group will be demonstrated. This will be shown to be assisted by guidelines provided by the ECtHR, compromised capabilities stipulated by the Capabilities Approach, and specific threats caused to human dignity.

The Capabilities Approach is also discussed in terms of the impact on the relationship between dignity and vulnerability; identification of vulnerabilities of dignity and special protection groups; and influences the construct of human rights and special protection rights. The focus of the approach on what the person is able to be and do, and the method of identifying identifies how 
innate, internal, and combined capabilities need to be supported are emphasised. They are drawn on primarily to prove how the approach acknowledges threats to dignity and the ways in which the person or group is vulnerable. Furthermore, how the approach identifies the capabilities required to counter threats and vulnerabilities, the outcome for human rights to achieve, and the measure for equality in dignity are shown to instruct the content and application of both universal and special protection human rights.

Finally, the chapter constantly draws on characteristics of special protection and through linking the construction of international special protection instruments and a capabilities approach to measurement, begins to demonstrate how special protection is justified in internal law.

\subsection{Synthesis}

The relationship between human dignity and vulnerability is intricate. The fact that both are inherent to the human condition is fundamental common ground. Dignity is the person's 'inherent worth,' with the characteristics of personality and individuality embodied in dignity. ${ }^{635}$ Vulnerability is also ontological, inherent to being human, and inevitable. Both concepts are universal by virtue of their ontological nature; the values of human dignity; and the human capacity to suffer, which makes the person vulnerable. Vulnerability poses many threats to dignity, and is viewed, in contrast to dignity, as a weakness. When a person becomes vulnerable human dignity is injured. In return, human dignity that is threatened or damaged causes and exacerbates vulnerability. Using the holistic definition, dignity comprises the freedom to self-determine, autonomy, equality, human need and personality. The vulnerability framework has demonstrated that each is exposed to threat, and the outcome of the vulnerability suffered harms dignity. This aspect of the relationship questions the inviolability of human dignity. Given the fact that vulnerability can diminish dignity, and in extreme cases cause loss of dignity, it proves its greatest threat. The holistic definition of human dignity also rejects the principal role of rationality. Nor does it insist on agency, ability for active striving or sentience. Therefore, persons or groups lacking these qualities also possess inherent worth. This approach to entitlement allies human dignity to the 'vulnerable subject' who is not representative of the rational thinking, liberal, independent, and capable person, but is vulnerable nonetheless to threats to dignity. In this way dignity recognises its own weaknesses, vulnerabilities, and the ways in which dignity can be harmed or lost. It is for protection from the same that dignity turns to human rights.

${ }^{635}$ Doron Shultziner, 'Human Dignity - Functions and Meanings' (2003) 3(3) GJ 1,2 <http://www.bepress.com/gj/topics/vol3/iss3/art3> accessed 24 March 2016 
Dignity also informs who can turn to human rights. When dignity is based in existence prior to agency and freedom to self-determine ${ }^{636}$ the entitlement to human rights which are grounded in, and serve it, is by virtue of being human, and is similarly not grounded in capability or capacity. The holder of human dignity is the holder of human rights. Furthermore, it proves the role of dignity in human rights as 'the right to have rights. ${ }^{637}$ Human dignity is recognised as grounding human rights, however, the association with vulnerability has led to both being credited with underpinning the nature, content and application of human rights. Given that human dignity provides the 'supreme value' for rights, all aspects of its nature are absorbed by human rights. Therefore, rights are inviolable, and the substantive components inalienable. The effect of violations of human dignity are most frequently felt across a range of feelings and aspects of well-being. Therefore, if rights are to provide a complete and equal protection for dignity they must be indivisible. ${ }^{638}$

Human dignity provides the moral basis of rights. It supplies the moral content and universal values which make rights universal, with the pillars of dignity grounding fundamental rights. Violations of these values and treatment which humiliates or degrades provide the normative basis of rights. Therefore, the content of human rights must be established by neediness and vulnerability of humans. ${ }^{639}$ Embodied vulnerability informs rights to protect the fundamentals for existence, living conditions and well-being for individuals and groups, providing a universal ethical basis for rights ${ }^{640}$ which attract a universal ethical duty ${ }^{641}$ Therefore, it, too, provides moral content for rights. As rights respond to vulnerability, the detail of the various types and outcomes also inform the content. With vulnerability caused by, and causing, violations of dignity, it is the source of rights norms. Furthermore, in responding to the universal capacity to suffer, rights are grounded in this capacity.

The pillars of human dignity provide the guidance and broad subjects for rights, and vulnerability the specifics. The influence of human dignity over content and norms of human rights is based in

${ }^{636}$ Catherine Dupré 'Human dignity and the withdrawal of medical treatment: a missed opportunity?' (2006) 6 EHRLR 678, 690

${ }^{637}$ Hannah Arendt The Origins of Totalitarianism (Brace \& Co, 1951) 294-295 (as cited in John Helis 'Hannah Arendt and Human Dignity: Theoretical Foundations and Constitutional Protection of Human Rights' (2008) 1(3) JPL 73, 74 <www.ccsenet.org/journal.html> accessed 24 March 2016

${ }^{638}$ Georg Lohmann, "Die Menschenrechte: Unteilbar und gleichgewichtig?” in Menschenrechtszentrum der Universita" t Potsdam (ed.), Studien zu Grund- und Menschenrechten11 (Potsdam: Universita" tsverlag Potsdam, 2005), pp. 5-20. (as cited in Jürgen Habermas, 'The Concept of Human Dignity and The Realistic Utopia Of Human Rights' (2010) 41(4) Meta 464, 468-469).

${ }^{639}$ Corinna Mieth 'The Double Foundation of Human Rights in Human Nature' in Marion Albers, Thomas Hoffmann, Jon Reinhardt (eds), Human Rights and Human Nature (Springer 2014) 11-12

${ }^{640}$ Turner quotes Ignatieff; 'Relativism is the invariable alibi of tyranny. There is no reason to apologize for the moral individualism at the heart of human rights...t is precisely this that makes it attractive to dependent groups' Ignatieff 2001, 74-75 (as cited in B.S. Turner, Vulnerability and Human Rights (2010; Pennsylvania University State Press) p.7)

${ }^{641}$ A. Grear, Redirecting human Rights: Facing the Challenge of Corporate Legal Humanity, (2010; Palgrave Macmillan) 167. 
respect and treatment which degrades and humiliates. Vulnerability presents the outcomes of disrespected dignity, treatment, and the numerous threats to the person which rights must protect against. Content of rights must provide objective and subjective respect for all components of dignity, influencing both treatment and perception of the person or group. With the aim being 'respect,' rights must conform to either desist from acting, or take positive action. The measure of 'treatment that humiliates or demeans' which rights must prevent involves self-respect, and the norms taken from ' $[A]$ ny sort of behaviour or condition that constitutes a sound reason for a person to consider his or her self-respect injured. ${ }^{642}$ This is not to ignore the norms set by the outcomes of vulnerability. The full range of treatment, defined in embodied vulnerability as anything which impacts the physical, psychological, emplacement, and enselfment of the person ${ }^{643}$ affects selfrespect, and informs the treatment required by institutions and the state to be built into rights. The precariousness of self-respect amongst the vulnerable, including issues of adaptive preference, makes it necessary for human rights to meet objective standards of how a person 'ought' to respect herself. It also provides a basis for the need for special protection for vulnerable groups, as definitions of embodied vulnerability view the psychological self as vulnerable due to lack of respect for human dignity. Building respect for self-determination, autonomy and the capability to be and do valuable functionings into human rights is key to the protection of psychological human dignity, particularly for the vulnerable person. An inability to exercise any of these leads to psychological dependency and an undermining of self-respect.

Staying with embodied vulnerability, physical and psychological vulnerability illustrates what is required of rights in terms of existence, standards of living, and protection from abuse. It is also a primary indicator of inevitable dependency, which if not recognised by rights will cause further vulnerability and harm to dignity. The person is made vulnerable by virtue of emplacement by threats to where and with whom a person lives. Vulnerability of enselfment occurs when the moral and spiritual self is harmed. Human rights must protect dignity against each of the outcomes associated with these vulnerabilities. The clearest indication of how to achieve this is provided by reference to the resilience and assets available through the institutions which are built via rights. Financial and material assets must be provided to overcome vulnerability caused by lack of essential needs identified by dignity including sustenance and shelter. Human assets including healthcare must be included in rights to support personal capabilities. Human rights must also enable social interactions and relationships, and appropriate accommodation if vulnerabilities relating to emplacement are to be addressed. Also included in social assets are necessary welfare provisions.

${ }^{642}$ A. Margarlit, The decent society (HUP 1996) 9

${ }^{643}$ See chapter 5, 'Vulnerability,' heading 5.3.1.1, 'Embodied Vulnerability.' 
Existential vulnerability requires human rights to facilitate practice of beliefs, religion and moral values. As a group, older people experience extreme or particular vulnerabilities related to each of these. Therefore, the protection offered by human rights must be tailored to adequately respond to each.

Given the range of assets required to defend the inherently vulnerable person against that caused by threats to dignity, protection by civil and political and socio-economic rights is necessary. Protection grounded in respect would translate in a strict human rights context as a duty not to interfere, and therefore, would be better suited to civil and political rights. Such translation is more applicable to a narrow interpretation of dignity, used to argue its underpinning of civil and political rights. The explicit content of freedom and fundamental rights not only attract largely negative duties, but also appeal to the principles of freedom, autonomy and equality for their execution. Furthermore, to use a narrow definition of human dignity to underpin human rights would not serve the vulnerable subject, who should take centre stage in the construct and application of rights. A purely negative duty version of respect would see the liberal subject the focus of human rights.

Given the broader interpretation of human dignity provided by Dupré, a focus on negative duty and first generation rights alone would not protect the whole person, or the person's whole dignity, and would dismiss "half of the human rights equation. ${ }^{644}$ Essential factors of existence and personality would be exposed to threat, and left vulnerable. Of particular importance to older people is the exclusion of those 'for whom autonomy means little without the necessities of life. ${ }^{645}$ The inclusion of dignity in socio-economic rights and special protection instruments demonstrates the acceptance of its applicability to both generations of rights which respond to vulnerability. This, and the fact that respect for dignity is also manifested in treatment derived from positive duties confirms that dignity relates foremostly to existence. The International Bill of Rights acknowledges the scope of human dignity, and how it prompts interdependence between civil and political and socio-economic rights. The UDHR and ICCPR remind the rights holder of the need for freedom to enjoy socioeconomic rights if basic freedoms for dignity are to be achieved. Additionally, the ICESCR outlines the relevance of the relationship between the two types of rights to the overarching relationship between human rights and human dignity by stating the right to '...self-determination. By virtue of that right they freely determine their political status and freely pursue their economic, social and

\footnotetext{
${ }^{644}$ C Scott \& P Macklem, 'Constitutional Ropes of Sand or Justiciable Guarantees? Social Rights in a New South African Constitution' (1992) 141 Unv of Pennsy/vania LR 1,29 (as cited in Sandra Liebenberg, 'The Value of Human Dignity In Interpreting Socio-Economic Rights'21 S Afr. J. on Hum. Rts. $12005,1,2)$

${ }^{645}$ C Scott \& P Macklem, 'Constitutional Ropes of Sand or Justiciable Guarantees? Social Rights in a New South African Constitution' (1992) 141 Unv of Pennsy/vania LR 1,29 (as cited in Sandra Liebenberg, 'The Value of Human Dignity In Interpreting Socio-Economic Rights'21 S Afr. J. on Hum. Rts. 1 2005, 1, 2)
} 
cultural development. ${ }^{646}$ Furthermore, a capabilities approach to human rights implementation creates the opportunity to choose between capabilities and the rights which enable them, thereby allowing the person the freedom to self-determine. As the outcome of this choice is the measure of equality in dignity, second generation rights have an involvement in the entire concept of human dignity.

This is not to undermine the pivotal roles of freedom, autonomy, and dignity to both sets of rights. The freedom to self-determine makes it possible to exercise autonomy, which enables the individual to exercise the interest held in rights. ${ }^{647}$ Through this the person has the opportunity to choose to be and do what is of value, coercive decisions are prevented, and the affiliation with selfdetermination is complete when it enables this freedom. The cooperation between the two is complete when, through the application of this process to either generation of rights so that inherent worth is respected, the individual achieves equality in human dignity.

Civil and political and socio-economic rights are underpinned by, and respond to conceptual principles of vulnerability, and the vulnerabilities presented in the framework. Vulnerability harms all aspects of dignity, causing suffering. The capacity to suffer therefore calls for a solution from both generations of rights. Vulnerability also draws out links between the two types of rights. By viewing them from the perspective of vulnerability, civil and political rights are shown to provide the opportunity to highlight the need for, and improve access to, chosen socio-economic rights. Furthermore, many socio-economic rights are informed by, and give effect to, fundamental first generation rights. Some civil and political rights serve various vulnerabilities and protect dual aspects of dignity. The right to liberty, for example also serves the 'emplacement' vulnerability; the rights to manifest one's religion and freedom of expression respond to vulnerabilities of 'enselfment,' whilst also providing for self-determination and autonomy. Rights which explicitly provide for freedom and autonomy also combat vulnerabilities of existence and well-being. In this way they also protect 'embodied personalities' as they enable choice over, inter alia, assistance with dependencies, where and how to live, and associations to make. Anti-discrimination civil and political rights also prevent marginalisation and inequality on the basis of embodied vulnerability. Others, by creating the social environment for life and development contribute to the ontological resilience necessary to combat embodied vulnerability. The role of socio-economic rights from the

${ }^{646}$ Article 1, ICESCR

${ }^{647}$ See Chapter 1, 'Concepts and Introduction to Human Rights,' heading 1.5.2 'Interest Theory.' 
perspective of embodied vulnerability is simpler than that of civil and political, as individual rights are 'directly connected to the protection of human life. ${ }^{648}$

The best examples of the relationship between human dignity, vulnerability, and human rights are provided by special protection rights instruments. The groups in need of special protection are identified by the vulnerabilities and suffering particular to their members. The further guidance of the ECtHR is also helpful in the identification of groups, and, for the purposes of this thesis, specifically in answering the problem of whether older people require special protection. Once the 'particular' vulnerabilities of the group are identified as a result of distinct group-based experiences, the type and severity of harm it causes must also be particular, or have aggravated effect on that group. When the group is also marginalised or discriminated against, and is more vulnerable than most, these are also considered reasons by the ECtHR for special human rights protection. ${ }^{649}$

Vulnerability does not operate alone, however, in the identification of special protection groups. Human dignity drives both the identification of groups, and the creation of new human rights to protect them when the norms provided by humiliation and degradation find no response in existing rights. ${ }^{650}$ Furthermore, new instances of humiliation and degradation are frequently identifiable by natural condition, such as age. ${ }^{651}$ These threats to human dignity, and experiences of violation, also lie at the heart of the creation of special protection groups and rights.

The human rights instruments created to provide special protection to these groups will answer, initially to the vulnerabilities which define the group. These vulnerabilities will be identified in section two with direct reference to the vulnerabilities framework. They will also be considered in respect of the guidance implemented by the ECtHRts with regard to whether the vulnerabilities of older people qualify for special protection. The outcomes, harm suffered, and potential for aggravated vulnerability will inform the content. The response will incorporate the combination of civil and political and socio-economic rights necessary to provide the resilience against the specific vulnerabilities, and the assets required to overcome the outcomes. Human rights must build the institutions necessary to defend against all forms of vulnerabilities suffered, and also protect against their precariousness if protection itself is not to become vulnerable. In this way the rights protect human dignity against the specific threats and injury which are caused by, and cause, the

\footnotetext{
${ }^{648}$ B.S. Turner, Vulnerability and Human Rights (2010; Pennsylvania University State Press) 10

${ }^{649}$ See Lourdes Peroni \& Alexandra Timmer, 'Vulnerable Groups: The promise of an emerging concept in European Human Rights Convention law,' 1057-1065

${ }^{650}$ Jürgen Habermas, 'The Concept of Human Dignity and The Realistic Utopia Of Human Rights' (2010) 41(4) Meta 464, 468

${ }^{651}$ Which is regularly accompanied by problems of infirmity and living circumstance including deprivation, isolation, and dependence.
} 
vulnerabilities creating the need for special protection. Special protection instruments identify the vulnerabilities, in addition to the universal, which harm the members of a vulnerable group and those aspects of human dignity most at risk. In this way the rights can be interpreted and implemented to protect them. The identification of the vulnerabilities particular to the group is, therefore, informative as to the ways in which the dignity of its members is at risk. This principle will be used to identify the risks to the dignity of older people. The exercise is ongoing throughout the thesis, however, work undertaken by the UN Principles of Older Persons and The Inter-American Convention on Protecting the Human Rights of Older Persons point to how the dignity of this group is at risk. The headings under which the UNPOP gathers the principles to achieve the well-being of older people, identify broad areas of vulnerability. Dependence as a result of lack of assets for existence; social support; development; accommodation of one's choice appropriate to needs and declining capacity; and a general lack of material assets comprise the first set of vulnerabilities. Integration and participation in society comprises the next. The heading which identifies care necessary to combat dependency identifies the need for family and community involvement, healthcare to optimise well-being, autonomy, and rehabilitation. Significantly, mention is made of the need to respect all aspects of human dignity once in institutional care. Self-fulfilment and security, freedom from pathogenic vulnerability, and equality are also principles to guide the treatment of this group. From this the dignity of older people can be determined to be at risk from external threats to include: financial; perception; stereotyping; emplacement; lack of opportunity to develop and self-determine; and access to resources. Internal threats include physical and psychological decline, including loss of autonomy. Ultimately, individually and combined, each will also threaten equality and self-respect. From this base, how the dignity of older people is at risk will be further explored in sections two and three of this thesis.

Identifying a group as vulnerable provides the solution to the inability of rights to protect against those vulnerabilities that fall outside the universal. In this way the vulnerable person, with specific threats to dignity, who falls outside the protection of the universal is placed at the heart of human rights. This resonates with Fineman's 'vulnerable subject,' who is not representative of the liberal, rational thinking, independent, capable person who exists for a time between the most vulnerable stages of life. Dupré's claim that autonomy and being born in freedom do not necessarily equate to human dignity also has applicability to this subject. Examinations of human rights instruments have shown that the vulnerable subject shares its position in universal human rights with the liberal subject, which is another catalyst for special protection rights. Whilst every person is a member of a class of vulnerability, the 'particular' vulnerabilities and the harm they cause, associated with a minority class of vulnerability identify the most vulnerable subjects. It is only by placing this person 
at the heart of human rights which respond to those vulnerabilities that the failures of the universal rights, which are equally tailored to the liberal subject, are overcome. The rights, defined by vulnerability and the specific threats to dignity then provide a comprehensive defence to both.

When human dignity unites with the vulnerable subject in this way it also confirms that dignity is 'a matter for every person,' and every person is a rights holder regardless of natural condition or circumstance. ${ }^{652}$

The rationale of placing the vulnerable subject at the heart of rights has similarities with the aim of the Capabilities Approach of determining what a person is able to be and do. The vulnerable subject in the Capabilities Approach is disadvantaged by virtue of inadequacies in innate, internal and combined internal and external capabilities. These capabilities represent, and are represented by, all pillars of human dignity. The capabilities approach places this person at the heart of human rights considerations, and from the perspective of what the vulnerable subject is able to be and do, informs human rights of the capabilities to make available. This enables the person to choose between alternative lives to achieve valued outcomes.

Similarly to human dignity and vulnerability, capabilities underpin human rights. Additionally, the approach is a means to ensure rights respond to vulnerability and protect dignity. Significantly, due to functionings representing 'the full range of person's goals...not limited to civil and political freedoms,' the approach serves both civil and political and socio-economic rights. Thus it serves all vulnerabilities of the vulnerability framework, and correspondingly, all aspects of human dignity. The capabilities approach assists the content of human rights to protect the vulnerable person and dignity by attending to 'needs gaps' and by directing the outcome to be achieved. The subjects of capabilities influence the subject matter of rights. Those capabilities vital to well-being correlate to fundamental rights. Others related to functionings considered sufficiently important to well-being, supportive of human dignity, and responsive to vulnerability can instruct the subject of new rights. By considering both generations of rights equally, and in line with the principle of the approach that capabilities are provided in accordance with need, the gaps traditionally associated with socioeconomic need are filled. By using the capability to choose and to achieve valued functionings as the outcome of human rights, the approach achieves two objectives. Firstly, it ensures equality in dignity. Also, the capability achieved identifies vulnerabilities. To ensure human rights adequately respect dignity and protect against vulnerability, the capabilities approach informs how human rights must be applied. It states that the standard of equality is the minimum acceptable to achieve human dignity. Such minimum is dependent upon the pillar of human dignity in question and the

${ }^{652}$ Catherine Dupré, The Age of Dignity (Hart Publishing, 2015) 22 
capabilities possessed to counter the threats faced in the lived situation. To use any other metric other than outcome would not guarantee equality of dignity. The capabilities approach highlights the shortcomings of measuring equality in dignity achieved by human rights via resource distribution or expressed satisfaction. An equal distribution of resources is unable to respond to the needs of the most vulnerable, and expressed satisfaction is susceptible to inaccuracies caused by adaptive preference. These metrics cannot, therefore, accurately determine whether human rights have achieved equality in human dignity either through their content, the duty commanded, or the implementation of rights in a concrete situation.

The approach goes further in measuring human dignity, and in establishing whether equality in dignity is achieved by providing guidance as to thresholds to be achieved for capabilities. All capabilities vital to existence, and providing the measure for fundamental human rights must, in accordance with the approach, meet a 'bare minimum' standard, below which '...a life will be so impoverished that it will not be human at all.' The threshold for achieving valued functionings and flourishing is stated as that "beneath which those characteristic functions are available in such a reduced way that, ... we will not think it is a good human life. ${ }^{653}$ The threshold of equality is required for capabilities which would not fulfil need, respect human dignity, or protect against vulnerability through any lesser standard. This is of particular relevance to individuals or groups already vulnerable in such areas. In order to diminish or prevent discriminatory treatment, capabilities relating to civil and political rights tend to attract a threshold of equality. Since this threshold is inappropriate for resource-dependent socio-economic rights, the related capabilities require the 'ample minimum' threshold. ${ }^{654}$ However, it must be remembered that human dignity is inherently individual, regardless of group membership. For this reason, and to avoid stereotyping of vulnerable groups, the capability threshold needed to achieve equal human dignity must be set individually in response to the vulnerability faced in each situation. ${ }^{655}$

The capabilities approach can provide means of identifying vulnerable groups when those vulnerabilities are common to its members. The findings necessary to this are initially the vulnerabilities evidenced in innate, internal and combined capabilities. Also influential are gaps in provision of specific needs. Finally, any outcome of capabilities which falls below the given threshold and causes vulnerability is a means of identification. The group thus identified as falling

${ }^{653}$ M.C. Nussbaum, 'Human Capabilities, Female Human Beings' in M.C. Nussbaum \& Glover, J. (eds), Women, Culture and Development A Study of Human Capabilities (1995; Clarendon Press) 81

${ }^{654}$ M Nussbaum, 'The Capabilities of People with Cognitive Disabilities,' 'Metaphilosophy,' Vol. 40, Nos. 3-4, July 2009; 331, 336; M.C. Nussbaum, Creating Capabilities The Human Development Approach (2011; Harvard University Press, Cambridge) 41

${ }^{655}$ M Nussbaum, 'The Capabilities of People with Cognitive Disabilities,' 'Metaphilosophy,' Vol. 40, Nos. 3-4, July 2009; 331, 337-338 
outside the universal and not protected by the existing human rights construct requires its own special 'purpose' capabilities in addition to the listing of vital capabilities which support fundamental rights. ${ }^{656}$ Individuals within the group are able to select their chosen 'capability set' from those available through the bespoke capabilities listing. The special purpose capabilities listing generates special protection human rights, informing them as to content and outcome. On the issue of thresholds of capabilities to be achieved by special protection rights, the capabilities approach demands the same thresholds to be met for vulnerable individuals and groups as the person not in need of special protection. ${ }^{657}$. In this way it demands equal outcomes for human dignity.

The interrelation of human dignity, vulnerability and capabilities characterise special protection. Evidence of the incorporation and influence of each, independently and combined, is increasing in international law. Special protection human rights instruments cite the vulnerabilities which prompted their creation in preambles, and make reference to them in individual rights aimed at defending against them. In response to the vulnerabilities, they also instruct on the aspects of human dignity most at risk and most relevant to the needs of the group. This provides direction on focus, interpretation, and implementation of rights. Examples of instruments that give credence to special protection as a solution to the problem of vulnerable groups not served by the 'universal protection of human rights' include the UNCRC, CEDAW, and UNCRPD. Make connection here The UNCRC provides an example of how special protection is justified in international law and points to vulnerabilities derived from each category of the vulnerability framework, including: physical and mental immaturity, decision-making capacity, abuse, exploitation, dependency, and a reliance on assets such as healthcare. The pillars or interpretations of dignity it identifies as its focus include: freedom; equality; tolerance; the provision of 'poverty, food, health...and other needs;' self-reliance; and restoration of dignity following violation. Both the UNCRPD and CEDAW cite discrimination as a primary need for special protection. In response to this there are regular references to equality in preambles as an overarching aim, and in individual rights to direct their application. The UNCRPD is explicit about the attention to be paid to human dignity in the interpretation and implementation of rights. The preamble states the need for respect for inherent dignity, autonomy, freedom to make choices and independence. Throughout the rights there is reference to independence, equality of opportunity, evolving capacities, identity, involvement in decision-making, need for financial support and healthcare, respect for age specific needs, and the restoration of dignity to victims of violation. Each special protection instrument includes civil and political and socio-economic rights. In this way

\footnotetext{
${ }^{656}$ A. Sen, 'Human Rights and Capabilities,' Journal of Human Development Vol.6 No.2, July 2005, 152, 159; See also Chapter 6, 'The Capabilities Approach,' 'Listing Vital Capabilities.'

${ }^{657}$ Caroline Harnacke, 'Disability and Capability: Exploring the Usefulness of Martha Nussbaum's Capabilities Approach for the UN Disability Rights Convention,' Journal of Law, Medicine and Ethics, Winter 2013, 768, 775 
the full range of vulnerabilities suffered are recognised, allowing for the necessary assets to be provided. Also, the treatment required for complete protection of human dignity is enabled. With equal importance given to both sets of rights, the duty of the state, whether positive or negative, is engaged.

Using this approach to characterise special protection receives further justification in international law in the obligations placed on the state to deliver human rights and given outcomes. They increasingly include duties of 'result ... conduct and the de facto ... human rights position of individuals and groups. ${ }^{658}$ Under such obligations the state must effect given outcomes and treatments in order to provide rights relevant to need and situation. This requires resource distribution and provision of institutional assets according to need. Furthermore, by instructing the measurement of adequacy of human rights provision in concrete situations, this approach to special protection becomes instructive as to how rights should be adapted, interpreted and implemented in order to make them relevant to the most vulnerable needing protection of human dignity.

\subsection{Conclusion}

The relationship that exists between human dignity, vulnerability and the capabilities approach has been shown to be of central importance to the concept of human rights, and when this concept is required to broaden its scope to produce special protection human rights. All are demonstrated to influence the nature and content of human rights, and to provide norms for treatment. Each also contributes to determining the vulnerable subject, in this case a group, and how this subject might not be protected by the current construct of human rights. Ultimately, they combine to identify vulnerabilities specific to the group, and the ways in which human dignity is at risk. They determine what characterises special protection. From this, a need for special protection, and the form that takes can be established. It also allows for the justification of special protection in international law.

The relationship between human dignity, vulnerability and human rights is particularly interconnected and complex. With dignity and vulnerability both inherent to the human condition they give human rights their universal nature. However, they take opposing positions in doing so. Human dignity is the inherent worth or value of the person which vulnerability weakens. Whilst the value of the person is universal, so too, is the capability to suffer. In respecting inherent worth human rights must provide the resilience and assets to combat vulnerability. The definition of human dignity as comprising freedom, autonomy, equality, human need, and personality provides the definitive areas for embodied vulnerability and the further weaknesses associated with

${ }^{658}$ Polly Vizard, Sakiko Fukuda-Parr \& Diane Elson, 'Introduction: The Capability Approach and Human Rights,' Journal of Human Development and Capabilities, Vol. 12, No. 1, February 2011, 1, 7 
dependency to attack. It is also the basis of moral content and values of rights, the violations of which provide norms of inhuman and degrading treatment in which disrespect of dignity is grounded. By presenting the outcomes of this treatment, vulnerability also contributes to the norms and content of human rights. Each of the pillars of human dignity is demonstrated to be exposed to the harm of embodied, institutional, and pathogenic vulnerability. Therefore, it is significant that both concepts underpin civil and political and socio-economic rights. By recognising existence needs, human dignity is able to call on socio-economic rights for protection. Similarly, by viewing civil and political rights as more than indirectly associated to vulnerability, the harm caused by issues such as marginalisation, discrimination, emplacement, enselfment, self-determination, and autonomy can be fully identified and defended against.

The way in which human dignity and vulnerability influence human rights becomes of significance to special protection rights once the vulnerable subject or group is identified. The two concepts are instrumental in this task. Vulnerability goes beyond its relationship with human dignity to identify special protection groups, as the framework can be used to measure the degree to which any group meets the categories set out by the ECtHR in identifying vulnerable groups. Furthermore, the capabilities approach makes a strong contribution to the identification of these groups. When innate, internal or combined capabilities are sufficiently compromised so as to create vulnerabilities specific to a group, generating a type and degree of harm also particular to that group the potential to harm human dignity exists. By identifying the capabilities responsible, the approach also stipulates the outcomes to be achieved by human rights providing for those capabilities, thereby also informing and providing norms for special protection human rights.

The capabilities approach is instrumental in protecting human dignity via its metric of equality. By focusing on what a person is able to be and do not only are vulnerabilities in capabilities exposed, but definitive outcomes determined. By relating to what a person values being and doing these outcomes are also influenced by freedom and autonomy. Furthermore, they do not leave human dignity exposed or the inherent worth of the person undervalued in the way that equal distribution of resources or reliance on expressed satisfaction would.

The fundamentals of identifying a group for the purposes of special protection identified will be applied to older people in the next section. This will be combined with analysis of current human rights conclusion in section three to draw conclusion as to whether they comprise a vulnerable group in need of special protection. The relationship between human dignity, vulnerability and human rights will be further explored in section two with direct application to the situation of older people. Following this, the two concepts will be explored in regard to current human rights 
provision and application in case law. The capabilities approach will provide further assistance in measuring the efficacy of human rights provision, and through identifying outcome in the context of specific vulnerabilities and situations, will report on the protection provided to human dignity. The approach will also be instrumental in assessing how vulnerabilities related to capabilities and to the vulnerabilities framework are supported, and areas in which special protection is needed. 
PART III

RESEARCHING OLDER PEOPLE FOR HUMAN RIGHTS 
Introduction to Part III

The question of identification of older people as a special protection group is furthered in Part III of the thesis, which undertakes an examination of the methods of identifying and defining older people, and the threats and vulnerabilities faced by the group. The rationales of processes and principles offering explanations of the threats faced by older people are explored through theories of ageing. The theories are also examined to ascertain causes of vulnerabilities; circumstances experienced by older people; and criteria by which the group is defined, and often stereotyped. The inevitability of embodied vulnerability and dependency are represented by the inevitabilities of the ageing process. Therefore, the thesis includes a synopsis of the risks and outcomes of physical and cognitive ageing, which will be associated to age as part of the discussion to apply an appropriate age to the group. The task of identifying the range of vulnerabilities to which older people are subjected provides a means of identification for special protection purposes. Moreover the process highlights some of the issues involved in settling a single age to define the group, whilst also providing direction for the same. Chronological age is also briefly investigated as a measure of older age and a means of group identification, with the focus on the widespread standard of pensionable age and the alternative method of 'years left to live.' Biological ageing and the cessation of employment take on greater significance through the principle of the interrelated nature of vulnerability. Both are recognised as examples of vulnerability attracting further vulnerability. The need to balance a universal measure with the heterogenic nature of older people, the complexities and variety of vulnerabilities suffered, and cultural relativity combine to create a situation with clear similarities to the identification of children as a special protection group. Therefore, the discussions of States parties to the UNCRC on this topic provide guidance for the determination of an age at which special protection becomes available to the group. The study of the vulnerabilities of the group aims to identify similar themes, despite disparities in manifestation, experienced by older people generally, considering as many geographical regions as the confines of the thesis permits. This informs Part IV, comprising an examination of human rights provision, and evaluation of the case for and against special protection for older persons. 


\section{CHAPTER 8}

\section{THEORIES OF AGEING}

\section{$8.1 \quad$ Introduction}

Prior to reviewing theories of ageing, a synopsis of the concept of Successful Ageing is included in order to provide broad indicators for risk of vulnerable outcomes for older people. No single definition of successful ageing exists. However, most incorporate recognised themes such as physical and mental health, the ability to perform functions of daily living, and a capacity to adapt to change and adopt coping strategies. The three-component definition developed from the MacArthur Foundation Research Network on Successful Aging became the operative standard at the turn of the century. The factors identified for successful ageing were: 'low probability of disease and disease-related disability, high cognitive and physical functional capacity, and active engagement with life. $^{659}$ This hypothesis placed greatest importance on active engagement; most specifically that which is socially beneficial or involves social contact. ${ }^{660}$ The examination of the theories, and later investigation of the lived vulnerabilities of older people will frequently make reference to these themes of successful ageing.

Theories of ageing provide direction as to processes and situations that create threats and outcomes of vulnerability for older people. A requirement of special protection would be to prevent identified causes of specified threats and outcomes. Various theories will be discussed in this chapter in order to present the rationales for perceptions, lived situations and a broad range of vulnerabilities experienced by the group. The first theories reviewed have been in part disputed, but remain of value to the debate, either due to description of processes and outcomes, or contribution made to development of related theories. The discussion opens with Modernisation Theory. The theory claims that precariousness of the institution of the family, lone living, poverty, reduced social engagement, loss of self-respect, and downgraded status of older people are the result of a modernised society. The fact that abandonment is disputed as a consequence of modernisation is acknowledged. However, recognition by the U.N. in the M.I.P.A.A. ${ }^{661}$ of the described processes, and resulting vulnerabilities on older people of modernisation, makes it a viable guide as to cause, outcome, and identification of the group. Productivity of older people is a key feature of

\footnotetext{
${ }^{659}$ JW Rowe, RL Kahn 'Successful Aging,' The Gerontologist vol.17, No4 (1997) 433, .

660 'JW Rowe, RL Kahn 'Successful Aging,' The Gerontologist vol.17, No4 (1997) 433, 434. Based on research results of Herzog \& Morgan (1992).

${ }^{661}$ Madrid International Plan of Action on Ageing
} 
Modernisation Theory, which argues declining productivity to be a major factor in loss of status. This, coupled with changes to the nature of the productivity of older people is the subject of Productivity Theory, and the vulnerabilities perceptions surrounding productivity attract. Views of 'usefulness' and dependency as reasons for damaging stereotyping, discrimination, and the negative worth of older people will be explained by brief reference to the Marxist Theory of Productive and Unproductive Labour. Of significance is the subsequent potential for perceptions developed from this reasoning to class the group as having a negative effect on resources. Thus, the group would be at risk of vulnerability to discrimination, including discriminatory resource allocation, and loss of selfrespect.

The significance of social engagement to successful ageing is the theme of the next two sections of the chapter. The view that disengagement is necessary, and initiated by the older person, is countered by the argument supporting engagement and activity. Activity Theory overtly promotes social engagement, thereby identifying vulnerabilities associated with reduced or non-engagement. Significantly for exercises of identifying a vulnerable group, markers signalling the situations in which vulnerabilities can take effect are singled out by this theory, and will be further examined in addition to recognition to the vulnerabilities they generate.

The final theory included in this study of ageing theory represents a departure from traditional methods of identification of older people as a group and by vulnerabilities. Life Course Theory recognises the heterogeneity of older people. The theory begins by determining the period of history in which the person lived, in addition to personal history. This is largely determinative of an individual's accumulated disadvantage, which is the basis of later life vulnerability. The influence of the events of linked lives, or relationships, and human agency over personal life events, trajectories and transitions is explored as a concept. This principle, together with rejection of standardised patterns of life cycle combine to offer a rationale which opens further debate in the next chapter concerning the age at which special protection for the group should be applicable.

\subsection{Modernisation Theory}

Modernisation Theory is primarily a descriptive account of the processes and effects of industrialisation and social change. The theory ultimately concludes that older people are 
abandoned by society and the family, and their status downgraded. Since the conception of the theory, both claims have been widely contested. Nonetheless, Modernisation Theory remains an accepted historical description, and provides a point of reference for problems facing older people as a social group in developing countries transitioning to industrialism. The processes and outcomes stated in Modernisation Theory are recognised as causes of vulnerability in ageing populations in developing countries by the U.N. in the VIPAA ${ }^{662}$ and MIPAA. ${ }^{663}$ This section will explain Modernisation Theory and the rationale of how reducing numbers in the workforce; declining familial support; and downgrading of status can identify older people as a group, and combine to make the group vulnerable. Many of the outcomes feature in ageing theories discussed later in this chapter, demonstrating common themes in the vulnerabilities of older adults.

\subsubsection{Industrialisation, urbanisation, and isolation}

Modernisation Theory explains the modernised society as transformed ${ }^{664}$ economically, politically and socially. ${ }^{665}$ The practices of modernisation '...originated in the industrial revolution of England...and in the political revolution in France, ${ }^{666}$ with motivation claimed to be national and personal prosperity.

\subsubsection{Industrialisation and the effects on older people}

The theory states that economic transformation owes its success to the changes in production processes, technological and educational developments, each having negative effects on older people. The introduction of division of labour and automated working practices meant that a single family, or person within the family, was no longer the single source of specific products. Nor was the expertise of the older members of society required for the new industrial age. These themes have continued in economic and industrial transformation, which require rapidly updated skills compatible with a technological age and technology appropriate education, which older adults lack. Furthermore, employers are reticent to invest in training members of the workforce with limited

\footnotetext{
${ }^{662}$ The Vienna International Plan of Action on Ageing

663 The Madrid International Plan of Action on Ageing

664 Described by Cowgill as the 'transformation of a total society.' Donald O. Cowgill, 'The Aging of Populations and Societies,' AAPSS, 415 (Sep 1974) 1, 11

${ }^{665}$ Reinhard Bendix, 'Tradition and Modernity Reconsidered,' Comparative Studies in Society and History,' Vol.

9. No. 3 (April 1976) 292, 330 https://doi.org/10.17/S0010417500004540 accessed 10/04/2011

666 Reinhard Bendix, 'Tradition and Modernity Reconsidered,' Comparative Studies in Society and History,' Vol.

9. No. 3 (April 1976) 292, 329 https://doi.org/10.17/S0010417500004540 accessed 10/04/2011
} 
employment life. These factors combine to downgrade the status of older employees. ${ }^{667}$ Modernisation Theory contends that the downgrading of status keeps pace with the momentum of economic modernisation. The theory describes younger generations with 'no reverence for the aged deriving from their superior knowledge, ${ }^{668}$ and a modern economy which subsequently 'fosters social and intellectual separation of the generations ... the young are in the stream of progress; $\ldots$ the old stand still and suffer by comparison ... the status relationships are reversed. ${ }^{669}$ Furthermore, the response to the fact that '...death no longer creates openings in the labour force as it once did"670 has been to ensure retirement from the workforce, thereby causing problems of poverty, declining engagement in relationships, declining self-esteem, and deepening loss of status.

\subsubsection{Urbanisation, changes to family structure, and loss of family support}

Successful modernisation achieves the 'total destruction of all traditional elements' of a society. ${ }^{671}$ The breakdown of the traditional family is claimed as part of this destruction. The urbanisation and migration of younger workers during the first industrialisation initiated the replacement of extended families with 'neo-local marriage practices. ${ }^{672}$ Such practices have not precluded extended family living arrangements, but they tend increasingly to be during times of adversity, and temporary. ${ }^{673}$ The vulnerabilities caused by these changes to the family fall into the 'nuclear hardship' category, and are related to income, health, or social-support. ${ }^{674}$ The precariousness of the institution of the family forces older adults to look to alternative institutions for assets and resilience to vulnerability ${ }^{675}$

\footnotetext{
${ }^{667}$ Donald O. Cowgill, 'The Aging of Populations and Societies,' AAPSS, 415 (Sep 1974) 1, 13

${ }^{668}$ Donald O. Cowgill, 'The Aging of Populations and Societies,' AAPSS, 415 (Sep 1974) 1, 15

669 Donald O. Cowgill, 'The Aging of Populations and Societies,' AAPSS, 415 (Sep 1974) 1, 13

${ }^{670}$ Donald O. Cowgill, 'The Aging of Populations and Societies,' AAPSS, 415 (Sep 1974) 1, 12

${ }^{671}$ S.N. Eisenstadt, 'Studies of Modernization and Sociological Theory,' 'History and Theory,' Vol. 13, No. 3 (Oct 1974) $225-252,233$.

${ }^{672} \mathrm{Neo}-$-local marriage practices begin with younger family members leaving traditional family arrangements to found a family and work independently of the extended family. Peter Laslett, 'Family, kinship and collectivity as systems of support in pre-industrial Europe: A consideration of the 'nuclear-hardship' hypothesis,' 'Continuity and Change' 3 (2) (1988) 153-175, 153

${ }^{673}$ Peter Laslett, 'Family, kinship and collectivity as systems of support in pre-industrial Europe: A consideration of the 'nuclear-hardship' hypothesis,' 'Continuity and Change' 3 (2) (1988) 153-175, 155

${ }^{674}$ R.M. Smith, 'Some issues concerning families and their property in rural England 1250-1800', cited in Peter Laslett, 'Family, kinship and collectivity as systems of support in pre-industrial Europe: A consideration of the 'nuclear-hardship' hypothesis,' 'Continuity and Change' 3 (2) (1988) 153-175,153

${ }^{675}$ See Chapter 5, 'Vulnerability,' 5.3.1.2, 'Institutional Vulnerability,' which includes the family amongst the institutions described as created to defend against vulnerability, and which are themselves vulnerable.
} 
during the dependency anchored in older age. ${ }^{676}$ The assets required include the range of physical, human, and social as defined by Kirby under institutional vulnerability. ${ }^{677}$

The conscious abandonment of older family members amid lost familial obligation is most frequently contested on grounds of cultural relativism and material constraint. Research has also claimed it not to be representative of 'history nor...contemporary arrangements' in industrialised society. ${ }^{678}$ However, assertions of the dependency of older family members on institutions other than the family are not without substance.

\subsubsection{Filial Obligation}

The arrangements spoken of in Modernisation Theory and contemporary accounts of family support are rationalised in principles of filial obligation, which will be briefly explained. The focus of filial obligation in this thesis is that held by younger adults towards older family members. The obligation is reciprocal, in return for parental support during childhood. ${ }^{679}$ Significantly, 'reciprocal' has not been translated in the hierarchy of priorities of the adult child as equal to the care received. In reality it is applied through the notion of 'transitive order.' The care received from a parent is, instead, 'repaid' to the child of the adult ahead of any duty to the ageing parent. ${ }^{680}$

\footnotetext{
${ }^{676}$ See Chapter 5, 'Vulnerabilty,' 5.3.2.2, 'Fineman's Thesis,' which describes dependency as anchored at either end of life.; Peter Laslett, 'Family, kinship and collectivity as systems of support in pre-industrial Europe: A consideration of the 'nuclear-hardship' hypothesis,' 'Continuity and Change' 3 (2) (1988) 153-175, 155 ${ }^{677}$ Burgess depicts the situation well as '...the older person ... can no longer count as a matter of right and of moral and legal obligation on economic support by his children. He is less and less likely, if needed, to be offered a home by a son or a daughter. If ill, particularly with a chronic ailment his children are more and more likely to shift his care to a hospital rather than to provide a bed in their home. If lonely, he must more and more look elsewhere than to his descendants to provide companionship and sociability. In short he must seek elsewhere for the satisfaction of his needs - financial, health and social. In Western cultures he turns to the government or other organisations.'E.W. Burgess (ed.) Ageing in Western Societies (1960; Chicago, University of Chicago Press) p.17, (as cited in Isabella Aboderin, 'Modernisation and ageing theory revisited: current explanations of recent developing world and historical Western shifts in material family support for older people,' Ageing \& Society 24 (1) (2004) 29, 31

${ }^{678}$ Isabella Aboderin, 'Modernisation and ageing theory revisited: current explanations of recent developing world and historical Western shifts in material family support for older people,' Ageing \& Society 24, 2004, 2950, 31. See O'Rand, A.M. 1990 'Stratification and the life course. In Binstock, R.H. and George, L.K. (eds.), Handbook of Aging and the Social Sciences, $3^{\text {rd }}$ edition. Academic, San Diego, California, 130-148 (as cited in Isabella Aboderin, 'Modernisation and ageing theory revisited: current explanations of recent developing world and historical Western shifts in material family support for older people,' Ageing \& Society 24, 2004, 2950)

${ }^{679}$ See A.W. Gouldner, 'The norm of reciprocity: a preliminary statement,' American Sociological Review, 1960, 25, 161-178,

${ }^{680}$ See H.R. Moody, 1993 (as cited in Isabella Aboderin, “Conditionality' And 'Limits' Of Filial Obligation,' Working Paper Number WP205, Conceptual Levers For Developing A Better Understanding Of The Motivational Basis And Societal Shifts Or Patterns In Old Age Family Support,9)
} 
No matter what the older generation has done for the younger, each generation's primary obligation is transitive. That is, we 'repay' the generosity of the preceding generation by giving in turn to our successors ... Whatever claims older people may have are limited by this overriding transitive obligation across the chain of generations. ${ }^{681}$

The prioritisation of financial, material, time, space, and emotional needs of the youngest family members ahead of the oldest justifies institutional provision of the assets needed to defend against vulnerability. ${ }^{682}$

The duty and practice exists, to varying degrees, 'in most, if not all, societies of this world.' The inconsistent nature of the obligation leads to precariousness in times of social and economic transition. ${ }^{683}$ In contemporary Western societies continued changes to the family institution ${ }^{684}$ has reduced long-term care-giving by family members. Thus the institutional assets required by the elderly are material, health and daily living care. ${ }^{685}$

In all societies there is evidence of mutual obligations and responsibilities between aged parents and their adult children, but these obligations appear to be less clear and less binding in modern societies ... there is considerable resistance to it, and state insurance and assistance programs have been instituted as partial substitutes for such filial responsibility. ${ }^{686}$

\footnotetext{
${ }^{681}$ H.R. Moody, 1993, 229 (as cited in Isabella Aboderin, “Conditionality' And 'Limits' Of Filial Obligation,' Working Paper Number WP205, Conceptual Levers For Developing A Better Understanding Of The Motivational Basis And Societal Shifts Or Patterns In Old Age Family Support,9)

${ }^{682}$ Isabella Aboderin, 'Conditionality' And 'Limits' Of Filial Obligation,' Working Paper Number WP205, Conceptual Levers For Developing A Better Understanding Of The Motivational Basis And Societal Shifts Or Patterns In Old Age Family Support, 12

${ }^{683}$ Isabella Aboderin, “Conditionality' And 'Limits' Of Filial Obligation,' Working Paper Number WP205, Conceptual Levers For Developing A Better Understanding Of The Motivational Basis And Societal Shifts Or Patterns In Old Age Family Support, 2

${ }^{684}$ Including second families, childless adults, lone-living across age groups, and mobility. Isabella Aboderin, “Conditionality' And 'Limits' Of Filial Obligation,' Working Paper Number WP205, Conceptual Levers For Developing A Better Understanding Of The Motivational Basis And Societal Shifts Or Patterns In Old Age Family Support, 3

${ }^{685}$ Isabella Aboderin, “Conditionality' And 'Limits' Of Filial Obligation,' Working Paper Number WP205, Conceptual Levers For Developing A Better Understanding Of The Motivational Basis And Societal Shifts Or Patterns In Old Age Family Support, 2-3. Aboderin refers to research for her observations, including: African Union/HelpAge International, 2003; Aboderin, 2004; Booth 1892; 1894; 1899; Means, Richards and Smith, 2003; Clarke, 1995; Grundy, 1995; Bengston et al, 2003, and Katz et al, 2003.

${ }^{686}$ D.O. Cowgill, 'A theory of aging in cross-cultural perspective.' In D.O. Cowgill, and L.D. Holmes, (eds.) Ageing and Modernization. Appleton-Century-Crofts. New York, 307 (as cited in Isabella Aboderin, 'Modernisation and ageing theory revisited: current explanations of recent developing world and historical Western shifts in material family support for older people,' Ageing \& Society 24, 2004, 29, 36
} 
The notion of declining filial obligation, and the Modernisation Theory explanation for older persons' experiences are both crystallised and disproved by research. Given the fact of an ageing global population, the thesis turns to examples to highlight how the description provided by Modernisation Theory is being mirrored, and also how cultural relativity prevents principles of the theory, particularly abandonment of older persons, being universally accepted.

Whilst the conclusions and universal application of Modernisation Theory have been criticised, the processes and outcomes which it describes are recognisable in the modernised West, and in developing countries. For this reason the U.N. adopted the explanation of events, the threats they present to older people, and how the group becomes vulnerable, in the Political Declaration and Madrid International Plan of Action on Ageing ratified at the second World Assembly on Ageing (MIPAA). ${ }^{687}$

Areas of the MIPAA which focus on developing countries describe situations and problems facing older people as a group which mirror the experience of the West. The 'exodus of young adults' to industrialised and urban areas in transitioning countries creates circumstances in which 'older persons may be left behind without traditional family support and even without adequate financial resources. ${ }^{688}$ The urban setting for this group in transitioning economies and societies, as described by the MIPAA, exemplifies the abandonment described earlier by Burgess, and the issues of declining filial obligation: Older people '...often face loss of social networks and suffer from the lack of a supporting infrastructure...which can lead to their marginalization and exclusion, in particular if they are ill or disabled. ${ }^{689}$ In addition, the life experience can become one of, 'crowded housing, poverty, loss of economic autonomy and little physical and social care from family members who must earn their living outside the home. ${ }^{690}$

Although disputed, particularly with regard to conclusions of the abandonment of older people, Modernisation Theory provides a description of processes in the West which serve as a useful

\footnotetext{
687 'Migration, urbanisation, the shift from extended to smaller, mobile families ... and other socio-economic changes can marginalize older persons ... taking away their purposeful economic and social roles and weakening their traditional sources of support. ${ }^{687}$ UN 2002:9 (as cited in Isabella Aboderin, 'Modernisation and ageing theory revisited: current explanations of recent developing world and historical Western shifts in material family support for older people,' Ageing \& Society 24, 2004, 2950,34 )

${ }^{688}$ Issue 3.29, Political Declaration and Madrid Internal Plan of Action on Ageing, 8-12 April 2002, United Nations, New York.

${ }_{689}$ Issue 3.31, Political Declaration and Madrid Internal Plan of Action on Ageing, 8-12 April 2002, United Nations, New York

${ }^{690}$ Issue 3.31, Political Declaration and Madrid Internal Plan of Action on Ageing, 8-12 April 2002, United Nations, New York
} 
indicator of potential problems faced by the group in transitioning countries. The threats and resultant vulnerabilities which the theory identifies include: reduction in relationships and activities, removal from the workforce, poverty, loss of status, lone living, and lack of family support. Individually and combined these provide a means of recognising older persons as a societal group, the risks posed to human dignity, and the areas in which special protection might be sought. As an aspect of modernisation, and a viable threat in itself, identification of older people by productivity is discussed next.

\subsection{Productivity}

The productivity, or contribution of the individual, economically and socially, has been used throughout history as a means of identifying older people. Defining the group in this way is founded in societal perceptions of 'usefulness' and negative dependency on institutions. Therefore, such an approach to identification of the group also identifies vulnerability to negative stereotyping, prejudice, and discriminatory treatment. The outcome of such threats contributes to older people becoming vulnerable to abandonment, isolation, and poverty.

\subsubsection{Productivity as 'usefulness'}

Definition by 'usefulness' is grounded in the Marxist Theory of Productive and Unproductive labour in which the person is directly valued by what she/he produces. ${ }^{691}$ From this, a societal hierarchy is created, creating negative perceptions of the elderly. The person able to produce the raw materials of the economy tops this hierarchy. ${ }^{692}$ Domestic or family care is seen as having little worth, ${ }^{693}$ whilst those with little or no ability to contribute are least useful. The central concern in the productivity model is for the economy rather than the older person. Motivation is the net effect of the group on the economy, the balance between input and demand on resources. Thus dependent older adults unable to contribute can be perceived as having a negative effect on resources, suggesting the potential danger for restricting institutional assets to more productive members of

\footnotetext{
${ }^{691}$ For in-depth coverage of the theory see C. Marx, Capital I, 1 pp. 42-43, cited in I. Gough, 'Marx's Theory of Productive and Unproductive Labour,' 'New Left Review' I/76 pp 47-72 (1972)

${ }^{692}$ See generally J. Davis and M. Stack, 'Applying Marx's Theory of Value: The Role of Knowledge in the Production of Commodities,' www.net4dem.org Accessed 28/07/2014

${ }^{693}$ M. Brogden, Geronticide: Killing the Elderly (2001; Jessica Kingsley Publishing) 57
} 
society. ${ }^{694}$ It is possible to associate older people with type and degree of productivity (See Activity and Life Course Theories later in this chapter). However, should this combine with negative stereotyping and societal prioritisation, the institutional assets and resources on which older persons become reliant could be limited. In this situation the group will lack the resources to defend against threats. The likelihood of the specific threats materialising and individuals becoming vulnerable will increase as a result. ${ }^{695}$

\subsubsection{Productivity as 'successful ageing'}

Productivity has also been included in definitions of 'successful ageing' ${ }^{696}$ which interprets productivity as a 'broad range of acts that infuse our lives with meaning. ${ }^{697}$ The ways in which older people can be considered productive is described by Robert Butler in the concept of productive ageing:

'I did not interpret the concept productive aging to be formal work...the bedridden person can be productive, helpful to their caregivers. I consider taking care of myself to be productive. The principal concept of productive aging is to remain constructive in relationship to the larger society and immediate environment as long as possible. ${ }^{698}$

${ }^{694}$ J. Morgan, 'Unpaid Productive Activity Over The Life Course,' 1986 cited in J. Hinterlong, N. Morrow-Howell, M Sherraden, M., 'Productive Aging: Principles and Perspectives' in . Morrow-Howell, J. Hinterlong, and M.Sherraden, (eds.) Productive Aging: Concepts and Challenges (2001; The John Hopkins University Press,) 7 This perception of older people and treatment equivalent to restricting assets to younger people more able to contribute is identifiable throughout history, e.g.:

'When a 'savage' feels that he is a burden to his tribe: when every morning his share of food is taken from the mouths of the children - who every day has to be carried across the stony beach or the virgin forest, on the shoulders of younger people...he begins to repeat what the old Russian peasants say... 'I live other people's life. It is time to retire.' Prince Kropotkin, 'Mutual Aid Among Savages', cited in M. Brogden, Geronticide: Killing the Elderly (2001; Jessica Kingsley Publishing) 60.

The eminent scientist and anthropologist, Jared Diamond, reports on his longitudinal studies of traditional societies and how they treat those no longer 'of use' as, 'neglecting their elderly and not cleaning or feeding them until they die, or by abandoning the elderly ... or by encouraging the elderly to commit suicide, or by killing older people.' He also tells of the more brutal custom of Paraguay's Aché Indians who 'assign certain young men the task of killing old people with an axe or spear, or burying them alive.' J.Diamond, 'How Societies Can Grow Old Better,' T.E.D. Lectures February 2013.

${ }^{695}$ See Chapter 5, 'Vulnerability,' definition of vulnerability

${ }^{696}$ See generally H.R. Moody, 'Productive Aging and the Ideology of Old Age,' in N. Morrow-Howell, J. Hinterlong, and M. Sherraden, (eds.) Productive Aging: Concepts and Challenges (2001; The John Hopkins University Press)

${ }^{697}$ J. Hinterlong, N. Morrow-Howell, and M. Sherraden, 'Productive Aging: Principles and Perspectives' in N. Morrow-Howell, J. Hinterlong, and M. Sherraden, (Eds.) Productive Aging: Concepts and Challenges (2001; The John Hopkins University Press) 8

${ }^{698}$ R.N. Butler, 'Revisiting Productive Aging,' in 'Productive Ageing,' Memorial Issue, 2011; International Longevity Center, Tokyo, 68, cited in I. Holmeroia, M. Ferreira, P, Wija, et al, Productive Ageing Conditions and Opportunities (2012; International Longevity Centre Czech Republic Centre for Expertise in Longevity and Longterm Care Faculty of Humanities, Charles University in Prague) 
This approach alleviates accusations of over dependency by older people unable to contribute economically. The move away from attributing an economic value to activity is positive for perceptions of the group. However, for successful ageing to require the person to be in any way productive confirms productivity as the means through which life is validated. ${ }^{699}$

8.4 Disengagement Theory, Selective Optimization with Compensation Model, and Socioemotional Selectivity Theory

The theories explored in this section of the chapter offer explanations for the disengagement of older people from society. Whether justified as inevitable, necessary, or an aspect of successful ageing, each argues that the older individual 'de-socialises.' This process, for these theories, identifies older people as a group. Following this determination of the methodologies and purpose of disengagement, the thesis will later examine the dangers presented by the outcomes of disengagement, whether by the individual or society, to older people.

\subsubsection{Disengagement Theory}

As with Modernisation Theory, Disengagement Theory offers an explanation for a situation in which the status and involvement of older people in society are declining. Disengagement Theory opposes the thrust of Modernisation Theory that 'society withdraws from the older person, leaving him stranded, ${ }^{700}$ proposing that the individual voluntarily collaborates with society, instigating withdrawal.

Disengagement Theory explains the relationship between society and older people by the latter's 'permitted deviance' from norms of behaviour. The theory states that society identifies the group by the different norms chosen. ${ }^{701}$ Once identified, '...society....begins to retreat from the [aged at the

\footnotetext{
${ }^{699}$ H.R. Moody, 'Productive Aging and the Ideology of Old Age,' in N. Morrow-Howell, J. Hinterlong, and M. Sherraden, (Eds.) Productive Aging: Concepts and Challenges (2001; The John Hopkins University Press, ) 181 ${ }^{700}$ Elaine Cumming, Lois R. Dean, David S. Newell, and Isabel McCaffrey, 'Disengagement - A Tentative Theory of Aging,' 'Sociometry,' Vol.23, No.1 (1960) 23-35,23.

${ }^{701}$ Elaine Cumming, Lois R. Dean, David S. Newell, and Isabel McCaffrey, 'Disengagement - A Tentative Theory of Aging,' 'Sociometry,' Vol.23, No.1 (1960) 23-35, 25
} 
last confines of life] or, what amounts to the same thing, he retreats from it. ${ }^{702}$ Disengagement is, for this theory, universal, inevitable and intrinsic: ${ }^{703}$

normal ageing is a mutual withdrawal or 'disengagement' between the ageing person and others in the social system to which he belongs - a withdrawal initiated by the individual himself or by others in the system. ${ }^{704}$

As part of this process, the range and volume of functions performed, and the degree of involvement of those in which participation is maintained, are reduced. Furthermore, any remaining interaction is socio-emotional, which also eventually declines. This 'de-socialisation' occurs, according to Disengagement Theory, at recognised stages of life, ${ }^{705}$ until disengagement is complete. ${ }^{706}$

The claims made by the theory are derived from research data of a broad sample of adults aged 40 to 85 during the period 1954 to $1958 .^{707}$ Reference will be made to this research to aid explanation of the reasoning of the theory. However, the reporting of the research findings has encountered criticism which will be addressed under the heading 'Criticisms of Disengagement Theory.' The first facet of disengagement is reduction in number and types of interaction with society, measured by 'Interaction Index' and 'Social Life-space." ${ }^{708}$ A numerical measure of contact which conforms to societal norms, The Interaction Index reported $14 \%$ of ages 50 to 54 as having few interactions, compared with $82 \%$ of ages 70 to 74 years. Social Life-space, the range of dealings with family, friends, colleagues and local community, is a victim of productivity, or perceived worth, of the older adult. $^{709}$ The study showed the number of roles performed to reduce with age. Those claiming to perform 'a small number of roles' increased from 39\% for ages 50 to 54 , to $92 \%$ for ages 75 and over. ${ }^{710}$ The effect for men is reported as more sudden, relating the loss specifically to professional

\footnotetext{
${ }^{702}$ E. Durkheim, Suicide, (1951; Glencoe, The Free Press) p.484, cited in Elaine Cumming, Lois R. Dean, David S. Newell, and Isabel McCaffrey, 'Disengagement - A Tentative Theory of Aging,' 'Sociometry,' Vol.23, No.1 (1960) 23-35, 25

${ }^{703}$ Arlie Russell Hochschild, 'Disengagement Theory: A Critique and Proposal', American Sociological Review, Vol. 40, No. 5 (Oct., 1975), 553, 555

${ }^{704}$ E. Cumming, 'Further Thoughts on the Theory of Disengagement' in Gubrium, J.F. \& Holstein, J.A. (eds.), Aging and Everyday Life (2000; Oxford, Blackwell Publishers Inc) 25

${ }^{705}$ Allowing similarities to be drawn with Life Cycle principles.

${ }^{706}$ Disengagement is considered 'successful' when life is lived in little short of a solitary state. Arlie Russell Hochschild, 'Disengagement Theory: A Critique and Proposal,' 'American Sociological Review,' Vol. 40 (October 1975) 553-569, 553

${ }^{707}$ Kansas City Study of Adult Life 1954-1958, University of Chicago Committee on Human Development

${ }^{708}$ Elaine Cumming, Lois R. Dean, David S. Newell, and Isabel McCaffrey, 'Disengagement - A Tentative Theory of Aging,' Sociometry,' Vol.23, No.1 (1960) 23-35 at pp.25-26

${ }^{709} \mathrm{It}$ is worth noting that the measurement of perceived worth of a person in terms of productivity is contra to the 'inherent worth' of the individual as explained by human dignity.

${ }^{710}$ Kansas City Study of Adult Life 1954-1958, University of Chicago Committee on Human Development.
} 
roles, whilst women retain a diminishing socio-emotional role. ${ }^{711}$ The claim that 'de-socialisation' occurs at recognised stages of life is further defined by milestones for role reduction, including: children leaving the family home; retirement; and the death of a spouse. ${ }^{712}$ A discussion of life stages and milestones takes place in the Life Course Theory section of this chapter.

Disengagement Theory identifies changes to interactions as related to self-perception of life-space size. From a question contrasting perceived current numbers of interactions with perceived numbers at age $45,{ }^{713}$ the study concluded that perception of having no productive role, and reduced vertical and horizontal relationships, determines the beginning of disengagement. ${ }^{714}$ Selfperception, claims the theory, makes disengagement a self-fulfilling prophecy. Whilst still in employment and socially engaged, the study upon which this theory is based reported $41 \%$ of working men aged 50-59 as beginning to perceive a reduction of roles. The perception was held by $65 \%$ of non-working males over 70 . The figures for women in the same categories are $24 \%$ and $73 \%$ respectively. ${ }^{715}$

The qualitative aspect of disengagement sees Disengagement Theory borrow from the Role Theory ${ }^{716}$ analysis of the nuclear family relationship. Values of filial obligation are stated as reducing with each disengagement milestone. Continued disengagement, especially when following typical patterns, offers replacement relationship values for older adults receiving diminishing familial support. In search of roles of duty and esteem, older people engage in charitable or fraternal organisations, until final stages of engagement, comprising recreation with little or no interaction with others, are reached. ${ }^{717}$ Not mentioned by the theory, however, are the characteristics of interactions of individuals devoid of kinship or other relationships. In this situation, the final qualitative change sees the older person dependent on institutional support.

\footnotetext{
${ }^{711}$ W.A. Achenbaum, 'Re-engaging the Disengagement Theory of Aging: On the History and Assessment of Theory Development in Gerontology,' 'The Gerontologist,' Vol. 34, No.6 (1994) 756-763 ,758

${ }^{712}$ E. Cumming, 'Further Thoughts on the Theory of Disengagement' in J.F. Gubrium, \& J.A. Holstein (eds.), Aging and Everyday Life (2000; Oxford, Blackwell Publishers Inc) p.26

${ }^{713}$ Kansas City Study of Adult Life 1954-1958, University of Chicago Committee on Human Development, cited in Elaine Cumming, Lois R. Dean, David S. Newell, and Isabel McCaffrey, 'Disengagement - A Tentative Theory of Aging,' 'Sociometry,' Vol.23, No.1 (1960) 23-35, 27

${ }^{714}$ W.A. Achenbaum, 'Re-engaging the Disengagement Theory of Aging: On the History and Assessment of Theory Development in Gerontology,' 'The Gerontologist,' Vol. 34, No.6 (1994) 756-763 ,758

${ }^{715}$ Elaine Cumming, Lois R. Dean, David S. Newell, and Isabel McCaffrey, 'Disengagement - A Tentative Theory of Aging,' Sociometry,' Vol.23, No.1 (1960) 23-35,31

${ }_{716}$ Designed by Talcott Parsons. See Talcott Parsons, The Social System (1958; Glencoe, The Free Press)

${ }^{717}$ T. Parsons, The Social System (1958; Glencoe, The Free Press) 130, cited in Elaine Cumming, Lois R. Dean, David S. Newell, and Isabel McCaffrey, 'Disengagement - A Tentative Theory of Aging,' 'Sociometry,' Vol.23, No.1 (1960) 23, 32-33
} 


\subsubsection{Criticisms of Disengagement Theory}

As a theory of ageing, Disengagement Theory has encountered disapproval. Interpretation of the research on which the theory is based is criticised for taking a negative stance on the attitude of older persons to remaining engaged. The facts also state that $22 \%$ of ages 70 to 74 had 'a large number of roles;' $34 \%$ had 'high daily interaction with others;' $18 \%$ had a 'large life-space;' and 16\% did not perceive their life-space as constricted. ${ }^{718}$ Whilst this interpretation confirms negative selfperception of engagement, the argument that individuals instigate disengagement from society is unconvincing.

A weakened case for Disengagement Theory also questions the inevitability of disengaging. Furthermore, the position taken by the theory that successful ageing requires 'successful disengaging' is discredited, as is the claim that non-disengagers must belong to 'a biological and possibly psychological elite. ${ }^{719}$ However, the theory also recognises '...deterioration of 'communications' through declining mental and physical abilities' where '... more basic personality functions ... like 'drive' and 'self-motivation' have become defective' amongst this 'elite.,720 Therefore, Disengagement Theory contradicts the underlying assumption of voluntary disengagement by older people, presenting it as a result of compromised internal capabilities. ${ }^{721}$

Disengagement Theory maintains that the ageing process cannot be examined separately from the social system. By contextualising the mutual separation of the generations in the 'modernised society, ${ }^{722}$ the process is depicted as responding to the values of achievement and efficiency. In this way Disengagement Theory is sympathetic to Modernisation Theory, and views 'de-socialisation' as a 'mechanism for systematically disengaging older persons from major life roles, roles critical to social system maintenance. ${ }^{723}$ If disengagement is an aid to successful social adaptation as depicted by Modernisation Theory, the 'mutual withdrawal' intrinsic to 'normal ageing' becomes more difficult to defend. ${ }^{724}$

\footnotetext{
${ }^{718}$ Arlie Russell Hochschild, 'Disengagement Theory: A Critique and Proposal,' ‘American Sociological Association,' Vol.40, No. 5 (October 1975) 553-569, 555

${ }_{719}$ Arlie Russell Hochschild, 'Disengagement Theory: A Critique and Proposal,' 'American Sociological Review,' Vol. 40, No. (October 1975) 553-569 ,555. Author drawing on opinions of Riesman, Bertrand Russell, Toscanini, Bernard Baruch and Bernard Shaw.

${ }^{720}$ Elaine Cumming, Lois R. Dean, David S. Newell, and Isabel McCaffrey, 'Disengagement - A Tentative Theory of Aging,' 'Sociometry,' Vol.23, No.1 (1960) 23-35,32.

${ }_{722}^{721}$ See Chapter 6, 'Capabilities Approach,'

${ }^{722}$ E. Cumming and W.E. Henry Growing Old: The Process of Disengagement ( Basic Books, 1961)

${ }^{723}$ Patricia Passuth Lynott and Robert J. Lynott, 'Disengagement - Critical assessment of disengagement theory,' http://medicine.jrank.org/pages/483/Disengagement

724 ....when the old person is no longer able to carry out the minimum adaptive behaviour necessary to maintain health, or cleanliness or propriety ... someone else must enter the conjugal society ... and thus they
} 
The instigation of, or agreement to, disengaging is further discredited by association with Modernisation Theory, which sees disengagement as an outcome of loss of status. 'Aging has to do with the individual's passage through psychobiological stages; disengagement has to do with individual changes in social position. ${ }^{, 725}$ Disengagement becomes a response to the status accorded the older individual by modernised society. ${ }^{726}$

'Most old people do not control or own the means of production and cannot themselves determine whether or not to work. Most old people are forced out of the market world into the realm of activities with use value - care for the home, hobbies, volunteer work. ${ }^{727}$

Disengagement Theory asserts that as the older adult interacts with fewer social groups, each group increases in importance. The oldest old place greatest significance on the family group, ${ }^{728}$ yet this is often the first to disengage. The theory also maintains the growing inconsequentiality of secondary groups to the oldest individuals, together with an inability to connect with them. ${ }^{729}$ However, the modernised society, in which Disengagement Theory is contextualised, expects that such groups replace kinship.

\subsubsection{Selective Optimization with Compensation Model}

Despite criticism of the disengagement of older people from society as inevitable and universal, and inherent to successful ageing, Disengagement Theory has received support in recent, more accepted theories. The Selective Optimization with Compensation model ${ }^{730}$ defines successful ageing as 'the minimization of loss and the maximization of gains. ${ }^{731}$ To achieve this, the older adult must select, optimise, and compensate. Selecting activities and goals of most importance to an individual 'as a

return to the asymmetrical social condition of infants - their contribution ... lies not in what they do but what they are - members by birthright of a family. A very old person with no family ties has the pathos of an orphaned child and society deals with him accordingly.' E. Cumming, 'Further Thoughts on the Theory of Disengagement' in J.F. Gubrium \& J.A. Holstein (eds.), Aging and Everyday Life (2000; Blackwell) 36 ${ }_{725}$ Arlie Russell Hochschild, 'Disengagement Theory: A Critique and Proposal,' 'American Sociological Review,' Vol. 40, No. (October 1975) 553-569, 562

${ }^{726}$ Arlie Russell Hochschild, 'Disengagement Theory: A Critique and Proposal,' 'American Sociological Review,' Vol. 40, No. (October 1975) 553-569 at pp.563-564

${ }^{727}$ Arlie Russell Hochschild, 'Disengagement Theory: A Critique and Proposal,' 'American Sociological Review,' Vol. 40, No. (October 1975) 553-569, 554

${ }^{728}$ E. Cumming, 'Further Thoughts on the Theory of Disengagement' in J.F. Gubrium \& J.A. Holstein (eds.), Aging and Everyday Life (2000; Blackwell) 29

${ }^{729}$ This assertion is in agreement with Socioemotional Selectivity Theory which describes older people as choosing to maintain relationships of greatest emotional significance as part of successful ageing.

${ }^{730}$ Hereafter referred to as SOC. See P.B. Baltes and M.M. Baltes (1990)

${ }^{731}$ Chambers lists losses associated with vulnerability as 'becoming or being physically weaker, economically impoverished, socially dependent, humiliated or psychologically harmed.' Chapter 5 , 'Vulnerability' 
consequence of or in anticipation of changes in personal and environmental resources' is key. ${ }^{732}$ By recognising the need to respond to a reduced capability, whether defined by opportunity or ability, to participate in the same number and range of activities, the older person is able to optimise engagement. $^{733}$

'...utilizing remaining abilities at the highest level possible. Optimization may include focusing attention, persisting in...a goal, practicing skills, acquiring new resources or skills, and devoting more time or effort to a specific activity. ${ }^{734}$

Such optimisation achieves the goal of continued growth with age, which the model asserts as necessary for successful ageing, ${ }^{735}$ which in turn is dependent on continuous adaptation. ${ }^{736}$ SOC cites the need for adaptation to 'physical, social and psychological changes that go together with increasing age ${ }^{, 737}$ also a theme of definitions of vulnerability ${ }^{738}$ in order to meet individual goals when losses occur. Therefore, to respond to life events and social dynamics which reduce opportunities by 'abandoning activities that are less meaningful, selecting those...of higher priority and compensating for limiting conditions...to optimize the more restricted...alternatives ${ }^{739}$ is a means of coping with the 'external side of vulnerability.

The success of selection, optimisation and compensation is, however, ultimately limited by the ageing process. As the older person loses internal capabilities required, including physical and cognitive capacity, the ability to engage in the process is constrained. Therefore, the reason for the adaptation can eventually prevent further use of this coping mechanism against vulnerabilities associated with loss of relationships, social activity, and isolation.

\subsubsection{Socioemotional Selectivity Theory}

Socioemotional Selectivity Theory addresses the selection of the most emotionally important relationships by older people during the adaption process for successful ageing. Socioemotional

\footnotetext{
${ }^{732}$ Baltes \& Carstensen 1996, Francis McGuire and William Norman, 'The Role of Constraints in Successful Aging: Inhibiting or Enabling?

${ }^{733}$ Francis McGuire and William Norman, 'The Role of Constraints in Successful Aging: Inhibiting or Enabling?

${ }^{734}$ Francis McGuire and William Norman, 'The Role of Constraints in Successful Aging: Inhibiting or Enabling?' 96

${ }^{735}$ Francis McGuire and William Norman, 'The Role of Constraints in Successful Aging: Inhibiting or Enabling?' 96

${ }^{736}$ N. Steverink, S. Lindenberg \& J. Ormel, 'Towards Understanding Successful Ageing: Patterned Change in Resources and Goals,' 'Ageing and Society,' 18 (1998) 441-467, 444

${ }^{737}$ N. Steverink, S. Lindenberg \& J. Ormel, 'Towards Understanding Successful Ageing: Patterned Change in Resources and Goals,' 'Ageing and Society,' 18 (1998) 441-467, 442

${ }^{738}$ See Chapter 5, 'Vulnerability,' 'Definitions and descriptions of vulnerability.'

${ }^{739}$ Galit Nimrod and Douglas A. Kleiber, 'Reconsidering Change And Continuity In Later Life: Toward An Innovation Theory Of Successful Aging,' Int'I J. Aging and Human Development, Vol 65(1) 1-22, 2007, 1, 4
} 
selection, the theory asserts, is a conscious choice rather than coerced disengagement, influenced by three factors of growing older. The first is a declining need by the 'information rich' older person to use social interaction as a means of acquiring knowledge and information. Additionally, with a reducing requirement to establish a sense of self, the older individual has less need of a wide range of interactions. Finally, the interaction sought is required to have 'affective quality.' Thus, older people increase contact within relationships with kinship ties.

Significantly, this theory does not attempt to associate any stage of the processes of socioemotional selectivity, or similar processes in the previously discussed SOC, with age per se. Rather, the correlation is with perception of nearness to end of life. When advancing age is accompanied by an awareness of death the older person seeks emotional rather than complex relationships. The age at which this occurs complies with the individual experience of ageing. ${ }^{740}$

The three theories advance a similar pattern of disengagement. Each recognises a reduction in the number of relationships, and an increasing reliance and importance placed on those with ties of emotion and kinship. The rationale of the individual theories subtly depart from one another, however, similar themes exist. All maintain that the older individual disengages, voluntarily, as part of a successful ageing process. Whether socially or personally constructed, older people are exposed to threats to participation in relationships and activities, status, and self-respect as a result of disengagement. The beginning of disengagement serves as an indicator for the potential for the materialisation of these threats and the outcomes of the vulnerabilities they attract. Furthermore, if the person becomes unable to disengage as described by SOC this is an indicator of the loss of physical and cognitive abilities. In this way, identification by disengagement, and specifically by SCO can identify further threats to the dignity of older people, and the vulnerabilities of the group.

\subsection{Activity Theory}

The Activity Theory of ageing explores the contribution of activity to successful ageing. Identifying social engagement rather than de-socialisation as an underlying principle, the theory takes the opposing view to theories that promote disengagement. In doing so, the negative effects of disengagement and the potential the process has to expose older people to vulnerability are emphasised. The principles of Activity Theory particularly effective in identification of older persons as a group include: when equilibrium of activity is achieved; evidence of adaptation to role loss

\footnotetext{
${ }^{740}$ Francis McGuire and William Norman, 'The Role of Constraints in Successful Aging: Inhibiting or Enabling?' 97
} 
through activity; and life satisfaction. ${ }^{71}$ The reverse of these positive markers also signal risk of threat, and vulnerability to social isolation and inability or lack of opportunity to be and do valuable functionings, as described in the 'Capabilities Approach' chapter. ${ }^{742}$

The general rule employed by Activity Theory is a correlation between social connection and sense of fulfilment; 'The greater the activity, the greater one's life satisfaction." ${ }^{743}$ This rule directs the thrust of the theory, and contributes to ageing theory by providing the basis for development of further theories which endorse activity in ageing. Also influenced by this theory are models offering a compromise position between Disengagement and Activity Theories.

Specifically, the activity to which the theory refers is that defined as 'any regularized or patterned action or pursuit which is regarded as beyond routine physical or personal maintenance. ${ }^{744}$ Activity can be informal, formal, and solitary. ${ }^{745}$ Informal activity with family and friends, formal interaction with voluntary organisations, and solitary leisure pursuits or daily living activities are classed as predictors of life satisfaction. Informal activity creates greatest life satisfaction, followed by formal, with solitary activities contributing least to lives of older adults. ${ }^{746}$ The combination of activities from each category helps to identify older persons as a social group, and provides indicators of vulnerability to poverty, isolation, health problems, and dependency.

Activity Theory emphasises the need for equilibrium, or maintaining middle age roles and activity into old age, at least numerically. ${ }^{747}$ The rationale is informed by the manner in which the theory distinguishes between middle and older age; 'Except for the inevitable changes in...health, older

\footnotetext{
${ }^{741}$ R.C. Atchley, 'Activity Theory,' in R. Schulz, L.S. Noelker, K. Rockwood, R.L. Sprott (eds) The Encyclopedia of Aging $4^{\text {th }}$ edn. (2006; New York, Springer) p.9

${ }^{742}$ See Chapter 6, 'Capabilities Approach,'

${ }^{743}$ B.W. Lemon, 'An Exploration of the Activity Theory of Aging: Activity Types and Life Satisfaction Among InMovers to a Retirement Community, 'Journal of Gerontology' 27 (1972) 511-523,515, cited in C.F. Longino, 'Explicating Activity Theory: A Formal Replication,' 'Journal of Gerontology' Vol. 37, No. 6 (1982) 713-722 , 713

${ }^{744}$ B.W. Lemon, 'An Exploration of the Activity Theory of Aging: Activity Types and Life Satisfaction Among InMovers to a Retirement Community,' 'Journal of Gerontology' 27 (1972) 511-523 , 513

${ }^{745}$ Havighurst originally defined 'activity' as two-dimensional; Lemon et al later built on this definition and introduced the categories of formal, informal and solitary. M.R.J. Knapp, 'The Activity Theory of Aging: An Examination in the English Context,' 'The Gerontologist' Vol. 17 No. 6 (1977) 553-559, 554

${ }^{746}$ C.F. Longino \& C.S. Kart, 'Explicating Activity Theory: A Formal Replication,' 'Journal of Gerontology' Vol. 37, No. 6 (1982) 713-722, 714

${ }^{747}$ R.C. Atchley, 'Activity Theory,' in R. Schulz, L.S. Noelker, K. Rockwood, R.L. Sprott (eds) The Encyclopedia of Aging $4^{\text {th }}$ edn. (2006; New York, Springer) 10
} 
people are the same as middle aged with essentially the same psychological and social needs. ${ }^{178}$ This perception of older people highlights physical and cognitive vulnerability as a group identifier. Furthermore, by stressing the lack of difference between older and middle aged people, expectations and enactment of different behaviour or treatment cause vulnerabilities. As the theory asserts an instinct to desire and continue with all forms of activity, disengagement is viewed as a consequence of either social expectation or physiological incapacity. ${ }^{749}$ The older person therefore suffers 'aggravated vulnerability,' or vulnerability to numerous forms of threat. ${ }^{750}$

The crux of Activity Theory is the effect of imposed loss of roles and activities on the well being of the older adult; specifically to self-evaluation and associated outcomes. Activity Theory argues that the self is determined by roles performed in life. Thus, the self and others are viewed in terms of role-identities. $^{751}$ The quantity and quality of roles accumulated throughout life create the 'selfconcept,' something reinforced by the responses of others. The strongest endorsement of the self is received through informal activities in roles involving ties of kinship and affection. Any reduction or deterioration of such self-roles will create negative repercussions for self-perception during the ageing process, ${ }^{752}$ and self-respect, impacting dignity. ${ }^{753}$ Equally important to Activity Theory is to replace lost roles with like. Formal and solitary roles can only compensate for loss within the same category. Crucially, to replace either informal or formal roles with solitary activities, offers only 'symbolic or mentally construed audiences,' and minimal or imaged support. This outcome of reduced engagement is, therefore, most harmful to dignity, and attracts vulnerability to the physiological and psychological self. ${ }^{754}$

\footnotetext{
${ }^{748}$ R.J. Havighurst, 'Personality and Patterns of Aging,' 'Gerontologiest' 8 (1968) 20-23, cited in M.R.J. Knapp, 'The Activity Theory of Aging: An Examination in the English Context,' 'The Gerontologist' Vol. 17 No. 6 (1977) 553-559, 553

${ }_{749}$ M.R.J. Knapp, 'The Activity Theory of Aging: An Examination in the English Context,' 'The Gerontologist' Vol. 17 No. 6 (1977) 553-559, 553

${ }^{750}$ See Chapter 5, 'Vulnerability,'

${ }^{751}$ McCall, G.J. and Simmons, J.L., Identities and Interactions (1966; New York, Free Press) cited in B.W. Lemon, 'An Exploration of the Activity Theory of Aging: Activity Types and Life Satisfaction Among In-Movers to a Retirement Community,' 'Journal of Gerontology' 27 (1972) 511-523 , 513

${ }^{752}$ See Self-Perception Theory of Ageing

${ }^{753}$ B.W. Lemon, 'An Exploration of the Activity Theory of Aging: Activity Types and Life Satisfaction Among InMovers to a Retirement Community,' 'Journal of Gerontology' 27 (1972) 511-523 at pp. 513-514.

${ }^{754}$ B.W. Lemon, 'An Exploration of the Activity Theory of Aging: Activity Types and Life Satisfaction Among InMovers to a Retirement Community, 'Journal of Gerontology' 27 (1972) 511-523 , 514.
} 
Life satisfaction, 'the degree to which one is presently content or pleased with his general life situation, ${ }^{755}$ responds directly to self-concept. Satisfaction is significantly affected by loss of important roles and by negative life events, such as loss of a spouse, and best restored by increased regularity of informal activity. Activity Theory maintains that the number and regularity of informal interactions can determine whether life dissatisfaction is temporary or permanent, ${ }^{756}$ drawing inevitable comparison with the precariousness of the institution of the family ${ }^{757}$ associated with modernised society.

Activity Theory equates disengagement with unsuccessful ageing, describing the necessity of activity as follows:

'Activity provides various role supports necessary for reaffirming one's self-concept. The more intimate and the more frequent the activity, the more reinforcing and the more specific will be the role supports. Role supports are necessary for the maintenance of a positive self-concept which in turn is associated with high life satisfaction, ${ }^{758}$

Activity Theory argues activity and interaction in society essential to self-esteem and life satisfaction. Considering activity natural and instinctive to the older adult, the theory accuses disengagement of generating avoidable vulnerabilities. When added to inevitable vulnerabilities the group is at risk of 'aggravated vulnerability.' In this way Activity Theory strengthens the case against disengagement being 'natural, universal, inevitable and intrinsic' to the older person.

\subsection{Self-Perception Theory}

Perceptions of characteristics, traits, and expectations of capabilities and behaviour influence identification of older people as a group. Such perceptions, often stereotypical, direct selfperception and self-expectation. As with Activity Theory, Self-Perception Theory highlights the risk of exposing older people to unnecessary vulnerabilities, or hastening inevitable vulnerabilities via perception. This section will explore the effects of self-perception on older people. With reference

\footnotetext{
${ }^{755}$ B.W. Lemon, 'An Exploration of the Activity Theory of Aging: Activity Types and Life Satisfaction Among InMovers to a Retirement Community,' 'Journal of Gerontology' 27 (1972) 511-523, 513

${ }^{756}$ B.W. Lemon, V.L. Bengtson, and J.A. Peterson, 'An Exploration of the Activity Theory of Aging: Activity Types and Life Satisfaction Among In-Movers to a Retirement Community,' 'Journal of Gerontology' 27 (1972) 511-523, 515

${ }^{757}$ See Chapter 5, 'Vulnerability,' for role of institutions and institutional vulnerability.

758 Longino and Kart cited in B.W. Lemon, V.L. Bengtson, and J.A. Peterson, 'An Exploration of the Activity Theory of Aging: Activity Types and Life Satisfaction Among In-Movers to a Retirement Community,' 'Journal of Gerontology' 27 (1972) 511-523 , 515, cited in C.F. Longino \& C.S. Kart, 'Explicating Activity Theory: A Formal Replication,' 'Journal of Gerontology' Vol. 37, No. 6 (1982) 713-722 at pp. 717-718.
} 
to specific research projects the focus will be in the areas of: how older people perceive the social group to which they belong; the effects on cognitive behaviour; and influences over life expectancy and end of life decisions.

\subsubsection{Stereotyping and Self-stereotyping}

The Self-Perception Theory of ageing presents hypotheses of how self-perceptions of ageing are formed, and the effect of self-perception on successful ageing. Research undertaken at Yale University $^{759}$ into self-perception of older adults distinguished stereotyping from self-stereotyping. The 'stereotype threat ${ }^{760}$ faced by older people, is founded in the expectation by the majority that marginalised groups conform to social norms. This threat creates the social group to which they belong. Self-stereotyping, with the potential to injure self-respect and dignity, causing vulnerability, is pivotal to Self-Perception Theory. Self-stereotyping occurs when all thoughts, emotions and anxieties relating to ageing are internalised rather than expressed openly, which can manifest itself physiologically. ${ }^{761}$

The self-stereotypes held by older people are developed in youth, as early as the age of six. These initial views, which can be wholly opposed to more balanced views developed during the course of life, come to the fore when older. ${ }^{762}$ This coincides with a weakening will to reason against stereotypes as the person ages. ${ }^{763}$ Research undertaken by Harvard University into the effect of selfstereotyping on cognitive performance demonstrates this phenomenon, and is explained below. The same research quoted the perception held by a 78 year old participant of older people as a group as evidence of the ability of subliminal stereotypes to distort judgment and confidence. ${ }^{764}$ Perception of the group in this case was reported as 'senile, slow, sick, blind and stooped over.' This contrasted with the actual condition of the individual, as an 'alert, energetic, healthy woman with normal eyesight and good posture.'

\footnotetext{
${ }^{759}$ B.R. Levy, M.D. Slade, S.V. Kasl, S.R. Kunkel, 'Longevity Increased by Positive Self-Perceptions of Aging,' 'Journal of Personality and Social Psychology,' Vol. 83. No. 2 (2002) 261, 261.

Research undertaken of a sample of 660 individuals over 50 years of age taking part in the Ohio Longitudinal Study of Aging and Retirement community-based survey (OLSAR).

${ }^{760}$ Wheeler and Petty (2001), cited in B.R. Levy, M.D. Slade, S.V. Kasl, S.R. Kunkel, 'Longevity Increased by Positive Self-Perceptions of Aging,' 'Journal of Personality and Social Psychology,' Vol. 83. No. 2 (2002) 261, 261.

${ }^{761}$ B.R. Levy, M.D. Slade, S.V. Kasl, S.R. Kunkel, 'Longevity Increased by Positive Self-Perceptions of Aging,' 'Journal of Personality and Social Psychology,' Vol. 83. No. 2 (2002) pp. 261, 261.

762 'To Be or Not To Be: The Effects of Aging Stereotypes on the Will to Live,' 'Omega' Vol. 40(3) (1999-2000) 409-420, 410.

${ }^{763}$ B.R. Levy, M.D. Slade, S.V. Kasl, S.R. Kunkel, 'Longevity Increased by Positive Self-Perceptions of Aging,' 'Journal of Personality and Social Psychology,' Vol. 83. No. 2 (2002) pp. 261-270,261.

${ }^{764}$ B. Levy, 'Improving Memory in Old Age Through Implicit Self-Stereotyping,' 'Journal of Personality and Social Psychology,' Vol. 71 No. 6 (1996) 1092-1107,1092.
} 
The stereotypes implicitly accepted by older people are defined as, 'thoughts about the attributes and behaviours of the elderly that exist and operate without conscious awareness, intention or control. ${ }^{765}$ Subsequently, the beliefs held by older people of themselves as a group correlate to those held by society. ${ }^{766}$ A series of computerised laboratory trials at Harvard University ${ }^{767}$ determined that these thoughts can be triggered by formulaic images associated with increasing age. The trials identified a correlation between positive and negative self-stereotyping, function and exposure to group stereotyping, ${ }^{768}$ as participants adopted the persona and characteristics of the images to which they had been exposed. When exposure was to either senility or wisdom effects on memory function were evident. The impact of stimulus for senility resulted in diminished ability to recall 'immediate, learned, delayed and auditory' memory. ${ }^{769}$ The opposite effect was generated when participants were shown the stimulus for wisdom. ${ }^{770}$ Also affected were self-efficacy and opinion held of older people as a group. ${ }^{771}$

\subsubsection{Influence of societal opinion on self-stereotypes}

The development and internalisation of self-stereotypes are founded in societal opinion, subgrouping, existence of older role models and strength of character. ${ }^{772}$ The negative influence of societal stereotyping on self-stereotyping and subsequently individual capabilities is also represented in research by Harvard University. The subjects of the study comprised members of a Chinese community, in which societal beliefs are more positive than those of the West, and of a group of deaf older American citizens. Neither group had been systematically subjected to negative perceptions of older people, and all participants demonstrated higher memory function than hearing

\footnotetext{
${ }^{765}$ B.R. Levy, and M.R. Banaji, 'Implicit Ageism' in T.D. Nelson (ed.), Ageism: Stereotyping and Prejudice against Older Persons, (2002; M.I.T. Press) 51

${ }^{766}$ B.R. Levy, M.D. Slade, S.V. Kasl, S.R. Kunkel, 'Longevity Increased by Positive Self-Perceptions of Aging,' 'Journal of Personality and Social Psychology,' Vol. 83. No. 2 (2002) pp. 261-270 ,262.

${ }^{767}$ Research undertaken by Levy, B., Harvard University (1996) www.ReducingStereotypeThreat.org Accessed on $05 / 08 / 2012$

${ }^{768}$ The research participants comprised 90 individuals of over 60 years, with an average age of 73 years. Exposure consisted of displaying distinguishing characteristics of older people on a screen slower than the speed of awareness prior to physical and cognitive tests undertaken as part of the research. Levy 1996 cited in B.R. Levy, M.D. Slade, S.V. Kasl, S.R. Kunkel, 'Longevity Increased by Positive Self-Perceptions of Aging,' 'Journal of Personality and Social Psychology,' Vol. 83. No. 2 (2002) pp. 261-270,262

${ }^{769}$ B. Levy, 'Improving Memory in Old Age Through Implicit Self-Stereotyping,' 'Journal of Personality and Social Psychology' Vol. 71, No. 6 (1996) pp. 1092-1107,1097

${ }^{770}$ B. Levy, 'Improving Memory in Old Age Through Implicit Self-Stereotyping,' 'Journal of Personality and Social Psychology' Vol. 71, No. 6 (1996) pp. 1092-1107,1100

${ }_{771}$ B.R. Levy, M.D. Slade, S.V. Kasl, S.R. Kunkel, 'Longevity Increased by Positive Self-Perceptions of Aging,' 'Journal of Personality and Social Psychology,' Vol. 83. No. 2 (2002) pp. 261-270,262

772 B.R. Levy, M.D. Slade, S.V. Kasl, S.R. Kunkel, 'Longevity Increased by Positive Self-Perceptions of Aging,' 'Journal of Personality and Social Psychology,' Vol. 83. No. 2 (2002) pp. 261-270,262
} 
older American participants. ${ }^{773}$ Additionally, when compared to the memory capacity of younger Chinese participants, the older members of the cohort recorded 'no significant differences,' supporting the notion that societal stereotyping negatively impacts self-perception and quality of life. $^{774}$

Research is also informative on the impact of negative self-perception, caused by societal stereotyping, on life expectancy. ${ }^{775}$ Opinion on personal physical ability was related to self-rated health, ${ }^{776}$ Ioneliness, and mortality. ${ }^{777}$ Results reported 'considerable evidence that self-rated health influences survival,' and that 'loneliness [as a result of societal expectations of self-dependency] predicts survival and tends to correlate with another predictor of survival: depression. ${ }^{778}$ In the final analysis of the Yale longevity study, positive self-perception accounted for an increase in length of life of $50 \%$ above the median survival rate of those with a negative self-perception. Those with an optimistic opinion of the self and of growing older ${ }^{779}$ could expect to live 7.6 years longer. Underscoring the significance of negative stereotyping and self-perceptions on older people, the

\footnotetext{
${ }^{773}$ B. Levy \& E. Langer (1994). 'Aging free from negative stereotypes: Successful memory in China and among the American deaf,' 'Journal of Personality and Social Psychology,' 66, 989-997, cited in B. Levy 'Improving Memory in Old Age Through Implicit Self-Stereotyping,' 'Journal of Personality and Social Psychology' Vol. 71, No. 6 (1996) pp. 1092-1107, 1093

774 D. Schacter, A. Kaszniak, and J. Kihlstrom (1991) 'Models of Memory and the Understanding of Memory Disorders,' cited in B. Levy 'Improving Memory in Old Age Through Implicit Self-Stereotyping, 'Journal of Personality and Social Psychology' Vol. 71, No. 6 (1996) pp. 1092-1107,1093.

${ }^{775}$ Levy et al. assessed the relationship between self-perception and longevity using research of 660 individuals selected from 1,157 original participants aged over 50 years for the duration of 22 years, available from the Ohio Longitudinal Study of Aging and Retirement and the National Death Index. All 660 were fully functioning cognitively and lived as part of a community. The stereotyping standards which formed the basis of statements against which the over 50s gauged their perception of themselves were drawn from the Attitudes Toward Own Aging subscale. Research began in 1975; B.R. Levy, M.D. Slade, S.V. Kasl, S.R. Kunkel, 'Longevity Increased by Positive Self-Perceptions of Aging,' 'Journal of Personality and Social Psychology,' Vol. 83. No. 2 (2002) pp. 261-270,263

${ }^{776}$ Research of American adults between ages of 25-74 of low self-ratings of health. Data provided by National Health And Nutrition Examinations 1971-1975 and death records and from the 1982 and 1992 follow-up interviews. E.L. Idler, L.B. Russell and D. Davis, 'Survival, Functional Limitations and Self-rated Health in the NHANES I Epidemiologic Follow-Up Study,' 'American Journal of Epidemiology' 52 (9) (2000) 874-883

777 Cacioppo. J.T. et al. 'Lonely traits and concomitant physiological processes: The MacArthur Social Neuroscience Studies,' International Journal of Psychophysiology' 35 (2000) 143-154, cited in B.R. Levy, M.D. Slade, S.V. Kasl, S.R. Kunkel, 'Longevity Increased by Positive Self-Perceptions of Aging, 'Journal of Personality and Social Psychology,' Vol. 83. No. 2 (2002) pp. 261-270,264

778 B.R. Levy, M.D. Slade, S.V. Kasl, S.R. Kunkel, 'Longevity Increased by Positive Self-Perceptions of Aging,'

'Journal of Personality and Social Psychology,' Vol. 83. No. 2 (2002) pp. 261-270,264

${ }^{779}$ Measured up to 23 years earlier as part of the Yale University longevity study. ${ }^{779}$ B.R. Levy, M.D. Slade, S.V. Kasl, S.R. Kunkel, 'Longevity Increased by Positive Self-Perceptions of Aging,' 'Journal of Personality and Social Psychology,' Vol. 83. No. 2 (2002) pp. 261-270,261
} 
research reported that each one point increase of positivity represented a $13 \%$ fall in the risk of death. $^{780}$

Reduced life expectancy caused by negative self-perception is partly attributed to a loss of will to live. ${ }^{781}$ In hypothetical situations offering treatment for life-threatening conditions, ${ }^{782}$ participants were exposed to imagery of negative and positive perceptions of ageing, including: experience or decrepitude; being active or bed-ridden; kind or wrinkled. ${ }^{783}$ Older research participants exposed to negative primes were recorded as 'tending to refuse,' despite the alternative of imminent death. ${ }^{784}$ Decisions were largely unaffected by personal values, including religious beliefs, indicative of the strength of influence of negative stereotyping over matters of personality and enselfment. ${ }^{785}$

'It is clear ... that the will to live, which is an intensely personal decision, is also a societal decision in old age. Negative stereotypes of ageing, which are the prevailing ones, have the capacity to adversely affect not only the quality of life for the aged, but perhaps the duration of it. $^{, 786}$

Significantly, those presented with positive primes chose to live in similar proportions. The researchers interpret this as evidence of the robustness of internalised stereotypes and the proliferation of negative attitudes. Seeing the negative primes as strengthening and drawing from deeply held self-stereotypes learned from the earliest of ages, it was deduced that potential for

\footnotetext{
${ }^{780}$ B.R. Levy, M.D. Slade, S.V. Kasl, S.R. Kunkel, 'Longevity Increased by Positive Self-Perceptions of Aging,' 'Journal of Personality and Social Psychology,' Vol. 83. No. 2 (2002) pp. 261-270

${ }^{781}$ Research undertaken was subliminal, of the type used to establish how self-stereotyping occurs. The 64 community-based participants included both young and older people. B. Levy, O. Ashman \& I. Dror, 'To Be Or Not To Be: The Effects of Aging Stereotypes On The Will To Live,' 'Omega,' Vol.40(3) (1999-2000) 409-420; Thirty two participants were aged between 61 and 85 years, the remaining thirty two were aged between 18 and 35 years.

${ }^{782}$ The hypothetical situations in which participants were offered treatment for life-threatening illnesses included a $25 \%$ chance of complete recovery or $75 \%$ chance of death within the month, $50 \%$ chance of recovery or death within the month and $75 \%$ chance of recovery or $25 \%$ chance of death within the month. Should no treatment be chosen then the result in all cases would be death within the month.

782 B. Levy, O. Ashman \& I. Dror, 'To Be Or Not To Be: The Effects of Aging Stereotypes On The Will To Live,' 'Omega,' Vol.40(3) (1999-2000) 409-420,414

${ }^{783}$ B. Levy, O. Ashman \& I. Dror, To Be Or Not To Be: The Effects of Aging Stereotypes On The Will To Live,' 'Omega,' Vol.40(3) (1999-2000) 409-420,414.

${ }^{784}$ B. Levy, O. Ashman \& I. Dror, 'To Be Or Not To Be: The Effects of Aging Stereotypes On The Will To Live,' 'Omega,' Vol.40(3) (1999-2000) 409-420,409,416

785 B. Levy, O. Ashman \& I. Dror, 'To Be Or Not To Be: The Effects of Aging Stereotypes On The Will To Live,' 'Omega,' Vol.40(3) (1999-2000) 409-420,417.

${ }^{786}$ B. Levy, O. Ashman \& I. Dror, 'To Be Or Not To Be: The Effects of Aging Stereotypes On The Will To Live,' 'Omega,' Vol.40(3) (1999-2000) 409-420,417
} 
greater deviation from the norm lay in the reactions of those shown positive images rarely associated with ageing. ${ }^{787}$

\subsection{Life Course Theory}

Life-course theory, or life-course perspective, as it is more commonly known, offers a fundamental departure from traditional methods employed by ageing theories to identify older people as a group, and the vulnerabilities to which they are exposed. The theory argues against the standardised life cycle approach, a structure which defines life by phases of activity, fixed sequences of events and expected behaviour patterns, and milestones. A life-course perspective recognises the heterogeneity of older people, and incorporates principles of experiences of events and roles, social conditions, linked lives, and agency into descriptions. The theory recognises individualised rather than standardised life cycles. The individualised life cycle has been defined as 'choice biography, ${ }^{788}$ stressing the choice of the individual to participate in activities beyond any boundaries or restrictions imposed by age. With an emphasis on the heterogeneity of human nature, the concept of life-course does not aim to define social groups by chronological age, nor by a strict adherence to life-cycle definitions. By arguing against adherence to the standardised life cycle, Life-Course Theory rejects stereotypical perceptions of older people. This approach to identifying individuals and the social group and the treatment of them, therefore, works to lessen the vulnerabilities suffered. This section of the Ageing Theories chapter will examine the Life-Course Theory approach to identification of older people.

\subsubsection{Life Course}

The Life Course Theory adheres less strictly to the traditional structured life cycle approach and the inherent expectations. ${ }^{789}$ Life Course Theory perceives life to be an experience of events and roles, the order of which is of little consequence. Also influential are the present and historical social conditions of life. ${ }^{790}$ By defining the life course in terms of stages, trajectories, transitions, and events the individuality of every life can be determined. ${ }^{791}$

\footnotetext{
${ }^{787}$ B. Levy, O. Ashman \& I. Dror, 'To Be Or Not To Be: The Effects of Aging Stereotypes On The Will To Live,' 'Omega,' Vol.40(3) (1999-2000) 409-420,417

${ }^{788}$ M. Elchardus and W. Smits 'The Persistence of the Standardized Life Cycle,' 'Time \& Society' 2006; 15, 2/3 pp 303-326, 304

${ }_{789}$ M. Elchardus and W. Smits, 'The Persistence of the Standardized Life Cycle,' 'Time \& Society' 2006; 15, 2/3 pp 303-326, 306

790 J.T. Mortimer, and M.J. Shanahan, Handbook of the Life Course (2006; Springer, New York), 7

${ }^{791}$ G.H. Elder, 'Time, Human Agency and Social Change: Perspectives on the Life Course,' Social Psychology Quarterly,' March 1994; vol. 57, No. 1, 4-15,7
} 
The Life Course approach depicts a number of trajectories which occupy lengthy and identifiable periods of life, such as education, career, and family life. Within each trajectory are influential transitions which follow the socially constructed, or standardised, life course. ${ }^{792}$ Responding to social norms, these transitions include events such as marriage, career change and retirement. Association can be made between trajectories, transitions and chronological age. Events such as the end of working life often correspond with a specified age, others are appropriate to age ranges, including marriage, having a family, or when an adult is no longer suited to education or retraining. ${ }^{793}$ Life-Course Theory differs from standardised life cycle approaches by viewing the interaction of trajectories and transitions in conjunction with principles which underpin the theory's approach to, and classification of, human life. Specifically, the principles are: the interaction of human lives and historical periods; the timing of lives; and linked or independent lives. ${ }^{794}$

\subsubsection{Historical periods and timing of lives}

Life courses are moulded by historical periods. ${ }^{795}$ The generalities and events of the time will influence opportunities and limitations of life experiences, and distinguish life patterns of groups and individuals. $^{796}$ The Life Course approach to examining and explaining life stages rejects the agerelated standardisation of life experiences. However, the weight given to the timing of life makes birth year, and therefore age, significant to the approach when identifying groups, ${ }^{797}$ described as 'an aggregate of individuals anchored together in historical time - normally defined on the basis of birth year. ${ }^{798}$

Timing, or a 'temporal, age-graded perspective to social roles and events ${ }^{\prime 799}$ identifies life stages by patterns and age. The timings of events in life also explains some vulnerabilities of the group

\footnotetext{
792 C. Dewilde, 'A life-course perspective on social exclusion and poverty,' British Journal of Sociology, March 2003; Vol. 54, Issue 1, 109-128,118

${ }^{793}$ B.A. Mitchell, 'Life Course Theory,' International Encyclopedia of Marriage and Family, 2003; Encyclopedia.com April 6, 205. www.encyclopedia.com/doc/1G2-3406900275.html Accessed 07/04/2015; G.H. Elder, 'The Life Course as Developmental Theory,' 'Child Development,' February 1998; Vol.69, No. 1, 1-2 ${ }^{794}$ G.H. Elder 'Time, Human Agency and Social Change: Perspectives on the Life Course,' Social Psychology Quarterly,' March 1994; vol. 57, No. 1, 4-15,5

795 J.T. Mortimer and M.J. Shanahan, Handbook of the Life Course (2006; Springer) ,12

${ }^{796}$ G.H. Elder, 'Time, Human Agency and Social Change: Perspectives on the Life Course,' Social Psychology Quarterly,' March 1994; vol. 57, No. 1, 4-15,5

${ }^{797}$ G.H. Elder, 'Time, Human Agency and Social Change: Perspectives on the Life Course,' Social Psychology Quarterly,' March 1994; vol. 57, No. 1, 4-15,5

${ }^{798}$ G.H. Elder, 'Time, Human Agency and Social Change: Perspectives on the Life Course,' Social Psychology Quarterly,' March 1994; vol. 57, No. 1, 4-15,7

${ }^{799}$ G.H. Elder, 'Time, Human Agency and Social Change: Perspectives on the Life Course,' Social Psychology Quarterly,' March 1994; vol. 57, No. 1, 4-15,6
} 
through experiences of cumulative advantage or disadvantage of the period. ${ }^{800}$ Extremes of living standards and societal values are often experienced by those living through rapidly evolving times. ${ }^{801}$ This results in constant transition and changes to trajectories, potentially causing premature entry into later life stages. ${ }^{802}$ Therefore, it is possible to identify older people as a group by type and degree of advantage or disadvantage, and by commonality in changes to life direction. ${ }^{803}$

\subsubsection{Linked Lives}

The Life Course Theory accords with theories of ageing that recognise the role of relationship networks, particularly those involving ties of kinship and emotion. ${ }^{804}$ Within these relationships, transitions experienced by one party are able to trigger transitions in the lives of others. ${ }^{805}$ Referring back to Fineman's Dependency Thesis, it is possible to associate this principle to the inevitable dependency of one person generating derived dependency in another. When transitions occur in lives linked intergenerationally older people can experience the greatest effects. This is in agreement with issues of filial obligation raised earlier in the chapter. Decisions of younger generations to follow life trajectories have the potential to leave older people isolated and lacking support. Additionally, lives are no longer linked to workplace or community relationships exacerbate problems of isolation, self-perception and dependency. ${ }^{806}$

The key tenet of lives lived interdependently builds on the identification of a group by disadvantage as a result of historical lives and timing. Such disadvantage is intensified when links between lives are weakened or broken. The isolation, negative self perception and dependence it creates, subjects

\footnotetext{
${ }^{800}$ Known as the 'Matthew Effect,' the historical and social settings in which the life course is lived will set life directions, and can also perpetuate situations. Taken from the Gospel of St. Matthew in which he explains how it is possible that the poor and disadvantaged can remain so. Dannefer, D., 'Cumulative Advantage/Disadvantage and the Life Course: Cross-Fertilizing Age and Social Science Theory,' 'Journal of Gerontology,' 2013; Vol. 58B, No. 6, S327-S337 ,S327; Merton, R.K., 'The Matthew effect in science II: Cumulative advantage and the symbolism of intellectual property,' 'ISIS,' 79, 606-623,606, cited in D. Dannefer 'Cumulative Advantage/Disadvantage and the Life Course: Cross-Fertilizing Age and Social Science Theory,' 'Journal of Gerontology,' 2013; Vol. 58B, No. 6, S327-S337 ,S327.

${ }^{801}$ G.H. Elder, 'Time, Human Agency and Social Change: Perspectives on the Life Course,' Social Psychology Quarterly,' March 1994; vol. 57, No. 1, 4-15,5

${ }^{802}$ G.H. Elder, Kirkpatrick Johnson, M. and Crosnoe, R., 'The Emergence and Development of Life Course Theory,' in Mortimer, J.T. and Shanahan, M.J., Handbook of the Life Course, (2004; Springer, New York) ,13

${ }^{803}$ C. Dewilde, "A life course perspective on social exclusion and poverty,' British Journal of Sociology, March 2003; Vol. 54, Issue 1, 109-128, 117

${ }^{804}$ G.H. Elder, 'Time, Human Agency and Social Change: Perspectives on the Life Course,' Social Psychology Quarterly,' March 1994; vol. 57, No. 1, 4-15,6

${ }^{805}$ G.H. Elder, Kirkpatrick Johnson, M. and Crosnoe, R., 'The Emergence and Development of Life Course Theory,' in Mortimer, J.T. and Shanahan, M.J., Handbook of the Life Course, (2004; Springer, New York) ,13 ${ }^{806}$ G.H. Elder, 'Time, Human Agency and Social Change: Perspectives on the Life Course,' Social Psychology Quarterly,' March 1994; vol. 57, No. 1, 4-15,6
} 
of theories of ageing discussed earlier, become identifiable with older people by the Life-Course approach.

\subsection{Conclusion}

This study of principal theories of ageing has drawn on the reasoning which explains processes involved in the creation of threats and vulnerable outcomes common to older people. In this way, the theories provide a guide to identification of the group by experience of processes and the nature of threat and vulnerability posed. A further guide to the vulnerabilities of the group can be formulated from the positive and negative effects claimed by the theories on the notion of successful ageing. The hypotheses and practices discussed will inform later chapters in Part III of the thesis, most specifically Chapter 10 which examines what it means to be an older person in the U.K. with specific reference to type and prevalence of lived situations and vulnerabilities experienced. The rationale of the various theories will also provide clarity to the examination of human rights provision vis à vis lived problems and the outcomes of manifested threats in Part IV.

Despite aspects of Modernisation Theory being contested, the interrelation of lack of demand for older people in the workforce, migration, lack of family support and care is significant. The emphasis by the theory of this combination highlights the vulnerability of older people to loss of status, reduced self-respect, lone living, quantitative and qualitative loss of relationships and 'purposeful economic and social roles,' poverty, and social isolation. Partly in response to criticism of the abandonment outcome of modernised societies, by demonstrating that the outcome need not be purposeful proved it a reality. Changes to filial obligation, whether motivated by material constraint, prioritisation of the youngest family members over the oldest, or societal values, the lived experience of older people is increasingly familial separation and lack of support.

The theme of lack of productivity, present in Modernisation Theory directly takes on the issue of 'usefulness' in Productivity theories. This perception of older people is one of negative net effect on the economy and resources, with the potential to encourage the distribution of institutional assets to the more productive. Interpretations of productivity beyond economic are accorded little value, as are the older people involved in social or familial forms of productivity. Negative stereotyping creates further harm through expectation that older people 'disengage' from society, and as a result of negative self-perception of older people, de-socialisation occurs. Promoted as a coping strategy for adapting to life changes, disengagement is described as voluntary and necessary to successful ageing by Disengagement theories. These theories argue that the benefits of the ability to adapt 
outweigh the disadvantages of reduced 'active engagement with life.' The association of decreased number and range of activities with life events is accepted. Also accepted is the strength of selfperception and expectation to withdraw from relationships at the end of life trajectories, together with the influence of societal perceptions, practices and values. However, Activity Theory emphasises both the role of 'active engagement with life' in successful ageing and the outcomes caused by disengagement. Opposed to 'de-socialisation' and the subsequent harmful effects Activity Theory differentiates between middle-aged and older persons only on the basis of declining health. Thus, the maintenance of roles from middle-age into older age is essential. Moreover, any roles lost must be replaced with like roles. This direct opposition to the claims of Disengagement Theory targets the prevention of isolation. By taking the counter position to Disengagement theories, Activity Theory classifies disengagement and role loss as a process leading to vulnerabilities of marginalisation, social isolation and multiple health problems, (see Chapter 9) all of which contribute to the identification of older people as a group.

The link between activity and self-perception is significant to successful ageing as a factor in lifesatisfaction. Activity Theory and Self-Perception Theory recognise the risk of exposure to noninevitable vulnerabilities, or hastening inevitable vulnerability, presented by negative perceptions, stereotyping, and discrimination. Identification of the group through any of these factors is ultimately identification by means of societal rejection. In short, self-stereotyping by older people imposes risks of all types of harm generated by the negative stereotype. By adopting the persona, older people conform to all negative aspects of ageing and become exposed to the associated vulnerabilities.

In a departure from theories which are predominantly aligned to standardised life cycle, the LifeCourse Theory of ageing defines life individually by stages and events. Therefore, the lives of older people are not viewed in terms of expected processes. Instead, the period of history in which life is lived, influencing opportunities, advantages and disadvantages accumulated throughout life is key. The disadvantages a person gathers are augmented by events in the lives of those with whom the older person shares a relationship. Most influential are the relationships with ties of kinship and affection. Linking to Activity Theory and Modernisation Theory, Life-Course Theory cites examples of migration of younger family members, loss of employment, and loss of a spouse as of greatest importance to accumulation of disadvantage. The effect of the interaction of accumulated disadvantage with negative effect of an inter-linked life is intensification of isolation, poverty, selfperception, and dependency. The degree of vulnerability generated, is considered by this approach 
to be controlled by agency, making the vulnerability experience of the older person individual. Thus the heterogeneity of older people contributes to arguments against generic identification of the group, a point which will be returned to in the next chapter. Despite individual vulnerability experiences, structures, patterns and life changing events prompting, or prompted by, processes leading to vulnerability remain identifiable.

The direction provided by theories of ageing as to life processes, causes of threats and specific vulnerabilities suffered by older people will inform further identification of the group. The nature and range of vulnerabilities will contribute to the question of whether the group is deserving of special protection. The next chapter will explore the inevitable vulnerability of the person, described earlier in the thesis as biological. Following the risks and outcomes of inevitable vulnerability the chapter discusses the issues of identification of older people by chronological age, with particular reference to retirement age, years left to live, and the problems of defining an age for a special protection group. The research of older people is completed by an investigation of the actual vulnerabilities suffered, informed by the thinking and conclusions of ageing theories. 


\section{CHAPTER 9}

\section{DEFINING OLDER PEOPLE BY THE AGEING PROCESS AND CHRONOLOGICAL AGE}

\subsection{Introduction}

This chapter examines two of the most widely used identifiers of older people: physical and cognitive ill-health, and chronological age. The ageing process of physical and cognitive decline is the inevitable and ontological vulnerability which begets other vulnerabilities and inevitable dependency. ${ }^{807}$ The inevitability of this decline will be briefly explained for the purpose of further stating the type, variety and number of conditions that older people experience, and which progressively worsen with age, increasing biological and all other vulnerabilities associated to it. The intensity of the inevitable vulnerability suffered by older people will be introduced through the principles of co-morbidity, and compression and expansion of morbidity. The possibility of suffering from three categories of age-associated physical illness and cognitive disease simultaneously is stated in relation to the alternatives of decrepitude compressed into shorter periods of life, and living longer with longer periods of compounded ill-health. Cognitive disease is discussed separately in this chapter due to a degree of defined association with socio-economic and educational status. The association serves as an example of accumulated disadvantage, ${ }^{808}$ and aggravated vulnerability. Moreover, how coping mechanisms, developed as a result of cognitive disease, impact ability to undertake activities of daily living will be discussed, which can lessen dependency. The outcomes and effects will be illustrated in the lived vulnerabilities of older people in the U.K. in the next chapter.

Chronological age is a regular means of identification of older people. Difficulties in defining an exact age at which people are considered 'older' informs decisions relating to the point at which special protection should be made available to the group. Discussion will recognise that, as a single measure, it is unable to be sufficiently flexible to account for heterogeneity, whilst acknowledging the benefit of a generic standard. The chapter specifically reviews methodologies of setting retirement age and of deciding 'old age' through the approach of 'years left to live.' Retirement age is included as it is the universal reference, and this chapter reviews the influences which have resulted in regular changes to retirement age. The U.K. is used to demonstrate the principle that this life event has age related to it which cannot be fixed temporally or spatially. The 'years left to live' approach will be shown to take greater account of increases in longevity, and to be more

${ }^{807}$ See Chapter 5, 'Vulnerability,'

${ }^{808}$ As described in Life-Course Theory, see Chapter 8, 'Theories of Ageing,' . 
representative, at least in the West, of the age at which physical and cognitive illness significantly worsens.

The study of the methods of identifying older people advances to a discussion of the point at which special protection should be accessible to the group. Discussion to this point has informed the type, combination, and prevalence of vulnerabilities common to the group. Similarities can be drawn between the situation of older people and children. Therefore, the rationales of the States parties to the UNCRC in drafting the Convention and in deciding the point at which special protection is not needed by members of the group will be examined. The purpose is to make correlation, where relevant, to the position of older people, and for guidance in suggesting a point at which special protection should be made universally available to older people as a vulnerable group.

\subsection{Physical and cognitive ageing}

Physical and cognitive ageing is a key identifier of older people. The earlier examination of the concept of vulnerability ${ }^{809}$ found the 'ontological condition of our humanity' to be the starting point, and universal and inevitable factors of embodied vulnerability. ${ }^{810}$ The fact that it constantly exposes the person, particularly the older person, to threat ${ }^{811}$ with outcomes of vulnerability, is the reason for exploring the process and consequences of physical and cognitive ageing. The vulnerabilities which biological ageing brings to the lives of older people will be explored in the next chapter.

\subsubsection{Senescence}

Physical and cognitive ageing occurs by senescence, the 'time-related deterioration of the physiological functions. ${ }^{812}$ This inherent and inevitable ontological vulnerability ${ }^{813}$ is the '...[P]rogressive deterioration during the adult period of life that underlies an increasing vulnerability to challenges and a decreasing ability of the organism to survive. ${ }^{814}$ Senescence essentially prevents the body maintaining itself and from withstanding internal and external threat. ${ }^{815}$ The process is

\footnotetext{
${ }^{809}$ See Part II, Chapter 5, 'Vulnerability.'

${ }^{810}$ See Chapter 5, 'Vulnerability'

${ }^{811}$ See Chapter 5, 'Vulnerability'

${ }^{812}$ S.F. Gilbert, 'Developmental Biology' $6^{\text {th }}$ edition. Sunderland (MA): Sinaur Associates; 2000. Aging: The Biology of Senescence. Available from www.ncbi.nih.gov/books/NBK10041. Accessed on 10/08/2014

${ }^{813}$ See chapter 5, 'Vulnerability,' heading 5.3.1.1 'Embodied Vulnerability.'

${ }^{814}$ E.J. Masoro, 'Are Age-Associated Diseases and Integral Part of Aging?', in S.N. Austad \& E.J. Masoro, Handbook of the Biology of Aging ( $6^{\text {th }}$ edition), (2005; Academic Press) 44

815 R. Holliday, 'Aging is No Longer an Unsolved Problem in Biology,' 'Annals New York Academy of Sciences'2006; 1067: 1, 1 \& 5
} 
irreversible, ${ }^{816}$ ultimately resulting in death. ${ }^{817}$ However, the multiple degenerative, incurable diseases it causes are managed through institutional assets including health and social care, which aim to maintain health and prevent conditions worsening.

The science of the ruin of essential maintenance systems is beyond the scope of this work, as the aim is to explore the effects on older people, and the following section will examine when ageing begins, and the diseases it causes. However, the interested reader is directed to sources of scientific explanation of the process. ${ }^{818}$

\subsubsection{Progression of senescence and disease}

When human physiology begins to break down at the end of reproductive usefulness, the ageing phenotype is recognisable. ${ }^{819}$ Disease is integral to this phenotype, and therefore, to the embodied vulnerability of the older person. Some of the diseases of the ageing process have the same effect on the body as senescence, constantly and cumulatively attacking the constitution and function. ${ }^{820}$ Thus, ageing causes the human body to disintegrate, and intensifies the process of disease 'in everyone who lives long enough and the severity of their impact invariably increases with age. ${ }^{821}$

Diseases most related to older age fall into two classifications: 'age-dependent' and 'age-related. ${ }^{822}$ Age-dependent diseases are caused by senescence, and the effect intensifies with age. ${ }^{823}$ Age-

\footnotetext{
${ }^{816}$ E.J. Masoro, 'Are Age-Associated Diseases and Integral Part of Aging?', S.N. Austad \& E.J. Masoro, Handbook of the Biology of Aging ( $6^{\text {th }}$ edition), (2005; Academic Press) 44

${ }^{817}$ See generally; R. Holliday, 'Aging is No Longer an Unsolved Problem in Biology,' 'Annals New York Academy of Sciences'2006; 1067: 1-9; P.W. Estep 'The Promise of Human Life Span Extension,' 'Annual Review of Gerontology and Geriatrics,' 2007; Vol.27 pp.29-34; T.B. Kirkwood 'Why Does Aging Occur?,' 'Annual Review of Gerontology and Geriatrics,' Vol.21; 2001: 'Modern Topics in the Biology of Aging,' Springer Publishing Company. ProQuest ebrary. Accessed 07/08/2014

${ }^{818}$ For description of DNA, cell and tissue repair; protein repair or removal; efficiency of immune and healing systems see R. Holliday, 'Aging is No Longer an Unsolved Problem in Biology,' 'Annals New York Academy of Sciences'2006; 1067: 1-9, 5; For detail on molecular change and deterioration causing the numerous systems of cellular maintenance and repair to break down and not keep pace with the damage to the soma ('Soma' is the term for all cells other than reproductive cells that comprise the living being. B.A. Carries, \& S.J. Olshansky, 'Evolutionary Perspectives on Human Senescence,' 'Population and Development Review' Volume19, Issue 4 (Dec 1993), 793-806, 795) see L. Hayflick, 'Biological Aging Is No Longer an Unsolved Problem,' Ann. N.Y. Acad. Sci. 1100: 1-3 (2007),3; For the mutation, damage to communication between cells and death of cells causing disease and degeneration see Rattan, S.I.S., 'Theories of biological aging: Genes, proteins, and free radicals,' 'Free Radical Research,' December 2006; 40(12): 1230-1238,1231.

${ }^{819}$ B.A. Carnes, D.O. Staats and W.E. Sonntag 'Does senescence give rise to disease?' Mech Ageing Dev. 2008 Dec: 129(12): 693-699,696

${ }^{820}$ Specifically arteriosclerosis and osteoporosis, B.A. Carnes, D.O. Staats and W.E. Sonntag 'Does senescence give rise to disease?' Mech Ageing Dev. 2008 Dec: 129(12): 693-699, 694

${ }^{821}$ B.A. Carnes, D.O. Staats and W.E. Sonntag 'Does senescence give rise to disease?' Mech Ageing Dev. 2008 Dec: 129(12): 693-699, 698

${ }^{822}$ E.J. Masoro, 'Are Age-Associated Diseases and Integral Part of Aging?', S.N. Austad \& E.J. Masoro, Handbook of the Biology of Aging ( $6^{\text {th }}$ edition), (2005; Academic Press) ,45
} 
related disease is affiliated to age rather than integral to the ageing process. This form of disease worsens with age, but not, with few exceptions, ${ }^{824}$ at the pace of age-dependent disease. ${ }^{825} \mathrm{~A}$ third classification of disease is one which is not age-related, but carries more morbid outcomes for older people. $^{826}$

\subsubsection{Co-morbidity, compression and expansion of morbidity in old age}

Ageing occurs as the result of the failure of multiple maintenance systems. ${ }^{827}$ Therefore, the person inevitably becomes vulnerable to co-morbidity, 'the concurrent presence of two or more medically diagnosed diseases in the same individual... ${ }^{828}$ with the potential to suffer a combination of degenerative, progressive and infectious diseases. Some definitions of senescence state this intensification of vulnerability is compressed into the last years of life, meaning that '...chronic disease will occupy a smaller proportion of the typical life span. ${ }^{829}$ For the person not benefitting from compression of morbidity, increased longevity equates to increased time spent in conditions of incapacity. ${ }^{830}$ Whether co-morbidity compresses or extends the period of suffering, its degree will

\footnotetext{
${ }^{823}$ The biggest culprits from the age-dependent group are quoted as: diseases of the heart; cerebrovascular disease; osteoporosis; Alzheimer's Disease; Parkinson's Disease, osteoarthritis; loss of muscle mass; greater occurrence of tumours; disruption to the immune system; and atherosclerosis, an underlying cause of stroke. E.J. Masoro, 'Are Age-Associated Diseases and Integral Part of Aging?', S.N. Austad \& E.J. Masoro, Handbook of the Biology of Aging (6 ${ }^{\text {th }}$ edition), (2005; Academic Press) ,45; R. Holliday, 'Aging is No Longer an Unsolved Problem in Biology,' 'Annals New York Academy of Sciences'2006; 1067: 1-9;,3; R. Holliday, 'Aging is No Longer an Unsolved Problem in Biology,' 'Annals New York Academy of Sciences'2006; 1067: 1-9;,3; E. Schrami, \& J. Grillari, 'From cellular senescence to age-associated diseases: the miRNA connection 'Longevity \& Healthspan' 2012, pp1-10,2. www.longevithandhealthspan.co. Accessed 20/09/2014J

${ }^{824}$ The author cites forms of cancer, J.A. Brody \& E.L. Schneider, 'Diseases and disorders of aging: a hypothesis, ' 'Journal of Chronic Disease,' 39, m871-876, cited in E.J. Masoro, 'Are Age-Associated Diseases and Integral Part of Aging?', S.N. Austad \& E.J. Masoro, Handbook of the Biology of Aging (6 ${ }^{\text {th }}$ edition), (2005; Academic Press) ,45

${ }^{825}$ J.A. Brody \& E.L. Schneider, 'Diseases and disorders of aging: a hypothesis, ' 'Journal of Chronic Disease,' 39, m871-876, cited in E.J. Masoro, 'Are Age-Associated Diseases and Integral Part of Aging?', S.N. Austad \& E.J. Masoro, Handbook of the Biology of Aging ( $6^{\text {th }}$ edition), (2005; Academic Press) , 45

Identified examples of the diseases not intrinsic to senescence, but nonetheless age associated are multiple sclerosis and hypertension, E.J. Masoro, 'Are Age-Associated Diseases and Integral Part of Aging?', S.N. Austad \& E.J. Masoro, Handbook of the Biology of Aging ( $6^{\text {th }}$ edition), (2005; Academic Press) , 45

${ }^{826}$ infectious diseases making up many of the non age related diseases which can have mortal effects on the aged, E.J. Masoro, 'Are Age-Associated Diseases and Integral Part of Aging?', S.N. Austad \& E.J. Masoro, Handbook of the Biology of Aging ( $6^{\text {th }}$ edition), (2005; Academic Press), 45

827 R. Holliday, 'Aging is No Longer an Unsolved Problem in Biology,' 'Annals New York Academy of Sciences'2006; 1067: 1-9; at pp.1-3

${ }^{828}$ L.P. Fries, L. Ferrucci, J. Darer, J.D. Williamson \& G. Anderson, 'Untangling the Concepts of Disability, Frailty, and Comorbidity: Implications for Improved Targeting and Care,' Journal of Gerontology: Medical Sciences 2004, Vol. 59, No. 3, 255-263, 258

829 J.F. Fries, 'Aging, Natural Death and the Compression of Morbidity,' 'The New England Journal of Medicine,' July $17,1980,130$

${ }^{830} \mathrm{~K}$. Avlund, 'Disability in old age.' Longitudinal population based studies of the disablement process. Paper published as a thesis by the University of Copenhagen, April 14, 2004,315.
} 
be beyond 'common experiences of ordinary suffering.' In this way the older are among the most vulnerable, and potentially form a vulnerable group. ${ }^{831}$

\subsubsection{Cognitive disease}

Diseases involving cognitive decline are age-dependent and age-associated. The vulnerability and dependencies they create are both physical and psychological. Cognitive degeneration of old age manifests itself most notably in the 'executive functions' to: learn; remember; plan and perform activities which require co-ordination between different spheres of the brain. Once begun, alterations to these functions set a fast tempo. ${ }^{832}$ Research has proven that reasoning, memory, and speed of thinking are seriously affected in the over 70s, and severely affected amongst those over $80 .^{833}$

Whilst experience of vulnerability is individual, the effect of genetics and socio-economic background is particularly applicable to physiological vulnerability. ${ }^{834}$ They have a noticeable impact on vulnerability to cognitive failure, and will, therefore, be briefly explored. The manifestation of cognitive function and ability is not comparable to that of physical decline. The reasons for this are complex, but the outcome for the older person significant. Some concentration of the disease can be found in less advantaged socio-economic groups, and in some genetic make-up. Brain reserve capacity explains the latter, however, only the effects on older people will be considered here. Once again, brief explanation of the mechanics, and references for the interested reader are included below. ${ }^{835}$ The genetically advantaged will have a heightened threshold for severity of damage

\footnotetext{
${ }^{831}$ See chapter 5, 'Vulnerability,'

${ }^{832}$ P. Rabbitt C. Lowe, 'Patterns of cognitive aging,' Psychological Research (2000) 63: 308-316,308. The relevant areas of the brain are: pre-frontal areas (planning and executive performance), temporal cortex, hippocampus and limbic (learning and memory).

${ }^{833}$ Timothy A. Salthouse (Brown-Forman Professor of Psychology at the University of Virginia with a special interest in age-related cognitive decline) undertook research on the effects of various forms of dementia and the proportion of the ageing population they have the potential to impact in laboratory and community based studies. Changes to function relating to vocabulary, speed, reasoning and memory were measured. The research samples were of 997 adults tested for memory performance and 1,424 adults tested for vocabulary, reasoning and speed. T.A. Salthouse, 'What and When of Cognitive Aging, ' 'Current Directions in Psychological Science,' 2004; Volume 13, Number 4 140-144,140. Reasoning, memory and speed tests scored 70 year olds in the lowest $20^{\text {th }}$ percentile, and 80 year olds between the lowest $10^{\text {th }}$ and $20^{\text {th }}$ percentiles of the population. ${ }^{834}$ Exemplifying the cumulative disadvantage notion explained in Life-Course Theory.

${ }^{835}$ Brain reserve capacity comprises brain reserve and cognitive reserve. The measurement of brain reserve is brain size or neuronal count and will determine the extent of damage that can be sustained before it is outwardly manifested. The active cognitive reserve model is based on brain activity and coping mechanisms. The way in which brain mechanisms cope with damage also influences the timing of manifestation. M.S. Albert, K. Jones, C.R. Savage, L. Berkman, T. Seeman, D. Blazer, J.W. Rowe, 'Predictors of Cognitive Change in Older Persons: MacArthur Studies of Successful Aging', 'Psychology and Aging' Vol. 10, No.4 (1995) 578-589 ,585; Y. Stern, 'Cognitive Reserve and Alzheimer Disease,' 'Alzheimer Dis Assoc Disord,' Vol. 20, No. 2, (April-
} 
required before effects are manifested. ${ }^{836}$ The educationally advantaged will benefit from an acquired ability to make use of networks less susceptible to damage, and to exercise networks and tactics to compensate for lost functional capacity. ${ }^{837}$ The educational influences over coping mechanisms to defend against the threat of cognitive vulnerability are level and years in education. ${ }^{838}$ The results of relevant research are included to demonstrate the delaying effects of education on cognitive ageing. Research undertaken of 642 U.S. community-based residents aged over 65, none of whom were suffering from Alzheimer's Disease at the outset were observed at four yearly intervals. The risk of contracting the disease was proven to decrease by $17 \%$ for each year of education. ${ }^{839}$ The role of both level and years of education is demonstrated by studies of 1,296 community-dwelling over 75's in Sweden. The research showed most cases of dementia and Alzheimer's occurred within those with the lowest levels of educational attainment, whilst those with less than 8 years of education were twice as likely to develop Alzheimer's and almost twice as likely to develop other forms of dementia. Those with the least educational achievement manifested clinical signs of damage and diagnosed at earlier ages. ${ }^{840}$

These results point to sources of 'aggravated vulnerability' amongst older people, and reasons for some being considered most vulnerable. Another problem which occurs is the masking of dementia in those with better coping abilities. Personal traits can also disguise dementia in the older person. The more important the activity in hand is to the person, and the more determined they are to achieve it, contributes to success in performance. Also, when a task is reliant on both physical and mental ability; the more physically able the person, the less obvious cognitive problems can be. ${ }^{841}$

June 2006) 112-117,112; Y. Stern, 'What is Cognitive Reserve? Theory and Research Application of the Reserve Concept', 'Journal of the International Neuropsychological Society' 8 (2002) 448-460,448-450.

${ }^{836}$ Y. Stern, 'What is Cognitive Reserve? Theory and Research Application of the Reserve Concept', 'Journal of the International Neuropsychological Society' 8 (2002) 448-460,449

${ }^{837}$ Y. Stern, 'Cognitive Reserve and Alzheimer Disease,' 'Alzheimer Dis Assoc Disord,' Vol. 20, No. 2, (April-June 2006) 112-117,112

${ }^{838}$ Y. Stern, 'Cognitive Reserve and Alzheimer Disease,' 'Alzheimer Dis Assoc Disord,' Vol. 20, No. 2, (April-June 2006) $112-117,113$. Based on Rowe and Kahn's Theory of Successful Ageing.

The impact made on the circuitry of the developing brain sustains the individual into old age, at which stage it adopts the role of proxy for intellectual exercise which declines with age. Albert, M.S. et al, 'Predictors of Cognitive Change in Older Persons,' MacArthur Studies of Successful Aging, 'Psychology and Aging', 10, 578589, cited in Successful Aging,' 'The Gerontologist' vol.17, No.4, (1997) 443-440,439

${ }^{839}$ D.A. Evans, L.E. Hebert, L.A. Beckett et al., 'Education and Other Measures of Socioeconomic Status and Risk of Incident Alzheimer Disease in a Defined Population of Older Persons, ' 'Arch Neurology' 54 (11) (1997), 1399-1405, 1399.

${ }^{840}$ C. Qiu, L. Blackman, B. Winblad, et al., 'The Influence of Education on Clinically Diagnosed Dementia Incidence and Mortality Data from the Kungsholmen Project, ' 'Arch Neurology' 58 (2001) 2034-2039,2034

841 T.A. Salthouse, 'What and When of Cognitive Aging,' 'Current Directions in Psychological Science,' 2004; Volume 13, Number 4 140-144 at pp. 140-141 and interpretation of diagrammatic representation of information ,141 
Other compensatory mechanisms are the result of conscious behaviour. Adaptation of surroundings and activities to minimise both physical and mental effort presents an individual capable of performing chosen functions, with the inability to perform others left unseen. ${ }^{842}$ Furthermore, coping abilities can lead a person to have unrealistic self-belief. ${ }^{843}$ Success in combating threat is reliant on ability to cope and adapt to 'physical, social and psychological changes that go together with increasing age. ${ }^{844}$ However, loss of 'biological, mental and social reserves' ${ }^{845}$ in older people results in a distortion of the reality of one's condition and ability to overcome failing health and functionality. ${ }^{846}$ The culmination is the most frail suffering ill-health and disability, lacking the capacity to adapt to overcome threats, made more vulnerable by the belief that they are either in good health, or possess the cognitive and functional capabilities to overcome their vulnerable state.

Since physical and cognitive degeneration is anchored in later stages of life, and is the foundation of embodied vulnerability, it is a key means to identify older people as a vulnerable group. The exposure to extremes of intensity and types of ontological threat, and the simultaneous harm to both physical and cognitive function places older people 'beyond common experiences of ordinary suffering.' Furthermore, the interrelated nature of vulnerability creates the potential for such a degree of biological vulnerability to attract external vulnerabilities and reach into the entire vulnerability framework described in Part II of the thesis. Thus the older person suffering physical and cognitive vulnerabilities also becomes 'inevitably dependent' and dependent upon many institutions for provision of assets as resilience against a range of vulnerabilities. This, combined with the potential for cumulated disadvantage has the potential to make older people 'aggravated vulnerable.' Identification of older people as a social group by means of physical and cognitive vulnerability provides a basis, therefore, for qualification of the group as amongst the most vulnerable.

\footnotetext{
${ }^{842}$ T.A. Salthouse, 'What and When of Cognitive Aging,' 'Current Directions in Psychological Science,' 2004; Volume 13, Number 4 140-144 at pp. 140-141 and interpretation of diagrammatic representation of information , 142

${ }^{843}$ See 'Selective Optimisation with Compensation' model of successful ageing. N. Steverink, S. Lindenberg \& J. Ormel, 'Towards Understanding Successful Ageing: Patterned Change in Resources and Goals,' 'Ageing and Society,' 18 (1998) 441-467, 444. See generally 'Psychological Perspectives on Successful Ageing: The Model of Successful Optimization with Compensation' in P.B. Baltes, and M.M. Baltes, eds. Successful Aging: Perspectives from the Behavioral Sciences, (1993; Press Syndicate of the University of Cambridge) ${ }^{844}$ N. Steverink, S. Lindenberg \& J. Ormel, 'Towards Understanding Successful Ageing: Patterned Change in Resources and Goals,' 'Ageing and Society,' 18 (1998) 441-467, 442

${ }^{845} \mathrm{~N}$. Steverink, S. Lindenberg \& J. Ormel, 'Towards Understanding Successful Ageing: Patterned Change in Resources and Goals,' 'Ageing and Society,' 18 (1998) 441-467, 444

${ }^{846}$ P.B. Baltes, and M.M. Baltes, 'Psychological Perspectives on Successful Ageing: The Model of Successful Oprimization with Compensation' in P.B. Baltes, and M.M. Baltes, eds. Successful Aging: Perspectives from the Behavioral Sciences, (1993; Press Syndicate of the University of Cambridge) 6
} 


\subsection{Chronological age}

Chronological age is one of the most widely implemented, and one of the most widely criticised forms of identifying older people. Criticism largely stems from an inability to account for human diversity, and perceptions of imposed dependence. However, when identifying a group by threats to which the person is increasingly unable to adapt or defend against in later life stages, and vulnerabilities which are age-related, chronological age provides a generic standard.

This section will explore the methodologies of stipulating a precise age with specific reference to the widely accepted age of retirement, and the alternative approach of years left to live. The argument against using chronological age to identify life transitions, events, and stages has been made through Life-Course Theory in the previous chapter. Elements of this will be recognisable in discussions of the parties to the UNCRC, regarding the age at which special protection against group vulnerabilities should end. The principles involved have relevance to the situation of older people when determining an age at which special protection becomes available. In addition, identifiable ages at which the older person becomes vulnerable will be detailed in the next chapter. .

Agreement on a precise chronological age for older people has seen a variety of ages offered by demographers, sociologists, world organisations, and government departments. The United Kingdom Department for Work and Pensions has suggested that 'Those aged 50 years and over' 847 qualify as members of the group, whilst the World Health Organization quotes 'The age of 60 or 65 ... to be the beginning of old age, ${ }^{848}$ and reports the United Nations as citing 60 years. ${ }^{849}$ The most widely accepted and the age most implemented in the Western world is quoted as the age of retirement, that of 65 years. ${ }^{850}$

\subsubsection{Retirement age}

Retirement age provides the universal standard for identification of older people. The group is defined using this standard as, 'Those over retirement age, usually measured by the age at which a

\footnotetext{
${ }^{847} \mathrm{C}$. Derham, 'Services for Older People' (2004, Department for Work and Pensions) cited on www.communities.gov.uk. Accessed on 10/09/2010

${ }^{848}$ M. Gorman, 'Development and the rights of older people' (2000), cited in 'Definition of an older or older person'. World Health Organization Health statistics and health information systems. www.who.int/healthinfor/survey/ageingdefnolder. Accessed on 10/09/2011

849 'Definition of an older or older person'. World Health Organization Health statistics and health information systems. www.who.int/healthinfor/survey/ageingdefnolder. Accessed on 10/09/2011

${ }^{850}$ 'Definition of an older or older person'. World Health Organization Health statistics and health information systems. www.who.int/healthinfor/survey/ageingdefnolder. Accessed on 10/09/2011
} 
person is eligible for a state pension. ${ }^{851}$ Recognition of the point at which people become less able to be productive is an indicator of economic vulnerability and reducing social interaction, as discussed earlier in theories of productivity, disengagement, and activity.

Determination of a precise retirement age has proven to be responsive to issues of economic pressure on institutional provision of material assets, developments in skill set requirements, and opening the workplace to younger people.

A brief summary of the situation in the United Kingdom demonstrates the ranges of ages offered in attempts to respond to these problems. The Poor Law of 1832 included ages ranging from 40 to 80 as 'aged and infirm.' The age of 65 was proposed in the late 1800s, and increased to 70 in the Pensions Act of 1908. Driven by the need to increase employment opportunities for younger people, the pensionable age was set at 65 for men and 60 for women in the Pensions Bill of $1940 .{ }^{852}$ The future of pensionable age, and potentially the corresponding definition of older people is under continuous review. ${ }^{853}$ In attempts to lessen institutional vulnerability, the Pensions Bill proposes to unify pension ages between the sexes at 65 by $2018,{ }^{854}$ rising again to 67 by $2028{ }^{855}$ Of interest is the fact that had state pension age been raised in line with the increases in life expectancy since 1926, the present-day pensionable age would be $75 .{ }^{856}$ This age would concord with defining old age in terms of years left to live, described in Chapter 10. The U.K. provides an example of the influences over retirement ages in the developed world, and present settled age, and potential future ages. As the retirement age in the U.K. is set to increase, disparities between the economically non-productive ages of this country and developing countries increases. With the lowest non-productive age of African countries recorded at 50, global determination of older people as a group using retirement age would need to take such disparity into account.

Pensionable age is the universally accepted indicator of chronological 'old age.' However, agreement of precise age has proven susceptible to institutional vulnerability and the demands of modernised society and 'useful' productivity. The effects on older people are two-fold. For the active and productive individual, imposed retirement removes self-determination and

\footnotetext{
${ }^{851}$ Anthea Tinker, Older People in Modern Society $4^{\text {th }}$ edition (1997, Harlow: Addison Wesley Longman Limited) 7

${ }^{852}$ J. Roebuck, 'When Does Old Age Begin?: The Evolution of the English Definition', Journal of Social History, Vol. 12, No 3. (Spring, 1979) 416-428, 424. www.jstor.org Accessed 13/09/2011

${ }^{853}$ G. Osborne, the Rt Hon, 'We will lead the economy out of crisis', speech given on 06/10/2009, www.conservatives.com/News/Speeches/2009/10/George Osborne. Accessed 16/09/2011 ${ }^{854}$ 'Pensions Bill 2011 MP's Information Pack', www.dwp.gov.uk/policy/pensions-reform Accessed 25/09/2011 ${ }^{855}$ 'New state pension age: As we're all told to work longer, when will you be able to retire?' 23 March 2017, www.thisismoney.co.uk accessed 25 March 2017

${ }^{856}$ 'Pensions Bill 2011 MP's Information Pack', www.dwp.gov.uk/policy/pensions-reform Accessed 25/09/2011 
independence; hastens life events of later life stages and vulnerability; and creates a 'structured dependency' on institutional assets. Alternatively, setting retirement age to coincide when the person is already embodied and otherwise vulnerable exacerbates vulnerability.

\subsubsection{Years Left to Live}

An alternative approach to deciding a chronological 'old age' is identifying, using average age of longevity, years left to life. This method takes account of increasing longevity. ${ }^{857}$ Using constantly updated life expectancy projections, ${ }^{858}$ research sets the onset of old age at 15 years before death. Applying this formula to the United Nations life expectancy figures would increase the age from the presently set 65 years to 67 , thus redefining the group beyond current Western pensionable age. There would also be greater synergy with ages at which older people become vulnerable in the U.K., as demonstrated in the next chapter. However, it is recognised that whilst this might be representative of trends in the West, similar comparison cannot be made globally due to varying life expectancies between developed, developing, and underdeveloped countries. As a group, older people are identifiable by common vulnerabilities; however, identification of the group by a single chronological age is a complex matter which will be discussed in the following section.

\subsection{United Nations Convention on the Rights of the Child approach}

The various approaches to identifying older people explored earlier in Part III have demonstrated the complexities of the group. There is a need to identify the range of threats and vulnerabilities faced, the lack of coping capacities, the ways in which individuals become dependent and the assets and institutions upon which they rely, and the individuality of each life-course. The issues bear similarity to those faced by parties to the UNCRC when discussing the age at which special protection against vulnerabilities specific to the group would cease. Therefore, the remainder of this chapter will study the methodology and rationale of the drafters of the UNCRC for direction in determining the response of special protection to the group, and age or age ranges at which it ceases to be available.

There are fundamental similarities between the position of children and older people that make this exercise relevant. Both groups face a comparable range and complex interrelation of threats and vulnerabilities. Additionally, age is a key means of identification of type, timing, number and intensification of vulnerabilities and potential outcomes suffered, as will be further examined in the

\footnotetext{
${ }^{857}$ J. Roebuck, 'When Does Old Age Begin?: The Evolution of the English Definition', Population Bulletin, Vol. 63, No 4, December 2008, p.3. www.prb.org. Accessed 10/09/2011

${ }^{858}$ Sanderson and Scherbov 'Average remaining lifetimes can increase as human populations age', Nature, Vol. 435, 9 June 2005. www.nature.com/nature/journal. Accessed 20/09/2011; 'Rethinking Age and Aging', Population Bulletin, Vol. 63, No 4, December 2008, p.7 \& 16. www.prob.org. Accessed 10/09/2011
} 
next chapter. Furthermore, the motivation for the provision of special protection for children as a group can be argued to have application to older people; 'the child, by means of his physical and metal immaturity, needs special safeguards and care, including appropriate legal protection... ${ }^{859}$ The physical and cognitive vulnerabilities identified with older people can be likened to this 'immaturity' as physical capabilities and mental capacity is lost. Significantly, the immaturity of the child lessens with age due to 'evolving capacity,' reducing dependence on special safeguards and care. However, older people experience a deepening of such immaturity as capacity regresses, creating increasing dependency, and strengthening the case for special protection for this group.

\subsubsection{The size of the age group}

Defining the size of the age group was key to an overarching objective of the UNCRC: to make the protection of the Convention 'apply to as large an age group as possible. ${ }^{860}$ Fulfilling this objective required the negotiation of obstacles of; inter alia, cultural relativity, domestic legislation, and resource availability. ${ }^{861}$

Issues most influential over settling a single age for loss of special protection were: the age of majority; definitive ages of life events associated with adulthood; and national legislation. ${ }^{862}$ Aspects of discussions relevant to determination of an age, or age ranges for special protection for older people are explored at this stage.

The difficulties of attempting to associate age with a trajectory-defining event are summarised as whether the age should represent a floor or ceiling. In order to meet the objective of protecting as large a group as possible, ${ }^{863}$ the highest age of majority, applicable in more wealthy countries and developed regions was proposed. The General Assembly offered the compromise age of $15,{ }^{864}$

\footnotetext{
${ }^{859}$ Preamble, The United Nations Convention on the Rights of the Child (1989)

860 Report of the Working Group to the Commission on Human Rights, United Nations Document E/CN.4/L.1542, $36^{\text {th }}$ session, at paras 32-33

${ }^{861}$ Report of the Working Group to the Commission on Human Rights, United Nations Document E/CN.4/L.1542, $36^{\text {th }}$ session, at para 35

${ }^{862}$ Report of the Working Group to the Commission on Human Rights, United Nations Document E/CN.4/L.1542, $36^{\text {th }}$ session, 10 March 1980, at paras 32-33

${ }^{863}$ Report of the Working Group to the Commission on Human Rights, United Nations Document E/CN.4/L.1542, $36^{\text {th }}$ session, at paras 32-33

${ }^{864}$ The General Assembly had set the age limit at 15 in connection with the International Year of the Child. Report of the Working Group to the Commission on Human Rights, United Nations Document E/CN.4/L.1542, $36^{\text {th }}$ session, at para 32
} 
despite the warning of the HRC that to do so would deny many the 'right to special measures of protection. $^{865}$

Some states parties considered life events other than reaching majority more appropriate, including cessation of compulsory education and the legal age of marriage. In these cases, the age was frequently set at 14 , and stated as establishing 'a clear distinction between the concept of minor and that of child, since the former was protected under many national legislations while the latter was not. $^{\prime 866}$ The motivation for opposing the highest age of majority for the definitive age at which special protection for the child ends ${ }^{867}$ proved to be a combination of domestic legislation and pressure on limited resources. ${ }^{868}$ Possible compromise positions subsequently offered for debate attempted to strike a balance between obligation and limited resources for poorer nations. The Society for Comparative Legislation proffered the age of 16 as the cut off point for access to special protection, available 'in certain particular cases' to older children. The representative of Nepal focused more directly on the issue of resources rather than the identification of need in 'certain particular cases' by suggesting an imposed age of 16 could be raised by wealthier countries 'as they deem fit. ${ }^{869}$ The problems encountered in defining the child by an agreed chronological age led to calls for age to be discounted, as 'majority can be attained by satisfying criteria other than age. ${ }^{870}$ The issues of group identification by life-course event and ability as alternatives to age will be considered below, but are summarised well by the representatives of Finland, India and U.S.A. in this instance. The parties voiced concern over the use of a concept which they considered to have a context-dependent meaning and which varied between jurisdictions. ${ }^{871} \mathrm{~A}$ comparison of these

\footnotetext{
${ }^{865}$ Office of the High Commissioner for Human Rights, ICCPR General Comment Number 17: Article 24 (Rights of the child), at para. 4. Thirty-fifth session of Human Rights Committee $7^{\text {th }}$ April 1989.

${ }^{866}$ Report of the Working Group to the Commission on Human Rights, United Nations Document E/CN.4/L.1542, $36^{\text {th }}$ session, at para 32

${ }^{867}$ Comment by the representative of Kuwait. Report of the Working Group to the Commission on Human Rights, United Nations Document E/CN.4/1989/48 at para 81, cited in 'Legislative History of the Convention on the Rights of the Child,' Volume I, United Nations New York and Geneva, 2007 ,311

${ }^{868}$ Comment by the representative of Nepal. Report of the Working Group to the Commission on Human Rights, United Nations Document E/CN.4/1989/48 at para 82, cited in 'Legislative History of the Convention on the Rights of the Child,' Volume I, United Nations New York and Geneva, 2007 ,311

${ }^{869}$ The representative of Nepal reasoned this 'so as to take into account the concerns of poorer States who may not be able to shoulder the burdens imposed... for children up to 18 years of age.' Report of the Working Group to the Commission on Human Rights, United Nations Document E/CN.4/1989/48 at para 81, cited in 'Legislative History of the Convention on the Rights of the Child,' Volume I, United Nations New York and Geneva, 2007,311

${ }^{870}$ Comment by the representative of The Netherlands. Report of the Working Group to the Commission on Human Rights, United Nations Document E/CN.4/1989/48 at para 80, cited in 'Legislative History of the Convention on the Rights of the Child,' Volume I, United Nations New York and Geneva, 2007 ,311

${ }^{871}$ Comment by the representatives of Finland, India and The U.S.A. Report of the Working Group to the Commission on Human Rights, United Nations Document E/CN.4/1989/48 at para 79, cited in 'Legislative
} 
disadvantages with the benefit of adopting a chronological age factored in the final decision of the drafters of the Convention in the definition of the child:

...mentioning the age of 18 years would underline the recognition of the need to ensure special protection to human beings under that age. A definition based on the simple notion of majority would not...be desirable, taking into account the different solutions existing in various legal systems. ${ }^{872}$

\subsubsection{Stage of Life Abilities}

In an attempt to overcome the complexities involved in determining a chronological age, the method of group definition by stage of life abilities was offered rather than a single homogenous age. ${ }^{873}$ When these abilities are practices in accordance with the agency acknowledged in LifeCourse Theory, the logic of group identification by personal ability is aligned to individualised, rather than standardised life cycle. ${ }^{874}$ However, the influence of cultural relativity is significant in the practice of abilities, as life trajectories and transitions corresponding to different stages of life are observed differently. Chronological age will still be of relevance, in accordance with principles of age stratified life-course. ${ }^{875}$ When the right is bestowed, by means of legislation to undertake certain acts, it is possible to construe the child as no longer physically and mentally immature. ${ }^{876}$ This approach views such acts representative of stages of development, and only when the highest stage has been achieved can the child be considered fully mature. The weakness of this approach lies in cultural relativity. The range and number of activities is accompanied by an almost equally lengthy list of various age eligibilities, with some activities not subjected to a minimum age requirement. The physical ability to undertake activities does not necessarily correspond to the mental maturity required to adapt to effects of changes to life transitions and trajectories. As such, the stage of life

History of the Convention on the Rights of the Child,' Volume I, United Nations New York and Geneva, 2007, 311

${ }^{872}$ Comment by the representative of Portugal. Report of the Working Group to the Commission on Human Rights, United Nations Document E/CN.4/1989/48 at para 82, cited in 'Legislative History of the Convention on the Rights of the Child,' Volume I, United Nations New York and Geneva, 2007 ,311

${ }^{873}$ Representative of New Zealand. United Nations Document E/CN.4/1324/Add.5, cited in 'Legislative History of the Convention on the Rights of the Child,' Volume I, United Nations New York and Geneva, 2007 ,303

874 See Life-Course Theory

${ }^{875}$ Abilities will correspond to ages or age ranges, albeit subject to cultural relativity. See Life-Course Theory

${ }^{876}$ Examples of such acts represented in judicial law or custom used as indicators of maturity include to: live independently of parental supervision or guardianship, marry, drive a vehicle, undertake employment, voluntarily enter the armed services, provide testimony in a court, receive legal counselling and medical advice and treatment independent of parental consent. See New Zealand's submission to first Polish draft of UNCRC in United Nations Document E/CN.4/1324/Add.5, cited in 'Legislative History of the Convention on the Rights of the Child,' Volume I, United Nations New York and Geneva, 2007 ,303; 'Implementation Handbook for the Convention on the Rights of the Child,' $3^{\text {rd }}$ edition, Unicef, 2007,4 ; www.unicef.org. Accessed 02/09/2014 
abilities approach is not consistent with the need for special protection grounded in 'physical and mental immaturity, ${ }^{877}$ underscoring the need for a single accepted life event or chronological age.

When the Convention received its second reading, the idea of defining by ability was extended. The proposal offered by India was for a definition permitting individual States not merely to identify a child in terms of its own established age of majority, but to do so once 'age-limits for different purposes' are reached. $^{878}$ The immediate question which this raises is one of priority; which 'purpose' could trump all others. Whilst certain ages might mark milestones and transitions towards adulthood, they do not necessarily confirm that the individual is at the stage of physical and mental maturity at which the protection afforded by these principles is no longer required. The notion has relevance to older people who, by virtue of age loses the legal entitlement to some activities, all of which would compete as qualifications for the state of being 'old.' Accepting this means of definition would give priority to local classifications of the person and the local laws pertaining to them.

\subsubsection{Evolving capacity}

The concept of evolving capacity refers to the ability to 'take responsibility for decisions affecting their lives ${ }^{879}$ and underpins the notion that ability to undertake certain acts should mark the end of special protection. Evolving capacity prompted informal and formal recognition by states parties of stages of childhood, broadly categorised as the 'youngest young,' 'young child' and 'adolescent.' This categorisation assists identification of the degree of vulnerability by virtue of decision-making capacity and dependency to which a child can be exposed. ${ }^{880}$

\subsubsection{The case of older people}

The Council of Europe Committee of Ministers stated in their recommendations on the provision of human rights of older persons that it is 'useless to attempt to define when old age begins.' They continued to state that, in Europe at least, 'a person's age is no longer an indicator of health, wealth

\footnotetext{
${ }^{877}$ Preamble of UNCRC

${ }^{878}$ Report of the Working Group to the Commission on Human Rights, United Nations Document E/CN.4/1989/48 at para 76, cited in 'Legislative History of the Convention on the Rights of the Child,' Volume I, United Nations New York and Geneva, 2007 ,311

${ }^{879}$ G. Van Beuren, The International Law on the Rights of the Child, Save the Children/Martinus Nijhoff Publishers, Dordrecht, 1995, cited in G. Lansdown, 'The Evolving Capacities of the Child,' ,3 2005; Unicef. www.unicef-irc.org Accessed 04/09/2014

${ }^{880}$ G. Lansdown, 'The Evolving Capacities of the Child,' ,3 2005; Unicef. www.unicef-irc.org Accessed 04/09/2014
} 
and social status. ${ }^{881}$ However, if special protection for older people is to be considered, the point at which it becomes available must be determined. Furthermore, patterns of vulnerability and life events associated with older people are identifiable, and is the subject of Chapter 10. The definition of ageing provided by WHO as the 'process of progressive change in the biological, psychological and social structures of individuals ${ }^{\prime 882}$ have been addressed in the examination of theories of ageing, and patterns of their effect, with age correlations, are described in Chapter 10. Taking the UNCRC as a guide, this thesis will discuss the point at which special protection for older people should be universally available.

When determining the life trajectory event or specific age at which special protection is available to older people as a group, the example set by the drafters of the UNCRC should be followed. Of primary importance is that the protection must 'apply to as large an age group as possible. ${ }^{883}$ The States parties to the UNCRC deemed the event which legally represents the beginning of the adult life trajectory, and which is referenced to age, the most effective point to end special protection provision. Similarly, commencement of special protection for older people should coincide either with a trajectory ending event, or an age which represents the event, if a universal age exists for that event. In line with the primary aim, and in order to respect existing rights and advantages available either through legislation or policy at national levels, ${ }^{884}$ the age, or event representing age, must not be set too high.

In the case of the child, States parties were able to offer a range of life events which represented a level of maturity associated with adulthood. For older people, the life events are those which represent the end of trajectories and which attract vulnerabilities such as retirement, loss of relationships, ${ }^{885}$ and physical and cognitive ill-health. These life events of older people cannot, with the exception of retirement, attract an age recognised in either national or international law. Attempts to use events associated with ability, ${ }^{886}$ would encounter similar problems of cultural relativity as faced by drafters of the UNCRC.

\footnotetext{
${ }^{881}$ Explanatory Memorandum of Recommendation CM/Rec(2014)2 of the Committee of Ministers to member States on the promotion of human rights of older persons, Comment 8.

${ }^{882 ~ ' A ~ l i f e ~ c o u r s e ~ p e r s p e c t i v e ~ o f ~ m a i n t a i n i n g ~ i n d e p e n d e n c e ~ i n ~ o l d e r ~ a g e, ' ~ W o r l d ~ H e a l t h ~ O r g a n i s a t i o n, ~ G e n e v a, ~}$ 1999, 4 (as cited in Explanatory Memorandum of Recommendation CM/Rec(2014)2 of the Committee of Ministers to member States on the promotion of human rights of older persons, Comment 8).

883 Report of the Working Group to the Commission on Human Rights, United Nations Document E/CN.4/L.1542, 36 ${ }^{\text {th }}$ session, at paras 32-33

${ }^{884}$ Explanatory Memorandum of Recommendation CM/Rec(2014)2 of the Committee of Ministers to member States on the promotion of human rights of older persons, Comment 9.

${ }^{885}$ For example, widowhood.

${ }^{886}$ For example, when a person can no longer serve on a jury, serve in the armed forces, or drive a car. 
Some correlations with 'evolving capacity' can be drawn for the situation of older people. Stages of older age are also often referred to; 'young old age,' 'old age' and the 'oldest old' the equivalent markers of life states, each bearing features which help define old age vulnerabilities and needs, including regressing capacity, and loosely correlating to chronological ages. One of the primary outcomes of regressing capacity is the declining ability to take decisions, particularly those affecting independent living. Therefore, when an individual enters one of these stages of older age, there must be recognition of the intensity of vulnerability suffered, and any corresponding need when interpreting and applying special protection human rights.

Justification of a special protection group will be on the basis of the vulnerabilities suffered by members of that group. However, due to the range of vulnerabilities, the heterogenic nature of older people, and cultural relativity, it is not possible to decide a universal age based on a single vulnerability. If the age is to be that attached to a single event, then it is proposed that the event is one from which other life changing trajectories and transitions flow. However, as the earliest end of trajectory event which also attracts and causes numerous interrelated vulnerabilities, retirement, pensionable age, or age at which the person becomes economically non-productive remains the most suitable marker. With the cessation of work comes a reduction in income with associated consequences for poverty, diminished independence, reduced social integration and the potential for various forms of discrimination. Additionally, it can exacerbate any vulnerabilities of health and ability to care for oneself. As with reaching the age of majority, retirement age marks not only a transition, but a new trajectory in the life course of the individual, and of the group.

In order to protect the greatest number of vulnerable people, the stated age should be the lowest possible. This would also make protection available for the 'young old' with early onset of the vulnerabilities of older people. For this reason it is not suggested that States be given the opportunity to raise the age according to national retirement or pensionable age legislation and practices. Additionally, by adopting the lowest age, the need to consider lowering the age in 'certain particular cases' is negated. This thesis suggests the age of 50 years as the point at which special protection for older people as a group is accessible. This suggestion aims to make protection available to as wide a group as possible, by identifying the decade in which vulnerabilities associated with lack of ability to sustain an adequate standard of living due to employment issues begin to become apparent (See Chapter 10). 


\subsection{Conclusion}

This study of senescence, cognitive ageing and the methodology of the UNCRC in defining a special group identified key issues relating to a primary source of vulnerability for older people, and the accessibility of special protection.

Given that biological vulnerability comprises the inevitable vulnerability from which many others stem, the pattern of senescence is relevant to the lived vulnerabilities of older people. The facts that the older person is subject to co-morbidity, and that all diseases will cause progressive decrepitude 'in everyone who lives long enough and the severity of their impact invariably increases with age,' are part of the inevitably vulnerable condition. The intensity of physical and cognitive illness and associated dependencies are either compressed into the last few years of life, or longer lives are lived with prolonged years of illness. The next chapter which examines the reality of lived vulnerabilities, shows both arguments applicable to older people, albeit the number of years of illness in both cases has little variation.

Problems of cognitive disease have specific effect on older people, often already experiencing physical decline. The outcomes are primarily manifested in memory and reasoning, and therefore, in the more advanced cases, impact decision-making capacity. This has implications for provision and accessibility of special protection and will be considered further in Part II. Research studies have shown a link between socio-economic and educational status and cognitive disease. This is informative of the problem of cumulative disadvantage and aggravated vulnerability also applicable to older people, and which could be influential in the study of human rights provision for this group later in the thesis.

The inflexibility, and often inaccuracy, of identifying a special protection group by chronological age has attracted criticism as a definitive marker of accessibility to protection. Retirement age was demonstrated to be susceptible to economic instability and intergenerational need. The 'years left to live' approach is more accurate in identifying when vulnerabilities of ill health intensify. However, less intense vulnerabilities and the 'young old' are not protected. To this point, Part III has demonstrated the complexities of the group by reviewing the means of identifying older people. It is possible to draw parallels with the situation of children as a vulnerable group. As a result, the methodology of the drafters of the UNCRC has relevance to determining the accessibility of special protection for older people. With a primary aim of providing protection for as large a group as possible, the importance of selecting a trajectory-ending life event related to age was stated. Stage of life abilities are important indicators of capability, however, the selection of a single ability 
associated with stage of life is subject to complex barriers of cultural relativity and national legislation. Eligibilities, benefits and advantages in existence to varying degrees in different nations and legislative systems would be particularly at risk. Additionally, physical and mental abilities cannot be assumed to be synchronised. Physical ability cannot be equated to cognitive ability and decision-making capacity. Therefore, the life event used to determine accessibility to special protection must be one which marks the introduction of vulnerabilities, and is associated to an age permitting a suitably large group.

Suggestions of age differentiation and compromise positions of reducing the size of the group on the basis of age were considered. Suggestions by States parties to the UNCRC of reducing the universal age, to allow it to be raised in 'certain particular cases,' or by wealthier countries were rejected. The fundamental difference between the accessibility positions was influential in this decision. As a group, accessibility for older people requires definition of a point at which special protection begins rather than ends. In addition, the capacity of children evolves, whilst capacity of older people regresses. It was concluded that the earliest trajectory-ending life event which attracts vulnerabilities was retirement, or the end of viable economic productivity. Therefore, this event should be taken as the point at which special protection is accessible for older people. Employing the argument for using the lowest possible age in order to make the protection as widely accessible as possible; and incorporating pivotal issues including: lower life expectancy and lower healthy life expectancy in poorer regions; inconsistent pension and social security provision; and inconsistent living standards, the thesis suggests the lower age of 50 .

This chapter marks the end of the study of how older people become vulnerable, and how accessibility to special protection might be determined. The research into older people is concluded in the next chapter, which will study the lived vulnerabilities in terms of variety, intensity and prevalence in the U.K. 


\title{
CHAPTER 10
}

\section{WHAT IT MEANS TO BE AN OLDER PERSON:}

\section{RESEARCH OF THE VULNERABLE EXPERIENCE}

\begin{abstract}
We have shaped a society which is extremely harsh to live in when one is old. The tragedy of old age is not the fact that each of us must grow old and die but that the process of doing so has been made unnecessarily and at times excruciatingly painful, humiliating, debilitating and isolating through insensitivity, ignorance and poverty. ${ }^{887}$
\end{abstract}

\subsection{Introduction}

The aim of this chapter is to relate the vulnerable experiences of older people to the outcomes of threats detailed Theories of Ageing and the vulnerabilities framework devised in Part II of this thesis. Research of lived experiences is gathered under global themes of vulnerabilities applicable to older people. The chapter acknowledges that concrete situations will vary intra and inter regionally whilst recognising the universality of suffering, vulnerabilities and themes of the same. It must be noted at the outset the difficulties in obtaining information from some regions and nations due to a reticence to release details of the reality of the rights violations of older people. In this regard information available from expert bodies and the research of interested parties and individuals has proven invaluable.

Global themes are gathered under the broad headings of: health and disability; poverty; social isolation, disengagement, and loneliness; care and carers; abuse; discrimination; and women as a vulnerable sub-group. Each theme incorporates as many influential factors as available information permits, likewise regional comparisons.

\section{$10.1 \quad$ Health and Disability}

This section of the chapter explores issues of life-expectancy; healthy and disability-free lifeexpectancy; types of illness and disease suffered; and access to medical care.

Themes will be examined inter and intra-regionally, with detailed information provided on the case of the UK as an example of a developed country.

${ }^{887}$ R. Butler, Why survive? Being old in America. (Harper \& Row, 1975) 


\subsubsection{Healthy and disability-free life-expectancy}

This section of the chapter examines the healthy and disability-free life expectancy of older people at birth and at age 65 . The proportion of life, post 65 years, which can be lived in good health and disability free influences most aspects of the vulnerability experience of the group. Health and disability inform the extent and type of healthcare and care required by older people, the ability to be economically and otherwise productive, and actively engage in society. Physical and cognitive health should also direct decisions regarding retirement age. Economic precariousness has been demonstrated to direct legislation on the matter. ${ }^{888}$ However, viability of increasing the mandatory age of economic productivity should also be justified on the basis of quality of life left to live. ${ }^{889}$

Themes which emerge from this research include a correlation between discrepancies in life expectancy and healthy life expectancy and national economic health. Such discrepancy exists inter and intra-regionally. The UK will provide a detailed example of expectancy and trends. Europe demonstrates intra-regional discrepancy, and the situation in Asia and Africa.

The existence of inter and intra-regional discrepancies contradicts claims by States that special protection for older people can most efficiently be provided regionally rather than internationally. This point will be further discussed in Chapter $14{ }^{890}$ nonetheless it is informative to highlight that consistent themes, including causes of disparity in standards, would benefit from the response of an international normative and implementation standards. Varying degrees of accumulated advantage or disadvantage call for special protection which includes the needs of the lowest standards, and provide in accordance to need. On this basis, potential exists for a reliance on international duty in addition to positive State duty.

\footnotetext{
${ }^{888}$ See 9.3.2 Retirement Age

889 'Health expectancies at birth and at age 65 in the UK, based on 2011 Census health and disability prevalence data: 2010 to 2012,' 11, Office for National Statistics, 2016

${ }^{890}$ Progress of the United Nations on special protection for older people
} 
TABLE NUMBER 3

Healthy and Disability Free Life Expectancy at Birth in U.K. 2009-2011

\begin{tabular}{|l|l|l|l|l|}
\hline & $\begin{array}{l}\text { Age at Start } \\
\text { of III-health }\end{array}$ & $\begin{array}{l}\text { Healthy Life Expectancy } \\
\text { Percentage of Lifespan }\end{array}$ & $\begin{array}{l}\text { Age at Start } \\
\text { of Disability }\end{array}$ & $\begin{array}{l}\text { Disability Free Life } \\
\text { Expectancy }\end{array}$ \\
\hline Males & 64 & $81.9 \%$ & 64 & $81.5 \%$ \\
Fercentage of Lifespan \\
\hline Females & 66 & $80.2 \%$ & 65 & $78.5 \%$ \\
\hline
\end{tabular}

\section{TABLE NUMBER 4}

Changes in Healthy Life Expectancy at age 65 between 2000-2002 and 2009-2011: U.K. ${ }^{892}$

\begin{tabular}{|c|c|c|c|c|c|}
\hline & Years & $\begin{array}{l}\text { HLE } \\
\text { (years) }\end{array}$ & $\begin{array}{l}\text { Remaining Life } \\
\text { Expectancy }\end{array}$ & $\begin{array}{l}\text { Proportion of life in } \\
\text { "good" health (\%) }\end{array}$ & $\begin{array}{l}\text { Years in "not } \\
\text { good" health }\end{array}$ \\
\hline Males & $2000-02$ & 9.5 & 15.9 & 59.6 & 6.4 \\
\hline & 2009-11 & 10.7 & 18.0 & 59.3 & 7.3 \\
\hline $\begin{array}{l}\text { Change in } \\
\text { Estimate }\end{array}$ & & 1.2 & 2.1 & -0.2 & 0.9 \\
\hline Females & $2000-02$ & 10.8 & 19.0 & 56.8 & 8.2 \\
\hline & 2009-11 & 12.1 & 20.7 & 58.6 & 8.6 \\
\hline $\begin{array}{l}\text { Change in } \\
\text { Estimate }\end{array}$ & & 1.3 & 1.6 & 1.8 & 0.3 \\
\hline
\end{tabular}

The trend in years of life spent in "good" and "not good" health, and the healthy life expectancy at age 65 is instructive with regard to duration and severity of outcomes of vulnerability to biological threat. The fact that at age 65 women are living 1.3 years more and men 1.2 years more in good

\footnotetext{
${ }^{891}$ Statistics taken from Office for National Statistics 'Health Expectancies at Birth and at Age 65 in the United Kingdom: 2009-2011,' 4\&6

${ }^{892}$ Statistics taken from Office for National Statistics 'Health Expectancies at Birth and at Age 65 in the United Kingdom: 2009-2011,' 13
} 
health, must be balanced with the corresponding increases of 0.3 and 0.9 years in not good health. The increase in good health is 4.3 times greater than the increase in not good health for women, and 1.3 times greater for men. The study concludes that the trend has some negative outcomes. The improvement in relative terms for women is countered by a decline in absolute terms, and a decline in both relative and absolute terms for men. ${ }^{893}$ Significant facts for this age group is that $45 \%$ of remaining life for men, and $41.5 \%$ for women will be lived in "not good" health. The vulnerability experience of older people aged 65 and over is, therefore, showing a situation in which the arguments for "compression of morbidity" 894 and "failures of success" 895 are finely balanced.

\section{$\underline{\text { TABLE NUMBER } 5}$}

Changes in Disability-Free Life Expectancy at age 65 between 2000-2002 and 2009-2011: U.K.

\begin{tabular}{|l|l|l|l|l|l|}
\hline & $\underline{\text { Years }}$ & $\underline{\text { DFLE }}$ & $\begin{array}{l}\text { Remaining Life } \\
\text { (vears) }\end{array}$ & $\begin{array}{l}\text { Proportion of life } \\
\text { disability free (\%) }\end{array}$ & $\begin{array}{l}\text { Years spent with a } \\
\text { disability }\end{array}$ \\
\hline$\underline{\text { Males }}$ & $2000-02$ & 8.8 & 15.9 & 55.2 & 7.1 \\
\hline $\begin{array}{l}\text { Estimate } \\
\text { Femange in }\end{array}$ & $2009-11$ & 10.5 & 18.0 & 58.5 & 7.5 \\
\hline $\begin{array}{l}\text { Estimate } \\
\text { Change in }\end{array}$ & 1.7 & 2.1 & 3.3 & 0.3 \\
\hline
\end{tabular}

The vulnerability to disability for ages 65 and over shows an inclination towards increased longevity accompanied by an increased number of years lived with disability. The number of years lived

${ }^{893}$ Statistics taken from Office for National Statistics 'Health Expectancies at Birth and at Age 65 in the United Kingdom: 2009-2011,' 13

894 Increases in longevity are accompanied by years of ill health compressed into shorter periods at the end of life.

${ }^{895}$ Increases in longevity are accompanied by increased number of years lived in ill health.

${ }^{896}$ Statistics taken from Office for National Statistics 'Health Expectancies at Birth and at Age 65 in the United Kingdom: 2009-2011,' 14 
disability-free compared to years spent living with disability demonstrates a worsening situation with regard to vulnerability to disability in both relative and absolute terms. The situation for males, however, shows an increase in relative terms and decrease in absolute terms of disability health status. ${ }^{897}$ Nonetheless, the reality of remaining years lived with disability for this age group is $41.6 \%$ for women and $50 \%$ for men. Of older people aged 80 and over $59 \%$ have a disability. The fact that women have longer life expectancies than men has resulted in women also living longer in "fair" and "bad or very bad" health than men. ${ }^{898}$ There is potential, therefore, for dialogue surrounding the aggravated vulnerability of women within the group of older people. An estimated 4 million older people live with a limiting longstanding illness in the U.K. This equates to $36 \%$ of those aged $65-74$ and $47 \%$ of the 75 and over group. ${ }^{899}$

10.1.2 The intra-regional life expectancy and healthy life-expectancy in Europe

The intra-regional situation relating to life expectancy and healthy life expectancies is presented in table numbers 4 and 5 below

\section{$\underline{\text { TABLE NUMBER } 6}$}

Europe

EU 28 countries Healthy Life Expectancy v Life Expectancy at age 65: 2010-2015

\begin{tabular}{|c|c|c|c|c|c|c|c|c|c|c|c|c|}
\hline & $\underline{\mathrm{HLE}}$ & $\underline{\mathrm{LE}}$ & $\underline{\mathrm{HLE}}$ & $\underline{\mathrm{LE}}$ & $\underline{\mathrm{HLE}}$ & LE & $\underline{\mathrm{HLE}}$ & $\underline{\mathrm{LE}}$ & $\underline{\mathrm{HLE}}$ & $\underline{\mathrm{LE}}$ & $\underline{\mathrm{HLE}}$ & $\underline{\mathrm{LE}}$ \\
\hline & 2010 & & 2011 & & 2012 & & 2013 & & 2014 & & 2015 & \\
\hline Male & 8.7 & $\underline{17.5}$ & 8.5 & 17.7 & 8.5 & 17.7 & 8.5 & 17.9 & 8.6 & 18.2 & 9.4 & $\underline{17.9}$ \\
\hline Female & 8.8 & 21.0 & 8.6 & 21.3 & 8.5 & 21.1 & 8.6 & 21.3 & 8.6 & 21.6 & 9.4 & 21.2 \\
\hline
\end{tabular}

\footnotetext{
${ }^{897}$ Statistics taken from Office for National Statistics 'Health Expectancies at Birth and at Age 65 in the United Kingdom: 2009-2011,' 14

898 'Health expectancies at birth and at age 65 in the UK, based on 2011 Census health and disability prevalence data: 2010 to 2012,' 11, Office for National Statistics, 2016.

${ }^{899}$ Age UK estimates based on 'General Lifestyle Survey 2011,' Office for National Statistics 2013 and 'Mid 2014 based population projections,' Office for National Statistics 2015 (as cited in 'Later Life in the United Kingdom, January 2017,' Age UK, 8)

${ }^{900}$ Statistics taken from 'Healthy life years and life expectancy at age 65 by sex,' Eurostat http://ec.europa.eu/eurostat/tgm/refreshTableAction.do?tab=table\&plugin=1\&pcode=tepsr sp320\&language =en accessed 22/11/2017
} 
Europe highest and lowest healthy life expectancies - some comparison of accumulated advantage and disadvantage

\section{TABLE NUMBER 7}

European Intra-Regional Disparity in Healthy Life-Expectancy post 65: 2010-2015

\begin{tabular}{|c|c|c|c|c|c|c|c|c|c|c|c|c|}
\hline & \multicolumn{2}{|c|}{$\underline{2010}$} & \multicolumn{2}{|c|}{$\underline{2011}$} & \multicolumn{2}{|l|}{$\underline{2012}$} & \multicolumn{2}{|l|}{$\underline{2013}$} & \multicolumn{2}{|c|}{$\underline{2014}$} & \multicolumn{2}{|c|}{$\underline{2015}$} \\
\hline & $\underline{M}$ & $\underline{F}$ & M & $\underline{F}$ & $\mathrm{M}$ & $\underline{F}$ & $\underline{M}$ & $\underline{F}$ & $\underline{M}$ & $\underline{F}$ & $\underline{M}$ & $\underline{F}$ \\
\hline Norway & 14.5 & 15.7 & & & 15.3 & 16.0 & 15.0 & 14.8 & 15.3 & 15.9 & 15.3 & 15.3 \\
\hline Sweden & 12.3 & 13.7 & 11.9 & 13.2 & & & 12.9 & 13.8 & 15.2 & 16.7 & 15.7 & 16.8 \\
\hline Ireland & 10.9 & 11.1 & 10.9 & 11.8 & 10.9 & 12.2 & 10.9 & 12.1 & 11.4 & 12.3 & 11.4 & 12.0 \\
\hline Belgium & 10.4 & 9.7 & 9.8 & 10.3 & 10.6 & 11.0 & 10.8 & 10.9 & 11.0 & 11.0 & 11.2 & 11.0 \\
\hline France & 9.0 & 9.8 & 9.7 & 9.9 & 9.4 & 10.4 & 9.8 & 10.7 & 10.4 & 10.7 & 9.8 & 10.7 \\
\hline Slovakia & 3.3 & 2.8 & 3.5 & 2.9 & 3.5 & 3.1 & 4.2 & 3.7 & 4.3 & 3.6 & 4.1 & 3.8 \\
\hline Romania & 5.9 & 5.1 & 5.4 & 4.7 & 5.9 & 5.1 & 5.8 & 5.2 & 5.9 & 5.7 & 6.3 & 5.7 \\
\hline Hungary & 5.4 & 5.9 & 6.0 & 6.0 & 6.4 & 6.4 & 6.2 & 6.1 & 6.0 & 6.1 & 5.9 & 5.9 \\
\hline Slovenia & 6.6 & 7.2 & 6.2 & 6.9 & 7.3 & 6.9 & 7.2 & 7.6 & 7.8 & 8.6 & 8.2 & 7.6 \\
\hline
\end{tabular}

In Europe the greatest discrepancy is in years lived in healthy life. The divide is clear between the more wealthy and poorer European nations. The implication is older people in the poorer countries live a greater proportion of their lives, and later lives, in ill-health and with disability.

\subsubsection{Least Developed and Developing Countries}

The correlation between life expectancy and poverty is stark in the least developed countries, which report substantially lower life-spans than developed countries. African countries including Lesotho, Chad, Central African Republic, Angola, Sierra Leone, Côte d'Ivoire, Democratic Republic of the

\footnotetext{
${ }^{901}$ Statistics taken from 'Healthy life years and life expectancy at age 65 by sex,' Eurostat http://ec.europa.eu/eurostat/tgm/refreshTableAction.do?tab=table\&plugin=1\&pcode=tepsr sp320\&language =en accessed 22/11/2017
} 
Congo, Mozambique, and Nigeria reported life expectancies of under 55 years in comparison to the global average of 71.4 years in 2015 . The healthy life expectancy is reported as comparable to global averages of $87 \%$ of life. ${ }^{902}$ This comparison potentially reveals a discrepancy in causes of ill-health. Given the ages at which ill-health begins, the problems of healthcare provision of less developed States are less likely to be those of the "geriatric giants" countries. Infectious diseases remain responsible for $70 \%$ of years of lost life in 22 African countries. $^{904}$

Developing countries with increasing life expectancies and more Western life-styles are experiencing a mix of illnesses. Such countries are suffering a burden on healthcare provision as communicable and non-communicable diseases are prevalent. More than 100 countries are transitioning rapidly towards a greater proportion of deaths from non-communicable diseases and injuries, ${ }^{905}$ in the interim the demand remains for treatment of both forms of illness. The WHO has reported SouthEast Asia as an example of a region in which modernising countries are developing the "geriatric giants" of Western, developed countries, ${ }^{906}$ and the less developed nations report communicable illness, and illness caused by insanitary conditions amongst older people. ${ }^{907}$ The United Nations cites Sub-Saharan Africa as another of the poorer regions with intensifying burdens of non-communicable old age diseases ${ }^{908}$ adding to communicable diseases. Therefore, health systems are confronted with a demand for prevention and treatment of age-related and age-dependent illness and disability in response to an ageing population. This pressure on healthcare resources is additional to existing need to prevent and treat communicable disease, with malaria the greatest threat. ${ }^{909}$

Health experiences of older people in the poorest countries are exacerbated by accessibility and availability of healthcare, and discrimination. Research undertaken of the situation in Uganda is instructive in this regard. ${ }^{910}$ Location proved a primary barrier to accessibility of healthcare services,

\footnotetext{
902 'Least Developed Countries Health and WHO Country Presence Profile' World Health Organization Department of Country Cooperation and Collaboration with the United Nations System 2017, 2-3 http://apps.who.int/iris/bitstream/10665/255802/1/WHO-CCU-17.07-eng.pdf?ua=1 accessed 22/11/2017 903 See 9.2.1.1 Progression of senescence and disease 904 'World Health Statistics 2014,' World Health Organisation http://www.who.int/mediacentre/news/releases/2014/world-health-statistics-2014/en/ accessed 22/11/2017 905 'World Health Statistics 2014,' World Health Organisation http://www.who.int/mediacentre/news/releases/2014/world-health-statistics-2014/en/ accessed 22/11/2017 ${ }_{906}$ Including hypertension, diabetis, coronary artery disease. 'Health of the Elderly in South-East Asia: A Profile,' WHO Regional Office for South-East Asia 2004

${ }^{907}$ 'Health of the Elderly in South-East Asia: A Profile,' WHO Regional Office for South-East Asia 2004

${ }^{908}$ Accounting for more than half of the diseases of old age

${ }^{909}$ United Nations, 'Sub-Saharan Africa's growing population of older persons,' 5 http://www.un.org/en/development/desa/population/publications/pdf/popfacts/PopFacts 2016-1.pdf 910 Research comprised 64 older people in rural and non-rural areas of Uganda by personal interview and focus groups. Annet Nankwanga, 'Challenges of accessing healthcare services among older persons in Uganda.'
} 
with reports of individuals walking in excess of 5 kilometres to reach health centres. Another barrier is a lack of medical staff. Both were predominantly experienced in rural areas. ${ }^{911}$ Medical staff were also reported as being inadequately trained in geriatric conditions; and of demonstrating a lack of respect to older people. Often, older people reported younger people being prioritised for treatment and drugs. The only solution is for older people to pay for services which are otherwise free of charge. Furthermore, older people reported a lack of availability of medication and drugs. ${ }^{912}$

HelpAge International reported similar experiences in Tanzania. The survey quoted was undertaken by older people themselves monitoring older people's experiences of hospital visits, numbers of participants are not available. Disrespectful treatment, a form of humiliation and thus an insult to human dignity, proved a consistent theme. Of the participants, $40 \%$ reported feelings of being "mocked" by medical staff who considered them to be "not ill, just old." Moreover, $94 \%$ were charged for freely available treatment, and almost a third were unaware of how to apply for free healthcare. In excess of a third were made to wait between four and six hours to see a doctor. ${ }^{913}$

\subsubsection{Dementia}

\subsubsection{Dementia in the U.K.}

Research undertaken by the London School of Economics and the Institute of Psychiatry, King's College London provides detail on the prevalence of dementia in the U.K. Headline statistics summarise the situation. The research reports one person in five over the age of 80 and one person in 20 over the age of 65 suffering from the illness. ${ }^{914}$ Furthermore, the risk of occurrence increases with age, doubling with each five year increase within a given age range. ${ }^{915}$ As a result, the over $75 \mathrm{~s}$

Journal of Community and Health Sciences, (8) (2) 20151990 $<$ http://ichs.epubs.ac.za/index.php/ichs/article/view/88> accessed on 30 ${ }^{\text {th }}$ November 2017

${ }^{911}$ Annet Nankwanga, 'Challenges of accessing healthcare services among older persons in Uganda.' Journal of Community and Health Sciences, (8) (2) 2015 1990, <http://ichs.epubs.ac.za/index.php/ichs/article/view/88> accessed on $30^{\text {th }}$ November 2017

${ }_{912}$ Annet Nankwanga, 'Challenges of accessing healthcare services among older persons in Uganda.' Journal of Community and Health Sciences, (8) (2) 20151990 <http://jchs.epubs.ac.za/index.php/jchs/article/view/88> accessed on $30^{\text {th }}$ November 2017

${ }^{913}$ HelpAge International, 'Older people treated with disrespect by hospital staff' HelpAge International press release 13 May 2005 (as cited in 'Protecting the rights of older people in Africa' HelpAge International 2008, p.5)

${ }_{914}$ Research undertaken by the London School of Economics and the Institute of Psychiatry at King's College London on behalf of Dementia UK. Knapp, M., Professor and Prince, M., Professor, 'A Report into the Prevalence and Cost of Dementia,' (2007), 1.

${ }^{915}$ Research undertaken by the London School of Economics and the Institute of Psychiatry at King's College London on behalf of Dementia UK. Knapp, M., Professor and Prince, M., Professor, 'A Report into the Prevalence and Cost of Dementia,' (2007), 3. 
comprise $99.5 \%$ of dementia sufferers. Prevalence as a percentage of those aged 75 and over, and distribution by age, is represented below.

\section{TABLE NUMBER 8}

\section{Percentage of Dementia Sufferers by Age}

Age Range in Years

\begin{tabular}{|l|l|}
\hline $75-79$ & 5.9 \\
\hline $80-84$ & 12.2 \\
\hline $85-89$ & 20.3 \\
\hline $90-94$ & 28.6 \\
\hline 95 plus & 32.5 \\
\hline
\end{tabular}

In terms of actual figures, the report estimated 683,597 suffering from dementia in the U.K. in 2007, predicted to increase to 940,110 by the year 2021 and 1,735,087 by 2051 representing increases of $38 \%$ and $154 \%$ respectively. ${ }^{917}$ In accordance with the concept of accumulated disadvantage, ${ }^{918}$ a relationship between education and dementia can be established. The study of 6,885 people aged over 60 living in the community in the U.K. supports the Swedish findings in chapter $9 .{ }^{919}$ Selfreported memory failure of those aged 75 and over revealed approximately 10 percentage point differentiation between the least and highest educated. Amongst the 60-74 year age group a statistically important variation of 18 percentage points was reported.

\footnotetext{
${ }^{916}$ Research undertaken by the London School of Economics and the Institute of Psychiatry at King's College London on behalf of Dementia UK. Knapp, M., Professor and Prince, M., Professor, 'A Report into the Prevalence and Cost of Dementia,' (2007) ,3.

${ }^{917}$ Research undertaken by the London School of Economics and the Institute of Psychiatry at King's College London on behalf of Dementia UK. Knapp, M., Professor and Prince, M., Professor, 'A Report into the Prevalence and Cost of Dementia,' (2007), 4.

${ }^{918}$ See Life Course Theory

${ }^{919}$ See Cognitive Ageing; Steel, N, Huppert, F.S., McWilliams, B. and Melzer, D., 'Physical and Cognitive Function,' 'Health, Wealth and Lifestyles of the Older Population in England: The 2002 English Longitudinal Study of Ageing' , 285
} 
TABLE NUMBER 9 Self reported memory by education, age and sex (\% reporting fair or poor)

\begin{tabular}{|l|l|l|}
\hline Educational Attainment & Age group: 60-74 & Age group: 75+ \\
\hline Men & & \\
\hline Degree/Higher Education & $24.2 \%$ & $30.9 \%$ \\
\hline Intermediate Education & $31.9 \%$ & $37.2 \%$ \\
\hline No qualifications & $42.6 \%$ & $40 \%$ \\
\hline Women & & \\
\hline Degree/Higher Education & $21.8 \%$ & $26.1 \%$ \\
\hline Intermediate Education & $28.3 \%$ & $31.6 \%$ \\
\hline No qualifications & $31.7 \%$ & $36.4 \%$ \\
\hline
\end{tabular}

The association between education and prevalence of dementia provides a possible explanation for the number of dementia sufferers in low and middle-income countries is increasing at a greater rate than in high-income countries. Alzheimer's Disease International compared predicted growth rates between the groups of countries, and reported as follows:

${ }^{920}$ Steel, N, Huppert, F.S., McWilliams, B. and Melzer, D., 'Physical and Cognitive Function,' 'Health, Wealth and Lifestyles of the Older Population in England: The 2002 English Longitudinal Study of Ageing' , 285 
10.1.4.2

Predicted numbers of dementia sufferers in high-income and medium and

low-income countries

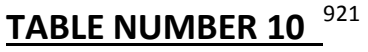

\begin{tabular}{|l|l|l|l|l|l|}
\hline Year & 2010 & 2020 & 2030 & 2040 & 2050 \\
\hline & $\begin{array}{l}\text { Approximate } \\
\text { numbers (m) }\end{array}$ & $\begin{array}{l}\text { Approximate } \\
\text { numbers (m) }\end{array}$ & $\begin{array}{l}\text { Approximate } \\
\text { numbers (m) }\end{array}$ & $\begin{array}{l}\text { Approximate } \\
\text { numbers (m) }\end{array}$ & $\begin{array}{l}\text { Approximate } \\
\text { numbers (m) }\end{array}$ \\
\hline $\begin{array}{l}\text { High-income } \\
\text { countries }\end{array}$ & 17 & 20 & 24 & 30 & 36 \\
\hline $\begin{array}{l}\text { Medium and } \\
\text { low-income } \\
\text { countries }\end{array}$ & 37 & 48 & 62 & 90 & 118 \\
\hline
\end{tabular}

With fewer resources available for health and care, the rapid rate of increase in sufferers exposes greater numbers of older people in the less wealthy countries to degrees of threat and vulnerability beyond that of wealthier countries.

\subsubsection{Accumulated Disadvantage}

The effect of accumulated disadvantage, recognised in Life-Course Theory, ${ }^{922}$ is evident in the health and disability experience of older people. Using socio-economic status, defined by factors of class, education, and income and wealth accumulated disadvantage in these areas have proven the most disadvantaged to have the lowest healthy life expectancy. ${ }^{923}$ All socio-economic factors generated discrepancy in illness-free and disability-free life expectancy, with the greatest effect associated to wealth and income. Accumulated disadvantage causes the most disparity in early old age, with the ages of 50 and 65 providing markers of stages of heightened vulnerability among the groups with lowest socio-economic status. The most influential factor was shown to be wealth and income. ${ }^{924}$ However, the force of the senescing process, outlined in Chapter $9,{ }^{925}$ negates influence of all

${ }^{921}$ Based on information available in 'World Alzheimer Report, 2010' Alzheimer's Disease International, http://www.alz.co.uk/research/files/WorldAlzheimerReport2010.pdf (as cited in 'Global Health and Aging,' 21, National Institute on Aging, 2011, <https://www.nia.nih.gov/research/publication/global-health-andaging/living-longer $>, 15$ accessed 10/04/2017.

922 Explained as disadvantage accumulated throughout a lifetime impacts the vulnerabilities experienced in older age.

923 Jagger et al 2008; Pongiglione et al 2015

924 James Namls. G. David Batty, James Nazroo, Andrew Steptoe (eds.) 'The Dynamics of Ageing: Evidence from the English Longitudinal Study of Ageing 2002-2015' Wave 7 Figure 4.11 'Proportion of remaining life spent without illness by income', 114-115

${ }^{925}$ See Chapter 9: 'Senescence,' 'Progression of senescence,' and 'Cognitive disease.' 
categories of socio-economic status in the oldest old, with the over 85s experiencing similar degrees of illness. ${ }^{926}$ The oldest old therefore experience greatest vulnerability and dependency as a result.

Disadvantage accumulated throughout a lifetime also impacts mortality, particularly in the "young old," a fact which also calls for the lowest possible age to provide the marker for access to special protection for older people, as discussed in Chapter $9 .{ }^{927}$

\subsection{Poverty}

Vulnerability to poverty can be the result of a range of threats. Severity of harm and concrete outcomes vary inter and intra-regionally, however, similar themes recur from an examination of the causes of poverty in older people. Such themes include: the ability to provide for oneself; the inability to obtain and maintain well paid employment; a physical inability to work; and the degree of State support including healthcare and long-term care. Also identifiable as themes are the higher proportion of older women living in poverty than men, and that the highest levels of older people in employment exist in countries with inadequate or no pension provision. The international aim is income security for older people sufficient to provide for an adequate standard of living. Also, the ability to provide for oneself should not impose a necessity to work beyond the State pensionable age. The ILO states that 'retirement pensions or similar programmes for income support at older ages are critical to the social protection of older persons. ${ }^{928}$

\subsubsection{Pension Provision}

The ILO reported a global average of older people above retirement age in receipt of a pension is $51.5 \%$ in $2015 .^{929}$ The reliance on public pensions by the poorest in society is evident in the proportion of income which comprises pension. On average, amongst the lowest 4 deciles in OECD countries, public pensions account for $80 \%$ of income for older people. Income from employment provides for only $5-9 \%$ of income. This compares to income from employment accounting for 20$40 \%$ of the income of those in the top 4 deciles across the same mix of countries. Dependency on

\footnotetext{
${ }^{926}$ James Namls. G. David Batty, James Nazroo, Andrew Steptoe (eds.) 'The Dynamics of Ageing: Evidence from the English Longitudinal Study of Ageing 2002-2015' Wave 7, 113-115. See also Beckett, 2000 the 'ageas-leveller' theory (as cited in James Namls. G. David Batty, James Nazroo, Andrew Steptoe (eds.) 'The Dynamics of Ageing: Evidence from the English Longitudinal Study of Ageing 2002-2015' Wave 7, 114). ${ }^{927}$ See Chapter 9: 'The size of the age group' and 'The case of older people.'

${ }^{928}$ International Labour Organisation, World Social Protection Report 2014/14 'Building economic recovery, inclusive development and social justice' http://www.ilo.org/ilostat accessed 30th November 2017 ${ }_{929}$ If the figure for China is removed, which now includes extensions to pension coverage in industry and agriculture for older people introduced in 2009 and 2011, the average falls to $45.6 \%$. International Labour Organisation 'World Social Protection Report,' 2015, 83 http://www.ilo.org/wcmsp5/groups/public/--dgreports/---dcomm/documents/publication/wcms 245201.pdf
} 
public pension schemes is high even in wealthy regions, comprising $60 \%$ of the average proportion of income of older people in Europe. ${ }^{930}$

\subsubsection{Regional Comparison of State Pension Provision}

$$
\text { 10.2.2.1 European Poverty Risks }
$$

Developed regions are not immune to poverty risks for older people. It is instructive that the more developed countries within developed regions can record some of the highest levels of poverty risk. Eastern European countries record the highest and lowest levels of poverty risk for older people. Against an average risk of $19 \%$ in 2008 , the risk in Latvia was $51 \%$, Estonia $39 \%$, and Bulgaria $34 \%$. Hungary recorded levels of $4 \%$, and the Czech Republic 7\%. The poverty risk level for the United Kingdom in the same year was $30 \%{ }^{931}$ It is instructive to note that poverty risk levels are influenced by States providing generous pension schemes vis à vis cost of living and low pension provision comparable to low national income levels. This reflects a low State pension provision in the UK in comparison with average income levels, and the reverse in the Czech Republic. ${ }^{932}$ Therefore, poverty levels of older people are not universally reflective of the national economic condition. A poverty theme in Europe identifiable with some of the poorest international regions involves poverty of older women. Across the EU countries women have a higher average poverty risk of $22 \%$ than men, which is $16 \%{ }^{933}$ Reflective of the highest levels of employment amongst older people are recorded in States that provide inadequate or no pension, in Europe $10 \%$ of older men and $6 \%$ of older women were in employment. ${ }^{934}$

\subsubsection{Africa}

The ILO reports $17 \%$ of people of older people of pensionable age in sub-Saharan Africa to be in receipt of pension income. This places demands on filial obligation, charity, and invariably results in an inability to retire. The significance of the informal economy resulted in $8.4 \%$ of the 2014 labour force contributing to pension insurance, continuing the trend for the next generation of older

\footnotetext{
${ }^{930}$ International Labour Organisation 'World Social Protection Report,' 2015, 74 http://www.ilo.org/wcmsp5/groups/public/---dgreports/---dcomm/documents/publication/wcms 245201.pdf ${ }_{931}$ Poverty levels were defined in the European region as having a disposable income of less than $60 \%$ of the national equivalised median income. Asghar Zaidi, 'Poverty Risks for Older People in EU Countries - An Update' European Centre Policy Brief January 2010

${ }_{932}$ Asghar Zaidi, 'Poverty Risks for Older People in EU Countries - An Update' European Centre Policy Brief January 2010

${ }_{933}$ Asghar Zaidi, 'Poverty Risks for Older People in EU Countries - An Update' European Centre Policy Brief January 2010

${ }^{934}$ International Labour Organisation, World Social Protection Report 2014/14 ‘Building economic recovery, inclusive development and social justice' http://www.ilo.org/ilostat accessed 30th November 2017
} 
people. The role of the informal economy, coupled with most countries in the Sub-Saharan region not providing non-contributory pensions has translated into Africa having the highest proportion of older people in employment in the world. In excess of half of men and one third of women aged over 65 were in employment in Africa in $2015 .{ }^{935}$

The European region demonstrated the difficulty in correlating poverty risk levels with the wealth of the nation. A key finding from the study of the African situation is a correlation between low rates of pension coverage and high levels of labour force participation among older persons. The ILO cites Zimbabwe as an example. A distinct relationship is identifiable between less than $10 \%$ of people of pensionable age receiving a pension, and $75 \%$ of men and $65 \%$ of women of pensionable age in employment. In South Africa, where $92 \%$ of over 65 s receive a pension, just $9 \%$ of the same age group were in employment in $2015 .{ }^{936}$

\subsubsection{Inter-regional Inequalities in Pension Coverage}

Income security is provided through pensions for $17 \%$ of older people in sub-Saharan Africa, compared to $37 \%$ in North Africa. The figure is $29.5 \%$ across the Middle East, and $56 \%$ in Latin America and the Caribbean. In Asia and the Pacific32\% of older people receive a pension, rising to an average of $47 \%$ including China. The regions in which most older people receive pension payments are North America and Europe, with average figures for the region of $90 \% .{ }^{937}$ The significance of State support for older people is further emphasised by the proportion of individuals in receipt of, or able to invest in contributory pensions. Looking to the future the ILO records a global figure of $25.4 \%$ ( $31 \%$ if China is included) currently contributing to pension schemes. Once more the regional inequalities are significant. North America records the global high of $98.5 \%$ of older people due to receive payments from contributory pension schemes, compared to $8 \%$ in subSaharan Africa. Europe enjoys mixed fortunes, with $89 \%$ of older people in Western Europe due to receive payments from contributory pension schemes, and 68\% in Central and Eastern Europe. The remainder of currently employed individuals currently contributing to pension schemes, by geographic region, vary between 34\% in Asia and the Pacific, 37\% in the Middle East, $38 \%$ in Latin

\footnotetext{
${ }^{935}$ International Labour Organisation, World Social Protection Report 2014/14 'Building economic recovery, inclusive development and social justice' http://www.ilo.org/ilostat accessed 30th November 2017; 'Isabella Aboderin, on ageing in sub-Saharan Africa,' Age International https://www.ageinternational.org.uk/policy-andresearch/ageing-international-development/ageing-population-of-africa/ accessed 22/11/2017

936 ILOSTAT Database http://www.ilo.org/ilostat/ accessed $28^{\text {th }}$ November 2017

${ }^{937}$ International Labour Organisation 'World Social Protection Report,' 2015, 83 http://www.ilo.org/wcmsp5/groups/public/---dgreports/---dcomm/documents/publication/wcms 245201.pdf
} 
America and the Caribbean, and $47 \%$ in North Africa. ${ }^{938}$ The ILO identifies further inequalities within regions and within countries. Older women suffer most aggravated vulnerability as a result of discrimination in the structure of pension schemes and payment in the workplace. ${ }^{939}$

\subsubsection{Poverty in Asia}

Identification of older people as a group is subject to cultural relativity. Of the various forms proposed in theories of ageing, significant markers in Asia include a reduction in roles due to physical decline, and greater involvement in roles allocated to older people. Chronological age "has little or no importance," therefore, the internationally assigned age of 65 is generally overridden in such societies by role, engagement and productivity. ${ }^{940}$ Negative self-perception is also extensive, particularly in societies experiencing pressure on filial obligation, and where productivity is an influential factor in identification. ${ }^{941}$ India is an example of a country where older people are subject to reduced filial obligation leaving older people exposed to "emotional neglect and lack of physical support." A large number of "older people has become vulnerable...they cannot take for granted that their children will be able to look after them when they need care in old age...implying an extended period of dependency and higher costs to meet health and other needs." ${ }^{\prime 942}$ Absolute poverty ${ }^{943}$ is identified as a significant problem in Asia Pacific. ${ }^{944}$ Therefore, older people suffering impoverishment, exacerbated by an inability to be economically productive, accumulated economic disadvantage, a lack of family or State support, and discrimination are amongst the world's

\footnotetext{
${ }^{938}$ International Labour Organisation 'World Social Protection Report,' 2015, 84 http://www.ilo.org/wcmsp5/groups/public/---dgreports/---dcomm/documents/publication/wcms 245201.pdf ${ }_{939}$ International Labour Organisation 'World Social Protection Report,' 2015, 88 http://www.ilo.org/wcmsp5/groups/public/---dgreports/---dcomm/documents/publication/wcms 245201.pdf ${ }^{940}$ Edward Gerlock, 'Age Discrimination in 5 continents: real issues, real concerns,' International Federation on Ageing Conference, Copenhagen 30 May - 2 June 2006, Age Concern, 3

${ }_{941}$ 'ageing is characterised for older people by becoming more and more of a burden on their family and the community' HelpAge Laos, Participatory Rapid Appraisal (PRA) (as cited in Edward Gerlock, 'Age Discrimination in 5 continents: real issues, real concerns,' International Federation on Ageing Conference, Copenhagen 30 May - 2 June 2006, Age Concern, 4)

${ }_{942}$ Macao Plan of Action 16-18 July 2001, (as cited in Edward Gerlock, 'Age Discrimination in 5 continents: real issues, real concerns,' International Federation on Ageing Conference, Copenhagen 30 May -2 June 2006, Age Concern, 4)

${ }^{943}$ Based on the international poverty line of US\$1 per capita per day at 1993 prices. Edward Gerlock, 'Age Discrimination 5 continents: real issues, real concerns' 31 May 2006, 12 'International Federation on Ageing Conference' Copenhagen 30 May-2 June 2006

${ }^{944} 800 \mathrm{~m}$, or two thirds of the world's poor live in the region. Edward Gerlock, 'Age Discrimination 5 continents: real issues, real concerns' 31 May 2006, 12 'International Federation on Ageing Conference' Copenhagen 30 May-2 June 2006
} 
poorest. ${ }^{945}$ Poverty is greater among older women in the region, as due to widowhood and a lack of pension provision all but one third live alone and in poverty. ${ }^{946}$

\subsubsection{Retirement}

\subsubsection{Expected Years of Retirement}

The OECD undertook a study of the expected years of retirement amongst males in a range of member countries in 2007. The results ranged from a high of 24 years in France, to 18.8 years in the U.K., 13.6 years in Japan, and 9.1 years in Mexico. ${ }^{947}$ This highlights discrepancies in the number of years of good health older people can expect post-retirement. Additionally, the disparities point to issues in attempting to allocate a single age for retirement as the access point for special protection, thereby strengthening the case for implementing the lowest possible age in order to make special protection available to as large a group as possible.

\subsubsection{Forced Retirement}

Retirement is a principal trajectory ending life event, and is adopted by this thesis as marking the latest point at which special protection should be accessible to older people. It has been identified as a life event which directly and indirectly attracts numerous vulnerabilities. Significantly, forced retirement is an indicator, or cause, of some. "...employees' failure to control retirement according to their wishes has adverse effects on health." ${ }^{\prime 948}$ Involuntary job loss is cited as causing problems with physical function and mental health among older workers. The outcome can be directly related to the value a person places on productive versus non-productive time, with investment in personal health responding to the latter. Additionally, if non-productive post-retirement time is not valued, neither is any improvement in health. Additionally, late-stage job loss causes financial hardship for older people relying on the last years of employment to provide for retirement. ${ }^{949}$

\footnotetext{
${ }^{945}$ Edward Gerlock, 'Age Discrimination 5 continents: real issues, real concerns' 31 May 2006, 12 'International Federation on Ageing Conference' Copenhagen 30 May-2 June 2006

${ }^{946}$ Edward Gerlock, 'Age Discrimination 5 continents: real issues, real concerns' 31 May 2006,12 'International Federation on Ageing Conference' Copenhagen 30 May-2 June 2006

947 'Global Health and Aging,' 21, National Institute on Aging, 2011, https://www.nia.nih.gov/research/publication/global-health-and-aging/living-longer

${ }_{948}$ Research undertaken of 778 Dutch older workers recently withdrawn from the labour force. Research undertaken in 1995 with a follow up study in 2001. The average age of participants in 1995 was 57 . The average at which participants retired was 60 , with a mandatory retirement age of 65 . Only $2.5 \%$ of participants worked until mandatory retirement age. Hanna van Solinge, 'Health Change in Retirement A Longitudinal Study among older workers in the Netherlands,' 'Research on Ageing,' 248 May 2007, <https://doi:10.1177/0164027506298223>

${ }^{949}$ Hanna van Solinge, 'Health Change in Retirement A Longitudinal Study among older workers in the Netherlands,' 'Research on Ageing,' 248 May 2007, <https://doi:10.1177/0164027506298223>
} 
A life-course perspective helps to explain the financial effect of late-stage job loss and accumulated disadvantage on older people. Using the "labourer" to describe the disadvantaged person, the stages of poverty were cited by Rowntree as "childhood...early midlife...old age." The disadvantaged child lives in poverty until he is able to earn money. However, when he heads a family "poverty will again overtake him." Finally, the disadvantaged "labourer" "too old to work...his income has never permitted his saving enough...to live upon for more than a very short time ${ }^{\prime 950}$ is most likely to suffer poverty post-retirement, particularly when that retirement is involuntary.

Reasons for involuntary retirement in the U.K. are predominantly redundancy or job loss and illhealth. The ELSA wave 7 showed involuntary retirement to have increased among men in the period 2000-2009, however, research for 201415 shows it as stable. The reasons for involuntary retirement are recorded as equally distributed between ill-health, ill-health of another, and redundancy. Throughout the ELSA longitudinal study voluntary retirement has always been lower than involuntary. The genders combined report reasons for retirement in relatively equal proportions as: voluntary, involuntary, and reaching retirement age. ${ }^{951}$ Older people in routine and manual employment are less likely to retire voluntarily, and continue to work until State pensionable age. Older people with a State pension only are more likely to be made to retire involuntarily than with a defined benefit pension. There is a distinct correlation between declining health and increasing involuntary retirement. In comparison to older people in "excellent" health, those in "poor" health are 4.5 times more likely to retire prior to State pensionable age, and 3 times more likely if in "good or fair" health. Age group and gender also defines retirement trends. The age group 60-74 are "significantly less likely to retire voluntarily" than ages 50-64, as are women. ${ }^{952}$ The research also reported approximately half of involuntary retirees to be in the poorest two wealth quintiles. ${ }^{953}$ Collectively, these findings point to a potential for financial need, or a wish to remain

\footnotetext{
${ }^{950}$ B.S. Rowntree, Poverty. A Study of Town Life, (1902, London, Thomas Nelson and Sons) (as cited in Caroline Dewilde, 'A life-course perspective on social exclusion and poverty,' British Journal of Sociology, Vol.54 Issue No. 1 (March 2003), 109, 111)

${ }^{951}$ Katey Matthews and James Nazroo, 'Retirement, well-being, engagement and social status,' 57,76 \& 77, in James Banks, G. David Batty, James Nazroo and Andrew Steptoe (eds.) 'The Dynamics of Ageing: Evidence from the English Longitudinal Study of Ageing 2002-2015'

${ }^{952}$ Katey Matthews and James Nazroo, 'Retirement, well-being, engagement and social status,' 87 in James Banks, G. David Batty, James Nazroo and Andrew Steptoe (eds.) 'The Dynamics of Ageing: Evidence from the English Longitudinal Study of Ageing 2002-2015'

${ }_{953}$ Katey Matthews and James Nazroo, 'Retirement, well-being, engagement and social status,' 87 , in James Banks, G. David Batty, James Nazroo and Andrew Steptoe (eds.) 'The Dynamics of Ageing: Evidence from the English Longitudinal Study of Ageing 2002-2015'
} 
active amongst older people. Falling social status accompanied involuntary retirement, also associated with the lowest levels of social engagement. ${ }^{954}$

Most social activity and highest standards of well-being were experienced prior to and following retirement by those voluntarily retiring. Additionally, the social status of voluntary retirees increased the most. ${ }^{955}$ Furthermore, more than half retiring voluntarily were reported as being in the top two wealth quintiles of respondents. ${ }^{956}$

\subsection{Consequences of retirement type on well-being}

Aspects of successful ageing, notably mental health, satisfaction with life, quality of life, and engagement, can be influenced by type of retirement. This section will report on findings of Wave 7 of the ELSA Longitudinal Study in these areas. ${ }^{957}$ Involuntary retirement is associated with higher levels of depression than voluntary retirement, with the greatest effects in the 70-74 and 75 plus age groups. ${ }^{958}$ Involuntary retirement also reports the lowest levels of satisfaction with life throughout the retirement transition period. However, a similar pattern of general decline occurs across all categories of retirement, variation is degree to which it is felt. Research reports the rate of change for all to be significant. It means everyone is less satisfied with life post retirement, but involuntary are least satisfied. ${ }^{959}$ The highest quality of life was reported amongst voluntary retirees both before and after retirement, and the lowest amongst involuntary retirees both before and after retirement. ${ }^{960}$ Patterns of social engagement prior and subsequent to retirement comply with Disengagement and Activity Theories. The highest levels of social engagement are experienced by

\footnotetext{
${ }^{954}$ Katey Matthews and James Nazroo, 'Retirement, well-being, engagement and social status,' 58 , in James Banks, G. David Batty, James Nazroo and Andrew Steptoe (eds.) 'The Dynamics of Ageing: Evidence from the English Longitudinal Study of Ageing 2002-2015'

955 Katey Matthews and James Nazroo, 'Retirement, well-being, engagement and social status,' 58 , in James Banks, G. David Batty, James Nazroo and Andrew Steptoe (eds.) 'The Dynamics of Ageing: Evidence from the English Longitudinal Study of Ageing 2002-2015'

${ }^{956}$ Katey Matthews and James Nazroo, 'Retirement, well-being, engagement and social status,' 57 , in James Banks, G. David Batty, James Nazroo and Andrew Steptoe (eds.) 'The Dynamics of Ageing: Evidence from the English Longitudinal Study of Ageing 2002-2015'

${ }^{957}$ The research used 15,239 observations of 2,177 individuals, reported in the 2014-2015 Wave. Katey Matthews and James Nazroo, 'Retirement, well-being, engagement and social status,' 87, in James Banks, G. David Batty, James Nazroo and Andrew Steptoe (eds.) 'The Dynamics of Ageing: Evidence from the English Longitudinal Study of Ageing 2002-2015'

958 Katey Matthews and James Nazroo, 'Retirement, well-being, engagement and social status,' 88-89, in James Banks, G. David Batty, James Nazroo and Andrew Steptoe (eds.) 'The Dynamics of Ageing: Evidence from the English Longitudinal Study of Ageing 2002-2015'

${ }^{959}$ Katey Matthews and James Nazroo, 'Retirement, well-being, engagement and social status,' 91 , in James Banks, G. David Batty, James Nazroo and Andrew Steptoe (eds.) 'The Dynamics of Ageing: Evidence from the English Longitudinal Study of Ageing 2002-2015'

960 Katey Matthews and James Nazroo, 'Retirement, well-being, engagement and social status,' 91, in James Banks, G. David Batty, James Nazroo and Andrew Steptoe (eds.) 'The Dynamics of Ageing: Evidence from the English Longitudinal Study of Ageing 2002-2015'
} 
older people who retire voluntarily, the least by involuntary retirees. Both categories experience a decline in social engagement prior to retirement, and an increase following retirement. The rate of recovery of social engagement after retirement is more positive for involuntary it takes 7 years to reach levels of social engagement enjoyed 10 years prior to retirement. Voluntary retirees take 10 years to achieve the same, a rate of change considered "significant" by the research. ${ }^{961}$

The research of ELSA concludes the worst effects of retirement to be felt by older people who retire involuntarily. They are the most financially vulnerable. Also, they are the only group of retired people who feel negative effects in all areas of mental health, social engagement, life satisfaction, quality of life, and social status.

\subsection{Social Isolation, Disengagement, and Loneliness}

The social isolation and disengagement of Modernisation and Disengagement Theories are primary causes of loneliness. The three are connected, yet separate concepts.

The type of loneliness suffered is dependent upon the relationship and roles lost. Therefore, it can be traced to migration of family members as a result of modernisation, loss of ties as disengagement occurs, or reduction of roles due to ill-health or being non-productive. 'Emotional loneliness is the absence of a significant other with whom a close emotional attachment is formed...and social loneliness is the absence of a social network consisting of a wide or broad group of friends, neighbours and colleagues. ${ }^{962}$ Loneliness is described as "perceived isolation...the distressing feeling that accompanies discrepancies between one's desired and actual social relationships." 963 The objective and actual separation from relationships, society, and support comprises social

\footnotetext{
${ }^{961}$ Katey Matthews and James Nazroo, 'Retirement, well-being, engagement and social status,' 91-92, in James Banks, G. David Batty, James Nazroo and Andrew Steptoe (eds.) 'The Dynamics of Ageing: Evidence from the English Longitudinal Study of Ageing 2002-2015'

${ }^{962}$ Vanessa Burholt, 'Safeguarding the convoy A call to action from the Campaign to End Loneliness,' 10 , Age UK, 2011

${ }_{963}$ Ye Luo, Louise C. Hawkley, Linda J. Waite, John T. Cacioppo, 'Loneliness, Health and Mortality in Old Age: A National Longitudinal Study,' Soc Sci Med 2012 Mar 74(6) 907

https://www.ncbi.nlm.nih.gov/pmc/articles/PMC3303190/. The problem can be associated with the rationale of the Capabilities Approach which attempts to reconcile that which a person values being and doing and that which the person is capable of being and doing.
} 
isolation. ${ }^{964}$ Feelings of self-worth, and therefore, dignity, can be harmed by disengagement, social isolation, and feelings of loneliness, in turn creating vulnerability to illness and further isolation. ${ }^{965}$

Studies of loneliness allow correlation to be made with engagement in emotional and social relationships, quoted in Chapter 9 as an aspect of successful ageing. Issues of cause and effect of lack of engagement and activity are often interrelated, and many impact both the emotional and social facets of loneliness. Loss of a spouse is a main cause of both types of loneliness. This event results in the loss of a central emotional relationship and has the effect of reducing access to the wider community. Lack of contact with other important relationships of kinship and emotion, including family members and friends is also significant in emotional and social loneliness. Other factors limiting engagement, and effects of reduced engagement include: self-esteem; satisfaction with life; and "income discomfort." Financial limitations restrict participation in activities, and reduce usage of paid services needed for independent living. Furthermore, the ability to reciprocate informal support received, and therefore, engagement in emotional relationships is also limited. ${ }^{966}$

Analysis of the findings of three research studies into loneliness, ${ }^{967}$ reported a prevalence of loneliness amongst the oldest old; "Of those aged 80 and over $40-50 \%$ say they are "often" lonely." ${ }^{\prime 968}$ Research on loneliness, conducted mostly in Western countries, has shown that at any given time, twenty to forty percent of older adults report feeling lonely, and from five to seven percent report feeling intense or persistent loneliness.

An increasing body of research has proven a link between declining social relationships, loneliness, social isolation, and ill-health and morbidity. "Social relationships, or the relative lack thereof, constitute a major risk factor for health-rivalling the effect of well established health risk factors

964 John T. Cacioppo, Louise C. Hawkley, Ronald A. Trusted, 'Perceived Social Isolation Makes Me Sad: Five Year Cross-Lagged Analyses of Loneliness and Depressive Symptomatology in the Chicago Health, Aging and Social Relations Study,' Psychol Aging 2010 Jun: 25(2): 453 https://www.ncbi.nlm.nih.gov/pmc/articles/PMC2922929/.

965 John T. Cacioppo, Louise C. Hawkley, Ronald A. Trusted, 'Perceived Social Isolation Makes Me Sad: Five Year Cross-Lagged Analyses of Loneliness and Depressive Symptomatology in the Chicago Health, Aging and Social Relations Study,' Psychol Aging 2010 Jun: 25(2): 453 https://www.ncbi.nlm.nih.gov/pmc/articles/PMC2922929/.

${ }^{966}$ Lena Dahlberg and Kevin J. McKee, 'Correlates of social and emotional loneliness in older people: evidence from an English community study,' 'Aging and Mental Health,' 541 http://dv.doi.org/10.1080/13607863.2013.856863 accessed 10/03/2017

967 J. DeJong Gierveld (1998), 'A review of loneliness: Concept and definitions, determinants and consequences'; D. Perlman, L.A. Peplau (1984) , 'Loneliness research: a survey of empirical findings' in L.A. Peplau, S.E. Goldston (eds.) 'Preventing the harmful consequences of severe and persistent loneliness' DHHS publication number ADM 84-12 US Government printing office Washington DC; M. Pinquart, S. Sörensen (2001) 'Influence on loneliness in older adults: a meta-analysis,' Basic Appl Soc Psychol 23: 245

968 Pearl A. Dykstra, 'Older adult loneliness: myths and realities,' Eur J Ageing 2009 June; 6(2) 91 
such as cigarette smoking, blood pressure...obesity and physical activity." ${ }^{969}$ Loneliness and social isolation are also associated with unhealthy practices, such as smoking, alcoholism, ${ }^{970}$ lack of exercise, ${ }^{971}$ obesity, ${ }^{972}$ and ill-health. The lack of influence by family and friends over such practices is cited as contributory. Social isolation and loneliness are, primarily due to associated physical and psychological problems and dependency, predictors of early admission to residential care. ${ }^{973}$

Additionally, a direct impact with morbidity levels has been established. ${ }^{974}$ Specific illnesses of older age are noted to have a connection with loneliness and isolation. Depressive symptoms are most acutely experienced in old age when the last remaining relationships with family and friends are lost, ${ }^{975}$ and suicidal behaviours are amongst other psychological problems associated with old age loneliness. ${ }^{976}$ Loneliness is an accepted forecast for depression; insomnia; ${ }^{977}$ mental health and

969 James S. House, Karl R. Landis, Debra Umberson, 'Social Relationships and Health,' Science, New Series (241) (4865) Jul 29 1988, 540. The effect on health is stated as being that of 15 cigarettes a day and 6 glasses of alcohol, Julianne Holt-Lunstad, Timothy B. Smith, J.Bradley Layton, 'Social relationships and mortality risk: a meta-analytic review,' PLOS Med 2010: 7(7), 2 <http://journals.plos.org/plosmedicine/article?id=10.1371/journal.pmed.1000316> accessed 4 April 2017 970 Akerlind I, Hörnquist JO 'Loneliness and alcohol abuse: a review of evidences of an interplay,' Soc Sci Med. 1992 Feb; 34(4):405-14(as cited in John T. Cacioppo, Louise C. Hawkley, Ronald A. Trusted, 'Perceived Social Isolation Makes Me Sad: Five Year Cross-Lagged Analyses of Loneliness and Depressive Symptomatology in the Chicago Health, Aging and Social Relations Study,' Psychol Aging 2010 Jun: 25(2): 453 ) https://www.ncbi.nlm.nih.gov/pmc/articles/PMC2922929/

${ }^{971}$ Hawkley LC, Thisted RA, Cacioppo JT, 'Loneliness predicts reduced physical activity: cross-sectional \&amp; longitudinal analyses,' Health Psychol. 2009 May; 28(3):354-63 (as cited in Ye Luo, Louise C. Hawkley, Linda J. Waite, John T. Cacioppo, 'Loneliness, Health and Mortality in Old Age: A National Longitudinal Study,' Soc Sci Med 2012 Mar 74(6) 907 https://www.ncbi.nIm.nih.gov/pmc/articles/PMC3303190/.)

${ }^{972}$ Lauder W, Mummery K, Jones M, Caperchione C, A comparison of health behaviours in lonely and nonlonely populations.Psychol Health Med. 2006 May; 11(2):233-45 (as cited in 'Perceived Social Isolation Makes Me Sad: Five Year Cross-Lagged Analyses of Loneliness and Depressive Symptomatology in the Chicago Health, Aging and Social Relations Study,' Psychol Aging 2010 Jun: 25(2): 453

https://www.ncbi.nlm.nih.gov/pmc/articles/PMC2922929/)

${ }^{973}$ D.W. Russell, D.E. Cutrona, A. de la Mora, R.B. Wallace, 'Loneliness and nursing home admission among rural older adults,' Psychol Aging 1997; 12(4): 574

${ }^{974}$ See generally Bert I. Uchino, 'Social Support and Health: A Review of Physiological Processes Potentially Underlying Links to Disease Outcomes,' Journal of Behavioural Medicine, Aug 2006 Vol 29, Issue 4, 377 https://link.springer.com/article/10.1007\%2Fs10865-006-9056-5 accessed 4 March 2017; Ye Luo, Louise C. Hawkley, Linda J. Waite, John T. Cacioppo, 'Loneliness, Health and Mortality in Old Age: A National Longitudinal Study,' Soc Sci Med 2012 Mar 74(6) 907 https://www.ncbi.nlm.nih.gov/pmc/articles/PMC3303190/

${ }^{975}$ https://www.ncbi.nlm.nih.gov/pmc/articles/PMC2922929/

${ }^{976}$ Goldsmith SK, Pellmar TC, Kleinman AM, Bunney WE. 'Reducing suicide: A national imperative.' National Academy Press; Washington, DC: 2002 (as cited in 'Perceived Social Isolation Makes Me Sad: Five Year CrossLagged Analyses of Loneliness and Depressive Symptomatology in the Chicago Health, Aging and Social Relations Study,' Psychol Aging 2010 Jun: 25(2): 453) https://www.ncbi.nlm.nih.gov/pmc/articles/PMC2922929/

${ }^{977}$ L. C Hawkley, K. J. Preacher and J.T. Cacioppo, 'Loneliness impairs daytime functioning but not sleep duration,' Health Psychol. 2010 Mar; 29(2):124-9. (as cited in Ye Luo, Louise C. Hawkley, Linda J. Waite, John T. Cacioppo, 'Loneliness, Health and Mortality in Old Age: A National Longitudinal Study,' Soc Sci Med 2012 Mar 74(6) 907 https://www.ncbi.nlm.nih.gov/pmc/articles/PMC3303190/) 
cognitive problems; ${ }^{978}$ and for rapid progression of Alzheimer's Disease, ${ }^{979}$ quoted as increasing the risk by $64 \% .{ }^{980}$ Moreover, loneliness is associated with the other "giants" of old age illness; vascular problems and hypertension. ${ }^{981}$ The findings of an analysis of 148 studies representing data from culturally diverse continents, involving participants with an average age of $64,{ }^{982}$ demonstrated social relationships to provide vulnerability-resisting assets and resilience against ill-health and morbidity. ${ }^{983}$ Quantitative and qualitative weakening of social relationships were found to increase the probability of death by $50 \%$, wielding an influence comparable with "well-established risk factors for mortality." ${ }^{1944}$ The fact that social integration has greater influence over risk of mortality than lone living, led to the warning of an increased risk of ill-health and death for older people both socially isolated and living alone. Furthermore, this outcome of modernisation, disengagement, lack of activity and loss of roles is taken as a key forecaster of admission to residential care or nursing home, ${ }^{985}$ introducing issues of emplacement vulnerability ${ }^{986}$ to the older person.

\footnotetext{
${ }^{978}$ Wilson RS, Krueger KR, Arnold SE, Schneider JA, Kelly JF, Barnes LL, Tang Y, Bennett DA Loneliness and risk of Alzheimer disease., Arch Gen Psychiatry. 2007 Feb; 64(2):234-40 (as cited in Ye Luo, Louise C. Hawkley, Linda J. Waite, John T. Cacioppo, 'Loneliness, Health and Mortality in Old Age: A National Longitudinal Study,' Soc Sci Med 2012 Mar 74(6) 907 https://www.ncbi.nlm.nih.gov/pmc/articles/PMC3303190/)

${ }^{979}$ Wilson RS, Krueger KR, Arnold SE, Schneider JA, Kelly JF, Barnes LL, Tang Y, Bennett DA 'Loneliness and risk of Alzheimer disease,' Arch Gen Psychiatry 2007 Feb; 64(2):234-40 (as cited in 'Perceived Social Isolation Makes Me Sad: Five Year Cross-Lagged Analyses of Loneliness and Depressive Symptomatology in the Chicago Health, Aging and Social Relations Study,' Psychol Aging 2010 Jun: 25(2): 453) https://www.ncbi.nlm.nih.gov/pmc/articles/PMC2922929/)

${ }^{980}$ Research of 2,173 non-demented, communal living older people over a 3 year period. Tjalling Jan Holwerda, Dorly J H Deeg, Aartjan T F Beekman, Theo G van Tilburg, Max L Sted, Cees Jonker, Robert A Schoevers, 'Research paper: Geelings of loneliness, but not social isolation, predict dementia onset: results from the Amsterdam Study of the Elderly' (AMSTEL) 2012, <https://www.researchgate.net/profile/Theo Van Tilburg/publication/233900548> accessed 4 March 2017 ${ }^{981}$ See Chapter 9 for examination of the senescing process and diseases of old age.

982 Involving 308,849 participants, with 51\% from North America, 37\% from Europe, 11\% from Asia, and 1\% from Australia. Across all studies, the average age of participants at initial evaluation was 63.9 years, and participants were evenly represented across sex ( $49 \%$ female, $51 \%$ male). Of the studies examined, $60 \%$ involved community samples, but $24 \%$ examined individuals receiving outpatient medical treatment, and $16 \%$ utilized patients in inpatient medical settings. Participants were followed for an average of 7.5 years. Julianne Holt-Lunstad, Timothy B. Smith, J.Bradley Layton, 'Social relationships and mortality risk: a meta-analytic review,' PLOS Med 2010: 7(7), <http://journals.plos.org/plosmedicine/article?id=10.1371/journal.pmed.1000316> accessed 4 April 2017 983 Julianne Holt-Lunstad, Timothy B. Smith, J.Bradley Layton, 'Social relationships and mortality risk: a metaanalytic review,' PLOS Med 2010: 7(7), $<$ http://journals.plos.org/plosmedicine/article?id=10.1371/journal.pmed.1000316> accessed 4 April 2017 ${ }_{984}$ Julianne Holt-Lunstad, Timothy B. Smith, J.Bradley Layton, 'Social relationships and mortality risk: a metaanalytic review,' PLOS Med 2010: 7(7), 1 $<$ http://journals.plos.org/plosmedicine/article?id=10.1371/journal.pmed.1000316> accessed 4 April 2017 985 Loneliness and nursing home admission among rural older adults. D.W. Russell,C.E. Cutrona,A. de la Mora, R.B. Wallace Psychol Aging. 1997 Dec; 12(4):574-89 (as cited in 'Perceived Social Isolation Makes Me Sad: Five Year Cross-Lagged Analyses of Loneliness and Depressive Symptomatology in the Chicago Health, Aging and Social Relations Study,' Psychol Aging 2010 Jun: 25(2): 453) https://www.ncbi.nlm.nih.gov/pmc/articles/PMC2922929/) ${ }^{986}$ See Vulnerability chapter.
} 


\subsubsection{Living Alone}

The lone-living theme of Modernisation Theory is evident in the living arrangements of older people in the U.K. Of the 7.7 million people living in single households in 2016, 3.7 million were aged 65 years and over. The figure is, therefore, comparable to the entire sector of the population aged 16 to 64. Recorded trends over the past two decades demonstrate the increasing vulnerability of older people to lone living. Numbers of those aged 65-74 in single occupancy households have increased by $16 \%$ during the period 1996 to 2016 from, reaching 1.6 million. The numbers living alone in the 75 and over age bracket increased by $15 \%$ during the same period to 2.1 million. ${ }^{987}$ Both increases were recorded as "statistically significant," and also of significance is that numbers of older people living alone increases with age. The heightened vulnerability of older women is exemplified by the disproportionate numbers of females living alone in the U.K. Research reported in 2016 showed $62 \%$ of the age group $65-74$ and $71.8 \%$ of those aged 75 and over living alone. ${ }^{988}$

The issue of lone-living introduces matters of cultural divide within regions, and shared practices between regions. These are issues of relevance when discussing the need for a Convention for the Rights of Older People in Part IV of the thesis. A cultural divide exists between Southern and Northern European countries, particularly evident in the family institution and, subsequently, living and care arrangements. Filial obligation and extended, rather than modernised nuclear families are more prevalent in the South. ${ }^{989}$ Of the European countries included in the SHARE survey, the prevalence of older people living with the wider family was greatest amongst Southern nations, with Spain, Italy and Israel with the greatest numbers. ${ }^{990}$ With the very different custom of older people living only with a spouse in the Northern countries, the countries with the highest levels of living with only a spouse are Sweden, Netherlands, and Germany. ${ }^{91}$ Of these, older people of the Netherlands reported specifically not wanting to live with extended family members, a cultural trend shared with Canada. ${ }^{992}$

\footnotetext{
987 'Families and households in the UK: 2016' Office for National Statistics, 13

${ }^{988}$ Due to a combination of a larger number of women in the population, and women having a higher life expectancy than men. 'Families and households in the UK: 2016' Office for National Statistics, 13

${ }^{989}$ Survey of Health, Ageing and Retirement in Europe (SHARE Project) 2004-2006, 267-8. Research was undertaken of 8,787 older people aged 65 or over in the following 12 countries: Denmark, Sweden, Austria, France, Germany, Switzerland, Belgium, Netherlands, Spain, Italy, Israel, and Greece.

${ }^{990}$ In Spain, $38 \%$ of older people lived with wider family, 32\% of older people in Italy, and $23 \%$ of older people in Israel. Survey of Health, Ageing and Retirement in Europe (SHARE Project) 2004-2006, 269

${ }_{991}$ In Sweden and the Netherlands $68 \%$ of older people live only with a spouse, and $67 \%$ in Germany. Survey of Health, Ageing and Retirement in Europe (SHARE Project) 2004-2006, 269

${ }_{992}$ Tilburg et al 2004 (as cited in Survey of Health, Ageing and Retirement in Europe (SHARE Project) 20042006, 268)
} 
These differences have implications for vulnerability to loneliness. With the expectation and practice of family provided care greater in Southern Europe, loss of family care is a major cause of Ioneliness. ${ }^{993}$ Throughout Europe health and living conditions are cited as causes of loneliness, and older people living alone who also suffer ill-health are ten times more likely to experience loneliness than those living with a spouse or partner and are in good health. ${ }^{994}$ The lack of dependence on extended family in Northern European countries is demonstrated by older people in this region recorded as least lonely when in good health and living with a spouse. ${ }^{995}$ It is possible to identify a link between lower educational levels and loneliness as a form of accumulated disadvantage. The European region distinctly demonstrates such a link, with a "statistically significant" prevalence occurring in Germany, Spain, France and Israel. ${ }^{996}$

\subsubsection{Filial Obligation}

The practice of filial obligation enjoys mixed success in regions where older people depend upon family members for shelter, care, and financial support.

\subsubsection{The Ghanaian Experience}

The Ghanaian experience of support of older persons is a combination of the Modernisation Theory processes of industrialisation and urbanisation, the transitive reciprocity of filial obligation, and material constraints on adult children to support parents. ${ }^{997}$ The pattern of industrialisation and urbanisation of the industrial revolution has not been exactly replicated, however, key economic and social changes are influential. Principally, the dependency on lineage, patrimony and property declined as younger adults migrated for employment. ${ }^{998}$ However, the limited success of economic transition, coupled with urbanisation has resulted in $80 \%$ of the workforce being employed in the informal sector, ${ }^{999}$ with the same number living on approximately $\$ 2$ per day. ${ }^{1000}$ Against this

\footnotetext{
${ }^{993}$ Survey of Health, Ageing and Retirement in Europe (SHARE Project) 2004-2006, 267-8

${ }^{994}$ Survey of Health, Ageing and Retirement in Europe (SHARE Project) 2004-2006.

${ }^{995}$ Survey of Health, Ageing and Retirement in Europe (SHARE Project) 2004-2006, 274

${ }^{996}$ Survey of Health, Ageing and Retirement in Europe (SHARE Project) 2004-2006, 271

${ }^{997}$ Ghana is explained by Aboderin as typifying the experience of older Africans. Isabella Aboderin, "Decline in Material Family Support for Older People in Urban Ghana, Africa: Understanding Processes and Causes of Change," J. Gerontol B Psychol Sci Soc Sci (2004) 59 (3): S128-S137 https://doi.org/10.1093/geronb/59.3.S128 ${ }_{998}$ Isabella Aboderin, "Decline in Material Family Support for Older People in Urban Ghana, Africa: Understanding Processes and Causes of Change," J. Gerontol B Psychol Sci Soc Sci (2004) 59 (3): S128-S137, 129 https://doi.org/10.1093/geronb/59.3.S128

${ }^{999}$ Ghana Statistical Service 2000. Ghana living standards survey 4. Accra: Ghana Statistical Service (as cited in Isabella Aboderin, "Decline in Material Family Support for Older People in Urban Ghana, Africa: Understanding Processes and Causes of Change," J. Gerontol B Psychol Sci Soc Sci (2004) 59 (3): S128-S137 https://doi.org/10.1093/geronb/59.3.S128)
} 
backdrop the situation has evolved whereby "...most continue to live with their families, destitution among the old has become increasingly evident, as has the "abandonment" of impoverished older people in hospitals by their families."1001 This also prompted the proposal of material constraint as the motivation for weakening filial obligation towards older family members, rather than an unwillingness to provide support. ${ }^{1002}$ Nonetheless, the situation is "exposing increasing numbers especially of urban elderly to destitution and poverty." ${ }^{1003}$

Aboderin's research reports a society simultaneously struggling to support, and abandoning older adults. Examination of Aboderin's intergenerational interviews demonstrates the change to familial support in this community. Historical accounts of the oldest generation described adult children providing most of the material support needed, complemented by young members of extended family. Significantly, costs of living ${ }^{1004}$ were low. The motivation for providing support was both reciprocity and duty. ${ }^{1005}$ Accounts of the current situation record a decline in support from adult children and younger members of the extended family. All poor, and many middle income older people receive no such material support or insufficient to provide for basic needs. The middle generation state this is due to increasing standards and costs of living, and an inability to provide for both the youngest and oldest generations. This exemplifies the hierarchy of priorities of filial obligation and transferred reciprocity. There has been a general acceptance by the older generations of a less binding filial obligation which exhibits normative changes in line with societal modernisation. In stark contrast to the example of South Korea, discussed below, this society does

\footnotetext{
1000 United Nations Development Programme 2002. Human development report 2002. New York: United Nations Development Programme (as cited in Isabella Aboderin, "Decline in Material Family Support for Older People in Urban Ghana, Africa: Understanding Processes and Causes of Change," J. Gerontol B Psychol Sci Soc Sci (2004) 59 (3): S128-S137 https://doi.org/10.1093/geronb/59.3.S128)

1001 Isabella Aboderin, "Decline in Material Family Support for Older People in Urban Ghana, Africa: Understanding Processes and Causes of Change," J. Gerontol B Psychol Sci Soc Sci (2004) 59 (3): S128-S137, 129 https://doi.org/10.1093/geronb/59.3.S128

1002 Treas, J. and Logue, B., 1986. Economic development and the older population. Population and Development Review, 12, 655-73; Esther Contreras de Lehr, "Aging and Family Support in Mexico," in Hal Kendig, Akiko Hashimoto \& Larry C Coppard, Family Support to the Elderly: The International Experience (Oxford University Press, Oxford , 1992), 221 (as cited in Isabella Aboderin, "Modernisation and ageing theory revisited: current explanations of recent developing world and historical Western shifts in material family support for older people," Ageing \& Society 24, 2004, 29-50, 40 \& 34)

1003 Isabella Aboderin, "Decline in Material Family Support for Older People in Urban Ghana, Africa: Understanding Processes and Causes of Change," J. Gerontol B Psychol Sci Soc Sci (2004) 59 (3): S128-S137, 128 https://doi.org/10.1093/geronb/59.3.S128

1004 Especially food, housing, medical care and basic education

1005 Isabella Aboderin, "Decline in Material Family Support for Older People in Urban Ghana, Africa: Understanding Processes and Causes of Change," J. Gerontol B Psychol Sci Soc Sci (2004) 59 (3): S128-S137, https://doi.org/10.1093/geronb/59.3.S128
} 
not view filial support as a value for future generations, with a growing expectation for older people to become self-reliant. ${ }^{1006}$

10.3.2.2 Filial Obligation in South Korea - a Success Story

South Korea provides an example of a response to global ageing which does not comply with Western priorities. Figures from the Korea National Statistics Office in 1998 demonstrated agreement by $91 \%$ of participants for adult children to support aged parents and be primary care givers. Only $2 \%$ of respondents viewed the state responsible for older parents, and $7 \%$ claimed that childless older people should be dependent on the state for support and care. Research reflected a change in attitude from the eldest son bearing all responsibility to it being shared among all children, ${ }^{1007}$ but that opinion solidly maintained that responsibility lay with the family rather than the state. ${ }^{1008}$ Furthermore, the traditional values of filial obligation show signs of persisting through further economic development. When asked to identify leading values for the nation in the twenty first century $83 \%$ of participants in a National Social Survey conducted by the Academy of Korean Studies (1999) cited support and care of parents. ${ }^{1009}$ In a similar study by the Academy, 93\% of graduates of Seoul National University strongly agreed that filial piety would play a leading role in Korean society in the future. ${ }^{1010}$ This example of cultural relativity is in stark contrast to that of developing sub-Saharan Africa, which gives credence to issues of lone-living experienced by older members of society.

\subsubsection{Social Isolation}

The Department of Health reported $36 \%$ of older people living in care homes and $19 \%$ living in private households as "rarely visited by relatives or friends," demonstrating that those living in

\footnotetext{
${ }^{1006}$ Isabella Aboderin, "Decline in Material Family Support for Older People in Urban Ghana, Africa: Understanding Processes and Causes of Change," J. Gerontol B Psychol Sci Soc Sci (2004) 59 (3): S128-S137, https://doi.org/10.1093/geronb/59.3.S128

${ }^{1007} 23 \%$ of 70,139 respondents viewed the eldest son solely responsible, $46 \%$ claimed all children able to support are responsible to do so, $22 \%$ that all sons and daughters should be care givers.

${ }^{1008}$ Ki-Soo Eun, "Changing Roles of the Family and State for Elderly Care: A Confucianism Perspective," in Vern L Bengston \& Ariela Lowerstein (eds.) Global Aging and Challenges to Families, (Aldine de Gruyter, New York, 2003) 260

${ }^{1009}$ Ki-Soo Eun, "Changing Roles of the Family and State for Elderly Care: A Confucianism Perspective," in Vern L Bengston \& Ariela Lowerstein (eds.) Global Aging and Challenges to Families, (Aldine de Gruyter, New York, 2003) 259

${ }^{1010}$ Ki-Soo Eun, "Changing Roles of the Family and State for Elderly Care: A Confucianism Perspective," in Vern L Bengston \& Ariela Lowerstein (eds.) Global Aging and Challenges to Families, (Aldine de Gruyter, New York, 2003) 259
} 
institutions to be at risk of social isolation, despite not living alone. Additionally, $6 \%$ in care homes and $2 \%$ living at home have "no visits at all."1011

\subsubsection{Homelessness}

The problem of homelessness is a growing one amongst older people, and is not restricted to poorer regions or nations. The issue is included at this stage of the chapter, as it occurs as the result of vulnerabilities created by cultural attitude and/or poverty. The Philippines provides an example of the fastest-growing community of "street elderly," a phenomenon occurring throughout Asia at a pace to challenge that of "street children." Older people are not merely homeless in such situations as a result of poverty resulting from an inability to be productive and a lack of State support, but also by virtue of family members leaving older family members in city streets to beg and survive without sustenance or shelter.

\subsection{Care and Carers}

Older people are also at risk of becoming derivatively dependent as a result of providing informal care. $^{1012}$ The UK Department of Work and Pensions reported in the year 2014/15 approximately 12\% of all 65-74 year olds, and a similar number of 75-84 year olds, provided informal care. The proportion of 55-64 year olds acting as carers was higher, at 15\%. ${ }^{1013}$ The U.K. census, 2011 recorded actual numbers of over $65 \mathrm{~s}$ in England and Wales providing informal care of 1.4 million. ${ }^{1014}$ This number represents an increasing trend among older people, expressed as a $35 \%$ increase over the previous census recording. Older people providing care are factually at risk of exacerbating existing vulnerabilities. Research undertaken by The Princess Royal Trust for Carers outlines the problems faced. ${ }^{1015}$ Proportions of those caring for a spouse were $45.4 \%$ of $60-69$ year olds and $67.4 \%$ of 70 and over. ${ }^{1016}$ Both categories of age groups devised by this research project recorded lengthy time periods for care provision, however, the older group spent slightly more years caring than the younger group. Of the over 70 s, $33.9 \%$ had spent $1-5$ years caring and $24.5 \% 25$ years or

\footnotetext{
${ }^{1011}$ Department of Health Report 2000

${ }^{1012}$ A person who is 'derivatively deprived' is someone, who as a result of providing care, becomes dependent, primarily on assets provided by institutions.

1013 'Family Resources Survey 2014/15,' Department of Work and Pensions, 10. https://www.gov.uk/government/uploads/system/uploads/attachment_data/file/531242/family-resourcessurvey-2014-15.pdf

1014 UK Census, 2011

${ }^{1015}$ Research of 639 carers aged 60 and over undertaken in the U.K. Breakdown of participants by region is: 74.4\% England , 12.5\% Scotland, 11.1\% Wales, 0.6\% N. Ireland, 0.2\% Isle of Man, 4.4\% unknown.

1016 'Always On Call, Always Concerned A Survey of the Experiences of Older Carers,' 14 The Princess Royal Trust for Carers, 2011
} 
more. This compared to $27.1 \%$ and $21.5 \%$ of $60-69$ year olds respectively. ${ }^{1017}$ Figures demonstrate the dependency on older people as carers, continuing into the more physically vulnerable years of life. The degree of dependency was also recognised as a contributory factor to worsening health. Once again, the over 70 s were most affected, with $65 \%$ providing over 60 hours of care per week. Of those aged 60-69 58.5\% provided care for the same number of hours. ${ }^{1018}$ One third of respondents in the research project delayed or cancelled treatment for their own health problems "due to the demands of caring," ${ }^{1019}$ and almost half stated that their health had deteriorated in the last year. ${ }^{1020}$ Mental health, primarily related to depression and anxiety, was affected in almost $70 \%$ of carers. ${ }^{1021}$ Almost two thirds of 60-69 year olds and over $65 \%$ of 70 plus reported a negative impact on specific physical manifestations of stress, exhaustion and the demands of manual work, and a reduction in the number and range of activities and engagements undertaken were reported. ${ }^{1022}$ The dependency upon older carers therefore creates situations of disengagement, preventing successful ageing for this sector of older people. Even in populations which have a higher expectation and dependence on institutional care, such as Northern Europe, ${ }^{1023}$ a married person caring for a spouse is reported as more lonely than one not caring for a spouse. ${ }^{1024}$

The correlation between receiving informal care and age is evident. Of 55-64 year olds $5 \%$ are dependent on informal care. This increases to approximately $12 \%$ of $65-74$ year olds and $15 \%$ of those in the 75-84 age group. The most marked increase is amongst the oldest old, with almost 35\% of 85 and over receiving informal care. ${ }^{1025}$

\subsection{Abuse of Older People}

The definition created by Action on Elder Abuse, accepted by WHO and the survey of prevalence of elder abuse in the U.K. undertaken by King's College, London, is informative to this section: 'A single

\footnotetext{
1017 'Always On Call, Always Concerned A Survey of the Experiences of Older Carers,' 15 The Princess Royal Trust for Carers, 2011

1018 'Always On Call, Always Concerned A Survey of the Experiences of Older Carers,' 15 The Princess Royal Trust for Carers

1019 'Always On Call, Always Concerned A Survey of the Experiences of Older Carers,' 17 The Princess Royal Trust for Carers

1020 'Always On Call, Always Concerned A Survey of the Experiences of Older Carers,' 18 The Princess Royal Trust for Carers

1021 'Always On Call, Always Concerned A Survey of the Experiences of Older Carers,' 20 The Princess Royal Trust for Carers

1022 'Always On Call, Always Concerned A Survey of the Experiences of Older Carers,' 18 The Princess Royal Trust for Carers

${ }^{1023}$ Survey of Health, Ageing and Retirement in Europe (SHARE Project) 2004-2006, 267-8

${ }^{1024}$ Survey of Health, Ageing and Retirement in Europe (SHARE Project) 2004-2006, 274

1025 'Family Resources Survey 2014/15,' Department of Work and Pensions, 10.

https://www.gov.uk/government/uploads/system/uploads/attachment_data/file/531242/family-resourcessurvey-2014-15.pdf
} 
or repeated act or lack of appropriate action occurring within any relationship where there is an expectation of trust, which causes harm or distress to an older person. ${ }^{1026}$

Age UK adapted information from two reports on the abuse of older people resulting in the following estimations. Abuse in private households was approximated at 342,000 victims per year. When extended to include care homes, the estimate was given as 500,000 , or in the region of $5 \%$ of older people. The same research was used to report in excess of 50 older people suffering neglect or abuse in their home by family, friends, neighbours or care workers each hour. ${ }^{1027}$ Analysis of 10,000 calls made by older people to the Action on Elder Abuse helpline is informative as to prevalence of abuse by age, gender, location in which abuse occurred, and types of abuse. In addition, profiles of abusers are available. Regarding victims, $67 \%$ of those reporting abuse were women, $22 \%$ men and $11 \%$ comprised men and women jointly reporting abuse. Of the latter, over half were residents of institutions, predominantly care homes. Categorisation by age found $78 \%$ of victims reporting abuse to be over 70 , and $16 \%$ were over 90 years old. Older people in the age range of 80-89 were found to be the most vulnerable to abuse. ${ }^{1028}$

The analysis of reported abuse by Action on Elder Abuse identified $46 \%$ of abusers to be relatives, and $34 \%$ as paid workers. Additionally, abuse was carried out by more than one person one third of circumstances. Of this "collusive abuse" almost a quarter was performed by family members. In addition, a practice of "abusive practices that are institutional and passed from one worker to another" was undertaken in $62 \%$ of cases of collusive abuse. ${ }^{1029}$ Regarding location of abuse, $64 \%$ of reported abuse took place in the older person's home, $23 \%$ in care homes, $5 \%$ in hospitals, and $4 \%$ in sheltered accommodation. The report noted the disproportionate amount of abuse occurring in care homes given that approximately $5 \%$ of older people lived in care homes at the time, and the fact that access to telephones is limited. ${ }^{1030}$ Findings such as these also point to the negative effect

\footnotetext{
1026 'UK Study of Elder Abuse and Neglect of Older People', Kings College, London, University of London. www.inpea.net/UK-Study-Abuse-Neglect-2007.pdf

1027 'Later Life in the United Kingdom,' January 2017, Age UK, 15 (citing 'UK Study of Neglect and Abuse of Older People, Prevalence Survey Report,' M.O'Keefe et al. for Department of Health and Comic Relief, 2007 and 'Elder abuse in Britain,' J. Ogg and G. Bennett, BMJ 305, October 1992)

${ }^{1028}$ Analysis of 10,000 reports of abuse between the period 1997-2004. 'Hidden Voices: Older People's Experience of Abuse Executive Summary. An analysis of calls to the Action on Elder Abuse helpline,' Action on Elder Abuse 2004, 2.

${ }^{1029}$ Analysis of 10,000 reports of abuse between the period 1997-2004. 'Hidden Voices: Older People's Experience of Abuse Executive Summary. An analysis of calls to the Action on Elder Abuse helpline,' Action on Elder Abuse 2004, 2.

${ }^{1030}$ Analysis of 10,000 reports of abuse between the period 1997-2004. 'Hidden Voices: Older People's Experience of Abuse Executive Summary. An analysis of calls to the Action on Elder Abuse helpline,' Action on Elder Abuse 2004, 3.
} 
of dependence on institutions, and the fact that in providing assets and resilience to vulnerability, it is possible for institutions to introduce pathogenic vulnerability into the lives of the most vulnerable.

\subsubsection{Regional Abuse of Older People}

$$
\text { 10.5.1.1 Africa }
$$

Whilst exact numbers are impossible to report in Africa, forms of abuse experienced by older people, most particularly older women, are specific to the region, and therefore are worthy of mention. Cultural beliefs and traditions make violent and exploitative abuse acceptable in some countries, particularly of older women. HelpAge International reported on the tradition of punishment for practicing witchcraft, and approximated that 1,000 older people are killed as a consequence of being accused of witchcraft in Tanzania alone. Most are women over the age of 50. ${ }^{1031}$

\subsubsection{Asia}

A survey undertaken of 1,991 abused older people in Japan reported a little over half committed by family members. ${ }^{1032}$ The average age of those abused was 81.6 years, and $76 \%$ of victims were women, ${ }^{1033}$ demonstrating the aggravated forms of vulnerability to which older women are exposed. The mistreatment consisted mainly of mental abuse, including verbal, ${ }^{1034}$ withholding meals or care, ${ }^{1035}$ and beatings or tying the older person to bed. ${ }^{1036}$ One third of the victims of abuse identified in this survey also demonstrated "adaptive preference," as self-perception formed as a result of negative stereotyping caused them to be accepting or unaware of the abuse. Comparison between the wealthiest nation in the Asian region and one of the poorest highlights similar numbers, perpetrators and patterns of abuse. A survey of older people in poor urban communities,

${ }^{1031}$ The organisation reported 2,700 killings between 2003-2006 in two regions of Tanzania (Mwanza and Shinyanga regions), $92 \%$ of whom were older women. 'Protecting the rights of older people in Africa' HelpAge International 2008, p.7

${ }^{1032}$ A survey of 1,991 abused older people, reported by medical or care professionals in 2005 found $52 \%$ of abuse to be committed by family members, primarily adult children. Shinya Ajima 'Intervention faces obstacles, efforts underway to stem abuse of elderly' January 2005 Global Action on Ageing http://globalage.igc.org/elderrights/world/2005/eldobstacles.htm

${ }^{1033}$ Shinya Ajima 'Intervention faces obstacles, efforts underway to stem abuse of elderly' January 2005 Global Action on Ageing http://globalage.igc.org/elderrights/world/2005/eldobstacles.htm

${ }^{1034}$ Suffered by $64 \%$ of victims, Shinya Ajima 'Intervention faces obstacles, efforts underway to stem abuse of elderly' January 2005 Global Action on Ageing http://globalage.igc.org/elderrights/world/2005/eldobstacles.htm

${ }^{1035}$ Suffered by $52 \%$ of victims, Shinya Ajima 'Intervention faces obstacles, efforts underway to stem abuse of elderly' January 2005 Global Action on Ageing http://globalage.igc.org/elderrights/world/2005/eldobstacles.htm

${ }^{1036}$ Suffered by $50 \%$ of victims, Shinya Ajima 'Intervention faces obstacles, efforts underway to stem abuse of elderly' January 2005 Global Action on Ageing http://globalage.igc.org/elderrights/world/2005/eldobstacles.htm 
undertaken for the Coalition of Services of the elderly, found over $40 \%$ of people between the ages of $56-65$ to have suffered abuse by children and family members comprising verbal, negligence, physical and sexual. ${ }^{1037}$

\subsection{Discrimination}

'Age discrimination is probably the least understood and least recognised of social prejudices and as such, potentially the most hazardous for a rapidly ageing society. ${ }^{1038}$ It is described as "...a systematic stereotyping of and discrimination against people because they are old, just as racism and sexism accomplish this with skin colour and gender."1039 As such, age discrimination is a socially construed concept due to the elements of "attitudes towards, discriminatory practices against, and institutional practices and policies that perpetuate stereotypes." ${ }^{1040}$

Age discrimination was the subject of the 2008 European Social Survey, ${ }^{1041}$ which highlighted factors associated to discrimination, and the noticeable divide between nations. The fact that the survey defined older people as aged 62 and above, based on the average age at which a person is perceived as "old," 1042 and subject to discrimination, supports the argument in Chapter 9 for not limiting access to special protection to the over 65s. The survey recorded a quarter of respondents as having experienced discrimination, with greater numbers and frequency in the higher age groups. ${ }^{1043}$ Europe is a region representative of cultural relativism, with a clear divide between North-Western

\footnotetext{
${ }^{1037}$ Edna Co et al 'From the Margins to the Center - Ageing: Situation, Services, Sustainability, and Some Policy Implications' (as cited in Edward Gerlock, 'Age Discrimination 5 continents: real issues, real concerns' 31 May 2006, 9 'International Federation on Ageing Conference' Copenhagen 30 May-2 June 2006)

${ }^{1038}$ S. Wait, E. Midwinter (2005) 'Promoting age equality in health care. A report for the alliance for health and the future,' (2005) (as cited in Wim J. A. van den Heuvel, Marc M. van Santvoort, 'Experienced discrimination amongst European old citizens,' European Journal of Ageing (2011), 291, https://doi 10.1007/s10433-0110206-4)

${ }^{1039}$ R.N. Butler 'Dispelling ageism - the cross-cutting intervention,' Ann Am Acad Polit Ss, 1989 vol.503 (pg.138

47) (as cited in Isla Rippon, Dylan Kneale, Cesar de Oliveira, Panayotes Demokakos, Andrew Stepote, 'Perceived age discrimination in older adults,' 'Age and ageing,' vol.43, issue 3, May 2014, 379 https://doi.org/10.1093/ageing/aft146)
}

${ }^{1040}$ R.N. Butler Ageism: a foreword. J Soc Issues 36:8-10 (1980) (as cited in Wim J. A. van den Heuvel, Marc M. van Santvoort, 'Experienced discrimination amongst European old citizens,' European Journal of Ageing (2011), 292, https://doi 10.1007/s10433-011-0206-4)

${ }^{1041}$ The survey was conducted in 28 European countries, and collected data from 14,364 participants.

1042 Researchers asked 3 age groups for a stated perception of old age; the average age was used as definition. The groups and ages quoted were as follows: young (15-39) people mention on average 60.7 years, middle aged (40-64) people 63.3 and the old (65 and over) 63.8. Wim J. A. van den Heuvel • Marc M. van Santvoort, 'Experienced discrimination amongst European old citizens,' European Journal of Ageing (2011), 294, https://doi 10.1007/s10433-011-0206-4

${ }^{1043}$ Wim J. A. van den Heuvel • Marc M. van Santvoort, 'Experienced discrimination amongst European old citizens,' European Journal of Ageing (2011), 291, https://doi 10.1007/s10433-011-0206-4 
and South-Eastern countries, where age discrimination is more prevalent and customary. ${ }^{1044}$ The general increase in age discrimination in Europe is related to retirement and care costs. ${ }^{1045}$

Perceptions by older people of age discrimination have been reported using the representative sample of older adults from the English Longitudinal Study (ELSA), ${ }^{1046}$ some of the key findings are included. The prevalence of discrimination against older people aged 65 and over was shown to be high amongst the 7,805 respondents to the ELSA research, with $36.8 \%$ reporting having experienced age discrimination. Little variation in age discrimination existed between the age groups, however, most discrimination was reported by the $70-79$ age group. ${ }^{1047}$

\subsubsection{Factors affecting discrimination in Asia}

The factors influencing discrimination of older people in Asia combine principles of a number of theories of ageing. The effects described in Modernisation Theory are evident in developing economies, ${ }^{1048}$ and most intensely felt in rural areas, ${ }^{1049}$ as noted in the MIPAA. ${ }^{1050}$ An example of the outcomes of a poor, modernising nation is the emerging phenomenon of "street elderly" in the Philippines, where older people survive by begging and sleeping on the streets. The problem of "Ione living" is worsened in this part of Asia as a result of the migration of women, the family members most likely to provide support to older people, for employment overseas. ${ }^{1051}$ The overseas migration of younger and female family members is a pattern replicated in countries including Indonesia, Thailand, Sri Lanka, India, Laos, and Myanmar. ${ }^{1052}$ Combination of modernisation with: little or no pension schemes or social security, ill-health and disability and lack of resources to provide healthcare, inability of family to care and support older people, changes to family structure-

\footnotetext{
${ }^{1044}$ Wim J. A. van den Heuvel Marc M. van Santvoort, 'Experienced discrimination amongst European old citizens,' European Journal of Ageing (2011), 291 \& 296, https://doi 10.1007/s10433-011-0206-4

${ }^{1045}$ Wim J. A. van den Heuvel Marc M. van Santvoort, 'Experienced discrimination amongst European old citizens,' European Journal of Ageing (2011), 297, https://doi 10.1007/s10433-011-0206-4

${ }^{1046}$ Isla Rippon, Dylan Kneale, Cesar de Oliveira, Panayotes Demakakos, Andrew Steptoe, 'Perceived age discrimination in older adults,' Age and Ageing 2014 43: 379. Using data from the English Longitudinal Study, Wave 5 (2010-2011). The analytical sample used comprised 7,805 respondents.

$104735.2 \%$ of ages $60-69$ reported experiencing age discrimination,

1048 Most notable are the processes of urbanisation, migration, changes to family structure and obligation to support older family members, and lack of demand for older workers. See Chapter 6

${ }^{1049}$ Edward Gerlock, 'Age Discrimination in 5 continents: real issues, real concerns,' International Federation on Ageing Conference, Copenhagen 30 May - 2 June 2006, Age Concern, 5

1050 See Chapter 6

${ }^{1051}$ Edward Gerlock, 'Age Discrimination in 5 continents: real issues, real concerns,' International Federation on Ageing Conference, Copenhagen 30 May - 2 June 2006, Age Concern, 5

1052 Edward Gerlock, 'Age Discrimination in 5 continents: real issues, real concerns,' International Federation on Ageing Conference, Copenhagen 30 May - 2 June 2006, Age Concern, 6
} 
becoming "nuclear" families. ${ }^{1053}$ Discrimination grounded in non-productivity of older people and dependence, a lack of State-provided security force 70 and 80 year olds to work in the fields in rural areas, and in the "informal economy" of urban slums. ${ }^{1054}$

\subsection{Women as a vulnerable sub-group}

Older women are regularly subject to aggravated vulnerability. This section briefly summarises some of the more aggressive forms of rights violations suffered by this sub-group. Older women in many African countries suffer aggravated vulnerability, particularly when widowed. This sub-group of older women can lose all social status and become marginalised, impoverished, and lack any security. The practice of preventing widows from inheriting or owning property often creates total dependence upon family members, which, due to changes to filial obligation, can result in isolation. Such impoverishment and isolation leads inevitably to an inability to access health care or information regarding rights and welfare entitlements. ${ }^{1055}$ Furthermore, some sub-Saharan, Indian sub-continent, and Asian communities limit the voting power of women: either by means of co-ercion or allocating a lesser value to votes cast by females. The productivity expectations of women is also subjected to discriminatory attitude in some cultures. The expectation is often for older women to carry the burden of caring for the youngest family members in addition to duties of subsistence. However, in many such cases older women receive no remuneration or State aid. Finally, the practice of torturing and killing women over the age of 50 using witchcraft as justification must be recognised as the greatest violation of human rights suffered by this sub-group of older people.

\subsection{Conclusion}

The findings of this chapter both support claims of previous chapters, and inform research of Part IV. The identification of global themes support the principles of theories of ageing and the ageing process discussed in chapters 8 and 9. Furthermore, the ideals of universality of suffering and vulnerabilities to which older people are subjected is proven. Each type of harm discussed is demonstrated to be applicable to older people as a group, in accordance with the requirements of vulnerable groups set out by the ECtHR. However, it is evident that the severity of harm differs inter and intra regionally, and correlation can often be drawn with availability of national resources.

\footnotetext{
${ }^{1053}$ Edward Gerlock, 'Age Discrimination in 5 continents: real issues, real concerns,' International Federation on Ageing Conference, Copenhagen 30 May - 2 June 2006, Age Concern, 5

${ }^{1054}$ The situation described by the International Federation on Ageing related to the Philippines, but is stated as exemplary of many other similar economies and cultures. Edward Gerlock, 'Age Discrimination in 5 continents: real issues, real concerns,' International Federation on Ageing Conference, Copenhagen 30 May - 2 June 2006, Age Concern, 6-7

1055 'Protecting the rights of older people in Africa' HelpAge International 2008, p.6
} 
These issues inform the research questions addressed in Part IV and the research undertaken. The universality of type of harm suffered by older people as a group combined with the regional disparity of degree of harm suffered supports the call for an international, rather than regional, response to rights for older people. The exacerbation of harm in poorer regions and countries supports the recommendation for positive international State duty as part of a Capabilities Approach to rights implementation in order to achieve equality in dignity and agreed thresholds of outcomes. Additionally, the vulnerable experiences identified can be used in conjunction with the vulnerabilities framework devised in Part II to examine the adequacy of the current human rights construct in Part IV. 


\section{CHAPTER 11}

\section{INTERNATIONAL HUMAN RIGHTS: THE NORMATIVE FRAMEWORK}

\section{A VULNERABILITY PERSPECTIVE}

\subsection{Introduction}

This chapter examines the normative protection provided older people by international human rights. The aim is to develop an answer to the research question of the adequacy of international rights to the needs of older people. In taking the vulnerability approach specific to this thesis, the structure of the examination adds to the originality of the research. The human rights instruments will be scrutinised in accordance with the vulnerability framework devised in Chapter 5. Furthermore, the process will be informed by the means of identifying older people as a group, and the vulnerable experiences which were the subjects of Part III. Specified rights will be examined directly in response to the vulnerabilities suffered by older people. The findings will also inform the answer to the question of how older people are vulnerable in society. The chapter will determine whether the normative provision of existing rights further exacerbates vulnerabilities. This relates directly to the relationship between the concepts of Human Dignity and Vulnerability, and human rights as defined by Chapter 5 , which also contributes to the originality of the thesis. As the blueprint for all subsequent human rights instruments, the examination begins with the UDHR. The ICCPR, ICESCR, UNCRPD and CEDAW follow. Therefore, the normative provision of generic rights, and those to which sub-groups of older people have access by virtue of aggravated vulnerability are explored. This method contributes to the debate surrounding the suitability of existing instruments, rather than a specific instrument of special protection, for the protection of interests held in rights by the group. Additionally, The Protocol to the African Charter on Human and Peoples' Rights on the Rights of Older Persons in Africa is examined using the same vulnerability framework and approach. This highlights normative provision which could be included in a discrete special protection instrument. Furthermore, it offers an answer as to whether numerous regional instruments could resolve the issue of protection of older people. Finally, regional instruments which include rights of older people are also included. The findings of protection in UDHR, ICCPR, ICESCR, UNCRPD AND CEDAW are tabulated, to be discussed in detail.

The chapter concludes with the application of a modified Capabilities Approach to determining normative human rights provision for older people. The modification of the Capabilities Approach and the subsequent listing of Fundamental Capabilities for Older People to ground normative content of special protection human rights contribute to the originality of this thesis. The 
vulnerability framework and experiences of older people form the basis of outcomes required of Fundamental Capabilities. This focus on vulnerability rather than existing rights to achieve capabilities listings and outcomes differs from the approach taken by Nussbaum and subsequent research undertaken for children. As outcomes, the listing informs the normative provision of special protection rights. Ultimately, the chapter contributes to the overarching question of the need for special protection for older people in international law. 


\subsection{Vulnerability in Human Rights Instruments}

Summary of Protection of Vulnerabilities of Older People by International Human Rights Framework

The following table provides an overview of the protection provided older people against specific vulnerabilities by international human rights. The analysis of normative provision is undertaken in the context of the vulnerabilities framework devised in Part II of the thesis, with the discussion informing the tabulated overview comprising the remainder of the chapter. The vulnerabilities highlighted represent broad headings of the lived experiences of the "differently vulnerable" group. The International Bill of Rights and special protection instruments to which some older people may have access (specifically the UNCRPD and CEDAW) are examined. Normative content of rights applicable to each vulnerability are scrutinised for the type and degree of protection provided to the interest held by older people in the right. The evaluation of each right, and the overall assessment of protection provided each vulnerability is represented as follows:

$\mathrm{N}$ (None) - No protection provided against specific vulnerability

L (Limited) - Provides protection against universal standards of vulnerability.

- Of limited relevance to, or provides limited protection against severity of harm caused older people.

- Limited interaction with other linked vulnerabilities.

P (Partial) - Provides protection against universal standards of vulnerability of relevance to older people.

- Provides satisfactory protection against some aspects of harm.

- The existing normative content has potential to provide greater protection if adequately developed or implemented.

- Recognises linked vulnerabilities.

G (Good) - Protects against most aspects of vulnerability and harm.

- The existing normative content as potential to provide protection specific to the vulnerability if adequately developed or implemented.

- $\quad$ Links well to other vulnerabilities.

F (Full) - Full protection provided against specific vulnerability. 
Examination of the normative rights provision refers strictly to the content of the rights instruments and recommendations for normative content in general comments documents of the associated committee. Reference can also be made to suggestions for normative content made by bodies and organisations quoted in general comments documents. "Special measures," "special procedures," and "special protection" as issues of implementation are included in the following chapter. Therefore, as they aid implementation suggestions which impact normative provision are not included in this chapter.

In order to support the argument by some UN Member States that gaps in the provision of rights of older people are not normative in nature, the examination undertaken in this chapter would be required to demonstrate full protection against all vulnerabilities.

Note: Findings are not disaggregated to represent the special case of women in Table Number 11. The situation of older women is included in the discussion. 
TABLE NUMBER 11: SUMMARY OF PROTECTION OF VULNERABILITIES OF OLDER PEOPLE BY INTERNATIONAL HUM

\begin{tabular}{|c|c|c|c|c|c|c|c|c|}
\hline Vulnerability & UDHR & & ICCPR & & ICESCR & & CRPD & \\
\hline \multicolumn{9}{|l|}{ Embodied } \\
\hline \multicolumn{9}{|l|}{ Physiological } \\
\hline Existence/Life & Art 3 & $\mathrm{~L}$ & $\begin{array}{l}\text { Art } 6 \\
\text { Draft GC } 36\end{array}$ & L & $==$ & $==$ & Art 10 & L \\
\hline Health & $\begin{array}{l}\text { Art } \\
25(1)\end{array}$ & $\mathrm{P}$ & & & $\begin{array}{l}\text { Art 11(1) } \\
\text { Art 11(2) } \\
\text { (a)(b) } \\
\text { General } \\
\text { Comment 12 } \\
\text { General } \\
\text { Comment } 4 \\
\text { Art } \\
12(1)(c)(d) \\
\text { GC6 } \\
\text { GC 14 }\end{array}$ & $\begin{array}{l}\mathrm{P}-\mathrm{G} \\
\mathrm{G}\end{array}$ & $\begin{array}{l}\text { Art } 25 \text { (b) } \\
\text { Art } 25 \text { (c) } \\
\text { Art } 25 \text { (d) }\end{array}$ & $\mathrm{P}$ \\
\hline
\end{tabular}




\begin{tabular}{|c|c|c|c|c|c|c|c|c|}
\hline Vulnerability & UDHR & & ICCPR & & ICESCR & & CRPD & \\
\hline \multicolumn{9}{|l|}{ Embodied } \\
\hline \multicolumn{9}{|l|}{ Poverty } \\
\hline Social Security & $\begin{array}{l}\text { Art } 22 \\
\text { Art } 25 \\
\text { (1) }\end{array}$ & G & $==$ & $==$ & $\begin{array}{l}\text { Art } 9 \\
\text { General } \\
\text { Comment } 6\end{array}$ & $P$ & $\begin{array}{l}\text { Art } 28 \\
(2)(b) \\
\text { Art } 25(c), \\
(e)\end{array}$ & $P$ \\
\hline Work & $\begin{array}{l}\text { Art } 23 \\
(1) \\
\text { Art } \\
23(3)\end{array}$ & L & $==$ & $==$ & $\begin{array}{l}\text { Art 6(1) } \\
\text { Art 6(2) } \\
\text { Art 7(a)(1)(2) } \\
\text { Art 7(1)(c) } \\
\text { Art 8(1)(a) }\end{array}$ & $\begin{array}{l}\mathrm{L} \\
\mathrm{L} \\
\mathrm{L}\end{array}$ & $==$ & $==$ \\
\hline
\end{tabular}




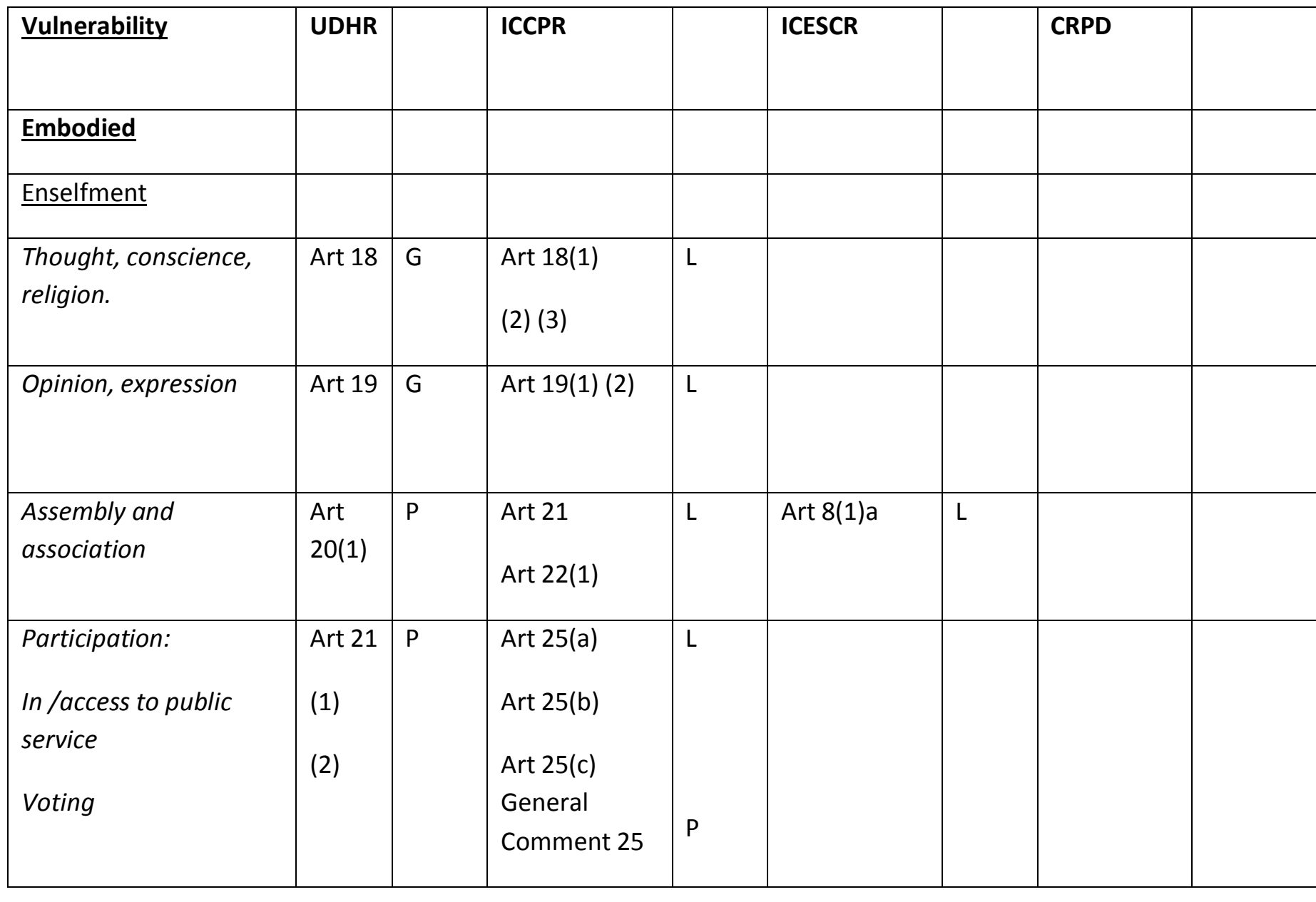




\begin{tabular}{|c|c|c|c|c|c|c|c|c|}
\hline Vulnerability & UDHR & & ICCPR & & ICESCR & & CRPD & \\
\hline Embodied & & & & & & & & \\
\hline Enselfment (continued) & & & & & & & & \\
\hline $\begin{array}{l}\text { Participation: } \\
\text { In the cultural life of } \\
\text { the community }\end{array}$ & $\begin{array}{l}\text { Art } \\
27(1)\end{array}$ & G & $==$ & $==$ & Art 15(1)(a) & $\mathrm{L}$ & & \\
\hline 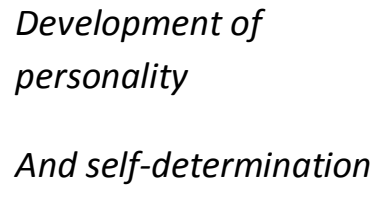 & $\begin{array}{l}\text { Art } 22 \\
\text { Art } \\
26(2)\end{array}$ & $\mathrm{L}$ & Art 1 & $\mathrm{~L}$ & $\begin{array}{l}\text { Art } 1 \\
\text { Art 6(2) } \\
\text { Art 13(1) }\end{array}$ & $\mathrm{L}$ & & \\
\hline Emplacement & & & & & & & & \\
\hline $\begin{array}{l}\text { Arbitrary interference } \\
\text { with family, home }\end{array}$ & Art 12 & $\mathrm{P}$ & Art 17(1) & $L$ & & & & \\
\hline $\begin{array}{l}\text { Including: } \\
\text { family assistance to } \\
\text { care for older people }\end{array}$ & $\begin{array}{l}\text { Art } \\
16(3) \\
\text { Art } 12 \\
\text { Art } 17\end{array}$ & P & Art 23(1) & $\mathrm{N}$ & $\begin{array}{l}\text { General } \\
\text { Comment } \\
\text { No. } 6\end{array}$ & $P$ & $\begin{array}{l}\text { Art 19(a) } \\
\text { Art 19(b) }\end{array}$ & $\mathrm{P}$ \\
\hline
\end{tabular}




\begin{tabular}{|c|c|c|c|c|c|c|c|c|}
\hline Vulnerability & UDHR & & ICCPR & & ICESCR & & CRPD & \\
\hline \multicolumn{9}{|l|}{ Embodied } \\
\hline \multicolumn{9}{|l|}{$\begin{array}{l}\text { Emplacement } \\
\text { (continued) }\end{array}$} \\
\hline $\begin{array}{l}\text { Right to own property } \\
\text { Stay in home as long as } \\
\text { possible }\end{array}$ & $\begin{array}{l}\text { Art } \\
17(1) \\
17(2) \\
\text { Art } 12 \\
\text { Art } \\
25(1)\end{array}$ & $P$ & & & $\begin{array}{l}\text { Art } 11 \\
\text { General } \\
\text { Comment } 4 \\
\text { General } \\
\text { Comment } 6\end{array}$ & G & & \\
\hline \multicolumn{9}{|l|}{ Institutional } \\
\hline Non Discrimination & Art 2 & $\mathrm{~N}$ & $\begin{array}{l}\text { Art 2(1) } \\
\text { Art4(1) } \\
\text { Art 3 }\end{array}$ & $\begin{array}{l}\mathrm{N} \\
\mathrm{N}\end{array}$ & $\begin{array}{l}\text { Art 2(2) } \\
4(1) \\
\text { Art } 3\end{array}$ & $\begin{array}{l}\mathrm{N} \\
\mathrm{N}\end{array}$ & $\begin{array}{l}\text { Preamble } \\
\text { Article } \\
8(1)(b)\end{array}$ & $\begin{array}{l}P \\
P\end{array}$ \\
\hline Recognition before law & Art 6 & L & Art 16 & L & & & & \\
\hline
\end{tabular}




\begin{tabular}{|c|c|c|c|c|c|c|c|}
\hline Vulnerability & UDHR & & ICCPR & & ICESCR & CRPD & \\
\hline \multicolumn{8}{|l|}{ Institutional (cont) } \\
\hline Legal capacity & & & & & & $\begin{array}{l}\text { Art } 12(2), \\
(3),(4)\end{array}$ & $\mathrm{P}$ \\
\hline $\begin{array}{l}\text { Equal before law, equal } \\
\text { protection of law }\end{array}$ & Art 7 & $\mathrm{~L}$ & Art 26 & $\mathrm{~L}$ & & & \\
\hline Effective remedy & Art 8 & $\mathrm{~L}$ & $\begin{array}{l}\text { Art 2(3)(a) } \\
\text { (b)(c) }\end{array}$ & $\mathrm{L}$ & & & \\
\hline \multicolumn{8}{|l|}{ Pathogenic } \\
\hline $\begin{array}{l}\text { All forms of abuse, } \\
\text { violence and neglect }\end{array}$ & Art 5 & $\mathrm{~L}$ & $\begin{array}{l}\text { Art } 7 \\
\text { Art 10(1) }\end{array}$ & $\begin{array}{l}\mathrm{L} \\
\mathrm{L}\end{array}$ & & $\begin{array}{l}\text { Art } 12(2) \text {, } \\
(3),(4)\end{array}$ & $\mathrm{P}$ \\
\hline $\begin{array}{l}\text { Torture, inhuman, } \\
\text { degrading treatment }\end{array}$ & & & $\begin{array}{l}\text { Art } 7 \\
\text { GC } 20\end{array}$ & $P$ & & & \\
\hline
\end{tabular}




\subsubsection{Universal Declaration of Human Rights}

\subsubsection{Embodied Vulnerability}

Of all threats carrying a risk of a vulnerable outcome, older people have least resilience to threats to the physical and psychological person. Documented vulnerabilities to illness; disease; disability; co-morbidity; and the extension of morbidity, combined with outcomes and "vulnerability experiences" of older people generate specific claims on the rights to life and health.

\section{Physiological Vulnerability}

\section{$\underline{\text { Life }}$}

The fundamental right relating to this primary cause of embodied vulnerability is the right to life. The UDHR states that "everyone has the right to life," the only limitation that of Article 29(2). ${ }^{1056}$ The stated prevention of arbitrary taking of life has limited relevance to the interests of older people. However, the travaux preparatoires of the instrument are informative as to the potential for the right to directly protect the interests of the group. The focus of the drafters of the Declaration was primarily the prevention of the taking of life; however, a subsidiary argument was made for the protection and continuation of life. Suggestions from States parties broadening the meaning and scope of the protection of life are directly relevant to vulnerabilities of older people, and are therefore proposed for inclusion in the right to life as part of special protection. The submission by France derived from the principle of intervention to protect humanity. ${ }^{1057}$ The approach taken to the right was explained as "...we are thinking of the right to live and protection of human life...Therefore, I think it is fundamental that we state that human beings have the right of existence." 1058 The change in terminology from "life" to "live" together with an emphasis on protection of life and existence is, in the context, suggestive of the continuation of life.

\footnotetext{
1056 'In the exercise of his rights and freedoms, everyone shall be subject only to such limitations as are determined by law solely for the purpose of securing due recognition and respect for the rights and freedoms of others and of meeting the just requirements of morality, public order and the general welfare in a democratic society.' See also William A. Schabas, The Universal Declaration of Human Rights The travaux prétoires,( 2013, CUP), cxvii

${ }^{1057}$ Explained in terms of the lack of intervention in World War II resulting in the loss of millions of lives

${ }^{1058}$ H.R. Com. 1st session-13th meeting-pages E-94, E-95
} 
Intervention for the protection of life was also advocated by the Chilean delegate. The need to protect against vulnerabilities of ill-health, poverty, and inability to be productive for any reason in order to maintain life were central to the interpretation of the right to life. The vulnerabilities identified fall into the classifications of inherent, internal, and external capabilities. Moreover, the suggestion of a positive duty to support compromised capabilities makes this interpretation of the right to life exemplary of the Capabilities Approach to human rights provision and special protection. ${ }^{1059}$

Every person has the right to life. This right extends to the right to life...of incurables...t includes the right to sustenance and support in the case of those unable to support themselves by their own efforts; and it implies a duty of the state to see to it that such support is made available. ${ }^{1060}$

The delegation from Uruguay interpreted the right to life as protection of life. Direction for application of the right is specific. All lives vulnerable by physical or mental illness are included, with the focus on maintaining life.

Human life is inviolable. The State shall grant protection to all persons born or those suffering from incurable diseases and those physically or mentally deficient are also entitled to it. ${ }^{1061}$

With the considerations of maintaining and promoting life failing to be included in the normative provision of the right, however, interests of older people in the right remained unmet, and a normative gap created.

\section{Health}

The UDHR is, nonetheless, responsive to the interconnected framework of vulnerability ${ }^{1062}$ and the principle of inevitable dependency ${ }^{1063}$ on the matter of protection against inevitable

${ }^{1059}$ See 6.5.4 'Securing human rights using a Capabilities Approach'

The suggestion of positive obligation was supported by France. E/CN.4/AC.1 'Summary Record of the Second Meeting [of the Drafting Committee of the Commission on Human Rights],' 11 ${ }^{1060} 1^{\text {st }}$ addendum of Draft Outline (first session) of International Bill of Rights. List of human rights and observations from members of Commission of Human Rights $25^{\text {th }}$ June 1947.

E/CN.4/AC.1/3/Add.1

${ }^{1061} 35^{\text {th }}$ meeting of Drafting Committee $2^{\text {nd }}$ session $17^{\text {th }}$ May $1948 . E / C N .4 / S R .35,13$

1062 explained in Part II as each aspect of vulnerability 'inextricably entangled with the other.' See 5.3.1.4 'The Interconnected Framework'

1063 'inevitable vulnerability' is the term used for the biological vulnerability, both physical and mental, experienced during old age. See 5.3.1.1 'Embodied Vulnerability' 
physiological vulnerability. The only direct reference to "old age" in the UDHR appears in Article 25 , in which the vulnerability of older people to ill-health and dependency is implicit. Protection against physical vulnerability is at the core of the objective to attain "health and well-being" in Article $25{ }^{1064}$ The right to an adequate standard of living necessary to achieve this also provides the right to "...food, clothing, housing and medical care and necessary social services." Therefore, if the interests of older people are sufficiently protected, the right has the potential to protect against the inevitable vulnerability to disease, illness, comorbidity, and extension of morbidity. The complexities of the vulnerability of health of older people due to the ageing process (Chapter 9), demonstrated in the findings of lived vulnerabilities (Chapter 10) require a suitably comprehensive human rights response. For an understanding of the meaning and treatment of "health" by the UDHR the travaux preparatoires are instructive. The normative standard proffered by the WHO of "The...highest attainable standard of health" as part of the claim that enjoyment of the same "is one of the fundamental rights of every human being"1065 is not featured in the Declaration. Furthermore, the instrument lacks a precise "right to health," on the grounds of, inter alia, sustainability. ${ }^{1066}$ However, reference to aspirations of the drafters of the instrument, whilst expressing minimal explicit protection for older people, and not directly reflected in the normative content of the Declaration, proffer some guidance as to the direction of related rights in future instruments to be examined in this chapter. The suggestion of a "right to maintenance of health...including old age" ${ }^{1067}$ in conjunction with the "preservation of...health through the highest standard of food, clothing, housing and medical care..." ${ }^{1068}$ imply, as a minimum, protection of existing standards. References to "continuously improving" ${ }^{\prime 1069}$ and "raising the standard of living,"1070 together with a

\footnotetext{
1064 'The right to a standard of living adequate for the health and well-being of him and his family...' Article 25(1) UDHR

${ }^{1065}$ World Health Organisation contribution to Working Paper on an International Bill of Rights, 8,13 January 1947 E/CN.4/W.4

1066 'the right to health...is too wide and depends on many, many circumstances from the...beginning of one's life,' Mr. Tepliakov, delegate from USSR, Drafting Committee on an International Bill of Human Rights International Bill of Rights Documented Outline, 285, 11 June 1947.

E/CN.4AC.1/3/Add.1

${ }^{1067}$ Mr. Tepliakov, delegate from USSR, Drafting Committee on an International Bill of Human Rights International Bill of Rights Documented Outline, 285, 11 June 1947 E/CN.4AC.1/3/Add.1

${ }^{1068}$ Report of the Drafting Committee to Committee of Human Rights. E/CN.4/95, 24 May 1948

${ }^{1069}$ UN Economic and Social Council, Commission on Human Rights Drafting Committee International Bill of Rights E/CN.4/AC.1/3/Add.1, 11 June 1947

${ }^{1070}$ Draft Declaration on Human Rights and Letter of Transmittal from the Cuban Delegation to the General Assembly of the UN E/HR/1, 12 February 1946, 7
} 
proposed "right to medical care," ${ }^{1071}$ are potential, although not definitive, indicators of objectives for prevention of ill-health, and maintenance and improvement of standards of health. It is instructive to the identification of normative gaps in the protection of older people that in addition to the omission of these indicators from the Declaration, in accordance with the "two polar ends of life" as the life stages at which the individual is most vulnerable and dependent, ${ }^{1072}$ the Article omits old age whilst acknowledging childhood for special protection. ${ }^{1073}$

The composite factors of the standard of living of Article 25 are related to further distinct vulnerabilities experienced by older people; specifically poverty and homelessness. Therefore, Article 25 will feature in the examination of normative provision against such risks, with the significance of each to the central objective of health and well-being implicitly acknowledged.

\section{Poverty}

Situations of vulnerability detailed in "Research of Older People" in Part III, together with the principle of inevitable dependency, and aspects of various theories of ageing, are evident in the causes of poverty among older people identified in the Report of the Independent Expert on Human Rights and Extreme Poverty. Collectively cited as "core factors" are: "lack of access to regular income and work and health care; declining physical and mental capacities; and dependency within the household." ${ }^{1074}$ Theories of Ageing, particularly Modernisation and Productivity Theories propose loss of status in the employment and productivity arena, resulting in inability to obtain or maintain employment per se, and most specifically employment corresponding to skills and abilities. ${ }^{1075}$ Research of lived vulnerabilities of older people reported in Part III demonstrate downgrading of employment opportunities available to the group, in part due to the unavailability of training to older people. The right to education states that "Technical and professional education shall be

\footnotetext{
${ }^{1071}$ Draft Outline of International Bill of Rights (prepared by the Division of Human Rights) 4 June 1947, Article 35, E/CN.4/AC.1/3

${ }^{1072}$ Fineman identifies the 'two polar ends of life' as the stages at which the individual is dependent. See 5.3.2.2 'Fineman's Thesis' 
made generally available." ${ }^{1076}$ It is evident that a reference to age or stage of career should be included in the normative content of the right in order to prevent age-related discrimination of entitlement. Reduced employment opportunities also create a vulnerability to "forced retirement."1077 The principle risk to older people is vulnerability to poverty. However, loss of status and forced retirement, in addition to poverty, were identified in Part III as recognised risk factors for ill-health and mortality. ${ }^{1078}$ The promise of Article 23 of "the right to work, to free choice of employment, to just and favourable conditions of work and to protection against unemployment, ${ }^{1079}$ is therefore proven to be discriminatory in the protection against multiple aspects of embodied vulnerability for older people.

Acknowledgement by Article 25 of "old age" as entitlement to security, cited as the "Right to Economic Security" ${ }^{1080}$ during drafting lessens vulnerability to poverty. The significance of the standard of living to the outcome of health and well-being is emphasised. This version of the right demonstrated an aim to protect older people from the threat of inability to be economically productive due to "disability or old age." Further acknowledgement of threat from the "eventuality of old age"1081 to an adequate standard of living echoes concerns of Productivity and Disengagement Theories of Ageing. ${ }^{1082}$ Therefore, "old age" is included as a reason for dependence on, and a right to, State security to facilitate protection, implicitly available to older people, against threats to health via standard of living. This single reference to older people in normative provision implies recognition of a particular vulnerability of older age to poverty, whilst serving to highlight the significance of exclusion of age as a ground for non-discrimination.

More directly related to poverty is Article 22. The statement that "Everyone, as a member of society, has the right to social security" is impliedly considered to include old age benefits. However, the lived vulnerabilities of older people collated in Part III gave an account of members of the group denied old age pensions, benefits, survivor benefits and healthcare

\footnotetext{
${ }^{1076}$ Article 26(1), UDHR

${ }^{1077}$ See 8.2.1.1 'Industrialisation and the effects on older people'; 9.3.1 'Retirement Age'

1078 See Chapter 10, 'What it Means to be an Older Person'

${ }^{1079}$ Article 23(1), UDHR

1080 U.S. suggestions for Redrafts of Certain Articles in Draft Outline E/CN/4/AC.1/8 11 June 1947

${ }^{1081}$ Draft Declaration of the International Rights and Duties of Man, Article 16 Formulated by the Inter-American Juridicial Committee, E/CN.4/2, 8 January 1947

${ }^{1082}$ See 8.3.1 'Productivity as 'usefulness'; 8.4.1 'Disengagement Theory'
} 
elements of social security. ${ }^{1083}$ Thus, without inclusion of specific old age benefits, a matter expanded on in the examination of the ICESCR, a normative gap exists with regard to protection from vulnerability to poverty in the UDHR.

\section{Enselfment}

The psychological, ${ }^{1084}$ spiritual and moral self offered by Turner, and existential influences included by Fineman in definitions of embodied vulnerability, ${ }^{1085}$ are predominantly represented as general statements of right in the UDHR. Some, including freedom of thought, conscience and religion ${ }^{1086}$ have not been demonstrably proven to be normatively inadequate for the protection of older people. However, aspects of "enselfment" represented in rights of participation require greater normative provision that statements of entitlement to a right. Freedoms to participate in cultural rights ${ }^{1087}$ and peaceful assembly and association ${ }^{1088}$ are reliant on older people being located in the community, and accessible links, as physical access serves as a barrier. Participation in government ${ }^{1089}$ and access to public service ${ }^{1090}$ are similarly vulnerable. In addition, research of lived vulnerabilities of older people in Part III highlighted problems of entitlement and access. Participation of older women in government elections is a victim of cultural relativity, with some applying discriminatory weighting to votes.

\section{Emplacement}

Emplacement was described in Part II as the place "where all physical, psychological, spiritual and moral experience takes place. ${ }^{\prime 1091}$ In response to the particular significance of family to the security and well-being of older people, as described in Part III, ${ }^{1092}$ this thesis

\footnotetext{
1083 See Chapter 10, 'What it Means to be an Older Person'

${ }^{1084}$ By including the psychological self, it becomes inseparable from the physical self, meaning 'embodiment' cannot be viewed purely in physical terms. Also, that the experience of living develops physical abilities, reason, habits and preferences demonstrates the permanent interlinking of the physical, psychological, spiritual and moral. This principle of 'enselfment' is borrowed from Pierre Bourdieu, Pascalian Meditations; 2000. B.S. Turner, Vulnerability and Human Rights. Essays on Human Rights, (2006; Pennsylvania State University Press) ,27

${ }^{1085}$ See 5.3.1.1 'Embodied Vulnerability'

${ }^{1086}$ Article 18, UDHR

1087 Article 27(1), UDHR

${ }^{1088}$ Article 20(1), UDHR

${ }^{1089}$ Article 21(1), UDHR

${ }^{1090}$ Article 21(2), UDHR

${ }^{1091}$ See 5.3.1.1 'Embodied Vulnerability'

${ }^{1092}$ See 8.2.2.1'Filial Obligation'
} 
included family life in the definition of "emplacement." 1093 Given the role of the "place" in the "living experience," and the inclusion of housing in the composition of "adequate standard of living," the standard of housing is relevant. However, normative standards as to what comprises "adequate" housing are not proffered by UDHR or the travaux preparatoires. For Turner, the proponent of emplacement, the greatest threat to "place" is removal from, or loss of, the home. The provision of housing is protected by the provision "the right to...housing...in the event of...old age." ${ }^{1094}$ However, findings of research into the lived experiences of older people reported in Part III have proven vulnerability to homelessness due to poverty a global theme.

Articles 12 and 17 of the UDHR, prima facie, protect against loss of the home. Statements including: "Everyone has the right to own property...;" 1095 "No one shall be arbitrarily deprived of his property;" ${ }^{1096}$ and the prevention of "...arbitrary interference with his...home ${ }^{\prime 1097}$ have proven inadequate for older people. Research of vulnerabilities of older people reported situations of older women being deprived the right to own property, and being removed from that property when widowed. Vulnerability to violation of emplacement exemplifies the interconnected nature of vulnerability, as homeless older women become vulnerable to loss of family and social engagement, poverty, and abuse. The normative provision required would prevent forced eviction of older people, and state the need for additional special protection of older women. Furthermore, the location of the home is vital to older people. In particular, older people living in rural communities in developing countries have limited "experience" of the life lived, as access to vital services, community, and public life is limited. No normative provision is made in the UDHR for location of homes of older people or transport facilities, creating a vulnerability to disengagement, lone living, isolation, and non-participation.

The UDHR states the need to protect the family as "the natural and fundamental group unit of society...entitled to protection by society and the State." ${ }^{1098}$ However, Article 16 does not extend to protecting the unit for purposes of care and support of older family members. In Part III Theories of Ageing explored filial obligation, reporting that lack of such care and

\footnotetext{
${ }^{1093}$ See 5.3.1.1 'Embodied Vulnerability'

1094 Article 25(1), UDHR

${ }^{1095}$ Article 17(1), UDHR

${ }^{1096}$ Article 17(2), UDHR

${ }^{1097}$ Article 12, UDHR

${ }^{1098}$ Article 16(3), UDHR
} 
support in societies where it is traditionally practiced is largely the result of inability rather than unwillingness. ${ }^{1099}$ Examination of lived vulnerabilities demonstrated the practice of filial obligation to be regionally widespread, including Africa, Asia, the Americas and Southern Europe. ${ }^{1100}$ However, situations of lone living, limited familial contact, lack of care, and poverty in these and other regions prove vulnerability to Turner's "exclusion" ${ }^{1101}$ from the place and family life aspects of emplacement. There is a need, therefore, to provide support to families wishing to practice filial obligation, to facilitate protection from vulnerability by virtue of emplacement.

\section{$\underline{\text { Institutional Vulnerability }}$}

The "defence system" of institutions which built up in response to threat ${ }^{1102}$ provides resilience and assets to protect against a range of vulnerabilities. Such "assets" are categorised by Kirby into physical, human, and social, and represent the assistance needed by those made dependent by virtue of vulnerability. ${ }^{1103}$ The vulnerability, or failure, of these institutions exacerbates the vulnerability of older people reliant upon them. The analysis by Turner of the role of human rights as "institution building" is instructive in this regard. When provision is made via human rights for institutions to offer adequate assets, failure is predominantly a matter of implementation. However, when human rights do not protect either the institutions or the assets provided, and vulnerable groups dependent upon them, the gap is normative.

In the context of the role of human rights as institution-building, and the fact that law is an institution upon which vulnerable groups are dependent, the primary failing of the Declaration and the blueprint it provides for subsequent human rights instruments is the recognition of older people before the law. The thesis borrows from Martin et al in this regard:

\footnotetext{
1099 See 8.2.2.1 'Filial Obligation'

1100 See Chapter 10

${ }^{1101}$ Refer to heading 5.3.1.1 'Embodied Vulnerability'

1102 As described by Turner 5.3.1.2 'Institutional Vulnerability'

${ }^{1103}$ See 5.3.2.2 'Fineman's Thesis'
} 
The lack of an international convention on the human rights of the older persons...limits the legal recognition of this vulnerable group. This situation simply compounds their vulnerable situation at both national and international levels. ${ }^{1104}$

[d]edicated human rights committees extend human rights to older persons; before an argument or complaint can be made about the violation of an older person or group of older persons' rights, applicants must first explain how supposedly universal law applies to them. As a matter of course human rights cannot be accessed by older persons in the current framework. ${ }^{1105}$

Furthermore, the UDHR omits to include "age" or "old age" as a prohibited ground for discrimination against entitlement to the declaratory rights included in the instrument. Such silence is indicative of "institutionalised ageism within legal frameworks."1106 Thus the position of older people is weakened, the legal force of rights undermined, and older people become "invisible as a group within the law."1107 Research of the vulnerabilities of older people has demonstrated that the generic statements "Everyone has the right to recognition everywhere as a person before the law,"1108 and "All are equal before the law and are entitled without any discrimination to equal protection of the law"1109 ${ }^{\prime 1}$ provide inadequate protection. A clear need for distinct inclusion of "older people" or non-discrimination on the grounds of age is required in the normative provision of these rights. Against such background, the institution-building role of human rights is at risk of failure, and consequently the institutions providing the reliance and assets upon which older people depend. ${ }^{1110}$

${ }^{1104}$ C. Martin, D. Rodrigues-Pinzon and B. Brown 'Human Rights of Older People and Universal Regional Legal Perspectives' (2015 Springer) 24-25

${ }^{1105}$ Rocio Barahona Riera, April 19, 2011, OEWG, New York (as cited in C. Martin, D. Rodrigues-Pinzon and B. Brown 'Human Rights of Older People and Universal Regional Legal Perspectives' (2015 Springer) 15

${ }^{1106}$ United Nations Department of Economic and Social Affairs Division for Social Policy and Development Programme on Ageing, Report of the Expert Group Meeting 'Rights of Older Persons' Convened in preparation for the report of the Secretary-General to the $64^{\text {th }}$ session of the General Assembly 5-7 May 2009, Bonn, Germany, 14

${ }^{1107}$ United Nations Department of Economic and Social Affairs Division for Social Policy and Development Programme on Ageing, Report of the Expert Group Meeting 'Rights of Older Persons' Convened in preparation for the report of the Secretary-General to the $64^{\text {th }}$ session of the General Assembly 5-7 May 2009, Bonn, Germany, 15

${ }^{1108}$ Article 6, UDHR

${ }^{1109}$ Article 7, UDHR

${ }^{1110}$ The institution-building role of human rights described by Turner, and the assets provided by institutions as described by Kirby, in Chapter 5 are incorporated into the vulnerability framework used 


\section{Pathogenic Vulnerability}

Pathogenic vulnerability has its origins in immoral or abusive behaviour. ${ }^{1111}$ Older people were demonstrated in Chapter 10 to be at greatest risk of specific forms of abuse: violence, financial, psychological and sexual. Of relevance is the fact that institutional assets have been proven to inadvertently introduce abuse into the lives of the vulnerable person, ${ }^{1112}$ and the propensity of embodied vulnerability to attract further vulnerability, particularly pathogenic. The only protection offered by the UDHR against pathogenic vulnerability is that enshrined in Article 5, prohibiting "torture...cruel, inhuman or degrading treatment or punishment." Examples of protection against pathogenic vulnerability exist in special protection instruments such as UNCRC and UNCRPD which identify the forms of treatment to which the groups are most vulnerable, and include special protection rights in addition to the generic right articulated in Article 5. The normative gap that exists in the UDHR is the result of not including a right to freedom from the specific forms of abuse and violence to which the group is vulnerable.

The forms, nuances, and intent of the right to security during the drafting process permit some protection from pathogenic vulnerability. The comment by the Netherlands that the vagueness of the term "security of the person" would be sufficient reason to replace it with the more explicit, if limiting, term "bodily integrity" offers guidance as to meaning of this element of Article 3 when protection is required from external threat, including violence and physical and mental abuse. ${ }^{1113}$ The UDHR recognises a form of pathogenic vulnerability of relevance to older people in the aspiration for "freedom from fear."1114 Whilst not included as an Article in the present instrument, nor given rights status in legally binding instruments, protection from abuse would be incomplete without the inclusion of "fear" in any listing.

in the present examination of human rights adequacy for older people. See 5.3.1.2 'Institutional Vulnerability'

${ }^{1111}$ See 5.3.1.3 Pathogenic Vulnerability

${ }^{1112}$ For example when abusive carers enter the home, or abuse treatment is experienced in care homes.

${ }^{1113}$ Collation of the Comments of Governments on the Draft International Declaration on Human Rights, Draft International Covenant on Human Rights and the Question of implementation E/CN.4/85 1 May 1948,17

${ }^{1114}$ Preamble, UDHR. 


\subsubsection{International Covenant on Civil and Political Rights}

\section{$\underline{\text { Embodied }}$}

\section{Physical and Mental}

\section{$\underline{\text { Life }}$}

In contrast to the general statement of the UDHR, the right to life in the ICCPR is specific in content and implementation. The right is definitively to the prevention of the arbitrary taking of life, and is "shrouded in the antiquated language of capital punishment." ${ }^{1115}$ Whilst there is a minimum age limit for the imposition of legal death penalties, no similar protection is offered to older people. Significantly there is no stated provision for the protection of human life per se in the instrument.

Greater scope is provided for the right to life, of relevance to the vulnerabilities of older people by the HRC in general comments. Significantly, general comment 6 is replaced by the draft general comment 36. However, it is instructive to note that the earlier general comment instructed that the right be broadly interpreted and that the "inherent right to life" be protected "in all stages of the life course," and possibly that measures be taken to increase life expectancy. ${ }^{1116}$ The inclusion of such normative provision in the right to life would view the life of the older person as to be actively preserved rather than protected from arbitrary State action. The protection provided would thereby be more appropriate to lived needs.

The draft general comment provides further proposal for the extension of the right to life beyond that stated in the ICCPR. The suggestion that the right include life-risking dangers and harms with the ability to cause indirect and non-immediate loss of life ${ }^{1117}$ would protect the interests of older people if inclusive of discriminatory and damaging practices. Based on discriminatory practices highlighted in theories of ageing and research findings of lived vulnerabilities of older people, this thesis suggests such practices include: culturally

\footnotetext{
${ }^{1115}$ William A. Schabas, The Universal Declaration of Human Rights The travaux prétoires, (2013, CUP), cxvii

${ }^{1116}$ U.N. Human Rights Committee, General Comment No. 6: The Right to Life, U.N. Doc.

HRI/GEN/1/Rev.9 (Vol. I) (Apr. 30, 1982).

${ }^{1117}$ Communication No. 821/1998,Chongwe v. Zambia, Views of the Committee of 25 Nov. 2000, 5.2.

Cf. Ilhan v Turkey, Judgment of the ECtHR of 27 June 2000, at 75-76; Rochela Massacre v Colombia,

I/A CHR Judgment of 11 May 2007, 127 (as cited in Yuval Shany and Nigel Rodley, 'Draft general comment No. 36 Article 6: Right to life,' 5. HRC $115^{\text {th }}$ session 19 October-6November 2015)
} 
permissible abusive, violent, and lethal acts against older women; ${ }^{1118}$ abandonment causing lack of support and care; social isolation; loss of, or removal from, home leading to homelessness; discriminatory treatment in times of disaster and emergency. Furthermore, parallels are drawn between the effects of abandonment and homelessness of older people and "disappearance," which the draft general comment cites as a threat to life and "removal...from the protection of the law."1119

Moreover, the proposed general comment addresses the non-absolute nature of the right to life. Freedom from arbitrary deprivation of life calls for normative definition of acts, often comprising violations of other rights, leading to the same. ${ }^{1120}$ Of the examples provided by the Committee, few include issues of direct relevance to older people. In accordance with the vulnerable experiences of older people, normative guidance would include: psychological and physical effects of abuse and inhuman degrading treatment; ${ }^{1121}$ interference with home and family life; ${ }^{1122}$ and recognition before the law. ${ }^{1123}$ Moreover, comprehensive protection is achievable via the reciprocal relationship between the generations of rights discussed in Chapter $5{ }^{1124}$ with normative guidance making reference to relevant aspects of Articles 11 and 12 of the ICESCR. ${ }^{1125}$

\section{Poverty}

The single contribution of the ICCPR to protection from vulnerability to poverty is contained in Article 22. The stated right to "form and join trade unions for the protection

\footnotetext{
1118 Such as accusations of witchcraft due to age.

${ }^{1119}$ See e.g., Communication No. 992/2001, Saker v. Algeria, Views of the Committee of 15 March 2006, 9.2 (as cited in Yuval Shany and Nigel Rodley, 'Draft general comment No. 36 Article 6: Right to life,' 6. HRC $115^{\text {th }}$ session 19 October-6November 2015)

${ }^{1120}$ Draft General Comment 36 cites for example, the killings of demonstrators exercising their right of freedom of assembly, using Report of the Special Rapporteur on extrajudicial, summary or arbitrary executions, 1 April 2014, 75; and gender-related violence involving the application of lethal force against women on account of discriminatory attitudes using González v. Mexico, Judgment of the I/A CHR of 16 Nov. 2009, 399-400. Yuval Shany and Nigel Rodley, 'Draft general comment No. 36 Article 6: Right to life,' 21. HRC $115^{\text {th }}$ session 19 October-6November 2015

${ }^{1121}$ Article 7, ICCPR

${ }^{1122}$ Article 17(1), ICCPR

${ }^{1123}$ Article 16, ICCPR

${ }^{1124}$ As a result of vulnerability underpinning human rights, the need for cooperation between and justiciability of both generations of rights exists

${ }^{1125}$ The right to a standard of living adequate for health. The right of everyone to the enjoyment of the highest attainable standard of physical and mental health.
} 
of...interests" ${ }^{\prime 126}$ should include the suggestion made in the ILO Recommendation that the right be maintained into retirement in order to alleviate poverty of older people.

\section{Enselfment}

The participation rights included in the ICCPR associated to the principle of enselfment include: freedom of thought, conscience and religion; ${ }^{1127}$ the right to hold opinions without interference; ${ }^{1128}$ the right to freedom of expression; ${ }^{1129}$ and the right to freedom of association. ${ }^{1130}$

In similar vein to the UDHR, little evidence exists to support claims of particular vulnerability of older people to prevention of the exercise of these rights. The normative content of Article 19, however, provides partial protection against the vulnerability of older people to the effects of negative stereotyping. ${ }^{1131}$ In placing "certain restrictions on the right [to freedom of expression]... which may relate...to the interests of other persons ${ }^{\prime 1132}$ the ICCPR has provided a broad category of limitations on the effects of discriminatory societal attitudes. In reality, this has proven ineffective protection of older people to the vulnerability of such effects. Therefore, a more complete normative provision would expressly reference groups vulnerable to negative stereotyping, including older people.

The barrier of physical access to the right to participate in public affairs and the right to vote receives nominal recognition in general comment 25 , stating that "impediments to freedom of movement which prevent persons entitled to vote from exercising their rights" should be overcome. ${ }^{1133}$ Furthermore, it is informative that the instruction that the right to vote, subject to "reasonable restrictions," ${ }^{1134}$ combined with Article $3^{1135}$ has not saved the inequalities in the value of votes between genders in some cultures.

\footnotetext{
${ }^{1126}$ Article 22(1), ICCPR

${ }^{1127}$ Article $18(1)$, ICCPR

${ }^{1128}$ Article 19(1), ICCPR

${ }^{1129}$ Article 19(2), ICCPR

${ }^{1130}$ Article 22(1), ICCPR

${ }^{1131}$ Article 19(3)(a) 'It may....be subject to certain restrictions, but these shall only be such as are provided by law and are necessary: (a) For respect of the rights or reputations of others'

${ }^{1132}$ HRC General Comment No. 10, Article 19 Freedom of opinion, 4

${ }^{1133}$ HRC General Comment 25 The right to participate in public affairs, voting rights and the right of equal access to public service, 12

${ }^{1134}$ HRC General Comment 25 The right to participate in public affairs, voting rights and the right of equal access to public service, 10

${ }^{1135}$ The right to equal enjoyment of the rights contained in the ICCPR between men and women
} 


\section{Emplacement}

\section{Family}

Following the lead of the UDHR, the ICCPR states the entitlement to protection by society and the State of the family unit ${ }^{1136}$ and prohibits arbitrary interference. ${ }^{1137}$ The instrument is flawed, however, in its recognition of the vulnerable and dependent "polar ends of life," signifying the need for special protection of the child, whilst omitting older family members. ${ }^{1138}$ In the context of civil and political rights the protection of older people within the family unit would, as with the child, focus on issues of participation and capacity.

\section{$\underline{\text { Institutional }}$}

The example of "institutionalised ageism within legal frameworks" ${ }^{1139}$ and the invisibility of older people "as a group within the law" ${ }^{1140}$ set by the UDHR is entrenched in the ICCPR as it remains silent on age as a prohibited ground for derogation from rights ${ }^{1141}$ in addition to discrimination in entitlement. ${ }^{1142}$ The normative gap inherent in recognition before the law of older people is referred to Article 12 of the CRPD. In accordance with the approach of the CRPD, the requirement for older people is recognition of legal capacity, and provision of support which respects the right, will and preferences of the individual. ${ }^{1143}$

\section{Pathogenic}

The ICCPR offers protection against abuse and violence via prohibition of inhuman and degrading treatment. ${ }^{1144}$ Whilst protection extends to acts causing physical pain and mental

\footnotetext{
${ }^{1136}$ Article 23(1), ICCPR

${ }^{1137}$ Article 17, ICCPR

${ }^{1138}$ Article 24, ICCPR Assembly 5-7 May 2009, Bonn, Germany, 14 Assembly 5-7 May 2009, Bonn, Germany, 15

${ }^{1141}$ Article 4(1), ICCPR

${ }^{1142}$ Article 2(1), ICCPR

${ }^{1143}$ Article 12, UNCRPD

${ }^{1144}$ Article 7, ICCPR
}

1139 United Nations Department of Economic and Social Affairs Division for Social Policy and Development Programme on Ageing, Report of the Expert Group Meeting 'Rights of Older Persons' Convened in preparation for the report of the Secretary-General to the $64^{\text {th }}$ session of the General

${ }^{1140}$ United Nations Department of Economic and Social Affairs Division for Social Policy and Development Programme on Ageing, Report of the Expert Group Meeting 'Rights of Older Persons' Convened in preparation for the report of the Secretary-General to the $64^{\text {th }}$ session of the General 
suffering no definition is provided regarding specific prohibited acts. ${ }^{1145}$ The focus of the prohibition predominantly takes the form of punishment, ${ }^{1146}$ and thus has limited application to the situation of older people. However, parallels can be drawn between the negative effects of "prolonged solitary confinement" ${ }^{1147}$ and social isolation of older people. In addition, a case for the inclusion of isolation in a defined list of abuse would necessitate a right to freedom from the societal causes of the same. Thus, a degree of protection from the institutional vulnerability of society would be provided. Protection will also be advanced, given the nature of the abuse of older people reported in Chapter 10, and claims that "The key shortcoming of human rights law in protecting older people from violence and interference is...it fails to capture are the actions of both private sector bodies and private individuals, ${ }^{11148}$ by the inclusion of abuse by private actors. ${ }^{1149}$ For the achievement of more complete protection, the normative gap in protection of older people from vulnerability to abuse and violence is referred to the UNCRPD, which includes: identification of sources and causes of abuse; support for the victim and caregiver; and recovery of victim. ${ }^{1150}$

\subsubsection{International Covenant on Economic, Social and Cultural Rights}

Health

The interests of older people are partially met in the universal right to the highest attainable standard of physical and mental health. ${ }^{1151}$ The manifestation of the ageing process creates a need for complex healthcare provision. Co-morbidity of age-dependent, age-related, and communicable illness; universality of the "Geriatric Giants" and regional occurrence in types

\footnotetext{
${ }^{1145}$ UN Human Rights Committee (HRC), CCPR General Comment No. 20: Article 7 (Prohibition of Torture, or Other Cruel, Inhuman or Degrading Treatment or Punishment), 4-5, 10 March 1992, Adopted at the Forty-fourth Session of the Human Rights Committee ${ }^{1146}$ UN Human Rights Committee (HRC),CCPR General Comment No. 20: Article 7 (Prohibition of Torture, or Other Cruel, Inhuman or Degrading Treatment or Punishment), 5, 10 March 1992, Adopted at the Forty-fourth Session of the Human Rights Committee ${ }^{1147}$ UN Human Rights Committee (HRC), CCPR General Comment No. 20: Article 7 (Prohibition of Torture, or Other Cruel, Inhuman or Degrading Treatment or Punishment), 6, 10 March 1992, Adopted at the Forty-fourth Session of the Human Rights Committee ${ }^{1148}$ Lindsay Judge, 'The Rights of Older People: International Law, Human Rights Mechanisms and the Case for New Normative Standards,' December 2008, 8

${ }^{1149}$ UN Human Rights Committee (HRC), CCPR General Comment No. 20: Article 7 (Prohibition of Torture, or Other Cruel, Inhuman or Degrading Treatment or Punishment), 2, 10 March 1992, Adopted at the Forty-fourth Session of the Human Rights Committee ${ }^{1150}$ UNCRPD, Article 16 ${ }^{1151}$ Article 12(1), ICESCR
} 
of illness; and the effects of compression and extension of morbidity, ${ }^{1152}$ combine to create particular interests in the right. The normative aim, must, therefore, be to: prevent ill health and disability; preserve existing levels of health; provide curative, rehabilitation treatment; and care of the terminally ill. ${ }^{1153}$ Within this are requirements to maintain the functionality and autonomy of older people. ${ }^{1154}$ Moreover, limitation of accumulated disadvantage requires a preventative approach in all stages of life. ${ }^{1155}$ The particular vulnerabilities of older people generate further interests of accessibility. Therefore, aims also requiring normative representation in the right include the physical and economic accessibility to "health facilities, goods and services."1156 Physical accessibility, as detailed in CESCR general comment 14 , is necessary not simply to medical services but influences over health including water and sanitation. The CESCR also stresses charges for health care to respond directly to individual economic circumstance in order not to discriminate against socially disadvantaged groups. $^{1157}$

Referring to Fineman's thesis of dependency, the "inevitable vulnerability" to physical and mental decline is accompanied by "inevitable dependency" on, primarily, care and assistance to accomplish activities of daily living, ${ }^{1158}$ and economic assistance. Normative

${ }^{1152}$ Conditions are described in Chapter 9. Co-morbidity is the contraction of more than one illness or disease. Age-dependent illness or disease is that experienced as part of the ageing process. Agerelated illness or disease is most prevalent in older age. Communicable illness or disease can be contracted at any stage of life, however, has more morbid effects in later life. Compression of morbidity is the process whereby most co-morbidity is experienced in the very last years of life; extension of morbidity describes increased life expectancy with longer periods lived with illness or disability. See 9.3.2 'Co-morbidity, compression and expansion of morbidity in old age' 1153 UN Committee on Economic, Social and Cultural Rights (CESCR), General Comment No. 6: The Economic, Social and Cultural Rights of Older Persons, 8 December 1995 Adopted at the Thirteenth Session of the Committee on Economic, Social and Cultural Rights, on 8 December 1995, E/1996/22, 34-35

${ }^{1154}$ CESCR General Comment No. 14: The Right to the Highest Attainable Standard of Health (Art. 12) Adopted at the Twenty-second Session of the Committee on Economic, Social and Cultural Rights, on 11 August 2000 Document E/C.12/2000/4, 25

${ }^{1155}$ UN Committee on Economic, Social and Cultural Rights (CESCR), General Comment No. 6: The Economic, Social and Cultural Rights of Older Persons, 8 December 1995 Adopted at the Thirteenth Session of the Committee on Economic, Social and Cultural Rights, on 8 December 1995, E/1996/22, 34-35

${ }^{1156}$ CESCR General Comment No. 14: The Right to the Highest Attainable Standard of Health (Art. 12) Adopted at the Twenty-second Session of the Committee on Economic, Social and Cultural Rights, on 11 August 2000 Document E/C.12/2000/4, 12(b)

${ }^{1157}$ CESCR General Comment No. 14: The Right to the Highest Attainable Standard of Health (Art. 12) Adopted at the Twenty-second Session of the Committee on Economic, Social and Cultural Rights, on 11 August 2000 Document E/C.12/2000/4, 12(b)

${ }^{1158}$ See Chapter 10 for description of activities of daily living 
reference to such dependency is required of the right to the highest attainable standard of physical and mental health for the maintenance and promotion of health.

Existing normative provision of Article 12 responds in a limited way, by specifying "medical service...in the event of sickness." 1159 It is informative that special protection concentrates on the health of the youngest in society, with no recognition of other vulnerable groups. ${ }^{1160}$ However, the attainment of the highest standard of health is dependent on the success of numerous rights relevant to the standard of living and societal institutions. Therefore, the potential exists for normative gaps to be filled by the reading of rights in conjunction with one another. The most comprehensive individual right of the ICESCR in this regard is the right to an adequate standard of living. ${ }^{1161}$

\section{Adequate standard of living}

The right to an adequate standard of living differs from that of the UDHR in two distinct ways. Firstly, the central objective of attaining the highest standard of health is implicit, rather than directly stated, in the ICESCR right. Furthermore, the present right ${ }^{1162}$ overtly includes "the continuous improvement of living conditions," which featured as a matter for discussion in travaux preparatoires of the UDHR right. The right occupies a central role in the protection of older people as a group, therefore aspects of the normative provision regarding food and housing will be examined.

\section{$\underline{\text { Food }}$}

Direct reference is made to "the fundamental right of everyone to be free from hunger" within Article 11. The meaning given to the normative content of Article 11 with regard to food is stated by the CESCR as "physical and economic access at all times to adequate food ("sufficient to satisfy the dietary needs of individuals," ${ }^{1163}$ ) or means for its procurement.."1164

\footnotetext{
${ }^{1159}$ Article $12(2)(d)$, ICESCR

${ }^{1160}$ Article $12(2)(a)$, ICESCR ' $t$ t]he reduction of the stillbirth-rate and of infant mortality and for the healthy development of the child.'

${ }^{1161}$ Article 11, ICESCR

1162 Article 11(1), ICESCR

${ }^{1163}$ CESCR General Comment 12 (Twentieth session, 1999)The right to adequate food (art. 11), 8 E/C.12/1999/5

${ }^{1164}$ CESCR General Comment 12 (Twentieth session, 1999)The right to adequate food (art. 11), 6 E/C.12/1999/5
} 
With accessibility, rather than a lack of food, the main protagonist for hunger, ${ }^{1165}$ the Committee suggests implied interpretations of accessibility which have relevance to older people in the context of health and financial limitations. The first concern of the Committee is that food costs should not compromise the ability to afford other essential aspects of living standards. ${ }^{1166}$ Whilst not definitively stated under the heading of Article 11, the normative requirement is for inclusion in social security provision. The need to make adequate food, physically accessible to "elderly" people, as "vulnerable individuals" is recognised in the general comment. In addition, the Committee makes reference to victims of natural disasters in this regard. Combined, the most vulnerable of older people, including those subject to discriminatory humanitarian treatment during times of natural disaster as identified in chapter 10, would receive protection against hunger if included in the normative content of the right.

\section{Housing}

\section{Adequate housing}

Provision and adequacy of the housing component of the right to an adequate standard of living are fundamental to the vulnerabilities of older people to health and homelessness. Adequacy of housing for older people is dependent upon the inclusion of specific norms in special protection. The multifaceted permutation of vulnerabilities of the group require the right to housing to comprise "...more than a mere shelter." ${ }^{1167}$ Objectives of the right for older people are complex. Initially, the aim is to lessen the inevitable dependency proposed in Fineman's thesis of vulnerability as accompanying inevitable ontological embodied vulnerability. ${ }^{1168}$ Additionally, stated norms, if framed around successful ageing, would stipulate the requirement for the residence to enable functions of daily living, support

${ }^{1165}$ CESCR General Comment 12 (Twentieth session, 1999)The right to adequate food (art. 11), 5 E/C.12/1999/5

${ }^{1166}$ CESCR General Comment 12 (Twentieth session, 1999)The right to adequate food (art. 11), 13 E/C.12/1999/5

${ }^{1167}$ United Nations, 'The Vienna International Plan of Action on Aging' adopted by the World Assembly on Aging held in Vienna, Austria from 26 July to 6 August 1982 ,Recommendation 19 ${ }^{1168}$ Fineman's thesis of vulnerability identifies two types of dependency. Inevitable dependency, and that referred to at this point, accompanies the inevitable embodied ontological vulnerability of old age. Derived dependency refers to the dependency of those involved in the care of the inevitably dependent older person. See 5.3.2.2 'Fineman's Thesis' 
abilities and needs of the individual. Accessibility to the community and facilities is required for fundamental needs and all forms of participation. ${ }^{1169}$

The UNCESCR refers explicitly to the definition provided by the Commission on Human Settlements and the Global Strategy for Shelter to the Year 2000 for direction in settling a normative standard of "adequacy" regarding housing, providing for an affordable, healthy living space accessible to community, facilities, and services. ${ }^{1170}$ Further guidance for normative provision for the right to adequate housing is contained within the general comment of direct relevance to vulnerabilities of older people. Inclusion of security of tenure ${ }^{1171}$ aims to protect owners, tenants, and occupiers of property from forced eviction. However, older people, in particular older women, have been demonstrated to remain victims of homelessness due to discriminatory practices relating to property ownership; the normative stipulation of non-discrimination in Articles 2.2 and 3 of the ICESCR ${ }^{1172}$ proving inadequate to prevent it.

The principles of accessibility associated to the right to food are essential also to adequate housing. The instruction to make adequate housing available to disadvantaged groups is explicitly inclusive of "the elderly," which combined with the instruction for affordability ${ }^{1173}$ and adaptation of housing to function needs ${ }^{1174}$ also enables the older person to live at home for as long as possible.

${ }^{1169}$ United Nations, 'The Vienna International Plan of Action on Aging' adopted by the World Assembly on Aging held in Vienna, Austria from 26 July to 6 August 1982 , Recommendation 22 1170 'Adequate shelter means ... adequate privacy, adequate space, adequate security, adequate lighting and ventilation, adequate basic infrastructure and adequate location with regard to work and basic facilities - all at a reasonable cost.' UN Committee on Economic, Social and Cultural Rights (CESCR),General Comment No. 4: 'The Right to Adequate Housing (Art. 11 (1) of the Covenant),' 13 December 1991,E/1992/23, 7

${ }^{1171}$ With tenure meaning 'rental (public and private) accommodation, cooperative housing, lease, owner-occupation, emergency housing and informal settlements, including occupation of land or property' CESCR General Comment No. 4: The Right to Adequate Housing (Art. 11 (1) of the Covenant) Adopted at the Sixth Session of the Committee on Economic, Social and Cultural Rights, on 13 December 1991 (Contained in Document E/1992/23) 8(a)

${ }^{1172}$ General comment No. 7: The right to adequate housing (art. 11 (1) of the Covenant): Forced evictions, 10 Sixteenth session (1997)

${ }^{1173}$ CESCR General Comment No. 4: The Right to Adequate Housing (Art. 11 (1) of the Covenant) Adopted at the Sixth Session of the Committee on Economic, Social and Cultural Rights, on 13 December 1991 (Contained in Document E/1992/23) 8(c)

${ }^{1174}$ CESCR General Comment No. 6: The Economic, Social and Cultural Rights of Older Persons Adopted at the Thirteenth Session of the Committee on Economic, Social and Cultural Rights, on 8 December 1995 (Contained in Document E/1996/22), 33 


\section{Poverty}

The interconnected nature of vulnerability and the principle of inevitable dependency, described in Chapter $5{ }^{1175}$ are evident in the causes of poverty among older people identified in the Report of the Independent Expert on Human Rights and Extreme Poverty. Situations of vulnerability detailed in "Research of Older People" in Part III are collectively cited as "core factors" of poverty for older people: "lack of access to regular income and work and health care, declining physical and mental capacities, and dependency within the household."1176

The vulnerability of older people to poverty is dependent upon a combination of rights to protect the interests of the group. The "opportunity to gain his living by work which he freely chooses or accepts"1177 is not universally fulfilled. In response, detailed normative provision is required to protect older people against the influences of devaluation of skills ${ }^{1178}$ and stereotypes of inability to be "productively useful.."1179 Difficulties of gaining and maintaining employment commensurate with ability ${ }^{1180}$ would be addressed by inclusion of the following in the right: access to training and retraining; ${ }^{1181}$ employment of choice in public and private sectors; ${ }^{1182}$ access to promotion; ${ }^{1183}$ and equality of remuneration. ${ }^{1184}$ Further defence against vulnerability to poverty requires rights to voluntary retirement ${ }^{1185}$ and flexibility in qualifying ages for old-age pension. ${ }^{1186}$

\footnotetext{
${ }^{1175}$ See 5.3.1.4 'The interconnected Framework'; 5.3.2.2 'Fineman's Thesis'

${ }^{1176}$ Magdalena Sepulveda, 'Report of Independent Expert on Human Rights and Extreme Poverty, Rapporteur,' 15, UNGA HRC $14^{\text {th }}$ session Agenda item 3, 'Promotion and protection of all human rights, civil, political, economic, social and cultural rights, including the right to development,' 31 March 2010

${ }^{1177}$ Article 6, ICESCR

${ }^{1178}$ This key aspect of Modernisation Theory is described in 8.2.1.1 'Industrialisation and the effects on older people'

${ }^{1179}$ This key aspect of Productivity Theory is described in 8.3.1 'Productivity as 'usefulness"

${ }^{1180}$ As explained in Chapter 10

${ }^{1181}$ International Labour Organization R162-Older Workers Recommendation, 1980 (162) 5(b)(ii)

1182 International Labour Organization R162-Older Workers Recommendation, 1980 (162) 5(b)(i)

1183 International Labour Organization R162-Older Workers Recommendation, 1980 (162) 5(b)(iv)

1184 International Labour Organization R162-Older Workers Recommendation, 1980 (162) 5(b)(d)

1185 International Labour Organization R162-Older Workers Recommendation, 1980 (162) 21(a)

${ }^{1186}$ International Labour Organization R162-Older Workers Recommendation, 1980 (162) 21(b)
} 
Defence against vulnerability to poverty is also reliant on "the right of everyone to social security, including social insurance." ${ }^{\prime 1187}$ Poverty statistics and circumstances of older people detailed in Chapter $10^{1188}$ present the case for explicit normative standards to replace the implicit equating of "social insurance" with old age benefits. Inclusivity as discussed in Chapter 9 is relevant in this regard. Setting a ceiling on the age at which old-age benefits are paid extends protection; the maximum age of 65 , with flexibility to be lowered in situations, inter alia, of unhealthy working environment, ${ }^{1189}$ is proposed for inclusion in the right by this thesis. To further achieve inclusivity and equal access to norms embodied in rights essential for successful ageing, ${ }^{1190}$ the recommendation by the ILO $^{1191}$ and CESCR ${ }^{1192}$ for compulsory State provision of old-age social insurance is proposed by this thesis for inclusion in the right. In addition, the inclusion of an obligation for States parties to

provide non-contributory old-age benefits and other assistance for all older persons...reaching the age prescribed in national legislation...not entitled to an oldage pension or other social security benefit or assistance and have no other source of income $^{1193}$

would serve to lessen the normative gap.

The special case of poverty among older women necessitates bespoke protection. It is informative that recognising "the equal right of men and women to the enjoyment of all

${ }^{1187}$ Article 9, ICESCR 'The States Parties to the present Covenant recognize the right of everyone to social security, including social insurance.'

${ }^{1188}$ See Chapter 10

${ }^{1189}$ Article 26(2), International Labour Organization C102-Social Security (Minimum Standards) Convention, 1952 (No 102); Article 15(2)(3), International Labour Organization C-128 Invalidity, OldAge and Survivors' Benefits Convention, 1967 (No. 128)

${ }^{1190}$ Including, but not limited to: adequate standard of living; highest attainable standards of health; and participation. See 8.1 for definition and description of model of Successful Ageing.

${ }^{1191}$ International Labour Organization C102-Social Security (Minimum Standards) Convention, 1952 (No 102); International Labour Organization C-128 Invalidity, Old-Age and Survivors' Benefits Convention, 1967 (No. 128)

${ }^{1192}$ UN Committee on Economic, Social and Cultural Rights (CESCR),General Comment No. 6: The Economic, Social and Cultural Rights of Older Persons, 8 December 1995 Adopted at the Thirteenth Session of the Committee on Economic, Social and Cultural Rights, on 8 December 1995, E/1996/22, 27

${ }^{1193}$ UN Committee on Economic, Social and Cultural Rights (CESCR), General Comment No. 6: The Economic, Social and Cultural Rights of Older Persons, 8 December 1995 Adopted at the Thirteenth Session of the Committee on Economic, Social and Cultural Rights, on 8 December 1995, E/1996/22, 30 
economic, social and cultural rights"1194 has not saved the vulnerability experience of older women. Referring specifically to instances in which this sub-group suffering aggravated discrimination receive neither survivor benefit nor social security, ${ }^{1195}$ revision of normative content is proposed. To combat justification of this practice on the basis of nonproductivity, an obligation to provide "adequate support" for women is essential. The Proclamation on Ageing argues the case on grounds of "productive ageing," described in Chapter 8. Special protection should heed the observation made in the Proclamation on Ageing of the "largely unrecognized contributions to the economy and the well-being of society" made by women as deserving of "adequate support" ${ }^{1196}$ Those reliant upon spousal support would require a right to old age benefit payments. ${ }^{1197}$

\section{Emplacement}

The theoretical principle of "emplacement", proposed by Turner, ${ }^{1198}$ and adopted by this thesis, is sustained by the Vienna International Plan of Action on Aging. The effects of comorbidity, decrepitude, abandonment, loss of productive status and traditional family practices, negative stereotyping, disengagement, and isolation combine to make the home "the Centre of virtually all of [older peoples'] activities."1199 The specific threat which vulnerability of security of emplacement causes to the psychological and physical health, mortality, and engagement of older people contributes to the normative objective that they remain at home, to enable life to be lived in the place of choice for as long as possible. ${ }^{1200}$

\footnotetext{
${ }^{1194}$ Article 3, ICESCR

1195 See Chapter 10

${ }^{1196}$ Proclamation on Ageing 2(h)

${ }^{1197}$ Article 21(1), International Labour Organization C-128 Invalidity, Old-Age and Survivors' Benefits Convention, 1967 (No. 128); Article 60(1), International Labour Organization C102-Social Security (Minimum Standards) Convention, 1952 (No 102)

1198 'Emplacement' is described by Turner in Chapter 5 as 'the place where life is lived.,' and modified by this thesis to include not merely the residence, but the family also. Older people become vulnerable to loss of both. Given the nature of the ageing process and experiences of ageing defined in Theories of Ageing (Chapter 8) more of life is lived in the residence, making the right to housing key to 'emplacement.'

${ }^{1199}$ United Nations, 'The Vienna International Plan of Action on Aging' adopted by the World Assembly on Aging held in Vienna, Austria from 26 July to 6 August 1982 ,64

${ }^{1200}$ This point is also recognised by the CESCR. UN Committee on Economic, Social and Cultural Rights (CESCR), 'General Comment No. 6: The Economic, Social and Cultural Rights of Older Persons,' 8 December 1995 Adopted at the Thirteenth Session of the Committee on Economic, Social and Cultural Rights, on 8 December 1995, E/1996/, 33
} 
In accordance with the principles of emplacement, and recognition by the ICESCR that the family unit is the fundamental unit of society, intergenerational strengthening, in response to cultural values and autonomy, should be included in the normative rights protecting against vulnerability to security of "place." The primary means of maintaining the "family" element of emplacement is the enablement of the practice filial obligation. Therefore, social security provision is required to include support for family members wishing to provide support and care of older family members, and for older people living alone or as couples, wishing to remain at home. ${ }^{1201}$ Such provision would also protect carers of older people against vulnerability to "derived dependency," posited by Fineman as the result of being unable to support oneself due to responsibilities associated with caring. ${ }^{1202}$

\subsubsection{The Convention on the Rights of Persons with Disabilities}

The intention of the drafters was to facilitate widespread accessibility to the special protection of rights and interests offered by the UNCRPD. In accordance with Article $1^{1203}$ of the Convention, protection extends to any person suffering disability and vulnerabilities of enselfment. Furthermore, the Convention explicitly recognises "age" amongst grounds for aggravated discrimination experienced by people with disabilities. ${ }^{1204}$ Therefore, older people with disabilities have access to the special protection offered in addition to generic human rights instruments. The distinction between older people with and without disabilities is a significant one to draw, particularly since many of the special protections included in the instrument are of relevance, but not available to, non-disabled older people. $^{1205}$ Rights which normatively respond to the interests and vulnerabilities of older people per se will be included in this examination of the UNCRPD for purposes of informing the content of special protection for the group.

\footnotetext{
${ }^{1201}$ UN Committee on Economic, Social and Cultural Rights (CESCR), General Comment No. 6: The Economic, Social and Cultural Rights of Older Persons, 8 December 1995 Adopted at the Thirteenth Session of the Committee on Economic, Social and Cultural Rights, on 8 December 1995, E/1996/22, 31; VIPAA, Recommendation 29 ${ }^{1202}$ See 5.3.2.2 'Fineman's Theory'

1203 '[p]ersons with disabilities include those who have long-term physical, mental, intellectual or sensory impairments which in interaction with various barriers may hinder their full and effective participation in society on an equal basis with others.' Article 1, UNCRPD

${ }^{1204}$ Preamble ( $\left.p\right)$, UNCRPD

${ }^{1205}$ Arlene S Kanter, 'The United Nations Convention on the Rights of Persons with Disabilities and its Implications for the Rights of Elderly People Under International Law' Georgia State University Law Review, Vol. 25 Issue 3, Spring 2009, Article 4, 527, 555
} 
The UNCRPD offers a form of protection pertinent to all vulnerable groups. In adopting the social model of disability, the Convention views society, rather than the disability, as the cause of discriminatory treatment. ${ }^{1206}$ Changing the societal perception of disability serves, in part; to benefit older people suffering the effects of negative stereotyping and discrimination discussed in theories of ageing and experiences of vulnerability in Part II. However, earlier discussion and research has demonstrated harmful societal attitudes towards older people to reach beyond disability. Therefore, all forms of special protection provided for the group would benefit from such an approach.

The UNCRPD does not categorically state age as a prohibited ground for discrimination, however, concern is raised for "aggravated discrimination" experienced by the person with disabilities on the basis of, inter alia, age. ${ }^{1207}$ The Convention develops this point further via the need to raise awareness of aggravated negative stereotyping and harmful practices against disabled people also discriminated by age. ${ }^{1208}$ It is informative that the UNCRPD expands on the generic definition of discrimination by including any denial of the notion of "reasonable accommodation;" an equality tool aimed at "strengthening protection against discrimination" on a case-by-case basis and in response to concrete situations, "without imposing a disproportionate burden" on the State. ${ }^{1209}$ The underlying principle can be allied to the ideal of not providing equal treatment, ${ }^{1210}$ but equality in opportunity, despite the severity of individual vulnerability and lack of capabilities. ${ }^{1211}$ That concrete situations might be improved in order to enable the application of rights, or that special protection rights might be adapted in accordance with vulnerability, is an ideal transferable from the CRPD to a special protection instrument for older people.

\footnotetext{
${ }^{1206}$ Arlene S Kanter, 'The United Nations Convention on the Rights of Persons with Disabilities and its Implications for the Rights of Elderly People Under International Law' Georgia State University Law Review, Vol. 25 Issue 3, Spring 2009, Article 4, 527, 551

${ }^{1207}$ CRPD, Preamble $(p)$

${ }^{1208}$ CRPD, Article 8(1)(b) 'Awareness raising'

${ }^{1209}$ Marianne Hirschbert and Christian Papadopoulos “Reasonable Accommodation' and 'Accessibility': Human Rights Instruments Relating to Inclusion and Exclusion in the Labor Market,' 'Societies' 16 Jan 2016, 6,3, 9-10 www.mdpi.com/2075-4698/6/1/3/pdf accessed 10/05/2017; UNCRPD, Article 2

${ }^{1210}$ See 6.2.2.4 'Thresholds of Capabilities'

${ }^{1211}$ See 6.2.2.1 'Basic, internal and combined capabilities'
} 


\section{Embodied Vulnerability}

\section{Standard of Living}

Unlike the UDHR, the UNCRPD does not explicitly state health as an aim of the right to an adequate standard of living. ${ }^{1212}$ However, the components remain the same. ${ }^{1213}$ Thus adequacy in all would similarly contribute to the health of the individual. Notably, the right becomes one to adequate standard of living and social protection, with older people specifically included in the right to the latter. Following the example of the UDHR, the Convention states the right to access by "older persons with disabilities" to social protection and poverty reduction programmes. ${ }^{1214}$ The "vicious cycle of poverty and disability, each a cause and consequence of the other,"1215 is, therefore, acknowledged as a particular threat to older people, comprising a disadvantaged sector of people with disabilities. Whilst not directly identified in further subsections of Article 28, provisions of the right precisely address vulnerabilities and dependencies experienced by older people.

Poverty is a theme of the right as access to retirement ${ }^{1216}$ and disability-related State benefits ${ }^{1217}$ is included. If actively inclusive of older people, the normative content of Article 28 , which provides for assistance to families "living in situations of poverty," ${ }^{1218}$ is able to respond to derivative dependency of carers, explained in Chapter 5 as institutional dependence of the person caring for the inevitably dependent individual. ${ }^{1219}$ Additionally, the inability, rather than unwillingness, to perform filial obligation, described by ageing theories ${ }^{1220}$ and the associated lack of financial, social, and health care available to older people could be alleviated. ${ }^{1221}$

\footnotetext{
${ }^{1212}$ Article 28, UNCRPD

${ }^{1213}$ Including adequate food, clothing and housing, and clean water

${ }^{1214}$ Article 28(1)(b), UNCRD

${ }^{1215}$ Arlene S Kanter, 'The United Nations Convention on the Rights of Persons with Disabilities and its Implications for the Rights of Elderly People Under International Law' Georgia State University Law Review, Vol. 25 Issue 3, Spring 2009, Article 4, 527, 566

${ }^{1216}$ Article 25(1)(e), UNCRPD

${ }^{1217}$ Article 25(1)(c), UNCRPD

${ }^{1218}$ Article 28(2)(b), UNCRPD

${ }^{1219}$ Inevitable dependency is the form of dependency born of inevitable vulnerability, itself defined as the biological vulnerability experienced at the polar ends of life. Derived dependency is that established in the person caring for the inevitably dependent person. Derived dependency relies on institutional, largely financial, support. See 5.3.2.2 'Fineman's Thesis'

${ }^{1220}$ See 8.2.2.1 'Filial Obligation'

${ }^{1221}$ Article 25(1)(c), UNCRPD
} 
$\underline{\text { Health }}$

The right to the highest attainable standard of health in the UNCRPD makes explicit provision for older people under the subsection "health services needed...specifically because of their disabilities." ${ }^{1222}$ However, the possibility also exists for a normative gap in the provision of healthcare not specifically related to said disability.

Further protection against "inevitable vulnerability" provided by Article 25, addresses issues of accessibility and participation; also of relevance to older people. Furthermore, the principles involved have broad application to international human rights of older people as a group. Norms of accessibility include equality with others to availability, quality and standard of free or affordable health care; geographical accessibility; and discrimination on the basis of disability. Prohibition on the basis of disability of provision of health care, security or insurance provides no protection to older people where such discrimination, in addition to the denial of freely available medication is proven practice. ${ }^{1223}$ Furthermore, older people living in rural areas are not better served by access to health services as a result of disability than older people without disability, despite the provision in Article 25 that health services for people with disabilities be located "as close as possible to people's own communities, including rural areas." ${ }^{1224}$ The situation of older people in rural areas of developing countries particularly reflects the abandonment hypothesis of Modernisation Theory, discussed in Chapter 8, and recognised in the Madrid International Plan of Action on Ageing. The plan reports aggravated forms of abandonment in rural areas comprising physical, and care and support. ${ }^{1225}$ The State can be viewed as mirroring this treatment when medical services are not accessible in remote areas.

\footnotetext{
${ }^{1222}$ Article 25(b), UNCRPD

${ }^{1223}$ Health insurance is unavailable to older people in many parts of the developing world, practice in the Philippines provided such an example in research of experiences of vulnerability of older people in Part III. Older women are particularly at risk of denial of health and social insurance.

Article 25(e) prohibits 'discrimination against persons with disabilities in the provision of health insurance, and life insurance where such insurance is permitted by national law, which shall be provided in a fair and reasonable manner.' Article $25(\mathrm{f})$ prohibits 'discriminatory denial of health care or health services or food and fluids on the basis of disability.'

${ }^{1224}$ Article 25(c), UNCRPD.

1225 Older people in rural areas are physically abandoned as a result of migration of family members to industrial areas, and abandoned in terms of support and care. Issue 3.29, Political Declaration and Madrid Internal Plan of Action on Ageing, 8-12 April 2002, United Nations, New York.
} 
The inclusion of participation in Article 25 places the disabled person at the centre of the decision-making and objective-setting process regarding healthcare and treatment. ${ }^{1226}$ This approach, if extended to older people as part of the group of people with disabilities, has relevance to the considerations of capacity in the construction of human rights of older people generally.

\section{$\underline{\text { Emplacement }}$}

The normative expression of the right to live independently and be included in the community serves to protect some of the vulnerabilities associated with emplacement experienced by older people. In order to prevent enforced institutionalisation, Article 19 states people with disabilities "are not obliged to live in a particular living arrangement." With the choice of "place of residence and where and with whom" a person lives, ${ }^{1227}$ risks to emplacement are lessened. The right to access to support in response to the inevitable dependency accompanying inevitable vulnerability included in Article $19^{1228}$ reduces the need for removal from the "place where life is lived,"1229 thereby protecting the emplacement of the individual. Moreover, the right partially contributes to the interpretation of the right to liberty for older people ${ }^{1230}$ facing policies prioritising institutionalisation over community support. ${ }^{1231}$

The right to respect for home and the family ${ }^{1232}$ is directed at rights to marry and found a family, ${ }^{1233}$ and comprehensively at the needs and protection of children with disabilities. ${ }^{1234}$ The needs of older people with disabilities relating to family are not included in Article 23. However, vulnerabilities relating to emplacement, the psychological and physical self can be eased by adopting an approach similar to that of children. The "equal rights...to family life...and to prevent concealment, abandonment, neglect and segregation of children with

\footnotetext{
${ }^{1226}$ Article 25(d), UNCRPD

${ }^{1227}$ Article 19(a), UNCRPD

${ }^{1228}$ Article 19(b), UNCRPD

${ }^{1229}$ See definition of 'emplacement,' in 5.3.1.1 'Embodied Vulnerability'

${ }^{1230}$ Combining the right to movement and the right to a family life

${ }^{1231}$ Arlene S Kanter, 'The United Nations Convention on the Rights of Persons with Disabilities and its Implications for the Rights of Elderly People Under International Law' Georgia State University Law Review, Vol. 25 Issue 3, Spring 2009, Article 4, 527, 565

${ }^{1232}$ Article 23 UNCRPD

${ }^{1233}$ Article 23(1) UNCRPD

${ }^{1234}$ Article 23(2) UNCRPD
} 
disabilities"1235 requires provision of services and support. Furthermore, the right to home and family can extend to wider family when the immediate family is unable to care for a child with disabilities. ${ }^{1236}$ Inclusion of older people with disabilities in such a right would protect against vulnerabilities of emplacement and associated socially constructed embodied vulnerabilities related to abandonment, lone living, disengagement, and loss of relationships.

$\underline{\text { Institutional Vulnerability }}$

The approach of the UNCRPD to equal recognition before the law addresses capacity. With capacity a major vulnerability encountered by older people, exemplified in part by the threat of dementia detailed in Chapter 9, ${ }^{1237}$ the treatment of the right has far reaching implications for older people. Normative objectives focus on achieving "legal capacity on an equal basis with others in all aspects of life" by means of support, rather than complete transferral of the exercise of capacity to a third party. ${ }^{1238}$ Realisation of the same is stated as necessitating prevention of interference with will and preferences, and exercise of undue influence over the incapacitated person. ${ }^{1239}$ In a review of the implications of the UNCRPD for older people, Kanter rationalised this supportive approach on the basis of negating the risks of pathogenic vulnerabilities of neglect and abuse, and the emplacement vulnerability of institutionalisation for individuals lacking capacity. ${ }^{1240}$

\subsubsection{Convention on the Elimination of All Forms of Discrimination Against Women}

As a Convention of special protection, the objective of CEDAW is to protect the interests of women in human rights, and specifically to achieve gender equality in rights. Nonetheless, and in similar vein to the CRPD, reference is made to older women in normative provision of the instrument in rights specific to particular vulnerabilities of the sub-group. Therefore, this chapter relies largely on the comments of CEDAW General Recommendation No. 27 for guidance as to normative provision.

\footnotetext{
1235 Article 23(3) UNCRPD

${ }^{1236}$ Article 23(5) UNCRPD

${ }^{1237}$ See 9.2.3 'Cognitive Disease'

${ }^{1238}$ Article 12(2)(3), UNCRPD

1239 Article 12(4) UNCRPD

${ }^{1240}$ Arlene S Kanter, 'The United Nations Convention on the Rights of Persons with Disabilities and its Implications for the Rights of Elderly People Under International Law' Georgia State University Law Review, Vol. 25 Issue 3, Spring 2009, Article 4, 527, 560
} 


\section{Embodied Vulnerability}

\section{Physiological Vulnerability}

\section{$\underline{\text { Health }}$}

The Convention aims to provide gender equality in access to healthcare per Article $12,{ }^{1241}$ extending the right to women living in rural areas in Article $14 .{ }^{1242}$ Gender-specific healthcare is provided in relation to pregnancy only. ${ }^{1243}$ Therefore, with regard to type of healthcare the right fails to serve the most vulnerable of women. CEDAW General Recommendation No. 27 aims to supplement the normative provision of the Convention with regard to access and type of healthcare available to older women. The Recommendation recognises the disproportionate reduction in age-related care for women in age-related and gender-specific care and long-term care. ${ }^{1244}$ Furthermore, the propensity for exclusion from State-funded health schemes and lack of health insurance is noted. ${ }^{1245}$ As a result, the Committee states the need for a right to affordable and accessible health care for all geriatric illness and gender-specific illnesses of old age. ${ }^{1246}$ The right should include physical, mental, and emotional health; ${ }^{1247}$ long-term; and palliative health care. The right to give free and informed consent to healthcare is stated as a requirement of normative provision for older women. ${ }^{1248}$

\section{Poverty}

Life-course discrimination in rights to equal payment and entitlement to pensions and social security generates greater vulnerability to poverty amongst older women. CEDAW aims to rectify the life-course accumulated disadvantage via the provision of equality in skills-related

\footnotetext{
${ }^{1241}$ Article 12(1), CEDAW

1242 Article 14(b), CEDAW

1243 Article 12(2), CEDAW

1244 CEDAW General Recommendation No. 27 on older women and protection of their human rights, 12, 16 December 2010 CEDAW/C/GC/27

1245 CEDAW General Recommendation No. 27 on older women and protection of their human rights, 21, 16 December 2010 CEDAW/C/GC/27

${ }^{1246}$ CEDAW General Recommendation No. 27 on older women and protection of their human rights, 45, 16 December 2010 CEDAW/C/GC/27

${ }^{1247}$ CEDAW General Recommendation No. 27 on older women and protection of their human rights, 46, 16 December 2010 CEDAW/C/GC/27

1248 CEDAW General Recommendation No. 27 on older women and protection of their human rights, 45, 16 December 2010 CEDAW/C/GC/27
} 
employment opportunity; payment; and training. ${ }^{1249}$ The single direct reference to the situation of older women in Article 11 (employment) states the right to social security in retirement. ${ }^{1250}$ The Committee recommends specific inclusions in normative provision for older women. The sub-group of vulnerable older people should have the right to participate in paid work without discrimination on the basis or either age or gender, and freedom from forced retirement. ${ }^{1251}$ Furthermore, retirement age and pension provision must be stated as gender-equal. ${ }^{1252}$ The Committee addresses the position of older women as carers, or have been unable to secure employment during the life-course. Rights to social benefits for carers, ${ }^{1253}$ and non-contributory State pensions must be available to older women. ${ }^{1254}$

\section{Participation}

Both the Convention and the Committee make no further normative provision for older women beyond the generally stated right to gender equality in Article 4(1) of CEDAW.

\section{Personal Development}

The CEDAW Committee recommends the content of rights to development should stipulate the full development and advancement of women throughout the life-course in order to protect against vulnerability to accumulated disadvantage in old age. ${ }^{1255}$

\section{Emplacement}

The CEDAW Committee corrects significant normative gaps in rights provision with regard to vulnerabilities of emplacement. The right to social security is stated as including the right to social and economic benefits for older women caring for elderly relatives, ${ }^{1256}$ which would

\footnotetext{
1249 Article 11(1), CEDAW

${ }^{1250}$ Article 11(1)(e), CEDAW

${ }^{1251}$ CEDAW General Recommendation No. 27 on older women and protection of their human rights,

41, 16 December 2010 CEDAW/C/GC/27

1252 CEDAW General Recommendation No. 27 on older women and protection of their human rights, 42, 16 December 2010 CEDAW/C/GC/27

${ }^{1253}$ CEDAW General Recommendation No. 27 on older women and protection of their human rights, 43, 16 December 2010 CEDAW/C/GC/27

${ }^{1254}$ CEDAW General Recommendation No. 27 on older women and protection of their human rights, 44, 16 December 2010 CEDAW/C/GC/27

${ }^{1255}$ CEDAW General Recommendation No. 27 on older women and protection of their human rights, 30, 16 December 2010 CEDAW/C/GC/27

${ }^{1256}$ CEDAW General Recommendation No. 27 on older women and protection of their human rights, 43, 16 December 2010 CEDAW/C/GC/27
} 
contribute to a right to live where and with whom one chooses. Additionally, normative provision must be made for the right to inherit and own property and land, ${ }^{1257}$ a right which would protect against vulnerability to homelessness of older women in traditional societies.

\section{$\underline{\text { Institutional }}$}

\section{$\underline{\text { Non-Discrimination }}$}

Both the Convention and the Committee make no further normative provision for older women beyond the generally stated right to gender equality in Article 4(1) of CEDAW

\section{Legal}

The Convention states gender equality before the $\operatorname{law}^{1258}$ and in legal capacity ${ }^{1259}$ in the normative provision of Article 15. Special normative protection for older women is limited to redress for the infringement of rights, and against discrimination of legal capacity on grounds of age or gender by means of the General Recommendation No. $27 .{ }^{1260}$

\section{Pathogenic}

The Convention is silent on the issue of abuse and violence against women. However, the General Recommendation refers to the need for protection against violence in domestic and institutional settings, and sexual violence against older women. Moreover, issues of cultural relativity would be protected against with the inclusion of abuse and violence founded in traditional practices and beliefs. ${ }^{1261}$ Additionally, a right to property and land ownership would protect older women against abuse and violence associated with homelessness. ${ }^{1262}$

${ }^{1257}$ CEDAW General Recommendation No. 27 on older women and protection of their human rights, 48, 16 December 2010 CEDAW/C/GC/27

1258 Article 15(1), CEDAW

1259 Article 15(2), CEDAW

${ }^{1260}$ CEDAW General Recommendation No. 27 on older women and protection of their human rights, 34, 16 December 2010 CEDAW/C/GC/27

${ }^{1261}$ CEDAW General Recommendation No. 27 on older women and protection of their human rights, 37, 16 December 2010 CEDAW/C/GC/27

1262 CEDAW General Recommendation No. 27 on older women and protection of their human rights, 52, 16 December 2010 CEDAW/C/GC/27 


\subsection{Selected Regional Human Rights Instruments}

Normative gaps identified in the protection against vulnerability of older people resulting from the examination of the International Bill of Rights are provided for, to some degree, in a range of regional human rights instruments. The relevant rights aiming at providing special protection against specific vulnerabilities, and the guidance available for a set of rights for the group, are explored below.

Of the regional instruments examined, age was also excluded as a basis for not discriminating against individuals and groups in the principal human rights instruments of Africa and the Americas. Age is absent from the African Charter on Human and Peoples' Rights; American Convention on Human Rights; Inter-American Declaration of Principles on Freedom of Expression; and Protocol of San Salvador regarding discrimination and entitlement. Regional instruments not silent on age in this context are the Andean Charter and the Association of Southeast Asian Nations ${ }^{1263}$ Declaration. The Andean Charter couples grounds for non-discrimination with intolerance, ${ }^{1264}$ thereby addressing issues of negative stereotyping, also considered a form of group identification of older people. ${ }^{1265}$ The ASEAN Declaration chooses the approach of making no "distinction of any kind" between people when stating entitlement to rights, whilst also overtly including age in a comprehensive listing of grounds. ${ }^{1266}$

The fact that older people are not explicitly protected from discrimination can, to varying degrees, be compensated for by direct inclusion and reference to special protection in rights. Examination of the regional instruments found the Banjul Charter to incorporate Turner's thesis of embodied vulnerability, which includes all aspects of the being, in the broad statement that "the aged and the disabled shall also have the right to special measures of protection in keeping with their physical or moral needs." ${ }^{1267}$

The Protocol of San Salvador explicitly recognises the need of older people for special protection. The "consequences of old age" is stated as the rationale for emphasising the right of older people to social security, as physical and mental incapacity is recognised. Furthermore, the effects of loss of social security benefits by dependents, including old age

\footnotetext{
${ }^{1263}$ Hereafter referred to as ASEAN

${ }^{1264}$ The Andean Charter, Article 10

1265 See 8.6 'Self-Perception Theory'

${ }^{1266}$ ASEAN Human Rights Declaration (2012), General Principle 2

1267 The African Charter on Human and Peoples' Rights (1981) Article 18(4)
} 
dependents are overcome by the right to the social security of the deceased. ${ }^{1268}$ Moreover, in compliance with comments from the Inter-American Commission on Human Rights, the instrument is alone in providing the right to "protection of the elderly." 1269 The recommendation initially stated to "include certain relevant groups...that have not yet been the object of international protection in the area of human rights such as the elderly...often they are obliged to live under seriously unprotected conditions." ${ }^{1270}$ The comment insisted as an "especially vulnerable group...they must receive priority attention." ${ }^{1271}$ The right created in response $\mathrm{e}^{1272}$ is definitive that "Everyone has the right to special protection in old age," with a focus on vulnerabilities related to existence, health, productivity, status and independence. The non-productive group identity of Productivity Ageing Theory is addressed with "the opportunity to engage in a productive activity suited to their abilities and consistent with their vocations or desires."1273 The final contribution towards successful ageing ${ }^{1274}$ comprised encouragement of engagement, ${ }^{1275}$ as States are asked to "Foster the establishment of social organizations aimed at improving the quality of life for the elderly." ${ }^{\prime 276}$ The method of providing opportunity "suited to...ability and consistent with...vocations or desires" complies also with freedom to determine the direction of life. ${ }^{1277}$ In placing the obligation on the State to make this right available to older people "unable to provide for themselves" a Capabilities Approach is adopted.

The inclusion by the Andean Charter of age in non-discrimination and tolerance requirements is extended to groups of older people made additionally vulnerable by

\footnotetext{
${ }^{1268}$ Additional Protocol to the American Convention on Human Rights in the Area of Economic, Social and Cultural Rights 'Protocol of San Salvador' Article 9(1)

${ }^{1269}$ Additional Protocol to the American Convention on Human Rights in the Area of Economic, Social and Cultural Rights 'Protocol of San Salvador' Article 17

1270 Inter-Am. C.H.R., 137-144 Ann. Rep. 1983-4, OEA/Ser. P/L/II.63, doc. 10 (1984), (as cited in Diego Rodriguez-Pinzon \& Claudia Martin, 'The International Law Status of Elderly Persons,' American University International Law Review (AM. U. INT'L L. REV.) 2003 Vol.18, Issue 4, 995)

1271 Inter-Am. C.H.R., 137-144 Ann. Rep. 1983-4, OEA/Ser. P/L/II.63, doc. 10 (1984), (as cited in Diego Rodriguez-Pinzon \& Claudia Martin, 'The International Law Status of Elderly Persons,' American University International Law Review (AM. U. INT'L L. REV.) 2003 Vol.18, Issue 4, 915)

1272 Diego Rodriguez-Pinzon \& Claudia Martin, 'The International Law Status of Elderly Persons,' American University International Law Review (AM. U. INT'L L. REV.) 2003 Vol.18, Issue 4, 995 ${ }^{1273}$ Article 17(b) Protection of the Elderly

${ }^{1274}$ See 8.1 for description of Successful Ageing

${ }^{1275}$ Theories of Disengagement which view older people disengaging from society as a natural and necessary part of ageing are countered by Activity Theory, which is consistent with the concept of Successful Ageing.

${ }^{1276}$ Article 17(c)

${ }^{1277}$ See 4.2.4.1 'Freedom'
} 
migrant, refugee or stateless status. Specifically, the provision of identity papers reduces the risk of inaccessibility of both generations of rights. ${ }^{1278}$ The Charter further protects older people with the inclusion of a category of rights of older adults. Significantly, the Charter does not conflate the rights of older people with those of persons with disabilities. Whilst the groups, in some instances, experience shared vulnerabilities, both are treated as vulnerable by the instrument, and allocated rights accordingly. The themes of the rights of older people in the Charter correlate to those identified by the UN Working Paper on the need for rights of older people. Protection against violence, including domestic violence ${ }^{1279}$ is stipulated. Appropriate attention to the needs of older people is called for by public and private services, ${ }^{1280}$ including social security. ${ }^{1281}$ Additionally, the right to participate in society $^{1282}$ and decision-making on public issues is included. ${ }^{1283}$

The approach of the South East Nations Declaration to discrimination is inclusive of individuals and groups, emphasising the rights of "vulnerable and marginalised groups" as an "inalienable, integral and indivisible part of human rights and fundamental freedoms." Significantly, similarly to the Andean Charter, "the elderly" are included among such groups, distinct from "persons with disabilities." Further ASEAN instruments acknowledge the principle that vulnerable groups experience conditions beyond the scope of generic rights, applying the notion in two distinct age-related situations. Recognising the aggravated vulnerability of women to abuse, the Declaration On The Elimination Of Violence Against Women And Elimination Of Violence Against Children states the need for an "age-responsive approach" to violence against women. ${ }^{1285}$ Additionally, the propensity of older people to the risk and effects of poverty prompted the inclusion of "older people" in an equitable right to social protection on a needs-based, approach ${ }^{1286}$ in the Declaration On Strengthening Social Protection.

\footnotetext{
${ }^{1278}$ Article 50(3); Article 59(1)

${ }^{1279}$ Andean Charter, Article 47(1) Rights of older adults

${ }^{1280}$ Andean Charter, Article 47(2) Rights of older adults

${ }^{1281}$ Andean Charter, Article 47(4) Rights of older adults

${ }^{1282}$ Andean Charter, Article 47(5) Rights of older adults

${ }^{1283}$ Andean Charter, Article 47(3) Rights of older adults

${ }^{1284}$ ASEAN Human Rights Declaration (2012), General Principle 4

${ }^{1285}$ ASEAN Declaration On The Elimination Of Violence Against Women And Elimination Of Violence Against Children In Asean (2004) (3)

${ }^{1286}$ ASEAN Declaration On Strengthening Social Protection (2013), Principle 1
} 


\subsection{Instruments protecting rights of older people}

This thesis now considers a regional instrument of human rights of older people. This will substantiate earlier recognition that older people require special protection against specific vulnerabilities unavailable in existing international law.

The Protocol to the African Charter on Human and Peoples' Rights on the Rights of Older Persons in Africa

The Protocol provides guidance for a partial structure for normative protection of older people. It is necessary to note that the instrument is responsive to regional issues, however, themes are applicable to older people as a group. The Protocol exhibits important normative gaps, demonstrating a lack of understanding or commitment to some fundamental needs of older people. Nonetheless the ways in which some existing gaps are recognised is informative to a special protection Convention. In the first instance the instrument instructs States to incorporate the United Nations Principles for Older People into domestic law, and declares this specific "soft law" of the UN as the basis of rights provision in the region. ${ }^{1287}$ The Protocol does not strictly follow the structure of the UNPOP. As a result, and in accordance with the vulnerability framework used in this chapter, the vulnerabilities recognised by the instrument will be gathered under the framework headings.

Embodied Vulnerability

$\underline{\text { Physiological Vulnerability }}$

$\underline{\text { Life }}$

The Protocol does not explicitly include any reference to the right to life, therefore, there is a lack of focus on existence or promotion of life. However, Article 8 instructs the 'elimination of harmful traditional practices including witchcraft accusations' known to lead to death.

$\underline{\text { Health }}$

The Protocol recognises specific problems experienced by older people in accessing and affording health services. Therefore States are instructed to enable access and to provide

${ }^{1287}$ Article 1, The Protocol to the African Charter on Human and Peoples' Rights on the Rights of Older Persons in Africa. UNPOP is discussed in Chapter 13 'Progress of the United Nations' 
medical insurance cover. Furthermore, health services must be able to provide for specific health needs of the group. ${ }^{1288}$ The instrument makes specific reference to residential care, which is not represented in international law. Older people are stated as entitled to 'optional and affordable care.' Therefore, the ability to stay in one's home for as long as possible, ${ }^{1289}$ and problem of exclusion on the basis of financial status are brought to the fore. ${ }^{1290}$ Furthermore, care provision is instructed to meet international standards. ${ }^{1291}$ Palliative care is also introduced as a requirement for older people. ${ }^{1292}$ Additionally, the aggravated vulnerability of older people in conflict and disaster situations is expected to receive 'priority...assistance....are not left without needed medical assistance and care." ${ }^{1293}$

\section{Adequate Standard of Living}

The Protocol makes no reference of specific vulnerabilities related to an adequate standard of living, including adequate food and suitable housing. The implication is that international or regional normative provision is the standard available to older people.

\section{Poverty}

Problems associated with pension provision, social security and employment opportunities are acknowledged in the Protocol. The objective of pension payments to all older people is addressed through instructions for adequate pensions and forms of social security to be paid to previously employed individuals. Furthermore, payment must be made to all individuals unable to contribute to pension schemes. This would ease the poverty situation of older women in particular in this region. ${ }^{1294}$

\footnotetext{
${ }^{1288}$ Article 15, The Protocol to the African Charter on Human and Peoples' Rights on the Rights of Older Persons in Africa

${ }_{1289}$ Which also addresses vulnerabilities of 'emplacement'

${ }^{1290}$ Article 11(1), The Protocol to the African Charter on Human and Peoples' Rights on the Rights of Older Persons in Africa

${ }^{1291}$ Article 11(2), The Protocol to the African Charter on Human and Peoples' Rights on the Rights of Older Persons in Africa

${ }^{1292}$ Article 11(3), The Protocol to the African Charter on Human and Peoples' Rights on the Rights of Older Persons in Africa

${ }^{1293}$ Article 14, The Protocol to the African Charter on Human and Peoples' Rights on the Rights of Older Persons in Africa

${ }^{1294}$ Article 7, The Protocol to the African Charter on Human and Peoples' Rights on the Rights of Older Persons in Africa
} 


\section{Emplacement}

This instrument provides in part for vulnerability to emplacement in Article 11, mentioned above, making residential care 'optional.' ${ }^{1295}$ Further protection is provided emplacement of older people by the stipulation to 'provide incentives to family members who provide home care for older persons.' This permits the practice of filial obligation to families who are 'willing but unable' to care for older family members. ${ }^{1296}$

\section{Enselfment}

Aspects of enselfment included in the Protocol are limited, but recognise fundamental universal requirements of older people. The need is stated for opportunities for education; ${ }^{1297}$ to participate in cultural activity and socio-economic programmes. ${ }^{1298}$ Furthermore, States are instructed to enable access to the community. ${ }^{1299}$ The method of achievement is a matter for individual States.

\section{$\underline{\text { Institutional Vulnerability }}$}

The principle institutional vulnerabilities addressed in the Protocol are legal recognition and discrimination. The main issues are recognised, and domestic legislation is to be implemented to achieve equal access to justice and equality before the law. Furthermore, legal assistance must be available to older people. Decision-making is also addressed in the instrument. ${ }^{1300}$ The stipulation for decision-making to be without interference protects the freedom and autonomy of the individual, who must also be free to choose a party to make decisions and act on personal wishes if necessary. For the person lacking capacity legal and societal assistance must be available for supported decision-making. ${ }^{1301}$

\footnotetext{
${ }^{1295}$ Article 11(1), The Protocol to the African Charter on Human and Peoples' Rights on the Rights of Older Persons in Africa

${ }^{1296}$ Article 10, The Protocol to the African Charter on Human and Peoples' Rights on the Rights of Older Persons in Africa

${ }^{1297}$ Article 16, The Protocol to the African Charter on Human and Peoples' Rights on the Rights of Older Persons in Africa

${ }^{1298}$ Article 17, The Protocol to the African Charter on Human and Peoples' Rights on the Rights of Older Persons in Africa

${ }^{1299}$ Article 18, The Protocol to the African Charter on Human and Peoples' Rights on the Rights of Older Persons in Africa

${ }^{1300}$ Article 4, The Protocol to the African Charter on Human and Peoples' Rights on the Rights of Older Persons in Africa

${ }^{1301}$ Article 5, The Protocol to the African Charter on Human and Peoples' Rights on the Rights of Older Persons in Africa
} 
Discrimination of older people is recognised, giving credence to the earlier argument that older people are excluded from prohibited grounds for discrimination. Moreover, the reality of cultural relativity acting as a barrier to implementation is implicitly acknowledged as Article 3 aims for the elimination of all forms of discrimination, cultural stereotypes and marginalisation. ${ }^{1302}$ Taking this approach also helps alleviate problems of loss of status discussed in Theories of Ageing.

\section{Pathogenic Vulnerability}

The vulnerability of older people to abuse and violence is recognised in general terms, and with regard to the sub-set of older women. The instrument therefore acknowledges pathogenic vulnerability as a universal problem for older people in addition to the regional aggravated vulnerability suffered by women. Harmful traditional practices aimed at older people must not just be prohibited, but criminalised as a deterrent. Witchcraft practices are specified in this regard. ${ }^{1303}$ Whilst these are stated as general harmful practices, it is noted that traditionally, women account for the majority of victims. In addition, the following article specifically addresses protection of women from abuse. Forms of abuse identified include violence, sexual abuse, and gender discrimination. Significantly, the role of inheritance laws are cited as a source of abuse, and in response domestic legislation is required to change such legislation and protect against the abuse generated. ${ }^{1304}$

\footnotetext{
${ }^{1302}$ Article 3(1), The Protocol to the African Charter on Human and Peoples' Rights on the Rights of Older Persons in Africa

${ }^{1303}$ Article 8, The Protocol to the African Charter on Human and Peoples' Rights on the Rights of Older Persons in Africa

${ }^{1304}$ Article 9, The Protocol to the African Charter on Human and Peoples' Rights on the Rights of Older Persons in Africa
} 


\subsection{Devising normative provision of special protection human rights using a Capabilities}

\section{Approach}

Findings of research of lived experiences and normative provision of the existing international rights framework reveal the protection required from human rights by older people. In light of the argument made earlier by this thesis that the concepts of Vulnerability and Human Dignity both underpin human rights, the findings are proposed to inform the basis of normative provision of special protection for older people. The examination of the normative content of the existing international rights framework in this chapter was undertaken using the Vulnerable Subject approach at the heart of Fineman's thesis of vulnerability. ${ }^{1305}$ When compared to the lived vulnerabilities of older people identified in Part III, and normative suggestions of General Comments, the existing construct was demonstrated to be inadequate in fulfilling the interests of older people in rights. In order to achieve normative provision underpinned by Human Dignity and Vulnerability aimed at achieving protection from specific vulnerabilities and equality of dignity, this thesis employs and develops aspects of a Capabilities Approach. Of significance is the notion of a central listing of capabilities.

\subsubsection{Listings of capabilities - an overview}

The idea of basic or central capabilities and a listing of the same have been discussed earlier in the thesis (Chapter 6). ${ }^{1306}$ The notable difference between the opinions held by Sen and Nussbaum centres on universality. The latter argued for a single list of central capabilities with universal application, derived from, and able to inform human rights. These central capabilities are also promoted by Nussbaum as the entitlement of all people, to be achieved via human rights. Sen, however, disagrees with the idea of a "single frozen list" to be applied in all circumstances. His solution is to create bespoke listings to "serve a purpose" and respond to particular situations. The basic capabilities of Sen, and central capabilities of Nussbaum are categorised by domains fundamental to well-being. The categorisation of domains is subtly different. Sen aligns the domains of basic capabilities to development, whilst Nussbaum grounds domains of central capabilities in human rights.

\footnotetext{
${ }^{1305}$ Martha Albertson Fineman proposed that the Vulnerable Subject, rather than the Liberal Subject should be at the centre of human rights considerations. See 5.3.2.2 'Fineman's Thesis' ${ }^{1306}$ See 6.2.2.1 'Basic, internal and combined capabilities'
} 
11.5.2 Methods of development of thematic domains and listings of capabilities

This thesis considered various procedures in the creation of the listing of Fundamental Capabilities for older people. Sen insisted on a role for public discourse in the creation of capabilities. Despite not producing a listing, Sen views any construction to be grounded in societal choice. The outcome would be a subjective listing of valued beings, doings and capabilities. ${ }^{1307}$ The process of democratic deliberation is stated by Crocker as essential to the continued development and relevance of capabilities listings. The focus on valuing capabilities and garnering attitude towards them ${ }^{1308}$ facilitates a methodology to respond to continual change. Methods of producing listings have not always taken heed. Nussbaum grounded the domains of Central Capabilities in international human rights, using philosophical discussion to produce an "objective but incomplete and revisable" listing. ${ }^{1309}$ Capabilities were extracted from the existing international human rights framework. The domains into which the capabilities were categorised are representative of fundamental rights, or a combination of rights. Nussbaum's listing has been accused of producing a listing lacking legitimacy ${ }^{1310}$ by those claiming that to have legitimacy, capabilities listings require investigation of the needs of the end-user of the capabilities. ${ }^{1311}$

Burchardt et al have since created a list of central capabilities for children. The research once more employed a rights-centred approach, focused on the Convention on the Rights of the Child, and substantiated via consultation with specialist groups. ${ }^{1312}$ The researchers propose a capabilities listing of "states of being and doing that are protected and promoted in international law," derived of existing rights for use in $21^{\text {st }}$ century Britain. ${ }^{1313}$ The result represents valued outcomes of human rights.

\footnotetext{
${ }^{1307}$ David A. Crocker 'Sen and Deliberative Democracy' in Alexander Kaufman (ed) Capabilities Equality: Basic Issues and Problems (New York, Routledge, 2006), 170-171

${ }^{1308}$ David A. Crocker 'Sen and Deliberative Democracy' in Alexander Kaufman (ed) Capabilities Equality: Basic Issues and Problems (New York, Routledge, 2006)

${ }_{1309}$ David A. Crocker 'Sen and Deliberative Democracy' in Alexander Kaufman (ed) Capabilities Equality: Basic Issues and Problems (New York, Routledge, 2006), 170-171

${ }^{1310}$ See Ingrid Robeyns 'Selecting Capabilities for Quality of Life Measurement' 'Social Indicators Research' (2005)74: 191-215, https://link.springer.com/content/pdf/10.1007\%2Fs11205-005-65241.pdf accessed 11/10/2017; David A. Crocker 'Sen and Deliberative Democracy' in Alexander Kaufman (ed) Capabilities Equality: Basic Issues and Problems (New York, Routledge, 2006)

${ }^{1311}$ Ingrid Robeyns 'Selecting Capabilities for Quality of Life Measurement' 'Social Indicators Research' (2005)74: 191-215, 199 https://link.springer.com/content/pdf/10.1007\%2Fs11205-005-6524-1.pdf accessed 11/10/2017

${ }^{1312}$ Specialist consultation on the list of central and valuable capabilities for children

${ }^{1313}$ Polly Vizard \& Tania Burchardt 'Developing a capability list for the Equality and Human Rights Commission: The problem of domain selection and a proposed solution combining human rights and
} 
11.5.3 Development of thematic domains and a listing of fundamental capabilities for older people

The aims and methodology of development of thematic domains and a listing of fundamental capabilities for older people adds to the existing body of research in a number of areas. This thesis supports the principle that universality provides a floor rather than a ceiling for human rights provision, and adopts the approach of a capabilities listing with "special purpose" proffered by Sen. In devising the "special purpose" the thesis placed the Vulnerable Subject at the heart of the process. Therefore, principles of the approaches by Sen and Fineman, and the conclusions derived in Chapter 7 regarding the relationship between the concepts of Human Dignity and Vulnerability, and human rights were combined to achieve an original approach to devising thematic domains and fundamental capabilities.

This difference in focus, resulting from combining a Vulnerability Thesis with the Capabilities Approach produced a number of "purposes" to the listing. The first principal purpose is to underpin and inform special protection rights for older people. This is achieved via identification of the vulnerabilities of older people requiring the protection of human rights. Earlier research traced the vulnerabilities of older people in accordance with the vulnerabilities framework devised in Part II. Normative provision by the existing international framework was subsequently examined in accordance with stated vulnerabilities and the vulnerabilities framework. Thus, normative gaps and interests held by older people in rights have been represented from the perspective of vulnerability, and are instructive of the need for supplementary protection. Identified vulnerabilities and normative gaps are related at this stage to the circular process between human rights, dignity and vulnerability, which formed the basis for the argument in Chapter 7 that both concepts should underpin human rights. When existing human rights provide insufficient resilience to threats to human dignity, the risk of the threat manifesting as vulnerability is exacerbated. A lack of human rights protection against vulnerabilities serves to further insult human dignity. Therefore, the proposed objective of human rights which the list underpins is protection of the vulnerabilities which inform the listing of special purpose capabilities. Thus, the listing informs special protection rights for older people, in addition to being informed by principles, objectives and the minimum core of international rights. The second "purpose" of the listing of fundamental capabilities is to provide the outcome to 
be achieved by human rights. This draws on Nussbaum's theme that human rights facilitate access to the entitlement of fundamental capabilities. In this context the capabilities are dependent upon human rights protecting against specific vulnerabilities. Each fundamental capability embodies outcomes of valued capabilities, states of being and doing, and equality of dignity. As outcomes, the third "purpose" of the listing is to inform implementation of human rights, and form the basis of indicators to measure implementation, which will be discussed in the next chapter.

The structure of the Thematic Domains and listing of capabilities by this thesis differs from constructs by Nussbaum and research undertaken the field of Capabilities since. The initial reference point taken by this research is the vulnerabilities framework devised in Chapter 5 . The vulnerabilities framework represents vulnerabilities by facets of life. The subsequent arrangement of vulnerabilities within the framework reflects concrete situations and lived outcomes of vulnerability experienced by older people. The Thematic Domains into which fundamental capabilities are gathered, in the first instance, takes the same approach. Themes of vulnerabilities are collated into which individual vulnerabilities, specific to particular aspects or functions of life, are gathered. An examination of the international human rights framework in the context of the decided thematic domains and individual vulnerabilities resulted in partnering individual rights to the same. The purpose of the partnering developed from identification of normative gaps to the incorporation of international human rights objectives and principles into thematic domains and the listing of capabilities. Significantly, this research incorporated universal rights and instruments of special protection to which sub-sets of older people have access; specifically the CRPD and CEDAW. The aim of the structure of the Thematic Domains created in this thesis is to inform what is required of existing and future rights, by means of reflecting the significance of the vulnerabilities framework to the situation of older people, whilst maintaining the influence of human rights principles and objectives. Unlike the existing body of work in this area, the creation of Fundamental Capabilities for older people did not begin with, or was primarily influenced by, the international framework of rights. Universal rights are not argued to have the capacity to resolve all situations of insults to dignity or vulnerability. Nor are concrete situations to which no existing right applies considered beyond the scope of human rights per se. The existing framework was not considered the ultimate measure of violation of dignity or the ultimate protection against vulnerability. The Vulnerable Subject was the primary focus. The lived vulnerabilities, interest held in rights by the Vulnerable Subject, and 
normative gaps from the international framework were the sources from which Fundamental Capabilities were derived.

Democratic deliberation is represented in a different form in the development of thematic domains and fundamental capabilities by this thesis to the strict methodology of Sen. The preference of Sen for the deliberation of the users of context-specific capabilities would be the choice of this research. However, in the instant context of older people and the vulnerabilities experienced by the group, the inability to have opinion heard contributes to vulnerability. In addition, the context of the listing of this thesis for older people is international, in contrast to the single nation context of Burchardt et al. To garner opinion via international forums is beyond the scope of this work. However, research gathered lived experiences of vulnerability via international research undertaken by NGOs, expert groups and individuals, national and regional data gathering organisations, and global bodies such as the WHO. Furthermore, when a context-specific listing is being produced, existing research is a necessary source contributing to legitimacy. ${ }^{1314}$ Moreover, it is argued that the resulting domains and capabilities benefit from democratic deliberation, given that international human rights were formed from international discussions, the consensus of principles, objectives and the minimum core. ${ }^{1315}$

The methodology adopted by this thesis aims to circumvent two criticisms of constructions of capabilities listings. The original listing proposed by Nussbaum has been accused of lacking legitimacy, due to being grounded in existing international human rights and philosophical debate. In addition, this thesis claims that a dependency on established rights limits the scope of any fundamental capabilities listing, particularly for vulnerable groups requiring special protection. The normative gaps in rights provision identified earlier in the chapter proves that to ground a capabilities listing for older people purely in the current construct of human rights would be inadequate.

In placing the Vulnerable Subject at the centre of the Thematic Domains human rights are drawn on in a manner which responds to lived vulnerabilities. Human rights are asked to provide specific solutions, in the form of Fundamental Capabilities, to vulnerabilities. The most threatened aspects and modes of life, and of successful ageing, identify the interests

\footnotetext{
1314 Ingrid Robeyns 'Selecting Capabilities for Quality of Life Measurement' 'Social Indicators Research' (2005)74: 191-215, 201 https://link.springer.com/content/pdf/10.1007\%2Fs11205-005-6524-1.pdf accessed 11/10/2017

${ }^{1315}$ Tania Burchardt, Tiffany Tsang, and Polly Vizard, 'Specialist consultation on the list of central and valuable capabilities for children'. Equality and Human Rights Commission Research report 41, 2009 
held in human rights by older people which existing, or special protection rights need to fulfil to protect against vulnerabilities. The Fundamental Capabilities derived are tabulated below, and form the basis of the examination of implementation in the next chapter.

11.5.4 Fundamental Capabilities

$\underline{\text { TABLE NUMBER } 12}$

Fundamental Capabilities of Older People

\section{THEMATIC DOMAINS FUNDAMENTAL CAPABILITIES}

To be able to:

1. LIFE

(A) Avoid premature mortality, and have life maintained and prolonged, when possible, in accordance with increased life expectancy

(B) Be protected from arbitrary taking of life

2. SUCCESSFUL AGEING (A) Health:

i. Attain the highest possible standards of physical and mental health

ii. Maintain and prolong years of life lived in good health and disability-free

iii. Delay co-morbidity, and experience compressed rather than extended morbidity

iv. Have access to preventative, curative, rehabilitative, and specialist medical care

v. Have access to palliative care

vi. Prevent ill-health and maintain health through:

- Nutritionally adequate sustenance; housing and living conditions enabling healthy living; care and support with living

vii. Minimise the negative effects of societal practices on health in older age, including: retirement; social isolation; negative stereotypes and perceptions

(B) Activity:

i. Partake in occupations and activities of one's choice, commensurate with ability

ii. Update skills and impart knowledge and skills to next generation

(C) Engagement:

i. Form and maintain beneficial relationships including: ties of kinship and emotion; professional; in the community. 


\section{THEMATIC DOMAINS FUNDAMENTAL CAPABILITIES}

To be able to:

3. INVIOLABILITY OF THE HUMAN BODY

4. INDEPENDENCE
(A) Practice autonomy and self-determination, with the aid of supportive decision-making if necessary, with regard to: own body and institutional detention

i. Be involved in decisions regarding medical treatment, including psychiatric

ii. Be involved in decisions regarding continuation or withdrawal of medical treatment

iii. Be involved in decisions regarding care provision

iv. Be involved in decisions of detention; including short and long term medical, psychiatric, and residential detention

(B) Be free from physical, psychological, financial, and sexual abuse; violence; exploitation; and neglect.

i. Free from physical, psychological, financial, and sexual abuse - including domestic abuse, where "domestic" includes residential care

ii. Free from physical and sexual violence - including domestic, where "domestic" includes residential care

iii. Free from neglect, including: personal care, malnutrition and dehydration

iv. Free from physical or mental harm as a result of punishment and exclusion

v. Free from fear of all forms of abuse, violence, exploitation, neglect and of not being included in decision-making

vi. Access support and rehabilitation for all forms of abuse, violence, exploitation and neglect

(A) Live to the greatest extent possible free from "inevitable dependencies" of inevitable embodied vulnerability:

i. To have care enabling performance of activities of daily living

ii. To have housing adapted, if necessary, and adequate to, physical and mental vulnerabilities

(B) To have financial means to sustain independence:

(C) To have a home

(D) To have ability to access services and the community 


\section{THEMATIC DOMAINS FUNDAMENTAL CAPABILITIES}

To be able to:

5. DEVELOPMENT AND

(A) Be respected and accepted for contribution made to FLOURISHING society, and choice of productive activity, whether or not economically productive.

(B) Develop personality, to include:

i. Education and professional training

ii. Freedom of opinion and expression

iii. Freedom of association

6. PARTICIPATION

(A) Participate in and contribute to aspects of and influences over social, economic and political life. Including:

i. family life

ii. public and democratic life

iii. cultural and community life

7. EMPLACEMENT

(A) To experience life the "place" of one's choosing.

(B) To maintain family life in that "place", including family care and support in accordance with cultural and personal choice.

8. RESISTANCE TO

(A) To be able to strengthen resilience to vulnerabilities VULNERABILITY through institutional assets providing:

i. Access to financial and material benefits when vulnerable through not achieving minimum threshold for healthy standard of living.

ii. Access to capabilities necessary to compensate for compromised innate or internal abilities, causing inability to counter or adapt to threats

iii. Ability to maintain supportive networks including family, in the community, and cultural.

iv. Access to existential assets by enabling practice of beliefs, religion and moral values.

v. Assets available through the legal institution, including: non-discrimination by any institution in provision of assets on basis of age; recognition before the law; recognition of particular vulnerabilities of older people in the administration and interpretation of rights. 


\section{THEMATIC DOMAINS FUNDAMENTAL CAPABILITIES}

To be able to:

9. LEGAL CAPACITY (A) Maintain legal capacity

(B) Have supported decision-making in all decisions regarding oneself, particularly:

i. Where and with whom to live

ii. Medical treatment

iii. Type of care and where to receive it

iv. Financial matters

10. ACCESS TO JUSTICE

(A) Access legal services required for information on, and exercise of rights; and remedy for violation

\subsection{Conclusion}

The examination undertaken in this chapter employing a method combining vulnerability and adapted Capabilities Approach, designed as part of this thesis, concludes that none of the vulnerabilities of older people, or the interests held in rights by the group are fully protected by the normative provision of international law. Gaps were proven in all human rights applicable to the distinct vulnerabilities of older people categorised as embodied, institutional, and pathogenic. The effect of this, given the relationship between the concepts of Human Dignity and Vulnerability, and human rights is to exacerbate existing vulnerabilities. Human rights which do not protect the person against threats to dignity result in vulnerability. If the vulnerable subject is not at the heart of all questions of human rights, including normative content of rights, the subject suffers outcomes of vulnerability, working to further insult dignity. Thus the vicious circle continues. The vulnerable subject is made more vulnerable. The exposure of the normative content of rights to the vulnerabilities of older people also responds to claims by Member States of the UN that any gaps in the protection of rights of older people are not normative in nature. The findings of this research also contribute to the research question of how older people are vulnerable in society. 
The high reliance by this group on economic, social and cultural rights also argues the case for special protection containing a broad base of human rights. Therefore, if the older person is to have access to rights from both generations that are justiciable, a discrete Convention is necessary.

The examination of the African Protocol served to highlight normative provision which could be included in a special protection instrument. Whilst cultural differences were demonstrated to exist, common themes are internationally applicable for which international standards are required. Furthermore, regional instruments do not necessarily include the full range of vital provision. This argument serves as a counter to that offered by UN Member States that a series of regional instruments, rather than a single international instrument would protect the rights of older people.

The Capabilities Approach was chosen for the final stage of the chapter; to devise a means of informing the normative content of special protection rights for older people. The rationale was grounded in the focus of Capabilities on what a person is able to be and do, and what the person values being and doing. The Approach provides a means to identify the opportunities needed to achieve outcomes of capabilities. The thesis devised a "special purpose" listing of Fundamental Capabilities to inform the normative content and to provide the outcome to be achieved through rights. This thesis proposes this approach as a suitable method of devising the normative content of special rights for older people.

The following chapter completes the examination of international rights by exploring implementation. Furthermore, the listing of Fundamental Capabilities devised in this chapter will be utilised to determine the adequacy of implementation of existing international rights in the context of the vulnerabilities of older people. 


\section{CHAPTER 12}

\section{IMPLEMENTATION GAPS IN UN FRAMEWORK}

Special protection requires both adequate normative provision and implementation that enables access to, and exercise of, rights in order to fulfil the interests held by a particular vulnerable group. Discrepancy between de jure and de facto human rights contribute to the "downward spiral of persistent violations" reported as experienced by older people in the Follow-up to the Second World Assembly on Ageing. ${ }^{1316}$

\subsection{Introduction}

This chapter examines the degree to which gaps in the implementation of human rights contribute to the inadequacy of the UN framework of human rights in the promotion of dignity and protection against vulnerabilities experienced by older people. The findings will develop the answer to the question of the necessity of special protection for older people in international human rights law offered in the previous chapter. The approach of the Vulnerable Subject, central to the vulnerability thesis of Fineman, influenced the examination of normative provision, and identified required outcomes not provided for in the current framework. Normatively, the framework was demonstrated to be incomplete in areas of interests of older people in rights. The argument against the need for special protection for older people regularly rests on, inter alia, the claim that any gap in protection of the rights of older people is one of implementation rather than normative provision. ${ }^{1317}$ The question of implementation in this context will be addressed as follows. The "special purpose $^{\prime 1318}$ listing of Fundamental Capabilities developed in the previous chapter ${ }^{1319}$ provides the basis for the examination of implementation of rights in the existing international framework. The instructions for implementation included in the instruments and corresponding General Comments are made in the context of universal rights, or special protection for a given population group to which older people may have access. ${ }^{1320}$ This chapter will view said instructions from the perspective of the degree to which such

\footnotetext{
${ }^{1316}$ Follow-up to the Second World Assembly on Ageing: Report of the Secretary-General, Submitted to the United Nations General Assembly, A/64/127, July 2009

${ }^{1317}$ Léon Poffé, 'Towards a New United Nations Human Rights Conventon for Older Persons?' Human Rights Law Review, 2015, 15, 591-601, 599

${ }^{1318}$ Using the approach of Sen to listings of Capabilities

${ }^{1319}$ Resulting from identification of vulnerabilities of older people in Part III, normative gaps in human rights instruments, and normative suggestions in General Comments

${ }^{1320}$ Such as the CRPD and CEDAW
} 
implementation gives effect to the Fundamental Capabilities developed for older people. Furthermore, the occasions when implementation closes normative gaps to achieve Fundamental Capabilities will be highlighted. The combined findings regarding gaps in normative provision and implementation of rights will inform the answer to the issue of progress by the UN on providing for the interests held by older people in rights, and ultimately, the position on the need for special protection.

Following a brief overview of aspects of implementation, the chapter explores instructions for implementation provided in the instruments and General Comments of the Treaty Monitoring Bodies. Specifically, the ICCPR, ICESCR, UNCRPD and CEDAW are examined in this context. Of significance is the fact that these instruments contain universal rights or special protection rights to which some older people may have access by virtue of disability or gender. The discussion, therefore, considers issues of implementation of existing normative provision from two perspectives. The first is in accordance with vulnerabilities of older people; the second with the Fundamental Capabilities identified from the earlier exercise of examining the international framework and vulnerabilities of older people.

The chapter then continues with discussion of a Capabilities Approach to human rights provision for older people. Aspects of the Capabilities Approach to human rights are drawn upon as a means to aid implementation of special protection rights which normatively provide for the Fundamental Capabilities devised in the previous chapter. The process advocated is one in which the rights-holder is given the opportunity to exercise the right which facilitates the entitlement to the outcome of the Fundamental Capability. Emphasis is placed on, inter alia, obligations of de facto, ${ }^{1321}$ a broad class of human rights, ${ }^{1322}$ positive State and international duty, and indicators grounded in Fundamental Capabilities.

This investigation of an implementation gap vis à vis human rights provision for older people therefore continues to develop answers to research questions offered earlier in the thesis. The chapter particularly contributes to the question of a special protection Convention for older people. The relationship between the concepts of vulnerability and human dignity, and human rights, was viewed as significant to the content and aims of human rights in Part II. This was emphasised in the examination of the vulnerabilities of older people in Part III, and of the normative framework in the previous chapter. The view of human rights

${ }^{1321}$ which provide clarity to implementation measures required for the achievement of Fundamental Capabilities, and for the measurement of the adequacy of human rights in concrete situations 1322 Inclusive of both generations of rights 
implementation through the lens of the Capabilities Approach further illustrates, together with the normative gaps identified earlier, the inadequacies of existing international human rights for older people. The next chapter will consider the progress on special protection for older people in light of the findings of the implementation issues and normative gaps in the existing international framework.

\subsection{Implementation}

Implementation is the means by which rights de jure become rights de facto. The international framework advocates, and is reliant upon, various methods of implementation, as part of an often complex process. The implementation obligation of States parties, as outlined in Chapter 1 comprises the respect, protection, and fulfilment of rights. ${ }^{1323}$ Such obligations comply with those of the broad categories of conduct and result. Obligations of conduct require the State to perform in a certain manner; to act or omit to act. The focus of result obligations is the achievement of a particular result, such as the establishment or maintenance of a situation. Whilst the situation is stipulated, the means of achievement is a matter of choice for the State. This thesis determines it necessary for obligations of special protection to be guided by two principal objectives. The first is to abolish discriminatory practices, legislation and policy. The indeterminate normative position on discrimination of older people, discussed previously, places greater responsibility on implementation to compensate for the precariousness of non-discrimination. In brief, broad suggestions included in General Comments of the Treaty Monitoring Bodies in this regard include: review of existing legislation, policy and practices; ${ }^{1324}$ introduction of non-discriminatory legislation and policy; ${ }^{1325}$

The second objective is to overcome situations in which "... the general conditions of a certain part of the population prevent or impair their enjoyment of human rights," aimed at removing discrimination in fact. ${ }^{1326}$ Such "conditions" predominantly require positive corrective State action. This action also includes the introduction of legislation and policy,

\footnotetext{
${ }^{1323}$ The obligation to respect requires the State to refrain from acting; protect requires action to prevent non-State actors and private persons interfering with the exercise of the right; fulfil requires the State to take positive action in order to give effect to the right.

${ }^{1324}$ CRPD General Comment No. 1 Equal recognition before the law Eleventh session 31 March-11 April 2014, 25

${ }^{1325}$ CRPD General Comment No. 1 Equal recognition before the law Eleventh session 31 March-11 April 2014, 26

${ }^{1326}$ HRC General Comment 18 Non-discrimination, 10 November 1989 37th Session at 26, 10. Adopted by Human Rights Treaty Bodies, U.N. Doc. HRI/GEN/1/Rev.1 at 26 (1994)
} 
however, there is often a resource requirement, which limits the response by less wealthy States parties.

\subsubsection{Resources}

Implementation of resource-dependent rights can be subject to limited means and sustainability. Traditionally for poorer States parties, provision for the burgeoning ageing population is unsustainable. Therefore, pressure to implement legislation and practice in compliance with universal human rights, such as provision of non-contributory pensions, healthcare, adequate and accessible housing has resulted in developing countries reporting a lack of mechanisms necessary to provide for vulnerable groups and individuals. ${ }^{1327}$ This obstacle to implementation is notably becoming a feature of global change, as instances of poverty among older people ${ }^{1328}$ and general increased demand for welfare provision, has extended beyond developing countries, with implications for rights provision of older people generally. The UN therefore included the principle of progressive realisation in the ICESCR in response to this obstacle to implementation. ${ }^{1329}$

Progressive realisation stands accused of permitting States to neglect the duty to improve conditions such that rights might be exercised, "depriving the obligation of all meaningful content." $^{1330}$ The danger exists for progressive realisation to justify not implementing the right in question due to resource constraints, or for arbitrary implementation of the obligation. ${ }^{1331}$ This problem aligns to the threat of lack of commitment to implementation warned of by Kofi Annan, ${ }^{1332}$ with particular implications for the most vulnerable in need of "preferential treatment" to correct conditions preventing access to, or exercise of, specific

\footnotetext{
${ }^{1327}$ Specific reference was made to South Asia in this instance. Hossain, K. 1997 Promoting Human Rights in the Global Market Place. Amsterdam: Vrije Universiteit. (as cited in Cees J. Hamelink, 'Human rights. The implementation gap' The Journal of International Communication 04 April 2012, 63. http://dx.doi.org/10.1080/13216597 accessed 10/08/2017)

${ }^{1328}$ See chapter 10

1329 ICESCR, Article 2(1) 'Each State Party to the present Covenant undertakes to take steps, individually and through international assistance and co-operation, especially economic and technical, to the maximum of its available resources, with a view to achieving progressively the full realization of the rights recognized in the present Covenant by all appropriate means, including particularly the adoption of legislative measures.'

${ }^{1330}$ CESCR General Comment No. 3 Annex III, 9 E/1991/23 (1990)

${ }^{1331}$ Roth cites the example of South African President Thebo Mbeki's refusal to treat HIV infected mothers with donated drugs to prevent mother-to-child transmission of the disease. Kenneth Roth, 'Defending Economic, Social and Cultural Rights: Practical Issues Faced by an International Human Rights Organisation' Human Rights Quarterly Vol 26, No. 1, Feb 2004, 63, 69 http://www.jstor.org/stable/20069716 accessed 4/11/2016

${ }^{1332}$ Kofi Annan, Former Secretary-General of the United Nations, 'In Larger Freedom: Towards Development, Security and Human Rights for All' http://www.humanrights.com/voices-for-humanrights/human-rights-challenges.html accessed 30/10/2017
} 
rights. However, the correct application of progressive realisation proves it to be an effective tool for implementation of resource-dependent rights. Whilst the realisation of the right is not expected to be immediate, the setting of goals must be immediate, and the movement towards them "expeditious and effective." 1333 The obligation of result permits States parties to adopt measures of choice, however, minimum essential levels must be achieved, and every effort must be demonstrated to have been made to use the maximum available resources in the reporting to the TMBs. ${ }^{1334}$ Moreover, the definition of "maximum available resources" is stated by the CESCR as not limited to the resources of an individual State, but to the international community. ${ }^{1335}$ Therefore, there is scope to prevent the subsistence of conditions which prevent the exercise of rights for groups of people by virtue of limited domestic resources.

\subsubsection{Margin of Appreciation}

The integration of human rights into domestic law is a key requirement of implementation. However, the HRC recognises the potential for domestic law and policies, particularly when the individual State is at liberty to chose the method for achievement of the result obligation, to obstruct implementation. The Special Rapporteurs reporting on the draft general comment for the right to life quoted problems associated with reliance on domestic legislation for implementation, notably in relation to the interpretation of the term "arbitrary" creating inconsistency in implementation ${ }^{1336}$ Hamelink goes further, claiming that the degree of variation in implementation of rights impacts de facto outcomes such that they "reach a borderline when they violate the core principles of human rights law." In such cases, the margin of appreciation permitted in implementation can be cited as a cause of implementation gaps in the rights of the UN framework. In the case of older people subject to entrenched discriminatory practices, this manifestation of cultural relativity could prove particularly problematic to the attainment of Fundamental Capabilities and giving effect to interests in rights.

\footnotetext{
${ }^{1333}$ CESCR General Comment No. 3 Annex III, 9 E/1991/23 (1990)

${ }^{1334}$ CESCR General Comment No. 3 Annex III, 9-10 E/1991/23 (1990)

1335 CESCR General Comment No. 3 Annex III, 13 E/1991/23 (1990)

${ }^{1336}$ Yuval Shany and Nigel Rodley, Rapporteurs HRC Draft General Comment No. 36 Article 6: Right To life, 16 115th session 19 October - 6 November 2015 CCPR/C/GC/R.36/Rev.2
} 


\subsubsection{Knowledge of rights-holders}

Kofi Annan also cites knowledge as a primary obstacle to the implementation of rights. As the entitlement to protection of the interests held in human rights is unknown to many of the most vulnerable, including older people, a fundamental obligation of States parties is to inform and educate vulnerable groups of the meaning and accessibility of rights. ${ }^{1337}$

\subsubsection{Monitoring}

"Human rights monitoring requires a focus on data related to attainments and enjoyments of rights for the most vulnerable and the marginalized population groups." ${ }^{1338}$ The United Nations advocates a change from the focus on national or regional averages to one of monitoring within a population group. This approach permits accurate assessment of discrimination, inequality, and rights violations of the group. ${ }^{1339}$ This thesis considers it necessary to also monitor sub-groups within vulnerable groups. In the context of older people this would permit for the monitoring of the rights implementation situation of older people, and for example, older women as a vulnerable sub-group. Currently, older people rely on disaggregated information which has proven inadequate (see Reporting 12.2.5 below). Therefore, this thesis argues that it is necessary to monitor older people as a vulnerable group, which also contributes to the argument for a special protection Convention for the group.

\subsubsection{Reporting}

As part of the monitoring process of the implementation of rights, the UN TMBs require all States parties to report on key aspects. The aims of the reporting requirements are broadly to demonstrate commitment of States parties to the Treaty rights, and to monitor progress of rights implementation particularly in situations where conditions prevent implementation. Given the primary objectives of reporting listed blow any failure by States to comply with reporting duties proves a major obstacle to implementation.

\footnotetext{
${ }^{1337}$ Cees J. Hamelink, 'Human rights. The implementation gap' The Journal of International Communication 04 April 2012, 58. http://dx.doi.org/10.1080/13216597

${ }^{1338}$ United Nations 'Human Rights Indicators: A Guide to Measurement and Implementation,' 133 http://www.ohchr.org/Documents/Publications/Human rights indicators en.pdf accessed 20/09/2017

1339 United Nations 'Human Rights Indicators: A Guide to Measurement and Implementation,' 22 http://www.ohchr.org/Documents/Publications/Human rights indicators en.pdf accessed 20/09/2017
} 
- The review of the national implementation of human rights

- The review of measures to achieve compliance of domestic legislation and policy to rights and Treaty aims

- Measure progress in the exercise of rights, including vulnerable groups

- Identification of problems in the approach to implementation

- Development of goals, including to achieve progressive realisation, and a review of the policies aimed at achieving goals.

- Facilitation of national and international scrutiny of measures and implementation ${ }^{1340}$

Treaty Monitoring Bodies cite reporting inadequacies as a persistent obstacle to effective monitoring of implementation gaps in many of these areas. Of significance in the context of this thesis is how inadequacies in the reporting of the above, and other aspects of the implementation impact fulfilment of the interests of older people. Moreover, how older people feature in the reporting of States parties is cited by Judge as providing "at least a sense of governments' commitment to furthering the rights of older people." Therefore, ahead of the examination of implementation of human rights instruments, the recognition of the group in the reporting to various TMBs is stated.

States parties reports to the Secretary General recorded the following: Of 124 reports relating to the HRC in the period 2000-2008, 3 concerned action taken against age discrimination, ${ }^{1341}$ and 1 mentioned the vulnerability of older people in long term care homes. Of 122 reports relating to the ICESCR in the period 2000-2008, 25 mentioned rights of older people. ${ }^{1342}$ Of these 8 referenced pension provision and retirement age; 4 referred to the vulnerability to poverty; 3 quoted anti-discrimination legislation enacted to protect older people; 3 cited potential health and social service risks; 3 cited potential housing and social care risks. The exacerbated vulnerability of older people in situations of natural disaster was recorded in 2 reports, and issues of older women recorded in 2 reports. Of 190

\footnotetext{
${ }^{1340}$ UNHRI Compilation of Guidelines on the Form and Content of Reports to be Submitted by States Parties to the International Human Rights Treaties Report of the Secretary-General, 5 HRI/GEN/2/Rev.6

${ }^{1341}$ UNHRC Chinsung Chung, 'The necessity of a human rights approach and effective United Nations mechanism for the human rights of the older person,' para $47 \mathrm{~A} / \mathrm{HRC} / \mathrm{AC} / 4 / \mathrm{CRP} .1$

1342 UNHRC Chinsung Chung, 'The necessity of a human rights approach and effective United Nations mechanism for the human rights of the older person,' para $47 \mathrm{~A} / \mathrm{HRC} / \mathrm{AC} / 4 / \mathrm{CRP} .1$
} 
reports relating to CEDAW 32 recorded issues of older women. ${ }^{1343}$ Vulnerability to poverty featured in 7 reports, specific vulnerabilities of older women in rural areas in 3; pension provision in 8; abuse in 3; health and social service provision in 3; and ability to own land in property in 3 reports. If reporting is to be taken as indicative of the implementation of rights to fulfil interests of older people, and of the Fundamental Capabilities devised by this thesis, the claim of "age blindness" by States ${ }^{1344}$ appears viable. Furthermore, many references to older people did not confirm that positive action had been implemented to overcome the situation, with many simply raising awareness.

\subsubsection{Indicators}

Indicator systems and reporting are essential to monitoring. The UN states the need for indicators to be contextually relevant, comprise reliable quantitative and qualitative data, and be regularly reported. Therefore, indicators directly responsive to special protection rights, derived of vulnerabilities and human dignity particular to lived experiences of the group, ideally underpinned by Fundamental Capabilities would be most context specific.

The UN records the indicators most regularly used in monitoring the realisation of human rights as: progress on policies and legislation; fulfilment of conduct and result obligations; and the outcomes of rights. Furthermore, for the purposes of performance indication, the UN recommends the integration of benchmarks and targets. However, reference is made at this point to the statement in General Comment No. 1; "global benchmarks are of limited use, whereas national or other more specific benchmarks can provide an extremely valuable indication of progress." In serving the objective to assess progress of realisation of obligations included in the Covenant, the scope of benchmarks must reach beyond the general, to analyse the performance of States parties in identified areas of concern. Therefore, benchmarks specific to vulnerabilities, and to States, particularly for rights subject to progressive realisation, are recommended. ${ }^{1345}$ This is in contrast to civil and political rights for which the outcome of a violation of rights is predominantly measured in

\footnotetext{
${ }^{1343}$ UNHRC Chinsung Chung, 'The necessity of a human rights approach and effective United Nations mechanism for the human rights of the older person,' para $47 \mathrm{~A} / \mathrm{HRC} / \mathrm{AC} / 4 / \mathrm{CRP} .1$

${ }^{1344}$ UNHRC Chinsung Chung, 'The necessity of a human rights approach and effective United Nations mechanism for the human rights of the older person, 'A/HRC/AC/4/CRP.1

${ }^{1345}$ CESCR General Comment No.1 'Reporting by States Parties,' 6 Adopted at the Thirteenth Session of the Committee on Economic, Social and Cultural Rights, on 27 July 1981 (Contained in Document $\mathrm{E} / 1989 / 22)$
} 
terms of breach of State obligations of conduct and result. ${ }^{1346}$ Given the inter-linked nature of Thematic Domains, Fundamental Capabilities and the vulnerabilities of older people, and the fact that Fundamental Capabilities are the outcome of rights, a move towards unified indicators is recommended when possible. This argument is aligned to the view of the UN that use of different indicators between the generations of rights sits uneasily with the interdependent nature of all human rights. ${ }^{1347}$

Whether measurement is of the realisation of universal human rights in the general population, or in concrete situations of vulnerable individuals, indicators must be grounded in international human rights standards. However, when developed in response to experiences of vulnerability, a more accurate measure of the effect given to rights for vulnerable groups and individuals is achieved. ${ }^{1348}$

\subsection{Implementation gaps by thematic domains}

This section of the chapter examines implementation of existing rights in the context of the Fundamental Capabilities listing devised in the previous chapter.

\subsubsection{Life}

(A) Avoid premature mortality, and have life maintained and prolonged, when possible, in accordance with increased life expectancy

The vulnerabilities, normative gaps, and subsequent Fundamental Capabilities identified for older people in the instant thematic domain could benefit from implementation of recommendations made by the Human Rights Committee. The broader normative view taken by the HRC of the right develops an implementation methodology in accordance with an expectation of the maintenance and prolonging of life in response to increased life expectancy. A positive duty to employ measures to lessen conditions "that may eventually

\footnotetext{
${ }^{1346}$ United Nations 'Human Rights Indicators: A Guide to Measurement and Implementation,' 25 http://www.ohchr.org/Documents/Publications/Human rights indicators en.pdf accessed 20/09/2017

${ }^{1347}$ United Nations 'Human Rights Indicators: A Guide to Measurement and Implementation,' 25 http://www.ohchr.org/Documents/Publications/Human rights indicators en.pdf accessed 20/09/2017

${ }^{1348}$ United Nations 'Human Rights Indicators: A Guide to Measurement and Implementation,' 133 http://www.ohchr.org/Documents/Publications/Human rights indicators en.pdf accessed 20/09/2017
} 
give rise to direct threats to life,"1349 including "the prevalence of life threatening diseases, ${ }^{1350}$...hunger, malnutrition and extreme poverty and homelessness ${ }^{\prime 1351}$ is stated. In addition, long-term measures are suggested to enable access to essentials including food, ${ }^{1352}$ healthcare and healthy living conditions, ${ }^{1353}$ and medical treatments. ${ }^{1354}$ The Committee also recognises the interdependence of the right to life with other civil and political rights, and calls for rights to be conjointly interpreted. Most relevant to older people in this regard is the association with, and instruction to protect against, inhuman and degrading treatment with a view to the threat posed to life. ${ }^{1355}$ Moreover, co-operation between the two generations of rights would be necessary for fulfilment of interests of older people in the right to life, defined in Fundamental Capabilities. Such co-operation remains unacknowledged by the HRC. Instruction on reporting and monitoring relates directly to recording and accounting for acts resulting in death by the State and State actors. Instances of reporting on statistical or factual indicators are extremely limited, and of no relevance to older people.

\section{(B) Be protected from arbitrary taking of life}

Normative provision of the right to not be arbitrarily deprived of life ${ }^{1356}$ and instruction to States to "refrain from engaging in conduct resulting in deprivation of lives"1357 is open to

${ }^{1349}$ Yuval Shany and Nigel Rodley, Rapporteurs HRC Draft General Comment No. 36 Article 6: Right To life, 28 115th session 19 October - 6 November 2015 CCPR/C/GC/R.36/Rev.2

${ }^{1350}$ Concluding Observations: Kenya (2012), para. 9 (as cited in Yuval Shany and Nigel Rodley, Rapporteurs HRC Draft General Comment No. 36 Article 6: Right To life, 28 115th session 19 October - 6 November 2015 CCPR/C/GC/R.36/Rev.2)

${ }^{1351}$ General Comment 6, at para. 5. Concluding Observations: Canada (1999), at para 12 (as cited in Yuval Shany and Nigel Rodley, Rapporteurs HRC Draft General Comment No. 36 Article 6: Right To life, 28 115th session 19 October - 6 November 2015 CCPR/C/GC/R.36/Rev.2)

1352 Concluding Observations: Democratic People's Republic of Korea (2001), at para. 12. (as cited in Yuval Shany and Nigel Rodley, Rapporteurs HRC Draft General Comment No. 36 Article 6: Right To life, 28 115th session 19 October - 6 November 2015 CCPR/C/GC/R.36/Rev.2)

${ }^{1353}$ Concluding Observations: Israel (2014), at para. 12. (as cited in Yuval Shany and Nigel Rodley, Rapporteurs HRC Draft General Comment No. 36 Article 6: Right To life, 28 115th session 19 October - 6 November 2015 CCPR/C/GC/R.36/Rev.2)

${ }^{1354}$ Yuval Shany and Nigel Rodley, Rapporteurs HRC Draft General Comment No. 36 Article 6: Right To life, 28 115th session 19 October - 6 November 2015 CCPR/C/GC/R.36/Rev.2

${ }^{1355}$ No one shall be subjected to torture or to cruel, inhuman or degrading treatment or punishment. ICCPR, Article 7.

1356 ICCPR, Article 6, The inherent right to life.

${ }^{1357}$ Yuval Shany and Nigel Rodley, Rapporteurs HRC Draft General Comment No. 36 Article 6: Right To life, 11 115th session 19 October - 6 November 2015 CCPR/C/GC/R.36/Rev.2 
issues of cultural relativity. The problems associated with reliance on domestic legislation and legislative provision of the term "arbitrary" can create inconsistency in implementation. ${ }^{1358}$ On this basis, the Article directly relating to the right to life, with limited normative applicability to older people, has the potential to further limit protection via implementation. Draft General Comment 36 develops the original intention of the right to life through instructions to "take exceptional measures of protection towards vulnerable persons." Older people are excluded from the listing of those considered vulnerable. However, the implementation order would serve to protect some older women, as the duty to protect extends to "alleged witches."1359

Draft Comment No. 36 includes implementation suggestions with the potential to overcome normative gaps in the right to life. However, given that the majority of the suggested measures are not binding on States parties, and achievable by means of the choice of individual States, the potential for implementation to compensate for normative gaps in the right to life is limited. Additionally, as the General Comment remains in draft format, suggested implementation remains aspirational. Thus implementation, as it exists, is unable to compensate for gaps in current normative provision in order to correct the right to life such that it protects against vulnerabilities of older people.

\subsubsection{Successful Ageing}

(A) Health

The CESCR is persuasive, rather than assertive, in recommendations for implementation of the right to the highest attainable standard of physical and mental health in General Comment No. 6. ${ }^{1360}$ The Committee yields to the Vienna International Plan of Action on Ageing for implementation recommendations. Guidelines for States to execute via health policy are aligned to the proposed draft General Comment 36 of the civil and political right to life, and General Comment 14 of the right to the highest attainable standard of health. The Committee suggests the following for inclusion in health policy: preservation of healthy life; preventative, rehabilitative and palliative treatment; maintenance of functional

\footnotetext{
${ }^{1358}$ Yuval Shany and Nigel Rodley, Rapporteurs HRC Draft General Comment No. 36 Article 6: Right To life, 16 115th session 19 October - 6 November 2015 CCPR/C/GC/R.36/Rev.2

${ }^{1359}$ Yuval Shany and Nigel Rodley, Rapporteurs HRC Draft General Comment No. 36 Article 6: Right To life, 26 115th session 19 October -6 November 2015 CCPR/C/GC/R.36/Rev.2. See also: Report of the Special Rapporteur on extrajudicial, summary or arbitrary executions of 27 May 2009, para. 68 ${ }^{1360}$ CESCR General Comment No. 6 (1995) The economic, social and cultural rights of older persons
} 
capacity; and minimising effects of cumulative disadvantage. However, States are instructed to merely "take account" of the normative content of the VIPAA. ${ }^{1361}$ The inability to definitively instruct inclusion of the "soft law" in domestic policy also impacts on the use of indicators and monitoring. The suggestions for health policy provide a strong basis for statistical and qualitative indicators, and a measure of the success of implementation in compensating for normative gaps in the fulfilment of interests of older people in the right. Furthermore, the Fundamental Capabilities identified as outcomes necessary for the fulfilment of the right to the highest standard of physical and mental health for the group correspond to such indicators. ${ }^{1362}$

Allocation of resources will control the fulfilment of interests in rights. Therefore, equity requires States parties to interpret and implement the underlying principles of accessibility and availability in accordance with non-discrimination as stated in Article 2.2, ${ }^{1363}$ prohibiting "denying or limiting equal access for all persons."1364 However, the guarantee enunciated fails to include age as a ground for non-discrimination, resulting in the risk for States to fail in the obligation of respect. The exclusion of "vulnerable groups" per se, and older people specifically from the listing of groups to be guaranteed non-discriminatory access to "preventative, curative, and palliative health services"1365 could exacerbate gaps in the implementation of the right for older people. Similarly, the direction by the CESCR for the duty to provide non-discriminatory availability, accessibility and quality of health care in the private sector is cited without reference to the group. The potential implementation gap is not limited to unequal access to the right, but to prevention of the critical "preferential treatment" required by the vulnerabilities specific to the group.

\footnotetext{
${ }^{1361}$ CESCR General Comment No. 6 (1995) The economic, social and cultural rights of older persons, 34

${ }^{1362}$ Indicators are stated as being based on the normative content of Article 12, which demonstrates normative gaps in the provision of the right to health for older people. CESCR General Comment No. 14 The right to the highest attainable standard of health (article 12), 57, 5811 August 2000

E/C.12/2000/4; Article 12 (2) (a) International Convention on Economic, Social and Cultural rights. The provision for the reduction of the stillbirth-rate and of infant mortality and for the healthydevelopment of the child ${ }^{1363}$ CESCR General Comment No. 14 The right to the highest attainable standard of health (article 12), 3011 August $2000 \mathrm{E} / \mathrm{C} .12 / 2000 / 4$

${ }^{1364}$ CESCR General Comment No. 14 The right to the highest attainable standard of health (article 12), 3411 August $2000 \mathrm{E} / \mathrm{C} .12 / 2000 / 4$

${ }^{1365}$ CESCR General Comment No. 14 The right to the highest attainable standard of health (article 12), 3411 August 2000 E/C.12/2000/4
} 
Traditional practices and harmful societal attitudes are recognised as third party influences against which the State has a duty to protect. The CESCR makes explicit reference to women in this regard. ${ }^{1366}$ However, the opportunity is not taken to protect against societal perceptions, and subsequent treatment, of older people, for example, to levy charges for medical care on older people which are available free-of-charge to younger people. The single express inclusion of older people by the Committee in implementation of the obligation to protect prohibits violent medical procedures.

By virtue of CEDAW, more precise instruction is provided on policies and measures to be implemented for older women. CEDAW General Recommendation No. 27 lists the inclusion of the following in health care policy: elimination of user fees; training of health workers in geriatric illnesses; medical treatment of age-related chronic and non-communicable diseases; long-term health and social care; screening for diseases prevalent in older women; and palliative care. ${ }^{1367}$

Older people with access to the protection of the CRPD could benefit from "measures" which States parties are encouraged to implement to provide for special health needs, ${ }^{1368}$ and prevent discriminatory treatment of people with disabilities. ${ }^{1369}$

Suggestions by the CESCR for implementation of retirement-preparation programmes via domestic policy would assist in overcoming barriers to "successful ageing" caused by this new life trajectory. Such policies are primarily information-giving and facilitation in the fields of pensions, further occupational or voluntary activities, development and cultural activities, and achieving successful ageing. ${ }^{1370}$ Policy must also extend trade union rights to older people continuing to work beyond retirement age. ${ }^{1371}$

Factors of restricted resources and marginal discretion relating to local health issues influence the rationale for the instruction by the CESCR to report primarily on domestically

\footnotetext{
${ }^{1366}$ Citing female mutilation as a harmful traditional practice

${ }^{1367}$ CEDAW General recommendation No. 27 on older women and protection of their human rights, 45, 16 December 2010 CEDAW/C/GC/27

${ }^{1368}$ CRPD, Article 25(b)

${ }^{1369}$ CRPD, Article 25(f)

${ }^{1370}$ CESCR General Comment No. 6 'The economic, social and cultural rights of older persons,' 24 Adopted at the thirteenth session ( $39^{\text {th }}$ meeting), on 24 November 1995

${ }^{1371}$ CESCR General Comment No. 6 'The economic, social and cultural rights of older persons,' 25 Adopted at the thirteenth session ( $39^{\text {th }}$ meeting), on 24 November 1995
} 
decided benchmarks and indicators. ${ }^{1372}$ This thesis suggests indicators, both fact-based and qualitative in nature to monitor implementation. Implementation is viewed in this regard as representative of normative provision required to fulfil interests of older people in rights, and to compensate for normative provision in the existing framework.

The structure of the vulnerabilities framework, and the framework of thematic domains and fundamental capabilities based on it allow for recognition of the inter-linked nature of vulnerability, and the inter-dependent nature of rights. Therefore, aspects related to the right to an adequate standard of living are included in this section.

In recognition of the fundamental significance of the right to food, the CESCR suggests incorporation into domestic law. The Committee thus authorises domestic courts to order implementation of obligations and effective remedy, to include compensation and nonrepetition of violations. ${ }^{1373}$ Progressive realisation receives specific guidance from the CESCR in attempts to ensure effective implementation of the right to food. The situation of vulnerable groups is acknowledged in instruction for implementation of the right to food. Specifically, the Committee guides the process of giving effect to the right for such rightsholders by stating the need for "preferential treatment" "Even where a State faces severe resource constraints"1374.

In order to prevent repeated violations of the right States parties are advised to monitor obstacles to implementation in addition to the generally required changes to legislation and implementation of measures to fulfil obligations (under articles 2.1 and 23). The direction given lacked specific reference to monitoring the same for vulnerable groups. Therefore,

${ }^{1372}$ CESCR General Comment No. 14 Substantive Issues Arising In The Implementation of the International Covenant on Economic, Social and Cultural Rights. The right to the highest attainable standard of health (article 12 of the International Covenant on Economic, Social and Cultural Rights) 2000, 53 \& 57

${ }^{1373}$ CESCR General Comment No. 12 'Substantive Issues Arising in the Implementation of the International Covenant on Economic, Social and Cultural Rights' The right to adequate food (art. 11), 32-33 (Twentieth session, 1999) 12 May 1999 EC.12/1999/5

${ }^{1374}$ CESCR General Comment No. 12 'Substantive Issues Arising in the Implementation of the International Covenant on Economic, Social and Cultural Rights' The right to adequate food (art. 11), 28 (Twentieth session, 1999) 12 May 1999 EC.12/1999/5 
there is potential for obstacles specific to implementation of the right for older people to be overlooked or subsumed by inclusive reference to "all."1375

The General Comment dedicated to the economic, social and cultural rights of older people makes no reference to specific methods of implementation of the right to food for the group. It is insufficient to surmise that the focus on social security by the Committee would wholly correct inability to access food. The CESCR would more fully protect the interests of older people in the right if implementation addressed situations of natural disaster, ${ }^{1376}$ and ease of physical accessibility, particularly for those living in remote areas, in addition to financial aid or social security.

General Comment No. 6 refers once more to the VIPAA for the recommendation of housing policy in the context of an adequate standard of living for older people. Implementation of the proposals would largely succeed in overcoming gaps in normative provision with direct impact on outcomes of the instant Fundamental Capability, successful ageing, and emplacement. The physical and mental embodied vulnerabilities of older people are recognised in the recommendation to incorporate provision of accommodation suitable to changing abilities in housing policy. ${ }^{1377}$ Such policy would have the effect of improving standards of living and enabling the older person to remain at home for as long as possible. Health of older people would also benefit from implementation of housing policy included under the earlier capability to successful ageing. Given the association identified between social isolation, disengagement and health in Part III, housing development and transportation aimed at facilitating social integration is of relevance to this facet of attaining adequate standards of living and the highest possible standards of physical and mental health.

\section{(B) Activity}

In response to the normative provision of the ICESCR, the CESCR obliges States to formulate and implement employment policy and allocation of resources to increase the employment rate amongst, inter alia, disadvantaged groups. Also included are positive measures to

${ }^{1375}$ CESCR General Comment No. 12 'Substantive Issues Arising in the Implementation of the International Covenant on Economic, Social and Cultural Rights' The right to adequate food (art. 11), 31 (Twentieth session, 1999) 12 May 1999 EC.12/1999/5

${ }^{1376}$ Research of older people in Part III demonstrated discrimination against older people in the allocation of aid.

${ }^{1377}$ VIPAA Recommendation 19; CESCR General Comment No. 6 'The economic, social and cultural rights of older persons,' 33 Adopted at the thirteenth session ( $39^{\text {th }}$ meeting), on 24 November 1995 
provide training and education. ${ }^{1378}$ If included in the catch-all "disadvantaged groups" this instruction by the CESCR could facilitate implementation of the right such that the instant Fundamental Capability could be achieved. However, without any specific reference to older people, it falls to General Comment No. 6 to further consider the instructions of General Comment No. 18. The former instructs States parties to implement measures to prevent discrimination on the grounds of age in opportunities for employment, and in occupation. ${ }^{1379}$ Therefore, it is incumbent on States parties to fulfil this interest held by older people in the right to work.

\section{(C) Engagement}

In an attempt to overcome vulnerability to social isolation, the CESCR refers to Recommendation 20 of the VIPAA. States parties are, therefore, instructed on urban rebuilding and development, and directed to "pay special attention" to the needs of older people in policy and legislation. ${ }^{1380}$ If implemented, further suggestion by the VIPAA, supported by the CESCR, would provide transportation in accordance with innate and internal capabilities, ${ }^{1381}$ enabling access to vital services and the community in policy. ${ }^{1382}$

\subsubsection{Inviolability of the Body}

(A) Practice autonomy and self-determination, with the aid of supportive decisionmaking if necessary, with regard to: own body and institutional detention

The normative limitation of the right to self-determination included in the ICCPR ${ }^{1383}$ is not saved by implementation instructions issued by the HRC with regard to this Fundamental Capability. It is necessary to defer to Article $9^{1384}$ of the ICCPR for reference to autonomy or self-determination directly related to the instant Fundamental Capability. However, implementation of the right in order to achieve the outcome of the Fundamental Capability

\footnotetext{
${ }^{1378}$ CESCR General Comment No. 18 The Right to Work (Art. 6 of the Covenant), 26-27 6 February 2006, E/C.12/GC/18

${ }^{1379}$ CESCR General Comment No. 6 The Economic, Social and Cultural Rights of Older Persons, 228 December 1995,E/1996/22

${ }^{1380}$ VIPAA Recommendation 20; CESCR General Comment No. 6 'The economic, social and cultural rights of older persons,' 33 Adopted at the thirteenth session (39 ${ }^{\text {th }}$ meeting), on 24 November 1995

${ }^{1381}$ Innate capabilities are the physical and mental capabilities and traits a person is born with. Internal capabilities are innate capabilities developed throughout life.

${ }^{1382}$ VIPAA Recommendation 22; CESCR General Comment No. 6 'The economic, social and cultural rights of older persons,' 33 Adopted at the thirteenth session ( $39^{\text {th }}$ meeting), on 24 November 1995 ${ }^{1383}$ ICCPR, Article 1 'By virtue of that right they freely determine their political status and freely pursue their economic, social and cultural development' ${ }^{1384}$ Right to liberty and security of the person
} 
is limited when a narrow interpretation of the right is adopted. ${ }^{1385}$ The HRC attempts to correct the prevalence of narrow interpretation by States parties, demonstrated in the reporting of implementation of the right. The Committee stresses that implementation must include individuals deprived of liberty due to, inter alia, involuntary hospitalization and mental illness. ${ }^{1386}$ The non-implementation of the right in such cases would affect all older people detained in such institutions without the opportunity to exercise self-determination, autonomy, or assisted decision-making. The Committee broadens the scope of the obligation of Article 9 to include private bodies and individuals authorised by the State to exercise powers of detention. ${ }^{1387}$ However, the strengthening of implementation processes in this instance is dependent upon a normative interpretation of "detention," inclusive of the detention of older people in medical, psychiatric, and residential institutions.

The Committee instructs States parties on measures to be implemented as part of obligations of result and positive conduct in relation to deprivation of liberty resulting from involuntary detention in hospital, and by virtue of disability. Provision of community-based social care services to individuals suffering from psychosocial disability demonstrates how targeted implementation processes work to narrow gaps in normative provision. However, the approach requires further development if the same is to be achieved for older people. If not discriminated against on the grounds of age, potential exists for implementation to overcome normative gaps in the fulfilment of interests in the right held by older people. This is particularly relevant given that the HRC instructs that disability per se is insufficient reason for implementing a deprivation of liberty. Moreover, the Committee also instructs the introduction of mental health legislation to prevent "arbitrary" detention. ${ }^{1388}$ However, as discussed above, implementation becomes subject to domestic legislation of "unlawfulness" and interpretations of "arbitrariness," limiting the scope of the right to liberty to realise the Fundamental Capability.

\footnotetext{
${ }^{1385}$ HRC General Comment No. 35 Article 9 (Liberty and security of person), 516 December 2014 Adopted by the Committee at its 112th session (7-31 October 2014), 3 CCPR/C/GC/35 1386 754/1997, A. v. New Zealand, para. 7.2 (mental health) as cited in HRC General Comment No. 35 Article 9 (Liberty and security of person), 516 December 2014 Adopted by the Committee at its 112th session (7-31 October 2014), $3 \mathrm{CCPR} / \mathrm{C} / \mathrm{GC} / 35$

${ }^{1387}$ HRC General Comment No. 35 Article 9 (Liberty and security of person) 16 December 2014 Adopted by the Committee at its $112^{\text {th }}$ session (7-13 October 2014), 8 CCPR/C/GC/35 ${ }^{1388}$ HRC General Comment No. 35 Article 9 (Liberty and security of person), 1916 December 2014 Adopted by the Committee at its 112th session (7-31 October 2014), 3 CCPR/C/GC/35
} 
Supported decision-making is reliant upon implementation of the right to equal recognition before the law. Methods of implementation most applicable to older people in this regard are those stated by the Committee on the Rights of Persons with Disabilities. The Committee proposes supported decision-making in place of substituted decision-making on the grounds of "universal legal capacity." ${ }^{\text {"1389 }}$ Implementation therefore recognises "all persons, regardless of disability or decision-making skills," as "inherently possessing legal capacity. ${ }^{\prime 1390}$ The underlying direction for implementation is the abolition of presumption of a lack of legal capacity that is "discriminatory on the basis of disability in purpose or effect." ${ }^{\prime 1391}$ Moreover, objectives of implementation of supported decision-making include overcoming practices of substituted decision-making detrimental to autonomy. Those most targeted by the CRPD in implementing the right include: removal of capacity; third party appointment of substitute decision-maker; appointment of substitute decision-maker against the will of the individual; and decisions based in objective "best interests" rather than subjective interests and preferences of the individual. ${ }^{1392}$ The Committee cites legislation permitting substitute decision-making, specifically by guardianship or trusteeship to be replaced with that which provides supported decision-making. ${ }^{1393}$ Areas specifically determined as requiring implementation of supported decision-making in the CRPD General Comment include medical treatment and the right to liberty, discussed above in the context of institutional detention. Protection of inclusive decision-making extends to the stipulation that policy and legislation must not manipulate supported decision-making for purposes of limiting rights governing medical treatment or liberty. ${ }^{1394}$

Older people with access to the special protection of the CRPD would benefit from the approach of "universal legal capacity" facilitated via supported decision-making, assuming that age is considered a ground for non-discrimination. However, the risks created by societal perception of older people and the self-perception which results, discussed at

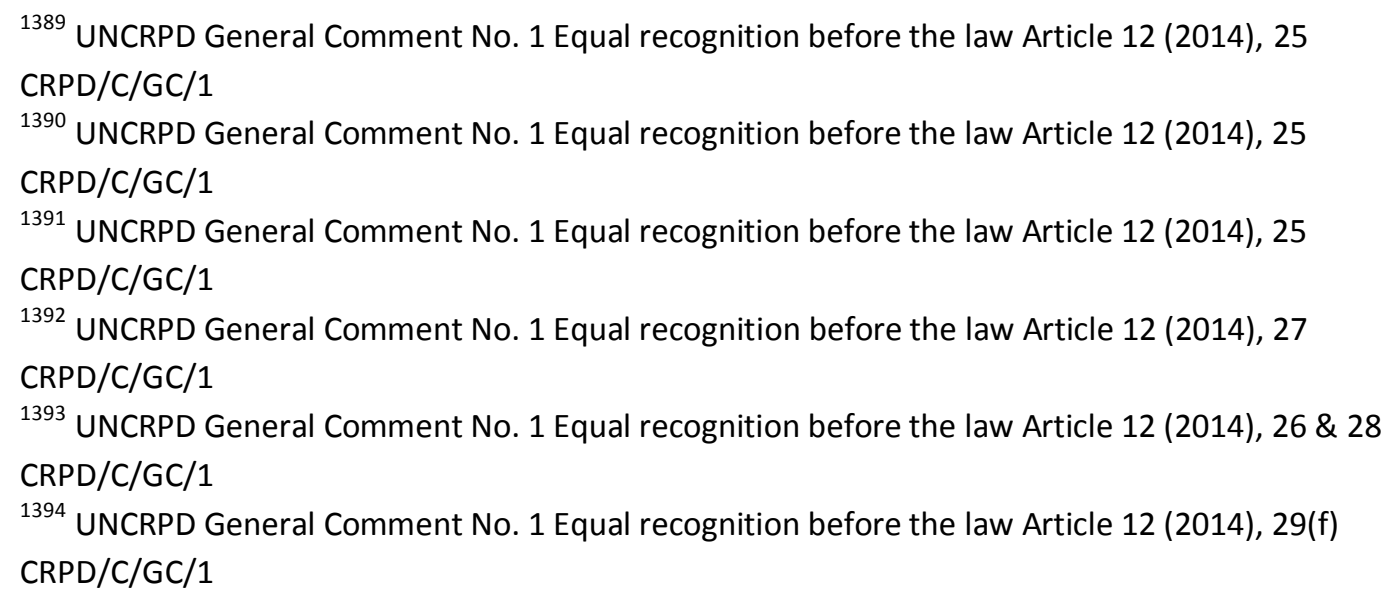


length in Chapter $9,{ }^{1395}$ coupled with the precarious representation of age in nondiscrimination human rights provision, cannot universally guarantee such protection. Therefore, if normative gaps in rights provision are to be overcome, and the outcome of the Fundamental Capability to be achieved, implementation is required to make the same provision for older people.

(B) Freedom from all forms of abuse, violence, exploitation, and neglect

The normative contribution of the ICCPR to this aspect of the Fundamental Capability to inviolability of the body is contained in Article $7 .{ }^{1396}$ The implementation of the freedom from treatment is interpreted by the UN in negative terms; reliant on the conduct obligation of respect. The focus of the HRC, in maintaining this obligation and not extending the reach beyond the stated normative content, is not inclusive of the interests in the right of older people. Therefore, whilst gaps in implementation of the normative content of the right are difficult to argue, implementation does not assist in achieving the outcome of the Fundamental Capability incorporating the valued capabilities and functionings of the group.

In order to achieve more comprehensive implementation of the right, the Committee adds to the obligation of the State. The General Comment places a positive duty on the State to protect "dignity and mental and physical integrity" through legislation and "other measures." ${ }^{1397}$ Furthermore, the Committee instructs that Articles 7 and 10 be considered in conjunction when appropriate. ${ }^{1398}$ This thesis argued in the previous chapter that persons deprived of liberty should include older people detained in medical, psychiatric, or residential care institutions. Therefore, the ground would be laid for instruction to impose measures or legislation necessary to the protection of older people as defined in the listing of capabilities. Furthermore, the group would qualify for the threshold of inhuman and degrading treatment applied to detainees under the control of the State. In the absence of such implementation, older people are subject to imprecise thresholds sufficient to constitute inhuman and degrading treatment, which become a matter for judicial interpretation. The Capabilities Approach broadly divides thresholds into standards of

\footnotetext{
1395 Theories of Ageing

${ }^{1396}$ The right to freedom from torture, inhuman and degrading treatment or punishment

${ }^{1397}$ HRC General Comment No. 20 Article 7 (Prohibition of Torture, or Other Cruel, Inhuman or Degrading Treatment or Punishment), 10 March 1992 Adopted at the Forty-fourth Session of the Human Rights Committee, 2

${ }^{1398}$ Article 10 (1), ICCPR 'All persons deprived of their liberty shall be treated with humanity and with respect for the inherent dignity of the human person'
} 
"equality" and "bare minimum;"1399 the former largely engaged by civil and political rights, the latter by socio-economic rights. However, given the nature of the embodied vulnerabilities of older people, this thesis suggests the threshold of "bare minimum" be implemented to further limit inadequacies in implementation of the right.

General Comment No. $20^{1400}$ exemplifies attempts by the HRC to narrow implementation gaps, by extending bearers of the negative duty to include the State, private entities and individuals acting in official or private capacities. ${ }^{1401}$ Given the scope of inhuman and degrading treatment suffered by older people, the locations where it takes place, and perpetrators, implementation of this obligation, as amended, is necessary to achieve the outcomes of the Fundamental Capabilities. Article 16 of the CRPD ${ }^{1402}$ supports HRC General Comment No 20 in this regard. The Convention on the Rights of Persons with Disabilities instructs States parties to implement legislation, policy and any other appropriate measures to protect against violence, exploitation and abuse "within and outside the home."1403 Implementation methods employed by the CRPD extend beyond legislation, and develop policy to include, for example, "protection services" to facilitate recovery and social reintegration of victims. ${ }^{1404}$ Policy for education is also directed to educate family and caregivers on recognition, avoidance, and reporting of abuse. ${ }^{1405}$ Finally, the CRPD instructs the monitoring of implementation via independent bodies. ${ }^{1406}$

The HRC also recognises the significance of reporting and measuring the success of implementation. Explicitly, States should inform the Committee of legislation and measures adopted, and methods used to give effect to Article 7. ${ }^{1407}$ In addition, the Treaty Monitoring Board requires information on the legislative, administrative, judicial and other measures

\footnotetext{
${ }^{1399}$ See Chapter 6, 'Capabilities Approach'

${ }^{1400}$ (Prohibition of Torture, or Other Cruel, Inhuman or Degrading Treatment or Punishment), 10 March 1992 Adopted at the Forty-fourth Session of the Human Rights Committee

${ }^{1401}$ HRC General Comment No. 20 Article 7 (Prohibition of Torture, or Other Cruel, Inhuman or Degrading Treatment or Punishment), 10 March 1992 Adopted at the Forty-fourth Session of the Human Rights Committee, 2

${ }^{1402}$ Freedom from exploitation, violence and abuse, Article 16 CRPD

${ }^{1403}$ Article 16(1), CRPD

${ }^{1404}$ Article 16(4), CRPD

${ }^{1405}$ Article 16(2), CRPD

${ }^{1406}$ Article 16(5), CRPD

${ }^{1407}$ HRC General Comment No. 20 Article 7 (Prohibition of Torture, or Other Cruel, Inhuman or Degrading Treatment or Punishment), 10 March 1992 Adopted at the Forty-fourth Session of the Human Rights Committee, 14
} 
taken to prevent and punish acts of torture and cruel, inhuman and degrading treatment. ${ }^{1408}$ However, the Committee would improve implementation by instructing reporting and monitoring of aggravated vulnerabilities of population groups, including older people, to violations of this right.

The CEDAW is specific on State obligation to protect older women against violence. Signatories to the Treaty are instructed to draft legislation precisely determining types of violence suffered by older women, and prohibiting all such acts. Included are domestic and sexual violence and violence in institutional settings. Furthermore, acts of violence against older women permitted by culture are also instructed to be legislated against. The obligation also specifies prosecution and punishment of all acts. ${ }^{1409}$ This approach to specific identification of forms of abuse and violence are required for older people as a group. Moreover, it informs indicators and measurement of outcome.

\subsubsection{Independence}

(A) Live to the greatest extent possible free from "inevitable dependencies" of inevitable embodied vulnerability:

The CESCR General Comment No. 6 draws on the UNPOP interpretation of "independence." Therefore, independence is viewed in terms of health and care. ${ }^{1410}$ Reference to care and support is made in the context of familial care, which this thesis considers under the later Fundamental Capability of "To maintain family life in that "place", including family care and support in accordance with cultural and personal choice." ${ }^{1411}$ The Fundamental Capability to have care enabling performance of activities of daily living refers specifically to social and personal care.

CEDAW instructs States parties to implement social care measures to facilitate independent living for older women. ${ }^{1412}$ Of the human rights instruments, the CRPD calls for the

\footnotetext{
${ }^{1408}$ HRC General Comment No. 20 Article 7 (Prohibition of Torture, or Other Cruel, Inhuman or Degrading Treatment or Punishment), 10 March 1992 Adopted at the Forty-fourth Session of the Human Rights Committee, 8

${ }^{1409}$ CEDAW General recommendation No. 27 on older women and protection of their human rights 16 December 2010, 37 CEDAW/C/GC/27

${ }^{1410}$ General Comment No. 6 'The economic, social and cultural rights of older persons,' 30 Adopted at the thirteenth session ( $39^{\text {th }}$ meeting), on 24 November 1995, 5

${ }^{1411}$ See Fundamental Capability 7B

${ }^{1412}$ CEDAW General recommendation No. 27 on older women and protection of their human rights, 45, 16 December 2010 CEDAW/C/GC/27
} 
implementation of policies of most relevance to the needs of older people to live independently. The Convention states the need for "effective and appropriate measures to facilitate access to" personal assistance necessary to support living at their place of residence. ${ }^{1413}$ However, the vulnerabilities of older people to inability to achieve the Fundamental Capability to have care enabling performance of activities of daily living are most appropriately recognised by Age Platform Europe. ${ }^{1414}$ The NGO suggests the implementation of the following in health policy: health and social care for activities of daily living (ADL) and instrumental activities of daily living (IADL). The former includes eating, bathing, dressing, grooming, housekeeping, and leisure. Instrumental activities of daily living relate to issues such as managing one's finances, shopping, using the telephone, transportation, and in some countries other activities such as taking medication. Policy is advised to allow delivery of such assistance "in various settings spanning the continuum from the beneficiary's home to intermediate care and (semi-) residential facilities." 1415

\section{(B) To have financial means to sustain independence}

The CESCR instructs on implementation of the right to social security by means of policy and law in the context of older people. Implementation will be subject to the limits of available resources. Nonetheless, the policy to be implemented must provide for the normative stipulation of non-contributory old-age benefits and social services, ${ }^{1416}$ and survivor benefits of the older person reliant on the pension of the breadwinner. ${ }^{1417}$

The CESCR also specifies the informal economy for attention in implementation of the right to social security. Focus on this sector of society could lessen a gap in the implementation of the right stated for older people when those employed in the informal economy, or living in rural areas are not well-served. Implementation is similarly restricted by giving effect in accordance with the maximum of available resources. "Measures" to be undertaken by States parties, however, can be more complex than for older people outside the informal

\footnotetext{
${ }^{1413}$ CRPD, Article 19(b)

${ }^{1414}$ AGE Platform Europe is a European network of non-profit organisations of and for people aged $50+$, which aims to voice and promote the interests of the 190 million citizens aged $50+$ in the European Union and to raise awareness on the issues that concern them most. http://www.ageplatform.eu/about-age accessed 10/04/2016

1415 http://www.age-platform.eu/about-age accessed 10/04/2016

${ }^{1416}$ CESCR General Comment No. 19 The right to social security (article 9) Thirty-ninth session 5-23 November 2007, 15 E/C.12/GC/19

${ }^{1417}$ CESCR General Comment No. 19 The right to social security (article 9) Thirty-ninth session 5-23 November 2007, 21 E/C.12/GC/19
} 
economy. The practice of informal social security schemes attracts the obligation for States to implement measures to prevent obstacles to access, in addition to the obligation to act to support such schemes. The Committee suggests adoption of universal pension and health care schemes to include those once employed in the informal economy to ensure equity. ${ }^{1418}$ Ultimately, the objective of all forms of implementation is to give effect to the normative provision (per General Comment 19 rather than the Convention) to financially provide for older people that an adequate standard of living and health can be achieved.

The CESCR responded to the limitations to implementation inherent in progressive realisation by stipulating non-discrimination obligations of immediate effect in compliance with Article 2.2 of the Convention. ${ }^{1419}$ Also in accordance with Article 2.2, States parties are obliged to "take steps," therefore; the action taken is a matter for the State, to fulfil the right to social security in order to fulfil the rights to an adequate standard of living and the highest attainable standard of health. However, as documented earlier, the Convention is unable to offer absolute guarantee of non-discrimination against older people due to exclusion of age as a ground for non-discrimination. Additionally, legislation and policy introduced to implement the normative requirement of social security must be given priority. In order to fulfil such obligations of immediate effect States are instructed to implement by virtue of international cooperation, if necessary. ${ }^{1420}$

CEDAW specifies the obligation to add age and gender to grounds for non-discrimination in legislation and policy required to facilitate equality in opportunity to work and payment of wages and social security. ${ }^{1421}$ Pensions policy which States parties are obliged to introduce must be non-discriminatory towards older women. CEDAW considers it necessary for States to introduce temporary special measures, if necessary, to ensure adequate pension provision to women. ${ }^{1422}$ Such measures are a matter for the individual State, complying with the obligation of result. Equality of older women with men in the pensions arena is also

\footnotetext{
${ }^{1418}$ CESCR General Comment No. 19 The right to social security (article 9) Thirty-ninth session 5-23 November 2007 E,34 /C.12/GC/19

${ }^{1419}$ CESCR General Comment No. 19 The right to social security (article 9) Thirty-ninth session 5-23 November 2007, 40 E/C.12/GC/19

${ }^{1420}$ CESCR General Comment No. 19 The right to social security (article 9) Thirty-ninth session 5-23 November 2007, $41 \mathrm{E} / \mathrm{C} .12 / \mathrm{GC} / 19$

${ }^{1421}$ CEDAW General recommendation No. 27 on older women and protection of their human rights 16 December 2010, 41 CEDAW/C/GC/27

${ }^{1422}$ CEDAW General recommendation No. 27 on older women and protection of their human rights 16 December 2010, 42 CEDAW/C/GC/27
} 
stated as a requirement in the implementation of non-contributory pensions. ${ }^{1423}$ The Committee advocates treatment to correct conditions ${ }^{1424}$ for non-economically productive older women. The entitlement to social benefits for undertaking care of family members should also be included in policy. ${ }^{1425}$

Statistical monitoring of the disparity and extent of unequal pay is not specifically required by the Committee. However, requirement is made of States parties to monitor the impact of gender-related pay gaps on older women. ${ }^{1426}$ General Comment 12 recognises the need to implement inter-dependent policies corresponding to inter-related human rights. For example, measures to facilitate access to physical resources as defined by Kirby in chapter $4^{1427}$ for older people; employment appropriate to skills, with remuneration sufficient for an adequate standard of living; and property and land ownership for older women, ${ }^{1428}$ should inter-link in response to the inter-linked nature of vulnerability.

The CESCR instructs States parties on policy regarding poverty in old age. Non-contributory old age pensions or the equivalent support should be incorporated into domestic administration for individuals lacking resources adequate to provide a healthy standard of living. In order to correct the particular vulnerability of older women to poverty, the Committee instructs equality for women to be stipulated in such policy. ${ }^{1429}$ The CESCR fails to address inequality between the genders in ownership of property, however. In not recognising this normative gap, the subsequent opportunity to compensate by means of stipulating implementation measures was also missed by the Committee.

Implementation of social security is stated by the CESCR as requiring incorporation into either policy or legislation of survivors' benefits for the inheritance of social security benefits

\footnotetext{
${ }^{1423}$ CEDAW General recommendation No. 27 on older women and protection of their human rights 16 December 2010, 44 CEDAW/C/GC/27

${ }^{1424}$ A situation attributed to a 'downward spiral of human rights violations.'

${ }^{1425}$ CEDAW General recommendation No. 27 on older women and protection of their human rights 16 December 2010, 43 CEDAW/C/GC/27

${ }^{1426}$ CEDAW General recommendation No. 27 on older women and protection of their human rights 16 December 2010, 41 CEDAW/C/GC/27

${ }^{1427}$ The resilience to vulnerability was categorised by Kirby as 'physical' (material and financial assets) 'social' (social interactions and relationships) and 'human' (innate or developed abilities to make the most of a given situation). Fineman added 'existential (beliefs, religion and moral values)

${ }^{1428}$ CESCR General Comment No. 12 'Substantive Issues Arising in the Implementation of the International Covenant on Economic, Social and Cultural Rights' The right to adequate food (art. 11), 26 (Twentieth session, 1999) 12 May 1999 EC.12/1999/5

${ }^{1429}$ CESCR General Comment No. 6 'The economic, social and cultural rights of older persons,' 21 Adopted at the thirteenth session ( $39^{\text {th }}$ meeting), on 24 November 1995
} 
or pension by a dependent older person. ${ }^{1430}$ Significantly, the Committee also stipulates the incorporation by States parties into legal administration of the provision of non-contributory state pensions for the individual lacking contribution payments or any other means of personal support. The obligation of poorer States parties is to make such provision to the maximum of available resources. ${ }^{1431}$ However, the international obligation must be triggered when the maximum of available resources is insufficient to provide a standard of living adequate to a healthy life.

\section{(C) To have a home}

The only right of the ICCPR which can be applicable to this Fundamental Capability and to the vulnerabilities identified in Part III is Article 17, ${ }^{1432}$ where "interference" would effect loss of, or removal from, the home. The same right is also of relevance to the capability to choose where and with whom to live, corresponding to vulnerability of emplacement of older people. Implementation of the civil and political right imposes the negative conduct obligation, together with the result obligation to impose legislation and measures to protect against interference. However, in similar vein to the right to life, this right is reliant on action permitted in accordance with domestic law for implementation. The HRC describes implementation thus: "...it is precisely in State legislation above all that provision must be made for the protection of the right set forth in that article." 1433 Therefore, "arbitrariness" which stands the test of domestic "unlawfulness" proves problematic for TMBs to monitor and control. As part of the monitoring of the implementation of the right, the Committee specifies information to be included in State reporting, providing a blueprint for all rights subject to the "arbitrariness" clause. Detail of the relevant domestic legislation and actions considered "arbitrary"; organs within the legal system authorised to "interfere" with the right; de facto versus legal interference; method, substance, and remedy of complaints. ${ }^{1434}$

\footnotetext{
${ }^{1430}$ CESCR General Comment No. 6 'The economic, social and cultural rights of older persons,' 29 Adopted at the thirteenth session ( $39^{\text {th }}$ meeting), on 24 November 1995

${ }^{1431}$ CESCR General Comment No. 6 'The economic, social and cultural rights of older persons,' 30 Adopted at the thirteenth session ( $39^{\text {th }}$ meeting), on 24 November 1995

${ }^{1432}$ ICCPR, Article 17(1) No one shall be subjected to arbitrary or unlawful interference with his privacy, family, home or correspondence.

${ }^{1433}$ HRC General Comment No. 16 Article 17 (Right to Privacy) The Right to Respect of Privacy, Family, Home and Correspondence, and Protection of Honour and Reputation, 2 Adopted at the Thirtysecond Session of the Human Rights Committee, on 8 April 1988

${ }^{1434}$ HRC General Comment No. 16 Article 17 (Right to Privacy) The Right to Respect of Privacy, Family, Home and Correspondence, and Protection of Honour and Reputation, 6 Adopted at the Thirtysecond Session of the Human Rights Committee, on 8 April 1988
} 
This right is included amongst those cited as one of the most badly reported. Therefore, it is not possible to conclude that implementation overcomes normative gaps.

The CESCR contributes to the ability to have a home via suggestions made in General Comment No. 7. ${ }^{1435}$ The Committee acknowledges the association of security of tenure with Article $17(1)$ of the ICCPR. ${ }^{1436}$ The suggestion of legislation to protect against loss of home specifically instructs for the repeal of any existing legislation not compatible with objectives of the Covenant, and which does not protect against violations of the right to adequate housing. ${ }^{1437}$ Specifically, the instruction is for "legislation providing security of tenure, and protection from eviction," and "legislation prohibiting any form of eviction". ${ }^{1438}$ Older people and women are stipulated as most vulnerable to the effects of the loss of a home which include violations of other rights. ${ }^{1439}$ However, implementation is accepted as restricted by the availability of resources. ${ }^{1440}$ As a result, progressive realisation can limit the protection offered against the vulnerability to homelessness for older people in both developed and developing countries. ${ }^{1411}$ The obligation to ensure domestically legitimate forced eviction does not create homelessness, or violate other human rights ${ }^{1442}$ is the general protection to which older people would need to appeal in this situation.

The Committee is particularly prescriptive with the reporting element of implementation of the right to adequate housing as it instructs on inclusion of statistical data: "the number of persons evicted within the last five years and the number of persons currently lacking legal protection against arbitrary eviction or any other kind of eviction." ${ }^{1443}$

The most prescriptive protection available to older people against homelessness is the implementation of the right to an adequate standard of living and social protection

\footnotetext{
${ }^{1435}$ CESCR General Comment No. 7 Article 11(1), The right to adequate housing, forced evictions, 9. $16^{\text {th }}$ session (1997)

${ }^{1436}$ Freedom from interference with the home

${ }^{1437}$ CESCR General Comment No. 7 Article 11(1), The right to adequate housing, forced evictions, 9. $16^{\text {th }}$ session (1997)

${ }^{1438}$ CESCR General Comment No. 7 Article 11(1), The right to adequate housing, forced evictions, 19.

$16^{\text {th }}$ session (1997)

${ }^{1439}$ CESCR General Comment No. 7 Article 11(1), The right to adequate housing, forced evictions, 16. $16^{\text {th }}$ session (1997)

${ }^{1440}$ CESCR General Comment No. 7 Article 11(1), The right to adequate housing, forced evictions, 16. $16^{\text {th }}$ session (1997)

${ }^{1441}$ See chapter 10 for details on homelessness

${ }^{1442}$ CESCR General Comment No. 7 Article 11(1), The right to adequate housing, forced evictions, 16.

$16^{\text {th }}$ session (1997)

${ }^{1443}$ CESCR General Comment No. 7 Article 11(1), The right to adequate housing, forced evictions, 19. $16^{\text {th }}$ session (1997)
} 
enshrined in the CRPD. The instruction to States parties to ensure access by persons with disabilities to public housing programmes ${ }^{1444}$ would assist the older person with access to the CRPD by virtue of disability.

(D) To have ability to access services and the community

General Comment 6 of the CESCR draws on Recommendations of the VIPAA for implementation instructions. Building and planning legislation is informed to 'pay special attention to' the problems of ageing. This would include locating homes close to communities and services and providing relevant transport facilities. ${ }^{1445}$ The result would also have a positive effect on capabilities outcomes of engagement and participation. The CRPD also stipulates that States take "effective measures" to facilitate affordable mobility through the provision of aids and technology. ${ }^{1446}$

\subsubsection{Development and Flourishing}

(A) Be respected and accepted for contribution made to society, and choice of productive activity, whether or not economically productive.

The instrument which provides most explicitly for implementation of this outcome is CEDAW General Recommendation No 27. Implementation of the recommendation which states that

State parties must recognize that older women are an important resource to society, and have the obligation to take all appropriate measures, including legislation, to eliminate discrimination against older women

should be universally implemented to protect both genders of older people.

(B) Develop personality

CEDAW General Recommendation No 27 is also explicit regarding the implementation of rights to achieve this outcome. The obligation on States is to facilitate policies which provide full development and advancement of women throughout life. ${ }^{1447}$ The same approach needs to be taken for all older people if this outcome is to be attained by all older people.

${ }^{1444}$ CRPD, Article 28(d)

${ }^{1445}$ CESCR General Comment No. 6 'The economic, social and cultural rights of older persons,' 30

Adopted at the thirteenth session ( $39^{\text {th }}$ meeting), on 24 November 1995, 33

${ }^{1446}$ Article 20, UNCRPD

${ }^{1447}$ CEDAW General Recommendation No. 27, 30 


\subsubsection{Participation}

(A) Participate in and contribute to aspects of and influences over social, economic and political life

Multiple factors can contribute to an inability to participate for older people. The logistic barriers were the subject of implementation of access to services and the community, above. Denial on the basis of discrimination requires the intervention of legal capacity. The CRPD General Comment No. 1 stipulates that implementation of participation legislation must recognise that decision-making ability cannot justify exclusion from the right to vote, stand for election, or undertake jury service. Therefore, States must implement legislation stating equality before the law for all lacking decision-making capacity. ${ }^{1448}$ In addition to the contribution by the CRPD to older people with decision-making incapacity, the CEDAW provides a standard applicable to older people generally, but particularly in undeveloped countries. CEDAW recognises the barrier to participation caused by women not being provided with identification documentation. ${ }^{1449}$ However, the problem is widespread in developing countries amongst older people. Therefore, the obligation placed on States Parties to implement measures to facilitate the right to vote, possibly by means of legislation or provision of identification papers, for women should apply generally to older people. ${ }^{1450}$

\subsubsection{Emplacement}

(A) To experience life the "place" of one's choosing.

The two instruments of special protection in this examination of implementation provide the most appropriate examples of the method required to achieve this capabilities outcome. CEDAW stipulates that States must facilitate the removal of "barriers...that hinder the mobility of older persons and lead to forced confinement., ${ }^{1451}$ In addition, the CRPD instructs States Parties to take effective and appropriate measures to facilitate the opportunity to choose where and with whom to live, and to implement measures which prevent the individual being obliged to live in "a particular living arrangement." ${ }^{1452}$ Whilst of particular relevance to women and to persons with disabilities, the principles of choice, not

\footnotetext{
${ }^{1448}$ UNCRPD General Comment No. 1 (2014) Article 12: Equal recognition before the law, 48-50 CRPD/C/GC/1

1449 CEDAW General Recommendation 27, 17

1450 CEDAW General Recommendation 27, 39

${ }^{1451}$ CEDAW General Recommendation No. 27, 48

${ }^{1452}$ Article 19(a), UNCRPD
} 
to be institutionalised against one's wishes, and to have the facility not to be confined should be implemented for all older people.

(B) To maintain family life in that "place", including family care and support in accordance with cultural and personal choice.

General Comment No. 6 recognises the need to give effect to recommendations included in the Vienna International Plan of Action on Ageing. The CESCR targets older people living alone, older couples preferring to live at home, and low-income families willing but unable to support and care for older family members. As a result, a positive obligation, to be borne by the State and NGOs is asserted to create social services to facilitate institutional assets and social practices to fulfil the interests of older people. ${ }^{1453}$ Gen Rec 27 is once again explicit with regard to this outcome, and therefore bears reproduction for implementation for all older people. States parties are instructed to provide social services to facilitate independent living in the person's own home for as long as possible. ${ }^{1454}$ Furthermore, social benefits must be provided to older women caring for older relatives. This policy should be universally implemented to assist family care and support of older people generally. ${ }^{1455}$

\subsubsection{Legal Capacity}

\section{(A) Maintain legal capacity}

The main basis for denying legal capacity to older people is lack of decision-making capability. As discussed under the right to participation, above, the CRPD provides direction for implementation of the right to equal recognition before the law ${ }^{1456}$ in such a way that the individual maintains legal capacity. Maintaining legal capacity is also reliant on support in the decision-making process, which is the subject of the capability outcome below.

\section{(B) Have supported decision-making in all decisions regarding oneself}

The CRPD recognises the problems inherent in substituted decision-making and states that '...the exercise of legal capacity must respect the rights, will and preferences of persons...and

\footnotetext{
${ }^{1453}$ CESCR General Comment No. 6 'The economic, social and cultural rights of older persons,' 30 Adopted at the thirteenth session ( $39^{\text {th }}$ meeting), on 24 November 1995; Madrid International Plan of Action on Ageing, Recommendation 29

${ }^{1454}$ CEDAW General Recommendation No. 27, 48

${ }^{1455}$ CEDAW General Recommendation No. 27, 43

${ }^{1456}$ Article 12 , UNCRPD
} 
should never amount to substitute decision-making. ${ }^{1457}$ Therefore, all States Parties are instructed to implement supported decision-making via legislation and policy. ${ }^{1458}$ This would involve legislation or special measures to facilitate a right to allocate parties of the individual's choosing to act to give effect to personal will and preferences. Also, the support could involve advance decision-making; public and private parties; and varying degrees of support in accordance with capacity and type of decision. ${ }^{1459}$ Correct implementation of the right to equal recognition before the law enables capacity in the context of all rights, particularly those related to autonomy and to freedom from abuse and ill-treatment. Therefore, older people would be protected in situations of greatest vulnerability due to a lack of capacity, including: where and with whom to live; receipt of medical treatment; type of care and where to receive it; financial matters. ${ }^{1460}$ Moreover, implementation of substituted decision-making must not permit limitation of other fundamental rights. ${ }^{1461}$

\subsubsection{A Note on Implementation of Non-Discrimination}

Implementation of non-discrimination was demonstrated in the previous chapter to constitute an unsettled area of normative provision. The Committee states implementation of the obligation to ensure the rights of the Covenant to all people "without distinction of any kind"1462 is restricted specifically by the failure to include "age" as a ground for nondiscrimination in the normative provision. ${ }^{1463}$ The HRC comments directly on the limited grounds for non-discrimination cited in Article 2(1) of the ICCPR, ${ }^{1464}$ with an expectation for grounds beyond those stated to influence implementation. With specific reference to the right to equality before the law the Committee states, “...the application of the principle of non-discrimination...is not limited to those rights which are provided for in the

\footnotetext{
${ }^{1457}$ UNCRPD General Comment No. 1 (2014) Article 12: Equal recognition before the law, 17 $\mathrm{CRPD} / \mathrm{C} / \mathrm{GC} / 1$

${ }^{1458}$ UNCRPD General Comment No. 1 (2014) Article 12: Equal recognition before the law, 25 $\mathrm{CRPD} / \mathrm{C} / \mathrm{GC} / 1$

${ }^{1459}$ UNCRPD General Comment No. 1 (2014) Article 12: Equal recognition before the law, 17-19 $\mathrm{CRPD} / \mathrm{C} / \mathrm{GC} / 1$

${ }^{1460}$ UNCRPD General Comment No. 1 (2014) Article 12: Equal recognition before the law, 25 $\mathrm{CRPD} / \mathrm{C} / \mathrm{GC} / 1$

${ }^{1461}$ UNCRPD General Comment No. 1 (2014) Article 12: Equal recognition before the law, 29(f) $\mathrm{CRPD} / \mathrm{C} / \mathrm{GC} / 1$

${ }^{1462}$ ICCPR, Article 2 (1)

${ }^{1463}$ HRC General Comment No. 18 Non-discrimination, 9 Adopted at the Thirty-seventh Session of the Human Rights Committee, on 10 November 1989

${ }^{1464}$ Article 2, ICCPR '.... without distinction of any kind, such as race, colour, sex, language, religion, political or other opinion, national or social origin, property, birth or other status'
} 
Covenant," ${ }^{1465}$ and should not be implemented as such. There is an expectation, therefore, that any gap in normative provision for older people in this regard would be corrected via implementation. However, this is reliant on the introduction of self-measures and scrutiny by the TMB. ${ }^{1466}$ Included among these are measures of "unequal treatment" ${ }^{1467}$ introduced to achieve equality of outcome. ${ }^{1468}$ The HRC recommends unequal or preferential treatment for groups vulnerable to discrimination in fact or inequalities in dignity and capabilities outcomes. "For example, in a State where the general conditions of a certain part of the population prevent or impair their enjoyment of human rights, the State should take specific action to correct those conditions." ${ }^{1469}$ The lack of reporting for scrutiny of such measures contributes to imprecise identification of gaps in implementation of State obligation regarding older people, and prevents precise remedial action. Normative provision demonstrates that whilst age is the motivation for some examples of "unequal treatment, ${ }^{1470}$ this does not extend to older age. Without definitive normative basis, or instruction regarding implementation of rights for older people, conditions are such that normative gaps persist, and for implementation to be inadequate.

Specific issues of monitoring and reporting contribute to gaps in implementation of nondiscrimination. The HRC cites a proliferation of States parties rehearsing provisions in national constitutions or legislation proscribing discrimination, rather than recording de facto acts of discrimination, as the primary barrier to identification of practices and the development of implementation tools. ${ }^{1471}$ This practice is particularly prevalent in relation to legislation, measures and judicial decisions of equality between the sexes, ${ }^{1472}$ before the

${ }^{1465}$ HRC General Comment No. 18: Non discrimination Adopted at the Thirty-seventh Session of the Human Rights Committee, on 10 November 1989, 12

${ }^{1466}$ HRC General Comment No. 18: Non discrimination Adopted at the Thirty-seventh Session of the Human Rights Committee, on 10 November 1989, 4

${ }^{1467}$ HRC General Comment No. 18: Non discrimination Adopted at the Thirty-seventh Session of the Human Rights Committee, on 10 November 1989, 8

${ }^{1468}$ HRC General Comment No. 18: Non discrimination Adopted at the Thirty-seventh Session of the Human Rights Committee, on 10 November 1989, 8

${ }^{1469}$ HRC General Comment No. 18: Non discrimination Adopted at the Thirty-seventh Session of the Human Rights Committee, on 10 November 1989, 10

${ }^{1470}$ Article 6(5), ICCPR 'Sentence of death shall not be imposed for crimes committed by persons below eighteen years of age (and shall not be carried out on pregnant women);' Article 10(3), ICCPR 'Juvenile offenders shall be segregated from adults and be accorded treatment appropriate to their age and legal status'

${ }^{1471}$ HRC General Comment No. 18 Non-discrimination, 9 Adopted at the Thirty-seventh Session of the Human Rights Committee, on 10 November 1989

${ }^{1472}$ ICCPR, Article 3 
law, ${ }^{1473}$ and the obligation to implement human rights without distinction. ${ }^{1474}$ The Committee specifically cites gaps in implementation caused as a result of a lack of reporting on discrimination in fact by public bodies, private bodies, individuals, and the community. ${ }^{1475}$ This thesis suggests that reporting of such de facto discrimination, specific to the vulnerabilities of older people, should be grounded in principles of theories of ageing, including: loss of status; disengagement; perceptions of productivity; abandonment and social isolation.

\subsection{A Capabilities Approach to Implementation}

\subsubsection{The capability to the right to the capability}

The methodology of the Capabilities Approach in the implementation of human rights is summarised as providing the capability to the right to the capability: the opportunity to access the right that provides the outcome of capability. An overview of the process, below, refers to the explanation of the Capabilities Approach of chapter 6 .

The capability to the right requires the "opportunity" aspect of the version of the approach proffered by Sen, including the "opportunity to choose," "to exercise agency," and "to achieve valuable combinations of...what a person is able to do or be." The process of converting valuing beings and doings into the ability to be and do begins with opportunity to overcome obstacles inherent in basic, internal or external capabilities, which the State has a positive duty to provide. The opportunity aspect of the Capabilities Approach is, therefore, accessibility to the right: "...to put them in a position of capability to function in that area." ${ }^{1476}$ The process continues by translating the de jure right into a de facto right. When the normative content of the right, and the Vital Capabilities structured to underpin that right, correspond directly to the interests of the rights-holder, the objective of implementation is to achieve de facto the outcome of the central capability and the capability to "...function in a variety of areas of central importance." ${ }^{1477}$

\subsection{The United Nations Implementation Framework}

\footnotetext{
1473 ICCPR, Article 26

1474 ICCPR, Article 2(1)

${ }^{1475}$ HRC General Comment No. 18 Non-discrimination, 9 Adopted at the Thirty-seventh Session of the Human Rights Committee, on 10 November 1989

${ }^{1476}$ Martha Nussbaum Capabilities as Fundamental Entitlements: Sen and Social Justice, Feminist Economics, 9:2-3, 33-59, 370DOI: 10.1080/1354570022000077926

${ }^{1477}$ Martha Nussbaum 'Human Rights and Human Capabilities' Harvard Human Rights Journal Vol. 20, 21
} 
The inadequacies of State reporting and monitoring of rights implementation for purposes of identification of gaps has been repeatedly acknowledged by the United Nations in General Comments and expert reports. Ultimately, the UN identified the need for "a structured and consistent approach for translating universal human rights standards into indicators that are contextually relevant and useful at country level." ${ }^{1478}$ Such indicators are recognised by the UN as needing to be grounded in normative provision, and capable of measuring compliance with State duty. ${ }^{1479}$ In response, the UN developed a conceptual and methodological framework for identifying indicators which assists in measuring outcomes of rights. Principles of the framework borrow from the Capabilities Approach, ${ }^{1480}$ substantiating the premise of a Capabilities Approach to implementation. However, an examination of the methodology, specifically attributes of rights and indicators, demonstrates that the UN implementation framework fails to account for the vulnerabilities of older people.

The requirement of the implementation process to give effect to the normative content of rights remains central to discussion. The United Nations implementation framework was devised on the basis of attributes of each right representative of the normative content. From these a combination of structural, process, and outcome indicators were developed. Structural indicators denote the treaties, domestic legislation to be implemented with time frames. Process indicators measure how quantitative, qualitative, fact and subjective indicators will be sued. Process indicators in the UN framework direct outcome indicators. Furthermore, process indicators monitor the progressive realisation of human rights. ${ }^{1481}$ Outcome indicators were strongly derived from the UN Millennium Development Goals, ${ }^{1482}$

\footnotetext{
${ }^{1478} \mathrm{HRI}$ 'Report on Indicators for Promoting and Monitoring the Implementation of Human Rights,' 5 Twentieth meeting of chairpersons of the human rights treaty bodies Geneva, 26-27 June 2008 Seventh inter-committee meeting of the human rights treaty bodies Geneva, 23-25 June 2008, 6 June $2008 \mathrm{HRI} / \mathrm{MC} / 2008 / 3$

${ }^{1479} \mathrm{HRI}$ 'Report on Indicators for Promoting and Monitoring the Implementation of Human Rights,' 5 Twentieth meeting of chairpersons of the human rights treaty bodies Geneva, 26-27 June 2008 Seventh inter-committee meeting of the human rights treaty bodies Geneva, 23-25 June 2008, 6 June $2008 \mathrm{HRI} / \mathrm{MC} / 2008 / 3$

${ }^{1480}$ This is merely observational, as the UN does not credit the Capabilities Approach as the source

${ }^{1481}$ HRI 'Report on Indicators for Promoting and Monitoring the Implementation of Human Rights,' 19 Twentieth meeting of chairpersons of the human rights treaty bodies Geneva, 26-27 June 2008 Seventh inter-committee meeting of the human rights treaty bodies Geneva, 23-25 June 2008, 6 June $2008 \mathrm{HRI} / \mathrm{MC} / 2008 / 3$

${ }^{1482}$ Millennium Development Goals are: 1 . To eradicate extreme poverty and hunger; 2 . Achieve universal primary education; 3 . Promoted gender equality; 4 . Reduce child mortality; 5 . Improve maternal health; 6. Combat HIV, AIDS, Malaria and other diseases; 7. Ensure environmental sustainability; 8 . Global partnerships for development
} 
which are heavily focused on problems of developing countries. Recognising the need to consider the potential of individual rights as represented in both generations, twelve rights, evenly balanced between the two generations were selected upon which the framework was built, and from which attributes and indicators were developed. The framework thus devised by the UN assists in facilitating measurement of a broad interpretation and application of rights. Comparison of the attributes to the Fundamental Capabilities devised by this thesis for older people is made in Table number 11. The purpose is to illustrate attributes with applicability to the interests held by older people in human rights, and those which do not assist in achieving the outcomes of human rights stated as necessary for older people.

12.5.1 Comparison of United Nations implementation framework with Fundamental Capabilities for older people

The rationale for the comparison between the UN attributes of rights and indicators with the Fundamental Capabilities for older people lies in the role of the latter. The reader is reminded that the Fundamental Capabilities are grounded firstly in the vulnerabilities and threats to dignity of older people, supported by objectives and underlying principles of international human rights. As a result of the relationship discussed in Part II between the concepts of Vulnerability and Human Dignity and human rights, these capabilities underpin normative special protection rights for older people. Furthermore, the fact that Fundamental Capabilities are the outcomes facilitated by human rights, results in them providing the standard to be attained via structural, process and outcome objectives; to be measured by indicators.

The UN framework takes the attributes upon which to base indicators from universal international rights, demonstrated in the previous chapter to contain normative gaps when compared to the vulnerabilities of older people. Attributes taken from normatively inadequate rights are shown in Table number 11 to have little correspondence to the capabilities outcomes identified in this thesis as necessary to avoid outcomes of vulnerabilities for older people. Moreover, the outcome indicators derived from these attributes by the UN provide little measurement of the capabilities outcomes. Ultimately, despite adopting a Capabilities-esque Approach, the United Nations fails to overcome normative gaps in international human rights, and to adequately implement universal rights in order to protect the interest held in rights by older people. 
The framework is not saved by disaggregation. A statement is included that indicators must be applied in accordance with disaggregation as set out in meta-data sheets. However, a survey of the disaggregation instructions demonstrated disaggregation to be ineffectual to older people. The indicator reporting the proportion of complaints received on the right not to be subjected to torture etc., aimed at identifying patterns of abuse towards population groups requires disaggregation by age. Thus, it is possible to identify patterns of abuse towards older people using this indicator. The other indicator specifying disaggregation by age, which has applicability to older people, is "reported cases of forced evictions." However, interest of the UN in this indicator lies in children and younger people aged under 18. 
$\underline{\text { TABLE NUMBER } 13}$

COMPARISON OF UNITED NATIONS RIGHTS ATTRIBUTES WITH FUNDAMENTAL CAPABILITIES OF OLDER PEOPLE

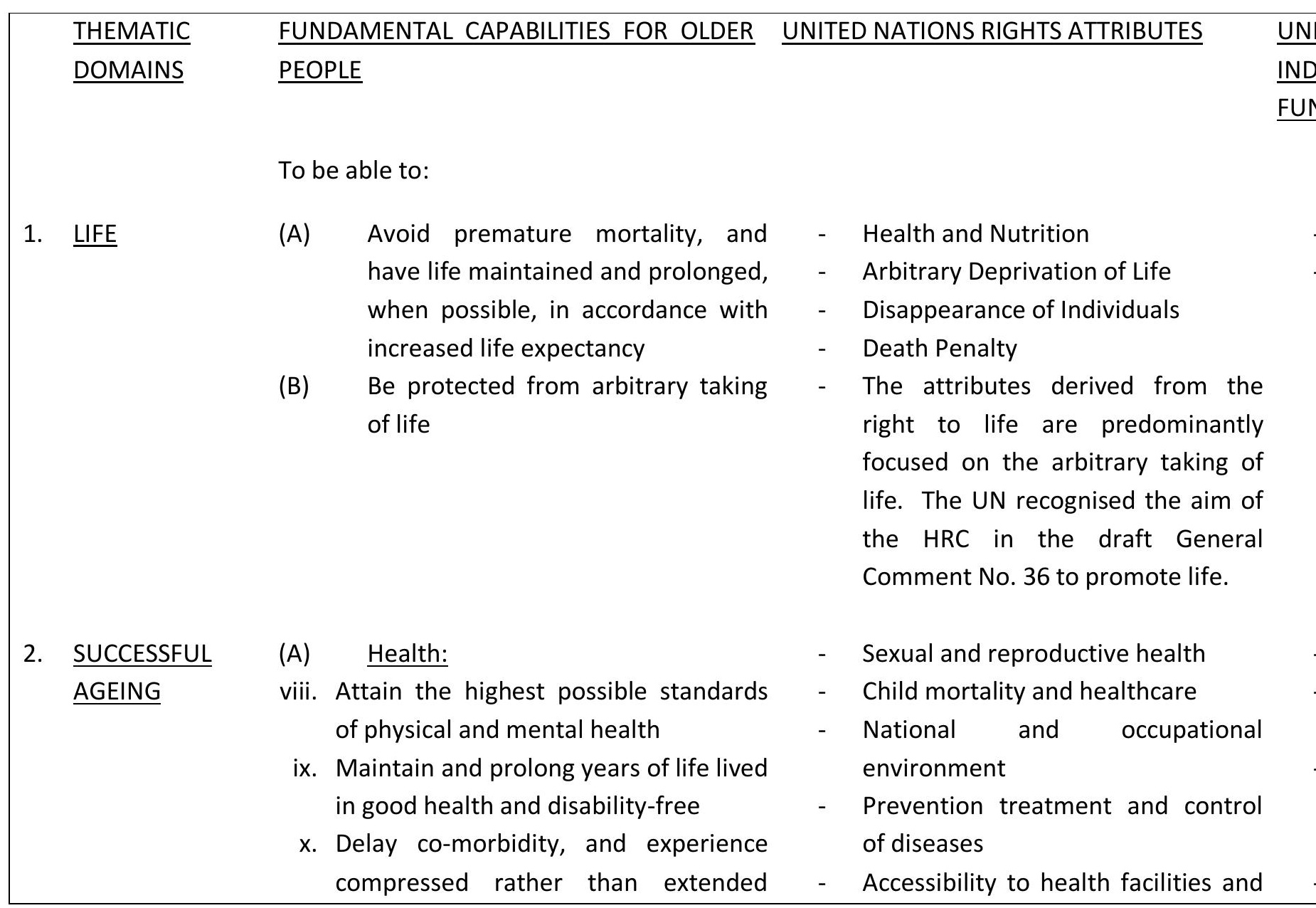


morbidity

xi. Have access to preventative, curative, rehabilitative, and specialist medical care

xii. Have access to palliative care

xiii. Prevent ill-health and maintain health through:

- Nutritionally adequate sustenance; housing and living conditions enabling healthy living; care and support with living

xiv. Minimise the negative effects of societal practices on health in older age, including: retirement; social isolation; negative stereotypes and perceptions

(B) Activity:

iii. Partake in occupations and activities of one's choice, commensurate with ability

iv. Update skills and impart knowledge and skills to next generation

(C) Engagement:

ii. Form and maintain beneficial relationships including: ties of kinship and emotion; professional; in the community. essential medicines

- Habitability of housing

- Accessibility to Services 


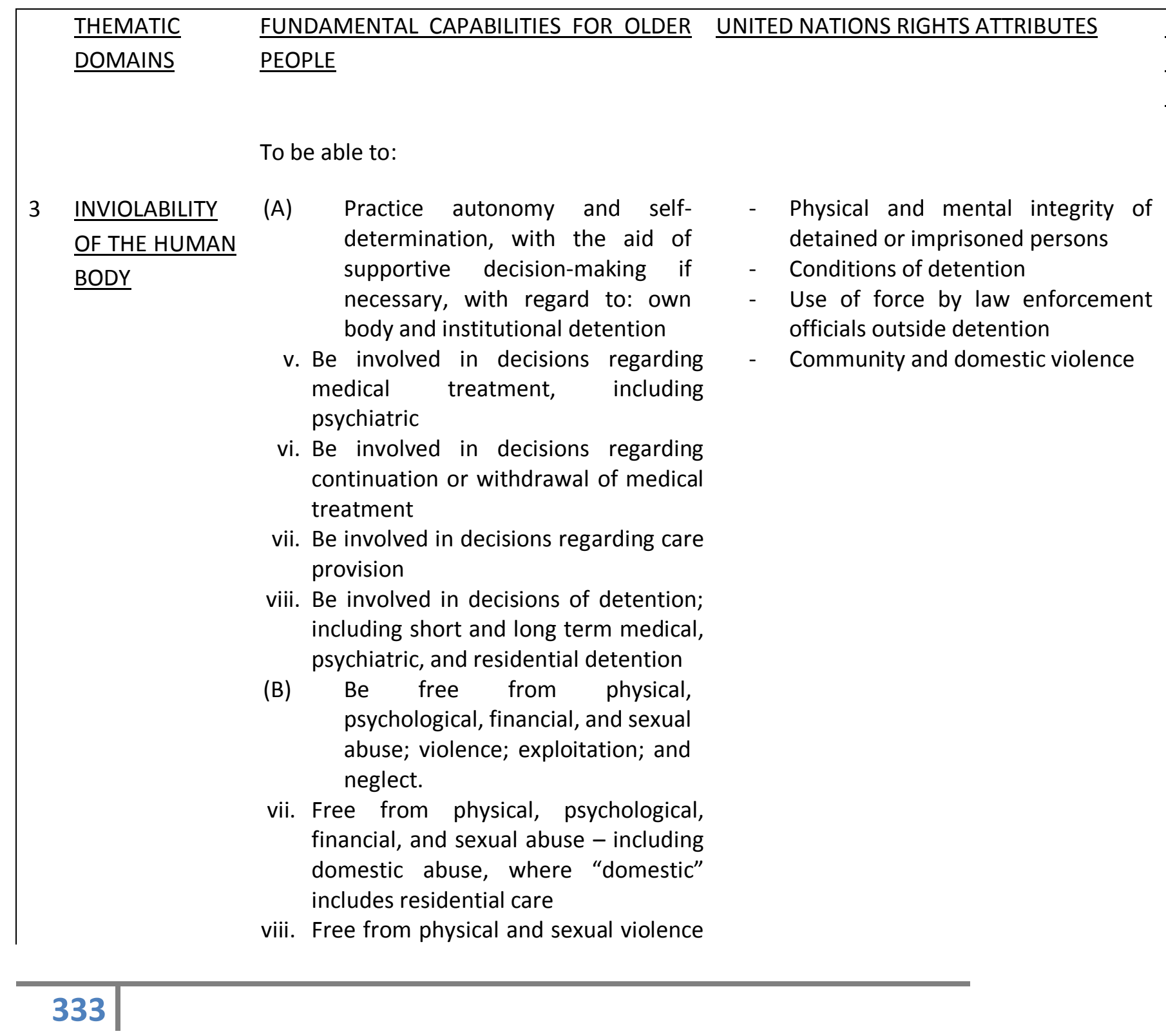




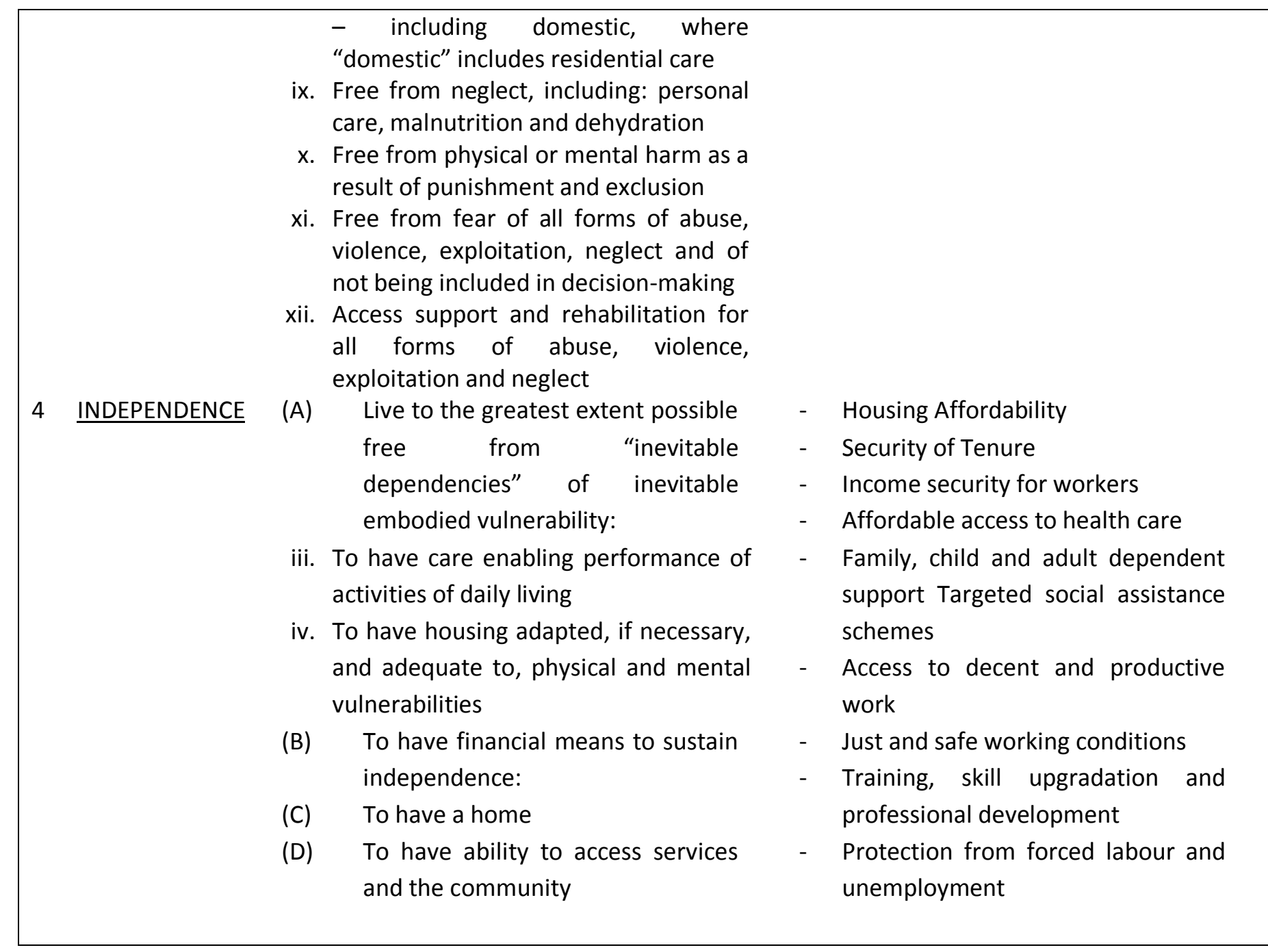




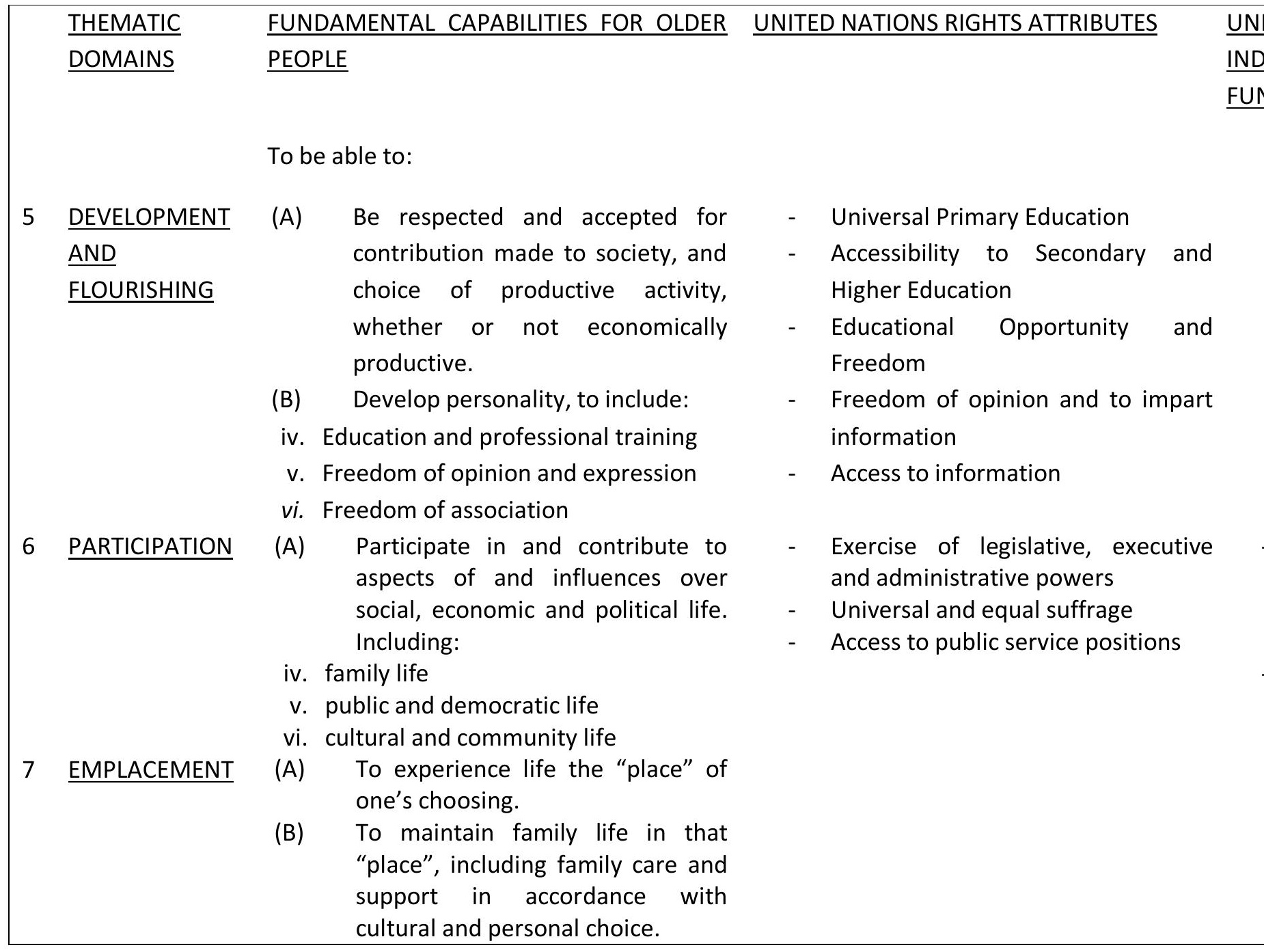




\begin{tabular}{|c|c|c|c|}
\hline \multirow[b]{3}{*}{8} & $\frac{\text { THEMATIC }}{\text { DOMAINS }}$ & $\begin{array}{l}\text { FUNDAMENTAL CAPABILITIES FOR OLDER } \\
\text { PEOPLE }\end{array}$ & \multirow[b]{3}{*}{$\begin{array}{ll}\text { - } & \text { Affordable access to health care } \\
\text { - } & \text { Family, child and adult dependent } \\
& \text { support } \\
\text { - } & \text { Targeted social assistance schemes }\end{array}$} \\
\hline & & To be able to: & \\
\hline & $\frac{\text { RESISTANCE TO }}{\text { VULNERABILITY }}$ & $\begin{array}{l}\text { To be able to strengthen resilience } \\
\text { to vulnerabilities through institutional } \\
\text { assets providing: } \\
\text { vi. Access to financial and material } \\
\text { benefits when vulnerable through not } \\
\text { achieving minimum threshold for } \\
\text { healthy standard of living. } \\
\text { vii. Access to capabilities necessary to } \\
\text { compensate for compromised innate } \\
\text { or internal abilities, causing inability } \\
\text { to counter or adapt to threats } \\
\text { viii. Ability to maintain supportive } \\
\text { networks including family, in the } \\
\text { community, and cultural. } \\
\text { ix. Access to existential assets by } \\
\text { enabling practice of beliefs, religion } \\
\text { and moral values. } \\
\text { x. Assets available through the legal } \\
\text { institution: non-discrimination by any } \\
\text { institution in provision of assets on } \\
\text { basis of age; recognition before the } \\
\text { law; recognition of vulnerabilities of } \\
\text { older people in administration and } \\
\text { interpretation of rights. }\end{array}$ & \\
\hline
\end{tabular}




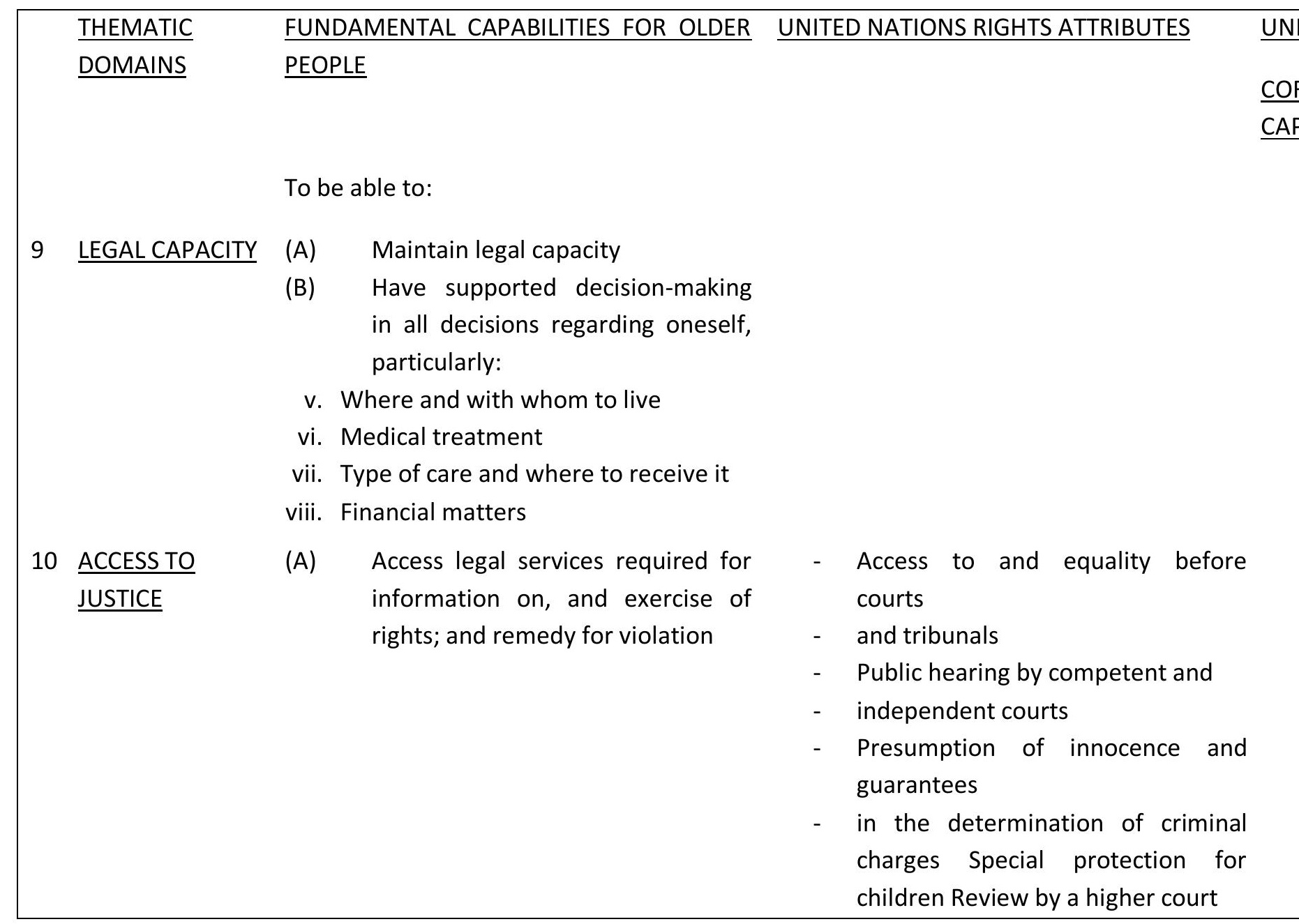




\section{Conclusion}

This chapter explored the implementation of human rights to complete the study of adequacy of international rights for the protection of older people. The examination was undertaken from the perspective of the Fundamental Capabilities and capabilities outcomes devised in the previous chapter. Principal areas demonstrated to limit implementation included:

- resource allocation

- exclusion of older people from reporting to the TMBs by the Member States

- a lack of de facto State obligations

- a lack of de facto indicators in areas of rights relating to older people

- margin of appreciation

Furthermore, given that the role of implementation is to give effect to legal rights, implementation is proven to be limited by the inadequacy of normative provision of international rights for older people.

Comparison of the UN Framework of Implementation with the Fundamental Capabilities and capabilities outcomes demonstrated the gaps relating to devising and deciding outcomes indicators of rights, and the aims that rights aspire to achieve. It further emphasised that older people are not in the contemplation of drafters of rights, or in the implementation of rights. The solution requires special protection rights grounded in vulnerabilities and Fundamental Capabilities derived from them. The rights so informed must achieve the capabilities outcomes measured by targeted de facto indicators. 


\section{CHAPTER 13}

\section{PROGESS BY THE UNITED NATIONS ON SPECIAL PROTECTION OF}

\section{OLDER PEOPLE}

\section{$13.1 \quad$ Introduction}

This chapter explores the progress made by the United Nations on special protection of older people via the Open Ended Working Group on Ageing. The General Assembly stated the OEWGA to exist:

For the purpose of strengthening the protection of the human rights of older persons by considering the existing international framework of the human rights of older persons and identifying possible gaps and how best to address them, including by considering, as appropriate, the feasibility of further instruments and measures. ${ }^{1483}$

The focus of the chapter is on areas considered to need 'special attention,' and on the question of a need for special protection and methods of provision. Some of the central observations of the examination of the international framework undertaken earlier in Part IV are identified in the second session of the OEWG as 'key areas for explicit consideration in a new instrument. ${ }^{1484}$ Progress in the specified areas is plotted in the first part of the chapter. It is instructive that discussion on these issues concluded in the fourth working session. The second part of the chapter focuses on methods proposed for future provision of the rights of older people. The provision of a distinct special protection Convention for older people is considered amongst proposals which largely advocate utilising the current construct of international rights, a series of regional instruments, implementing the MIPAA, or referring older people to use the CRPD.

\subsection{Key Areas for explicit consideration in a new instrument}

\subsubsection{Age Discrimination}

It was stated in the first session that very little attention was paid in the international human rights framework to equality and non-discrimination of older people, and virtually nothing that addresses the multiple forms of discrimination that older people can experience. ${ }^{1485}$ The point was developed in the second session with the suggestion that age be recognised as a necessary prohibited ground

\footnotetext{
1483 UNGA Resolution adopted by the General Assembly on 21 December 2010 [on the report of the Third Committee (A/65/448)] 65/182. Follow-up to the Second World Assembly on Ageing Sixty-fifth session Agenda item 27 (c) A/RES/65/182 4 February 2011, 28

${ }^{1484}$ Víctor Abramovich, Executive Secretary of the Southern Common Market Institute of Public Policy on Human Rights and former member of the Inter-American Commission on Human Rights in Report of the OEWGA, 23 August 2011, A/AC.2781/2011/5, 9

${ }^{1485}$ Report of the OEWGA, 17 May 2011, A/AC.278/2011/4, 10
} 
for discrimination, as present exclusion or dependence upon "other status" by instruments has proven unsatisfactory. ${ }^{1486}$ Criticism of General Comments as a source of normative provision for older people was stated in the third session of OEWG. Highlighting the reluctance of Member States to accept the Committee comments as binding, and to include older people in reports to TMBs, protection against age discrimination was concluded inadequate. ${ }^{1487}$ Moreover, the exclusion of older people from reports confirms the accusation of 'age blindness' in State reporting by Chung. ${ }^{1488}$

\subsubsection{Equality before the law}

Formal equality before the law was identified as a broad need area in the second working session, which could support issues of autonomy and provide supported decision-making. ${ }^{1489}$

\subsubsection{Retirement Age}

Retirement age was stated as requiring 'further consideration' in the first working session of the Group. ${ }^{1490}$

\subsubsection{Right to the highest possible standards of health}

The first session of the OEWG identified access to and availability of health services in addition to long-term care as requiring attention. ${ }^{1491}$ At the third session of the OEWG long term health care was again raised. The suggested was that long-term care and assistance with daily living to include: assistance with personal hygiene; getting in or out of bed; and getting dressed should be available as a minimum social service. ${ }^{1492}$

The WHO Director of Ageing and Life Course identified specific needs and action in the second session of the OEWG. The first suggestion of promoting health during the life-course is reflective of earlier observations in this thesis of the effects of accumulated advantage and disadvantage. This

\footnotetext{
${ }^{1486}$ Víctor Abramovich, Executive Secretary of the Southern Common Market Institute of Public Policy on Human Rights and former member of the Inter-American Commission on Human Rights in Report of the OEWGA, 23 August 2011, A/AC.2781/2011/5, 9

${ }^{1487}$ Alejandro Morlachetti, Professor of Law at the University of Buenos Aires in the Report of the OEWG, 2124 August 2012 A/AC.278/2012/1, 8

${ }^{1488}$ Chinsung Chung, 'The necessity of a human rights approach and effective United Nations mechanism for the human rights of the older person' January 2010 A/HRC/AC/4/CRP.1

${ }^{1489}$ Víctor Abramovich, Executive Secretary of the Southern Common Market Institute of Public Policy on Human Rights and former member of the Inter-American Commission on Human Rights in Report of the OEWGA, 23 August 2011, A/AC.2781/2011/5, 9

1490 Report of the OEWGA, 17 May 2011, A/AC.278/2011/4

1491 Report of the OEWGA, 17 May 2011, A/AC.278/2011/4, 6

${ }^{1492}$ Anne-Mette Kjaer Hesselager, Head of Section, Law and International Affairs, Ministry of Social Affairs and Integration of Denmark in the Report of the OEWG, 21-24 August 2012 A/AC.278/2012/1, 10
} 
form of preventative treatment is followed by diagnostic and curative treatment, palliative care, and affordable medicines, also identified as need areas in the earlier examination of international rights provision. Long term care is cited as necessary, and to be available in institutions and at home. In an approach corresponding to the interlinked nature of vulnerability, and the effects of health drawn from theories of ageing, the right to the highest attainable standard of health was recognised as reliant on other rights. Due to the effects of disengagement on health, "environments that foster engagement by older persons" is included. The rights to adequate housing, social security, equality and non-discrimination are also recognised as impacting health outcomes and to be considered from such perspective in construction of normative provision. A factor offered as contributory to special needs is to view universality as a floor rather than a ceiling of rights provision. The WHO delegate advocated a "social protection floor" for older people, an approach also promoted as "affordable and feasible." ${ }^{1493}$ Significantly, a particular lack of knowledge and preparation for dementia was reported, and cited as needing to become a healthcare focus. ${ }^{1494}$

Requirements of the right to health developed as the OEWG sessions advanced. At the third session the international framework was accused of "falling short of securing older persons' right to...access to palliative care." The recommendation was made for a binding universal standard and a distinct right to palliative care. ${ }^{1495}$ The right to palliative care was reaffirmed in the third session by the Danish delegate. ${ }^{1496}$

Rehabilitation was suggested to be included in the right to health at the third session. ${ }^{1497}$

Concern was raised regarding non-consensual medical treatment amongst older people, and the proposal made for protection to be included in normative content of rights. ${ }^{1498}$

\subsubsection{Violence and Abuse}

Issues identified by the OEWG in the second session influencing protection centre on interlinked vulnerability and aggravated vulnerability. Correlation was drawn between low income and

\footnotetext{
${ }^{1493}$ Report of the OEWGA, 23 August 2011, A/AC.2781/2011/5, 10-11

${ }^{1494}$ Jan Killeen, Alzheimer's Disease International in the Report of the OEWGA, 23 August 2011, A/AC.2781/2011/5, 10-11

${ }^{1495}$ Amanda McRae, Disability Rights Researcher at Human Rights Watch in the Report of the OEWG, 21-24 August 2012 A/AC.278/2012/1, 9

${ }^{1496}$ Anne-Mette Kjaer Hesselager, Head of Section, Law and International Affairs, Ministry of Social Affairs and Integration of Denmark in the Report of the OEWG, 21-24 August 2012 A/AC.278/2012/1, 10

${ }^{1497}$ Anne-Mette Kjaer Hesselager, Head of Section, Law and International Affairs, Ministry of Social Affairs and Integration of Denmark in the Report of the OEWG, 21-24 August 2012 A/AC.278/2012/1, 10

${ }^{1498}$ Claudia Martin, Co-Director of the Academy on Human Rights and Humanitarian Law, in the Report of the OEWG, 21-24 August 2012 A/AC.278/2012/1, 13
} 
abuse; ${ }^{1499}$ older women and abuse to the extent of killings; ${ }^{1500}$ and neglect and abuse. ${ }^{1501}$ Furthermore, due to the effect and predisposal to multiple occurrences of abuse, calls were made for aspects of inhuman and degrading treatment traditionally categorised as torture to be classified as abuse in the case of older people. ${ }^{1502}$ Protection against abuse and violence from non-State actors, such as care institutions was identified during the second working session. ${ }^{1503}$ The call for a universal definition of abuse of older people to be incorporated into an international special protection instrument was also made at the third session. ${ }^{1504}$

\subsubsection{Social Protection and Social Security}

The propensity of older people to suffer poverty, the linked causes and outcomes of poverty caused OEWG delegates to identify problems and suggest solutions. Universal protection and special measures available through the international framework received strong criticism from the Special Rapporteur on extreme poverty during the second session of the OEWG. The response to the practice of "...States...not offering older persons the protection they deserve" specified universal standards for the group. These included "standards directly aimed at the right to social security and a universal pension scheme." Universal norms specific to the group would comply with principles of equality and non-discrimination, and be available on a the universal basis of age. ${ }^{1505}$ Additionally, the ILO representative proposed flexible retirement, ${ }^{1506}$ a solution offered previously in this thesis.

The Danish representative quoted the European Report on Development 2010 in the third session, stating that 'universal access to basic social protection is feasible and affordable.' On that basis all older people with physical and mental incapacity should be provided for in accordance with need. ${ }^{1507}$

\footnotetext{
${ }^{1499}$ Kieren Fitzpatrick, Director of Asia Pacific Forum in the Report of the OEWGA, 23 August 2011, A/AC. 2781/2011/5, 12

${ }^{1500}$ Teresa Minja Chair Tanzania Special Protection Network in the Report of the OEWGA, 23 August 2011, A/AC.2781/2011/5, 12

${ }^{1501}$ Kieren Fitzpatrick, Director of Asia Pacific Forum in the Report of the OEWGA, 23 August 2011, A/AC.2781/2011/5, 12

${ }^{1502}$ Report of the OEWGA, 23 August 2011, A/AC.2781/2011/5, 13

${ }^{1503}$ Víctor Abramovich, Executive Secretary of the Southern Common Market Institute of Public Policy on Human Rights and former member of the Inter-American Commission on Human Rights in Report of the OEWGA, 23 August 2011, A/AC.2781/2011/5, 9

${ }^{1504}$ Report of the OEWG, 21-24 August 2012 A/AC.278/2012/1, 12

1505 Special rapporteur on extreme poverty in the Report of the OEWGA, 23 August 2011, A/AC.2781/2011/5, 13

${ }^{1506}$ Representative of the International Labour Organisation in the Report of the OEWGA, 17 May 2011, A/AC.278/2011/4, 9

${ }^{1507}$ Anne-Mette Kjaer Hesselager, Head of Section, Law and International Affairs, Ministry of Social Affairs and Integration of Denmark in the Report of the OEWG, 21-24 August 2012 A/AC.278/2012/1, 10
} 
The ILO also contributed to social protection in the $4^{\text {th }}$ session of the OEWG. Making specific reference to developing countries, the representative stated the ILO goal that "at no time during one's life should one be without social protection." Recommendations of "monitoring, increasing resources, improving communication and awareness of the importance of social protection, and removing impediments to receive social protection"1508 were cited as necessary if social protection is to be treated as a right. ${ }^{1509}$

\subsubsection{Employment}

The first session of the OEWG recognised the problem of an inability by older people to attain and maintain employment corresponding to skills. In response, the representative of the ILO suggested life-long training. ${ }^{1510}$ In addition to reduced employment opportunities for older people, the situation regarding older people in rural areas of poorer countries was identified as requiring a solution. This sub-group of older people are particularly vulnerable to the loss of status and lack of suitable employment skills for urban roles advocated in Modernisation Theory ${ }^{1511}$

\subsection{Methods of Provision}

The General Assembly stated the principal objectives of the OEWGA to "inform a decision about whether new measures - be that a UN Convention; a Special Rapporteur; an independent expert; implementation efforts or some other mechanism - are needed." ${ }^{\prime 1512}$ The direction of progress in this area is examined in this section of the chapter.

Debate on the method of delivering protection of rights of older people centred during some sessions on the "key areas for explicit consideration in a new instrument." ${ }^{1513}$ It was suggested in the fifth session that social security and the right to health follow the example of the European Commission Social Investment Package. This would instruct Member States on the structure of

\footnotetext{
${ }^{1508}$ Alejandro Bonilla-García, Director of the Social Protection Department of the Policy Portfolio of ILO in the Report of the OEWG, 21-24 August 2012 A/AC.278/2012/1, 13

${ }^{1509}$ Some delegates questioned whether 'social protection' constituted a right.

${ }^{1510}$ Representative of the International Labour Organisation in the Report of the OEWGA, 17 May 2011, A/AC.278/2011/4, 9

${ }^{1511}$ Salvacion Basiano of the Confederation of Older Persons' Associations of the Philippines in the Report of the OEWGA, 23 August 2011, A/AC.2781/2011/5, 14

1512 UNGA Resolution adopted by the General Assembly on 21 December 2010 [on the report of the Third Committee (A/65/448)] 65/182. Follow-up to the Second World Assembly on Ageing Sixty-fifth session Agenda item 27 (c) A/RES/65/182 4 February 2011, 28

${ }^{1513}$ Víctor Abramovich, Executive Secretary of the Southern Common Market Institute of Public Policy on Human Rights and former member of the Inter-American Commission on Human Rights in Report of the OEWGA, 23 August 2011, A/AC.2781/2011/5, 9
} 
social security and health provision policy, without the need for incorporation into an international rights instrument. Investment packages following the EC model would include investment in health issues including long-term care and provision of carers. ${ }^{1514}$ The WHO Public Health Model was also suggested notably with regard to palliative care and provision of medication. However, it was contended that a Convention on the rights of older people would be required to 'highlight the critical need for palliative care; define state obligations, assure monitoring; and improve quality of care. ${ }^{1515}$ Support for a Convention for provision of social support and health care was offered by the delegate from Malaysia, stating that reliance on domestically defined structures and services had proven inadequate, and that 'a comprehensive piece of legislation focused on older persons' was necessary. During the fifth session delegates questioned the rights status of social protection and therefore whether it warranted inclusion in a human rights instrument. Other reasons for not binding nations to social protection and, indeed, a Convention included the cost burden. ${ }^{1516}$

The fact that the 'invisibility of older persons and their negative stereotype was old and deeply rooted in our society' led to the suggestion that the problem lay in social recognition. This, asserted Israel Doron, could not be corrected by implementation of the MIPAA. The negative stereotype required the intervention of an international legally binding Convention. ${ }^{1517}$ The viability of the MIPAA was the focus of further discussion centred on age discrimination in the context of employment. Endorsement of the Plan by 156 Member States accorded the instrument universal status, nullifying any need for 'a new norms-setting process' for this element of the 'key area' of discrimination.

\subsubsection{Against a Special Protection Convention}

The various solutions offered to the method of provision other than a Convention of Special Protection are included below.

\footnotetext{
${ }^{1514}$ Kasia Jurczak, policy analyst of the European Commission Directorate General for Employment, Social Affairs and Inclusion in the Report of the OEWGA, 12-15 August 2013, A/AC.278/2013/2, 12

${ }^{1515}$ Kathy Foley of the Open Society Foundation in the Report of the OEWGA, 12-15 August 2013, A/AC.278/2013/2, 12

${ }^{1516}$ Report of the OEWGA, 23 August 2011, A/AC.2781/2011/5, 13-14

${ }^{1517}$ Israel Doron, Head of Department of Gerontology, University of Haifa in the Report of the OEWGA, 12-15 August 2013, A/AC.278/2013/2, 14
} 


\subsubsection{Continue provision via existing international human rights instruments}

The concluding comments of the first working session of the Group reported the majority preference of to encourage the treaty bodies and human rights mechanisms to focus more on older persons and use existing instruments to achieve this. ${ }^{1518}$ This opinion has remained steadfast amongst delegates.

The second meeting concluded with delegates stating that 'existing international standards were sufficient but had been underutilized. ${ }^{1519}$ At the fourth session agreement with this position prevailed, citing the need not to add to the existing nine core human rights instruments and ten TMBs. ${ }^{1520}$

"Canada believes that we do not need to wait for a Convention to implement the current, binding human rights of all persons including older persons, without discrimination of any kind."1521

"Taking into consideration the discussions in the second review of the Madrid International Plan of Action on Ageing, we believe that the full implementation of existing frameworks which include UN human rights treaties, existing Special Rapporteurs and mainstreaming aging in the UN, including through the use of the Universal Periodic Review, is needed at this moment. These efforts will identify and improve gaps between the frameworks and the actual challenges faced by older persons."1522

\subsubsection{Normative v Implementation Gaps}

During the second working meeting of the Group claims were made that there were no gaps in normative provision of rights. However, gaps in implementation existed with specific regard to 'the particularities of older persons. ${ }^{1523}$

\subsubsection{In favour of a special protection international Convention}

The argument that existing international human rights standards apply to the protection of older persons is not disputed. However, in line with the argument presented in this thesis, claims that protection is adequate for older people are not accepted by proponents of a special protection Covenant. Claims that existing treaties include "provisions relevant to the human rights of older

\footnotetext{
${ }^{1518}$ Report of the OEWGA, 17 May 2011, A/AC.278/2011/4, 10

${ }^{1519}$ Report of the OEWG, 21-24 August 2012 A/AC.278/2012/1, 18

${ }^{1520}$ Report of the OEWG 24 September 2013 A/AC.278/2013/2, 16

${ }^{1521}$ Government of Canada Permanent Mission of Canada to the United NTIONS 'Note 0026' 6 May 2013, 1

${ }^{1522} \mathrm{https}$ ://social.un.org/ageing-working-group/documents/fourth/Japan.pdf accessed 14/11/2017

${ }^{1523}$ Report of the OEWG, 21-24 August 2012 A/AC.278/2012/1, 18 
persons" receives tepid acknowledgement in light of the fact that they also are "inadequate and fragmented in offering effective international protection to older persons." ${ }^{1524}$

A means of settling the ongoing debate surrounding the existence and nature of gaps in rights provision, which remains unresolved as at the last session of the OEWG, was offered at the first session. The inadequate collection and reporting of data identified in the last chapter was met by calls for improved data collection and the use of disaggregated statistics. ${ }^{1525}$

The most satisfactory solution, overcoming manipulation of existing universal rights, and application by sub-groups to special protection Conventions of other vulnerable groups, or reliance on regional approaches, is stated by some delegates as: 'universal standards and monitoring mechanisms in line with what had been put in place for other population groups, such as children or persons with disabilities.' This would lead also to a Special Rapporteur for older people and a bespoke special protection Covenant. ${ }^{1526}$ Recognition of areas in which the existing international framework has not provided for the interests held in rights by older people led to suggestions for such international standards to include allocation of resources to geriatric health care, reporting of violence, particularly in care institutions, and safeguards to facilitate consent for health-related decisionmaking. ${ }^{1527}$ Furthermore, universal standards for the quality and accessibility of healthcare, and long-term care were also highlighted as necessary, and achievable via a special protection instrument. ${ }^{1528}$

Additionally, by recognising persons with disabilities as a separate population group, this statement also supports arguments against that offered by some delegates that the UNCRPD offers sufficient protection for older people.

\subsection{Current Direction for the OEWG}

The fifth session of the OEWG marked a turning point in discussions. The inadequacy of existing mechanisms to guarantee fulfilment of the rights of older people was decided. However, the associated substantive issue of the mandate remained unfulfilled. The Chair reminded delegates that a 'normative gap at the international level must be filled through the adoption of a legally binding instrument.' Lack of progress in this aspect of the mandate was noted;

\footnotetext{
${ }^{1524}$ Mr. Mokhiber The Chief of the Development and Economic and Social Issues Branch, OHCHR in Report of the OEWGA, 23 August 2011, A/AC.2781/2011/5, 10

${ }^{1525}$ Report of the OEWGA, 23 August 2011, A/AC.2781/2011/5, 8

${ }^{1526}$ Report of the OEWGA, 23 August 2011, A/AC.2781/2011/5, 8

${ }^{1527}$ The Chief, Economic, Social and Cultural Rights Section, OHCHR, speaking on behalf of the Special Rapporteur Report of the OEWGA, 23 August 2011, A/AC.2781/2011/5, 11

${ }^{1528}$ The Pan American Health Organization Report of the OEWGA, 23 August 2011, A/AC.2781/2011/5, 12 
Let us be reminded one more time...this Working Group should dedicate itself to...considering, as appropriate, the feasibility of further instruments and measures...the General Assembly requested...the main elements that should be included in an international legal instrument to promote and protect the rights and dignity of older persons, which are not currently addressed sufficiently by existing mechanisms and therefore require further international protection ${ }^{1529}$

Debate of the issue of gaps in the 'key areas' was concluded by the Chair in the fifth session, '...we have been able to visit and, in some cases, revisit most of the concerns associated with the situation of the human rights of older persons worldwide...this is not sufficient to fulfil our mandate. ${ }^{1530}$

A virtually identical reminder was issued by the Chair in the sixth session of the Group, closing with the following:

...an increasing number of delegations and a unanimous and clear voice coming from civil society are requesting us to undertake the task of elaborating a convention. Can we continue turning a deaf ear to those calls? Can we ignore that part of our mandate? My response to both questions is no. ${ }^{1531}$

\subsection{Conclusion}

The progress of the OEWG has been successful in the identification of key areas requiring attention in order to fulfil the interests held in rights, and to protect against vulnerabilities experienced by older people. Largely the issues correspond to those identified by research of this thesis. However, progress on the method of provision of improvements in these areas is negligible. The debate continues between the issues of a special protection Convention and alternatives of utilising the existing international framework, the MIPAA, regional instruments and the CRPD. The concluding remarks by the Chair in the latest sessions are clearly calling for a distinct special protection instrument for older people as a vulnerable group.

\footnotetext{
${ }^{1529}$ Chair's summary of the key points of the discussions at the fifth session of the Open-ended Working Group on Ageing established for the purpose of strengthening the protection of the human rights of older persons in the Report of the OEWG 15 August 2014, A/AC.278/2014/2, 7

${ }^{1530}$ Chair's summary of the key points of the discussions at the fifth session of the Open-ended Working Group on Ageing established for the purpose of strengthening the protection of the human rights of older persons in the Report of the OEWG 15 August 2014, A/AC.278/2014/2, 7-8

${ }^{1531}$ Chair's summary of the key points of the discussions at the fifth session of the Open-ended Working Group on Ageing established for the purpose of strengthening the protection of the human rights of older persons in the Report of the OEWG 29 July 2015, A/AC.278/2015/2, 15
} 


\section{CHAPTER 14}

\section{CONCLUSIONS}

The thesis concludes by drawing together principal processes and findings of the research in the context of the primary research questions. Due to the interdependent nature of the questions, the approach taken will address each question individually with some inevitable inter-question discussion and referencing.

This thesis adopted the premise discussed in Chapter 5 that special protection is required for individuals with needs which lie beyond the universal and are not protected by the existing human rights construct. The question of defining older people as a group involved a complex and lengthy approach, which involved examination of Theories of Ageing, senescence, lived experiences of older people, and the concepts of Human Dignity and Vulnerability. All contributed to the issue of whether the group was protected by the existing international framework. In terms of identifying older people as a 'distinct and definable social group' the research implemented the first part of the process proposed by Mégret; to establish 'common characteristics or a shared experience."1532 Theories of Ageing have proven instructive in explaining societal attitudes, processes, and expectations of older people, and a not inaccurate predictor of outcome. In broad terms, the common characteristics can be divided by perception and fact. Societal perception of older people includes being unproductive; loss of physical and mental capability; and having a net negative economic and social effect. Shared facts identified by Theories of Ageing include, but are not limited to: poverty; social isolation; disengagement; diminished filial obligation; senescence; inability to maintain adequate standard of living; discrimination and aggravated discrimination. These shared theoretical characteristics were demonstrated to be de facto characteristics shared by older people following examination of the concepts of Human Dignity and Vulnerability and research of the situation of older people.

The relationship between the two concepts as defined by this thesis is key to identification of shared characteristics and also addresses part of the question regarding the significance of the concepts to human rights and special protection. If not adequately protected by human rights against threats to dignity, the materialisation of those threats subject the individual to risk of a vulnerable outcome. Similarly, when human rights are inadequate to protect against the risk, the individual is subject to an outcome of vulnerability. As part of a circular relationship, vulnerable outcomes serve to further violate dignity. Therefore, older people can be defined by common characteristics of threats to dignity, vulnerability, and vulnerable outcomes. Research of the situation of older people

${ }^{1532}$ Freædexric Mexgret, 'The Human Rights of Older Persons: A Growing Challenge' (11) (1) (2011) HRLR 37 
demonstrated vulnerabilities categorised as embodied, institutional, and pathogenic. The interlinked nature of vulnerability proved that experience of one form of vulnerability inevitably attracted others. Common themes of experienced vulnerabilities included: age-related illness and disability; inconsistent medical, health and social care provision in response to these illnesses and disabilities; and co-morbidity. The inevitable biological vulnerabilities contribute to poverty, and increase vulnerability to abuse and violence. The combination of physical and mental vulnerability and poverty contribute to a need for specialised housing, care, and subsistence not universally available or affordable. As a result, the individual may not be able to provide a standard of living adequate for dignity or health. A combination of these and vulnerabilities originating in societal change and attitude have the potential to generate vulnerabilities of social isolation, disengagement, and emplacement. Most particularly these relate to diminished filial obligation and loss of home. The inevitability of vulnerability is accompanied by the inevitability of dependence, primarily on institutions such as the family and the State. However, when these become vulnerable and fail, existing vulnerability is exacerbated. The 'aggravated' state of vulnerability experienced by the majority older people contributes to the shared characteristics of vulnerability. The relationship between the concepts of Vulnerability and Human Dignity results in threats and violations of specific facets of dignity by outcomes of vulnerability. As this thesis adopted the holistic definition of Human Dignity proposed by Dupré, the existence pillar is threatened by a lack of protection against all categories of vulnerability, not merely the more obvious effects of embodied vulnerability. Failure of institutions to provide resilience and the pathogenic vulnerability to abuse all threaten existence. The inevitable embodied vulnerability also threatens the pillars of autonomy and the freedom to self-direct. This is not merely by virtue of diminished decision-making capacity, but by the lack of opportunity to act resulting from biological vulnerability, including poverty. Further barriers to opportunity to exercise autonomy and freedom are created due to discrimination. All forms of discriminatory treatment threaten the equality in dignity due every person. Equality in dignity is reliant upon treatment which recognises the equal 'inherent worth' of every person. This thesis concluded that respect of inherent worth does not equate to equal treatment, but treatment responding to need and vulnerability in order to achieve equal dignity. Failure to do so is to cause feelings of humiliation or an insult to self-worth. Therefore, any form of humiliating treatment, causing a violation of self-worth violates dignity, and in return causes the person to be at risk of a vulnerable outcome. The number and range of vulnerabilities, together with the interlinked nature of vulnerability, results in older people sharing characteristics of vulnerability and threatened or violated dignity. 
This thesis also adopted the approach of the European Court of Human Rights to defining a group, and particularly for the purposes of special protection. Referring to the stated notion that special protection is required for individuals with needs which lie beyond the universal and are not protected by the existing human rights construct, it is also concluded that older people can be defined as a vulnerable group. The aim of recognising vulnerable groups was stated as to counter marginalisation, and the inability of human rights in their existing construct to respect, protect and fulfil the needs of the particularly vulnerable. ${ }^{1533}$ Thus "people are differently vulnerable;" this "difference" identifies a group and the "different" protection required. ${ }^{1534}$ The definition of this "difference" offered by the ECtHR serves to confirm older people as a distinct and definable social group for the purposes of special protection. The principles are: type of vulnerability suffered by the group; that the group comprises a minority of society; the group is marginalised or discriminated against; and is more vulnerable than most individuals ${ }^{1535}$ Furthermore, much of the vulnerability suffered by older people originates and subsists in social, historical and institutional influence, and therefore a perpetual threat to be shared by all older people. Vulnerability particular to a group need not necessarily be type of vulnerability, it can be particular by virtue of severity of harm caused, particularly in conjunction with other vulnerabilities. Vulnerability "particular" to a group, especially when that group suffers greater vulnerability than others, is one requiring discrete protection.

The relationship between the concepts of Human Dignity and Vulnerability described above in the context of defining older people as a social group for the purposes of special protection becomes more complex when considered in terms of the significance to human rights per se. This thesis concluded in Part II that the two concepts underpin human rights, rather than the traditional view that Human Dignity alone underpins rights. In addition to underpinning human rights, the promotion of dignity and protection against vulnerability are objectives of rights.

Human dignity is proposed as guiding and providing broad subjects of rights, and vulnerability the specifics to be addressed. Human dignity provides the moral basis of rights, and the pillars of dignity ground fundamental rights. Violations of these values and treatment which humiliates or degrades

\footnotetext{
${ }^{1533}$ The human rights universal is accused of particularly not protecting the marginalised. Lourdes Peroni \& Alexandra Timmer, 'Vulnerable Groups: The promise of an emerging concept in European Human Rights Convention law,' p.1062

${ }^{1534}$ Lourdes Peroni \& Alexandra Timmer, 'Vulnerable Groups: The promise of an emerging concept in European Human Rights Convention law,' p.1061

${ }^{1535}$ Lourdes Peroni \& Alexandra Timmer, 'Vulnerable Groups: The promise of an emerging concept in European Human Rights Convention law,' p.1057; Alajos Kiss v Hungary App. No 38832/06, 20 May 2010, 42 (as cited in Lourdes Peroni \& Alexandra Timmer, 'Vulnerable Groups: The promise of an emerging concept in European Human Rights Convention law,' p.1057
} 
provide the normative basis of rights. As rights should respond to vulnerability, the detail of the various types and outcomes also inform the content. With vulnerability caused by, and causing, violations of dignity, it provides the source of rights norms. Furthermore, in responding to the universal capacity to suffer, rights should be grounded in this capacity. Both concepts therefore inform the normative content of human rights.

By grounding human rights in vulnerability the role of institution-building is allocated to rights. Given the dependence of older people on resilience to threats and vulnerability provided by institutions, vulnerability demands that human rights build those institutions. For example; family must be enabled to support and care for older people; society must be enabled to engage with older people; the State must bear the duty to provide social security and essential services to older people.

The broader interpretation of Human Dignity adopted by this thesis combined with the range of outcomes of vulnerability relies on both generations of rights for protection. To do otherwise would not protect the whole person, or the person's whole dignity, and would dismiss "half of the human rights equation." ${ }^{1536}$

The particular vulnerabilities of older people were identified by examination of Theories of Aging, the ageing process and a study of research previously conducted by academics, expert bodies and international bodies. Instruments of international rights and special protection were surveyed from two aspects. The first directly compared the normative provision of rights with the vulnerabilities identified using the vulnerabilities framework devised in Chapter 5 . The findings demonstrated all rights in all instruments to be normatively inadequate for the provision of interests held in human rights by older people. The position necessitates older people to attempt to make an assortment of claims on rights incorporated in a variety of instruments. However, this does not provide the solution as the survey concluded that the overall provision of rights combined in all instruments to be normatively inadequate. In order to respond to the interests in rights and vulnerabilities of older people an approach similar to the one devised in this thesis is required. By adopting a combined vulnerabilities/capabilities approach a listing of Fundamental Capabilities and capabilities as outcomes was suggested to inform normative content and outcome of rights.

The examination of implementation of international rights also proved inadequate for the vulnerabilities of older people. The principal barriers to implementation were identified as:

${ }^{1536}$ C Scott \& P Macklem, 'Constitutional Ropes of Sand or Justiciable Guarantees? Social Rights in a New South African Constitution' (1992) 141 Unv of Pennsylvania LR 1,29 (as cited in Sandra Liebenberg, 'The Value of Human Dignity In Interpreting Socio-Economic Rights'21 S Afr. J. on Hum. Rts. 1 2005, 1, 2) 
- Resource allocation

- Exclusion of older people from reporting by Member States

- $\quad$ Lack of de facto State objectives

- $\quad$ Lack of de facto indicators

- Margin of appreciation

The comparison of the UN Framework of Indicators with Fundamental Capabilities and capabilities outcomes devised as part of the normative examination has proven that in devising outcome indicators the needs of older people were not included or measured.

The discussions of the Open Ended Working Group on Ageing with a mandate to identify problems of rights provision and to consider all methods of provision provided the focus of progress by the UN. The key areas identified as in need of attention correspond to the ways in which this thesis identified older people and vulnerabilities. However, little progress has been made on the methods of provision. There is minimal evidence of commitment to a special protection Convention for older people. Rather arguments gravitate towards implementation of the MIPAA, which is immediately limited by a lack of legally-binding status. Another solution favoured includes a series of individual regional instruments, which would incorporate a range of protections and standards. Finally, the well rehearsed solution of older people appealing to numerous existing instruments is offered. All have been proven inadequate for older people in this thesis. 


\section{BIBLIOGRAPHY}

Aboderin I, 'Modernisation and Ageing Theory Revisited: Current Explanations of Recent Developing World and Historical Western Shifts in Material Family Support for Older People' (2004) 24(1) Ageing and Society 29

Aboderin I, 'Decline in Material Family Support for Older People in Urban Ghana, Africa: Understanding Processes and Causes of Change' (2004) 59(3) Gerontol B Psychol Sci Soc Sci S128 Aboderin I, 'Conditionality' and 'Limits' of Filial Obligation: Conceptual Levers for Developing a Better Understanding of the Motivational Basis and Societal Shifts or Patterns in Old Age Family Support, Working Paper Number WP205 (Oxford Institute of Ageing: University of Oxford 2005)

Achenbaum W.A. and V.L. Bengston, 'Re-engaging the Disengagement Theory of Aging: On the History and Assessment of Theory Development in Gerontology' (1994) 34(6) The Gerontologist 756

Action on Elder Abuse, Hidden Voices: Older People's Experience of Abuse Executive Summary. An analysis of calls to the Action on Elder Abuse helpline (Help the Aged 2004)

Age UK, Safeguarding the convoy: A call to action from the Campaign to End Loneliness (2011)

---- Later Life in the United Kingdom (January 2017)

Ajima S, 'Intervention faces obstacles, efforts underway to stem abuse of elderly' (Global Action on Ageing, January 2005) http://globalage.igc.org/elderrights/world/2005/eldobstacles.htm accessed 20/04/2014

Akerlind I and Hörnquist J.O., 'Loneliness and alcohol abuse: a review of evidences of an interplay' (1992) 34(3) Soc Sci Med 405

Albert M.S., Jones K, Savage C.R., Berkman L, Seeman T, Blazer D and Rowe J.W, 'Predictors of Cognitive Change in Older Persons: MacArthur Studies of Successful Aging' (1995) 10:4 Psychology and Aging 578

Alkire S, 'Why the Capability Approach?' (2005) 6(1) Journal of Human Development 115

Alzheimer's Disease International, World Alzheimer Report 2010: The Global Economic Impact of Dementia (June 2011)

Anderson J and Honneth A, 'Autonomy, Vulnerability, Recognition and Justice' in Joel Christman and Joel Anderson (eds) Autonomy and the Challenges to Liberalism: New Essays (CUP 2005)

Andorno R, 'Human Dignity and Human Rights as a Common Ground for a Global Bioethics' (2009) 34(3) J Med Philos 223 
Annan K, Former Secretary-General of the United Nations, 'In Larger Freedom: Towards Development, Security and Human Rights for All' http://www.humanrights.com/voices-forhuman-rights/human-rights-challenges.html accessed 30/10/2017

Atchley RC, 'Activity Theory' in Schulz R and others (eds) The Encyclopedia of Aging (4th edn, Springer 2006)

Arendt $\mathrm{H}$, The Origins of Totalitarianism (Brace \& Co. 1951)

Baltes M.M. and Carstensen L.L., 'The Process of Successful Ageing' (1996) 16(4) Ageing and Society 397

Baltes P.B. and Baltes M.M., 'Psychological Perspectives on Successful Ageing: The Model of Successful Oprimization with Compensation' in Baltes P.B. and Baltes M.M. (eds), Successful Aging: Perspectives from the Behavioral Sciences (Press Syndicate of the University of Cambridge 1993)

Banks J, Batty G.D., Nazroo J and Steptoe A, The Dynamics of Ageing: Evidence from the English Longitudinal Study of Ageing 2002-2015 (Wave 7) (Institute for Fiscal Studies, 2016)

Barilan Y.M., Human Dignity, Human Rights, and Responsibility: The New Language of Global Ethics and Biolaw (MIT Press 2012)

Bay C, 'Self-Respect as a Human Rights: Thoughts on the Dialectics of Wants and Needs in the Struggle for Human Community' (1982) 4(1) HRQ 53

Bendix R, 'Tradition and Modernity Reconsidered' (1976) 9(3) Comparative Studies in Society and History 292 <https://doi.org/10.17/S0010417500004540> accessed 10 April 2011

Bisaz C, The Concept of Group Rights in International Law: Groups as Contested Right-Holders, Subjects and Legal Persons (Martinus Nijhoff Publishers 2012)

Boven T, 'Categories of Rights' in Moeckli D, Shah S and Sivakumaran S (eds) and Harris D (Consultant ed), International Human Rights Law ( $2^{\text {nd }}$ ed, OUP 2014)

Breda J and Schoenmaekers D, 'Age: A Dubious Criterion in Legislation' (2006) 26(4) Ageing and Society 429

Brogden M, Geronticide: Killing the Elderly (Jessica Kingsley Publishing 2001)

Brody J.A. and Schneider E.L., 'Diseases and disorders of aging: a hypothesis' (1986) 39 Journal of Chronic Disease 871

Brogden M, Geronticide: Killing the Elderly (Jessica Kingsley Publishing 2001)

Brown C.E., 'The Concept of Vulnerability and its Use in the Care and Control of Young People' University of Leeds www.etheses.ac.uk accessed 03/03/2016 
Brown K, 'Beyond protection: "the vulnerable" in the age of austerity' in Harrison M and Sanders $\mathrm{T}$ (eds), Social Policies and Social Control: New perspectives on the "not-so-big society" (The Policy Press, Bristol University Press 2015)

---- Vulnerability and Young People: Care and Social Control in Policy and Practice (The Policy Press, Bristol University Press 2016)

Burchardt T, 'Equality, Capability and Human Rights' Centre for Analysis of Social Exclusion, London School of Economics

Burgess E.W. (ed), Aging in Western Societies (Chicago University Press 1960)

Butler J, Frames of War: When is Life Grievable? (Verso, London, 2009)

Butler R.N., 'Dispelling ageism - the cross-cutting intervention' (1989) 503 Ann Am Acad Polit Ss

Butler R, 'Capabilities: A New Approach to Human Rights for the Elderly' (2015) 2(4) Edinburgh Student L. Rev 17

Cacioppo J.T. et al, 'Lonely Traits and Concomitant Physiological Processes: The MacArthur Social Neuroscience Studies' (2000) 35(2-3) International Journal of Psychophysiology 143

Cacioppo J.T., Hawkley L.C. and Thisted R.A., 'Perceived Social Isolation Makes Me Sad: Five Year Cross-Lagged Analyses of Loneliness and Depressive Symptomatology in the Chicago Health, Aging and Social Relations Study' (2010) 25(2) Psychol Aging 453

Carries B.A., and Olshansky S.J., 'Evolutionary Perspectives on Human Senescence' (1993) 19(4) Population and Development Review 793

Carnes B.A., Staats, D.O. and Sonntag W.E., 'Does senescence give rise to disease?' (2008) 129(12) Mech Ageing Dev 693

Carter I, 'Introduction' in de Wijze S. Kramer M.H. and Carter I (eds), Hillel Steiner and the Anatomy of Justice: Themes and Challenges (Routledge 2009)

---- 'Respect for Persons and the Interest in Freedom' in de Wijze S. Kramer M.H. and Carter I (eds), Hillel Steiner and the Anatomy of Justice Themes and Challenges (Routledge, 2009)

Ceranti L, 'Kant's Theory of Human Rights' in Cushman T (ed), Handbook of Human Rights (Routledge 2014)

Chung C, 'The necessity of a human rights approach and effective United Nations mechanism for the human rights of the older person' (4 December 2009) UN Doc A/HRC/AC/4/CRP.1

Claassen R, 'Human Dignity in the Capability Approach' in Düwell M, Braarvig J, Brownsword R and Mieth D (eds), The Cambridge Handbook of Human Dignity: Interdisciplinary Perspectives (CUP 2014) 
Cohen G.A., 'Equality of What? On Welfare, Goods and Capabilities' in Nussbaum M.C. and Sen A (eds), The Quality of Life (Oxford, Clarenden Press 1996)

Contreras de Lehr E, 'Aging and Family Support in Mexico' in Kendig $\mathrm{H}$ and Hashimoto $\mathrm{A}$ and Coppard L.C. (eds), Family Support to the Elderly: The International Experience (Oxford University Press 1992)

Comin F, Qizilbach M and Alkire S, The Capability Approach (CUP 2008)

Comin F, 'Capabilities and Happiness: Potential Synergies' (2005) 63(2) Review of Social Economy 161

Conte A and Burchill R, Defining Civil and Political Rights: The Jurisprudence of the United Nations Human Rights Committee $\left(2^{\text {nd }}\right.$ ed, Ashgate 2009)

Couser G.T., Vulnerable Subjects: Ethics and Life Writing (Cornell University Press 2004)

Cowgill D.O., 'A Theory of Aging in Cross-Cultural Perspective' in Cowgill D.O. and Holmes L.D. (eds), Ageing and Modernization (Appleton-Century-Crofts 1972)

---- 'The Aging of Populations and Societies,' (1974) 415(1) AAPSS 1

Cranston M, What are Human Rights? (The Bodley Head 1973)

Cruft R, 'Rights: Beyond Interest Theory and Will Theory?' (2004) 23(4) Law and Philosophy 347

---- 'Human Rights as Individualistically Justified: A Defence' in Brooks T (ed), Current Controversies in Political Philosophy (Routledge 2015)

Cumming E et al, 'Disengagement - A Tentative Theory of Aging,' (1960) 23(1) Sociometry 23

---- 'Further Thoughts on the Theory of Disengagement' in Gubrium J.F. and Holstein J.A. (eds.), Aging and Everyday Life (Blackwell Publishers Inc 2000)

Cumming E and Henry W.E., Growing Old: The Process of Disengagement (Basic Books 1961)

Dahlberg L and McKee K.J., 'Correlates of social and emotional loneliness in older people: evidence from an English community study' (2014) 18(4) Aging and Mental Health 504

Dannefer D, 'Cumulative Advantage/Disadvantage and the Life Course: Cross-Fertilizing Age and Social Science Theory' (2003) 58B(6) Journal of Gerontology S327

Darwall S, 'Review of Michael Rosen “Dignity: It's History and Meaning”' (Sept 2012) Notre Dame Philosophical Reviews

Davis J and Stack M, 'Applying Marx's Theory of Value: The Role of Knowledge in the Production of Commodities', www.net4dem.org accessed 28 July 2014 
Department for Work \& Pensions, Pensions Bill 2011 MP's Information Pack www.dwp.gov.uk/policy/pensions-reform accessed 25/09/2012

---- Family Resources Survey 2014/15 (28 June 2016)

https://www.gov.uk/government/uploads/system/uploads/attachment data/file/531242/family -resources-survey-2014-15.pdf accessed 01/07/2016

Derham C, 'Services for Older People' (Department for Work and Pensions, 2004)

Dewilde C, 'A life-course perspective on social exclusion and poverty' (2003) 54(1) British Journal of Sociology 109

Diamond J, 'How Societies Can Grow Old Better' TED Lectures (2013)

<https://www.ted.com/talks/iared diamond how societies can grow old better $>$ accessed 22 November 2015

Dixon R and Nussbaum M.C., 'Children's Rights and a Capabilities Approach: The Question of Special Priority' (2012) 97 Cornell Law Review 549

Donnelly J, Universal Human Rights in Theory and Practice $\left(2^{\text {nd }}\right.$ ed, Cornell University Press 2002)

Dupré C, 'Human dignity and the withdrawal of medical treatment: a missed opportunity?' (2006) 6 E.H.R.L.R. 678

---- 'Unlocking human dignity: towards a theory for the 21st century' (2009) (2) E.H.R.L.R. 190

---- The Age of Dignity: Human Rights and Constitutionalism in Europe (Hart Publishing 2015)

Dworkin R, Taking Rights Seriously (Duckworth 1977)

Dykstra P.A., 'Older adult loneliness: myths and realities' (2009) 6(2) Eur J Ageing 91

Edmundson W.A., An Introduction to Rights (CUP 2004)

Eisenstadt S.N., 'Studies of Modernization and Sociological Theory' (1974) 13(3) History and Theory 225

Elchardus M and Smits W, 'The Persistence of the Standardized Life Cycle' (2006) 15(2-3) Time \& Society 303

Elder Jr G.H., 'Time, Human Agency and Social Change: Perspectives on the Life Course' (1994) 57(1) Social Psychology Quarterly 4

---- 'The Life Course as Developmental Theory' (1998) 69(1) Child Development 1

Elder Jr G.H., Kirkpatrick Johnson M and Crosnoe R, 'The Emergence and Development of Life Course Theory,' (Springer 2003) 
Estep P.W., 'The Promise of Human Life Span Extension' (2007) 27 Annual Review of Gerontology and Geriatrics 29

Eun K-S, 'Changing Roles of the Family and State for Elderly Care: A Confucianism Perspective' in Bengston V.L. and Lowerstein A (eds), Global Aging and Challenges to Families (Aldine de Gruyter 2003)

Evans D.A., Helbert L.E., Beckett L.A. et al, 'Education and Other Measures of Socioeconomic Status and Risk of Incident Alzheimer Disease in a Defined Population of Older Persons' (1997) 54(11) Arch Neurology 1399

Fabre C, 'Preconception Rights' in de Wijze S. Kramer M.H. and Carter I (eds), Hillel Steiner and the Anatomy of Justice: Themes and Challenges (Routledge 2009)

Feser E, 'The Metaphysical Foundations of Natural Rights' in Cushman T (ed), Handbook of Human Rights (Routledge 2014)

Fineman M.A., 'Cracking The Foundational Myths: Independence, Autonomy, And SelfSufficiency' (2000) 8(13) Journal of Gender, Social Policy and the Law 13

---- The Autonomy Myth: A Theory of Dependency (The New Press 2004)

---- 'The Vulnerable Subject: Anchoring Equality in the Human Condition' (2008) 20(1) Yale J.L.\& Feminism 1

---- 'The Vulnerable Subject and the Responsive State' (2010-11) 60(2) Emory L.J. 251

Fitzgerald R, 'Human Needs and Politics: The Ideas of Christian Bay and Herbet Marcuse' (1985) 6(1) Political Psychology 87

Fredman S, Human Rights Transformed: Positive Rights and Positive Duties (OUP 2009)

Freeman M, Lloyd's Introduction to Jurisprudence $\left(7^{\text {th }}\right.$ ed, Sweet \& Maxwell 2001)

Fries J.F., 'Aging, Natural Death and the Compression of Morbidity' (17 July 1980) The New England Journal of Medicine

Fries L.P., Ferrucci L., Darer J., Williamson J.D. and Anderson G., 'Untangling the Concepts of Disability, Frailty, and Comorbidity: Implications for Improved Targeting and Care' (2004) 59:3 Journal of Gerontology: Medical Sciences 255

Galit N and DA Kleiber, 'Reconsidering Change And Continuity In Later Life: Toward An Innovation Theory Of Successful Aging' (2007) 65(1) International Journal of Aging and Human Development 1

Gasper D, 'What is the Capability Approach? Its Core, Rationale, Partners and Dangers'. Institute of Social Studies, The Hague, June 2006, Working Paper Series No. 428

Gearty C, Can Human Rights Survive? (CUP 2006) 
Gerwith A, The Community of Rights (University of Chicago Press 1996)

Gilbert S.F., Developmental Biology ( $6^{\text {th }}$ ed, Sinaur Associates 2000)

Goldsmith S.K., Pellmar T.C., Kleinman A.M., Bunney W.E., Reducing suicide: a national imperative (National Academy Press, Washington DC, 2002)

Gorman J, Rights and Reason: an Introduction to the Philosophy of Rights (Acumen Publishing Limited 2003)

Gough I, 'Marx's Theory of Productive and Unproductive Labour' (1972) 1/76 New Left Review 47

Gouldner A.W., 'The Norm of Reciprocity: A Preliminary Statement' (1960) 25(2) American Sociological Review 161

Grear A, Redirecting Human Rights: Facing the Challenge of Corporate Legal Humanity (Palgrave Macmillan UK 2010)

Grundy E, 'Ageing and vulnerable elderly people: European perspectives' (2006) 26(1) Ageing and Society 105

Habermas J, 'The Concept of Human Dignity and The Realistic Utopia of Human Rights' (2010) 41(4) Metaphilosophy 464

Habibi D.A., 'Human Rights and Politicized Human Rights; A Utilitarian Critique' (2007) 6(1) Journal of Human Rights 3

Haggard D, 'Choice vs Interest Theories of Rights' 'All Things Daniel Haggard' www.danielhaggard.com/choice-vs-interest-theories-of-rights accessed 12/12/2014

Hamelink C.J., 'Human rights: the implementation gap' (4 April 2012) 63 The Journal of International Communication http://dx.doi.org/10.1080/13216597 accessed 10/08/2017

Harel A, 'Theories of Rights' in Golding M.P. and Edmundson W.A. (eds), The Blackwell Guide to the Philosophy of Law and Legal Theory (Blackwell Publishing 2004)

Harnacke C, 'Disability and Capability: Exploring the Usefulness of Martha Nussnaum's Capabilities Approach for the UN Disability Rights Convention' (2013) 41(4) Journal of Law, Medicine and Ethics 768

Hart H.L.A., Essays on Bentham: Jurisprudence and Political Philosophy (OUP 1982) Harvey C, 'Talking about Human Rights' (2004) (5) E.H.R.L.R. 500

Hastings M, 'For an Interest Theory Conception of Human Rights' www.academia.edu accessed $01 / 04 / 2016$ 
Hawkley L.C., Thisted R.A., Cacioppo J.T., 'Loneliness predicts reduced physical activity: crosssectional \&amp; longitudinal analyses' (2009) 28(3) Health Psychol 354

Hawkley L.C., Preacher K.J. and Cacioppo J.T., 'Loneliness impairs daytime functioning but not sleep duration' (2010) 29(2) Health Psychol 124

Hayflick L, 'Biological Aging Is No Longer an Unsolved Problem' (2007) 1100 Ann. N.Y. Acad. Sci. 1

Helis J, 'Hannah Arendt and Human Dignity: Theoretical Foundations and Constitutional Protection of Human Rights' (2008) 1(3) Journal of Politics and Law 73

HelpAge International, Protecting the rights of older people in Africa (April 2008)

Hick R, 'The Capabilities Approach: Insights for a New Poverty Focus' (2012) 41(2) Journal of Social Policy 291

Hinterlong J, Morrow-Howell N and Sherraden, 'Productive Aging: Principles and Perspectives' in Morrow-Howell $\mathrm{N}$ and Hinterlong J and Sherraden $\mathrm{M}$ (eds), Productive Aging: Concepts and Challenges (The John Hopkins University Press 2001)

Hirschbert M and Papadopoulos C, "Reasonable Accommodation" and "Accessibility": Human Rights Instruments Relating to Inclusion and Exclusion in the Labor Market' (16 January 2016) Societies www.mdpi.com/2075-4698/6/1/3/pdf accessed 10/05/2017

Holliday R, 'Aging is No Longer an Unsolved Problem in Biology' (2006) 1067 Annals New York Academy of Sciences 1

Holt-Lunstad J and Smith T.B., 'Social relationships and mortality risk: a meta-analytic review' (2010) 7(7) PLOS Med 2

http://journals.plos.org/plosmedicine/article/file?id=10.1371/journal.pmed.1000316\&type=prin table accessed 4 April 2017

Holmeroia I et al, Productive Ageing Conditions and Opportunities (International Longevity Centre Czech Republic Centre for Expertise in Longevity and Long-term Care Faculty of Humanities, Charles University in Prague 2012)

Holwerdda T.J., Deeg D.J., Beekman A.T., van Tilburg T.G., Stek M.L., Jonker C and Schoevers R.A., 'Feelings of loneliness, but not social isolation, predict dementia onset: results from the Amsterdam Study of the Elderly (AMSTEL)' (2014) 85(2) J Neurol Neurosurg Psychiatry 135

Hochschild A.R., 'Disengagement Theory: A Critique and Proposal' (1975) 40(5) American Sociological Review 553

House J.S, Landis K.R. and Umberson D, 'Social relationships and Health' (1988) 241 Science 540

Idler E.L., Russell L.B. and Davis D, 'Survival, Functional Limitations and Self-rated Health in the NHANES I Epidemiologic Follow-Up Study' (2000) 52(9) American Journal of Epidemiology 874 
International Labour Organization (ILO), C102-Social Security (Minimum Standards) Convention, 1952 (No. 102)

---- C-128 Invalidity, Old-Age and Survivors' Benefits Convention, 1967 (No. 128)

---- R162-Older Workers Recommendation, 1980 (No. 162)

Judge L, 'The rights of older people: International law, human rights mechanisms and the case for new normative standards' (Age Concern International Symposium on the Rights of Older People, London, January 2009)

Kanter A.S., 'The United Nations Convention on the Rights of Persons with Disabilities and its Implications for the Rights of Elderly People Under International Law' (2009) 25(3) Georgia State University Law Review 527

Kateb G, Human Dignity (HUP 2011)

Khader S, 'Cognitive Disability, Capabilities, and Justice' (2008) 9(1), Essays in Philosophy, Article 11

Kirkwood T.B.L., 'Why Does Aging Occur?' (2001) 21 Annual Review of Gerontology and Geriatrics 41

Knapp M.R.J., 'The Activity Theory of Aging: An Examination in the English Context' (1977) 17(6) The Gerontologist 553

Knapp $M$ and Prince $M$, 'Dementia UK: A report into the prevalence and cost of dementia' (2007), prepared by the Personal Social Services Research Unit at the London School of Economics and the Institute of Psychiatry at King's College London for the Alzheimer's Society.

Kramer M.H. and Steiner H, 'Theories of Rights: Is There a Third Way?' (2007) 27(2) OJLS 281

Kramer M.H., 'Rights Without Trimmings' in Kramer M.H., Simmonds $\mathrm{N}$ and Steiner H (eds), $A$ Debate Over Rights: Philosophical Enquiries (OUP 2002)

---- 'Some Doubts About Alternatives to the Interest Theory of Rights' (September 1, 2011). University of Cambridge Faculty of Law Research Paper No. 44/2011. Available at SSRN: https://ssrn.com/abstract=1934749 accessed 17/03/16

Landesman B.M., 'Book review: The Decent Society. Avishai Margalit' (1997) 107(4) Ethics 729

Lansdown G, The Evolving Capacities of the Child (UNICEF 2005)

Laslett P, 'Family, Kinship and Collectivity as Systems of Support in Pre-Industrial Europe: A Consideration of the 'Nuclear-Hardship' Hypothesis' (1988) 3(2) Continuity and Change 153

Lauder W, Mummery K, Jones M and Caperchione C, 'A comparison of health behaviours in lonely and non-lonely populations' (2006) 11(2) Psychol Health Med 233 
Lemon B.W., Bengtson V.L. and Peterson J.A., 'An Exploration of the Activity Theory of Aging: Activity Types and Life Satisfaction Among In-Movers to a Retirement Community' (1972) 27(4) Journal of Gerontology 511

Levine $\mathrm{C}$ et al, 'The Limitations of "Vulnerability" as a Protection for Human Research Participants' (2004) 4(3) The American Journal of Bioethics 44

Levy B, 'Improving Memory in Old Age Through Implicit Self-Stereotyping' (1996) 71(6) Journal of Personality and Social Psychology 1092

Levy B, Ashman O and Dror I, 'To Be or Not To Be: The Effects of Aging Stereotypes on the Will to Live' (1999-2000) 40(3) Omega 409

Levy B.R. and Banaji M.R., 'Implicit Ageism' in Nelson T.D. (ed), Ageism: Stereotyping and Prejudice against Older Persons (MIT Press 2002)

Levy B.R. et al, 'Longevity Increased by Positive Self-Perceptions of Aging' (2002) 83(2) Journal of Personality and Social Psychology 261

Levy B and Langer E, 'Aging free from Negative Stereotypes: Successful Memory in China and among the American Deaf' (1994) 66(6) Journal of Personality and Social Psychology 989

Liebenberg S, 'The Value of Human Dignity in Interpreting Socio-Economic Rights' (2005) $21 \mathrm{~S}$ Afr. J. on Hum. Rts. 1

Longino Jr C.F. and Kart C.S., 'Explicating Activity Theory: A Formal Replication' (1982) 37(6) Journal of Gerontology 713

Lynott P.P. and Lynott R.J., 'Disengagement - Critical Assessment of Disengagement Theory' <http://medicine.jrank.org/pages/483/Disengagement> assessed 23 November 2015

Lyons D, 'Utility and Rights' in Waldron J (ed), Theories of Rights (OUP 1984)

Luo Y, Hawkley L.C., Waite L.J. and Cacioppo J.T., 'Loneliness, Health and Mortality in Old Age: A National Longitudinal Study' (2012) 75(6) 907

MacCormick N, H.L.A. Hart (Edward Arnold 1981)

Mackenzie C, Rogers W and Dodds S, Vulnerability: New Essays in Ethics and Feminist Philosophy (OUP 2014)

Macklin R, 'Dignity is a useless concept' (2003) 327 British Medical Journal 1419

Macdonald M, 'Natural Rights' in Waldron J (ed), Theories of Rights (OUP 1984)

Mann J, 'Dignity and Health: The UDHR's Revolutionary First Article' (1998) 3(2) Health and Human Rights 30

Margalit A, The Decent Society (HUP 1996) 
Martin C, Rodrigues-Pinzon and Brown B, Human Rights of Older People and Universal Regional Legal Perspectives (Springer 2015)

Masoro E.J., 'Are Age-Associated Diseases and Integral Part of Aging?' in Austad S.N. and Masoro E.J. (eds), Handbook of the Biology of Aging ( $6^{\text {th }}$ ed, Academic Press 2005)

Matthews K and Nazroo J, 'Retirement, well-being, engagement and social status' in Banks J, Batty D, Nazroo J and Steptoe A (eds), The Dynamics of Ageing: Evidence from the English Longitudinal Study of Ageing 2002-2015 (Wave 6) (The Institute for Fiscal Studies, October 2014)

McCrudden C, 'Human Dignity and Judicial Interpretation of Human Rights' (2008) 19(4) European Journal of International Law 655

McGuire F and W Norman, 'The Role of Constraints in Successful Aging: Inhibiting or Enabling?' in Jackson E.L. (ed), Constraints to Leisure (State College PA, Venture Publishing 2005)

Mechanic D and Tanner J, 'Vulnerable People, Groups, and Populations: Societal View' (2007) 26(5) Health Affairs 1220

Merton R.K., 'The Matthew Effect in Science II: Cumulative Advantage and the Symbolism of Intellectual Property' (1988) 79(4) ISIS 606

Mieth C, 'The Double Foundation of Human Rights in Human Nature' in Marion Albers, Thomas Hoffman and Jörn Reinhardt (eds), Human Rights and Human Nature (Springer 2014)

Mitchell B.A., 'Life Course Theory' (2003) International Encyclopedia of Marriage and Family; Encyclopedia.com <www.encyclopedia.com/doc/1G2-3406900275.html > accessed 7 April 2015

---- 'Human rights and social justice: shifting client control' ADA Australia National Conference, 23-24 March 2017, Gold Coast, Australia https://social.un.org/ageing-workinggroup/documents/eighth/TowardsConvention.pdf accessed 20th November 2017

Moody H.R., 'Productive Aging and the Ideology of Old Age,' in Morrow-Howell N and Hinterlong $\mathrm{J}$ and Sherraden M (eds), Productive Aging: Concepts and Challenges (The John Hopkins University Press 2001)

Mortimer J.T. and Shanahan M.J.,Handbook of the Life Course (Springer 2006)

National Institute on Aging, Global Health and Aging (2011)

<https://www.nia.nih.gov/research/publication/global-health-and-aging/living-longer>, accessed 10/04/2017

Nussbaum M.C. and Sen A (eds), The Quality of Life (Oxford, Clarenden Press 1996)

Nussbaum M.C., 'Human Capabilities, Female Human Beings' in Martha C. Nussbaum and Glover J (eds), Women, Culture and Development: A Study of Human Capabilities (Clarendon Press 1995) 
---- 'Capabilities and Human Rights' (1997) 66(2) Fordham Law Review 273

---- 'Symposium on Amartya Sen's Philosophy: 5 Adaptive Preferences and Women's Options' (2001) 17(1) Economics and Philosophy 67

---- 'Capabilities As Fundamental Entitlements: Sen And Social Justice' (2003) 9(2-3) Feminist Economics 33

---- Frontiers of Justice: Disability, Nationality, Species Membership (Harvard University Press 2006)

---- 'Human Rights and Human Capabilities' (2007) 20 Harvard Human Rights Journal 21

---- 'The Capabilities of People with cognitive Disabilities' (2009) 40(3-4) Metaphilosophy 331

---- 'Capabilities, Entitlements, Rights: Supplementation and Critique' (2011) 12(1) Journal of Human Development and Capabilities: A Multi-disciplinary Journal for People-Centered Development 23

---- Creating Capabilities: The Human Development Approach (Harvard University Press 2011)

---- Creating Capabilities: The Human Development Approach (HUP 2013)

O’Byrne D.J., Human Rights (Pearson 2003)

O'Keefe et al, UK Study of Neglect and Abuse of Older People, Prevalence Survey Report (Department of Health and Comic Relief, 2007)

O'Mahony C, 'There is no such thing as a right to dignity' (2012) 10(2) IJCL 551

O'Rand A.M., 'Stratification and the Life Course' in Binstock R.H. and George L.K. (eds), Handbook of Aging and the Social Sciences ( $3^{\text {rd }}$ edn, Academic Press 1990)

Office for National Statistics, National Population Projections, 2012 - based Statistical Bulletin (6 November 2013)

---- General Lifestyle Survey 2011 (2013)

---- National Life Tables, United Kingdom, 2010-2012 (21 March 2014)

---- Mortality, 2012 - based National Population Projections Reference Volume (28 March 2014)

---- Life Expectancy at Birth and at Age 65 by Local Areas in U.K., 2006-08 to 2010-12 (16 April 2014)

---- Population Estimates for UK, England and Wales, Scotland and Northern Ireland, Mid-2013

(26 June 2014) www.ons.gov.uk/ons/rel/pop-estimate accessed 02/08/2014

---- Health Expectancies at Birth and at Age 65 in the United Kingdom: 2009-2011 (2014) 
---- National population projections for the UK, 2014-based (2015)

---- 2011 UK Census

---- Families and households in the UK: 2016 (4 November 2016)

Ogg J and Bennett G, 'Elder abuse in Britain' [1992] BMJ 305

Osborne G, 'We will lead the economy out of crisis', speech given on 06/10/2009, www.conservatives.com/News/Speeches/2009/10/George Osborne. Accessed 16/09/2012

Parsons T, The Social System (The Free Press 1951)

Peroni L and Timmer A, 'Vulnerable groups: The promise of an emerging concept in European Human Rights Convention Law' (2013) 11(4) ICON 1056

Pinquart M and Sorensen S, 'Influences on Loneliness in Older Adults: a Meta-Analysis' (2001) 23(4) Basic and Applied Social Psychology 245

Poffé L, 'Towards a New United Nations Human Rights Convention for Older Persons?' (2015) 15 Human Rights Law Review 591

The Princess Royal Trust for Carers, 'Always On Call, Always Concerned A Survey of the Experiences of Older Carers' (2011)

Qiu C, Blackman L, Winblad B et al, 'The Influence of Education on Clinically Diagnosed Dementia Incidence and Mortality Data from the Kungsholmen Project' (2001) 58 Arch Neurology 2034

Rabbitt P and Lowe C, 'Patterns of cognitive aging' (2000) 63 Psychological Research 308

Rattan S.I.S., 'Theories of biological aging: Genes, proteins, and free radicals' (December 2006) 40(12) Free Radical Research 1230

Raz J, The Morality of Freedom (Clarendon Press 1986)

Riley S, 'Human dignity: comparative and conceptual debates' (2010) 6(1) IJLC 117

Rippon I, Kneale D, De Oliveira C, Demokakos P and Stepote A, 'Perceived age discrimination in older adults' (2014) 43(3) Age and Ageing 379

Robeyns I, 'The Capability Approach: a theoretical survey' (2005) 6(1) Journal of Human Development 93

---- 'The Capability Approach in Practice' (2006) 14(3) The Journal of Political Philosophy 351

Rodriguez-Pinzon D and Martin C, 'The International Law Status of Elderly Persons,'(2003)18(4) The American University International Law Review 995 
Roebuck J, 'When Does Old Age Begin?: The Evolution of the English Definition' (1979) 12(3) Journal of Social History 416

Rosen M, Dignity: Its History and Meaning (HUP 2012)

Roth K, 'Defending Economic, Social and Cultural Rights: Practical Issues Faced by an International Human Rights Organisation' (2004) 26(1) Human Rights Quarterly 63

Rowe J.W., 'Successful Aging' (1997) 17(4) The Gerontologist 443

Russell D.W., Cutrona C.E., de la Mora A and Wallace R.B., 'Loneliness and nursing home admission among rural older adults' (1997) 12(4) Psychol Aging 574

Salthouse T.A., 'What and When of Cognitive Aging' (2004) 13:4 Current Directions in Psychological Science 140

Sanderson W and Scherbov S, 'Average remaining lifetimes can increase as human populations age' (2005) 435 Nature www.nature.com/nature/journal accessed 20/09/2012

---- 'Rethinking Age and Aging' (2008) 63(4) Population Bulletin 3

Scanlon, 'Value, Desire and Quality of Life' in Nussbaum M.C. and Sen A (eds), The Quality of Life (Oxford, Clarenden Press 1996)

Schabas W.A., The Universal Declaration of Human Rights: the travaux préparatoires (CUP 2013)

Schachter O, 'Human Dignity as a Normative Concept' (1983) 77(4) AJIL 848

Schrami E and Grillari J, 'From cellular senescence to age-associated diseases: the miRNA connection' (2012) 1 Longevity and Healthspan www.longevithandhealthspan.co.uk accessed $20 / 09 / 2014$

Schröder-Butterfill E and Marianti R, 'A framework for understanding old-age vulnerabilities' (2006) 26(1) Ageing Society 9

Sen A, 'Equality of What?' (1979) The Tanner Lectures on Human Values. Delivered at Stanford University, May 221979

---- 'Well-being, Agency and Freedom' (1985) 82(4) Journal of Philosophy 169

---- 'The Standard of Living' in Sen A, Muellbauer J, Kanbur R, Hart K, and Williams B (eds), The Standard of Living: The Tanner Lectures on Human Values (CUP 1987)

---- On Ethics and Economics (Blackwell Publishing 1987)

---- 'Capability and Well-Being' in Nussbaum M.C. and Sen A (eds), The Quality of Life (Oxford, Clarenden Press 1996)

---- Development as Freedom (OUP 1998) 
---- 'Elements of a Theory of Human Rights' (2004) 32(4) Philosophy and Public Affairs 315

---- 'Human Rights and Capabilities' (2005) 6(2) Journal of Human Development 151

Shestack J.J., “The Philosophic Foundations of Human Rights,' (1990) 20(2) Hum.Rts.Q. 201

Shultziner D, 'Human Dignity - Functions and Meanings' (2004) 3(3) Global Jurist Topics 1. https://doi.org/10.2202/1535-167X.1110 accessed 24 March 2016

Simmonds N, 'Rights at the Cutting Edge' in Kramer M.H., Simmonds N and Steiner H (eds), $A$ Debate Over Rights: Philosophical Enquiries (OUP 2002)

Smith R.M., 'Some Issues Concerning Families and their Property in Rural England 1250-1800' in Smith R.M. (ed), Land, Kinship and Life-cycle (CUP 1984)

van Solinge $\mathrm{H}$, 'Health Change in Retirement A Longitudinal Study among older workers in the Netherlands' (2007) 29(3) Research of Aging 225

Statman D, 'Humiliation, dignity and self-respect' (2000) 13(4) Philosophical Psychology 523

Steiner H, An Essay on Rights (Blackwell 1994)

Stern Y, 'What is Cognitive Reserve? Theory and Research Application of the Reserve Concept' (2002) 8(3) Journal of the International Neuropsychological Society 448

---- 'Cognitive reserve and Alzheimer disease' (2006) 20(2) Alzheimer Dis Assoc Disord 112

Steverink N, 'Towards Understanding Successful Ageing: Patterned Change in Resources and Goals' (1998) 18 Ageing \& Society 441

Stone R, Civil Liberties and Human Rights ( $8^{\text {th }}$ ed, OUP 2010)

Sugden R, 'Welfare, Resources, and Capabilities: A Review of Inequality Re-examined by Amartya Sen' (1993) 31(4) Journal of Economic Literature 1947

Sumner L.W., Welfare, Happiness and Ethics (OUP 2003)

Tinker A, Older People in Modern Society (Addison Wesley Longman Limited 1997)

Timmer A, 'A Quiet Revolution: Vulnerability in the European Court of Human Rights' in Fineman M.A. and Grear A (eds), Vulnerability: Reflections on a New Ethical Foundation for Law and Politics (Routledge 2013)

Tomuschat C, Human Rights: Between Idealism and Realism ( $3^{\text {rd }}$ ed, OUP 2014)

Treas J and B Logue, 'Economic Development and the Older Population' (1986) 12(4) Population and Development Review 645 
Turner B.S., Vulnerability and Human Rights. Essays on Human Rights (Pennsylvania State University Press 2006)

UNICEF, Implementation Handbook for the Convention on the Rights of the Child $\left(3^{\text {rd }}\right.$ ed, UNICEF 2007)

Uchino B.N., 'Social Support and Health: A Review of Physiological Processes Potentially Underlying Links to Disease Outcomes' (2006) 29(4) Journal of Behavioural Medicine 377

United Nations, 'The Vienna International Plan of Action on Aging' adopted by the World Assembly on Aging held in Vienna, Austria from 26 July to 6 August 1982

---- 'Political Declaration and Madrid Internal Plan of Action on Ageing' (2002)

---- 'Human Rights Indicators: A Guide to Measurement and Implementation' (2012) UN Doc $\mathrm{HR} / \mathrm{PUB} / 12 / 5$

United Nations Commission on Human Rights (UNCHR) 'Summary Record of the Second Meeting [of the Drafting Committee of the Commission on Human Rights]' UN Doc E/CN.4/AC.1/3/Add.1

---- 'Summary Record of $35^{\text {th }}$ Meeting', Held on Friday 12 December 1947 (1947) UN Doc E/CN.4/SR.35

---- 'World Health Organisation contribution to Working Paper on an International Bill of Rights' (January 1947) UN Doc E/CN.4/W.4

---- 'Draft Outline of International Bill of Rights (prepared by the Division of Human Rights)' (4 June 1947) UN Doc E/CN.4/AC.1/3

---- 'Drafting Committee on an International Bill of Human Rights International Bill of Rights Documented Outline' (11 June 1947) UN Doc E/CN.4AC.1/3/Add.1

---- 'Report of the Drafting Committee to the Commission on Human Rights' (21 May 1948) UN Doc E/CN.4/95

UN Committee on Economic, Social and Cultural Rights (CESCR) 'General Comment No. 1: Reporting by States Parties' (27 July 1981) UN Doc E/1989/22

---- 'General Comment No. 3: The Nature of States Parties' Obligations (Art. 2, Para 1, of the Covenant)' (14 December 1990) UN Doc E/1991/23

---- 'General Comment No. 4: The Right to Adequate Housing (Art. 11 (1) of the Covenant)'. Adopted at the Sixth Session of the Committee on Economic, Social and Cultural Rights, on 13 December 1991. UN Doc E/1992/23

---- 'General Comment No. 6: The Economic, Social and Cultural Rights of Older Persons'.

Adopted at the Thirteenth Session of the Committee on Economic, Social and Cultural Rights. (8 December 1995) UN Doc E/1996/22 
---- 'General comment No. 7: The right to adequate housing (art. 11 (1) of the Covenant): Forced evictions' (1997) UN Doc E/1998/22

---- 'General Comment 12 (Twentieth session, 1999) The right to adequate food (art. 11)' (12 May 1999) UN Doc EC.12/1999/5

---- 'General Comment No. 14: The Right to the Highest Attainable Standard of Health (Art. 12)'. Adopted at the Twenty-second Session of the Committee on Economic, Social and Cultural Rights, on 11 August 2000 UN Doc E/C.12/2000/4

---- 'General Comment No. 18: The Right to Work (Article 6 of the Covenant)' (6 February 2006) UN Doc E/C.12/GC/18

---- 'General Comment No. 19: The right to social security (article 9)' (4 February 2008) UN Doc E/C.12/GC/19

United Nations Committee on the Elimination of Discrimination against Women (CEDAW) 'General recommendation No. 27 on older women and protection of their human rights' (16 December 2010) UN Doc CEDAW/C/GC/27

United Nations Committee on the Rights of Persons with Disabilities (UNCRPD) 'General Comment No. 1: Article 12: Equal recognition before the law' in Eleventh session 31 March - 11 April 2014 (19 May 2014) UN Doc CRPD/C/GC/1

United Nations Department of Economic and Social Affairs (DESA), World Population Ageing: 1950-2050 (2002)

---- Division for Social Policy and Development, Programme on Ageing, 'Report of the Expert Group Meeting: "Rights of Older Persons"' Bonn, Germany 5-7 May 2009

---- 'World Population Ageing Report 2013' (2013)

United Nations Economic and Social Council (ECOSOC) 'Draft Declaration on Human Rights and Letter of Transmittal from the Cuban Delegation to the General Assembly of the UN' (12 February 1946) UN Doc E/HR/1

---- 'Draft Declaration of the International Rights and Duties of Man Formulated by the InterAmerican Juridical Committee' (8 January 1947) E/CN.4/2

---- 'Commission on Human Rights Drafting Committee International Bill of Rights' (11 June 1947) UN Doc E/CN.4/AC.1/3Add.1

---- 'U.S. suggestions for Redrafts of Certain Articles in Draft Outline' (11 June 1947) E/CN/4/AC. $1 / 8$

---- 'Collation of the Comments of Governments on the Draft International Declaration on Human Rights, Draft International Covenant on Human Rights and the Question of implementation' (1 May 1948) E/CN.4/85 
UN Human Rights Committee (HRC), 'General Comment No. 6: Article 6 (Right to Life)' (30 April 1982) UN Doc HRI/GEN/1/Rev.9 (Vol. I)

---- 'CCPR General Comment No. 10: Article 19 Freedom of Expression' (29 June 1983)

---- 'CCPR General Comment No. 16: Article 17 (Right to Privacy), The Right to Respect of Privacy, Family, Home and Correspondence, and Protection of Honour and Reputation'. Adopted at the Thirty-second Session of the Human Rights Committee (8 April 1988)

---- 'CCPR General Comment No. 18: Non-discrimination' (10 November 1989) UN Doc HRI/GEN/1/Rev.1

---- 'CCPR General Comment No. 20: Article 7 (Prohibition of Torture, or Other Cruel, Inhuman or Degrading Treatment or Punishment)' (10 March 1992)

---- 'CCPR General Comment No. 25: The right to participate in public affairs, voting rights and the right of equal access to public service' (12 July 1996) UN Doc CCPR/C/21/Rev.1/Add.7

---- 'Consideration of reports submitted by States parties under article 40 of the Covenant : International Covenant on Civil and Political Rights : concluding observations of the Human Rights Committee : United Kingdom of Great Britain and Northern Ireland' (30 July 2008) UN Doc $\mathrm{CCPR} / \mathrm{C} / \mathrm{GBR} / \mathrm{CO} / 6$

---- 'CCPR General Comment No. 35: Article 9 (Liberty and security of person)'. Adopted by the Committee at its $112^{\text {th }}$ session (7-31 October 2014) UN Doc CCPR/C/GC/35

---- 'Draft General Comment No. 36: Article 6 Right to Life'. Prepared by Yuval Shany and Nigel Rodley, Rapporteurs (19 Oct - 6 Nov 2015) UN Doc CCPR/C/GC/R.36/Rev.2

United Nations General Assembly (UNGA) ‘Proclamation on Ageing’ (16 October 1992) UN Doc A/RES/47/5

---- 'Follow-up to the Second World Assembly on Ageing: Report of the Secretary-General' (July 2009) UN Doc A/64/127

---- 'Resolution adopted by the General Assembly on 21 December 2010 65/182: Follow-up to the Second World Assembly on Ageing' (4 February 2011) UN Doc A/RES/65/182

---- 'Resolution adopted by the General Assembly on 20 December 2012 67/139: Towards a comprehensive and integral international legal instrument to promote and protect the rights and dignity of older persons' (13 February 2013) UN Doc A/RES/67/139

---- 'Report of the Open ended Working Group on Ageing' at the 'Open ended Working Group on ageing first working session' (17 May 2011) UN Doc A/AC.278/2014/2

---- 'Report of the Open ended Working Group on Ageing' at the 'Open ended Working Group on ageing second working session' (23 August 2011) UN Doc A/AC.278/2011/5 
---- 'Report of the Open ended Working Group on Ageing' at the 'Open ended Working Group on ageing fifth working session' (15 August 2014) UN Doc A/AC.2781/2014/2

---- 'Report of the Open ended Working Group on Ageing' at the 'Open ended Working Group on ageing sixth working session' (29 July 2015) UN Doc AAC.278/2015/2

United Nations Human Rights Council (UNHRC) 'Promotion and protection of all human rights, civil, political, economic, social and cultural rights, including the right to development' (21 December 2009) UN Doc A/HRC/13/27

United Nations Human Rights Instruments (UNHRI) 'Report on Indicators for Promoting and Monitoring the Implementation of Human Rights' (6 June 2008) UN Doc HRI/MC/2008/3

---- 'Compilation of Guidelines on the Form and Content of Reports to be Submitted by States Parties to the International Human Rights Treaties, Report of the Secretary-General' (3 June 2009) UN Doc HRI/GEN/2/Rev.6

University of Chicago Committee on Human Development, 'Kansas City Study of Adult Life 1954$1958^{\prime}$

van den Heuvel W.J.A. and van Santvoort M.M., 'Experienced discrimination amongst European old citizens' (2011) 8(4) European Journal of Ageing 291

Vizard P, Fukuda-Parr S and Elson D, 'Introduction: The Capability Approach and Human Rights' (2011) 12(1) Journal of Human Development and Capabilities 1

Waldron J, Nonsense Upon Stilts: Bentham, Burke and Marx on the Rights of Man (Methuen 1987)

---- 'Rights in Conflict' (1989) 99(3) Ethics 503

---- 'Dignity, Rank and Rights' (2009) The Tanner Lectures on Human Values. Delivered at the University of California, Berkeley, April 21-23 2009

---- 'Is Dignity the Foundation of Human Rights?' (2013). New York University Public Law and Legal Theory Working Papers. 374

Wheeler S.C. and Petty R.E., 'The Effects of Stereotype Activation on Behavior: A Review of Possible Mechanisms' (2001) 127(6) Psychological Bulletin 797

Wilkinson R and Pickett K, The Spirit Level: Why Greater Equality Makes Societies Stronger (Bloomsbury Press 2010)

Wilson R.S., Krueger K.R., Arnold S.E., Schneider J.A., Kelly J.F., Barnes L.L., Tang Y, Bennett D.A., 'Loneliness and risk of Alzheimer disease' (2007) 64(2) Arch Gen Psychiatry 234 